Portland State University

PDXScholar

Civil and Environmental Engineering Master's

Project Reports

Civil and Environmental Engineering

2017

\title{
Seismic Evaluation of 196kV Transformer Bushings
}

Joanne R. Shields

Portland State University

Follow this and additional works at: https://pdxscholar.library.pdx.edu/cengin_gradprojects

Part of the Civil Engineering Commons

Let us know how access to this document benefits you.

\section{Recommended Citation}

Shields, Joanne R., "Seismic Evaluation of 196kV Transformer Bushings" (2017). Civil and Environmental Engineering Master's Project Reports. 35.

https://doi.org/10.15760/CCEMP.2

This Project is brought to you for free and open access. It has been accepted for inclusion in Civil and Environmental Engineering Master's Project Reports by an authorized administrator of PDXScholar. Please contact us if we can make this document more accessible: pdxscholar@pdx.edu. 


\title{
SEISMIC EVALUATION OF 196 KV TRANSFORMER BUSHINGS
}

BY

JOANNE SHIELDS

\begin{abstract}
A research project report submitted in partial fulfillment of the requirement for the degree of
\end{abstract}

MASTER OF SCIENCE

IN

CIVIL AND ENVIRONMENTAL ENGINEERING

Project Advisor:

Peter Dusicka, Ph D., P.E.

Portland State University

(C)2017 


\section{ACKNOWLEDGMENTS}

It has been a privilege to work with the doctors, engineers and other students during the course of this project. Thank you all for your help and support and especially to all the other students working in the iSTAR Laboratory during the time these test took place.

I would never have come across this project, if it wasn't for my professor Dr. Dusicka who had faith in me and entrusted me with the responsibility of testing these bushings. I would like to express my sincere and deepest gratitude for all of the support and for guiding me through testing these bushings in the iSTAR Laboratory.

This work was made possible with financial support by Bonneville Power Administration. Thank you for your valuable time and input during the testing of these bushings.

Looking back, if I did not have the help and support of the iSTAR Laboratory students the project of testing the bushings, seems as if it would have been impossible. I would like to give a big thank you to all the other students who helped out and stayed late hours to ensure testing remained on schedule. Thank you Ilya Planikov, John Stuart Garth, Marshall Stokes, Bruno, Selamawit Tesfayesus Mehary, M.S., Arlindo Pires Lopes, M.S., and everyone else who is not listed that helped to test the bushings, I could not have done it without you. 


\section{ABSTRACT}

Transformer bushings have shown to have an unsatisfactory performance during earthquakes and have therefore been chosen for further testing. How the bushings fail, and how this failure can be prevented has been analyzed. Two used $196 \mathrm{kV}$ bushings made by General Electric were chosen for seismic testing at the iSTAR laboratory located at Portland State University in Portland, OR. The multiple objectives that brought about these tests were: to determine how the bushings failed due to gasket extrusion at the porcelain-flange connection and to verify that the failure was due to pure tipping and not sliding, to determine the damping introduced when the bushing was supported by a flexible plate with a welded support structure and excited at large amplitudes, determine the natural frequency of the assembly, and to determine the effects of added mass to the top of the bushing. To meet the objectives, the bushings were tested using two different test set-ups: a stiff mounted setup, and a flexible mounted setup. For both test set-ups, the bushings were first mounted inside a turret to simulate an electrical transformer, and the turret was mounted to a flexible or stiff plate, depending on the test. The flexible or stiff plate tests were bolted to a one-direction shake table. The bushings were individually subjected to static and dynamic testing until failure due to oil leakage. 


\section{TABLE OF CONTENTS}

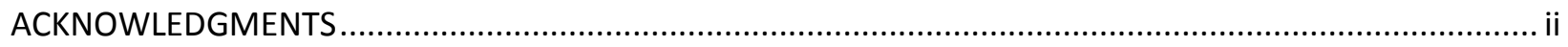

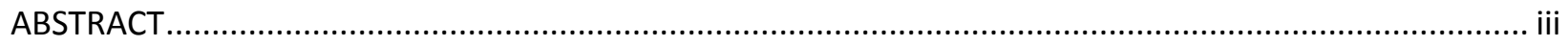

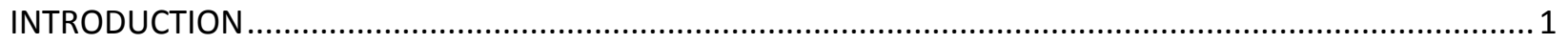

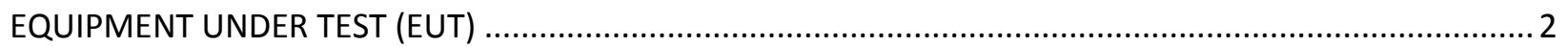

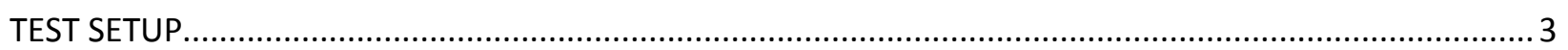

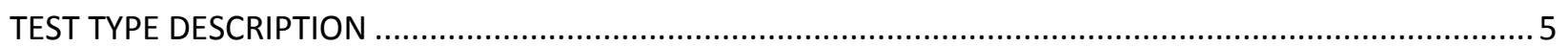

INSTRUMENTATION

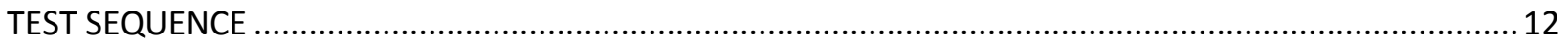

RESULTS AND DISCUSSION...................................................................................................

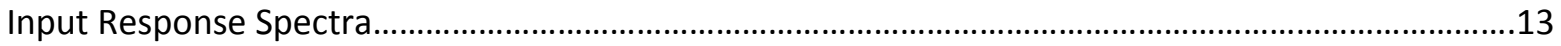

Maximum Moment During Dynamic Testing..................................................................................13

Maximum Accelerations for Ground Motions for Bushing 1............................................................15

Maximum Accelerations for Sine Beats for Bushing 1........................................................................16

Maximum Accelerations for Ground Motions for Bushing 2 …………………...................................17

Gasket Extrusion for Both Tests.........................................................................................................19

Bushing 1 Horizontal \& Vertical Rotation and Slippage...................................................................19

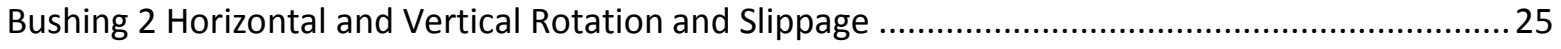

Bushing 1 Natural Frequency and Damping....................................................................................

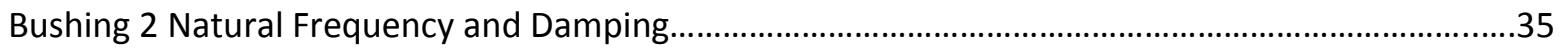

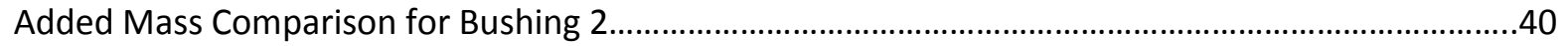

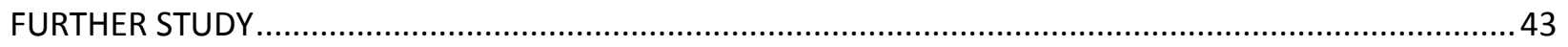

CONCLUSION

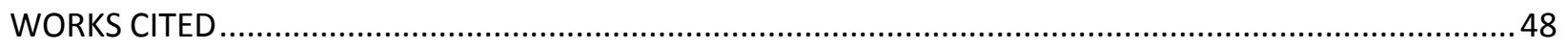

APPENDIX A .

APPENDIX B

APPENDIX C

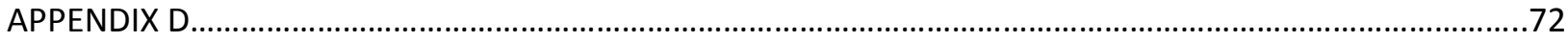

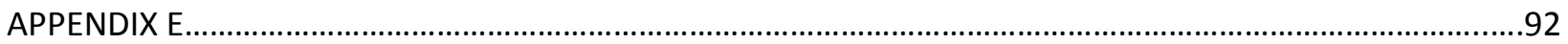

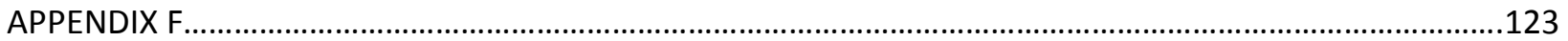




\section{INTRODUCTION}

Transformer bushings are a key component in power distribution and transmission for electrical transformers. Bushings can be mounted on the cover plate of transformers and insulate the voltage conductors. There are three parts to a high voltage bushing: the upper bushing, the bushing flange, and the lower bushing. The upper bushing extends outside the transformer, the bushing flange mounts the bushing to the transformer and is where steel visibly contacts the porcelain, and the lower bushing is inside the transformer and is usually encased in oil. The bushings are long and thin, and mainly comprised of porcelain which is a relatively brittle material. Due to the fragile nature of the bushings, they have proven to be the most vulnerable component of a transformer during an earthquake. During an Earthquake, the bushings can be fractured and leak oil, or the gasket can be extruded at the porcelain-steel flange connection and also leak oil. Past earthquakes in which bushings have showed an unsatisfactory performance are: 1989 Loma Prieta, 1994 Northridge, 1995 Kobe, and 1999 Izmit, 1999 Chi-Chi, and during 2010 in Chile. To gain more knowledge of how bushings fail, Dr. Leon Kempner of Bonneville Power Administration (BPA) and Dr. Anshel Schiff lead up seismic evaluations on transformer bushings through testing.

Static and dynamic tests were performed on two bushings that had been previously used to gain a better understanding of how $196 \mathrm{kV}$ transformer bushings fail. Previously, several earthquake investigations had been conducted and the extrusion of the gasket at the porcelain-flange connection had been observed. Although the deflections during the earthquake were unknown and there were cases where the porcelain's deflection was not considered significant, the gasket was still found to have protruded from the porcelain-flange interface. Earlier attempts to determine the failure mechanism have thus far been unsuccessful. Therefore, Lonnie Elder of ABB Power T\&D Company, Inc., proposed a theory. The theory considered the gasket of the bushing as being compressed into a groove in the flange by a large axial assembly load. This would create a small gap between the steel flange and the porcelain at the connection. When the bushing would be tilted due to horizontal base acceleration or an earthquake, the gap would open slightly and allow the highly compressed gasket to be squeezed out of the porcelain-flange interface, similarly to a fluid. Several versions of retainer rings have also been developed and tested to prevent the bushing from slipping at the porcelain-flange interface, and to prevent the gasket from being extruded. Therefore, a retainer ring was fabricated to fit the to-bettested bushing circumference and the retainer ring was lined with a self-adhesive rubber stripping. The self-adhesive rubber stripping was expected to accommodate the small changes in shape of the circumference of the ceramic diameter of the bushing that forms as part of the process as a ceramic bushing is made. The self-adhesive rubber was considered tough and to get the right thickness, the rubber was applied in layers. Therefore the rubber worked well for fitting the retainer ring to the bushing prior to testing.

To test the bushings adequately, two types of support structures were considered; a fixed support structure and a flexible support structure. In past experiments performed at the Pacific Earthquake Engineering Research Center (PEER), the bushing had not failed when mounted to a fixed support 
structure, however bushing have failed in the field during earthquakes. Therefore a support structure was devised to improve the representation of a transformer cover. For these tests, the transformer cover is represented as the flexible support structure. Both support structures have been compared in this evaluation.

There were several other objectives that were also considered for these tests. Previous seismic testing had shown that the core assembly has been negatively impacted during an earthquake. To ensure that there was no internal damage to the capacitor, the bushings are usually subjected to a production test after initially building the bushing. For the tests that look place at the iSTAR laboratory, it was assumed that the core assembly was not impacted during seismic testing, and a pull test was administered to establish a moment capacity for each bushing. Since the core assembly was not impacted, the moment capacity could possibly be used for seismic qualification in the future. According to Dr. Anshel Schiff, an independent study of seismic conductor loads on bushing was also being considered at the time of testing, therefore added mass was placed on the top of a bushing to see the effects of a conductor mass.

In summary, the objectives of the tests were:

1. Determine how bushings fail due to gasket extrusion at the porcelain-flange connection and to verify that the failure was due to pure tipping and not sliding or walking.

2. Determine the damping introduced when the bushing was supported on a flexible plate with a welded support structure and excited at large amplitude. The flexible plate was to simulate the effects of a bushing on a transformer cover.

3. Find the damping and natural frequency of the assembly.

4. Determine the effects of the bushing response due to added mass on the top of the bushing.

These objectives were planned to be achieved by testing in two stages. The first stage encompassed a complete setup for testing the bushing including ordering all parts and instrumentation for the project and a complete test sequence. The second stage encompassed testing the bushing and analyzing the data.

\section{EQUIPMENT UNDER TEST (EUT)}

Dr. Leon Kempner provided two center clamped, un-cemented "type U" 196 kV bushings. Figure and Figure in Appendix A give the specifications for the bushing, and Figure shows the bushing cross reference information. The name plates for each bushing are shown in Figure and Figure, which show that the bushings were manufactured in 1974. The name plate on the bushing showed the catalog number for the bushings as 11B430G3, a $146 \mathrm{kV}$ to GRD, and a $900 \mathrm{kV}$ BIL. The weight of the bushing was specified as 1000 pounds on the specification sheet in Figure, however the second bushing was weighed before testing, and the weight was found to be $874.27 \mathrm{lb}$. The upper bushing was wrapped prior to testing to prevent any small flying brittle pieces of ceramic that could develop during testing. 


\section{TEST SETUP}

The $196 \mathrm{kV}$ bushings were tested at the iSTAR laboratory at Portland State University. The laboratory was located on the lower level of the Science Research and Teaching Center (SRTC) at the address of 1719 SW $10^{\text {th }}$, Portland, Oregon, 97201. Stage one of the tests was conducted in the month of September and stage two was completed in October, 2013. Both bushings were tested on the iSTAR laboratory seismic shake table. The table is a hydraulic - dynamic system that has single degree of freedom movement in the horizontal direction. The table is moved by two 60-gal/min pumps that are parts of a 55-kip hydraulic actuator. Hydraulic fluid is supplied to the actuator at a pressure of 3,000 psi. The shake table rests on four hydraulic bearings that are essentially frictionless and provide little to no resistance to the motion of the table. The table has a maximum displacement of $+/-6$ inches, which is controlled by the length of the bearings of the table. The maximum velocity of the table is controlled by the flow rate of the pumps that can reach 40 inches per second. The dynamic motion of the table is displacement driven and operated by an input signal in terms of volts. The $9^{\prime}-10^{\prime \prime} \times 9^{\prime}-10^{\prime \prime}(3 \mathrm{~m} \times 3 \mathrm{~m})$ table was designed by MTS Systems Corporation.

To create the stiff set-up for testing, the first bushing was mounted to a turret, the turret mounted to a table mounting plate, and the table mounting plate was attached to the shake table, all by the use of A325 structural bolts. The turret was comprised of an existing turret from past tests, and a turret extension. The total turret height was taller than the lower portion of the bushing by $11 / 2^{\prime \prime}$. The existing turret and turret extension were created from steel piping and steel plates. The drawings for the existing turret and turret extension can be seen in Figure, and Figure. The table mounting plate that was used was 1 1/2" thick and is shown in Figure 911 and Figure. The elevation view of the stiff test set-up is shown in Figure and a photograph of the stiff test set-up is shown in Figure 1. Timber $2 \times 4$ 's were bolted to the shake table and a plastic barrier was added to contain the oil leakage during testing. 


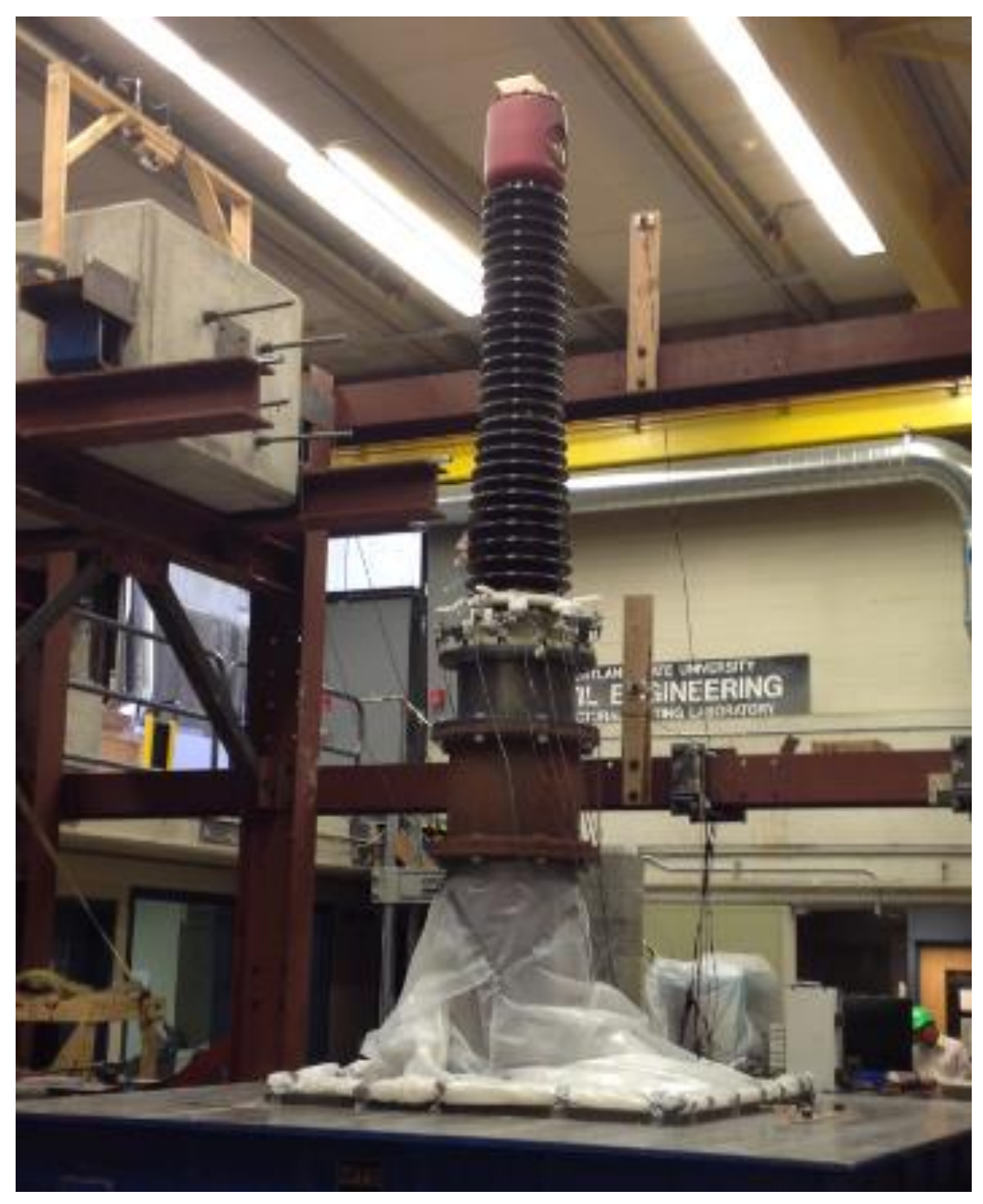

Figure 1: Full view of stiff setup for Bushing 1.

For the flexible set-up, the second bushing was also mounted to the turret, however the turret was mounted to the flexible system before being mounted to the table mounting plate. The table mounting plate was again bolted to the shake table. The flexible set-up involved $2 \times 4 \times 3 / 4$ " sections of HSS around the perimeter of a $1 / 2$ " thick steel plate to create curbs. The curbs are shown in Figure, the flexible plate is shown in Figure and Figure 12, and the elevation view of the flexible set-up is shown in Figure. A photograph of the entire flexible setup is shown in Figure 2 . A plastic barrier and $2 \times 4$ timber was again added to the perimeter to contain oil leakage during testing. 


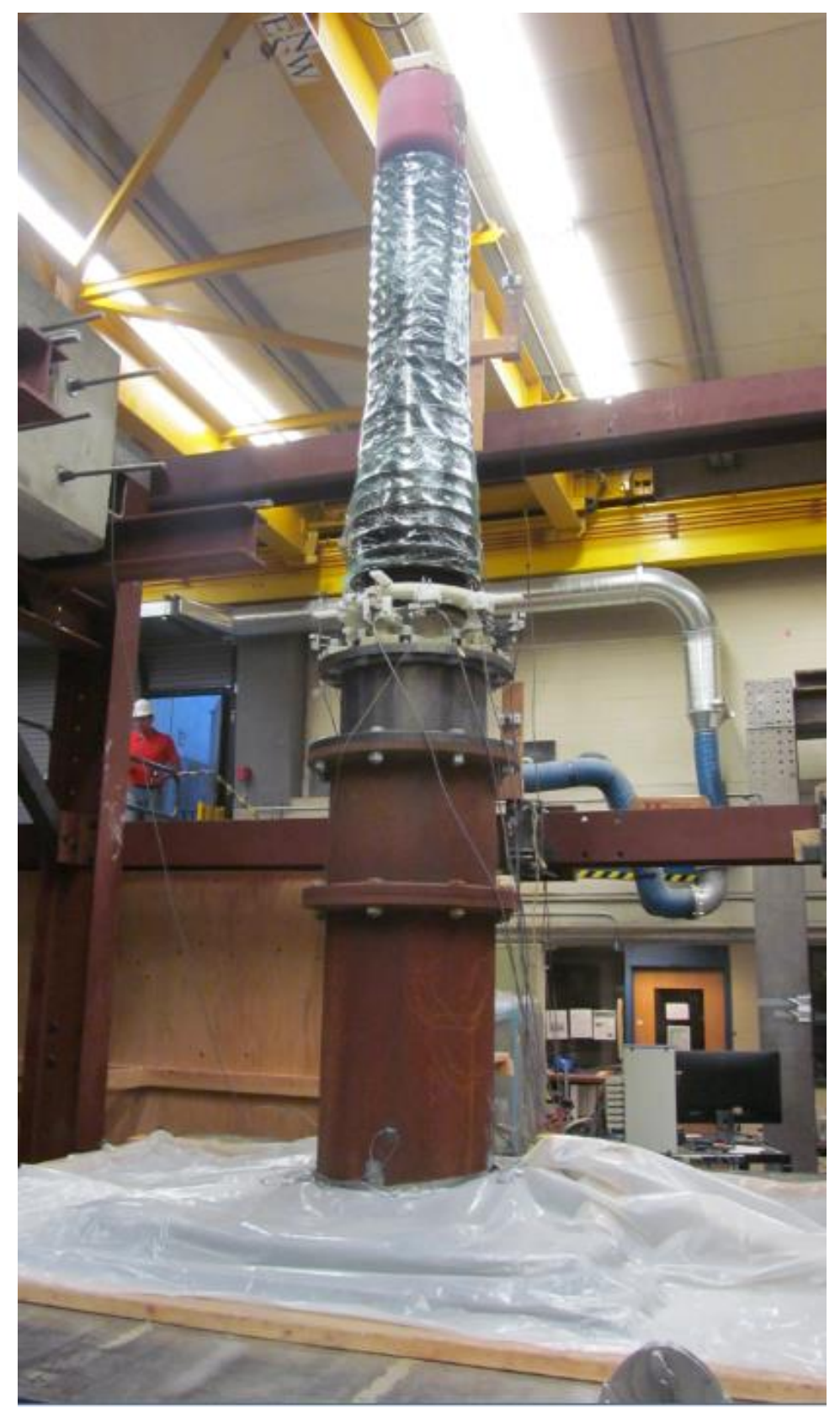

Figure 2: Full view of flexible set up. Plates are below plastic.

\section{TEST TYPE DESCRIPTION}

The snapback test was carried out by applying a load to the top of the bushing in the north/south direction until the load was safe but significant. The load that was applied varied with the test setup and the magnitude of the load was chosen to ensure that the bushing remained within the elastic region of its stress strain curve. The load was applied and suddenly released to let the bushing freely oscillate. The load was applied by the use of a steel cable, a quick release mechanism, a load cell, and a come-a-long. The steel cable was attached to the bushing by looping the steel cable around the top threads of the 
bushing and securing the cable from any vertical movement. The items were attached together in the previous order with shackles. The snapback test was performed to get the natural frequency and damping of the bushing for the fixed and flexible setups.

The static pull test was performed similarly to the snapback test, however the load was slowly released back to zero. The static pull tests were performed before prior to the snapback tests and was also used to find the natural frequency and free vibration.

The man-shake test was performed by manually shaking the top of the bushing at varying frequencies until a desired deflection was reached. Once the desired deflection was reached, the bushing was left to freely oscillate. The man-shake was performed at the top of the bushing to simulate periodic loading and to create low level motion. The man-shake is an alternative test to the snapback test to acquire the natural frequency and damping of the bushing.

The impact test was done with a soft-mallet, a hard-mallet, and the palm of a human hand. The location of impact was also at the top of the bushing was applied with enough force to create a small vibration in the bushing. The bushing was hit on the metal portion of the top cap of the bushing in the north/south and east/west directions. The impact test also provides data to determine the natural frequency and free vibration.

The table pulse test that was chosen for these bushing tests was done by using a half-cycle sine pulse force by means of the shake table. The half-cycle sine pulse is formed by adding a sine function with an amplitude $p_{o}$ that starts at time $t=0$ to a second sine function with the same amplitude, however the starting time is when the first sine wave reaches half the period therefore, $t=t_{d}$. The two sine waves essentially cancel each other out after reaching the time at which half the period is reached, thus leaving a half-cycle sine pulse. (Chopra). For the bushing tests, a time and frequency of $20 \mathrm{~Hz}$ were input into the shake table controllers to simulate the half-cycle sine pulse force. Once the force pulse had stopped, the bushing oscillated freely and the natural frequency and damping were obtained.

The sine sweep search test was done to determine the natural frequency of the bushing by oscillating the shake table after inputting a sine function. For this resonant frequency search test, the amplitude was held constant at $0.1 \mathrm{~g}$ while the table oscillated through every frequency in the range of $1 \mathrm{~Hz}$ to $33 \mathrm{~Hz}$. The resonant frequency could be seen visually during the sine sweep for each test setup by viewing the frequency at which the largest displacement was reached. The largest displacement was experienced when the forced frequency from the table motion and the natural frequency of the bushing were in phase with one another.

The Fourier Transform method was used to transform the time series response in the period-domain to a frequency domain. From the frequency-domain analysis of the dynamic response the natural frequency of the bushing set-up was determined.

A Sine beat test was performed to maximize the bushing deflection. The sine beat consists of a sinusoidal beat motion that matches the resonant frequency of the test set-up. At least 10 cycles of the resonant frequency beats were applied to the setup. 
The targeted Required Response Spectra was created according to the IEEE 693 Recommended Practice for Seismic Design of Substations, for a High required response spectrum of $0.5 \mathrm{~g}$. The formulas shown in Figure 3 for the high required response spectra of $0.5 \mathrm{~g}$ were used to create the desired required response spectra for each ground motion.

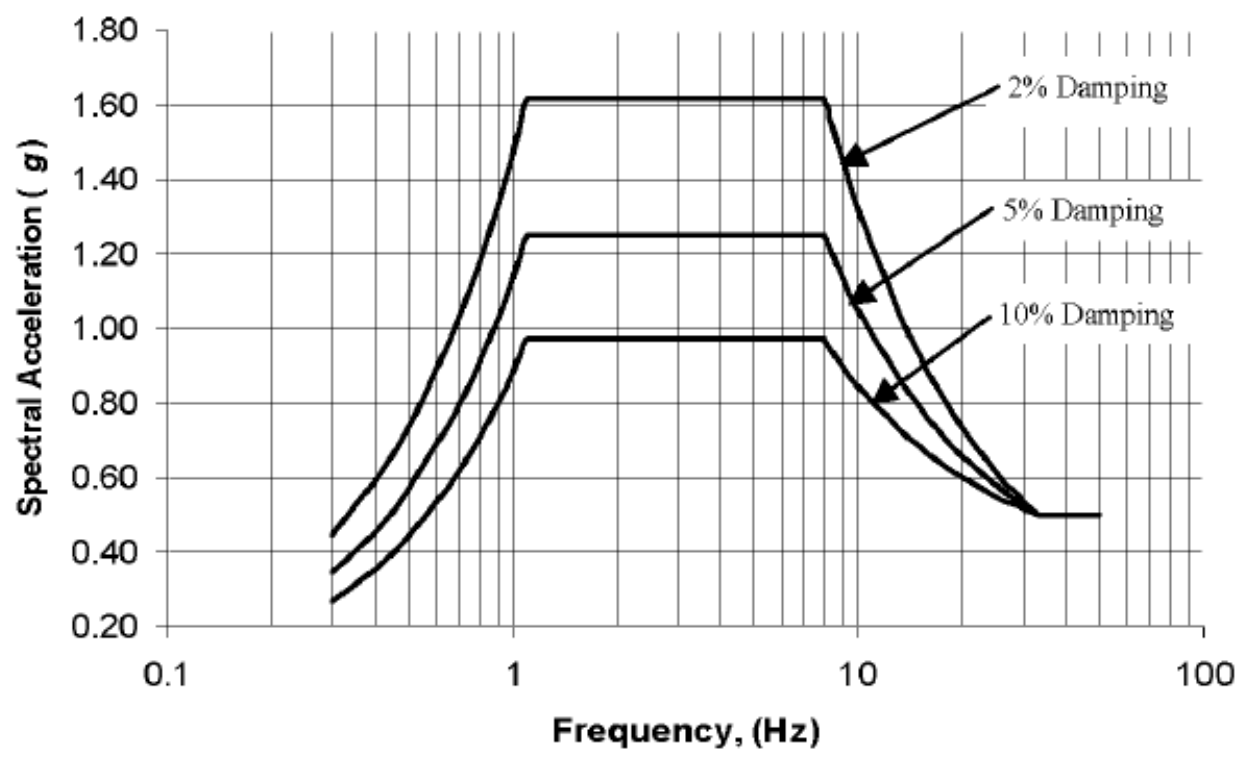

Spectral Accelerations, $S_{a}(g)$, for Frequencies, $f(\mathrm{~Hz})$

$$
\begin{array}{ll}
S_{a}=1.144 \beta f & \text { for } 0.0 \leq f \leq 1.1 \\
S_{a}=1.25 \beta & \text { for } 1.1 \leq f \leq 8.0 \\
S_{a}=(13.2 \beta-5.28) / f-0.4 \beta+0.66 & \text { for } 8.0 \leq f \leq 33 \\
S_{a}=0.5 & \text { for } f>33
\end{array}
$$

$\beta=(3.21-0.68 \ln (d)) / 2.1156$, where $d$ is the percent damping $(2,5,10$, etc. $)$ and $d \leq 20 \%$.

Figure 3: Required Response Spectra according to IEEE 693 Recommended Practice for Seismic Design of Substations.

During the free vibration tests, the natural frequency was found by counting the number of cycles and using the initial starting time and the time at the $\mathrm{n}^{\text {th }}$ cycle. The equation for finding the natural frequency is shown in Equation 1. The logarithmic decrement equation was used to find the damping coefficient and is shown as Equation 2.

$$
\begin{gathered}
\mathrm{f}_{\mathrm{n}}=\frac{n}{T_{n-T_{\sigma}}} \\
\xi=\frac{1}{2 n \pi} x \ln \left(\frac{y_{o}}{y_{n}}\right) x 100 \%
\end{gathered}
$$


Regarding Equation 1, $f_{n}$ is the natural frequency, $n$ is the number of cycles between time $T_{0}$ and $T_{n}, T_{0}$ is the initial time, and $T_{n}$ is the time at the $n^{\text {th }}$ cycle. For Equation $2, \xi$ is the damping coefficient, $n$ is the number of peak displacements, $y_{0}$ is the peak magnitude of the initial cycle, and $y_{n}$ is the peak magnitude of the $\mathrm{n}^{\text {th }}$ cycle.

To calibrate the strain gauges, the strain was related to the moment that was created from the pull test. The moment and strain were related through Equation 3 while the bushing remained within the elastic range of the stress strain curve.

$$
\mathbf{M}=\frac{\text { EEI }}{\mathrm{c}}
$$

For Equation 3, $\mathrm{M}$ is the moment, $E$ is the modulus of Elasticity, $I$ is the moment of inertia, $\varepsilon$ is the strain and $c$ is the distance from the neutral axis to the outermost fiber. For the purpose of these tests, $E$ $I$, and $c$ were considered constant. Therefore, the moment would be equal to some constant multiplied by the strain. Due to this relationship, when the bushing experienced a maximum moment, it will also have experienced a maximum strain. Therefore, the values of the moment and strain at the pull test were set equal to the maximum values of the table motion in which the equation is shown in Equation 4.

OR

$$
\mathbf{M}_{\mathrm{Max}}=\left(\frac{\varepsilon_{\max }}{\varepsilon}\right) \mathbf{M}
$$

(Equation 5)

For Equation 5, $\mathrm{M}_{\mathrm{Max}}$ is the maximum moment the bushing experienced during the table motion, $\varepsilon_{\max }$ is the maximum strain the bushing experienced during the table motion, $\varepsilon$ is the strain from the pull test, and $\mathrm{M}$ is the moment from the pull test.

\section{INSTRUMENTATION}

The necessary instrumentation that was needed for testing consisted of strain gauges, LVDT's, string pots and accelerometers. For the first bushing that was tested, the base number of instrumentation devices was thirty three with thirteen strain gauges, eleven LVDT's, four string pots, two one-direction accelerometers, and three three-direction accelerometers. However, it was necessary to add instrumentation during testing.

For Bushing 1, one string pot was added during Part 2 of the test sequence, and three accelerometers were added during Part 3 . The string pot was added to measure the displacement near the two piece connection of the upper bushing and was located 36-3/8" above the bushing flange. Three onedirectional accelerometers were added at varying locations to measure the acceleration in the northsouth direction. Two of these accelerometers were placed at the top of the bushing ( \pm $\pm 8 \mathrm{~g}$ and a $\pm 30 \mathrm{~g}$ ) 
and the third was also a $\pm 8 \mathrm{~g}$ accelerometer, however it was added to the location of the center of gravity of the bushing.

All of the instrumentation used to test the first bushing was also used to test the second bushing with a few more additions to the base around the flexible plate. For Part 1 of the test sequence, two LVDT's were added in which one measured the vertical displacement, and the other measured the horizontal displacement. The vertical LVDT was mounted to be 6 " from the perpendicular edge of the bottom flange of the turret while the horizontal LVDT was placed between the table mounting plate and the flexible setup. Two strain gauges were placed 1" away from the flange of the bottom of the turret with one strain gauge on the North side of the flexible plate, and the other on the south side.

The instrumentation additions what were necessary during testing are shown in Table 1 with the initial base instrumentation and the final amount for each test setup. Drawings for the planned instrumentation are shown in Figure 4 and Figure 5. Photographs of the instrumentation in place are shown in Figure 6 and Figure 7.

Table 1: Additions to base instrumentation.

\begin{tabular}{|l|r|r|r|r|r|}
\hline $\begin{array}{c}\text { Type of } \\
\text { Instrumentation }\end{array}$ & $\begin{array}{r}\text { Initial } \\
\text { amount }\end{array}$ & $\begin{array}{c}\text { Additions to } \\
\text { Bushing 1 }\end{array}$ & $\begin{array}{c}\text { Total } \\
\text { Instrumentation } \\
\text { Bushing 1 }\end{array}$ & $\begin{array}{c}\text { Additions to } \\
\text { Bushing2 }\end{array}$ & $\begin{array}{c}\text { Total } \\
\text { Instrumentation } \\
\text { Bushing 2 }\end{array}$ \\
\hline Strain gauge & 13 & 0 & 13 & 2 & 15 \\
\hline LVDT & 11 & 0 & 11 & 2 & 13 \\
\hline String Pot & 4 & 1 & 5 & 0 & 5 \\
\hline 1-D Accelerometer & 2 & 3 & 5 & 0 & 5 \\
\hline 2-D Accelerometer & 3 & 0 & 3 & 0 & 3 \\
\hline \hline Total & 33 & 4 & 37 & 4 & 41 \\
\hline
\end{tabular}




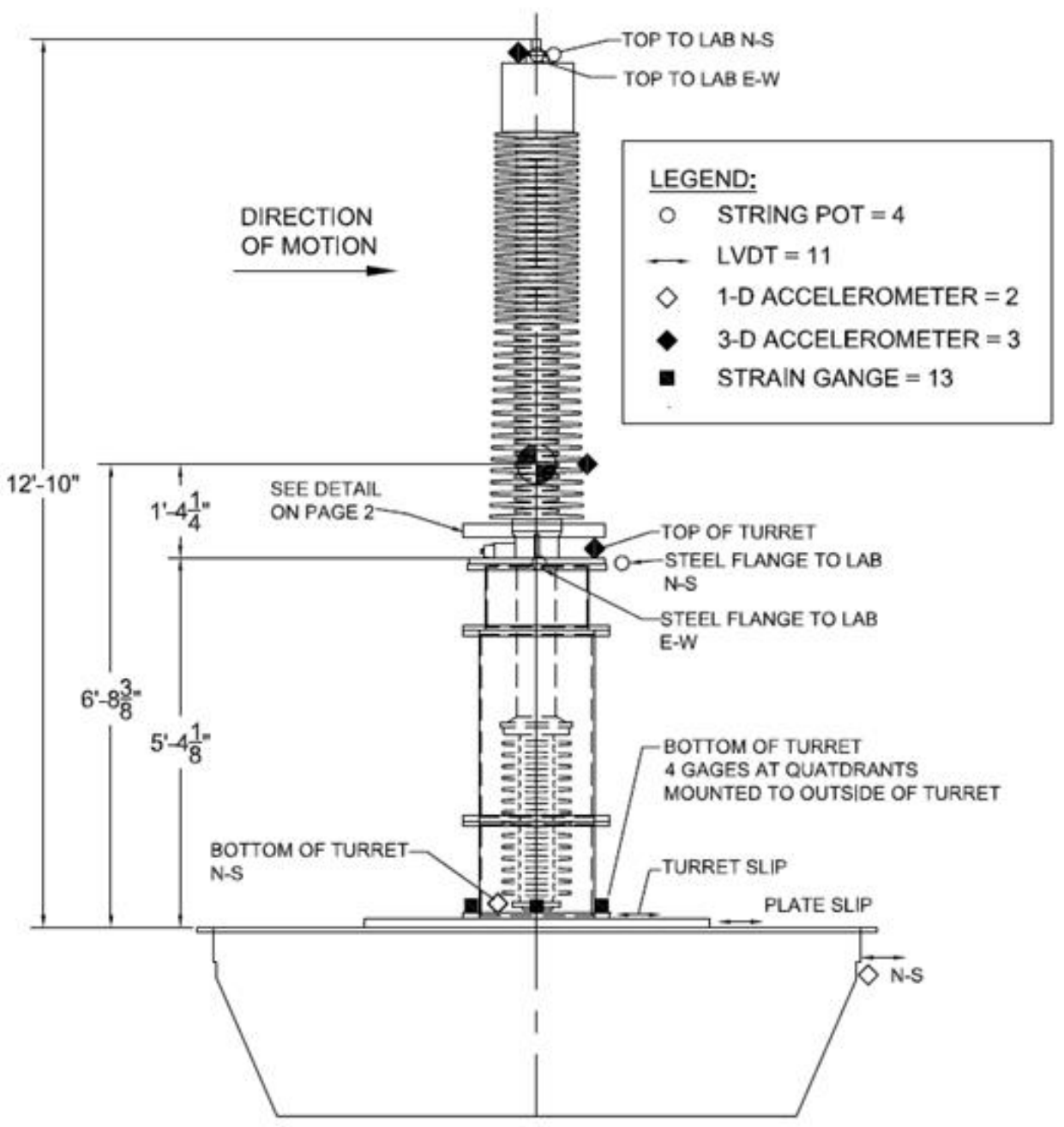

Figure 4: Initial instrumentation plan for both test set-ups. 


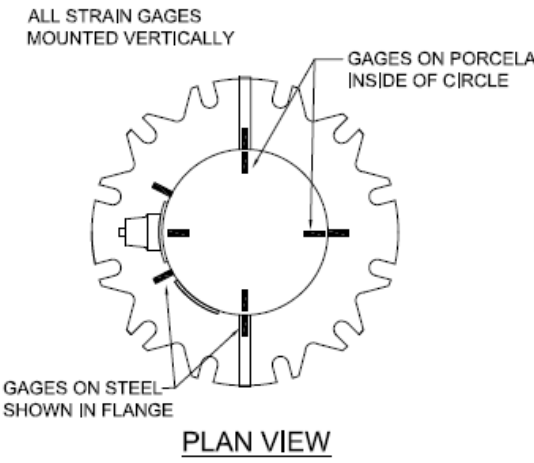

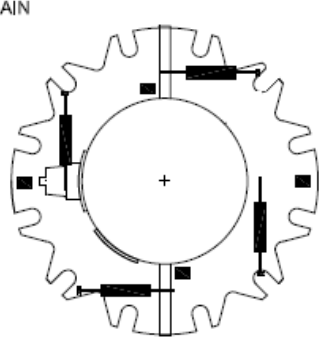

PLAN VIEW

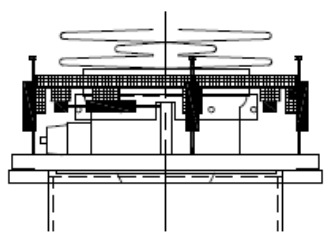

ELEVATION VIEW

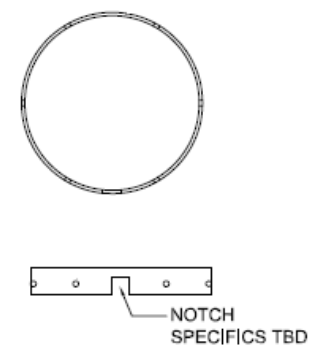

$\underline{\text { COLLAR }}$

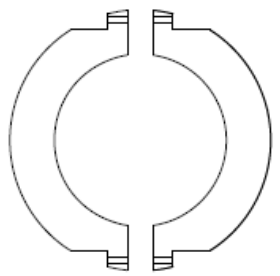

PLASTIC MOUNT

\section{STRAIN GAGES}

9 TOTAL

\section{$\underline{\text { LVDT'S }}$}

Figure 5: Detail of instrumentation at porcelain steel interface, plastic instrumentation mount, and proposed collar.

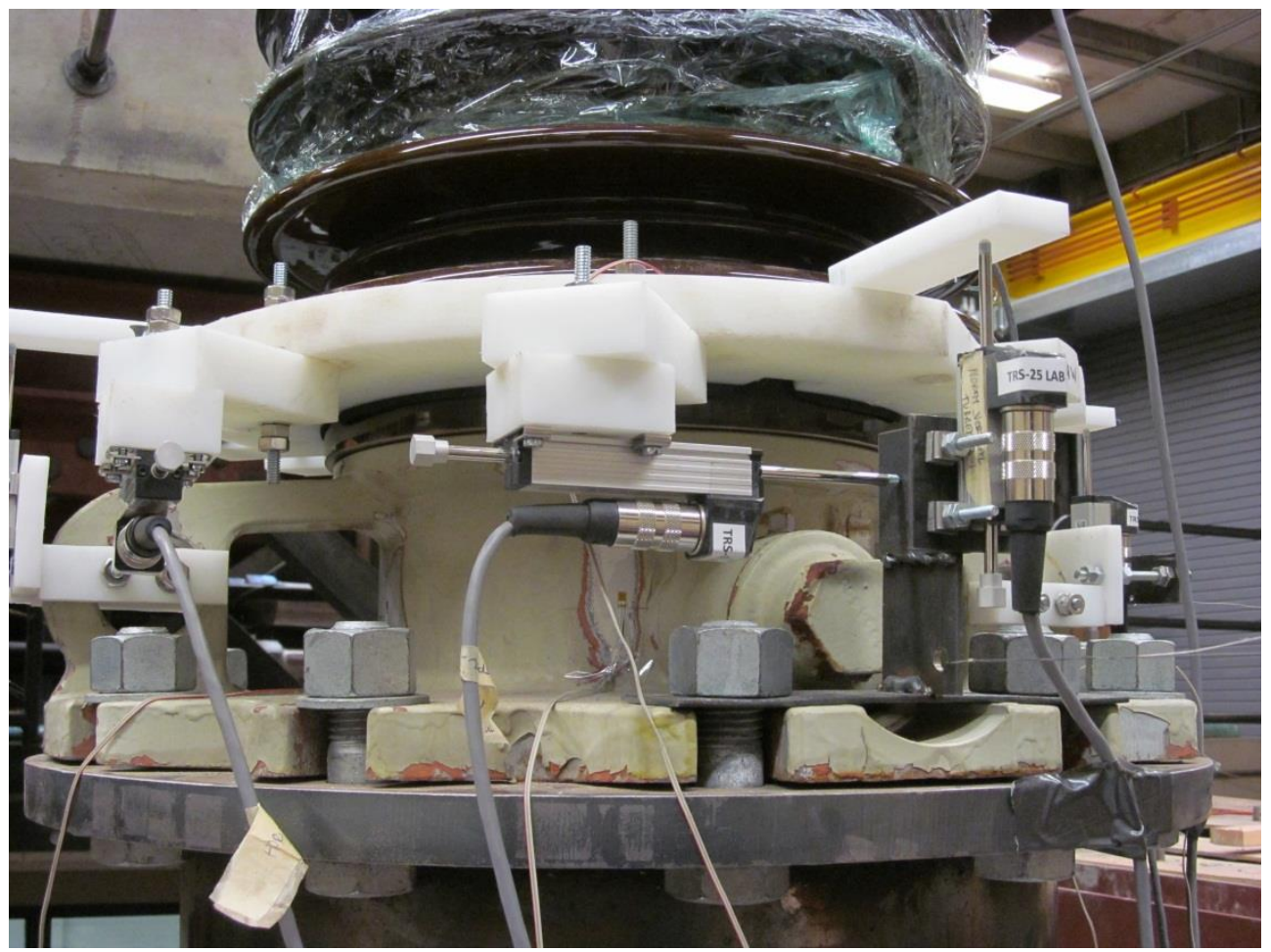

Figure 6: Photograph of LVDT's and instrumentation collar, northeast quadrant of bushing. 


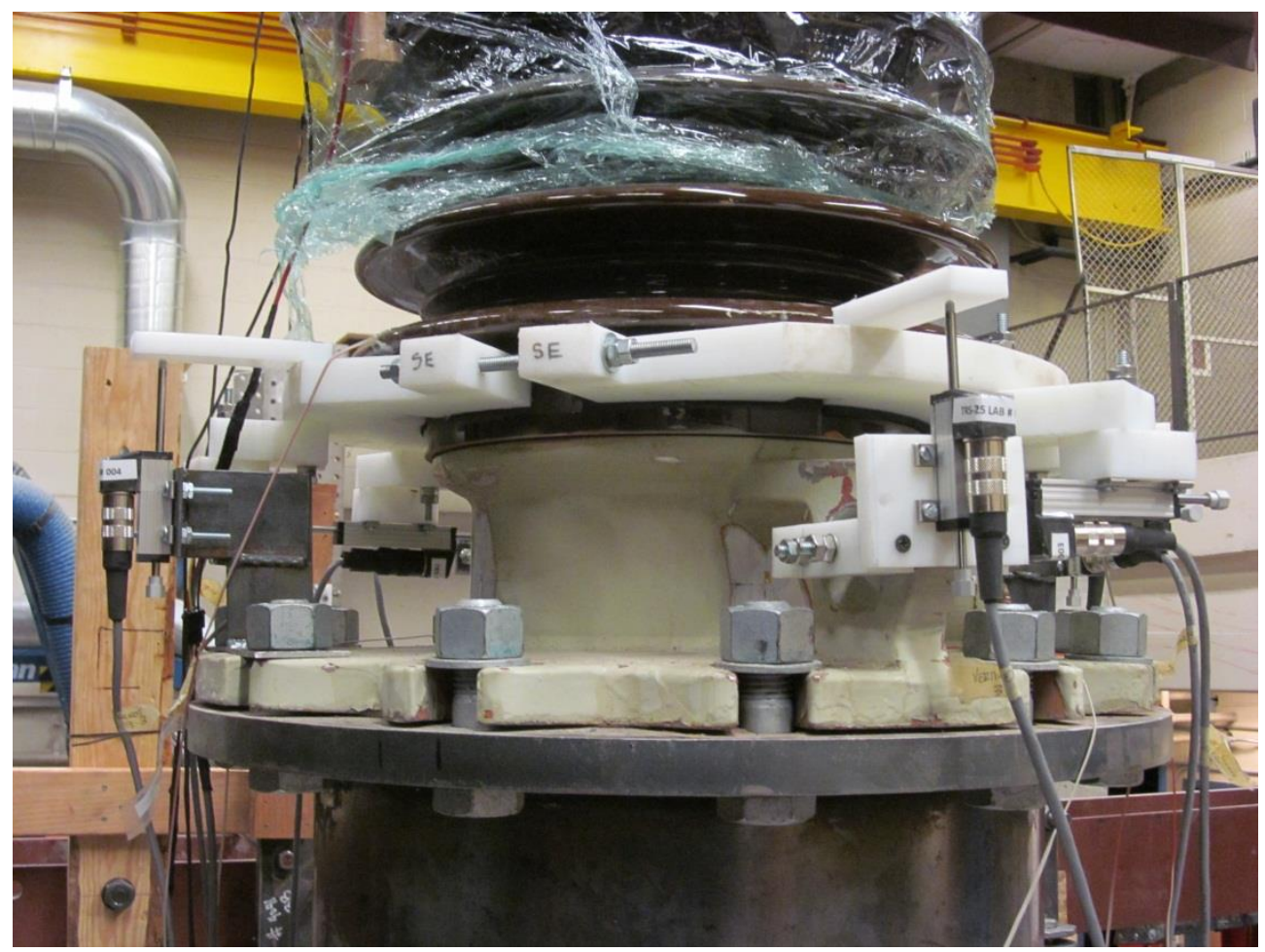

Figure 7: Photograph of LVDT's and instrumentation collar, southeast quadrant of bushing.

\section{TEST SEQUENCE}

For the first bushing tested, the bushing was mounted to the stiff setup described previously. The goals considered were: determine the stiff-mounted natural frequency and damping of the bushings, determine the response to various IEEE 693 excitation levels, as well as to see if the bushing failed during 1.0g required response spectra (RRS).

The test sequence for the second bushing involved testing the bushing on a flexible setup. The flexible setup was also described previously in the Test Setup section. The flexible setup was designed to consider the following objectives: determine the natural frequency and damping on a flexible setup, determine the effect of added mass on the bushing, determine the response to various IEEE 693 excitation levels, and to determine damping of large amplitude systems.

The test sequences for each bushing are shown in Appendix B. Each test sequence was separated into parts according to the day the sequence was tested. 


\section{RESULTS AND DISCUSSION}

\section{Input Response Spectra}

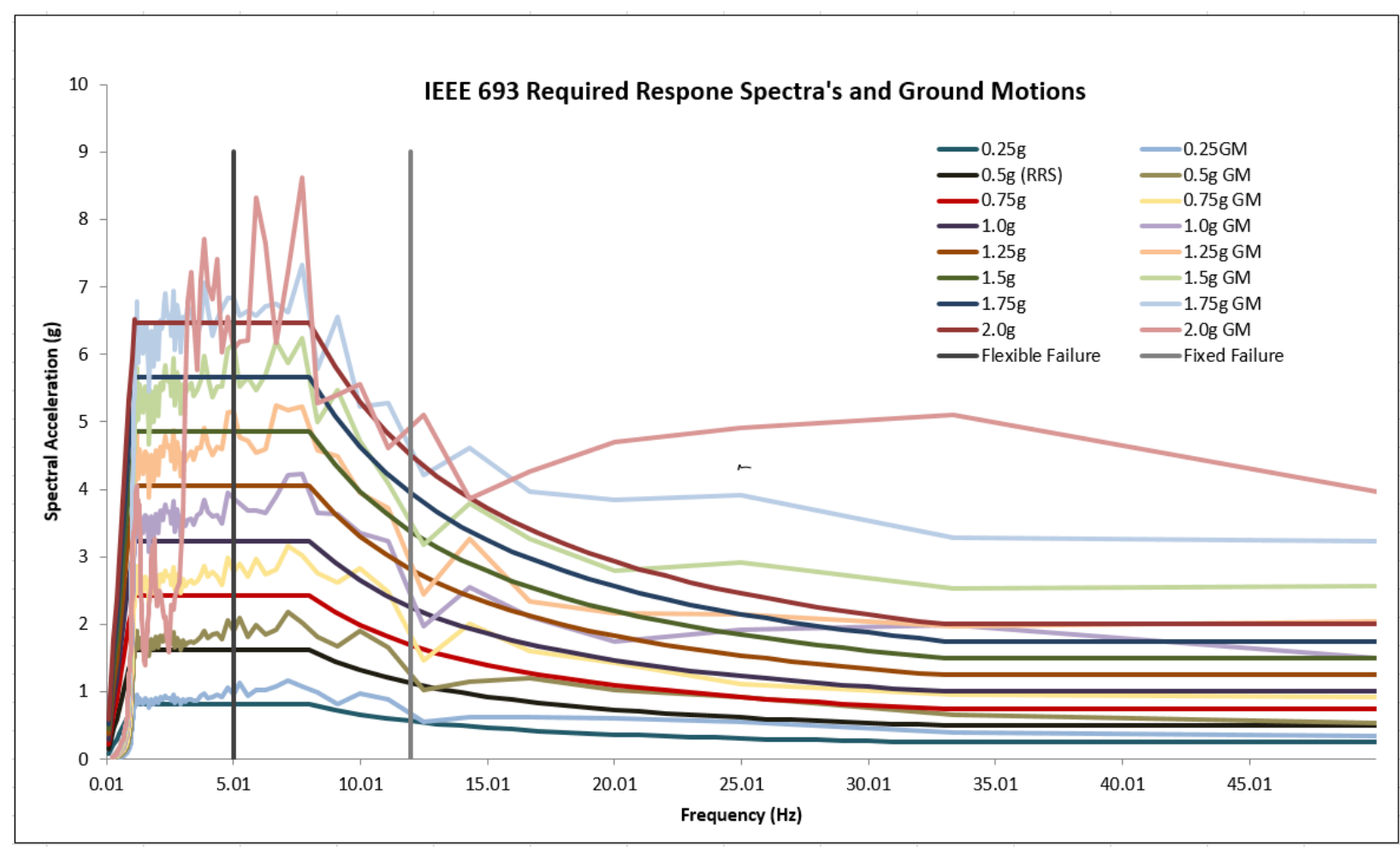

Figure 8: IEEE 693 Required Response Spectra's and Ground Motions.

The targeted Required Response Spectra (RRS) for the IEEE 693 ground motion is shown in Figure 8 with the percent damping assumed to be two percent. The Required Response Spectra amped up to meet the demand for testing. Figure 8 also shows the actual table motions overlaid on the Required Response Spectra. There are also two vertical lines shown in the figure, each representing the natural frequency for the different test Set-Ups. The light gray line represent the Fixed Set-Up and the dark grey line represent the Flexible Set-Up. The figure illustrates that the actual table motion cannot perfectly match the targeted table motion, however when both are compared along the natural frequency of each test Set-Up, the actual Ground Motions was close to the Required Response Spectra for many of the tests.

\section{Max Moment During Dynamic Testing}

To estimate the maximum moment that the second bushing could handle before failure at the porcelain/flange interface, the strain gauges on the steel flange and the moment were used. The maximum moment was found by using Equation 5. To see the linear relationship six dynamic tests were chosen, three from the ground motions, and three from the sine beats. For bushing 1, oil was first noticed after the $1.125 \mathrm{~g}$ sine beat. Table 2 shows the maximum estimated moment that was calculated for the table motion tests for bushing 1 . 
Table 2: The strain and estimated moment values for bushing 1 for selected tests.

\begin{tabular}{|c|c|c|c|c|c|}
\hline & $\begin{array}{l}\text { Strain } \max , \varepsilon_{\max } \\
\text { (in./in.) }\end{array}$ & $\begin{array}{l}\text { Strain, } \varepsilon \\
\text { (in./in.) }\end{array}$ & $\begin{array}{l}\text { Ratio of } \\
\varepsilon_{\max } / \varepsilon\end{array}$ & $\begin{array}{l}\text { Moment, M } \\
\text { (kips-in.) }\end{array}$ & $\begin{array}{c}\text { Max Moment, } \\
\mathrm{M}_{\text {Max }}=\left(\varepsilon_{\max } / \varepsilon\right)^{*} \mathrm{M} \\
\text { (kips-in.) }\end{array}$ \\
\hline \multicolumn{6}{|l|}{$0.25 \mathrm{~g}$ IEEE 693 Ground Motion } \\
\hline South & $3.81 E-05$ & $7.78 \mathrm{E}-05$ & 0.5 & 58.64 & 29 \\
\hline Northwest & $3.84 \mathrm{E}-05$ & 7.09E-05 & 0.5 & 58.64 & 32 \\
\hline Northeast & $3.30 \mathrm{E}-05$ & $6.69 \mathrm{E}-05$ & 0.5 & 58.64 & 29 \\
\hline \multicolumn{6}{|l|}{ 1.5g IEEE 693 Ground Motion } \\
\hline South & $1.19 \mathrm{E}-04$ & $7.78 \mathrm{E}-05$ & 1.5 & 58.64 & 90 \\
\hline Northwest & $1.17 \mathrm{E}-04$ & $7.09 \mathrm{E}-05$ & 1.7 & 58.64 & 97 \\
\hline Northeast & $9.62 \mathrm{E}-05$ & $6.69 \mathrm{E}-05$ & 1.4 & 58.64 & 84 \\
\hline \multicolumn{6}{|l|}{ 1.75g IEEE 693 Ground Motion } \\
\hline South & $1.33 \mathrm{E}-04$ & $7.78 \mathrm{E}-05$ & 1.7 & 58.64 & 100 \\
\hline Northwest & $1.25 \mathrm{E}-04$ & 7.09E-05 & 1.8 & 58.64 & 103 \\
\hline Northeast & $1.13 \mathrm{E}-04$ & $6.69 \mathrm{E}-05$ & 1.7 & 58.64 & 99 \\
\hline \multicolumn{6}{|l|}{ After $1.0 \mathrm{~g}$ Sine Beat } \\
\hline South & $2.64 \mathrm{E}-04$ & $7.78 \mathrm{E}-05$ & 3.4 & 58.64 & 199 \\
\hline Northwest & $1.31 \mathrm{E}-04$ & 7.09E-05 & 1.8 & 58.64 & 108 \\
\hline Northeast & $1.50 \mathrm{E}-04$ & $6.69 \mathrm{E}-05$ & 2.2 & 58.64 & 131 \\
\hline \multicolumn{6}{|l|}{ After $1.125 \mathrm{~g}$ Sine Beat } \\
\hline South & $2.71 \mathrm{E}-04$ & $7.78 \mathrm{E}-05$ & 3.5 & 58.64 & 204 \\
\hline Northwest & $1.37 \mathrm{E}-04$ & 7.09E-05 & 1.9 & 58.64 & 113 \\
\hline Northeast & $1.34 \mathrm{E}-04$ & $6.69 \mathrm{E}-05$ & 2.0 & 58.64 & 117 \\
\hline \multicolumn{6}{|l|}{ After $1.52 \mathrm{~g}$ Sine Beat } \\
\hline South & $3.18 \mathrm{E}-04$ & $7.78 \mathrm{E}-05$ & 4.1 & 58.64 & 240 \\
\hline Northwest & $1.46 \mathrm{E}-04$ & 7.09E-05 & 2.1 & 58.64 & 121 \\
\hline Northeast & $1.45 \mathrm{E}-04$ & $6.69 \mathrm{E}-05$ & 2.2 & 58.64 & 127 \\
\hline
\end{tabular}

For Bushing 1, the maximum force the bushing experienced was $679.85 \mathrm{lb}$ from the pull test. This force of $679.85 \mathrm{lb}$ was connected 85.26 inches above the position of the strain gauges. Using this force and distance, a moment of 58.64 kip-inches was created. At the time, the bushing was being pulled by a force of $679.85 \mathrm{lb}$. The strain gauge reading on the south, northwest, and northeast sides of the bushing were 7.78E-05, 7.09E-05, and 6.69E-05 in./in., respectively.

For Bushing 2, the maximum force of 267lb was used in the pull test, which gave a moment of 22.63 kips-inch. The strain gauge readings at the time the force was $267 \mathrm{lb}$ for the south, northwest and northeast gauges were 3.97E-05, 5.08E-5, and 2.15E-5, in./in., respectively. The maximum strains during the $0.25 \mathrm{~g}$ ground motion at the steel flange were $6.30 \mathrm{E}-05,4.39 \mathrm{E}-05$, and $4.91 \mathrm{E}-05 \mathrm{in}$./in., respectively. Therefore, for the $0.25 \mathrm{~g}$ ground motion, the maximum estimated moments the bushing experienced at the steel flange strain gauge locations were 35.91, 19.56, 51.68 kips-inch, respectively. Table 2 shows the maximum moment for each strain gauge location as 204, 113, and 117 kips-inch for bushing 1. Therefore the moments experienced by Bushing 2 from 0.25 ground motion test at each strain gauge location test were well below the moment capacity of the bushing at those locations. From this relationship, how close the second bushing was to failure during each dynamic test was evaluated. 


\section{Max Accelerations for Ground Motion for Bushing 1}

The maximum accelerations for Bushing 1 for each ground motion are shown in Table 3. These accelerations are also shown in Figure 999 for the various locations of the accelerometers. The bushing did not actually fail during the Ground Motion tests for the Fixed Set-Up. The figure illustrates that with the distance from the shake table the acceleration is increasing. This can be seen from the line representing the top of the bushing and how much higher the acceleration is at the top compared to the center of gravity and also shows the flexibility of the bushing. The top of the bushing reached $5.0 \mathrm{~g}$, when the table reached $3.63 \mathrm{~g}$. Due to the bushing showing no signs of oil leakage, Sine Beats were then used to fail the bushing.

Table 3: Absolute maximum accelerations for each ground motion dynamic test for Bushing 1.

\begin{tabular}{|l|c|c|c|c|c|c|c|c|}
\hline $\begin{array}{l}\text { Percentage of Ground } \\
\text { Motion }\end{array}$ & $\mathbf{5 0 \%}$ & $\mathbf{1 0 0 \%}$ & $\mathbf{1 5 0 \%}$ & $\mathbf{2 0 0 \%}$ & $\mathbf{2 5 0} \%$ & $\mathbf{3 0 0} \%$ & $\mathbf{3 5 0} \%$ & $\mathbf{4 0 0 \%}$ \\
\hline Response Spectra Input & $\mathbf{0 . 2 5 \mathrm { g }}$ & $\mathbf{0 . 5} \mathrm{g}$ & $\mathbf{0 . 7 5 g}$ & $\mathbf{1 g}$ & $\mathbf{1 . 2 5 g}$ & $\mathbf{1 . 5 g}$ & $\mathbf{1 . 7 5 g}$ & $\mathbf{2 g}$ \\
\hline Top of Bushing & 1.00 & 1.56 & 2.34 & 3.19 & 4.12 & 4.45 & 4.87 & 5.00 \\
\hline CG of Bushing & 0.52 & 0.79 & 0.99 & 1.40 & 1.82 & 2.31 & 2.62 & 2.98 \\
\hline Top of Turret & 0.38 & 0.60 & 0.84 & 1.31 & 1.74 & 2.21 & 2.67 & 3.10 \\
\hline Bottom of Turret & 0.28 & 0.47 & 0.73 & 1.22 & 1.56 & 1.95 & 2.57 & 2.99 \\
\hline Table & 0.25 & 0.53 & 0.89 & 1.44 & 1.91 & 2.46 & 3.03 & 3.63 \\
\hline
\end{tabular}

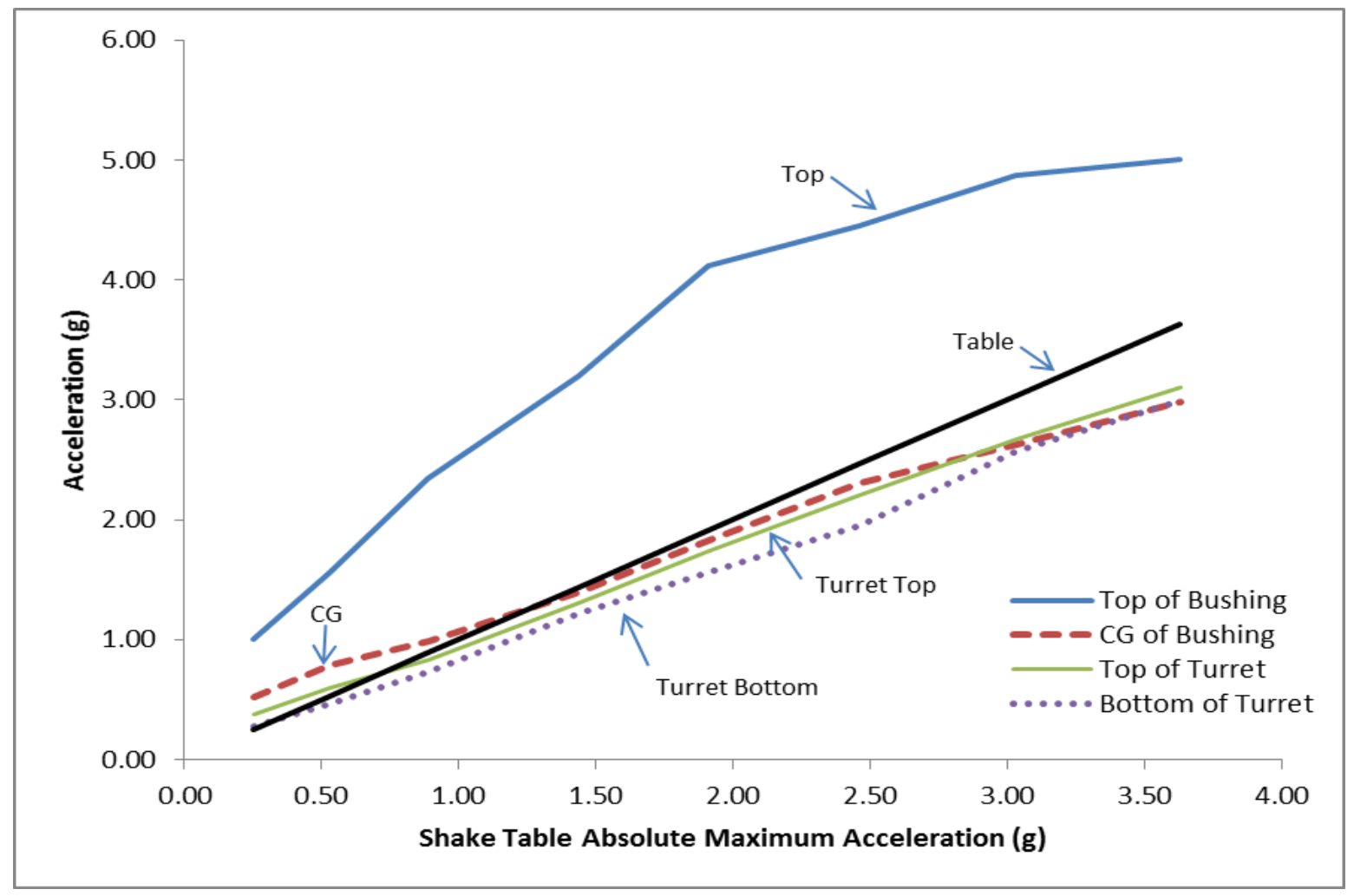

Figure 99: Absolute maximum acceleration comparisons vs. shake table maximum acceleration for the ground motion for Bushing 1. 


\section{Max Accelerations for Sine Beats for Bushing 1}

The maximum accelerations for the Sine Beat tests for Bushing 1 are shown in Table4. These accelerations are also shown in Figure 9910 for the various locations of the accelerometers. Oil was first seen during the $1.125 \mathrm{~g}$ Sine Beat test. The bushing was pushed much farther during the Sine Beat tests than it had been pushed with the ground motion tests. The top of the bushing reached $11.5 \mathrm{~g}$ when the table acceleration was only $1.4 \mathrm{~g}$. This is a much higher acceleration at the top of the bushing with a much lower table acceleration. The acceleration does show a hump in the top curve and oddly oil is seen at the dip in the curve. Therefore the test before oil was seen and the test in which oil was seen was investigated to determine which test actually caused the bushing to fail. However, the data proved that the bushing did indeed fail during the $1.125 \mathrm{~g}$ Sine Beat test.

Table 4: Absolute maximum accelerations for each sine beat dynamic test for Bushing 1.

\begin{tabular}{|c|c|c|c|c|c|c|c|}
\hline $\begin{array}{l}\text { Percentage of } \\
\text { Sine Beat }\end{array}$ & $\begin{array}{l}\text { Response } \\
\text { Spectra } \\
\text { Input }\end{array}$ & $\begin{array}{c}\text { Top of } \\
\text { Bushing }(4 \mathrm{~g} \\
+30 \mathrm{~g})\end{array}$ & $\begin{array}{c}\text { CG of } \\
\text { Bushing (4g) }\end{array}$ & $\begin{array}{c}\text { CG of } \\
\text { Bushing (8g) }\end{array}$ & $\begin{array}{l}\text { Top of } \\
\text { Turret }\end{array}$ & $\begin{array}{c}\text { Bottom of } \\
\text { Turret }\end{array}$ & Table \\
\hline $1.250 \%$ & $0.25 \mathrm{~g}$ & 4.57 & 1.83 & NA & 1.20 & 0.30 & 0.29 \\
\hline $5 \%$ & $0.2625 \mathrm{~g}$ & 5.00 & 2.05 & NA & 1.42 & 0.31 & 0.33 \\
\hline $10 \%$ & $0.275 \mathrm{~g}$ & NA & 2.24 & NA & 1.59 & 0.36 & 0.36 \\
\hline $20 \%$ & $0.3 \mathrm{~g}$ & NA & 2.37 & NA & 1.72 & 0.38 & 0.40 \\
\hline $30 \%$ & $0.325 \mathrm{~g}$ & NA & 2.43 & NA & 1.77 & 0.39 & 0.42 \\
\hline $50 \%$ & $0.375 \mathrm{~g}$ & NA & 2.70 & NA & 2.03 & 0.45 & 0.54 \\
\hline $70 \%$ & $0.425 \mathrm{~g}$ & NA & 2.96 & NA & 2.30 & 0.51 & 0.61 \\
\hline $100 \%$ & $0.5 \mathrm{~g}$ & 9.15 & 3.11 & NA & 2.61 & 0.67 & 0.76 \\
\hline $130 \%$ & $0.575 g$ & 9.64 & 3.31 & 3.44 & 2.84 & 0.78 & 0.82 \\
\hline $160 \%$ & $0.65 \mathrm{~g}$ & 9.92 & 3.42 & 3.49 & 2.97 & 0.81 & 0.85 \\
\hline $200 \%$ & $0.75 \mathrm{~g}$ & 10.48 & 3.72 & 3.85 & 3.35 & 0.93 & 0.97 \\
\hline $250 \%$ & $0.875 g$ & 11.07 & 3.99 & 4.13 & 3.67 & 1.04 & 1.10 \\
\hline $300 \%$ & $1 \mathrm{~g}$ & 11.58 & 4.28 & 4.31 & 3.91 & 1.06 & 1.25 \\
\hline $350 \%$ & $1.125 \mathrm{~g}$ & 11.54 & 4.38 & 4.43 & 3.89 & 1.27 & 1.39 \\
\hline $414 \%$ & $1.33 \mathrm{~g}$ & 12.12 & 4.88 & 5.02 & 4.27 & 1.48 & 1.64 \\
\hline $473 \%$ & $1.52 \mathrm{~g}$ & 12.32 & 4.98 & 5.30 & 4.24 & 1.64 & 1.89 \\
\hline
\end{tabular}




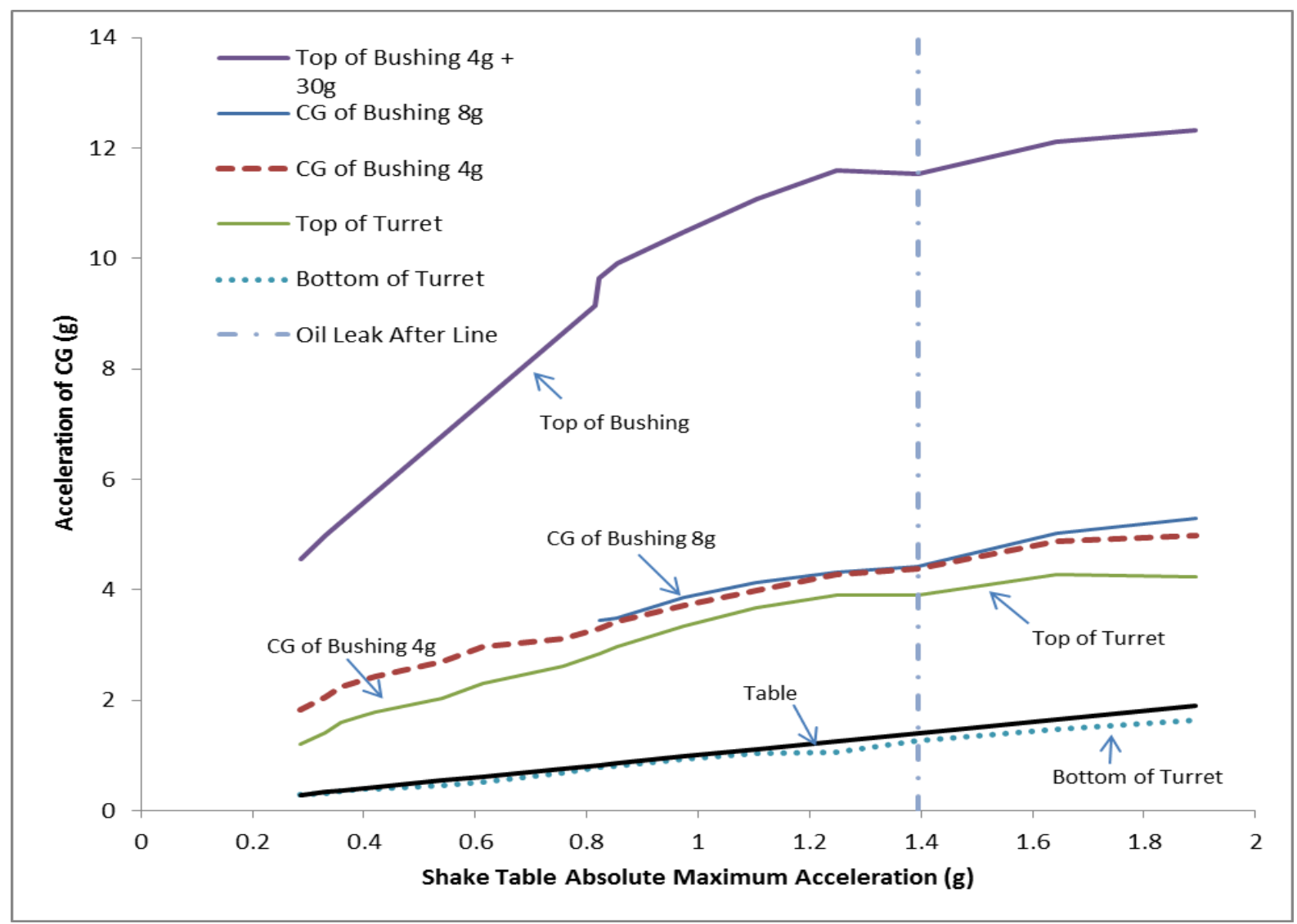

Figure 10: Absolute maximum acceleration comparisons vs. shake table maximum acceleration for the sine beats for Bushing 1.

\section{Max Accelerations for Ground Motion for Bushing 2}

The maximum accelerations for the Ground Motion tests for Bushing 2 are shown in Table5. These accelerations are also shown in Figure 9911 for the various accelerometer locations. Oil was first seen during the $1.5 \mathrm{~g}$ Ground Motion test. Here the top of the bushing maximum acceleration has humps and dips in the curve and can be explained by the $1 / 2$ in plate creating a more flexible system. Notice that there are two different accelerometers at the top of the bushing, however since they provided different results, both were included in the figure. The top of the bushing reached $9.5 \mathrm{~g}$ when the table reached $2.4 \mathrm{~g}$, this is a bit less than the previous test which reached $11.5 \mathrm{~g}$ when it failed. 
Table 5: Absolute maximum accelerations for each ground motion dynamic test for Bushing 2, with no weight added.

\begin{tabular}{|c|c|c|c|c|c|c|c|c|c|}
\hline $\begin{array}{l}\text { Percentage of Ground } \\
\text { Motion }\end{array}$ & $50 \%$ & $100 \%$ & $150 \%$ & $200 \%$ & $250 \%$ & $275 \%$ & $300 \%$ & $325 \%$ & $350 \%$ \\
\hline Response Spectra Input & $0.25 \mathrm{~g}$ & $0.5 \mathrm{~g}$ & $0.75 \mathrm{~g}$ & $1 \mathrm{~g}$ & $1.25 \mathrm{~g}$ & $1.38 \mathrm{~g}$ & $1.5 \mathrm{~g}$ & $1.63 \mathrm{~g}$ & $1.75 \mathrm{~g}$ \\
\hline Top of Bushing $8 \mathrm{~g}$ & 2.26 & 3.24 & 4.30 & 5.26 & 7.26 & 8.24 & 9.39 & 10.09 & 10.26 \\
\hline Top of Bushing 30g & 2.26 & 3.30 & 4.53 & 5.74 & 8.36 & 8.75 & 8.94 & 9.58 & 10.34 \\
\hline CG of Bushing 4g & 1.02 & 1.67 & 2.02 & 2.69 & 3.55 & 3.86 & 4.15 & 4.22 & 4.30 \\
\hline CG of Bushing 8g & 1.21 & 1.82 & 2.30 & 2.90 & 3.81 & 4.00 & 4.14 & 4.24 & 4.56 \\
\hline Top of Turret & 0.83 & 1.34 & 1.63 & 2.30 & 3.22 & 3.24 & 4.27 & 4.89 & 4.94 \\
\hline Bottom of Turret & 0.26 & 0.46 & 0.71 & 1.23 & 1.56 & 1.75 & 1.99 & 2.30 & 2.57 \\
\hline Table & 0.28 & 0.51 & 0.85 & $\operatorname{tgt} 1.44$ & 1.85 & 2.09 & 2.36 & 2.70 & 3.02 \\
\hline
\end{tabular}

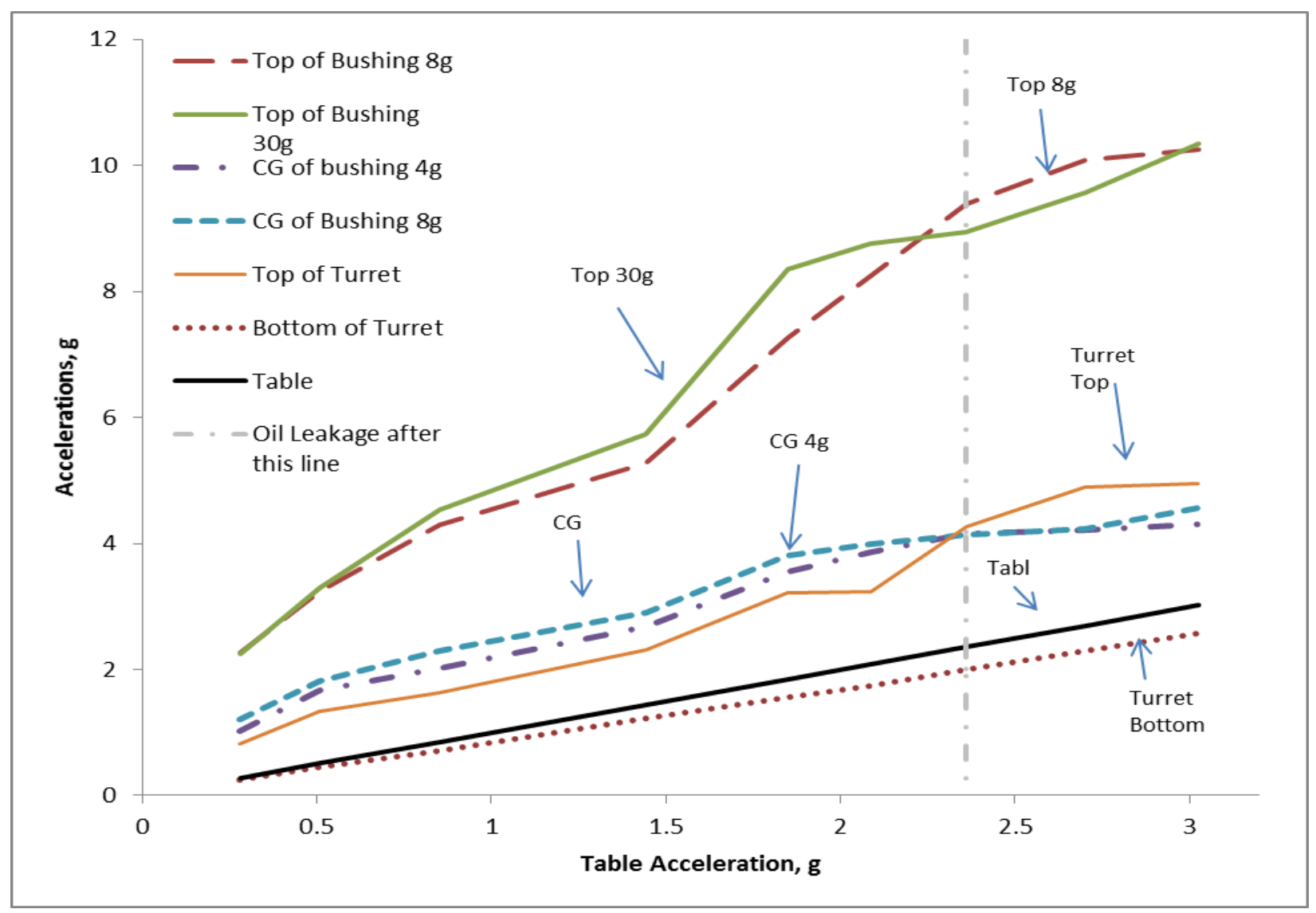

Figure 11: Absolute maximum acceleration comparisons vs. shake table maximum acceleration for the ground motion for Bushing 2.

Considering that for the Flexible Set-Up the top of the bushing reached a much higher table acceleration during a much lower table acceleration when comparing it to the Fixed Set-Up. An explanation can be found when looking at the Input Spectra, Figure 8. The Input Spectra shows that the Flexible Set-Up had a natural frequency of around $5 \mathrm{~Hz}$ during a much higher acceleration, whereas for the Fixed Set-Up the figure shows a lower acceleration at the natural frequency of around $12 \mathrm{~Hz}$. 


\section{Gasket Extrusion for Both Tests}

Neither test produced a gasket extrusion, therefore the method for preventing the gasket extrusion could not be investigated.

\section{Bushing 1 Horizontal and Vertical Rotation and Slippage}

The dynamic tests were assigned a number in the order of test sequence starting with the first ground motion (GM) test of $0.25 \mathrm{~g}$ as test number 1 . All dynamic tests following GM $0.25 \mathrm{~g}$ were tared to the same values in which GM $0.25 \mathrm{~g}$ was tared. The dynamic tests and corresponding number are shown in Table 6.

Table 6: Bushing 1 Dynamic test and corresponding number.

\begin{tabular}{|c|c|}
\hline Test & Test \# \\
\hline GM $0.25 \mathrm{~g}$ & 1 \\
\hline GM $0.50 \mathrm{~g}$ & 2 \\
\hline GM $0.75 \mathrm{~g}$ & 3 \\
\hline GM 1.0g & 4 \\
\hline GM $1.25 \mathrm{~g}$ & 5 \\
\hline GM 1.50g & 6 \\
\hline GM $1.75 \mathrm{~g}$ & 7 \\
\hline GM 2.0g & 8 \\
\hline GM 1.75g Repeat & 9 \\
\hline GM 2.0g Repeat & 10 \\
\hline SB $0.25 \mathrm{~g}$ & 11 \\
\hline SB $0.2625 \mathrm{~g}$ & 12 \\
\hline SB $0.275 \mathrm{~g}$ & 13 \\
\hline SB 0.3g & 14 \\
\hline SB $0.325 \mathrm{~g}$ & 15 \\
\hline SB $0.375 \mathrm{~g}$ & 16 \\
\hline SB $0.425 \mathrm{~g}$ & 17 \\
\hline SB $0.5 \mathrm{~g}$ & 18 \\
\hline GM 1.75g Rerepeat & 19 \\
\hline SB $0.5 \mathrm{~g}$ repeat & 20 \\
\hline SB $0.575 \mathrm{~g}$ & 21 \\
\hline SB $0.65 \mathrm{~g}$ & 22 \\
\hline SB $0.75 \mathrm{~g}$ & 23 \\
\hline SB $0.875 \mathrm{~g}$ & 24 \\
\hline SB 1.0g & 25 \\
\hline SB $1.125 \mathrm{~g}$ & 26 \\
\hline SB 1.34g & 27 \\
\hline SB $1.52 \mathrm{~g}$ & 28 \\
\hline
\end{tabular}


Bushing 1 Porcelain/Flange Interface - Horizontal Movement

The figures for the horizontal changes at the porcelain/flange interface are shown in Figures 12-15 for Bushing 1.

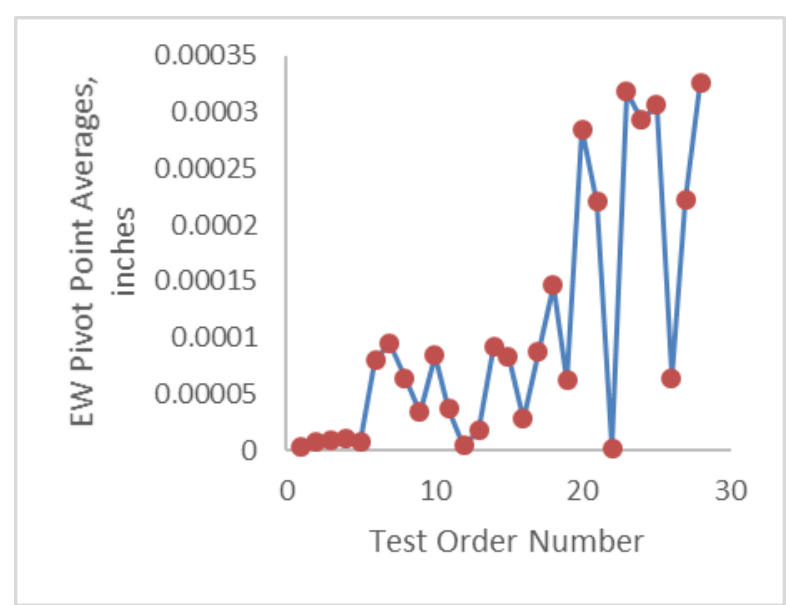

Figure 12: Horizontal Slippage of Bushing in the NS Direction (Direction of Table Motion) for Bushing 1.

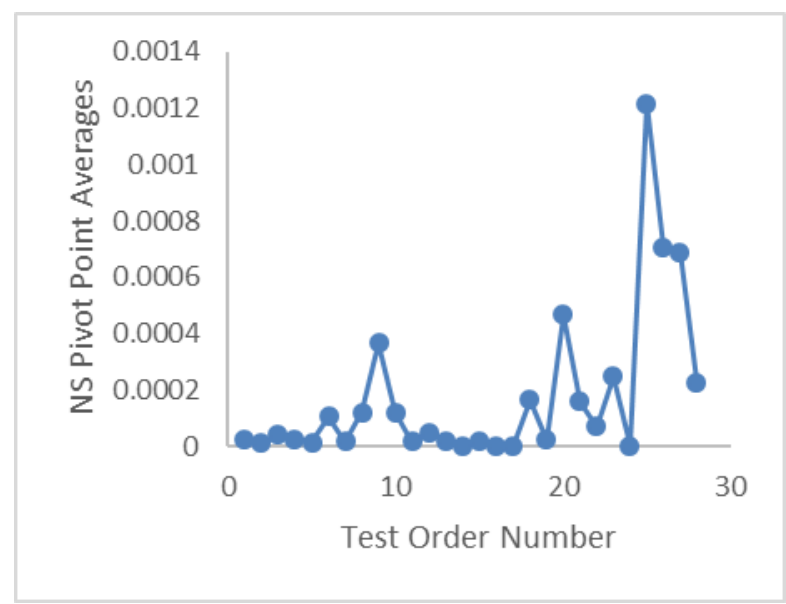

Figure 14: Horizontal Slippage of Bushing in the EW Direction for Bushing 1.

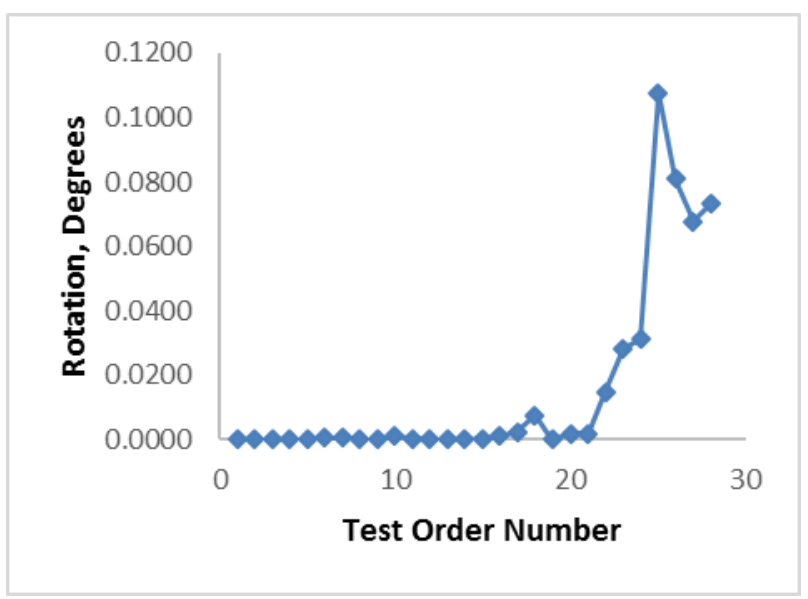

Figure 13: Horizontal Change in Rotation between the Start of the Dynamic Tests and the End of the Dynamic Tests in the EW Direction for Bushing 1.

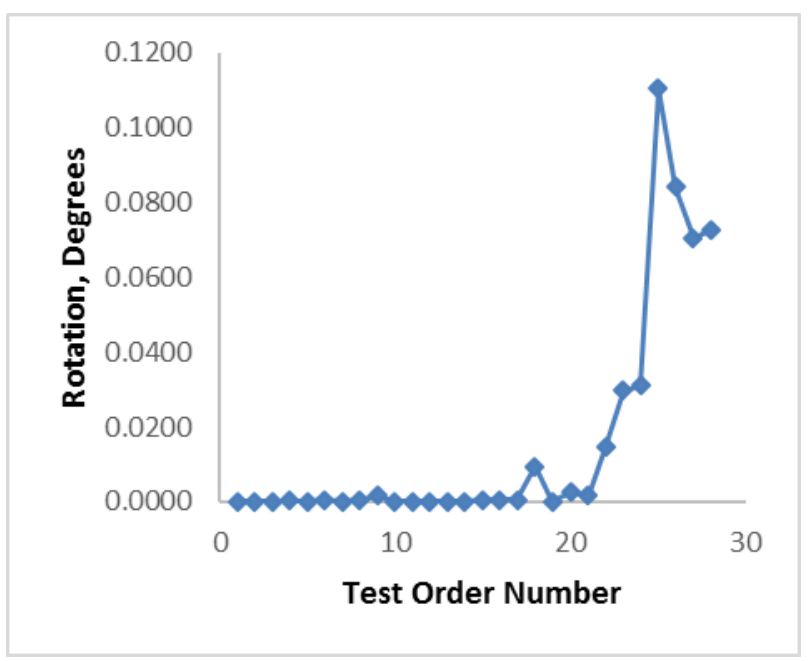

Figure 15: Horizontal Change in Rotation between the Start of the Dynamic Tests and the End of the Dynamic Tests in the NS Direction (Direction of Table Motion) for Bushing 1.

The horizontal slippage at the porcelain/flange interface between the porcelain and steel in the NorthSouth direction, or the direction of the shake table motion, can be seen in Figure12 for the bushing with the fixed setup. The approximate maximum slippage was 3.3E-4 inches for the last test of the $1.52 \mathrm{~g}$ sine beat. Figure14 shows that for the 1.0g sine beat (test 25) there was a maximum slippage of $1.22 \mathrm{E}-3$ inches. The change in horizontal rotation can be seen in Figure 13 and Figure 5 for the bushing on the fixed support. For both East-West and North-South axis, the results were expected to be similar since 
the diameter of both the porcelain and the steel was rigid. Figure 13 and Figure15 illustrate that the change in horizontal rotations for both axis are indeed very similar. The overall change in horizontal rotation between the start of the test and end of the test reached a maximum value during the $1.0 \mathrm{~g}$ sine beat, and was 0.1 degrees.

\section{Bushing 1 Porcelain/Flange Interface - Horizontal Rotation \& Slippage 1.125g Sine Beat} As previously mentioned, Oil was first seen during the 1.25g Sine Beat Test, therefore the next four figures represent the horizontal behavior of the bushing during the test which caused failure.

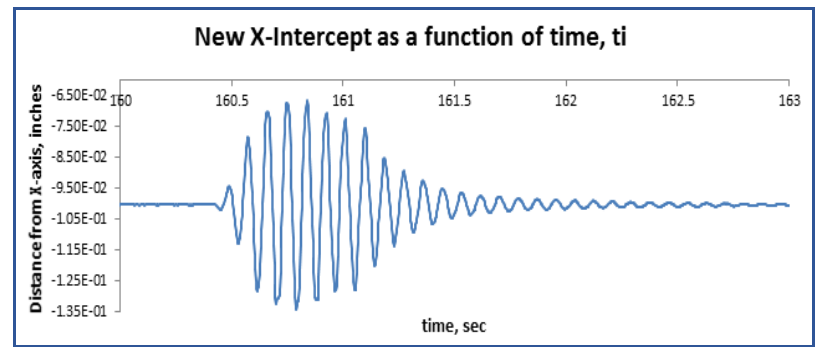

Figure 16: New X-Intercept as a funtion of time, ti

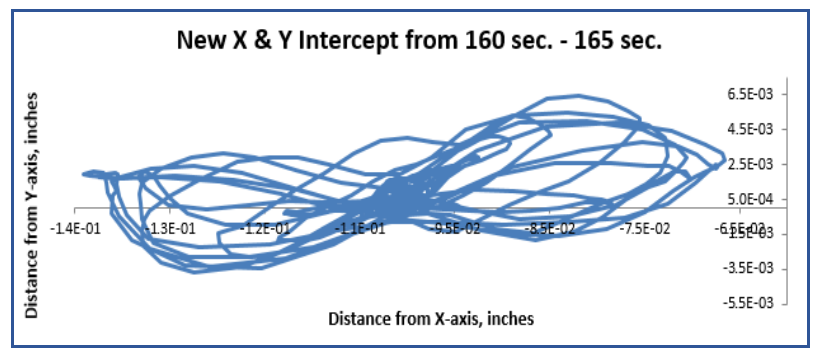

Figure 1810: New X \& Y Intercept from $160 \mathrm{sec}$ - $165 \mathrm{sec}$.

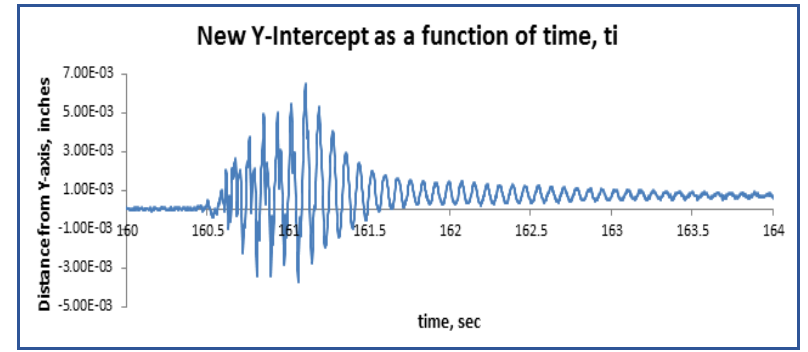

Figure 17: New Y-Intercept as a function of time, ti

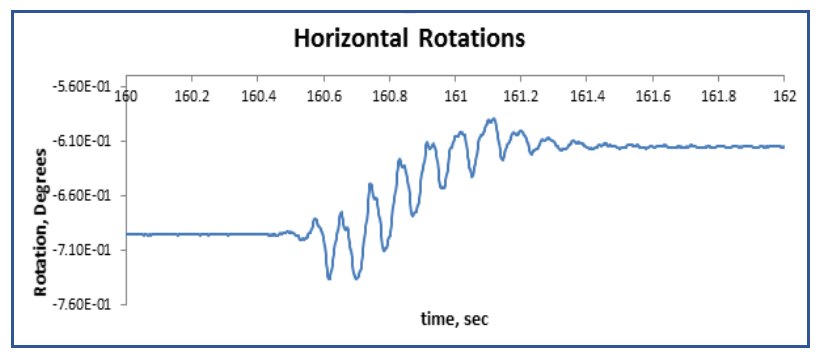

Figure 19: Horizontal Rotations.

These intercepts are from looking at the LVDT's at opposing quadrants and finding the intercept to determine the behavior of the bushing. Figure 16 shows that the $\mathrm{x}$ intercept is no longer at the original zero starting point and it has shifted towards the east quadrant of the bushing. The difference between the lower peak and upper peak is 0.066 inches. Figure 17 shows the $y$-intercept is pretty close to the zero starting point, however over time the y-intercept oscillations shift slightly towards the North quadrant, thus showing slippage. Difference between the lower peak and upper peak is 0.0098 inches and the overall slippage was approximately 0.005 inches.

Figure 18 represents the New $X$ and $Y$ intercept between the time of 60 and 65 second. The horizontal center of the bushing is moving in a figure eight motion during the timeframe. There was much more motion between the East and West quadrants horizontally as opposed to the North and South quadrants, however the center has shifted towards the East quadrant. Oil was first spotted on the plastic between the East and South quadrants which is explained by the fact that there was more 
motion between the East and West quadrants and the center of the bushing shifting towards the East quadrant.

Figure 19 represents the bushings horizontal rotation. You can see that the end oscillations of the tail have shifted upwards and are no longer oscillating around its original starting point which again represents that the bushing is horizontally slipping.

From the horizontal data, you can see that the bushing is spiraling around in a circular motion, with greater motion between the East and West quadrants.

\section{Bushing 1 Porcelain/Flange Interface - Vertical Movement}

The vertical changes at the porcelain/flange interface are shown in Figures 12-17 for Bushing 1.

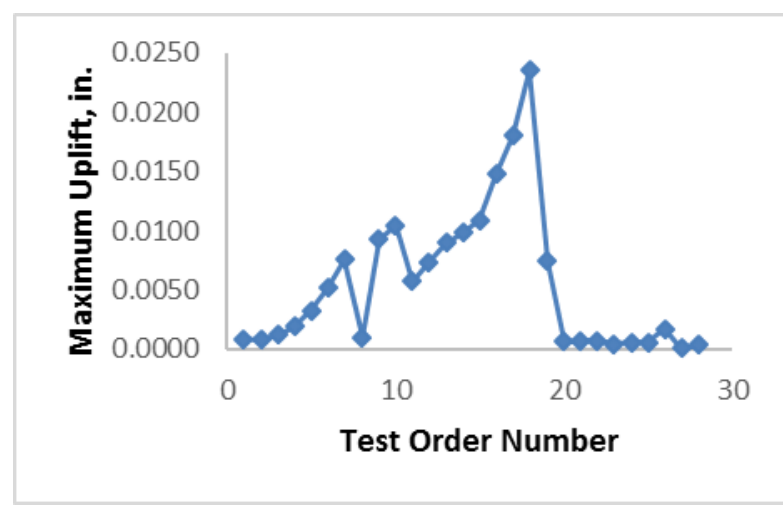

Figure 20: Maximum Vertical Displacement at North Quadrant of Porcelain/Flange interface for Bushing 1.

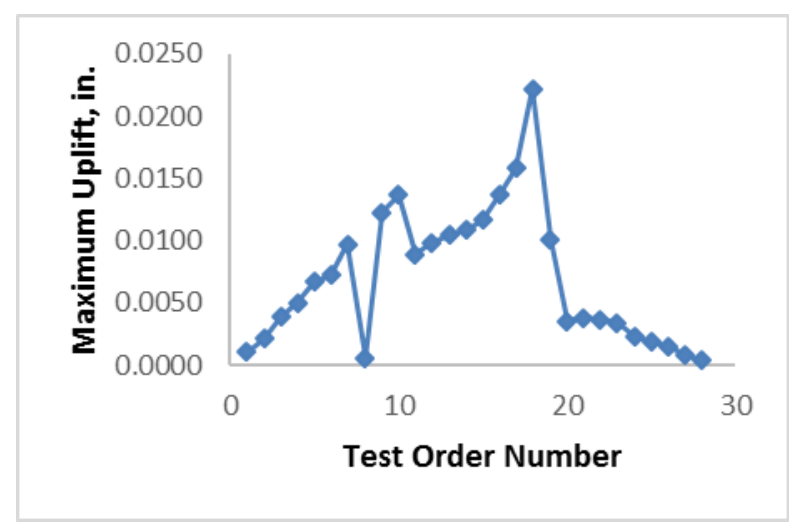

Figure 22: Maximum Vertical Displacement at South Quadrant of Porcelain/Flange interface for Bushing 1.

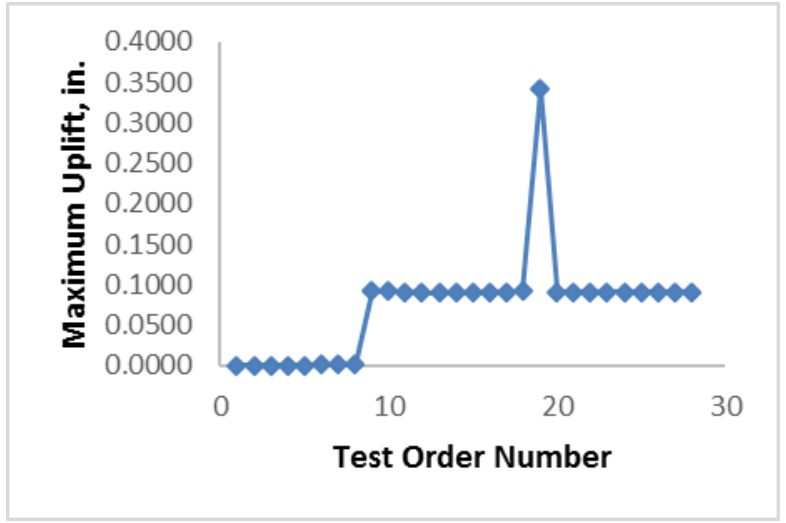

Figure 21: Maximum Vertical Displacement at East Quadrant of Porcelain/Flange interface for Bushing 1.

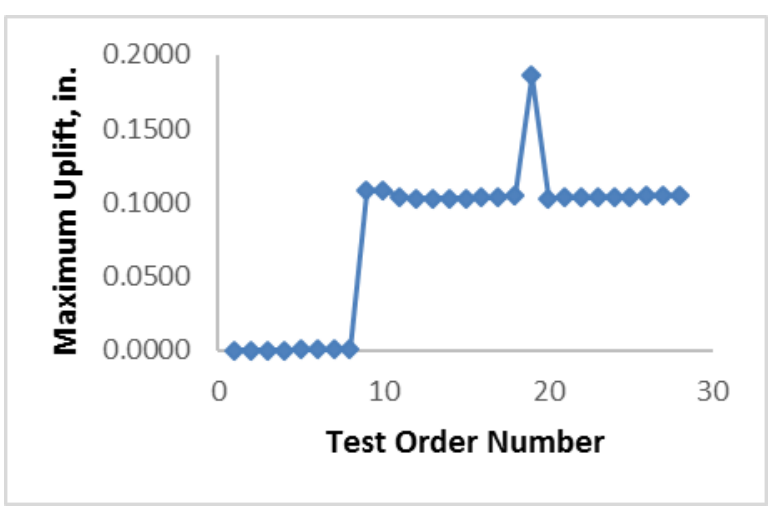

Figure 23: Maximum Vertical Displacement at West Quadrant of Porcelain/Flange interface for Bushing 1. 


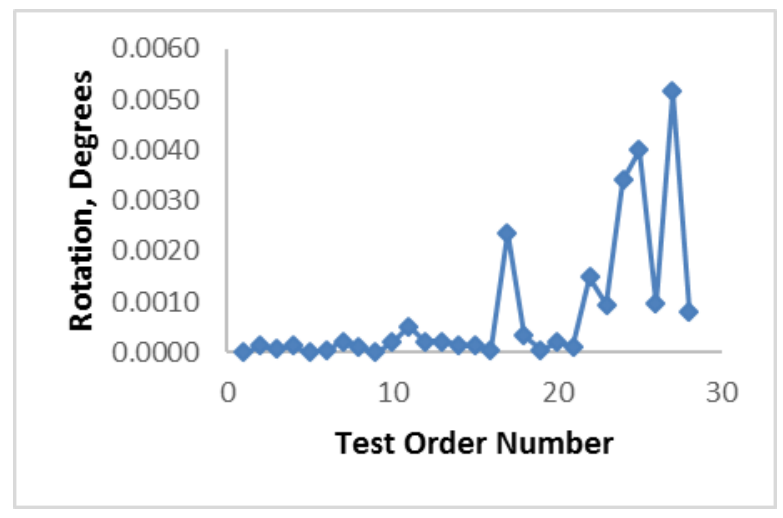

Figure 24: Vertical Change in Rotation between the Start of the Dynamic tests and the End of the Dynamic Tests in the EW Direction for Bushing 1.

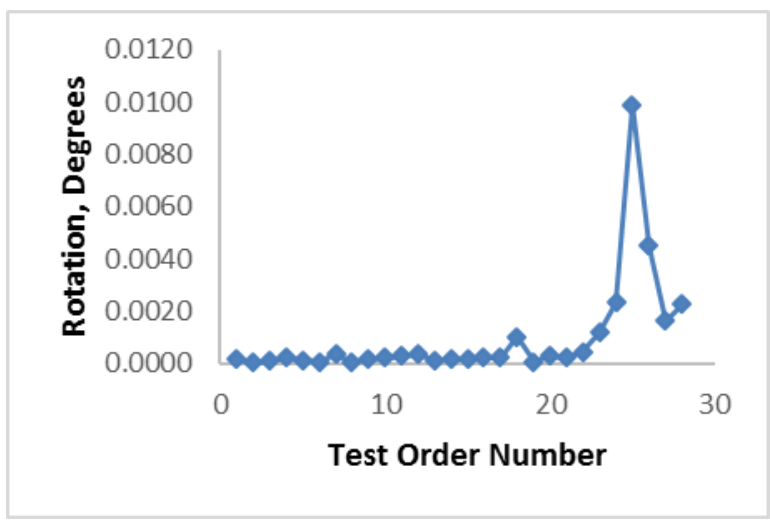

Figure 25: Vertical Change in Rotation between the Start of the Dynamic tests and the End of the Dynamic Tests in the NS Direction (Direction of Table Motion) for Bushing 1.

The vertical maximum displacements for the North and South quadrants of the bushing between the porcelain and steel at the porcelain/flange interface are shown in Figure20 and Figure22. As expected, the overall appearance of the maximum displacement figures are similar and the values are different. The difference in values was expected due to the change in the location of the pivot point of the bushing as the bushing was moved by the table motion. For the North and South quadrants, the maximum vertical displacements were found to be $2.35 \mathrm{E}-2$ and $2.22 \mathrm{E}-2$ inches, respectively, during the $0.5 \mathrm{~g}$ Sine Beat test (test 18). 'The East and West maximum displacement figures were also expected to be similar and are shown in Figure21 and Figure23. The maximum vertical displacement for the East and West quadrants was found during the $1.175 \mathrm{~g}$ ground motion re-repeat (test19) and was 3.4E-1, and 1.86E-1 inches, respectively. Test 19 was the third time that the $1.75 \mathrm{~g}$ ground motion dynamic test had been run and was also the first ground motion test run for part three of the test sequence for the fixed test setup. Since the bushing did not show oil leakage or any signs of failure until the $1.125 \mathrm{~g}$ sine beat test, the vertical maximum results for displacement for test 19 could not possibly have caused failure.

The vertical change in rotation between the start and end of each dynamic test are shown in Figure 24: Vertical Change in Rotation between the Start of the Dynamic tests and the End of the Dynamic Tests in the EW Direction for Bushing 1.24 and 25. The maximum value in the East-West direction was greatest for the 1.34g sine beat (test 27) with a value of 5.13E-3 degrees. Since the maximum value was found after oil leakage was noticed, it is unlikely that the maximum change in rotation in the East-West direction contributed to the failure of the bushing. However in the North-South direction, the largest value was found during test $1.0 \mathrm{~g}$ sine beat test (test 25 ) and was $9.91 \mathrm{E}-03$ degrees. 
Bushing 1 Porcelain/Flange Interface - Vertical Displacement \& Rotation 1.125g Sine Beat The next three figures represent the vertical displacement and rotation during the test that caused failure, the 1.125g Sine Best Test.

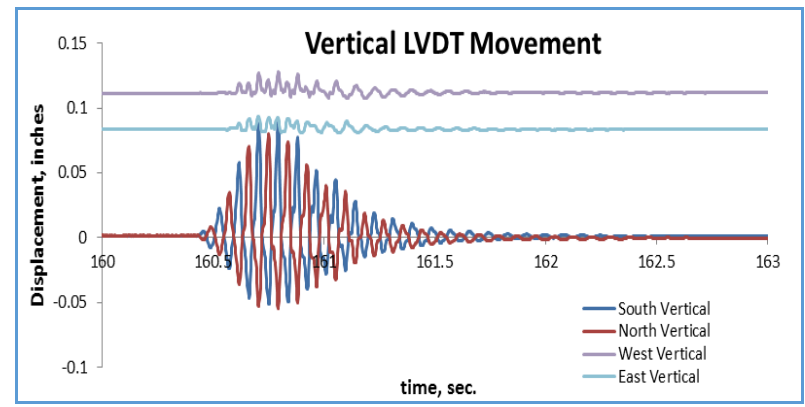

Figure 26: Vertical LVDT Movement.

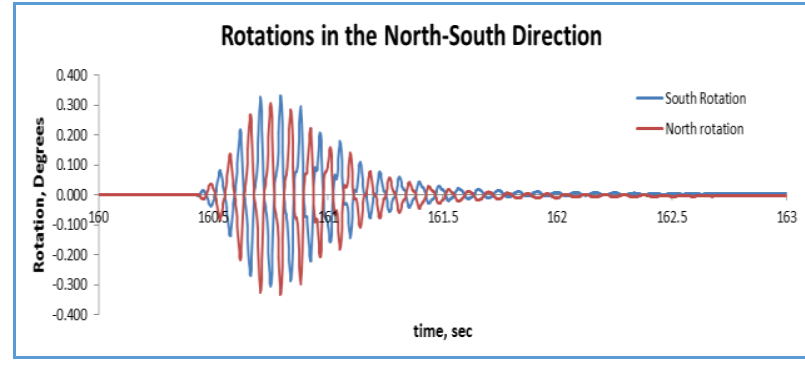

Figure 27: Rotations in the North-South Direction.

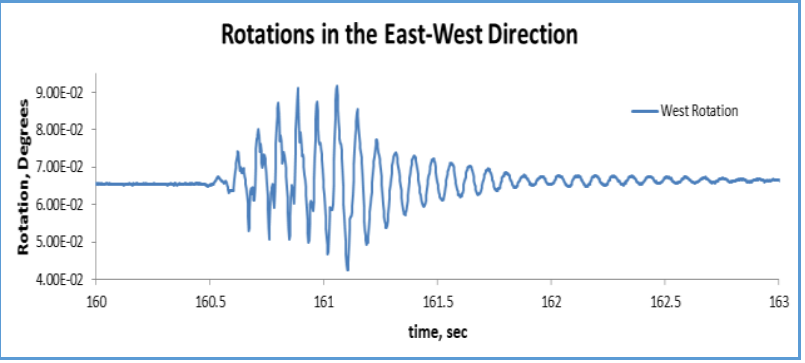

Figure 28: Rotations in the East-West Direction.

Figure 26 shows the North and South vertical displacements are much larger than the East and West displacements. The max change in displacements from the lowest to highest peaks are: the North and South were the same at 0.138 inches, the East reached 0.009 inches, and the West reached 0.015 inches. The South displacement is slightly higher than the North displacements, this could be due to the different layers of the bushing at the porcelain flange interface. The LV outlet was on the North side and the extra components of the LV outlet could have made the North quadrant of the bushing stiffer. The displacement is also higher for West quadrant than it is for the East quadrant and is odd because oil was first seen between the East and South quadrants.

Figure 27 and 28 represent the rotations at the quadrants of the bushing. The rotations for the North/South and East/West are mirror images of each other. The max rotation in the North and South was 0.33 degrees from the center of rotation whereas the max rotation in the East West was 0.048 degrees from the center of rotation. Therefore the rotation for the North and South was much higher. The bushing was definitely moving more in the North South direction which again makes sense considering it was the same direction as the shake table motion. 
Bushing 1 Porcelain/Flange Interface - Horizontal vs. Vertical Movement

The horizontal and vertical displacements for the Fixed Set-up are shown below in Figures 29 and 30. These two figures only show the displacements for the Sine Beat tests therefore for this comparison the test that caused failure test \#13. Figure 29 shows that there was much more horizontal displacement than vertical displacement during the Sine Beat tests. The maximum horizontal displacement was at the West quadrant and was 0.2 inches, the maximum vertical displacement was also at the west quadrant and was 0.13 inches. Therefore for the fixed Set-Up, the horizontal displacement appears to contribute more to the failure of the bushing than the vertical displacement.

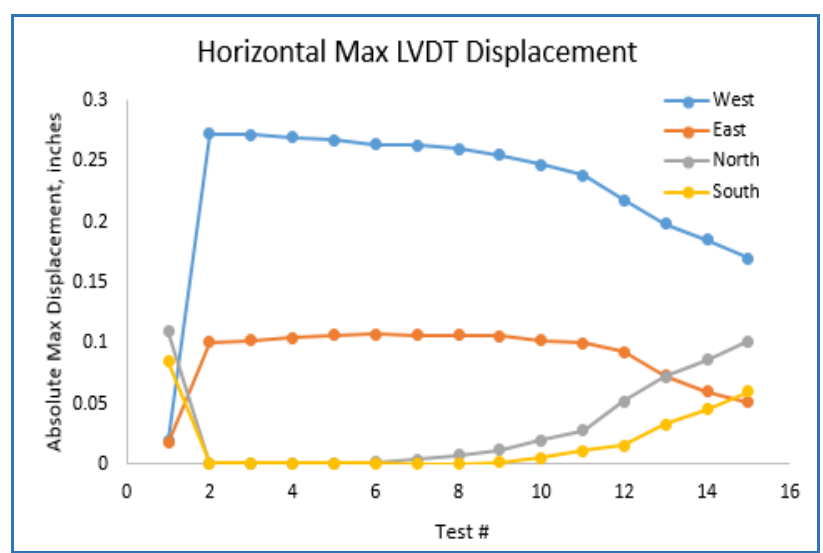

Figure 29: Horizontal MAX LVDT Movement

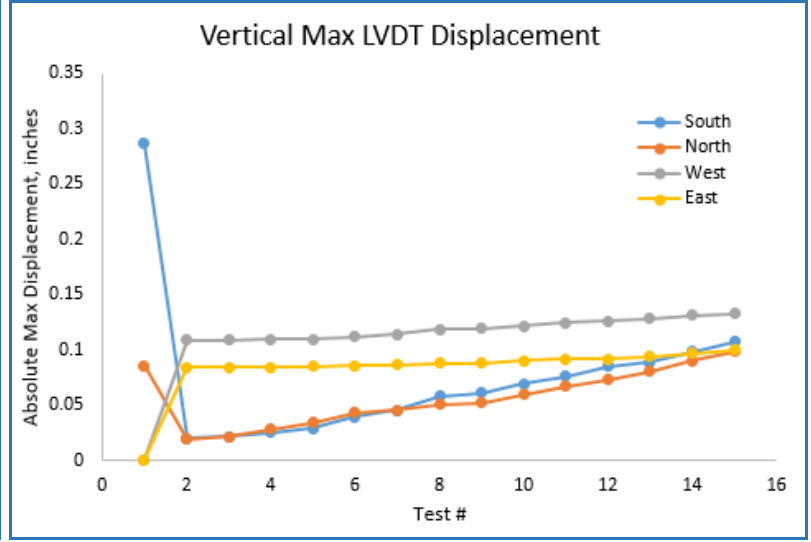

Figure 30: Vertical Max LVDT Displacement

From the vertical and horizontal displacements and rotation, the data shows the bushing failed due to horizontal slippage and rotation as well as vertical rocking. The bushings failure appeared to be caused more by the horizontal displacement than the vertical displacement.

\section{Bushing 2 Horizontal and Vertical Rotation and Slippage}

The dynamic tests for Bushing 2 were also tared with the first dynamic test performed for the flexible setup, GM $0.13 \mathrm{~g}$ with the $45 \mathrm{lb}$ weight added to the top of the bushing. The dynamic tests and corresponding numbers are shown in Table 7. 
Table 7: Bushing 2 Dynamic test and corresponding number.

\begin{tabular}{|c|c|}
\hline Test & Test \# \\
\hline 45lb Weight GM 0.13g & 1 \\
\hline 45lb Weight GM 0.25g & 2 \\
\hline 45lb Weight GM 0.38g & 3 \\
\hline 15lb Weight GM 0.25g & 4 \\
\hline Olb Weight GM 0.25g & 5 \\
\hline GM 0.25g redone & 6 \\
\hline GM 0.50g & 7 \\
\hline GM 0.75g & 8 \\
\hline GM 1.00g & 9 \\
\hline GM 1.25g & 10 \\
\hline GM 1.375g & 11 \\
\hline GM 1.50g & 12 \\
\hline GM 1.625g & 13 \\
\hline GM 1.75g & 14 \\
\hline
\end{tabular}

Bushing 2 Porcelain/Flange Interface - Horizontal Movement

The horizontal changes at the porcelain/flange interface are shown in Figures 31-34 for Bushing 2, the flexible Set-Up.

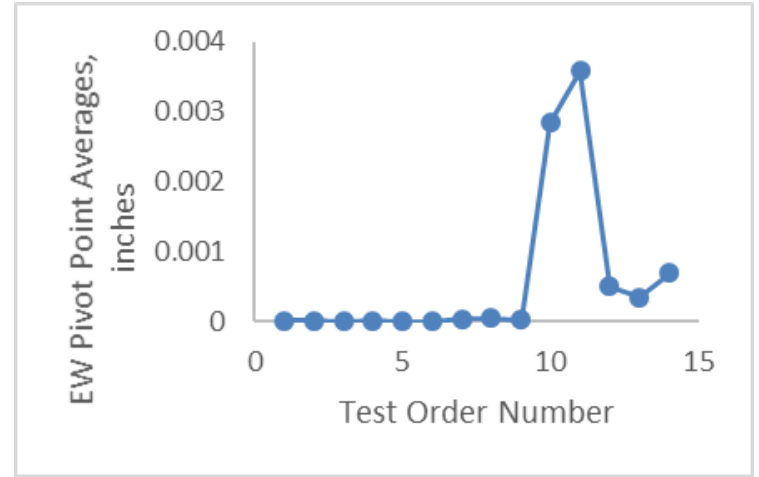

Figure 31: Horizontal Slippage of Bushing in the NS Direction (Direction of Table Motion) for Bushing 2.

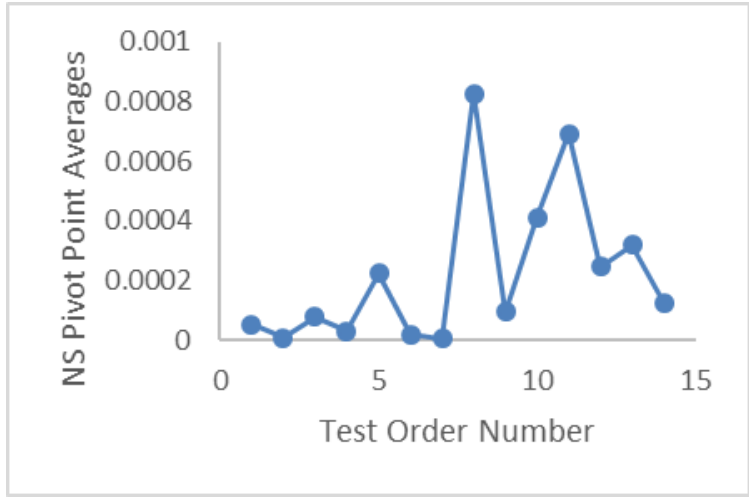

Figure 33: Horizontal Slippage of Bushing in the EW Direction for Bushing 2. 


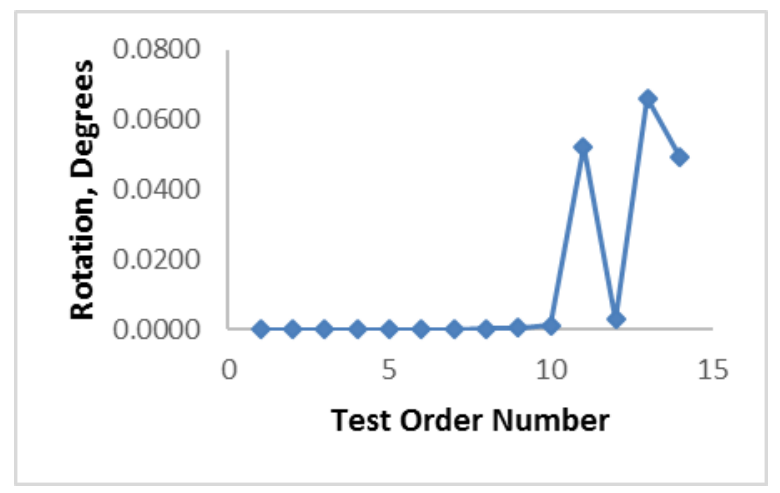

Figure 32: Horizontal Change in Rotation between the Start of the Dynamic Tests and the End of the Dynamic Tests in the EW Direction for Bushing 2.

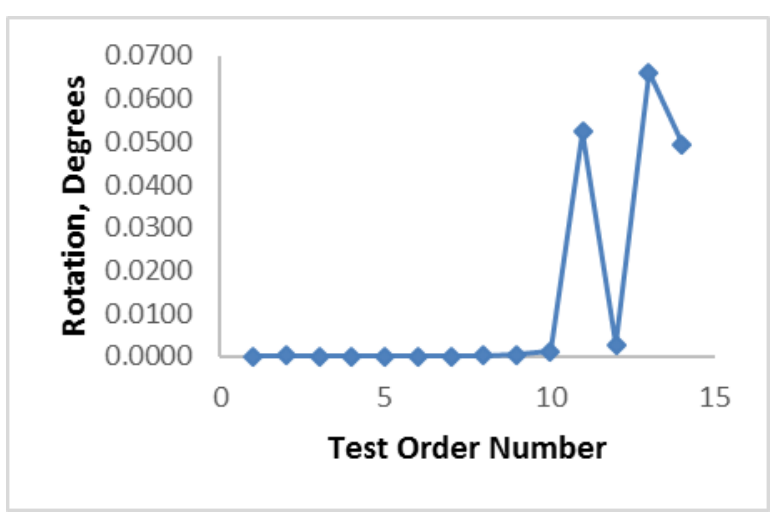

Figure 34: Horizontal Change in Rotation between the Start of the Dynamic Tests and the End of the Dynamic Tests in the NS Direction (Direction of Table Motion) for Bushing 2.

For the bushing bolted to the flexible setup, the horizontal slippage at the porcelain/flange interface for the North-South and East-West directions can are shown in Figures 31 and 32. For the North-South direction, the maximum slippage of $3.59 \mathrm{E}-3$ inches was found during the $1.375 \mathrm{~g}$ ground motion test (test 11 ). However the slippage did increase significantly for the $1.25 \mathrm{~g}$ ground motion test (test 10$)$. The slippage for the $1.25 \mathrm{~g}$ ground motion test was $2.85 \mathrm{E}-3$ inches, but for all previous tests the average of slippage was must less and was only $1.63 \mathrm{E}-5$ inches. Oil was first seen during the $1.50 \mathrm{~g}$ ground motion test (test 12 ) in which the slippage was much less and was only 5.04E-4 inches. For the East-West direction, the slippage varied more throughout the tests, and the values increased and decreased as testing was carried out. The maximum was found during the $0.75 \mathrm{~g}$ ground motion test (test 8 ) with a value of $8.27 \mathrm{E}-4$ inches. The test at which the maximum value was found appears to be random and does not correlate with the test that oil was first seen in, or even the test just before.

The horizontal change in rotation for the North-South and East-West axis between the porcelain and the steel at the porcelain/flange interface are shown in Figures 33 and Figure34. Both figures appear similar as expected and show an increase in the change in horizontal rotation for the $1.375 \mathrm{~g}$ ground motion (test 11) of 5.23E-2 degrees for both axis. The values reflect the change in averaging the first portion of the data before the ground motion began and the last portion of the data, after the dynamic test had been run, and taking the difference between the two averages. For the test that showed oil leakage, the $1.50 \mathrm{~g}$ ground motion (test 12 ), and the change in rotation actually dropped to $2.83 \mathrm{E}-3$ degrees for both axis. However, the change in rotation increased again during the test directly after the $1.50 \mathrm{~g}$ ground motion and was $6.63 \mathrm{E}-2$ degrees for the $1.625 \mathrm{~g}$ ground motion test. The change in rotation was also high for the $1.75 \mathrm{~g}$ ground motion test with a value of $4.94 \mathrm{E}-2$ degrees. Since oil leakage was seen during the $1.50 \mathrm{~g}$ ground motion test, the bushing on the flexible setup could not have failed when it experienced the maximum change in rotation at the porcelain/flange interface. 
Bushing 2 Porcelain/Flange Interface - Vertical Movement

The vertical changes at the Porcelain/flange interface are shown in Figures 35-40 for Bushing 2.

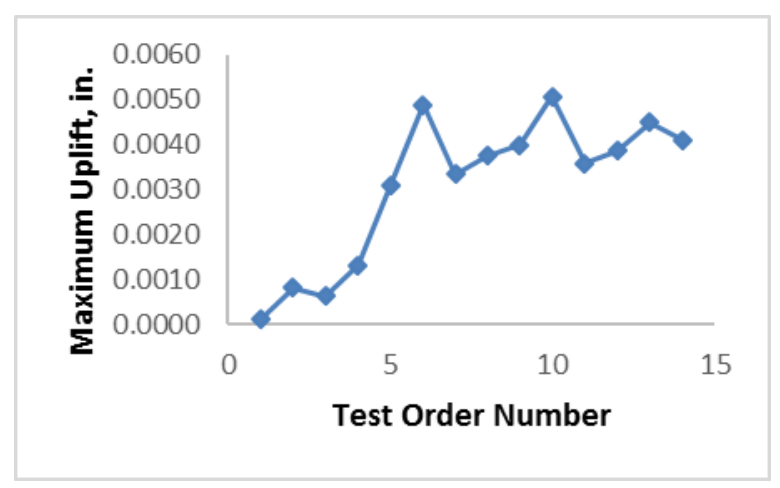

Figure 35: Maximum Vertical Displacement at North Quadrant of Porcelain/Flange interface for Bushing 2.

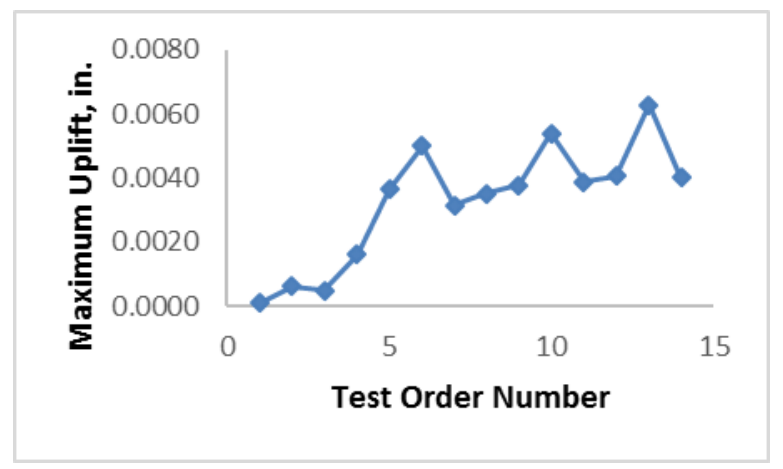

Figure 37: Maximum Vertical Displacement at South Quadrant of Porcelain/Flange interface for Bushing 2.

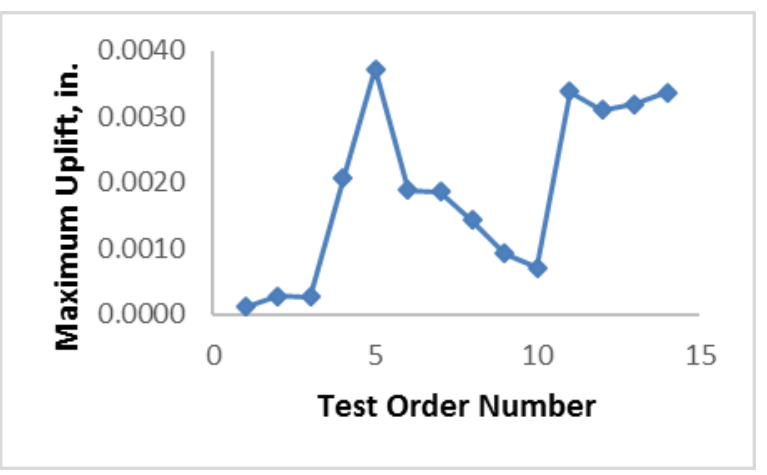

Figure 36: Maximum Vertical Displacement at East Quadrant of Porcelain/Flange interface for Bushing 2.

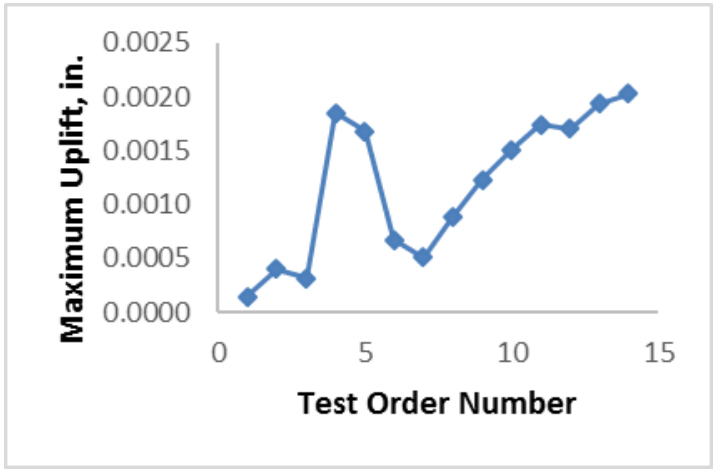

Figure 38: Maximum Vertical Displacement at West Quadrant of Porcelain/Flange interface for Bushing 2.

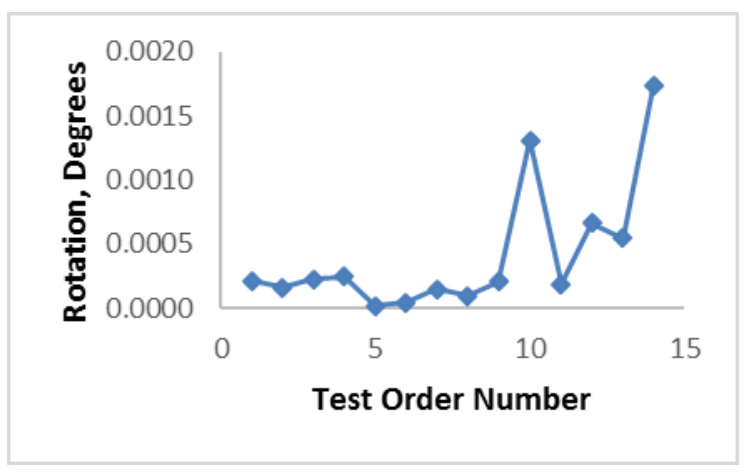

Figure 39: Vertical Change in Rotation between the Start of the Dynamic tests and the End of the Dynamic Tests in the EW Direction for Bushing 2.

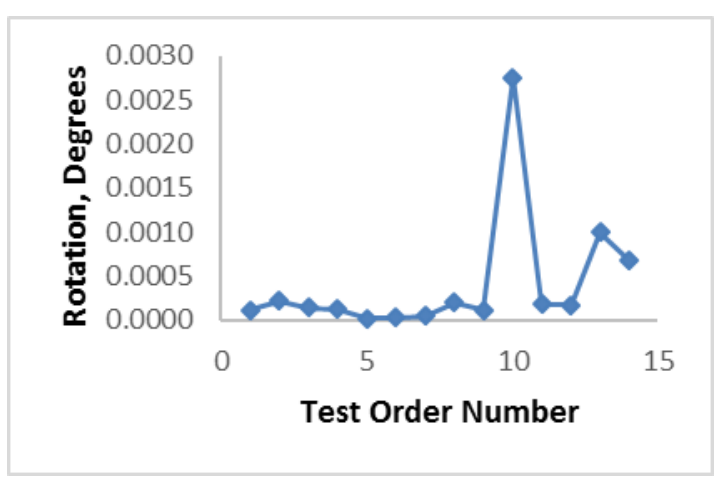

Figure 40: Vertical Change in Rotation between the Start of the Dynamic tests and the End of the Dynamic Tests in the NS Direction (Direction of Table Motion) for Bushing 2. 
The vertical displacements are shown in Figure 35-38 for each quadrants of the bushing on the Flexible Set-Up. The North and South quadrant figures appear to be similar with differing values, as expected. The maximum vertical displacement for the north quadrant was found during the $1.25 \mathrm{~g}$ ground motion test (test 10) at 5.07E-3 inches. However the maximum vertical displacement for the South quadrant was found during the $1.625 \mathrm{~g}$ ground motion test (test 13) at $6.29 \mathrm{E}-3$ inches, however this test was conducted after oil leaking was first discovered, therefore it could not have caused the failure of the bushing.

The vertical displacements for the East and West quadrants unexpectedly do not appear similar. The maximum displacement at the East quadrant was found during the $0.25 \mathrm{~g}$ ground motion test (test 5 ) and was $3.72 \mathrm{E}-3$ inches. However, during the $1.375 \mathrm{~g}$ ground motion test (test 11 ), the second largest vertical displacement was reached at a value of $3.38 \mathrm{E}-3$ inches. Whereas for the West quadrant, the displacement also peaked during the $0.25 \mathrm{~g}$ ground motion test with a value of $1.68 \mathrm{E}-3$ inches. Test 5 was the first ground motion test, $0.25 \mathrm{~g}$ ground motion, which the bushing was subjected to with no mass added to the top of the bushing. Due to the decrease in weight at the top of the bushing, it makes sense that the bushing had larger vertical displacements at not only the East and West quadrants but also the North and South quadrants which Figure and Figure illustrate. During the 1.37g ground motion test (test 11), the west quadrant reached a small peak of $1.75 \mathrm{E}-3$ inches before dropping slightly during the $1.50 \mathrm{~g}$ ground motion test. For the $1.50 \mathrm{~g}$ ground motion test, the values for the East and West quadrants were $3.11 \mathrm{E}-3$ and $1.71 \mathrm{E}-3$ inches, respectively.

The vertical change in rotation for the bushing on the flexible setup are shown in Figure and Figure for the East-West and North-South axis. Both figures show that the peak change in rotation before oil was seen was found during the 1.25g ground motion test (test 10) and for the East-West and North-South axis, the value were $1.31 \mathrm{E}-3$ degrees and $2.76 \mathrm{E}-3$ degrees respectively. Since these peak values of the change in rotation took place two tests before oil was noticed, they could not have contributed to the failure of the bushing.

Bushing 2 Porcelain/Flange Interface - Horizontal Rotation \& Slippage 1.5g Ground Motion The next four figures represent the horizontal behavior of the bushing for the Ground Motion which caused failure for the Flexible Set-Up, the $1.5 \mathrm{~g}$ Ground Motion. 


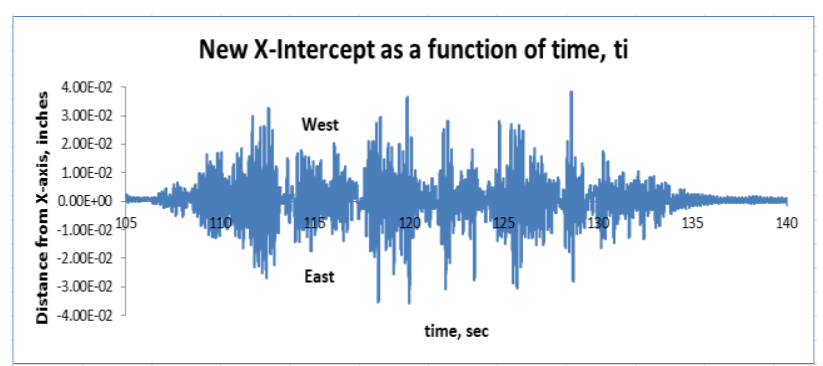

Figure 41: New X-Intercept as a function of time, ti

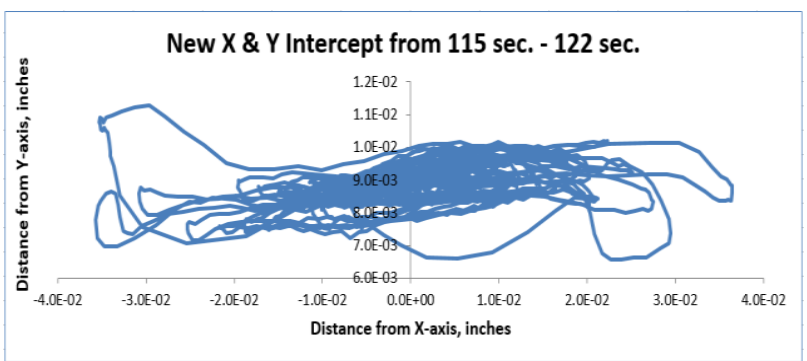

Figure 43: New $X$ \& $Y$ intercept from 115 sec. - 122 sec.

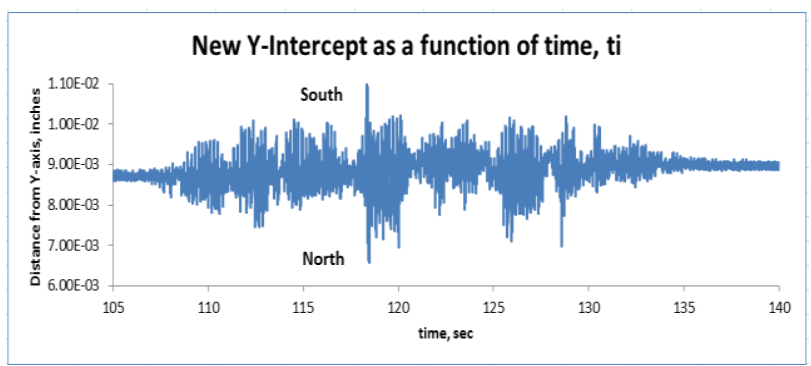

Figure 42: New $Y$ - Intercept as a function of time, ti

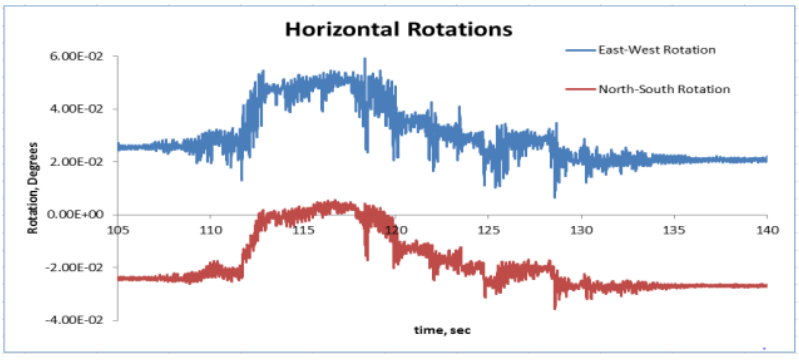

Figure 44: Horizontal rotations

Figure 41 shows the $x$-intercept as a function of time. The Difference between the lowest peak and the highest peak was 0.07 inches. The bushing displacement is pretty small, however take note that this is higher than the bushing displacement during the fixed set-up. Figure 42 shows the y-intercept as a function of time. Difference between the lowest peak and the highest peak was is 0.004 inches, which is actually less than the Fixed Set-Up.

The $X$ and $Y$ intercept is taken from the min and max peaks region of time from $115 \mathrm{sec}$. to $122 \mathrm{sec}$. You can see that the behavior is very different and is not similar to a figure 8 which was seen during the Fixed Set-Up and the behavior is more unpredictable. Also take note that the $x$-axis is shifting much more than the $\mathrm{Y}$-axis, this signifies that there is more horizontal movement between the East and West quadrants.

Figure 44 illustrates the horizontal rotations. Notice that the North/South and East/West rotations are not exact copies of one another and therefore we can tell that the bushing is slipping a bit in the horizontal direction as well as rotating.

\section{Bushing 2 Porcelain/Flange Interface - Vertical Displacement and Rotation 1.5g GM}

The next three figures represent the vertical displacement and rotation during the test that caused failure, the 1.5g Ground Motion Test. 


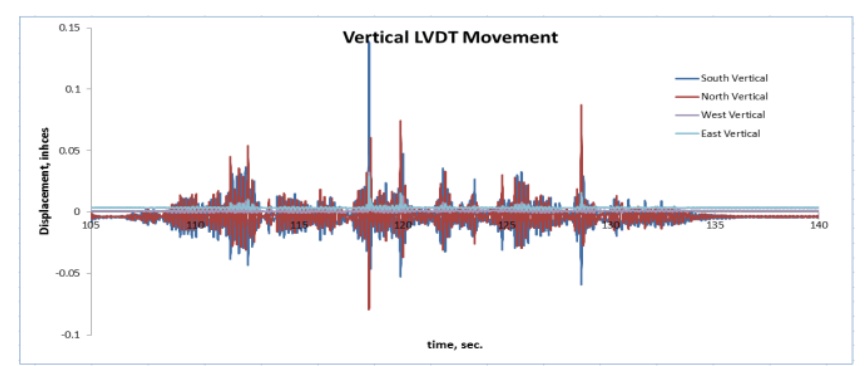

Figure 45: Vertical LVDT Movement

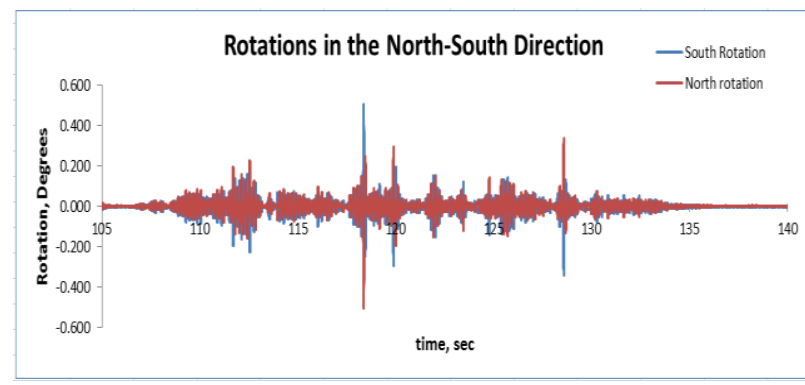

Figure 46: Rotations in the North - South Direction

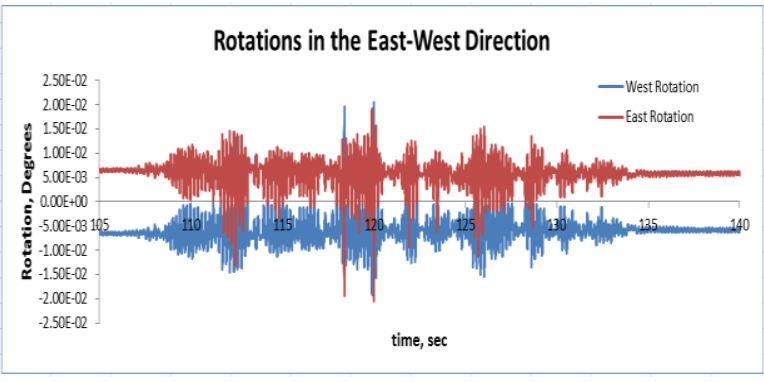

Figure 47: Rotations in the East-West Direction

Figure 45 shows the vertical LVDT movement all quadrants. The South vertical LVDT movement is shown in Blue and has the largest deflection. Oil was first seen in the South West quadrant of the bushing. Notice how the North and South LVDT's almost mirror each other, however the south displacements are larger. The East and West also mirror eachtoher, only this time the East has larger spikes. The maximum changes in displacements for the North, South, East and Wests from the lowest peaks to the highest peaks were 0.14 inches, 0.18 inches, 0.03 inches, 0.03 inches, respectively. The fact that the quadrants do not mirror the opposing quadrant makes sense considering the bushing is rocking around. The bushing was definitely moving more in the North South direction, again this is the same direction of shake table motion therefore it is expected. The South displacement is again higher than the North displacement, however the West quadrant is higher than it is for the East quadrant. Considering we are getting the maximum LVDT movement between the South and West quadrants, this explains why oil was seen between these quadrants.

Rotations for the North/South and East/West are shown in Figures 46 and 47. Notice that they are mirror images of each other. The max rotation in the North and South was 0.5 degrees from the center of rotation, this is higher than the first bushing were we found a 0.33 degree rotation. The max rotation in the East West was 0.02 degrees from the center of rotation, this is less than first bushing of 0.048 degree. There was much more vertical rotation between the North and South quadrants.

\section{Bushing 2 Porcelain/Flange Interface - Horizontal vs. Vertical Displacement 1.5g GM}

The horizontal and vertical displacements for the Flexible Set-up are shown below in Figures 48 and 49. For this comparison the test that caused failure was test \#6. Figure 49 shows that there was much more vertical displacement than there was horizontal displacement. Max horizontal displacement was at the 
West quadrant at 0.04 inches, while the max vertical displacement was at the North quadrant at 0.07 inches. For the Flexible Set-Up, the vertical displacement appears to contribute more to the failure than the horizontal displacement.

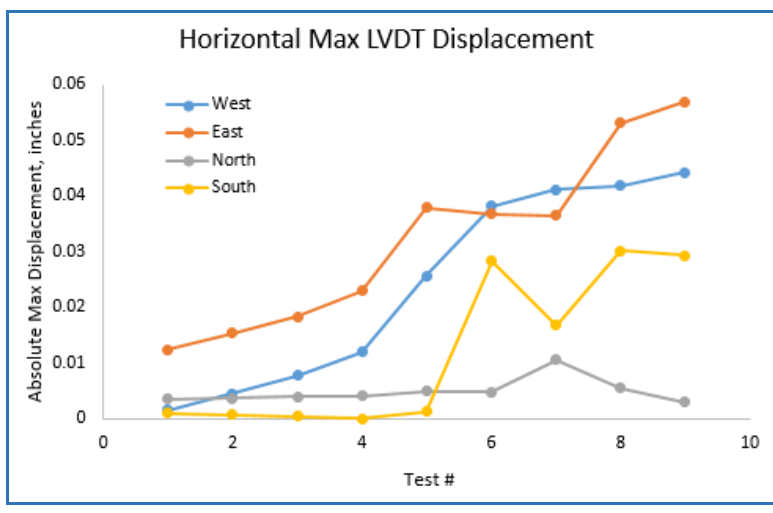

Figure 48: Horizontal Max LVDT Displacement

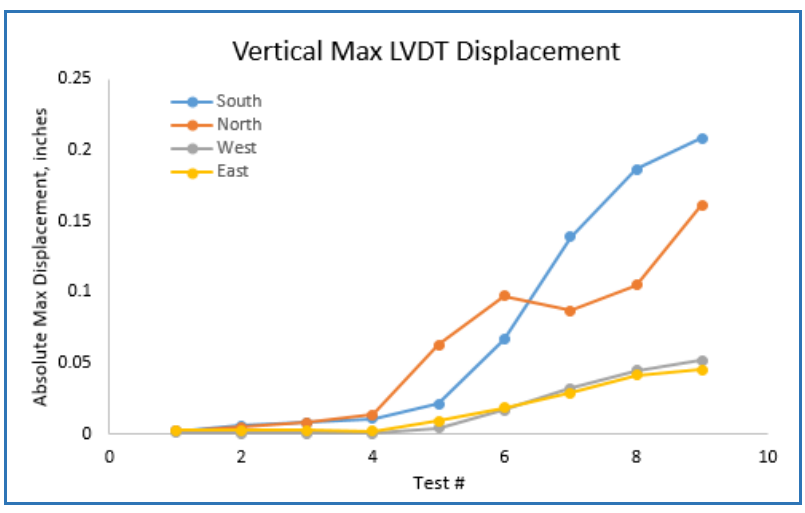

Figure 49: Vertical Max LVDT Displacement

From the horizontal and vertical displacements, slippage, and rotation, we can conclude that the bushing failed due to horizontal slippage and rotation was well as vertical rocking. However for the Flexible Set-Up the vertical displacement appeared to contribute more to the failure than the horizontal displacement.

\section{Bushing 1 Natural Frequency and Damping}

The natural frequency and percent damping for bushing 1 are shown in 8 . The table lists each test performed in the order of the test sequence for the stiff test setup.

Table 8: Bushing 1 natural frequency and percent damping in the order of test sequence for the stiff setup.

\begin{tabular}{|c|l|c|c|c|c|}
\hline$\#$ & \multicolumn{1}{|c|}{ Test Motion } & Fourier $\mathbf{f}_{\mathbf{n}}$ & Free Vib. $\mathbf{f}_{\mathbf{n}}$ & \% Damping & Notes \\
\hline 1 & EW Pull (East Compression) & 12.6 & 12.7 & 1.4 & \\
\hline 2 & EW Pull (West Compression) & 12.7 & 12.7 & 1.4 & \\
\hline 3 & NS Pull & 12.1 & 12.1 & 1.3 & \\
\hline 4 & EW Impact Soft Mallet (W Facing S) & 12.2 & 12.2 & 0.9 & See Note 1 \\
\hline 5 & NS Impact Soft Mallet(W Facing S) & 12.9 & 12.8 & 1.0 & \\
\hline 6 & EW Impact Soft Mallet (S Facing S) & 12.9 & 12.9 & 1.1 & \\
\hline 7 & NS Impact Soft Mallet (S Facing S) & 12.3 & 12.2 & 1.1 & \\
\hline
\end{tabular}




\begin{tabular}{|c|c|c|c|c|c|}
\hline 8 & EW Impact Hard Mallet & 12.8 & 12.8 & 1.1 & $\begin{array}{l}\text { If there were no apparent outliers, the } \\
\text { results for the three impact tests were } \\
\text { averaged. }\end{array}$ \\
\hline 9 & NS Impact Hard Mallet & 12.2 & 12.2 & 1.1 & \\
\hline 10 & Table Pulse before $0.25 \mathrm{~g} \mathrm{GM}$ & 12.0 & 0.1 & 1.7 & \\
\hline 11 & Sine Sweep before $0.25 \mathrm{~g} \mathrm{GM}$ & 11.5 & NA & NA & \\
\hline 12 & Table Pulse before $0.5 \mathrm{~g} \mathrm{GM}$ & 12.0 & 0.1 & 1.5 & \\
\hline 13 & Sine Sweep before 0.5g GM & 12.0 & NA & NA & \\
\hline 14 & Table Pulse before $0.75 \mathrm{~g} \mathrm{GM}$ & 12.0 & 0.1 & 1.7 & \\
\hline 15 & Sine Sweep before $0.75 \mathrm{~g} \mathrm{GM}$ & 11.9 & NA & NA & \\
\hline 16 & Table Pulse before 1.0g GM & 11.9 & 11.9 & 1.7 & \\
\hline 17 & Sine Sweep before $1.0 \mathrm{~g} \mathrm{GM}$ & 11.8 & NA & NA & \\
\hline 18 & Table Pulse before $1.25 \mathrm{~g} \mathrm{GM}$ & 12.0 & 12.0 & 1.6 & See Note 1 \\
\hline 19 & Sine Sweep before $1.25 \mathrm{~g} \mathrm{GM}$ & 12.1 & NA & NA & \\
\hline 20 & Table Pulse before 1.50g GM & 11.9 & 12.1 & 2.0 & $\begin{array}{l}\text { Bolts have been tightened prior to this } \\
\text { test. See Note } 1\end{array}$ \\
\hline 21 & Sine Sweep before $1.50 \mathrm{~g} \mathrm{GM}$ & 12.0 & NA & NA & \\
\hline 22 & Table Pulse before $1.75 \mathrm{~g} \mathrm{GM}$ & 12.1 & 12.0 & 2.2 & See Note 1 \\
\hline 23 & Sine Sweep before $1.75 \mathrm{~g} \mathrm{GM}$ & 12.0 & NA & NA & \\
\hline 24 & Table Pulse before $2.0 \mathrm{~g} \mathrm{GM}$ & 11.9 & 12.0 & 1.9 & \\
\hline 25 & Sine Sweep before $2.0 \mathrm{~g} \mathrm{GM}$ & 12.1 & NA & NA & \\
\hline 26 & Table Pulse before $1.75 \mathrm{~g}$ GM Repeat & 12.1 & 12.1 & 1.8 & \\
\hline 27 & Sine Sweep before 1.75g GM Repeat & 12.2 & NA & NA & \\
\hline 28 & Table Pulse before 2.0g GM Repeat & 12.0 & 12.1 & 2.0 & \\
\hline 29 & Sine Sweep before 2.0g GM Repeat & 12.1 & NA & NA & \\
\hline 30 & Table Pulse before Sine Beat & 12.2 & 12.1 & 1.7 & \\
\hline 31 & Sine Sweep before Sine Beat & 12.2 & NA & NA & \\
\hline 32 & NS Pull & 12.1 & 12.1 & 1.4 & $\begin{array}{l}\text { Taken from } \pm 8 \mathrm{~g} \text { accelerometer, } 4 \mathrm{~g} \text { not } \\
\text { available. }\end{array}$ \\
\hline 33 & NS Hand Impact Top Bushing & 12.2 & 12.2 & 1.2 & $\begin{array}{l}\text { Taken from } \pm 8 \mathrm{~g} \text { accelerometer, } 4 \mathrm{~g} \text { not } \\
\text { available. }\end{array}$ \\
\hline 34 & NS Hand Impact Porcelain Separation & 12.3 & 12.2 & 1.3 & $\begin{array}{l}\text { Taken from } \pm 8 \mathrm{~g} \text { accelerometer, } 4 \mathrm{~g} \text { not } \\
\text { available. Impacted on the Upper } \\
\text { Bushing }\end{array}$ \\
\hline 35 & $\begin{array}{l}\text { Table Pulse before } 1.75 \mathrm{~g} \mathrm{GM} \\
\text { Rerepeat }\end{array}$ & 12.0 & 12.0 & 1.9 & \\
\hline 36 & Table Pulse before Sine Beat Repeat & 12.1 & 12.0 & 2.0 & \\
\hline 37 & Table Pulse before $0.575 \mathrm{~g}$ Sine Beat & 11.9 & 12.0 & 2.2 & See Note 1 \\
\hline 38 & Table Pulse before $0.65 \mathrm{~g}$ Sine Beat & 11.8 & 12.0 & 2.3 & \\
\hline 39 & Table Pulse before $0.75 \mathrm{~g}$ Sine Beat & 12.0 & 12.0 & 2.0 & See Note 1 \\
\hline 40 & Table Pulse before $0.875 \mathrm{~g}$ Sine Beat & 12.0 & 12.0 & 2.0 & See Note 1 \\
\hline 41 & Table Pulse before 1.0g Sine Beat & 12.0 & 8.0 & 1.5 & See Note 1 \\
\hline 42 & Table Pulse before $1.125 \mathrm{~g}$ Sine Beat & 12.0 & 12.0 & 2.2 & See Note 1 \\
\hline 43 & Table Pulse before 1.34g Sine Beat & 12.0 & 12.0 & 2.4 & See Note 1 \\
\hline
\end{tabular}




\begin{tabular}{|l|l|c|c|c|l|}
44 & Table Pulse before 1.52g Sine Beat & 11.9 & 9.6 & 2.5 & See Note 1 \\
\hline 45 & Table Pulse after 1.52g Sine Beat & 12.0 & 12.0 & 2.4 & See Note 1 \\
\hline 46 & Sine Sweep after 1.52 Sine Beat & 11.9 & NA & NA & \\
\hline
\end{tabular}

General Note: The natural frequency was found by looking at the data from the $\pm 4 \mathrm{~g}$ accelerometer. When there were several impacts or pulses, the results for the natural frequency, and percent damping were averaged.

Note 1: At least one of the signal appears to have several modes for this type of test. This is apparent because the signal does not decay consistently. (example: one out of three of the signals does not decay consistently)

The natural frequencies for the bushing with the fixed support, Bushing 1, ranged from $11.5 \mathrm{~Hz}$ to 12.9 $\mathrm{Hz}$, in which the values can be seen in Table8. Within the range, the value of the natural frequency fluctuates without a pattern. For the pull, impact, and mallet tests the natural frequency ranged from 12.1-12.9 Hz. Once the dynamic tests began, the natural frequency remained in the lower tenths of $12 \mathrm{~Hz}$ and higher tenths of $11 \mathrm{~Hz}$. The data could appear to show that the natural frequency dropped slightly once dynamic testing had begun due to the motion of the shake table causing a more flexible response. However, the lowest natural frequency found was before the first $0.25 \mathrm{~g}$ ground motion dynamic test which shows the natural frequency changing unpredictably. The bolts which fastened the bushing to the shake table were also tightened during testing and produced unexpected results. The bolts were tightened after the $1.25 \mathrm{~g}$ ground motion and before the $1.50 \mathrm{~g}$ ground motion. Tightening the bolts should have produced a higher natural frequency by creating an overall stiffer system. However the data showed that before the bolts were tightened the natural frequency was $12.1 \mathrm{~Hz}$, and after the bolts were tightened the natural frequency was $11.9 \mathrm{~Hz}$. Therefore tightening the bolts may have caused the Fixed Set-up to become slightly more flexible at that time during testing, however it is difficult to determine if the slight drop in natural frequency was due to the tightening of the bolts or the $1.50 \mathrm{~g}$ ground motion. Oil leakage was first noticed after the $1.125 \mathrm{~g}$ sine beat dynamic test. It can be seen from the table that the natural frequency before and after the $1.125 \mathrm{~g}$ sine beat was $12 \mathrm{~Hz}$. Therefore oil leakage during the $1.125 \mathrm{~g}$ sine beat dynamic test did not affect the overall natural frequency of the bushing on the fixed setup.

Comparing the type of test which the change in natural frequencies, the table shows that between the static tests and dynamic tests there was really no difference in natural frequency, therefore any of the test types used was dependable.

The percent damping for the bushing on the fixed support ranged from $0.9-2.5$ percent, although before oil was noticed the percent damping range was $0.9-2.3$ percent. The percent damping fluctuated unpredictably before oil leaking was noticed, and the results can be seen in Table8. One reason why the percent damping varied could have been due to Note 1 in Table8. Note 1 states that "at least one of the signal appears to have several modes for this type of test. This is apparent because the signal does not decay consistently. (Example: one out of three of the signals does not decay consistently)". Therefore, the inconsistency in the percent damping could have been due to multiple modes, an example of multiple modes is shown in Figure 50. Before oil was first seen during the $1.125 \mathrm{~g}$ sine beat, the percent damping was 2.2 percent, however after the test the percent damping was 2.4 percent. In fact for the last three tests after oil was noticed the percent damping was either 2.4 or 2.5 
percent which was the highest the percent damping was calculated during the testing of the first bushing. Therefore oil leakage did cause the percent damping to increase slightly however due to multiples modes the data is inconclusive.

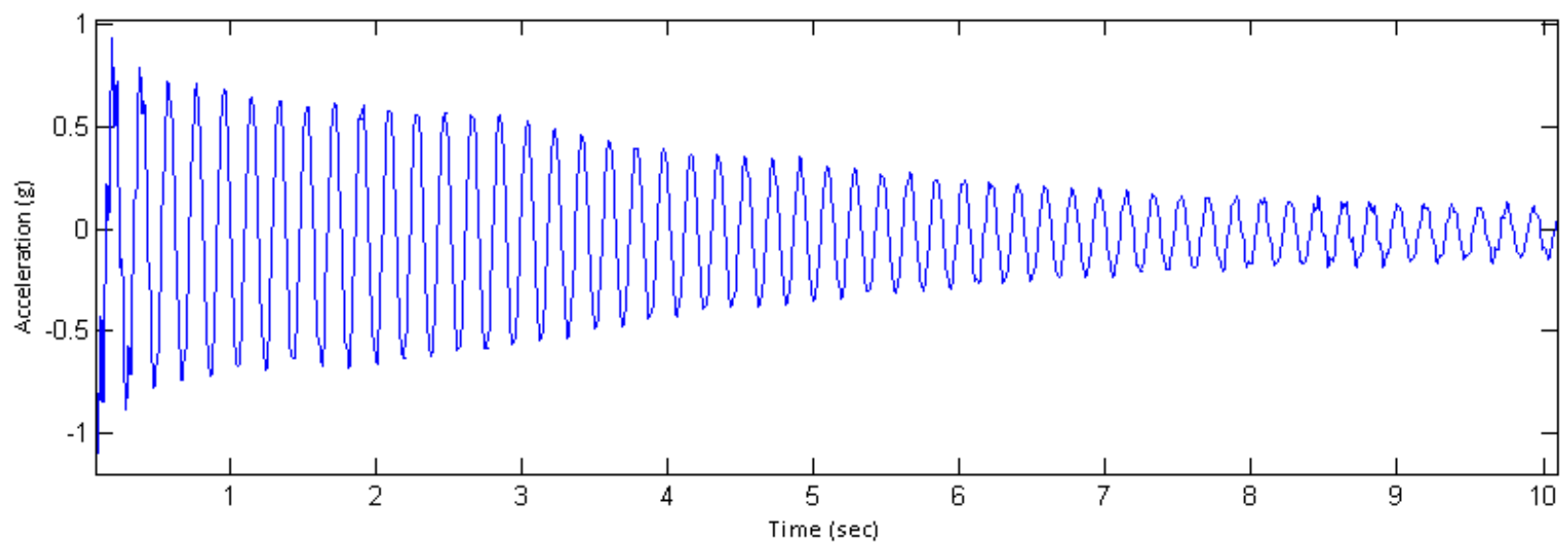

Figure 50: Example of signal with multiple modes.

\section{Bushing 2 Natural Frequency and Damping}

The natural frequencies for bushing 2 are shown in Table9. The table lists each test performed in order of the test sequence for the flexible test setup. Due to the large range of the percent damping found for the Flexible Setup, the values for each test are shown in

The natural frequency for the bushing in the Flexible Set-Up, bushing 2, ranged from $4.9-5.6 \mathrm{~Hz}$, with the highest value resulting from the first dynamic test with no mass on top of the bushing and the lowest value resulting from the last test. However before oil leakage was noticed that natural frequency ranged from $5.1-5.6 \mathrm{~Hz}$. The results for the natural frequency are shown in tests 11-30 of Table9. This table shows that the natural frequency consistently declines from test 19 - test 30 . However, if not for the dip in value of tests 17 and 18 the data would show a constant decrease in value from test 16-30. During test 17 and 18 the natural frequency was found to be $5.1 \mathrm{~Hz}$ during a sine sweep test and a repeat sine sweep test. Both sine sweep dynamic tests were performed before the $0.25 \mathrm{~g} \mathrm{GM}$, however during the sine sweep before the $0.25 \mathrm{~g}$ ground motion there was a strange noise. Upon inspecting the bushing there were no visible leaks or other changes. Even though there were no visible changes, the strange noise could explain the irregularity in the decrease in the natural frequency during testing. The slow drop in value of the natural frequency shows that the dynamic testing essentially caused the bushing to become less and less stiff as the tests continued to be completed until the bushing finally failed. Oil was first noticed after the $1.50 \mathrm{~g}$ ground motion. The natural frequency remained consistent from before the $0.75 \mathrm{~g}$ ground motion until before the $1.38 \mathrm{~g}$ ground motion. However, there was a small shift between the table pulse before the 1.38g ground motion and the table pulse after $1.38 \mathrm{~g}$ ground motion. During the 1.38g ground motion the natural frequency dropped from $5.3 \mathrm{~Hz}$ to $5.2 \mathrm{~Hz}$. It was also noted at the time the test sequence was being conducted that the bushing had appeared to shift 
during the $1.38 \mathrm{~g} \mathrm{GM}$ test. The slippage had been estimated by tracing the perimeter of the steel circumference on the porcelain circumference before the 1.38g ground motion test. After the $1.38 \mathrm{~g}$ ground motion test the line was no longer visible, therefore it was estimated that the bushing may have slipped during the $1.38 \mathrm{~g}$ ground motion test. After the $125 \% \mathrm{GM}$, a lab technician tightened all the bolts which mounted the transformer bushing to the turret and the turret to the plate. However, from Table 9 , it can be seen that the tightening of the bolts had no effect on the natural frequency of the test setup.

Again when comparing the type of test which the change in natural frequencies, the table shows that between the static tests and dynamic tests there was really no difference in natural frequency, therefore any of the test types used was dependable.

Error! Not a valid bookmark self-reference.10 shows that the percent damping fluctuates inconsistently for all the dynamic tests and ranges from $0.12-1.19$ percent. Due to the wide range in percent damping, a histogram was created and is shown in Figure 5150 to see if any outliers could be removed. However, according to the values, there were no outliers. Equation 2 shows that the percent damping is effected by the number of peak displacements and peak magnitudes of the cycles in the time series response. Due to the recorded time series response, the number of peak displacements for many of the tests had to change during the calculation for the percent damping. This could be the reason why the percent damping varied inconsistently throughout the tests. In conclusion the percent damping is inconclusive. 
Table .

Table 9: Bushing 2 natural frequencies in order of test sequence for flexible setup.

\begin{tabular}{|c|c|c|c|c|}
\hline$\#$ & Test Motion & Fourier $f_{n}$ & Free Vib. $f_{n}$ & Notes \\
\hline 1 & Pull with $45 \mathrm{lb}$ weight, NS & 5.1 & 5.0 & See Notes 2 , and 3 \\
\hline 2 & Impact, $45 \mathrm{lb}$ weight NS & 5.1 & 5.1 & See Notes 2 , and 3 \\
\hline 3 & Man-Shake, 45lb weight NS & 5.1 & 5.0 & See Notes 2 , and 3 \\
\hline 4 & Table Pulse before $0.25 \mathrm{~g}$ GM for $45 \mathrm{lb}$ weight & 5.0 & 5.0 & See Note 3 \\
\hline 5 & Sine Sweep before $0.25 \mathrm{~g}$ GM $45 \mathrm{lb}$ weight & 5.051 & NA & \\
\hline 6 & Pull with $15 \mathrm{lb}$ weight, NS & 5.1 & 5.1 & See Note 2 , and 4 \\
\hline 7 & Impact, $15 \mathrm{lb}$ weight NS & 5.2 & 5.2 & See Note 2 , and 4 \\
\hline 8 & Man-Shake, $15 \mathrm{lb}$ weight NS & 5.1 & 5.0 & See Notes 2 , and 3 \\
\hline 9 & Sine Sweep before $0.25 \mathrm{~g} \mathrm{GM} \mathrm{Ib} \mathrm{weight}$ & 5.09 & NA & \\
\hline 10 & Table Pulse before $0.25 \mathrm{~g} \mathrm{GM}$ for $15 \mathrm{lb}$ weight & 5.1 & 5.0 & See Note 3 \\
\hline 11 & Pull with no weight, NS & 5.4 & 5.4 & See Note 2 , and 5 \\
\hline 12 & Impact, no weight, NS & 5.5 & 5.4 & See Note 2 , and 5 \\
\hline 13 & Man-Shake, no weight, NS & 5.4 & 5.4 & See Note 2 , and 5 \\
\hline 14 & Impact, no weight, EW & 5.6 & 5.5 & See Note 3 \\
\hline 15 & Man-Shake, no weight, EW & 5.5 & 5.5 & See Note 3 \\
\hline 16 & Table Pulse before $0.25 \mathrm{~g} \mathrm{GM}$ for no weight & 5.4 & 5.4 & See Note 3 \\
\hline 17 & Sine Sweep before $0.25 \mathrm{~g} \mathrm{GM}$ & 5.1 & NA & \\
\hline 18 & Sine Sweep before $0.25 \mathrm{~g}$ GM Redone & 5.1 & NA & \\
\hline 19 & Table Pulse before $0.25 \mathrm{~g} \mathrm{GM}$ & 5.4 & 5.9 & See Note 3 \\
\hline 20 & Table Pulse before $0.50 \mathrm{~g} \mathrm{GM}$ & 5.4 & 5.5 & See Note 3 \\
\hline 21 & Table Pulse before $0.75 \mathrm{~g} \mathrm{GM}$ & 5.3 & 5.3 & See Note 3 \\
\hline 22 & Table Pulse before $1.0 \mathrm{~g} \mathrm{GM}$ & 5.3 & 5.3 & See Notes 1 , and 3 \\
\hline 23 & Table Pulse before $1.25 \mathrm{~g} \mathrm{GM}$ & 5.3 & 5.3 & See Notes 1 , and 3 \\
\hline 24 & Table Pulse before $1.38 \mathrm{~g} \mathrm{GM}$ & 5.3 & 5.3 & See Notes 1 , and 3 \\
\hline 25 & Table Pulse before $1.50 \mathrm{~g} \mathrm{GM}$ & 5.2 & 5.2 & See Notes 1 , and 3 \\
\hline 26 & Table Pulse before $1.63 \mathrm{~g} \mathrm{GM}$ & 5.2 & 5.2 & See Notes 1 , and 3 \\
\hline 27 & Table Pulse before $1.75 \mathrm{~g} \mathrm{GM}$ & 5.2 & 5.2 & See Notes 1 , and 3 \\
\hline 28 & Table Pulse after $1.75 \mathrm{~g} \mathrm{GM}$ & 5.2 & 5.2 & See Notes 1 , and 3 \\
\hline 29 & Sine Sweep after $1.75 \mathrm{~g} \mathrm{GM}$ & 4.9 & NA & \\
\hline 30 & Sine Sweep after $1.75 \mathrm{~g}$ GM Redone & 4.9 & NA & \\
\hline
\end{tabular}

General Note: The natural frequency was found by analyzing the data from the $\pm 4 \mathrm{~g}$ accelerometer unless otherwise specified.

The results for the natural frequency were averaged when there were several impacts or pulses performed consecutively.

Note 1: At least one out of the total number of the signals appeared to have several modes for this type of test. This is apparent because the signal does not decay consistently. (example: one pulse out of the three does not decay consistently.)

Note 2: $4 \mathrm{~g}$ Accelerometer data was not valid, $8 \mathrm{~g}$ Accelerometer data was used for analysis.

Note 3: For calculations, the difference between the max and min peaks was counted until the difference became 0.1 .

Note 4: For calculations, the difference between the max and min peaks was counted until the difference became 0.05 .

Note 5: For calculations, the difference between the max and min peaks was counted until the difference became 0.025 
The natural frequency for the bushing in the Flexible Set-Up, bushing 2, ranged from $4.9-5.6 \mathrm{~Hz}$, with the highest value resulting from the first dynamic test with no mass on top of the bushing and the lowest value resulting from the last test. However before oil leakage was noticed that natural frequency ranged from $5.1-5.6 \mathrm{~Hz}$. The results for the natural frequency are shown in tests 11-30 of Table9. This table shows that the natural frequency consistently declines from test 19 - test 30 . However, if not for the dip in value of tests 17 and 18 the data would show a constant decrease in value from test 16-30. During test 17 and 18 the natural frequency was found to be $5.1 \mathrm{~Hz}$ during a sine sweep test and a repeat sine sweep test. Both sine sweep dynamic tests were performed before the $0.25 \mathrm{~g} \mathrm{GM}$, however during the sine sweep before the $0.25 \mathrm{~g}$ ground motion there was a strange noise. Upon inspecting the bushing there were no visible leaks or other changes. Even though there were no visible changes, the strange noise could explain the irregularity in the decrease in the natural frequency during testing. The slow drop in value of the natural frequency shows that the dynamic testing essentially caused the bushing to become less and less stiff as the tests continued to be completed until the bushing finally failed. Oil was first noticed after the $1.50 \mathrm{~g}$ ground motion. The natural frequency remained consistent from before the $0.75 \mathrm{~g}$ ground motion until before the $1.38 \mathrm{~g}$ ground motion. However, there was a small shift between the table pulse before the 1.38g ground motion and the table pulse after $1.38 \mathrm{~g}$ ground motion. During the $1.38 \mathrm{~g}$ ground motion the natural frequency dropped from $5.3 \mathrm{~Hz}$ to $5.2 \mathrm{~Hz}$. It was also noted at the time the test sequence was being conducted that the bushing had appeared to shift during the 1.38g GM test. The slippage had been estimated by tracing the perimeter of the steel circumference on the porcelain circumference before the $1.38 \mathrm{~g}$ ground motion test. After the $1.38 \mathrm{~g}$ ground motion test the line was no longer visible, therefore it was estimated that the bushing may have slipped during the $1.38 \mathrm{~g}$ ground motion test. After the $125 \% \mathrm{GM}$, a lab technician tightened all the bolts which mounted the transformer bushing to the turret and the turret to the plate. However, from Table 9 , it can be seen that the tightening of the bolts had no effect on the natural frequency of the test setup.

Again when comparing the type of test which the change in natural frequencies, the table shows that between the static tests and dynamic tests there was really no difference in natural frequency, therefore any of the test types used was dependable.

Error! Not a valid bookmark self-reference.10 shows that the percent damping fluctuates inconsistently for all the dynamic tests and ranges from $0.12-1.19$ percent. Due to the wide range in percent damping, a histogram was created and is shown in Figure 5150 to see if any outliers could be removed. However, according to the values, there were no outliers. Equation 2 shows that the percent damping is effected by the number of peak displacements and peak magnitudes of the cycles in the time series response. Due to the recorded time series response, the number of peak displacements for many of the tests had to change during the calculation for the percent damping. This could be the reason why the percent damping varied inconsistently throughout the tests. In conclusion the percent damping is inconclusive. 
Table 10: Bushing 2 percent damping in the order of test sequence for the flexible setup.

\begin{tabular}{|c|c|c|c|c|c|c|c|c|}
\hline$\#$ & Description & $\begin{array}{c}\% \\
\text { Damping }\end{array}$ & \# & Description & $\begin{array}{c}\% \\
\text { Damping }\end{array}$ & \# & Description & $\begin{array}{c}\% \\
\text { Damping }\end{array}$ \\
\hline 1 & $\begin{array}{l}\text { NS Pull with } 45 \mathrm{lb} \\
\text { Weight }\end{array}$ & 0.43 & 24 & Impact, Olb, EW, 2nd & 0.59 & 47 & $\begin{array}{l}\text { Pulse before } 125 \% \mathrm{GM} \text {, } \\
\text { 2nd pulse }\end{array}$ & 0.44 \\
\hline 2 & $\begin{array}{l}\text { Impact, } 45 \text { lb weight } \\
\text { NS, 1st }\end{array}$ & 0.75 & 25 & Impact, Olb, EW, 3rd & 0.69 & 48 & $\begin{array}{l}\text { Pulse before } 125 \% \mathrm{GM} \text {, 3rd } \\
\text { pulse }\end{array}$ & 0.81 \\
\hline 3 & $\begin{array}{l}\text { Impact, } 45 \text { lb weight } \\
\text { NS, 2nd Impact }\end{array}$ & 0.57 & 26 & Impact, Olb, EW, 4th & 0.67 & 49 & $\begin{array}{l}\text { Pulse before } 138 \% G M, 1 s t \\
\text { pulse }\end{array}$ & 0.12 \\
\hline 4 & $\begin{array}{l}\text { ManShake, 45lb } \\
\text { weight NS, 1st }\end{array}$ & 0.81 & 27 & Man Shake, Olb, EW, 1st & 0.51 & 50 & $\begin{array}{l}\text { Pulse before } 138 \% \mathrm{GM} \text {, } \\
\text { 2nd pulse }\end{array}$ & 0.73 \\
\hline 5 & $\begin{array}{l}\text { ManShake, 45lb } \\
\text { weight NS, 2nd }\end{array}$ & 0.85 & 28 & Man Shake, Olb, EW, 1st & 0.49 & 51 & $\begin{array}{l}\text { Pulse before } 138 \% \mathrm{GM}, 3 \mathrm{rd} \\
\text { pulse }\end{array}$ & 0.87 \\
\hline 6 & $\begin{array}{l}\text { 45lb weight Pulse } \\
\text { before } 25 \% \mathrm{GM}, 1 \text { st } \\
\text { pulse }\end{array}$ & 0.78 & 29 & Man Shake, Olb, EW, 1st & 0.54 & 52 & $\begin{array}{l}\text { Pulse before } 150 \% G M, 1 \text { st } \\
\text { pulse }\end{array}$ & 0.15 \\
\hline 7 & $\begin{array}{l}45 \mathrm{lb} \text { weight Pulse } \\
\text { before } 25 \% \mathrm{GM}, 2 \text { nd } \\
\text { pulse }\end{array}$ & 0.81 & 30 & $\begin{array}{l}\text { Olb weight Pulse before } \\
25 \% \mathrm{GM}, 1 \text { st pulse }\end{array}$ & 0.72 & 53 & $\begin{array}{l}\text { Pulse before } 150 \% \mathrm{GM} \text {, } \\
\text { 2nd pulse }\end{array}$ & 0.25 \\
\hline 8 & $\begin{array}{l}\text { NS Pull with } 15 \mathrm{lb} \\
\text { Weight }\end{array}$ & 0.67 & 31 & $\begin{array}{l}0 \mathrm{lb} \text { weight Pulse before } \\
25 \% \mathrm{GM}, 2 \text { nd pulse }\end{array}$ & 0.75 & 54 & $\begin{array}{l}\text { Pulse before } 150 \% G M, 3 r d \\
\text { pulse }\end{array}$ & 0.43 \\
\hline 9 & $\begin{array}{l}\text { Impact, } 15 \text { lb weight } \\
\text { NS, 1st Impact }\end{array}$ & 0.59 & 32 & $\begin{array}{l}0 \mathrm{lb} \text { weight Pulse before } \\
25 \% \mathrm{GM}, 2 \text { nd pulse }\end{array}$ & 0.77 & 55 & $\begin{array}{l}\text { Pulse before } 163 \% \mathrm{GM}, 1 \mathrm{st} \\
\text { pulse }\end{array}$ & 0.22 \\
\hline 10 & $\begin{array}{l}\text { Impact, } 15 \text { lb weight } \\
\text { NS, 2nd Impact }\end{array}$ & 1.09 & 33 & $\begin{array}{l}\text { Pulse before } 25 \% \mathrm{GM} \text {, } \\
\text { 1st pulse }\end{array}$ & 0.77 & 56 & $\begin{array}{l}\text { Pulse before } 163 \% \mathrm{GM} \text {, } \\
\text { 2nd pulse }\end{array}$ & 0.72 \\
\hline 11 & $\begin{array}{l}\text { Impact, } 15 \text { lb weight } \\
\text { NS, 3rd Impact }\end{array}$ & 1.15 & 34 & $\begin{array}{l}\text { Pulse before } 25 \% G M \text {, } \\
\text { 2nd pulse }\end{array}$ & 0.86 & 57 & $\begin{array}{l}\text { Pulse before } 163 \% G M, 3 r d \\
\text { pulse }\end{array}$ & 0.35 \\
\hline
\end{tabular}




\begin{tabular}{|c|c|c|c|c|c|c|c|c|}
\hline 12 & $\begin{array}{l}\text { Impact, } 15 \text { lb weight } \\
\text { NS, 4th Impact }\end{array}$ & 1.06 & 35 & $\begin{array}{l}\text { Pulse before } 25 \% \mathrm{GM} \text {, } \\
\text { 3rd pulse }\end{array}$ & 0.72 & 58 & $\begin{array}{l}\text { Pulse before } 175 \% G M, 1 \text { st } \\
\text { pulse }\end{array}$ & 0.49 \\
\hline 13 & $\begin{array}{l}\text { ManShake, 15lb } \\
\text { weight NS, 1st }\end{array}$ & 1.17 & 36 & $\begin{array}{l}\text { Pulse before } 25 \% \mathrm{GM} \text {, } \\
\text { 4th pulse }\end{array}$ & 0.88 & 59 & $\begin{array}{l}\text { Pulse before } 175 \% \mathrm{GM} \text {, } \\
\text { 2nd pulse }\end{array}$ & 1.19 \\
\hline 14 & $\begin{array}{l}\text { ManShake, 15lb } \\
\text { weight NS, 2nd }\end{array}$ & 1.17 & 37 & $\begin{array}{l}\text { Pulse before } 50 \% \mathrm{GM} \text {, } \\
\text { 1st Pulse }\end{array}$ & 0.69 & 60 & $\begin{array}{l}\text { Pulse before } 175 \% \mathrm{GM}, 3 \mathrm{rd} \\
\text { pulse }\end{array}$ & 0.94 \\
\hline 15 & $\begin{array}{l}\text { 15lb weight Pulse } \\
\text { before } 25 \% \mathrm{GM}, 1 \mathrm{st} \\
\text { pulse }\end{array}$ & 0.84 & 38 & $\begin{array}{l}\text { Pulse before } 50 \% G M \text {, } \\
\text { 2nd Pulse }\end{array}$ & 0.65 & 61 & $\begin{array}{l}\text { Pulse before } 188 \% G M \\
\text { Repeat, 1st pulse }\end{array}$ & 0.61 \\
\hline 16 & $\begin{array}{l}15 \text { lb weight Pulse } \\
\text { before } 25 \% G M, 2 \text { nd } \\
\text { pulse }\end{array}$ & 0.45 & 39 & $\begin{array}{l}\text { Pulse before } 50 \% \mathrm{GM} \text {, } \\
\text { 3rd Pulse }\end{array}$ & 0.7 & 62 & $\begin{array}{l}\text { Pulse before } 188 \% G M \\
\text { Repeat, 2nd pulse }\end{array}$ & 0.85 \\
\hline 17 & $\begin{array}{l}\text { NS Pull with } 0 \mathrm{lb} \\
\text { Weight }\end{array}$ & 0.74 & 40 & $\begin{array}{l}\text { Pulse before } 75 \% \mathrm{GM} \text {, } \\
\text { 1st pulse }\end{array}$ & 0.78 & 63 & $\begin{array}{l}\text { Pulse before } 188 \% G M \\
\text { Repeat, 3rd pulse }\end{array}$ & 0.91 \\
\hline 18 & $\begin{array}{l}\text { Impact, } 0 \text { lb weight, } \\
\text { NS, 1st Impact }\end{array}$ & 0.6 & 41 & $\begin{array}{l}\text { Pulse before } 75 \% G M \text {, } \\
\text { 2nd pulse }\end{array}$ & 0.52 & 64 & $\begin{array}{l}\text { Pulse before } 188 \% G M \\
\text { Repeat, 3rd pulse }\end{array}$ & 0.91 \\
\hline 19 & $\begin{array}{l}\text { Impact, } 0 \text { Ib weight, } \\
\mathrm{NS} \text {, 2nd Impact }\end{array}$ & 0.51 & 42 & $\begin{array}{l}\text { Pulse before } 75 \% \mathrm{GM} \text {, } \\
\text { 3rd pulse }\end{array}$ & 0.33 & & & \\
\hline 20 & $\begin{array}{l}\text { Impact, } 0 \text { lb weight, } \\
\text { NS, 3rd Impact }\end{array}$ & 0.4 & 43 & $\begin{array}{l}\text { Pulse before } 100 \% \mathrm{GM}, \\
\text { 1st pulse }\end{array}$ & 0.83 & & & \\
\hline 21 & $\begin{array}{l}\text { Man Shake, } 0 \mathrm{lb}, \mathrm{NS} \text {, } \\
\text { 1st }\end{array}$ & 0.54 & 44 & $\begin{array}{l}\text { Pulse before } 100 \% G M \text {, } \\
\text { 2nd pulse }\end{array}$ & 0.85 & & & \\
\hline 22 & $\begin{array}{l}\text { Man Shake, } 0 \mathrm{lb}, \mathrm{NS} \text {, } \\
\text { 2nd }\end{array}$ & 0.55 & 45 & $\begin{array}{l}\text { Pulse before } 100 \% \mathrm{GM} \text {, } \\
\text { 3rd pulse }\end{array}$ & 0.76 & & & \\
\hline 23 & Impact, Olb, EW, 1st & 0.68 & 46 & $\begin{array}{l}\text { Pulse before } 125 \% \mathrm{GM} \text {, } \\
\text { 1st pulse }\end{array}$ & 0.09 & & & \\
\hline
\end{tabular}

The percent damping range is shown in the form of a histogram in Figure 5150. To determine if there were any outliers for the broad range of percent damping for bushing two, the median of the percent damping values was determined. The first quartile and third quartile were determined from finding the median of the first half of data and the second half. The outliers in the data would lie outside of the range $\left[Q_{1}-1.5(I Q R), Q_{3}+1.5(I Q R)\right]$, where $Q_{1}$ was the first quartile, $Q_{3}$ was the third quartile, and IQR was the inter quartile range. The inner quartile range was the difference between the third quartile and the first quartile. The range that specified outliers was found to be $[0.035,1.315]$, therefore no outliers were found. The range for the percent damping for the Flexible Set-Up was 0.1 to 1.2 percent damping. 


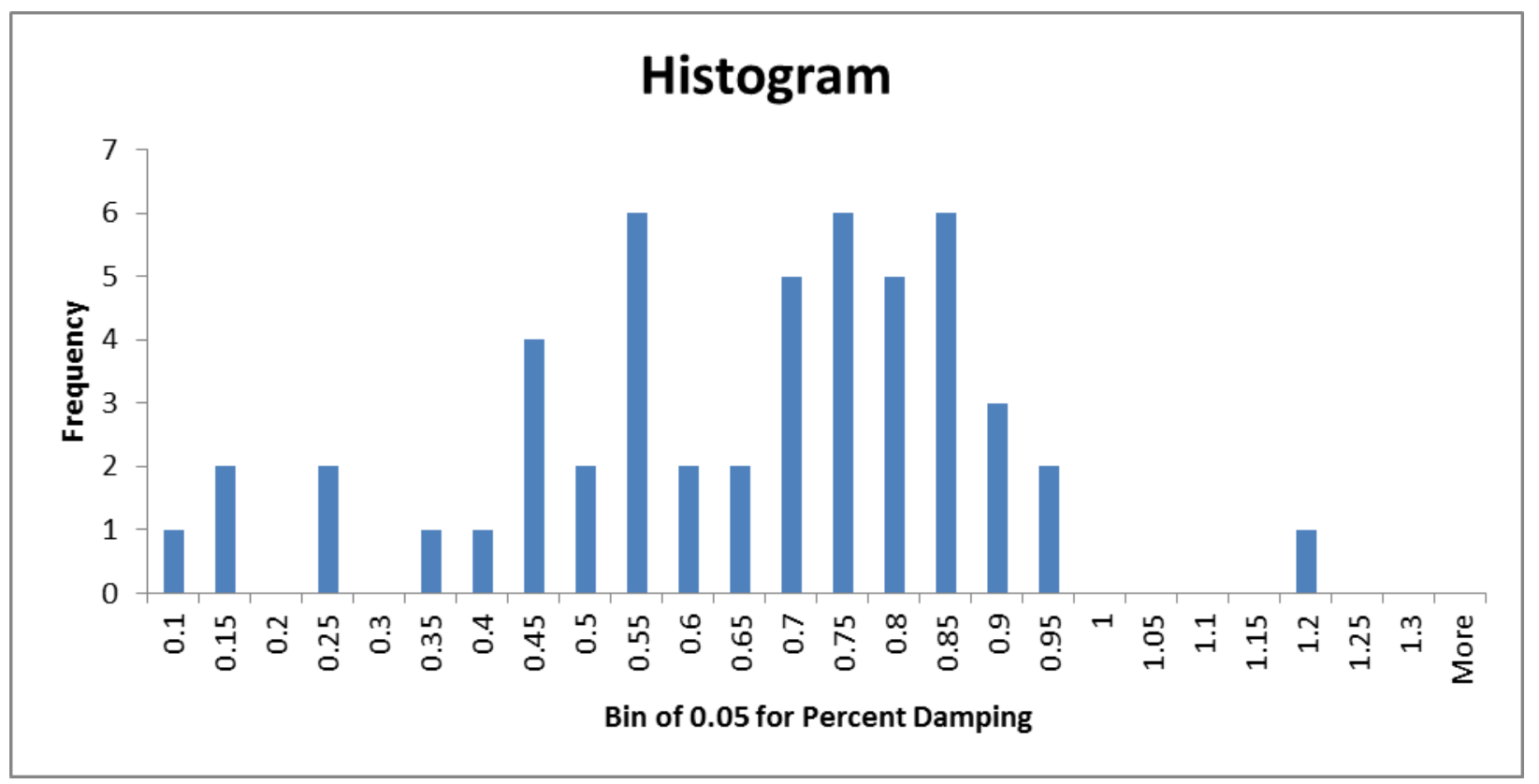

Figure 51: Histogram for the percent damping with no weight added for Bushing 2. Bin \# thickness of 0.05.

\section{Added Mass Comparison for Bushing 2}

The maximum acceleration comparisons for added mass are shown in Table 111. The added mass comparison involved a $45 \mathrm{lb}$. weight, a $15 \mathrm{lb}$. weight, and no added mass. The maximum accelerations were compared for the $50 \%$ of the ground motion, or $0.25 \mathrm{~g}$. Figure illustrates the changes between the added masses at each accelerometer location.

Table 11: Added mass comparisons for $0.25 \mathrm{~g}$ ground motion.

\begin{tabular}{|l|c|c|c|}
\hline \multirow{2}{*}{ Location of Accelerometers } & $45 \mathrm{lb}$ weight & $15 \mathrm{lb}$ weight & no weight \\
\cline { 2 - 4 } & $0.25 \mathrm{~g}$ & $0.25 \mathrm{~g}$ & $0.25 \mathrm{~g}$ \\
\hline
\end{tabular}




\begin{tabular}{|l|r|r|r|} 
Top of Bushing 8g & 0.951003 & 1.901963 & 2.160798 \\
\hline CG of Bushing 4g & 0.369222 & 0.797165 & 1.034135 \\
\hline CG of Bushing 8g & 0.481565 & 0.939781 & 1.184335 \\
\hline Top of Turret & 0.354327 & 0.656836 & 0.80748 \\
\hline Bottom of Turret & 0.449278 & 0.278898 & 0.266971 \\
\hline Table & 0.481927 & 0.276588 & 0.259197 \\
\hline
\end{tabular}

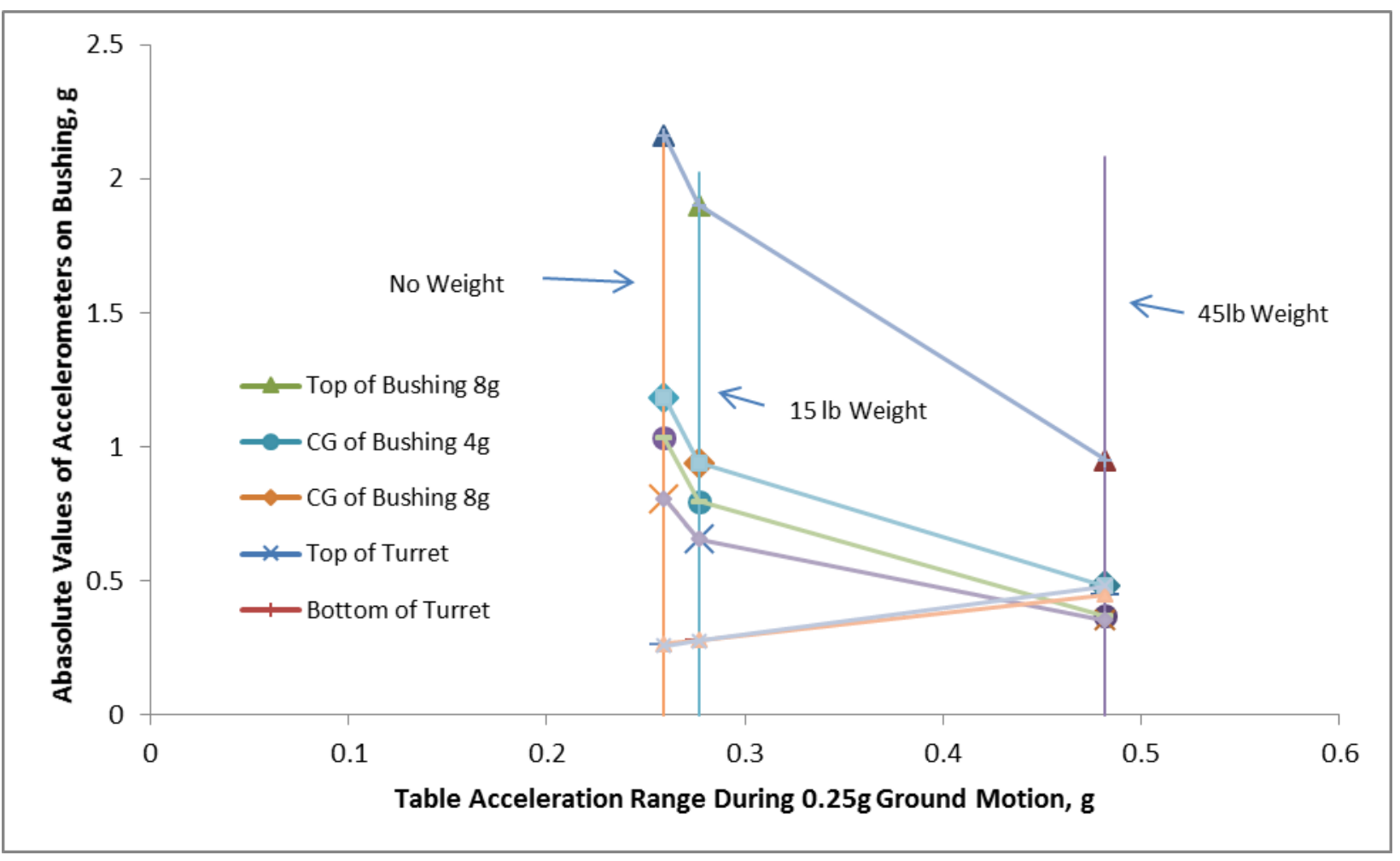

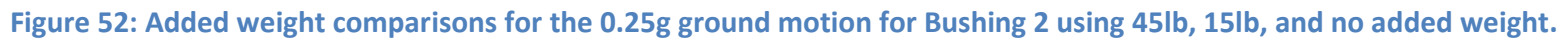

Adding mass to the top of the bushing affected the natural frequency, damping, and acceleration at specific locations on the bushing. The natural frequency for the $45 \mathrm{lb}$ weight ranged from $5.0-5.1 \mathrm{~Hz}$. This can be seen in Table 11 from the values in tests 1-5. Whereas, the natural frequency for the 15lb weight was slightly higher and ranged from 5.1-5.2 Hz. The values can be seen in tests 6-10 of Table 11 . As previously stated, the natural frequency was highest for the bushing with no added mass and ranged from $5.1-5.6 \mathrm{~Hz}$. The pattern shows that the as mass was added the natural frequency was reduced.

Figure 52 shows the different levels of the bushings acceleration at various points and compares the acceleration at the specified locations when mass was added to the top of the bushing. Prior to testing, the bushing mass was input into the $407 \mathrm{DAQ}$, the shake table controller to ensure the table ran 
properly. However when the mass of $15 \mathrm{lb}$ and $45 \mathrm{lb}$ was added, the input weight was not changed in the 407 controller. Therefore, the table accelerated at slightly different speeds due to the changing masses and this can be seen in Figure 52. In Figure 52 there are three vertical lines that connect the differing points of acceleration on the bushing. From the Figure, the data shows that when mass is added to the top of the bushing, the acceleration is reduced, similar to the natural frequency.

The percent damping varied with each test. For the $45 \mathrm{lb}$ weight, the $15 \mathrm{lb}$ weight, and no added mass the percent damping ranged from $0.43-0.85,0.45-1.17$, and $0.12-1.19$ percent, respectively. The range of percent damping was smallest for the largest added mass and the bushing with no added mass produced the largest range. The number of tests that were performed for the bushing with no mass was much greater than the number of tests that were completed for the added $45 \mathrm{lb}$ and $15 \mathrm{lb}$ masses which could explain the larger range in percent damping. Table10 shows that notes 2,3 , and 4 apply to finding the percent damping for the added masses. Notes 2,3 , and 4 specifically state the difference between the max and min peaks when calculating the percent damping. The difference between the maximum and minimum peaks changes could be the reason why the percent damping varied for the added masses on the bushing.

\section{FURTHER STUDY}

Since the natural frequency of the two different Set-Up's was very different, the bushing proved to be sensitive to how it was mounted. Therefore this brought about another question, was a turret best representing a transformer during testing? What if the bushing was modeled on a stand to try to represent a transformer cover better than a flexible plate. This brought about a new objective, to design a test stand for the bushing such that the flexible support results in approximately transformer support conditions. 
Therefore, a finite element model was created in Abaqus/CAE 6.13-2. The bushing was modeled on a steel frame with varying plate thicknesses, masses, and boundary conditions.

The model contained the full bushing stand and the bushing, however the bushing was modeled as a frame with the plate and bushing mass at the top of each HSS column, as a lumped mass system, and as a distributed mass system. The plate thicknesses varied between a 1/2 inch thick plate and a 5/8 inch thick plate. The bushing frame was restrained at the bottom of each corner of the frame to model how the frame would be bolted to the shake table. Restraints were also applied at the top of the top where the plate would be either bolted or welded to the steel frame. To represent the bolts or welds at the connection, a pinned and fixed boundary condition was applied between the plate and the frame. The masses that were used to simulate the bushing weights were $700 \mathrm{lb}, 1068 \mathrm{lb}$, and $1200 \mathrm{lb}$. The masses were based on two possible bushing masses and the mass of the bushing tested.

Before running the models, desired frequencies were determined for the different scenarios. For the stand with the plate and bushing mass at the top of each HSS column, the desired frequency was a frequency greater than $30 \mathrm{~Hz}$ laterally. Whereas, the wanted frequency for the bushing on the support structure with a distributed or lumped mass system was approximately $8 \mathrm{~Hz}$.

The size of the top plate that was modeled was a 68 inch by 68 inch square top plate with hole cut out of the center and diameter of 18 inches cut from the middle to hold the bushing. How the bushing was attached to the plate on the stand was modeled in two different ways. The distributed bushing and lumped mass bushing representations were tied to the inside diameter of the hole in the top plate and then to the bolt hole radius where the bushing would be fastened to the plate. For the lumped mass model, the mass was placed at approximately the location of the center of gravity of the bushing, located 17-1/4 inches above the top of the plate. For the distributed mass, the bushing was modeled similarly to the $196 \mathrm{kV}$ bushing with 91" rising above the top of the plate and 61.5" dropping below the plate.

The different models are shown in Figures 53-55, whereas an example of the rocking and vertical modes are shown in Figures 56-61. 


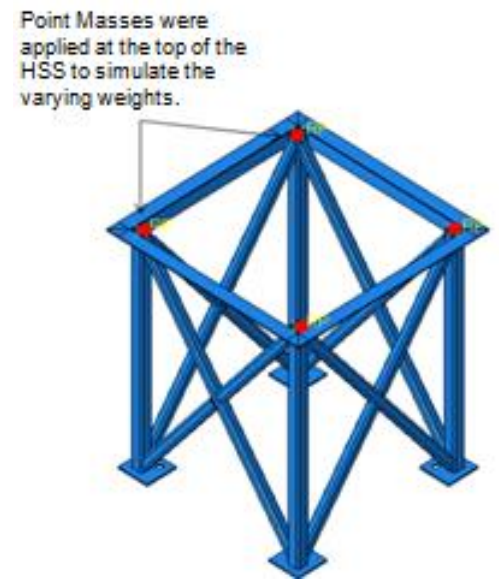

Figure 53: Bushing Support.

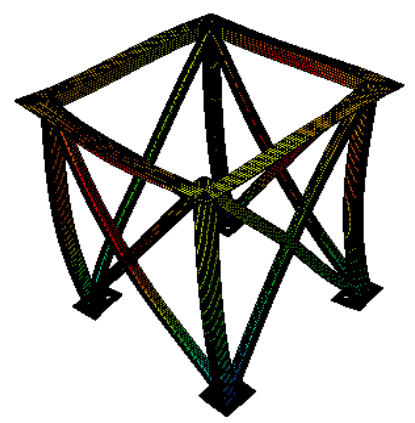

Figure 56: Rocking - Bushing Support.

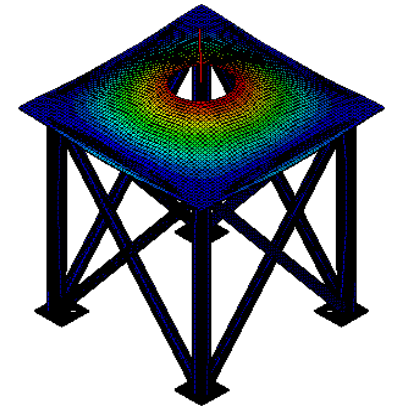

Figure 59: Vertical - Lumped Mass.

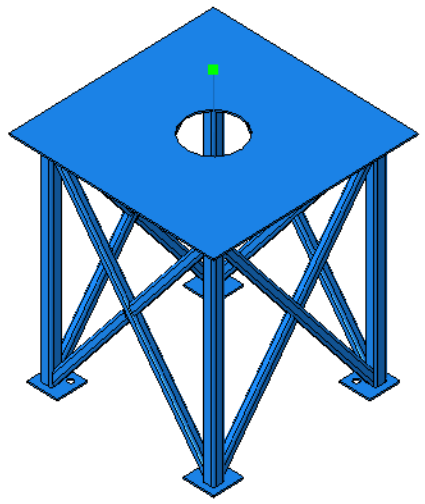

Figure 54: Lumped Mass on Frame.

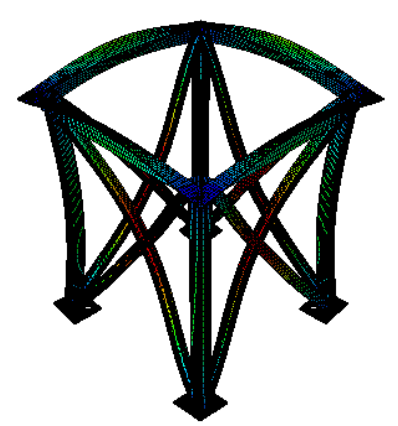

Figure 57: Vertical - Bushing Support.

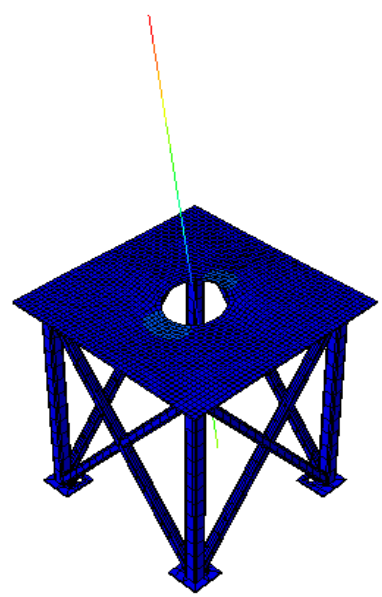

Figure 60: Rocking - Distributed.

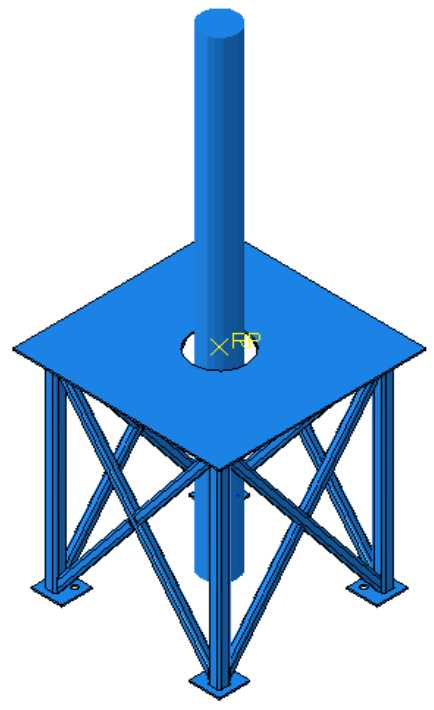

Figure 55: Distributed Mass on Frame.

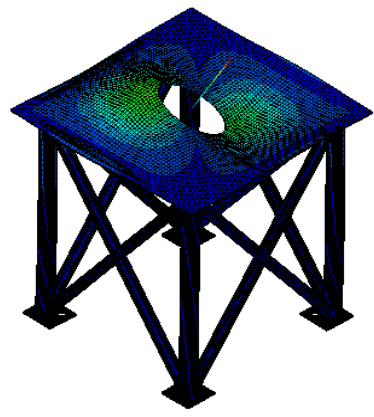

Figure 58: Rocking - Lumped Mass.

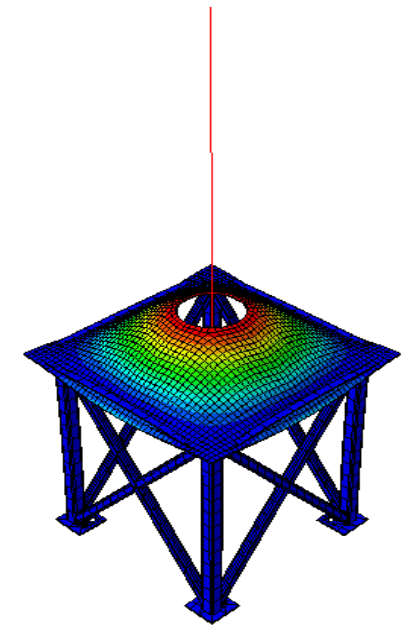

Figure 61: Vertical - Distributed. 
Table 2 illustrates the differences between how the bushing was represented in the Abaqus model. The point mass representation gave a rocking frequency between 12.2 and $19.4 \mathrm{~Hz}$ when the bushing was fixed to the inside edge of the plate, whereas for the same scenario, the distributed bushing frequency was between 5.9 and 9.4 for the two plates. Since the expected frequency of the model was approximately $8 \mathrm{~Hz}$, the distributed mass representation of the bushing proves to model a more real world scenario. This can be seen for the $1 / 2$ inch plate, and a bushing mass of $700 \mathrm{lb}$, the natural frequency was found to be $8 \mathrm{~Hz}$ and matches the expected frequency.

Table 2: Results for finite element analysis.

\begin{tabular}{|c|c|c|c|c|c|c|c|c|c|}
\hline \multirow[b]{3}{*}{$\begin{array}{c}\text { Plate } \\
\text { Thickness } \\
\text { (in.) }\end{array}$} & \multirow[b]{3}{*}{$\begin{array}{c}\text { Mass } \\
\text { (Ib) }\end{array}$} & \multicolumn{4}{|c|}{ Stand Frequencies with Point Mass } & \multicolumn{4}{|c|}{ Stand Frequencies with Distributed Bushing } \\
\hline & & \multicolumn{2}{|c|}{ Bushing Fixed to Inside Edge } & \multicolumn{2}{|c|}{ Bushing Fixed to Bolt Radius } & \multicolumn{2}{|c|}{ Bushing Fixed to Inside Edge } & \multicolumn{2}{|c|}{ Bushing Fixed to Bolt Radius } \\
\hline & & $\begin{array}{c}\text { Rocking } \\
\text { Frequency } \\
\text { (Hz) }\end{array}$ & $\begin{array}{c}\text { Vertical } \\
\text { Frequency } \\
(\mathrm{Hz})\end{array}$ & $\begin{array}{c}\text { Rocking } \\
\text { Frequency } \\
(\mathrm{Hz})\end{array}$ & $\begin{array}{l}\text { Vertical } \\
\text { Frequency } \\
(\mathrm{Hz})\end{array}$ & $\begin{array}{c}\text { Rocking } \\
\text { Frequency } \\
\text { (Hz) }\end{array}$ & $\begin{array}{c}\text { Vertical } \\
\text { Frequency } \\
\text { (Hz) }\end{array}$ & $\begin{array}{l}\text { Rocking } \\
\text { Frequency } \\
\text { (Hz) }\end{array}$ & $\begin{array}{c}\text { Vertical } \\
\text { Frequency } \\
\text { (Hz) }\end{array}$ \\
\hline \multirow{3}{*}{$1 / 2$} & 700 & 15.8 & 14.6 & 20.3 & 18.9 & 7.7 & 17.9 & 8.0 & 18.7 \\
\hline & 1068 & 12.9 & 12.1 & 16.0 & 16.7 & 6.2 & 14.8 & 6.5 & 15.5 \\
\hline & 1,200 & 12.2 & 11.5 & 15.1 & 14.9 & 5.9 & 14.1 & 6.1 & 14.7 \\
\hline \multirow{3}{*}{$5 / 8$} & 700 & 19.4 & 18.2 & 23.6 & 22.8 & 9.4 & 21.6 & 10.3 & 22.8 \\
\hline & 1068 & 15.9 & 15.2 & 19.4 & 19.0 & 7.6 & 18.1 & 8.3 & 19.1 \\
\hline & 1,200 & 15.0 & 14.4 & 18.4 & 18.1 & 7.2 & 17.1 & 7.9 & 18.1 \\
\hline
\end{tabular}

How the bushing was attached to the plate did produce different frequency results. When the point and distributed bushing masses were fixed to the bolt hole radius rather than the inside edge of the plate in which the bushing would rest, the results for both cases were higher than when the bushing was fixed to the inside edge of the plate. Since the bolt hole radius was only 1-1/2 inches outside of the inside edge of the plate, the results were expected to be close. The distributed bushing model output frequencies best represents the slight change in distance between the inside edge and bolt hold radius, and therefore appears to be a more accurate model.

The results from this model will allow a frame to be built to better represent how a bushing is attached to an electrical transformer in the future. The results will also allow the lab technician to better predict the rocking and vertical frequencies of the stand with the bushing mass due to the plate thickness and mass of the bushing during further testing. 


\section{CONCLUSION}

Neither bushing failed due to gasket extrusion. The bushings were cut in half at BPA after testing and we discovered the gaskets were cemented in place. The bushing bolted to the Fixed Set-Up (Bushing 1) did not fail due to pure tipping or pure sliding, it failed due to horizontal slippage and rotation as well as vertically rocking. Its failure appeared to be caused more by the horizontal displacement than the vertical displacement. The bushing bolted to the Flexible Set-Up (Bushing 2) also did not fail due to pure tipping or pure sliding, it again failed due to horizontal slippage and rotation as well as vertically rocking. However, the second bushings failure appeared to be caused more by the vertical displacement than the horizontal displacement. The percent damping for both bushing was inclusive due to multiple modes. The natural frequency range for the Fixed Setup and Flexible Set-up was $11.5 \mathrm{~Hz}-12.9 \mathrm{~Hz}$, and $5.1 \mathrm{~Hz}-$ $5.6 \mathrm{~Hz}$, respectively. Adding Mass to the top of the bushing decreased the acceleration and natural frequency of the flexible setup. The bushings have proven that they are sensitive to how they are mounted and the expected natural frequency on a stand with a $1 / 2$ flexible plate and $700 \mathrm{lb}$ bushing is 8 $\mathrm{Hz}$. 


\section{WORKS CITED}

Chopra, Anil K. Dynamics of Structures. Upper Saddle River: Pearson Education, Inc, 2007.

Elliott, Justin J. Seismic Performance of 230 kV Transformer Bushings. Portland: Portland State University, 2004.

IEEE. "IEEE Recommended Practice for Seismic Design of Substations." IEEE Std 693-2005. New York : Institute of Electrical and Electronics Engineers, Inc., 8 May 2006.

O'Claire, David E. Seismic Performance of 230 kV Transformer Bushings. Portland : Portland State University , 2004. 


\section{APPENDIX A}

\section{Figures}

\section{Table of Contents}

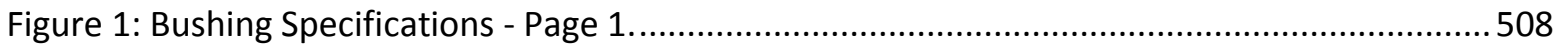

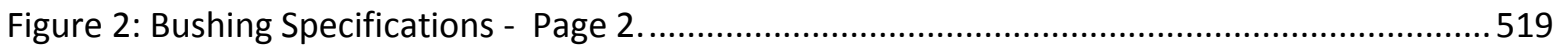

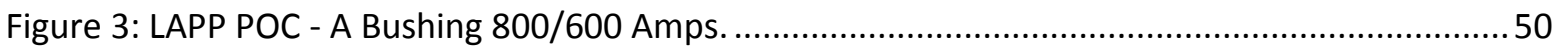

Figure 4: Bushing Cross Reference Information. ....................................................................... 51

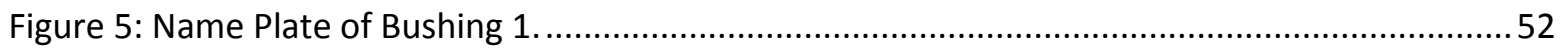

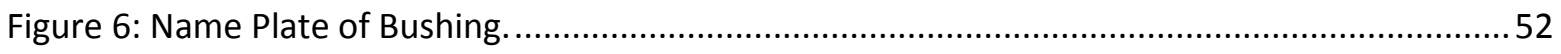

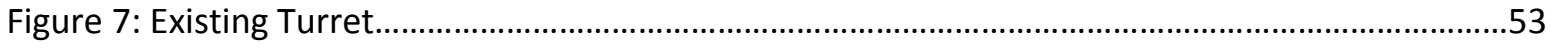

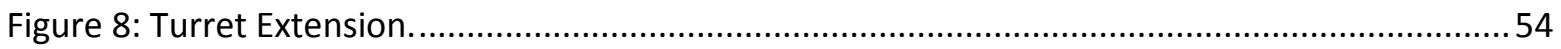

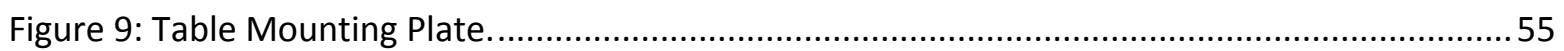

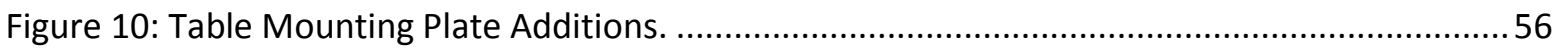

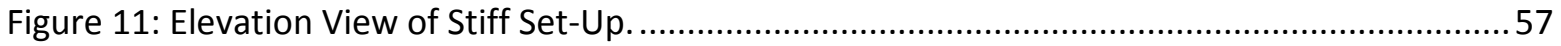

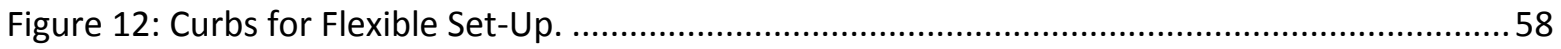

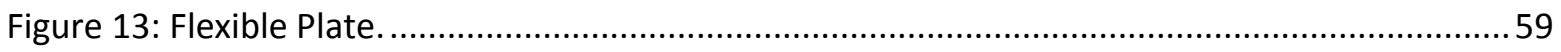

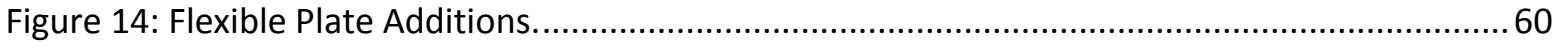

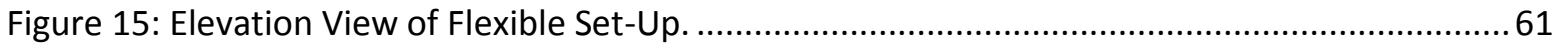




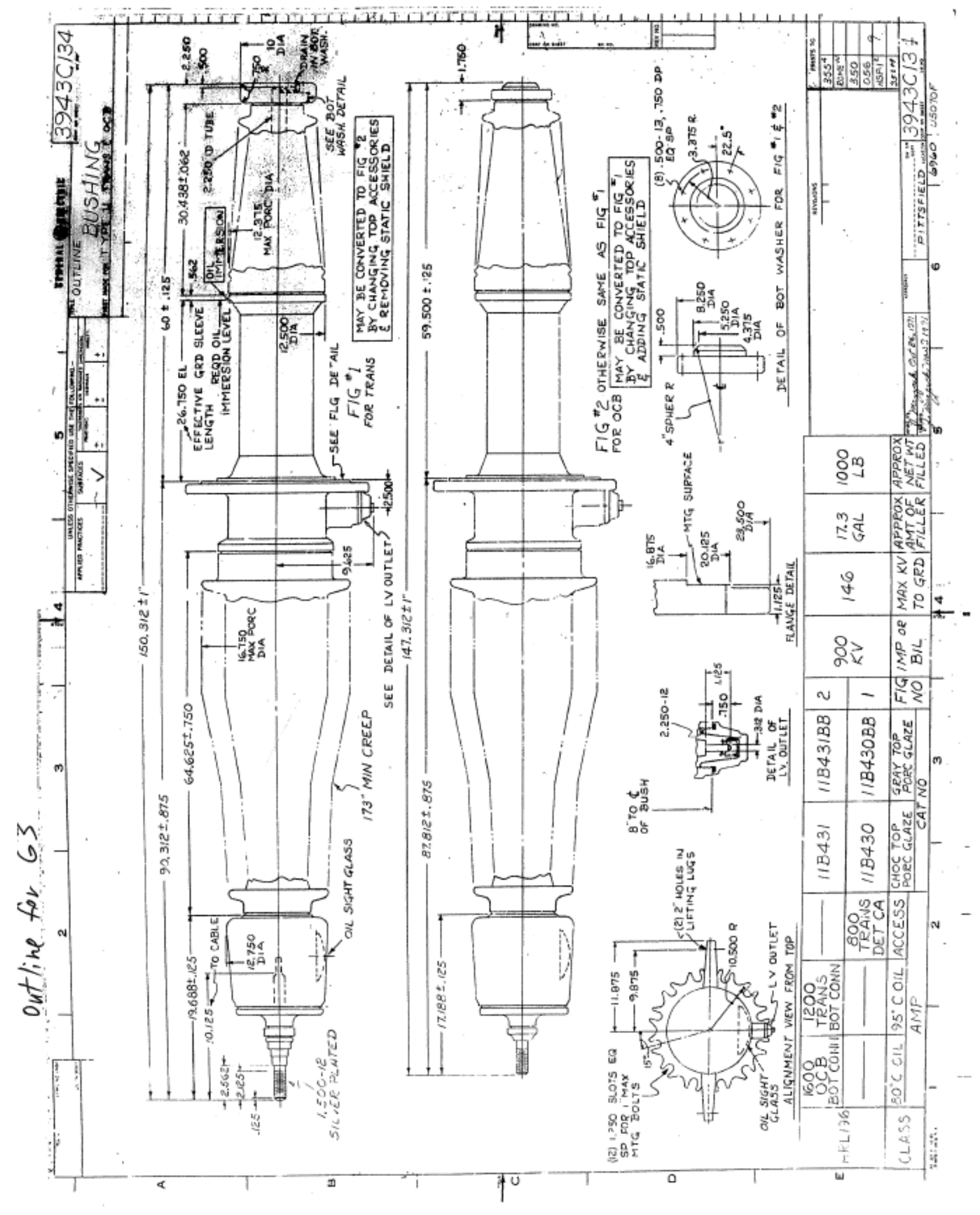

Figure 1: Bushing Specifications - Page 1. 


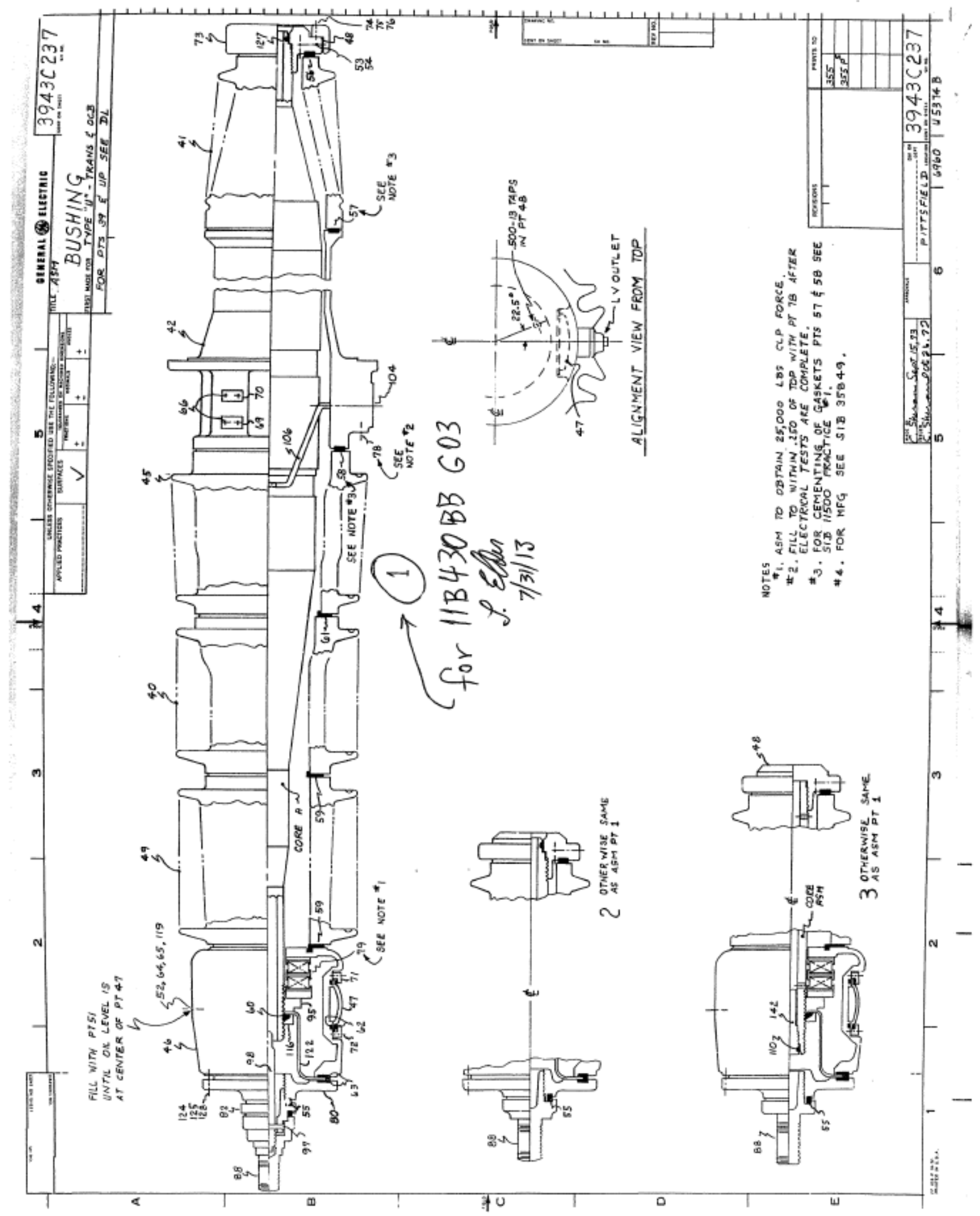

Figure 2: Bushing Specifications - Page 2. 


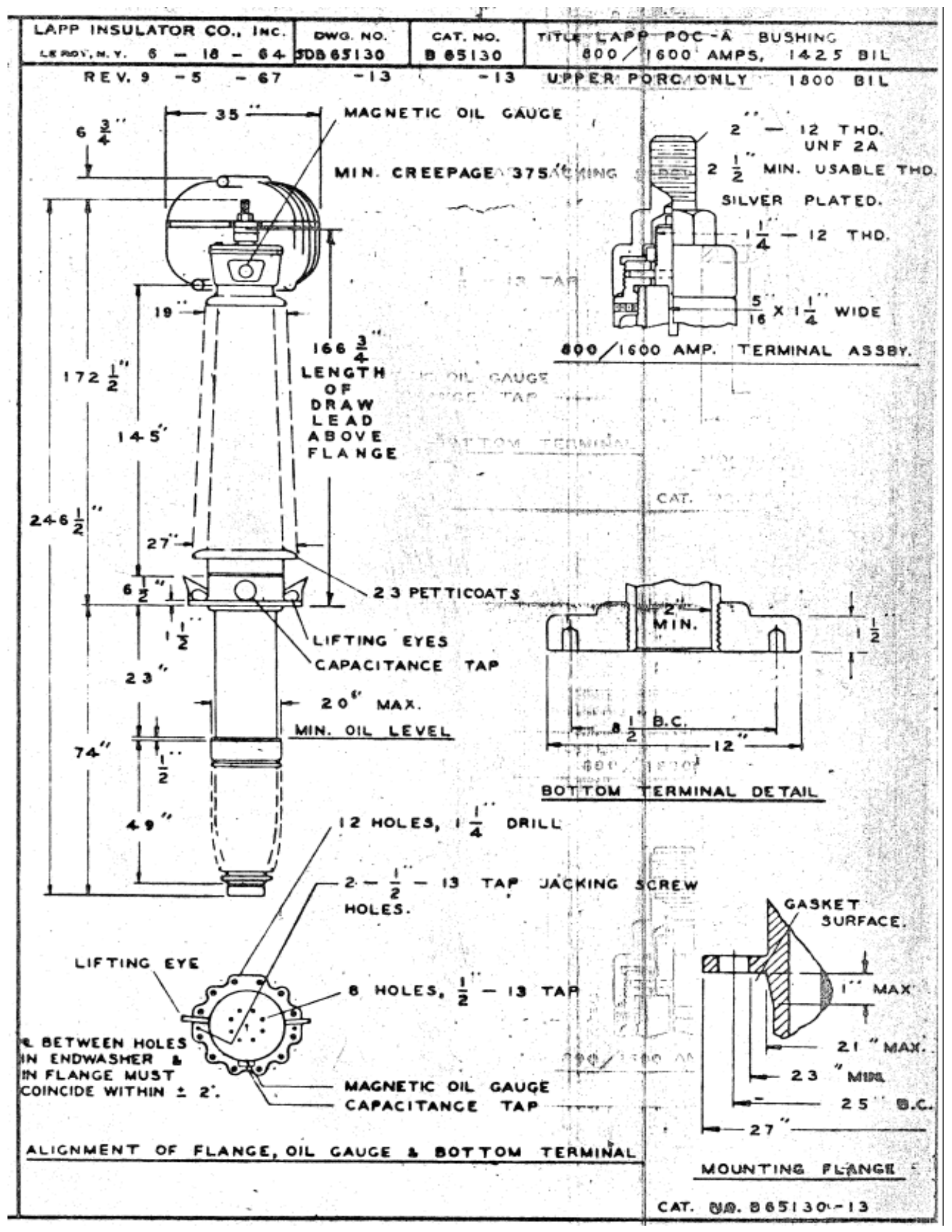

Figure 3: LAPP POC - A Bushing 800/600 Amps. 


\section{Bushing Cross Reference Information}

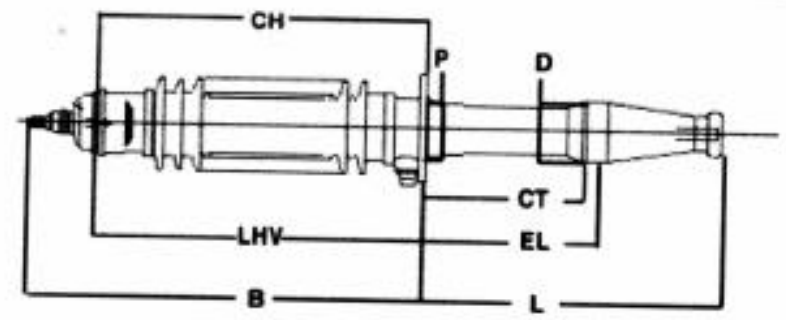

Original Bushing Information

\begin{tabular}{|c|c|c|c|}
\hline \multirow{2}{*}{\multicolumn{2}{|c|}{$\begin{array}{l}\text { Original Bushing Manufacturer: } \\
\text { Catalog Number: }\end{array}$}} & G.E. & \multirow[t]{2}{*}{ Mounting Position: } \\
\hline & & 11B430BB & \\
\hline Voltage Class (kV): & & 196 & BIL (kV): \\
\hline Application & - DrawLeac & -Bottom Connected & - Oil Circuit Breaker \\
\hline Current Rating (Amps) o & 800 & $\circ$ & 0 \\
\hline 196W0800XA (Amps) a & - 800 & a & $a$ \\
\hline
\end{tabular}

Replacement Information

ABB Style Number: 196w0800XA

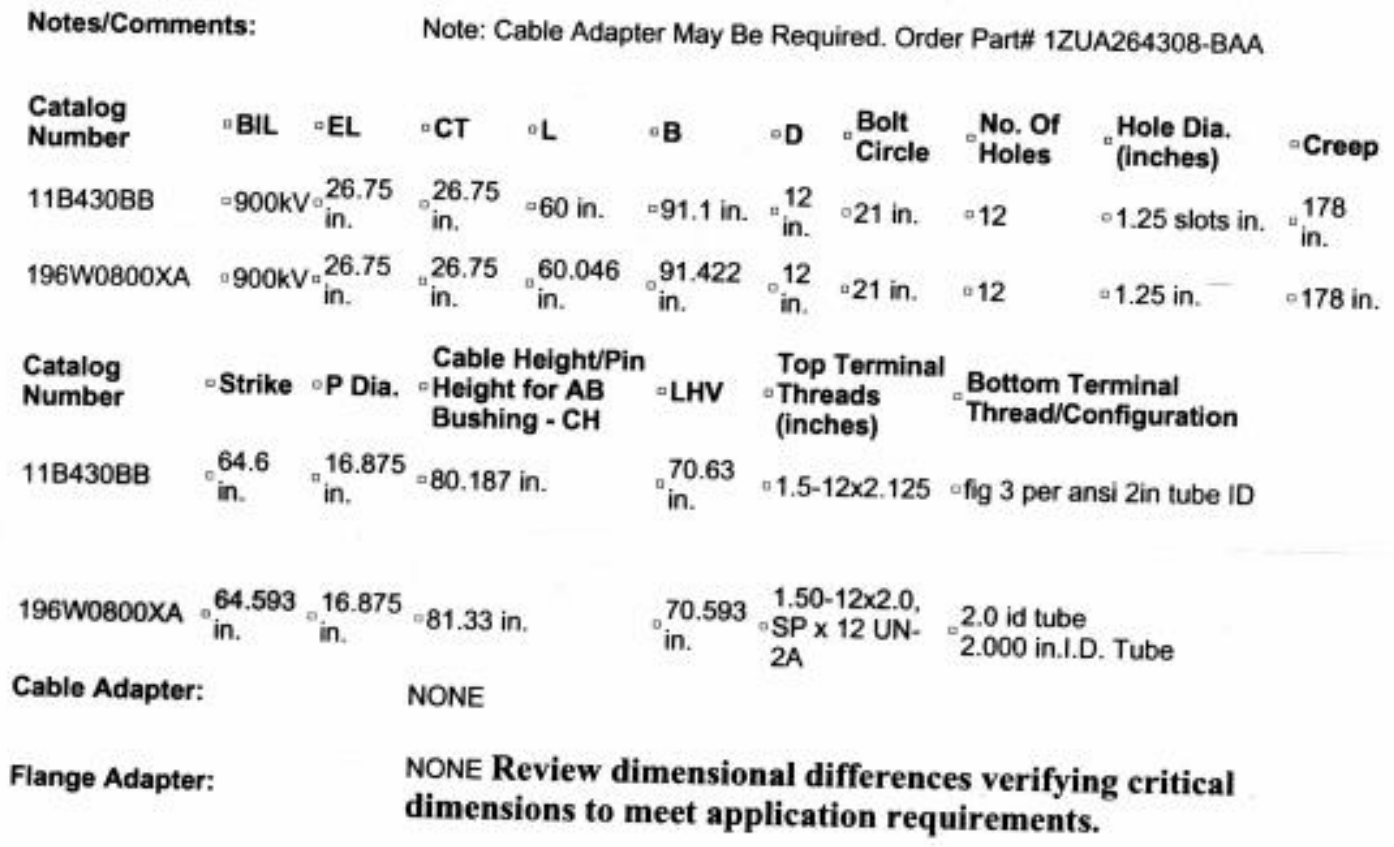

Figure 4: Bushing Cross Reference Information. 


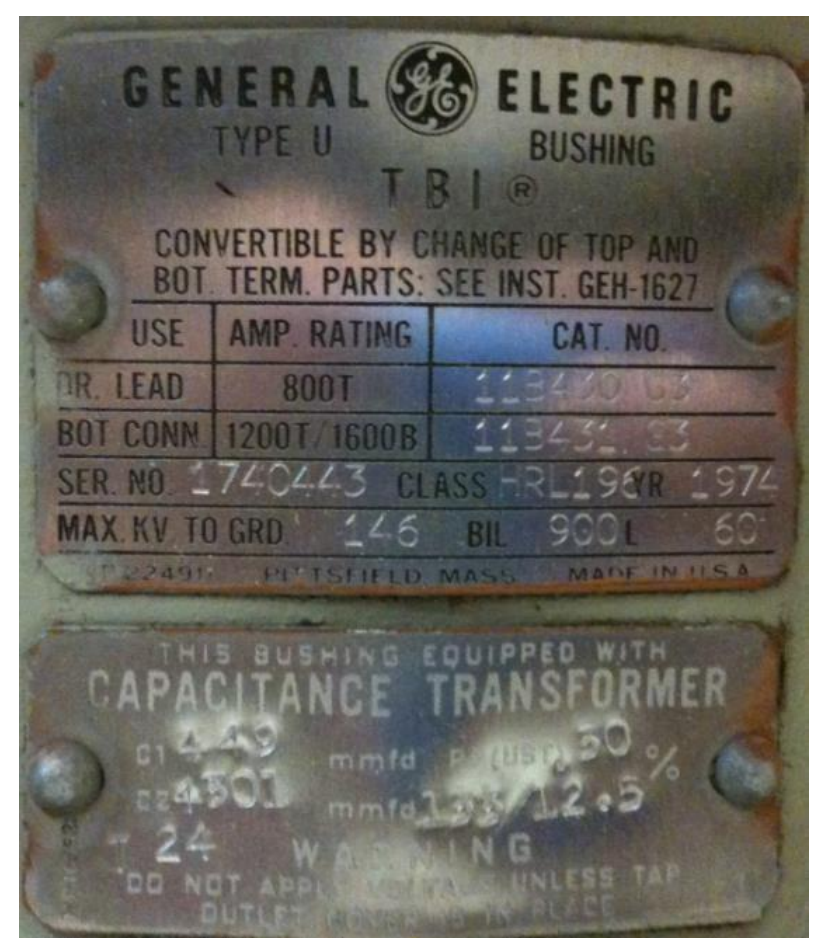

Figure 5: Name Plate of Bushing 1.

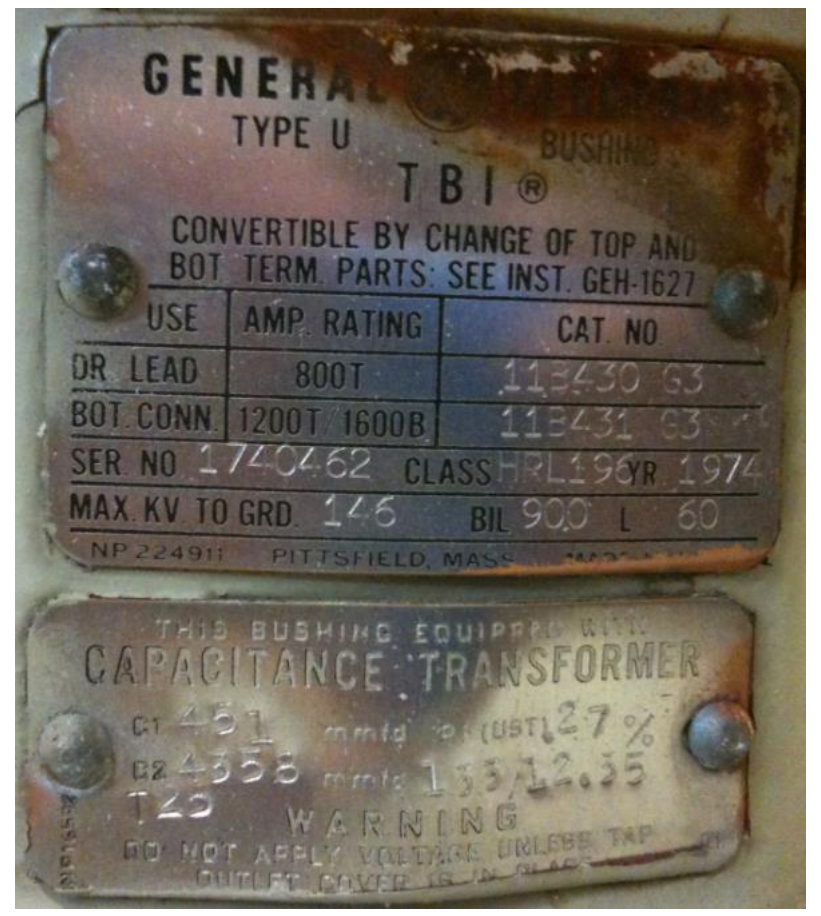

Figure 6: Name Plate of Bushing. 


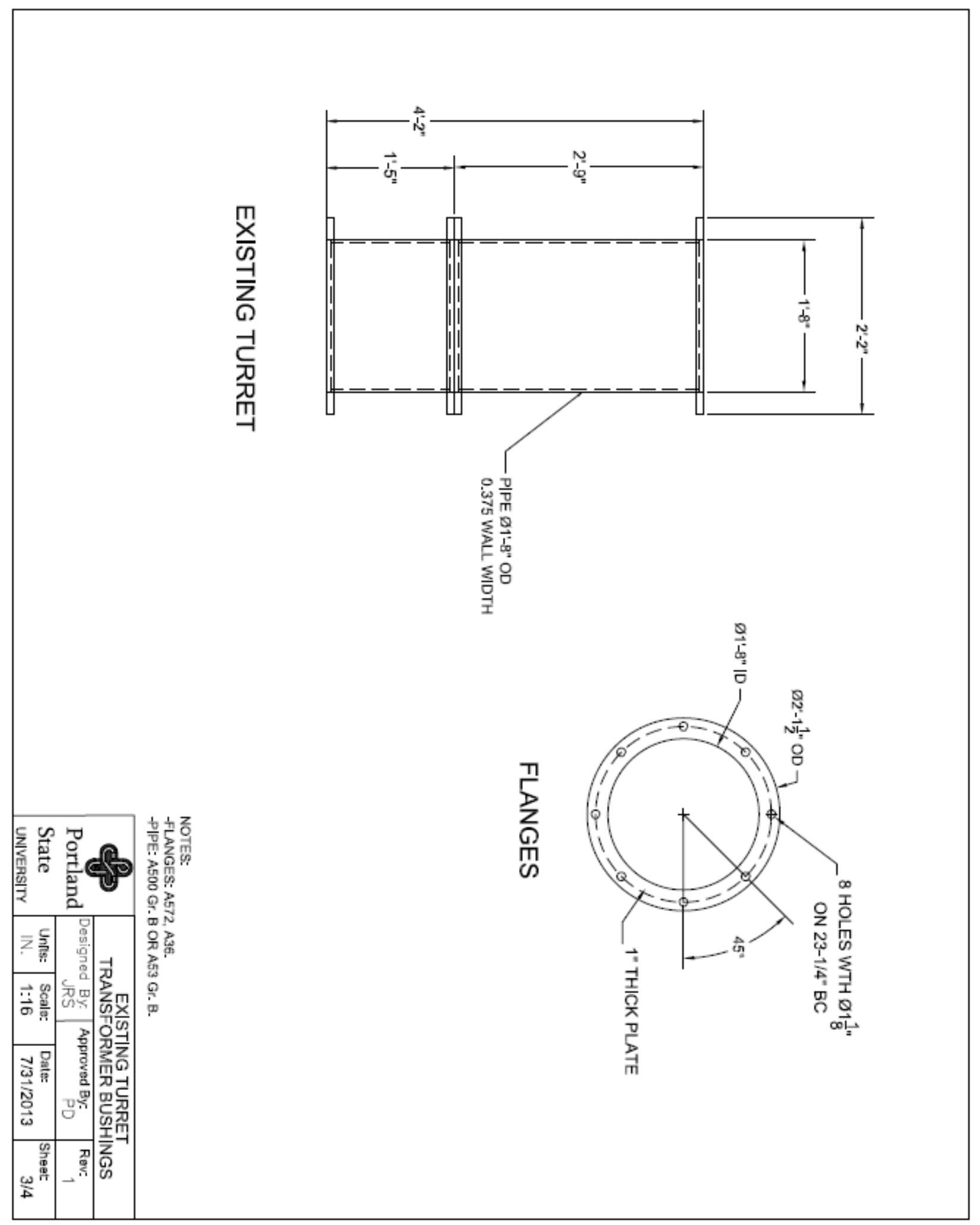

Figure 7: Existing Turret. 


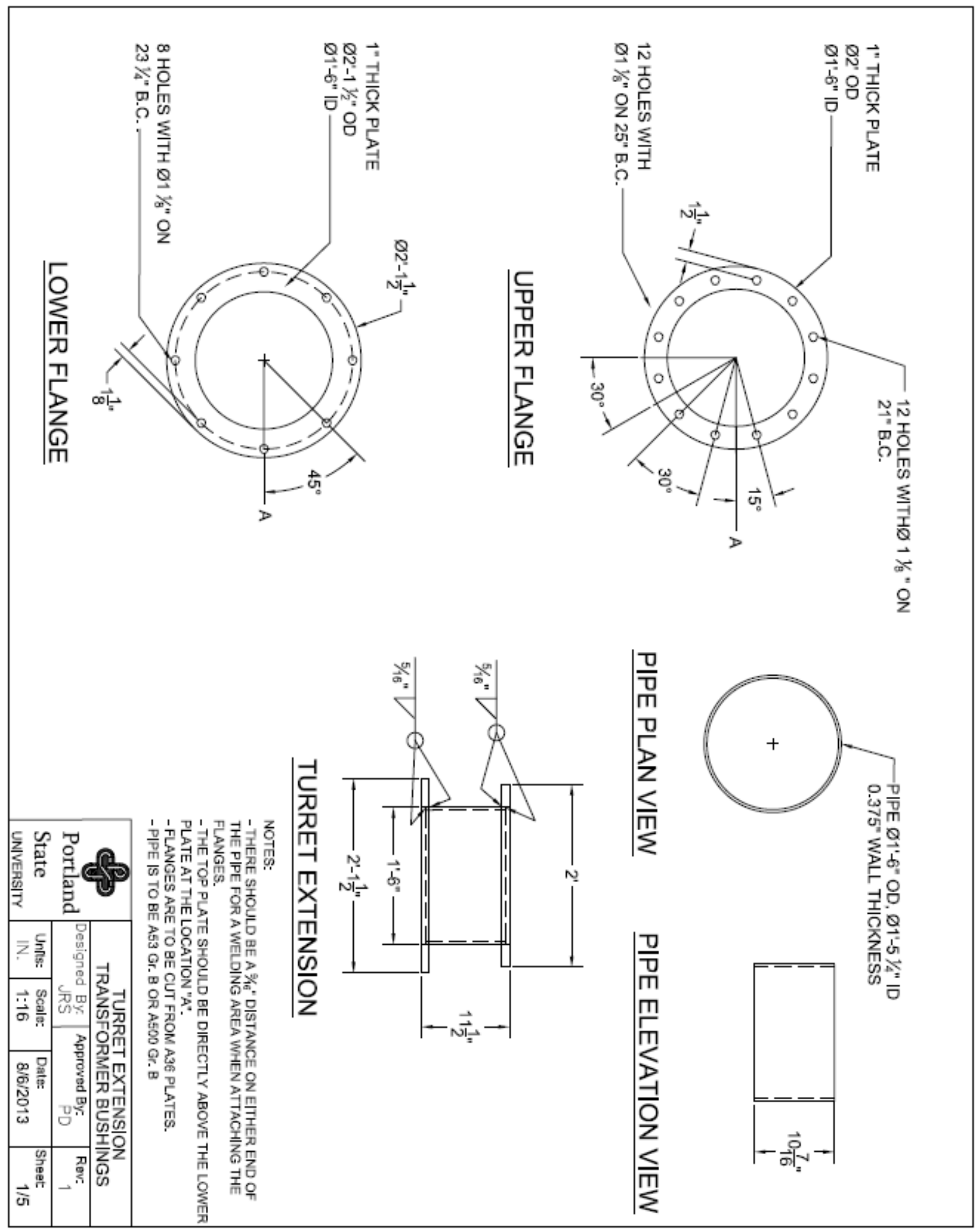

Figure 8: Turret Extension. 


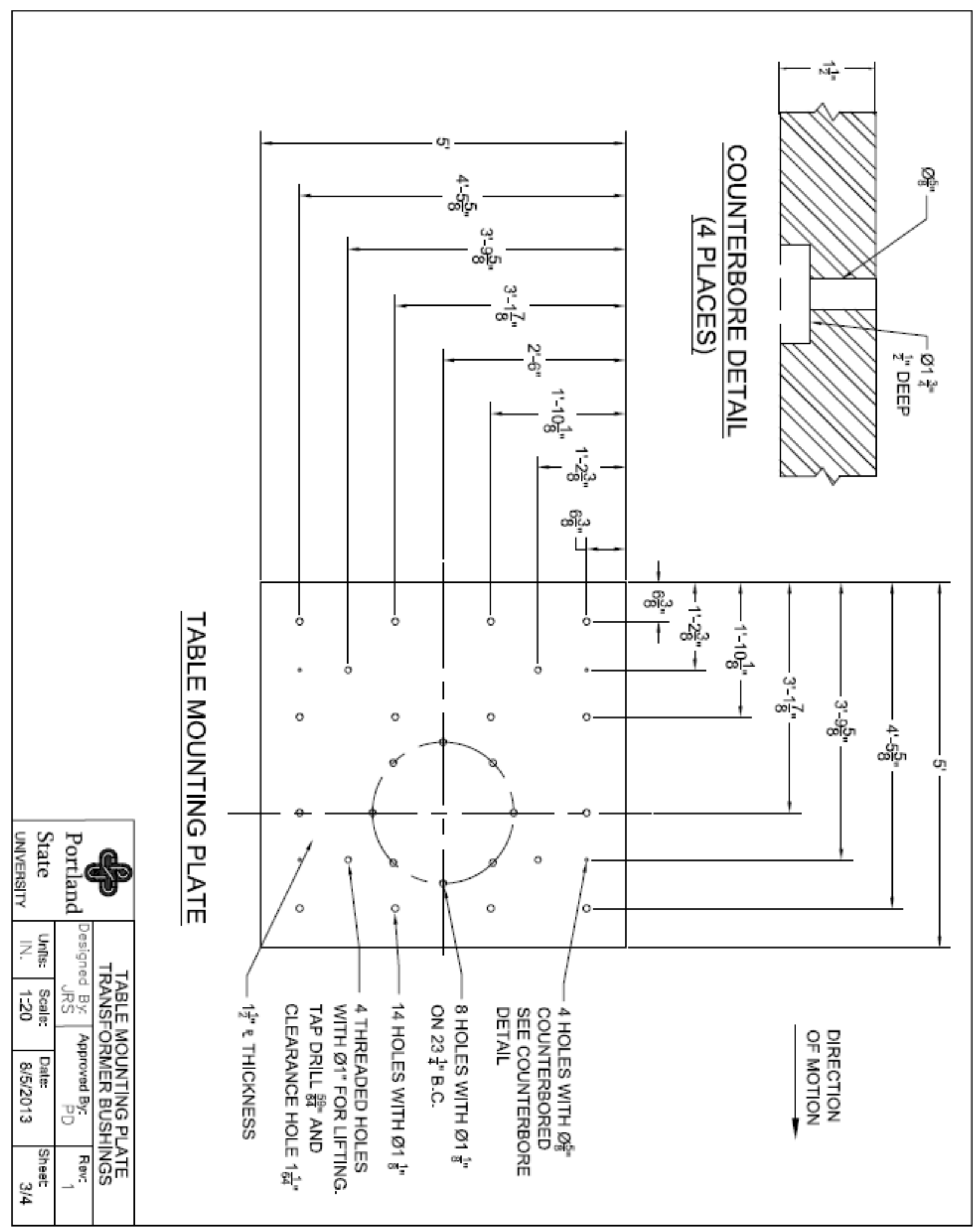

Figure 911: Table Mounting Plate. 


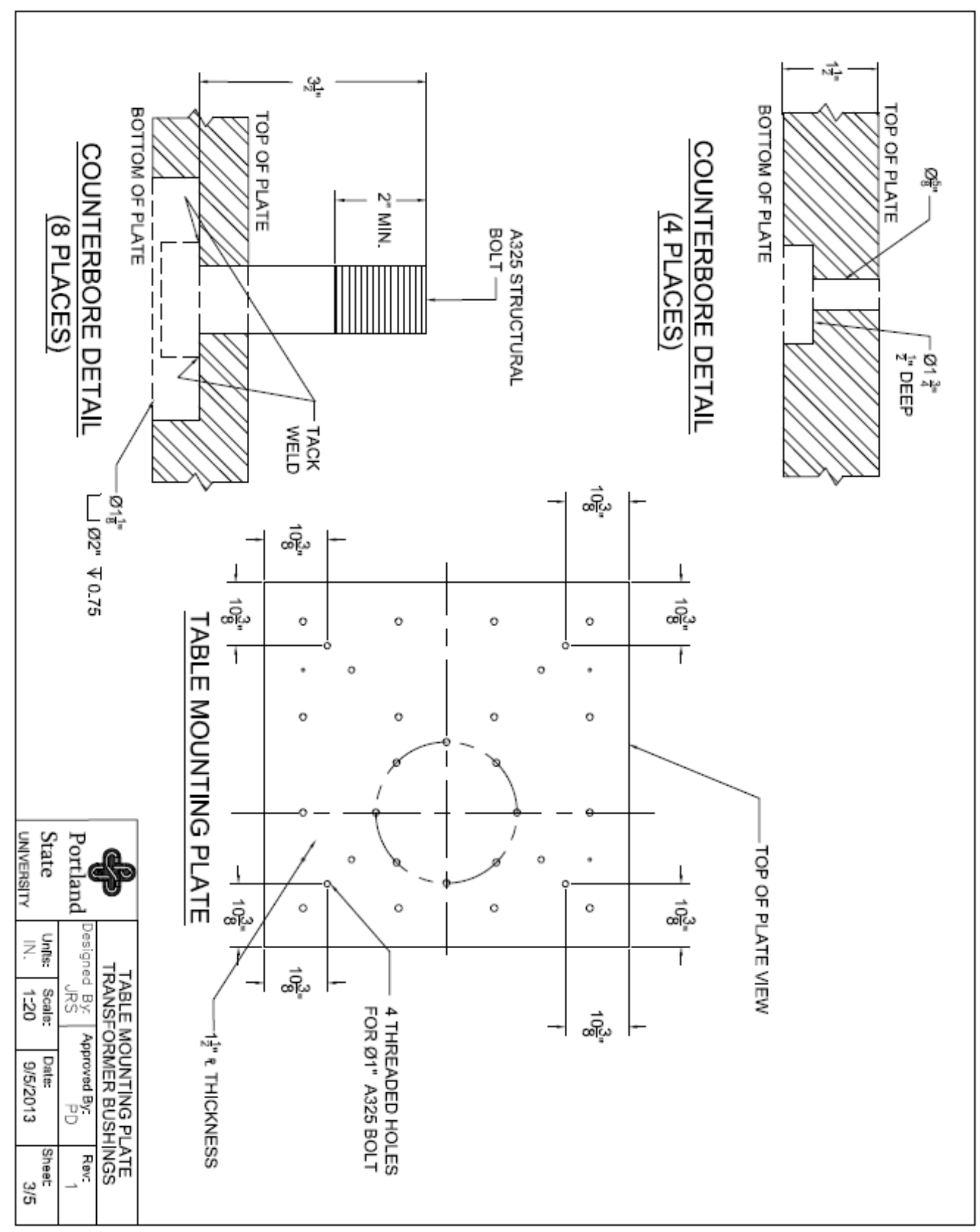

Figure 10: Table Mounting Plate Additions. 


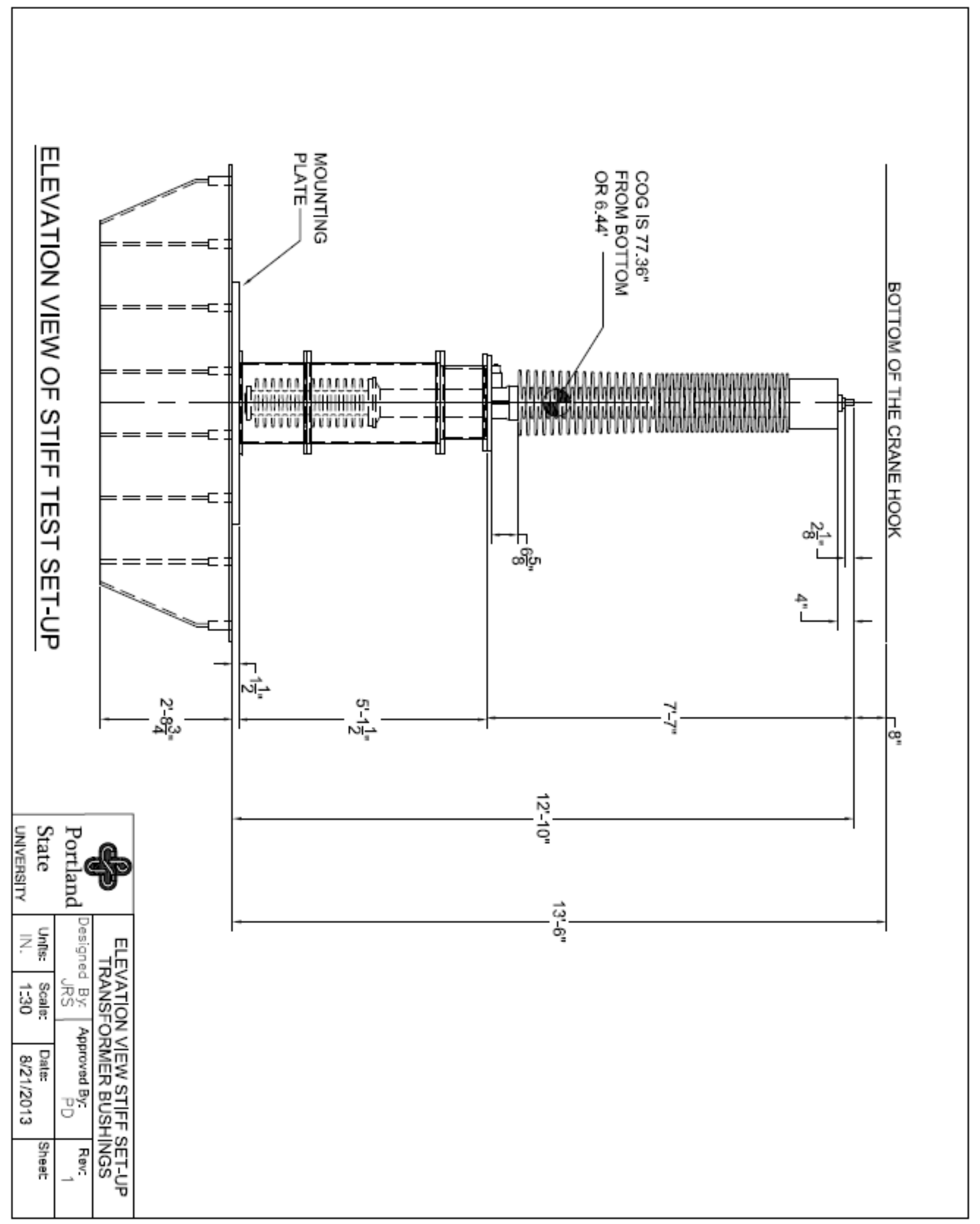

Figure 11: Elevation View of Stiff Set-Up. 


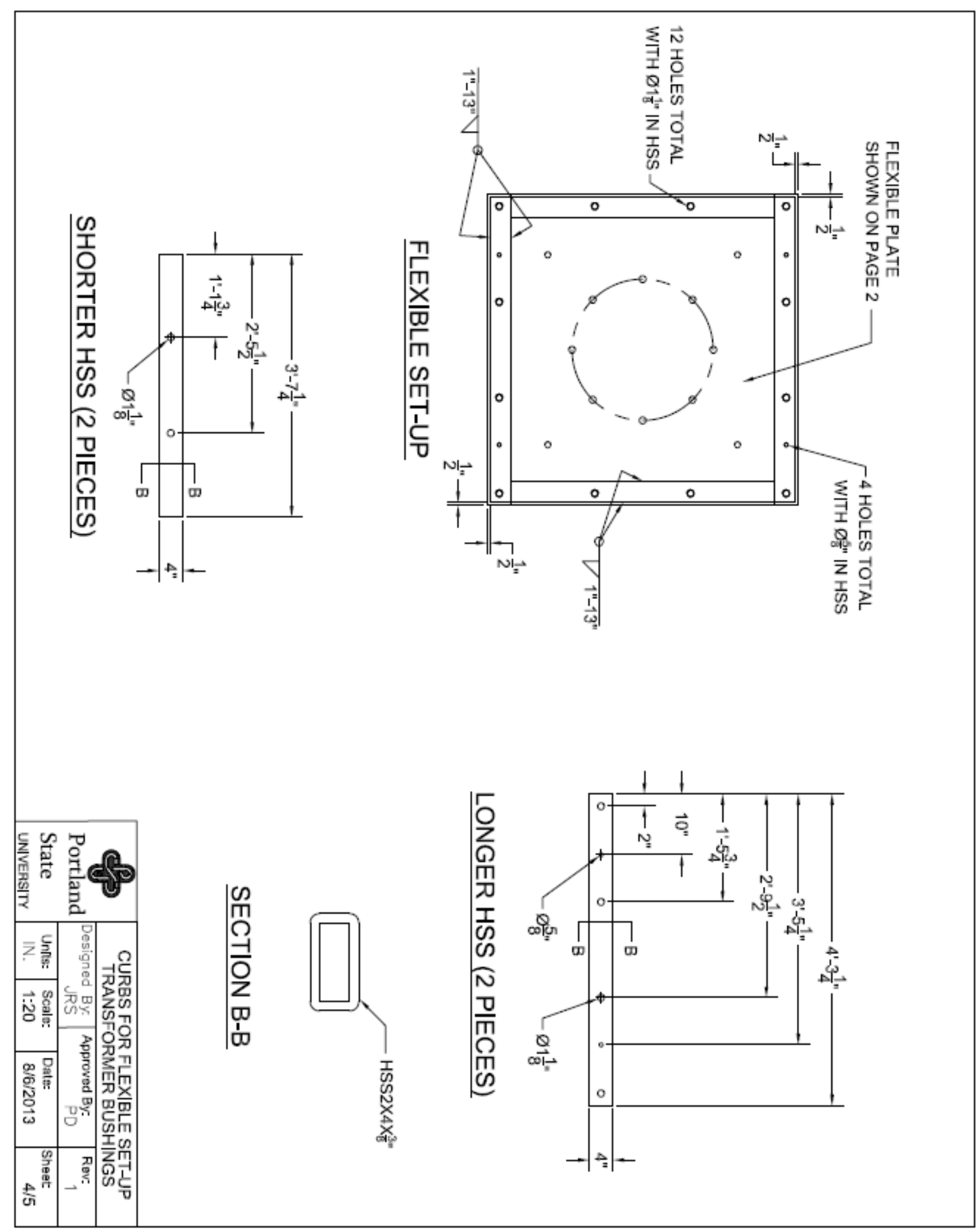

Figure 12: Curbs for Flexible Set-Up. 


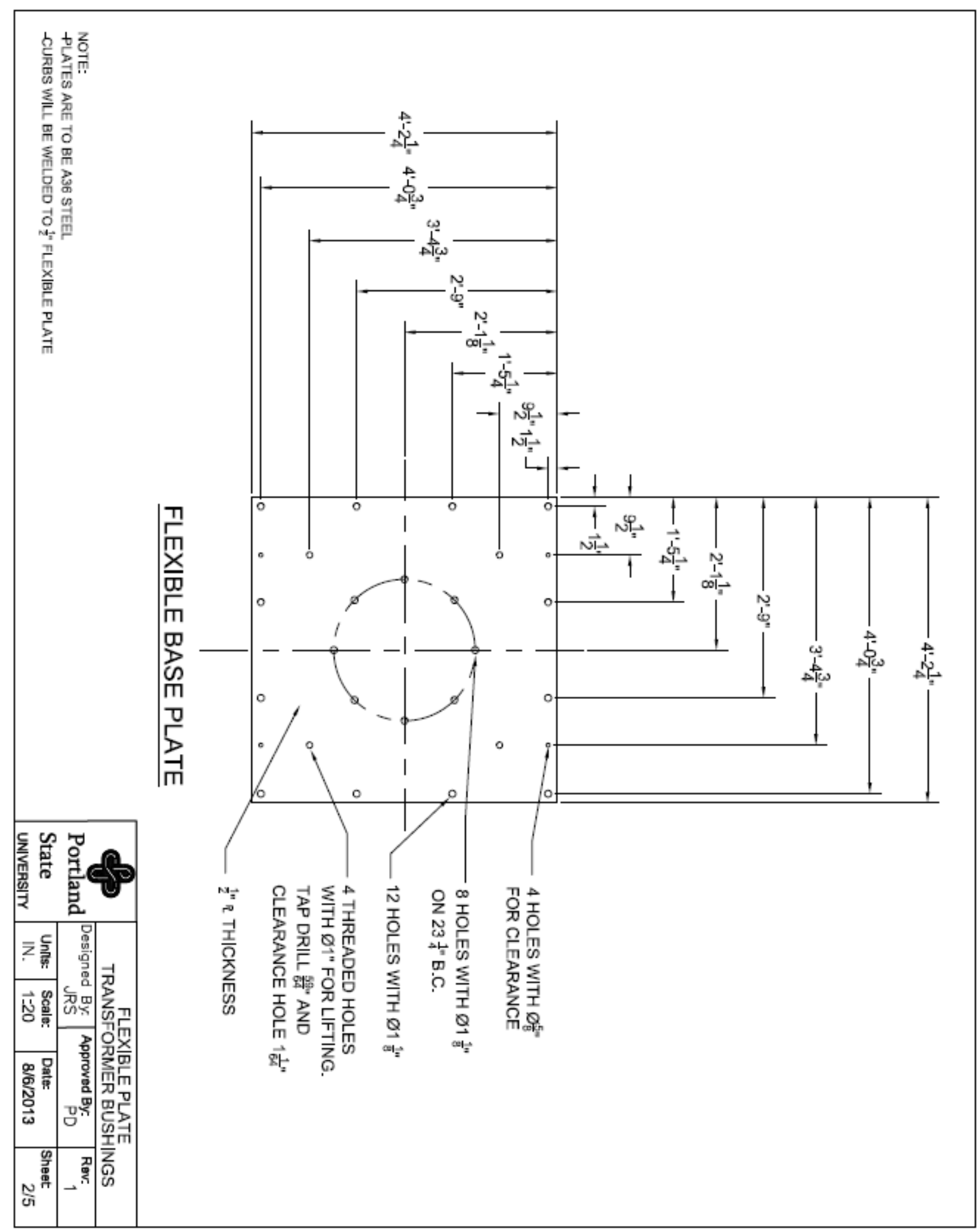

Figure 13: Flexible Plate. 


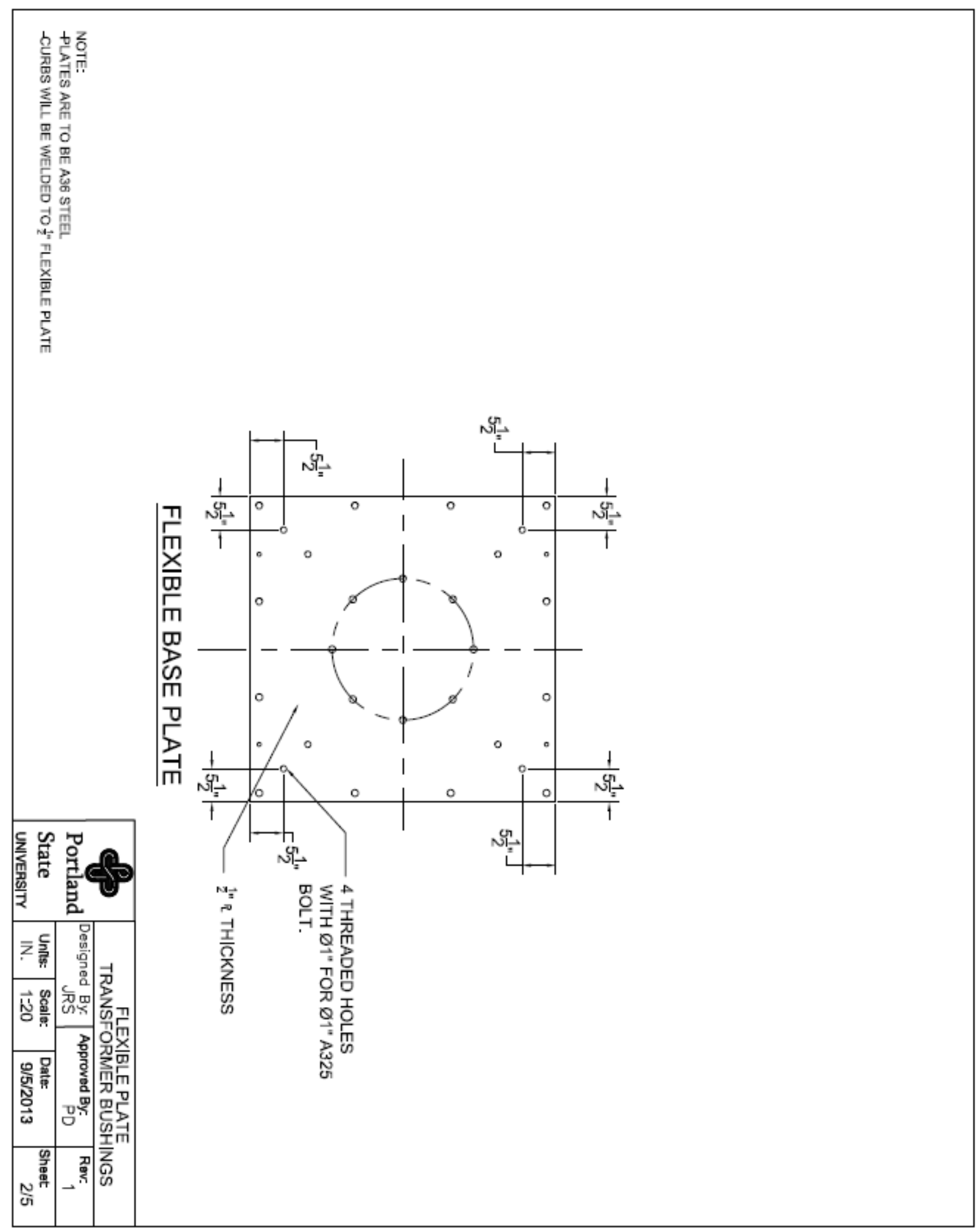

Figure 124: Flexible Plate Additions. 


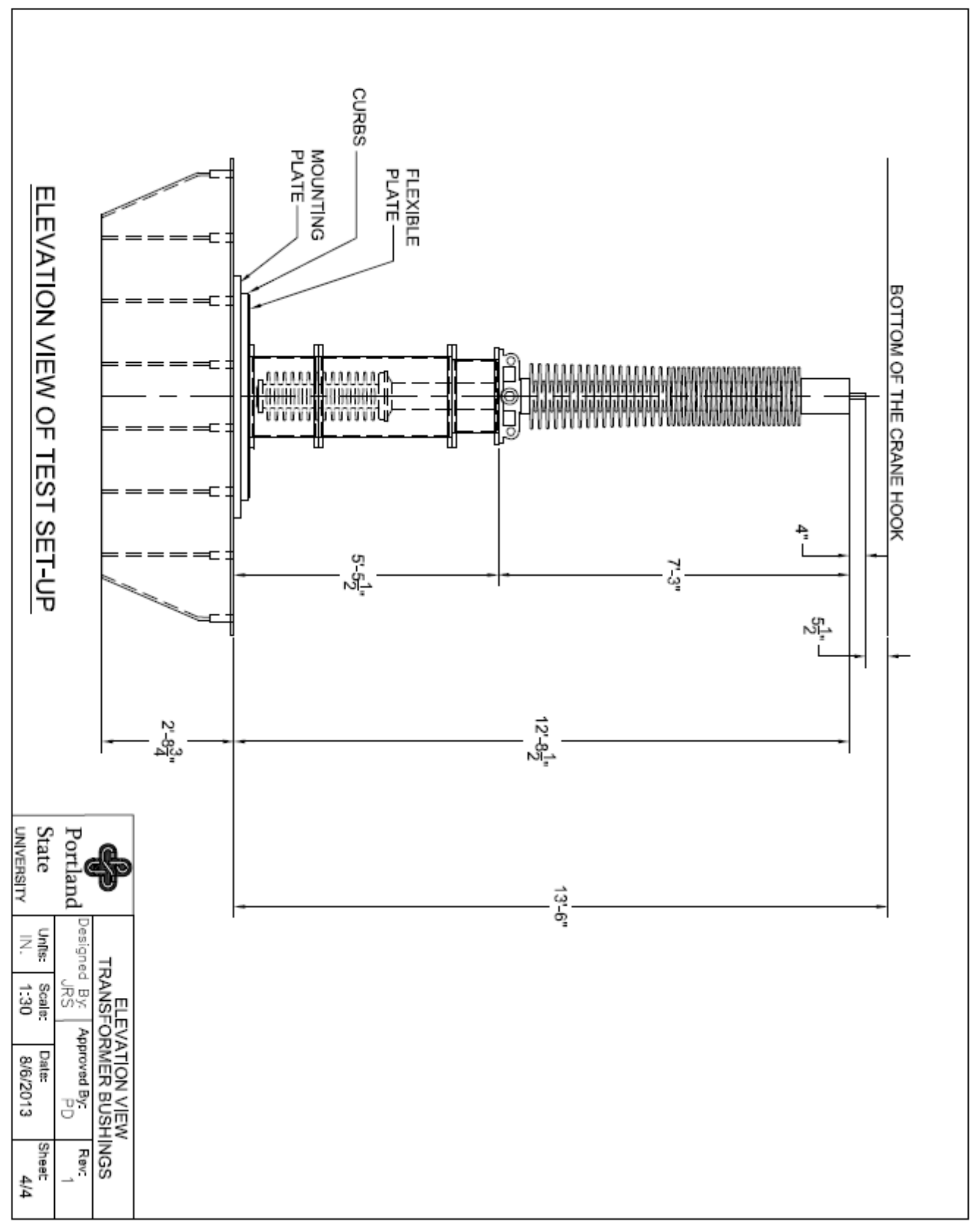

Figure 15: Elevation View of Flexible Set-Up. 


\section{Appendix B}

\section{Instrumentation List}

\section{Table of Contents}

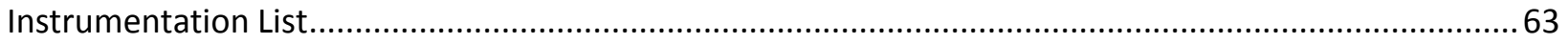


Table 3: Instrumentation.

\begin{tabular}{|c|c|c|c|c|}
\hline $\begin{array}{l}\text { Instrument } \\
\text { Name }\end{array}$ & Range/Capacity & Instrument $\mathrm{S} / \mathrm{N}$ & Manufacturer & Location Description \\
\hline $\begin{array}{l}\text { 1-D } \\
\text { Accelerometer }\end{array}$ & $+/-8 g$ & $141 \mathrm{~A}$ & Setra & Shake table accelerometer \\
\hline $\begin{array}{l}\text { 1-D } \\
\text { Accelerometer }\end{array}$ & $+/-4 g$ & $\begin{array}{l}\text { CXL04LP1 } \\
\text { LAB\#A001 }\end{array}$ & Crossbow & $\begin{array}{l}\text { South side of turrett, lower flange. Located } \\
37 / 8 \text { " from outside of turrett to center of } \\
\text { accelerometer. } X=N-S\end{array}$ \\
\hline $\begin{array}{l}\text { 1-D } \\
\text { Accelerometer }\end{array}$ & $+/-8 g$ & 790052 & Setra & Center of gravity on upper bushing. \\
\hline $\begin{array}{l}1-\mathrm{D} \\
\text { Accelerometer }\end{array}$ & $+/-8 g$ & 1256598 & Setra & Top of bushing \\
\hline $\begin{array}{l}\text { 1-D } \\
\text { Accelerometer }\end{array}$ & $+/-30 \mathrm{~g}$ & 1364860 & Setra & Top of bushing. \\
\hline $\begin{array}{l}\text { 3-D } \\
\text { Accelerometer }\end{array}$ & $+/-4 g$ & $\begin{array}{l}\text { CXL04GP3 } \\
\text { LAB\#A001 }\end{array}$ & Crossbow & $\begin{array}{l}\text { South side of turett, on top of the steel } \\
\text { flange. }+Y=\text { North, }+X=\text { West, }+Z=U p \text {. It is } \\
\text { mounted } 11 / 4 " \text { from the N-S center line to } \\
\text { the center of the accelerometer, and } 5 / 16 " \\
\text { above the steel flange to the bottom of the } \\
\text { accelerometer. }\end{array}$ \\
\hline $\begin{array}{l}\text { 3-D } \\
\text { Accelerometer }\end{array}$ & $+/-4 g$ & CXL04GP3 & Crossbow & $\begin{array}{l}\text { located at CG. }+Y=\text { North, }+Z=U p \text { South, }+X \\
=\text { West. Mounted } 11 / 2 " \text { from the outer } \\
\text { most part of the bushing to the center of } \\
\text { the accelerometer. }\end{array}$ \\
\hline $\begin{array}{l}\text { 3-D } \\
\text { Accelerometer }\end{array}$ & $+/-4 g$ & CXL04GP3 & Crossbow & $\begin{array}{l}\text { Top of the bushing. Mounted } 21 / 2 \text { " above } \\
\text { the top of the bushing to the bottom of the } \\
\text { accelerometer, and } 21 / 2 \text { " from the center } \\
\text { of the bushing rod to the center of the } \\
\text { accelerometer. }+Y=\text { North, }+X=\text { West, }+Z= \\
\text { Up. }\end{array}$ \\
\hline String Pot & $+/-12.5$ in. & $\begin{array}{l}\text { SM2-12 } \\
\text { LAB\#002 }\end{array}$ & Celesco & Top of Turret, N-S. \\
\hline String Pot & $+/-12.5$ in. & $\begin{array}{l}\text { SM2-12 } \\
\text { LAB\#004 }\end{array}$ & Celesco & Top of Turret, E-W. \\
\hline String Pot & $+/-12.5$ in. & SM2-12 & Celesco & Top of Bushing, E-W. Mounted on west side. \\
\hline String Pot & $+/-25$ in. & SM2-25 & Celesco & $\begin{array}{l}\text { Top of Bushing, N-S. Mounted on South } \\
\text { side. }\end{array}$ \\
\hline String Pot & $+/-25$ in. & SM2-25 & Celesco & $\begin{array}{l}\text { Bottom edge of upper section of upper } \\
\text { bushing. }\end{array}$ \\
\hline LVDT & $+/-1.18$ in. & $\begin{array}{l}\text { TRS-0025 } \\
\text { LAB\#001 } \\
\end{array}$ & Novotechnik & $\begin{array}{l}\text { Table mounting plate to turret, located on } \\
\text { north side of turret. }\end{array}$ \\
\hline LVDT & $+/-1.18$ in. & $\begin{array}{l}\text { TRS-0025 } \\
\text { LAB\#002 } \\
\end{array}$ & Novotechnik & $\begin{array}{l}\text { North, vertical, } 63 / 8 \text { " from the porcelain } \\
\text { circumference. }\end{array}$ \\
\hline LVDT & $+/-1.18$ in. & $\begin{array}{l}\text { TRS-0025 } \\
\text { LAB\#005 }\end{array}$ & Novotechnik & $\begin{array}{l}\text { West, vertical, } 61 / 4 \text { " from the porcelain } \\
\text { circumference. }\end{array}$ \\
\hline LVDT & $+/-1.18$ in. & $\begin{array}{l}\text { TRS-0025 } \\
\text { LAB\#004 }\end{array}$ & Novotechnik & $\begin{array}{l}\text { South, vertical, } 61 / 2 \text { " from the porcelain } \\
\text { circumference. }\end{array}$ \\
\hline LVDT & $+/-1.18$ in. & $\begin{array}{l}\text { TRS-0025 } \\
\text { LAB\#003 } \\
\end{array}$ & Novotechnik & $\begin{array}{l}\text { East, vertical, } 63 / 8 \text { " from the porcelain } \\
\text { circumference. }\end{array}$ \\
\hline LVDT & $+/-1.97$ in. & TRS-0050 & Novotechnik & Shake table to plate. \\
\hline
\end{tabular}




\begin{tabular}{|c|c|c|c|c|}
\hline $\begin{array}{c}\text { Instrument } \\
\text { Name }\end{array}$ & Range/Capacity & Instrument S/N & Manufacturer & Location Description \\
\hline LVDT & $+/-1.97$ in. & $\begin{array}{l}\text { TRS-0050 } \\
\text { LAB\#002 }\end{array}$ & Novotechnik & $\begin{array}{l}\text { North, horizontal, } 5 \text { 11/16" from steel } \\
\text { circumference. }\end{array}$ \\
\hline LVDT & $+/-1.97$ in. & $\begin{array}{l}\text { TRS-0050 } \\
\text { LAB\#005 }\end{array}$ & Novotechnik & $\begin{array}{l}\text { West, horizontal, } 5 \text { 11/16" from steel } \\
\text { circumference. }\end{array}$ \\
\hline LVDT & $+/-1.97$ in. & $\begin{array}{l}\text { TRS-0050 } \\
\text { LAB\#004 }\end{array}$ & Novotechnik & $\begin{array}{l}\text { South, horizontal, } 5 \text { 5/8" from steel } \\
\text { circumference. }\end{array}$ \\
\hline LVDT & $+/-1.97$ in. & TRS-0050 & Novotechnik & $\begin{array}{l}\text { East, horizontal, } 5 \text { 11/16" from steel } \\
\text { circumference. }\end{array}$ \\
\hline LVDT & $+/-1.97$ in. & TRS-0050 & Novotechnik & $\begin{array}{l}\text { Component of shake table. Inside the } \\
\text { actuator. }\end{array}$ \\
\hline LVDT & $+/-1.97$ in. & TRS-0050 & Novotechnik & $\begin{array}{l}\text { North, vertical, 6" from the edge of the } \\
\text { bottom flange of the turret. }\end{array}$ \\
\hline LVDT & +/-1.97 in. & TRS-0050 & Novotechnik & $\begin{array}{l}\text { North, horizontal, between table mounting } \\
\text { plate and flexbile setup. }\end{array}$ \\
\hline Strain Gage & $\begin{array}{c}20,000 \\
\text { microstrain }\end{array}$ & $\begin{array}{c}\text { KFH-3-120-C1- } \\
\text { 11L1M2R }\end{array}$ & $\begin{array}{l}\text { Omega Engineering } \\
\text { Inc. }\end{array}$ & $\begin{array}{l}\text { South facing, lower flange of turret. } 11 / 2 " \\
\text { about lower flange. }\end{array}$ \\
\hline Strain Gage & $\begin{array}{c}20,000 \\
\text { microstrain }\end{array}$ & $\begin{array}{c}\text { KFH-3-120-C1- } \\
\text { 11L1M2R } \\
\end{array}$ & $\begin{array}{l}\text { Omega Engineering } \\
\text { Inc. }\end{array}$ & East facing, lower flange of turret. \\
\hline Strain Gage & $\begin{array}{c}20,000 \\
\text { microstrain }\end{array}$ & $\begin{array}{l}\text { KFH-3-120-C1- } \\
\text { 11L1M2R }\end{array}$ & $\begin{array}{l}\text { Omega Engineering } \\
\text { Inc. }\end{array}$ & North facing, lower flange of turret. \\
\hline Strain Gage & $\begin{array}{c}20,000 \\
\text { microstrain }\end{array}$ & $\begin{array}{c}\text { KFH-3-120-C1- } \\
\text { 11L1M2R } \\
\end{array}$ & $\begin{array}{l}\text { Omega Engineering } \\
\text { Inc. }\end{array}$ & West facing, lower flange of turret. \\
\hline Strain Gage & $\begin{array}{l}20,000 \\
\text { microstrain }\end{array}$ & $\begin{array}{l}\text { KFH-3-120-C1- } \\
\text { 11L1M2R }\end{array}$ & $\begin{array}{l}\text { Omega Engineering } \\
\text { Inc. }\end{array}$ & $\begin{array}{l}\text { South facing, Steel neck of bushing. Located } \\
11 / 2 \text { " up from the steel flange to center of } \\
\text { gage. }\end{array}$ \\
\hline Strain Gage & $\begin{array}{l}20,000 \\
\text { microstrain }\end{array}$ & $\begin{array}{l}\text { KFH-3-120-C1- } \\
\text { 11L1M2R }\end{array}$ & $\begin{array}{l}\text { Omega Engineering } \\
\text { Inc. }\end{array}$ & $\begin{array}{l}\text { East facing, Steel neck of bushing. Located } 1 \\
1 / 2 \text { " up from the steel flange to center of } \\
\text { gage. }\end{array}$ \\
\hline Strain Gage & $\begin{array}{l}20,000 \\
\text { microstrain }\end{array}$ & $\begin{array}{l}\text { KFH-3-120-C1- } \\
\text { 11L1M2R }\end{array}$ & $\begin{array}{l}\text { Omega Engineering } \\
\text { Inc. }\end{array}$ & 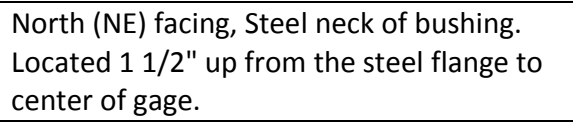 \\
\hline Strain Gage & $\begin{array}{l}20,000 \\
\text { microstrain }\end{array}$ & $\begin{array}{l}\text { KFH-3-120-C1- } \\
\text { 11L1M2R }\end{array}$ & $\begin{array}{l}\text { Omega Engineering } \\
\text { Inc. }\end{array}$ & $\begin{array}{l}\text { North (NW) facing, Steel neck of bushing. } \\
\text { Located } 11 / 2 \text { " up from the steel flange to } \\
\text { center of gage. }\end{array}$ \\
\hline Strain Gage & $\begin{array}{l}20,000 \\
\text { microstrain }\end{array}$ & $\begin{array}{l}\text { KFH-3-120-C1- } \\
\text { 11L1M2R }\end{array}$ & $\begin{array}{l}\text { Omega Engineering } \\
\text { Inc. }\end{array}$ & $\begin{array}{l}\text { West facing, Steel neck of bushing. Located } \\
11 / 2 \text { " up from the steel flange to center of } \\
\text { gage. }\end{array}$ \\
\hline Strain Gage & $\begin{array}{c}20,000 \\
\text { microstrain }\end{array}$ & $\begin{array}{c}\text { KFH-3-120-C1- } \\
\text { 11L1M2R } \\
\end{array}$ & $\begin{array}{l}\text { Omega Engineering } \\
\text { Inc. }\end{array}$ & $\begin{array}{l}\text { North facing, located on porcelain } 11 / 8 " \\
\text { from the bottom edge of the porcelain. }\end{array}$ \\
\hline Strain Gage & $\begin{array}{c}20,000 \\
\text { microstrain }\end{array}$ & $\begin{array}{l}\text { KFH-3-120-C1- } \\
\text { 11L1M2R }\end{array}$ & $\begin{array}{l}\text { Omega Engineering } \\
\text { Inc. }\end{array}$ & $\begin{array}{l}\text { West facing, located on porcelain } 11 / 8 " \\
\text { from the bottom edge of the porcelain. }\end{array}$ \\
\hline Strain Gage & $\begin{array}{c}20,000 \\
\text { microstrain }\end{array}$ & $\begin{array}{c}\text { KFH-3-120-C1- } \\
\text { 11L1M2R } \\
\end{array}$ & $\begin{array}{l}\text { Omega Engineering } \\
\text { Inc. }\end{array}$ & $\begin{array}{l}\text { South facing, located on porcelain } 11 / 8 " \\
\text { from the bottom edge of the porcelain. }\end{array}$ \\
\hline Strain Gage & $\begin{array}{c}20,000 \\
\text { microstrain }\end{array}$ & $\begin{array}{l}\text { KFH-3-120-C1- } \\
\text { 11L1M2R }\end{array}$ & $\begin{array}{l}\text { Omega Engineering } \\
\text { Inc. }\end{array}$ & $\begin{array}{l}\text { East facing, located on porcelain } 11 / 8 \text { "from } \\
\text { the bottom edge of the porcelain. }\end{array}$ \\
\hline Strain Gage & $\begin{array}{l}20,000 \\
\text { microstrain }\end{array}$ & $\begin{array}{l}\text { KFH-3-120-C1- } \\
\text { 11L1M2R }\end{array}$ & $\begin{array}{l}\text { Omega Engineering } \\
\text { Inc. }\end{array}$ & $\begin{array}{l}\text { North facing, located flexible plate } 1 " \text { from } \\
\text { the edge of turret flange. }\end{array}$ \\
\hline Strain Gage & $\begin{array}{l}20,000 \\
\text { microstrain }\end{array}$ & $\begin{array}{l}\text { KFH-3-120-C1- } \\
\text { 11L1M2R }\end{array}$ & $\begin{array}{l}\text { Omega Engineering } \\
\text { Inc. }\end{array}$ & $\begin{array}{l}\text { South facing, located flexible plate } 1 \text { " from } \\
\text { the edge of turret flange. }\end{array}$ \\
\hline
\end{tabular}




\section{Appendix C}

\section{Test Sequences}

\section{Table of Contents}

Test Sequence 1 - Turret and Bushing Stiff Mount - Part1 Date: 10/15/2013 .............................686

Test Sequence 1 - Turret and Bushing Stiff Mount - Part 2 Date: 10/16/2013 .............................697

Test Sequence 1 - Turret and Bushing Stiff Mount - Part 3 Date: 10/17/2013 ............................. 708

Test Sequence 2 - Turret \& Bushing Flexible Mount - Part1 Date: 10/29/2013 .............................. 70

Test Sequence 2 - Turret \& Bushing Flexible Mount - Part2 Date: 10/31/2013 ….......................... 71 


\section{Gage Calibration}

Apply a cantilever load of 500lb to calibrate the strain gauges

$\underline{X}$ EW Pull

$\underline{X}$ NS Pull

Notes: Sampling rate $=400$ points $/ \mathrm{sec}$, time step of ground motion $=0.0025$.

\section{System ID Dynamic}

$\underline{X}$ Impact Tests

$\underline{X}$ EW impact

$\underline{X}$ NS impact

$\underline{X}$ Table Pulse - (NS) using half sine function $(20 \mathrm{~Hz})$

Notes: The pulse was done three times.

$\underline{x}$ Sine Sweep $-(\mathrm{NS})$ acceleration $=0.1 \mathrm{~g}(1-33 \mathrm{~Hz})$

Notes: Sine sweep did not work. However it stopped after the expected resonant frequency, therefore there is no need to re-do the sine sweep. $f_{n}=11.5 \mathrm{~Hz}$.

\section{Earthquake Simulation}

$\underline{X}$ Amplitude $=25 \%$ of ground motion (NS)

$\underline{X}$ Visual inspection

$\underline{X}$ Table Pulse - (NS) using half sine function $(20 \mathrm{~Hz})$

Notes: The pulse was done three times.

$\underline{x}$ Sine Sweep (NS)

$\underline{\mathrm{X}}$ Repeated ground motion with new amplitudes

Amplitudes

\begin{tabular}{|c|c|c|c|c|c|c|}
\hline $50 \%$ & $75 \%$ & $100 \%$ & $125 \%$ & $150 \%$ & $175 \%$ & $200 \%$ \\
\hline $\mathrm{X}$ & $\mathrm{X}$ & $\mathrm{X}$ & $\mathrm{X}$ & $\mathrm{X}$ & $\mathrm{X}$ & - \\
\hline
\end{tabular}

Notes: The table stopped during the $200 \%$ ground motion.

Table pulse

Notes: Table pulse was not run. 


\section{Earthquake Simulation}

$\underline{X}$ Table Pulse - (NS) using half sine function $(20 \mathrm{~Hz})$

Note: three pulses were done.

$\underline{x}$ Sine Sweep (NS)

Note: $\mathrm{f}_{\mathrm{n}}=11.97 \mathrm{~Hz}$

$\underline{X}$ Amplitude $=175 \%$ of ground motion (NS)

$\underline{X}$ Visual inspection

$\underline{\mathrm{X}}$ Table Pulse - (NS) using half sine function $(20 \mathrm{~Hz})$

$\underline{X}$ Sine Sweep (NS)

Note: The natural frequency of the string pot visually appears to be around $7.5 \mathrm{~Hz}$ and is not to be confused with the natural frequency of the bushing when looking at data.

Bushing, $\mathrm{f}_{\mathrm{n}}=12.1 \mathrm{~Hz}$

$\underline{X}$ Amplitude $=200 \%$ of ground motion (NS)

$\underline{X}$ Table Pulse - (NS) using half sine function $(20 \mathrm{~Hz})$

Note: three pulses were done.

$\underline{x}$ Sine Sweep (NS)

Note: $f_{n}=12.16 \mathrm{~Hz}$

$\underline{x}$ Sine Beat (NS), $0.25 \mathrm{~g}$. Acceleration was looked at for the top of the bushing. A judgment was made

regarding what to run next. The acceleration showed that the top of the bushing was experiencing

$4.5 \mathrm{~g}$, therefore the bushing is expected to fail soon.

$\underline{X}$ Sine Beat (NS), 0.2625g.

$\underline{x}$ Sine Beat (NS), $0.275 \mathrm{~g}$.

$\underline{X}$ Sine Beat (NS), 0.3g.

$\underline{x}$ Sine Beat (NS), $0.325 \mathrm{~g}$.

$\underline{x}$ Sine Beat (NS), $0.375 \mathrm{~g}$. (50\% of original)

$\underline{x}$ Sine Beat (NS), $0.425 \mathrm{~g}$. (70\% of original)

$\underline{x}$ Sine Beat (NS), $0.5 \mathrm{~g}$. (70\% of original) 
Test Sequence 1 - Turret and Bushing Stiff Mount - Part 3 Date: 10/17/2013

\section{Testing Continued}

$\underline{X}$ SnapBack tests (Pull Test)

$\underline{X}$ Hand Impact Test at top of bushing

$\underline{X}$ Hand Impact Test at upper porcelain connection of two porcelain pieces.

$\underline{\mathrm{X}}$ Table Pulse $-(\mathrm{NS})$ using half sine function $(20 \mathrm{~Hz})$

Notes: The pulse was done three times.

$\underline{X} 175 \%$ of ground motion

$\underline{\mathrm{X}}$ Table Pulse - (NS) using half sine function $(20 \mathrm{~Hz})$

Notes: The pulse was done three times.

$\underline{X} 0.5 \mathrm{~g}$ Sine beat

$\underline{X}$ Visual inspection

$\underline{X}$ Table Pulse - (NS) using half sine function $(20 \mathrm{~Hz})$

Notes: The pulse was done three times.

$\underline{X} 0.575 \mathrm{~g}$ Sine beat

$\underline{X}$ Visual inspection

$\underline{X}$ Table Pulse - (NS) using half sine function $(20 \mathrm{~Hz})$

Notes: The pulse was done three times.

$\underline{x} 0.65 \mathrm{~g}$ Sine beat

$\underline{X}$ Table Pulse - (NS) using half sine function $(20 \mathrm{~Hz})$

Notes: The pulse was done three times.

$\underline{X}$ Visual inspection

$\underline{x} 0.75 \mathrm{~g}$ Sine beat

$\underline{X}$ Table Pulse - (NS) using half sine function $(20 \mathrm{~Hz})$

Notes: The pulse was done three times.

$\underline{X} 0.875 \mathrm{~g}$ Sine beat

$\underline{X}$ Visual inspection

$\underline{X}$ Table Pulse - (NS) using half sine function $(20 \mathrm{~Hz})$ Notes: The pulse was done three times.

$\underline{X} 1.0 \mathrm{~g}$ Sine beat

$\underline{X}$ Table Pulse - (NS) using half sine function $(20 \mathrm{~Hz})$

Notes: The pulse was done three times.

$\underline{X}$ Visual inspection

$\underline{X} 1.125 \mathrm{~g}$ Sine beat

$\underline{X}$ Table Pulse - (NS) using half sine function $(20 \mathrm{~Hz})$

Notes: The pulse was done three times.

$\underline{\mathrm{X}}$ Visual inspection 


\section{$\underline{X} 1.34 \mathrm{~g}$ Sine beat}

$\underline{X}$ Table Pulse - (NS) using half sine function $(20 \mathrm{~Hz})$

Notes: The pulse was done three times

$\underline{X}$ Visual inspection

Note: Pete Grushevskiy snaps back the string mot and it beaks ( MID_POR_SP)

$\underline{X} 1.52 \mathrm{~g}$ Sine beat

$\underline{X}$ Table Pulse - (NS) using half sine function $(20 \mathrm{~Hz})$

Notes: The pulse was done three times

$\underline{X}$ Visual inspection

$\underline{X}$ Sine Sweep $-(\mathrm{NS})$ acceleration $=0.1 \mathrm{~g}(1-33 \mathrm{~Hz})$ 
Test Sequence 2 - Turret \& Bushing Flexible Mount - Part1 Date: 10/29/2013

\section{Added Mass}

$45 \mathrm{lb}$ Weight

$\underline{X}$ Pull Test 250lb

X NS

$\underline{X} \mathrm{EW}$

$\underline{X}$ Man Shake/Impact . Both were done in NS and EW directions.

$\underline{X}$ Table Pulse - (NS) using half sine function $(20 \mathrm{~Hz})$

$\underline{X}$ Sine Sweep $-(\mathrm{NS})$ acceleration $=0.1 \mathrm{~g}(1-33 \mathrm{~Hz})$

$\underline{\mathrm{x}}$ Time History $=12.5 \%$ amplitude of ground motion.

$\underline{X}$ Time History $=25 \%$ amplitude of ground motion.

$\underline{X}$ Time History $=37.5 \%$ amplitude of ground motion.

End Notes: The bushing was inspected and showed no signs of oil leaks.

$15 \mathrm{lb}$ Weight

$\underline{x}$ Pull Test 250lb

$\underline{X}$ NS

$\underline{X} \mathrm{EW}$

$\underline{X}$ Man Shake/Impact. Both were done in NS and EW directions.

$\underline{X}$ Sine Sweep $-(\mathrm{NS})$ acceleration $=0.1 \mathrm{~g}(1-33 \mathrm{~Hz})$

$\underline{\mathrm{X}}$ Table Pulse - (NS) using half sine function $(20 \mathrm{~Hz})$

$\underline{X}$ Lowest Time History ( $25 \%$ of ground motion)

End Notes: The bushing was inspected and showed no signs of oil leaks 
Test Sequence 2 - Turret \& Bushing Flexible Mount - Part2 Date: 10/31/2013

\section{Earthquake Simulation}

$\underline{X}$ Table Pulse - (NS) using half sine function $(20 \mathrm{~Hz})$

$\underline{X}$ Amplitude $=25 \%$ of ground motion (NS)

$\underline{X}$ Visual inspection

$\underline{x}$ Table Pulse - (NS) using half sine function $(20 \mathrm{~Hz})$

$\underline{X}$ Amplitude $=50 \%$ of ground motion (NS)

$\underline{X}$ Visual inspection

$\underline{X}$ Table Pulse - (NS) using half sine function $(20 \mathrm{~Hz})$

$\underline{X}$ Amplitude $=75 \%$ of ground motion (NS

$\underline{X}$ Visual inspection

$\underline{X}$ Table Pulse - (NS) using half sine function $(20 \mathrm{~Hz})$

$\underline{X}$ Amplitude $=100 \%$ of ground motion (NS)

$\underline{X}$ Visual inspection

$\underline{x}$ Table Pulse - (NS) using half sine function $(20 \mathrm{~Hz})$

$\underline{X}$ Amplitude $=125 \%$ of ground motion (NS)

$\underline{X}$ Visual inspection

$\underline{X}$ Table Pulse - (NS) using half sine function $(20 \mathrm{~Hz})$

$\underline{X}$ Amplitude $=137.5 \%$ of ground motion (NS)

$\underline{X}$ Visual inspection

$\underline{X}$ Table Pulse - (NS) using half sine function $(20 \mathrm{~Hz})$

$\underline{X}$ Amplitude $=150 \%$ of ground motion (NS)

$\underline{X}$ Visual inspection

$\underline{X}$ Table Pulse - (NS) using half sine function $(20 \mathrm{~Hz})$

$\underline{X}$ Amplitude $=162.5 \%$ of ground motion (NS)

$\underline{X}$ Visual inspection

$\underline{X}$ Table Pulse - (NS) using half sine function $(20 \mathrm{~Hz})$

$\underline{X}$ Amplitude $=175 \%$ of ground motion (NS)

$\underline{X}$ Visual inspection

$\underline{X}$ Table Pulse - (NS) using half sine function $(20 \mathrm{~Hz})$-to set up for $187.5 \% \mathrm{GM}$ (we did not end up doing the ground motion)

$\underline{x}$ Sine Sweep $-(\mathrm{NS})$ acceleration $=0.1 \mathrm{~g}(1-33 \mathrm{~Hz})$

$\underline{X}$ Sine Sweep Redone- (NS) acceleration $=0.1 \mathrm{~g}(1-33 \mathrm{~Hz})$ 


\section{Appendix D}

\section{Interface Analysis at the Porcelain Flange Interface}

\section{Bushing 1 - Ground Motions}

\section{Table of Contents}

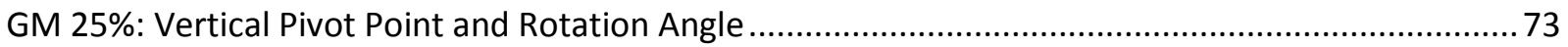

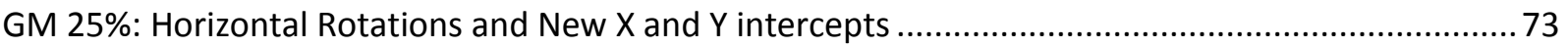

GM 50\%: Vertical Pivot Point and Rotation Angle ................................................................................ 74

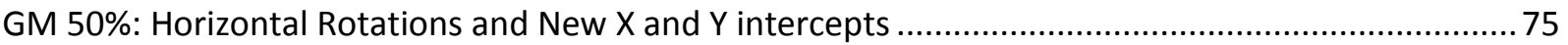

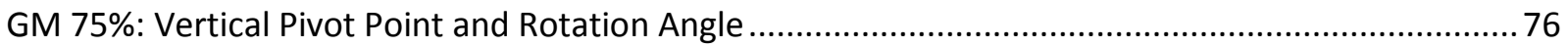

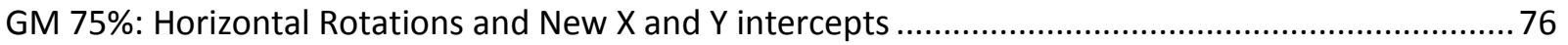

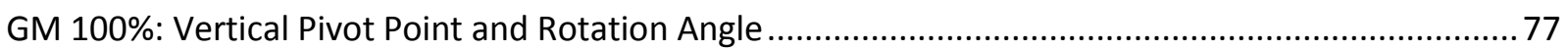

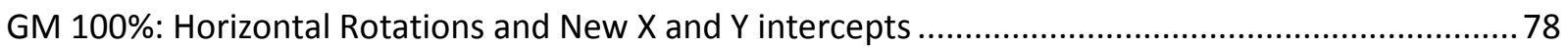

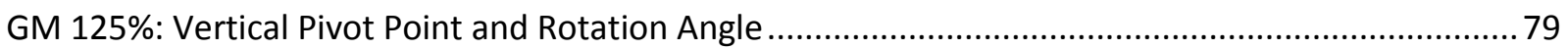

GM 125\%: Horizontal Rotations and New $X$ and $Y$ intercepts ......................................................... 79

GM 150\%: Vertical Pivot Point and Rotation Angle ........................................................................... 80

GM 150\%: Horizontal Rotations and New $X$ and $Y$ intercepts ......................................................... 81

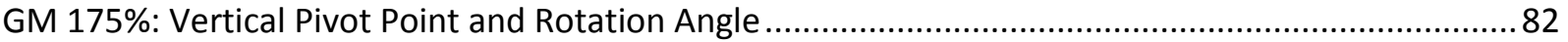

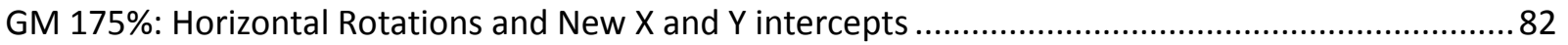

GM 175\% Repeat: Vertical Pivot Point and Rotation Angle............................................................... 83

GM 175\% Repeat: Horizontal Rotations and New $X$ and $Y$ intercepts............................................... 84

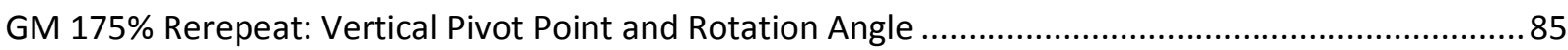

GM 175\% Rerepeat: Horizontal Rotations and New $X$ and $Y$ intercepts ............................................. 86

GM 200\%: Vertical Pivot Point and Rotation Angle .......................................................................... 87

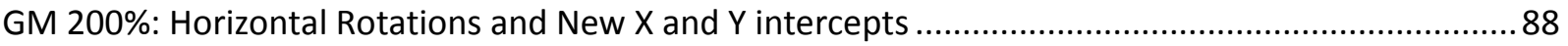

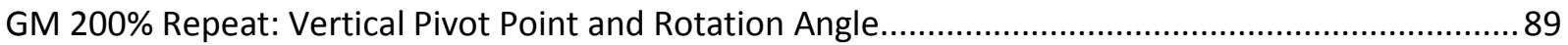

GM 200\% Repeat: Horizontal Rotations and New X and Y intercepts...............................................90 


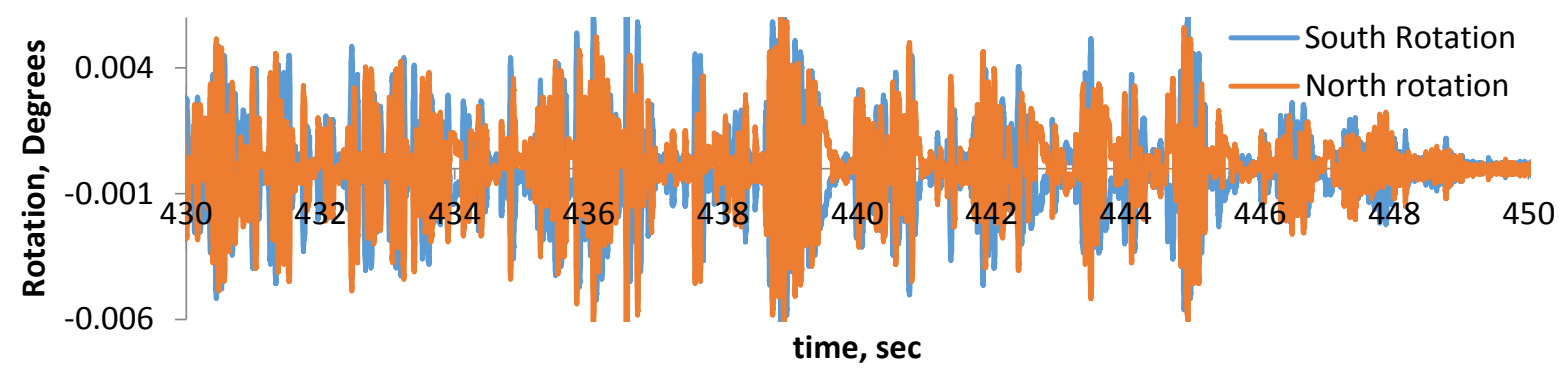

Figure 1: Rotations in the North-South Direction.

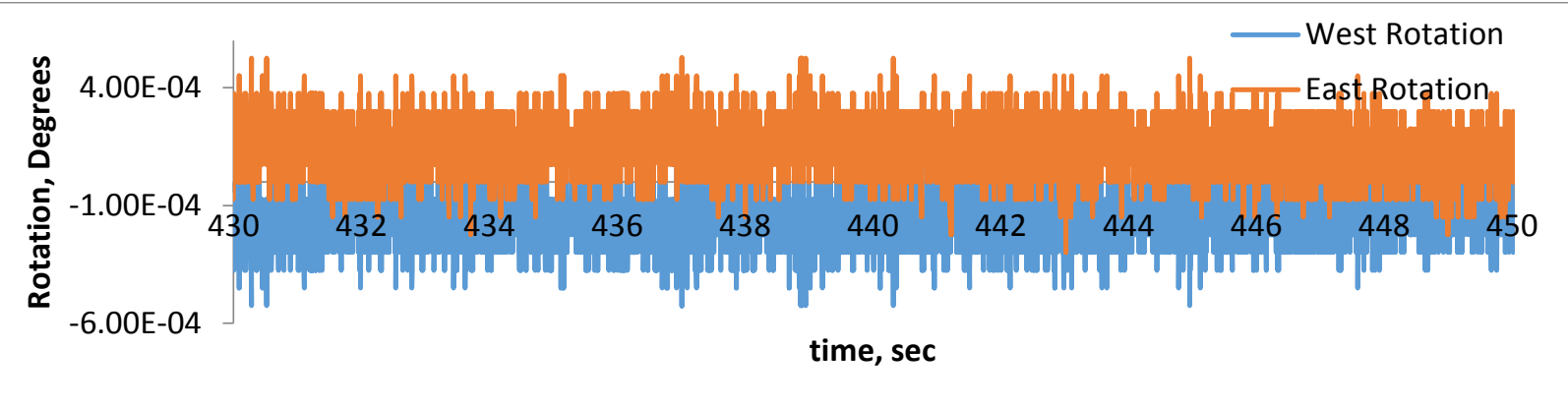

Figure 2: Rotations in the East-West Direction

\section{GM 25\%: Horizontal Rotations and New X and Y intercepts}

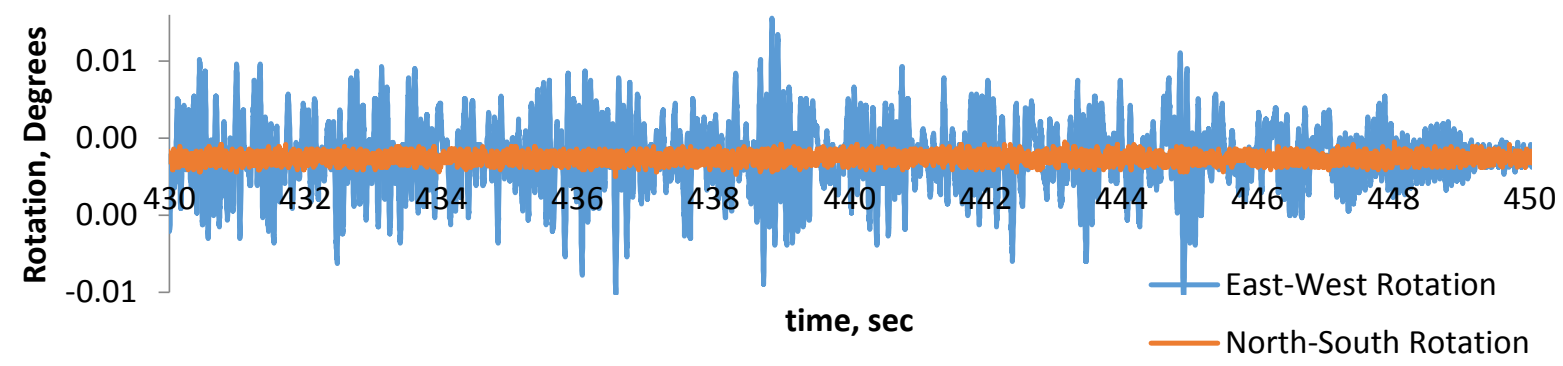

Figure 3: Horizontal Rotations.

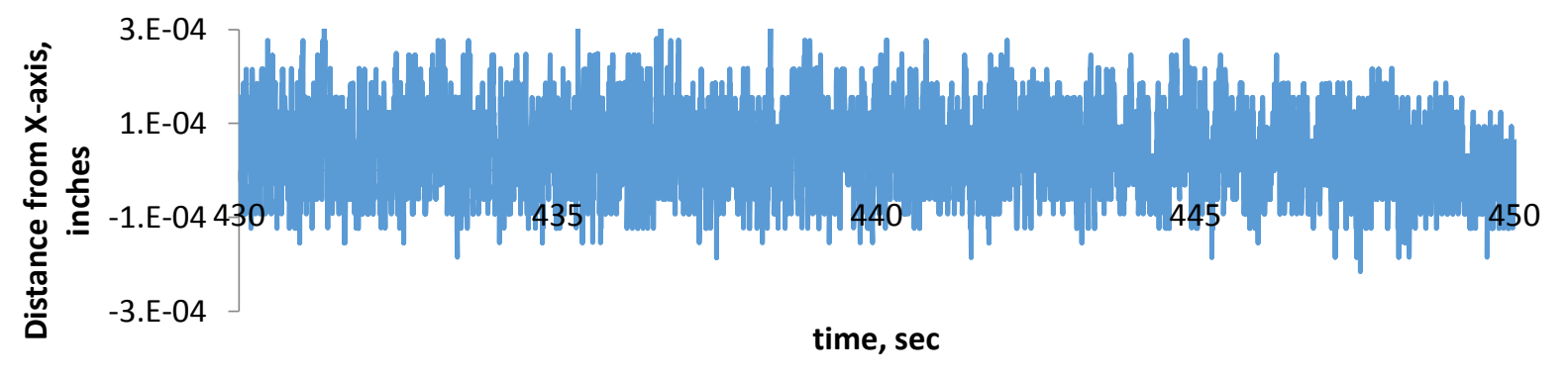

Figure 4: New X-Intercept as a function of time, ti. Negative is towards the east horizontal LVDT and positive is towards the west horizontal LVDT. 


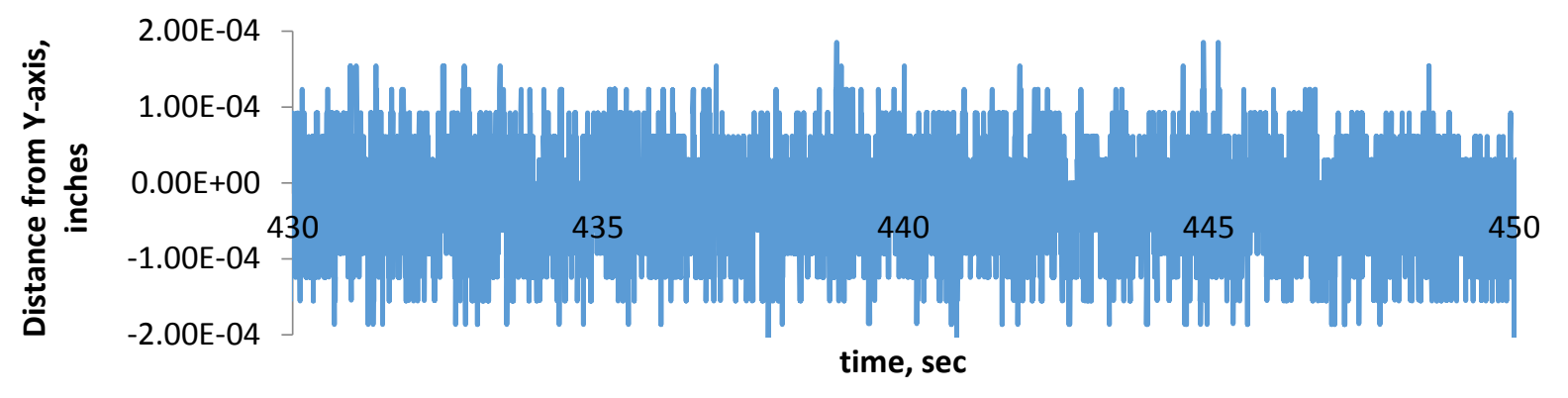

Figure 5: New Y-Intercept as a function of time, ti. Negative is towards the south horizontal LVDT and positive is towards the north horizontal LVDT.

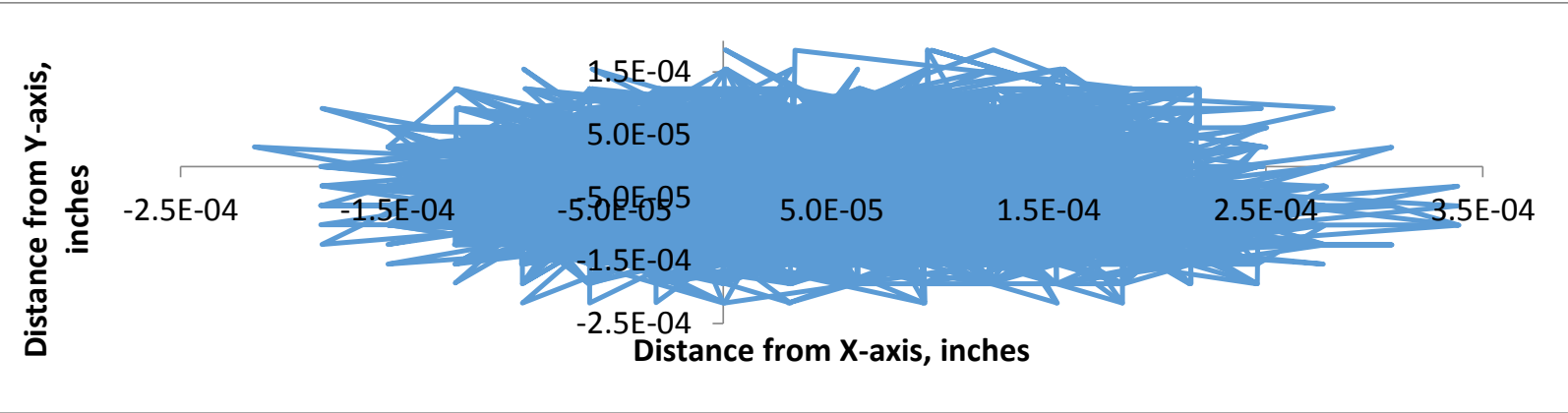

Figure 6: Changing $X \& Y$ Intercept as a function of time, ti.

\section{GM 50\%: Vertical Pivot Point and Rotation Angle}

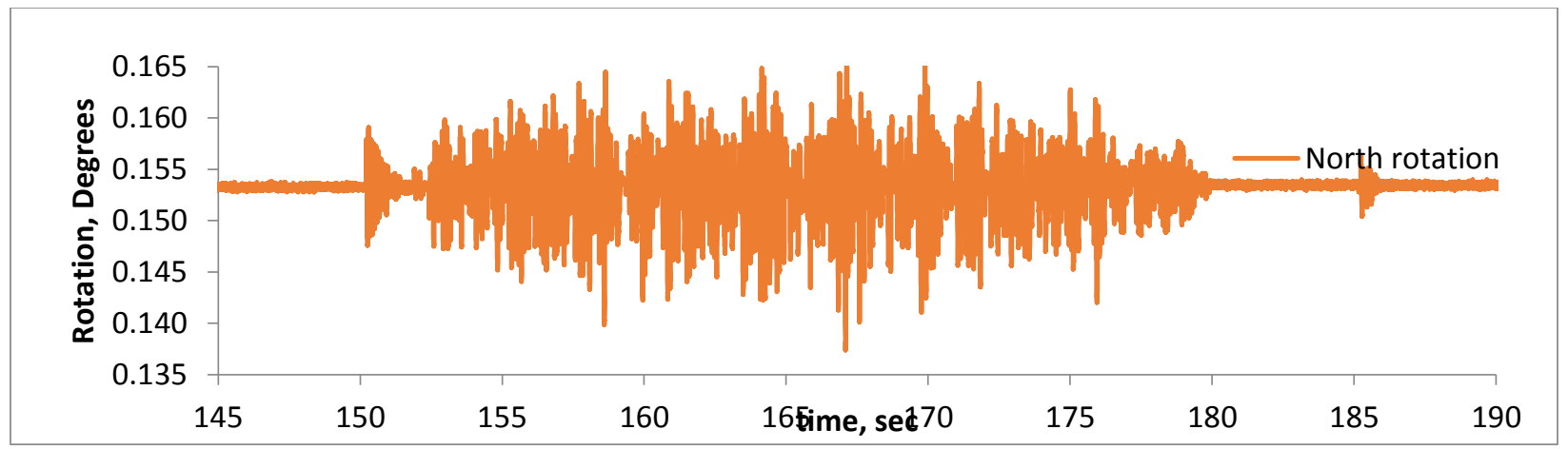

Figure 7: Rotations in the North Direction.

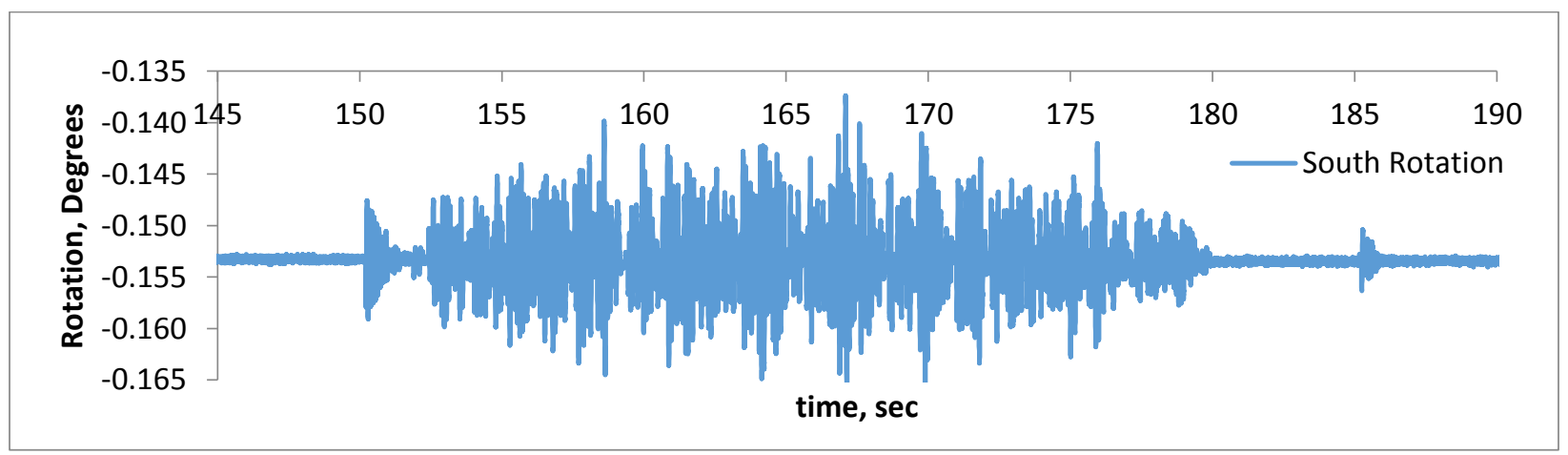

Figure 8: Rotations in the South Direction. 


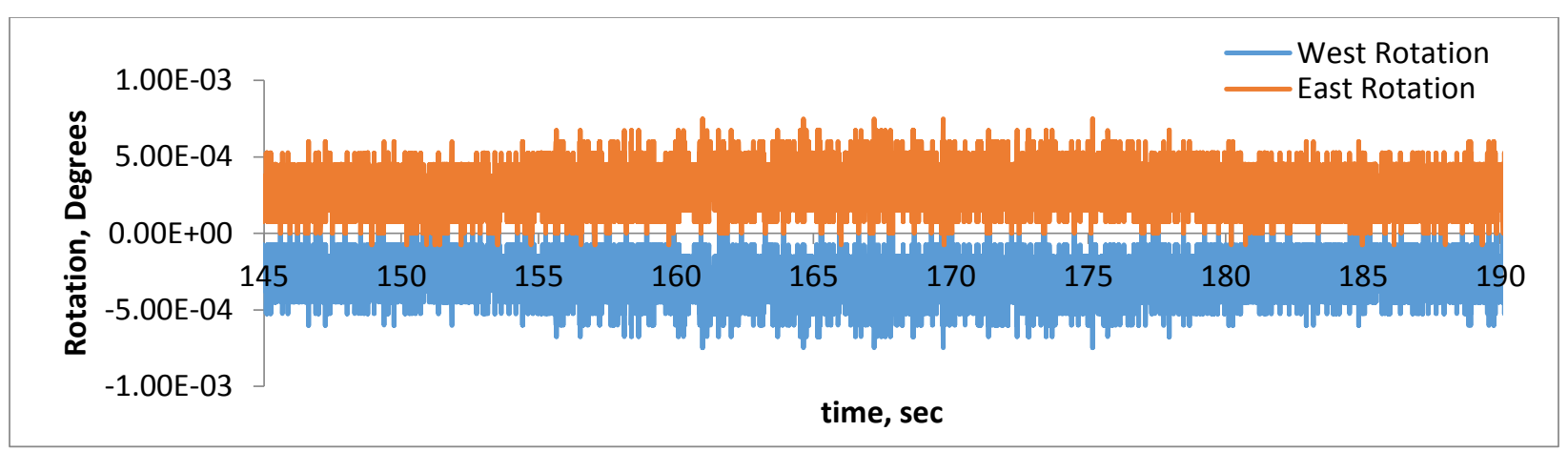

Figure 9: Rotations in the East-West Direction

GM 50\%: Horizontal Rotations and New X and Y intercepts

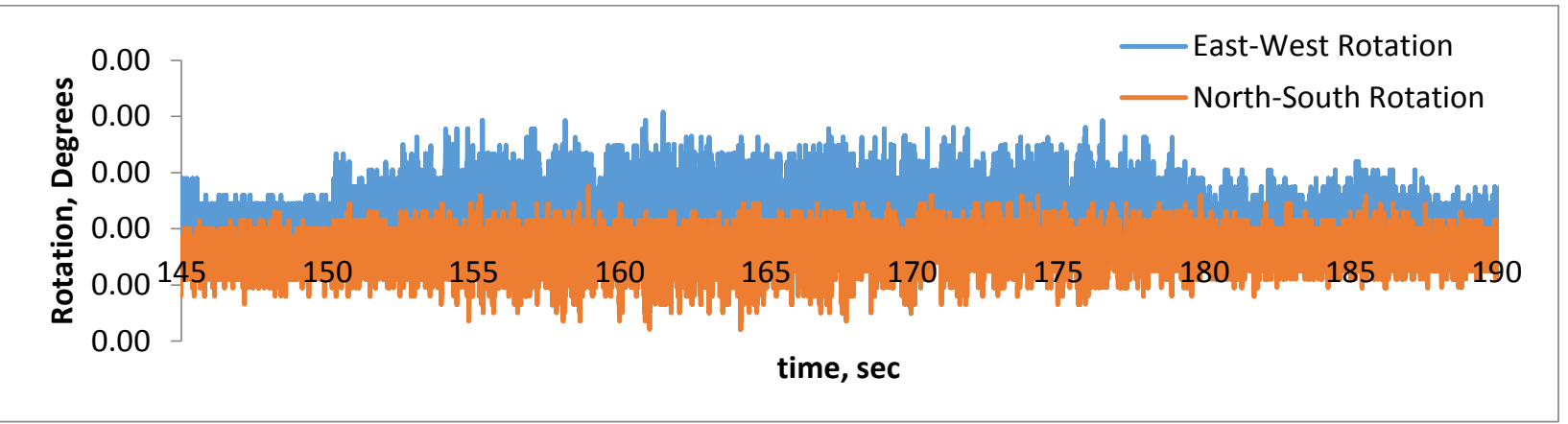

Figure 10: Horizontal Rotations.

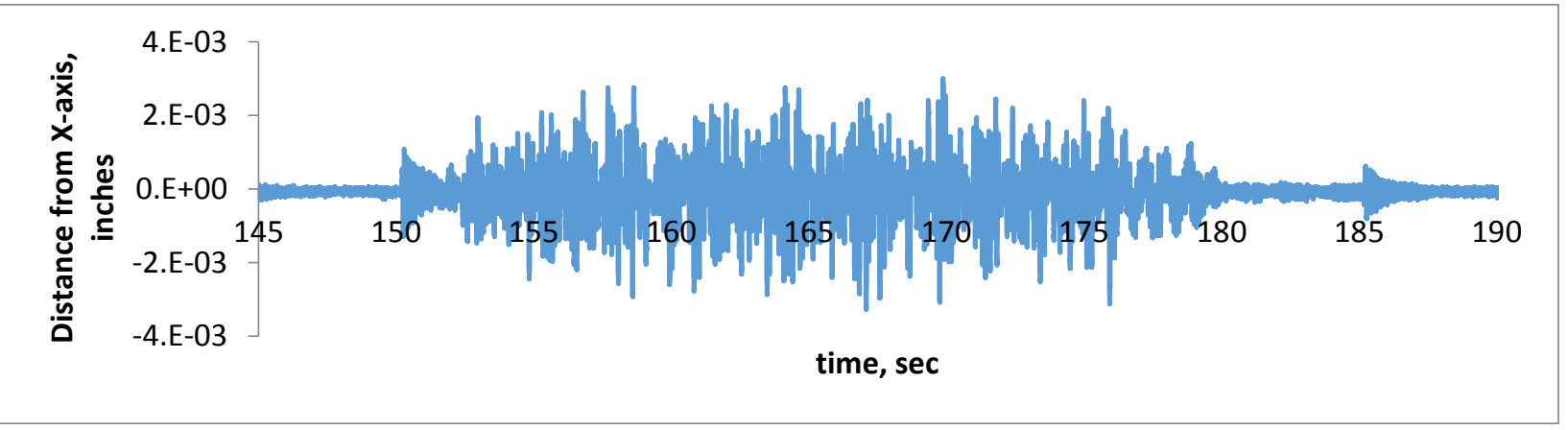

Figure 11: New X-Intercept as a function of time, ti. Negative is towards the east horizontal LVDT and positive is towards the west horizontal LVDT.

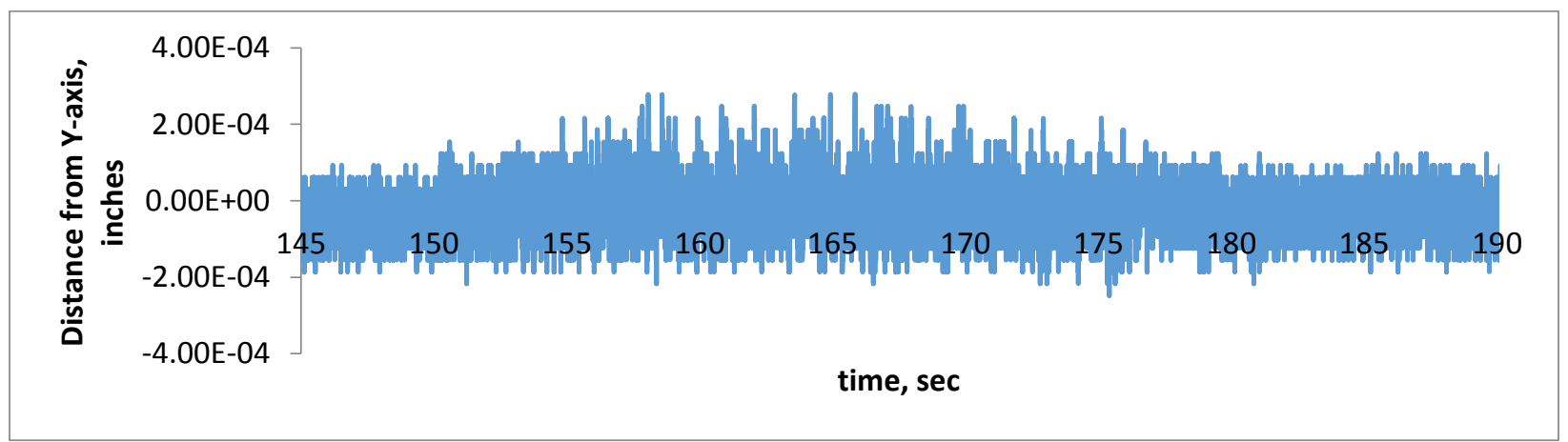

Figure 12: New Y-Intercept as a function of time, ti. Negative is towards the south horizontal LVDT and positive is towards the north horizontal LVDT. 


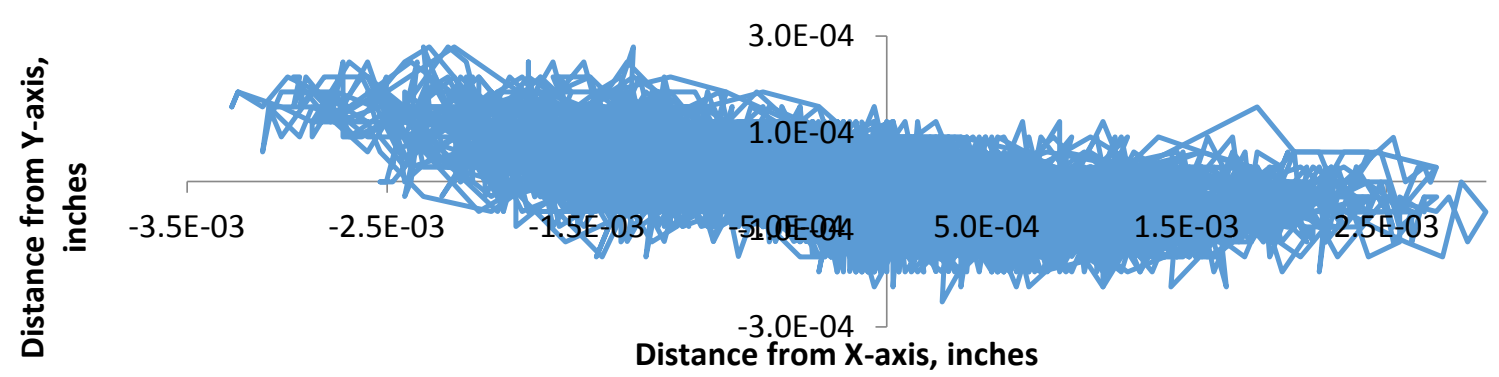

Figure 13: Changing $X \& Y$ Intercept as a function of time, ti.

\section{GM 75\%: Vertical Pivot Point and Rotation Angle}

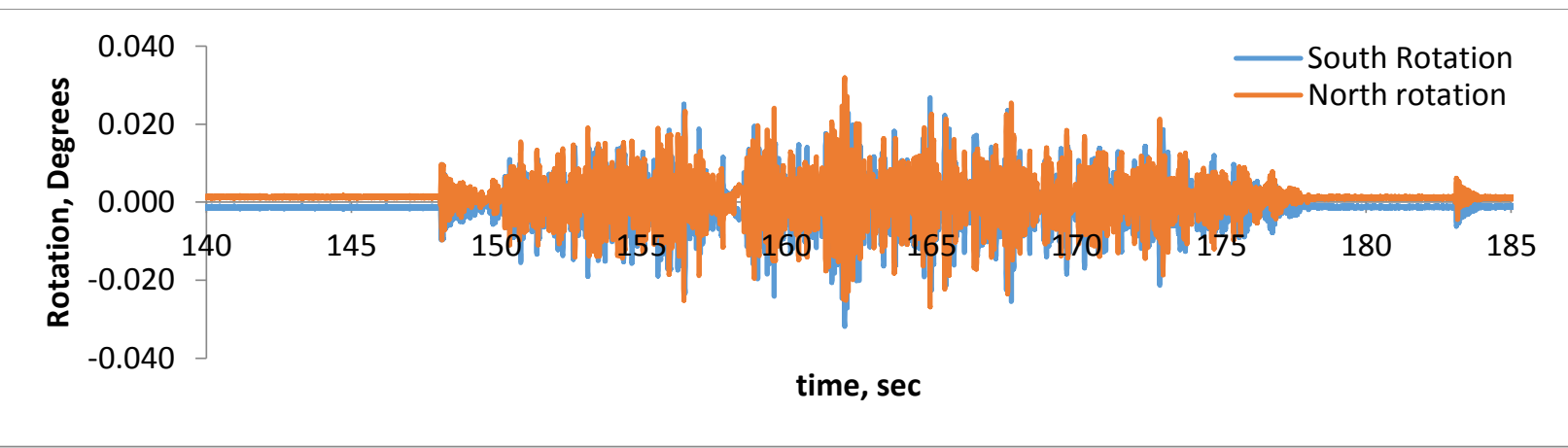

Figure 14: Rotations in the North-South Direction.

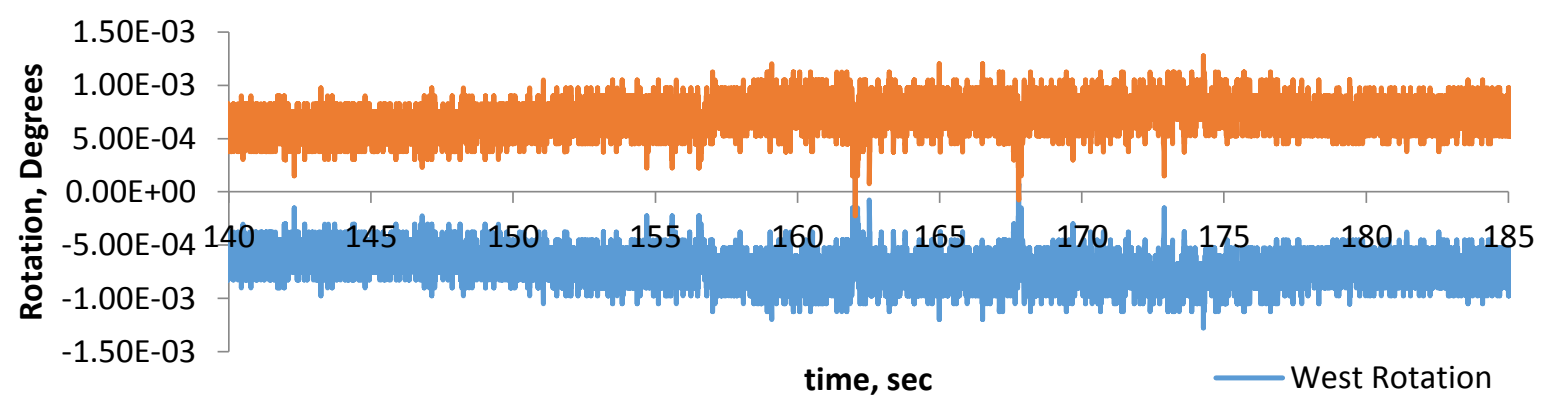

Figure 15: Rotations in the East-West Direction.

GM 75\%: Horizontal Rotations and New X and $Y$ intercepts

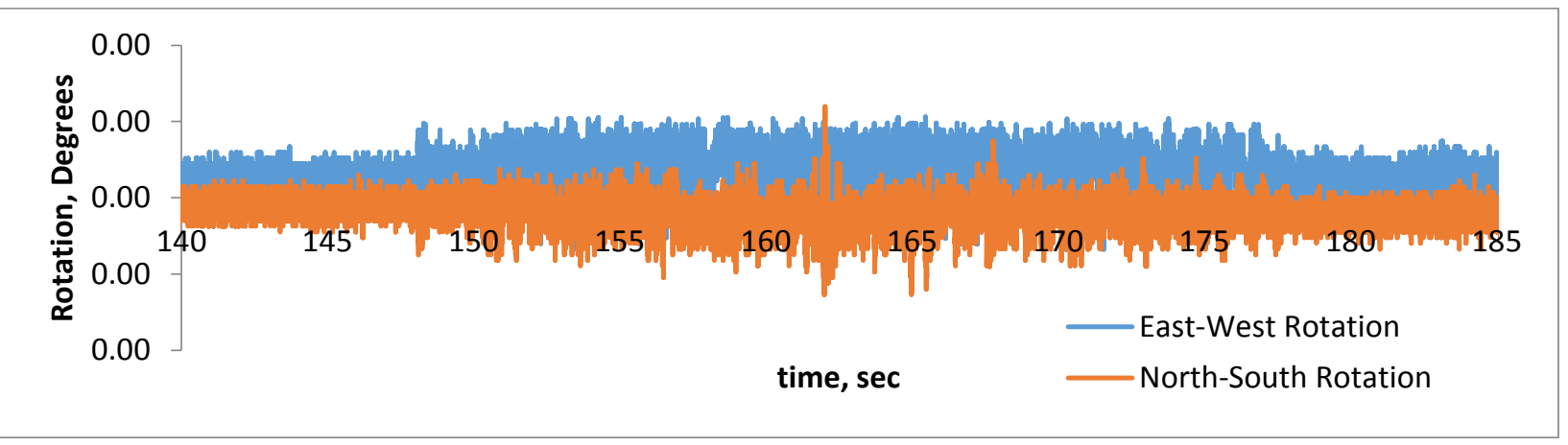

Figure 16: Horizontal Rotations. 


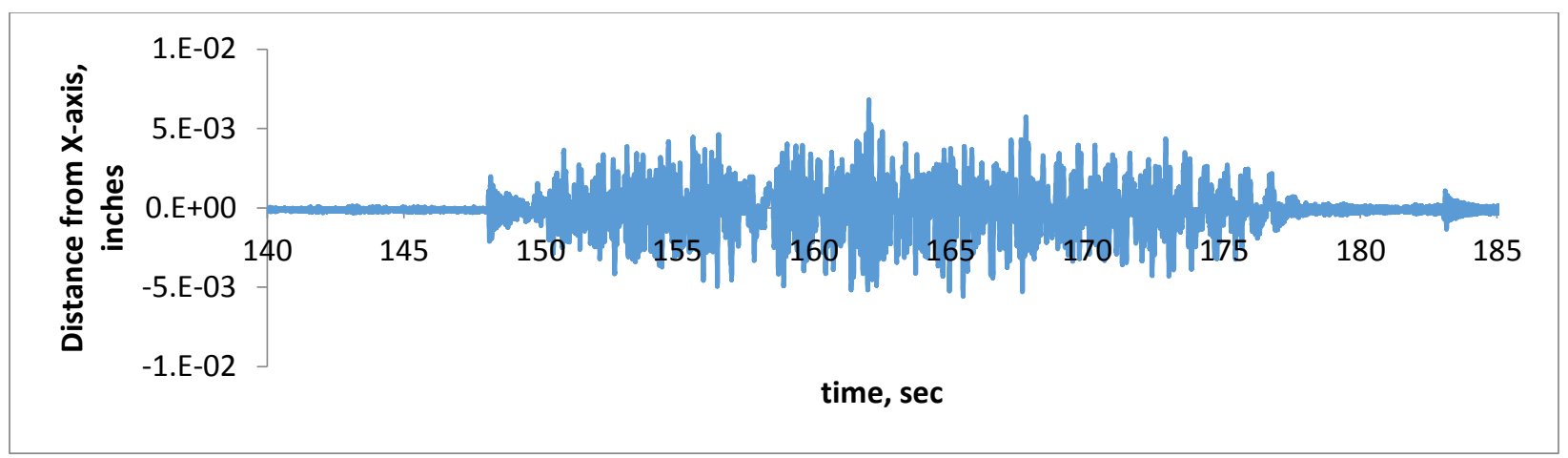

Figure 17: New X-Intercept as a function of time, ti. Negative is towards the east horizontal LVDT and positive is towards the west horizontal LVDT.

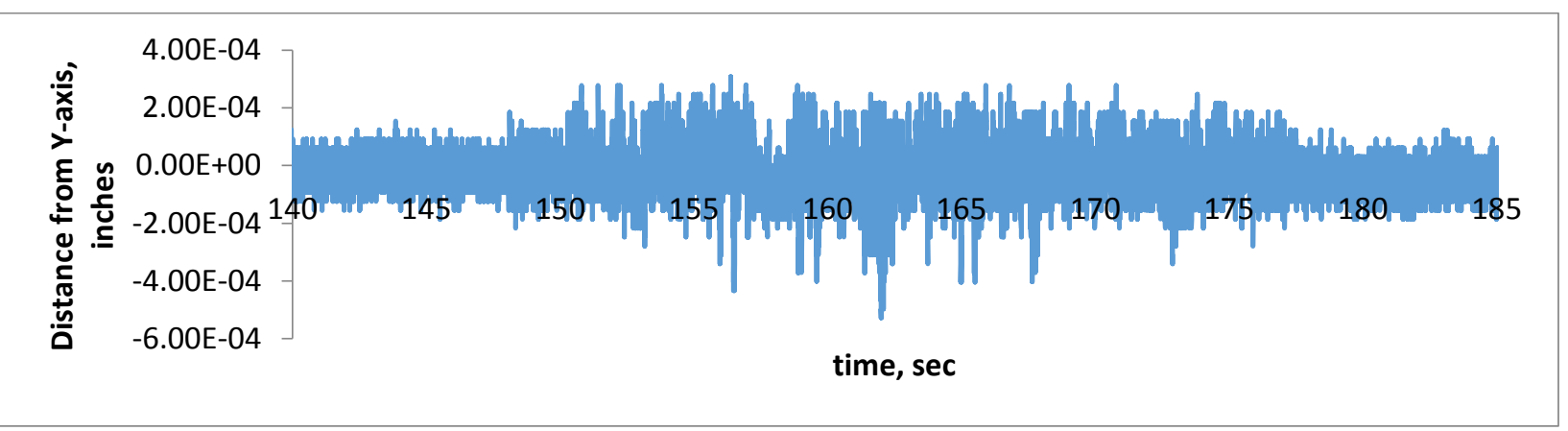

Figure 18: New Y-Intercept as a function of time, ti. Negative is towards the south horizontal LVDT and positive is towards the north horizontal LVDT.

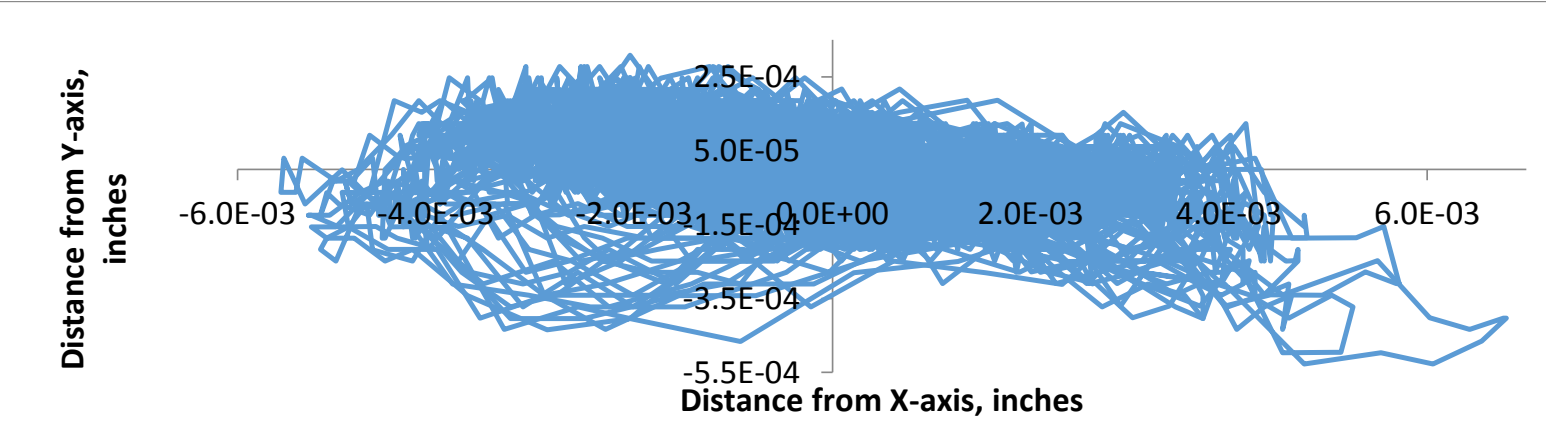

Figure 19: Changing X \& Y Intercept as a function of time, ti.

\section{GM 100\%: Vertical Pivot Point and Rotation Angle}

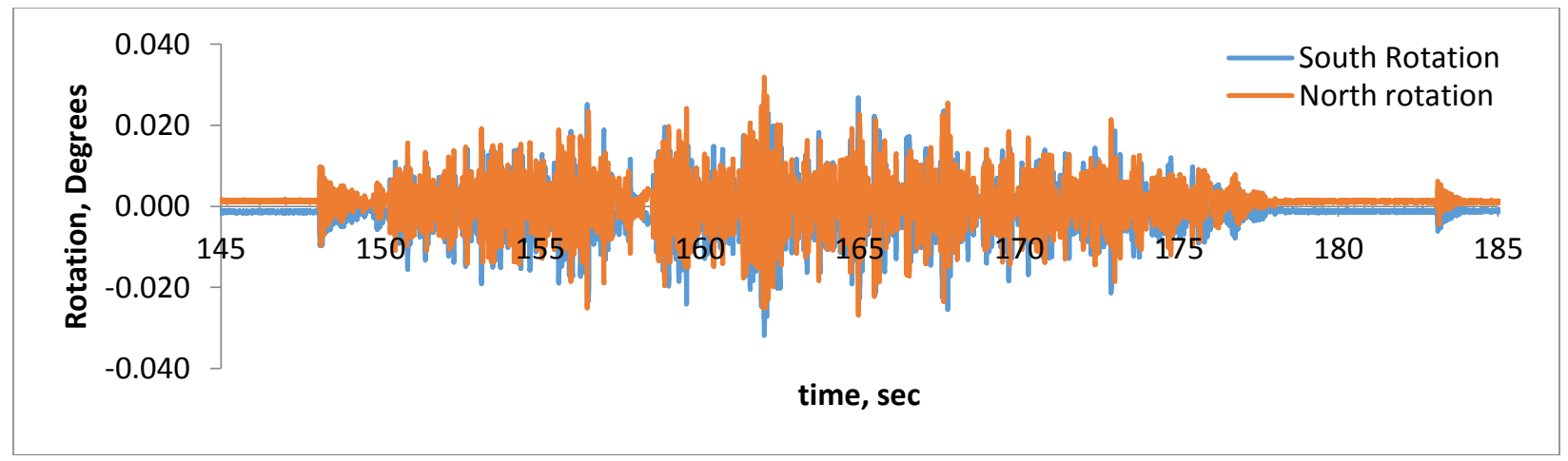

Figure 20: Rotations in the North-South Direction. 


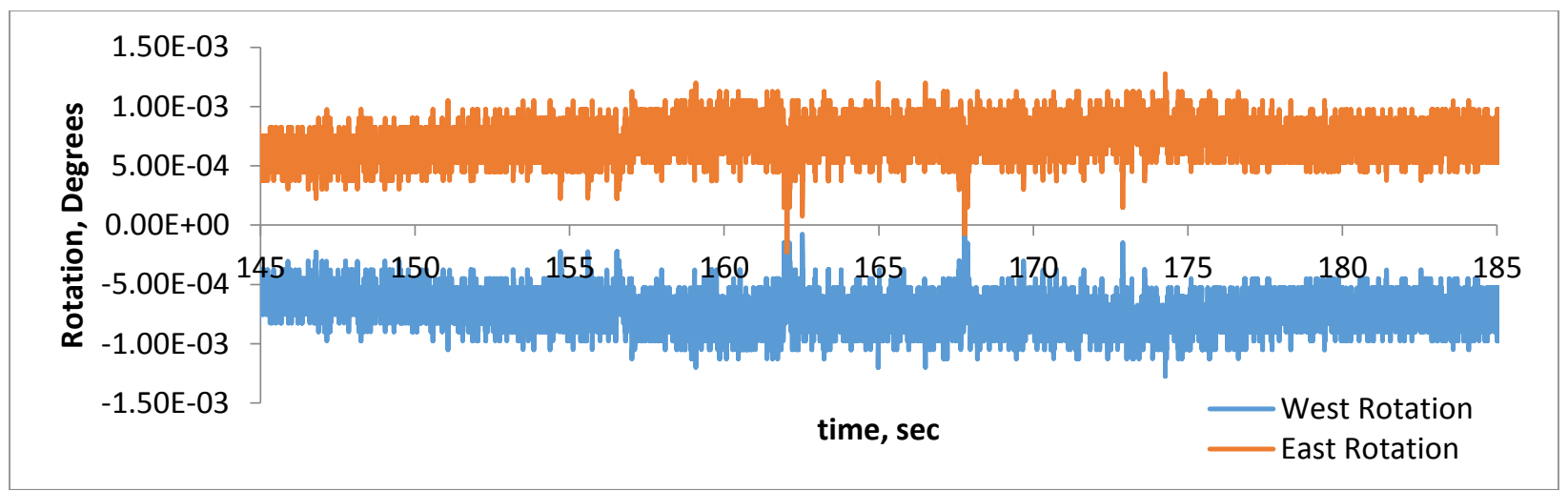

Figure 21: Rotations in the East-West Direction.

\section{GM 100\%: Horizontal Rotations and New X and Y intercepts}

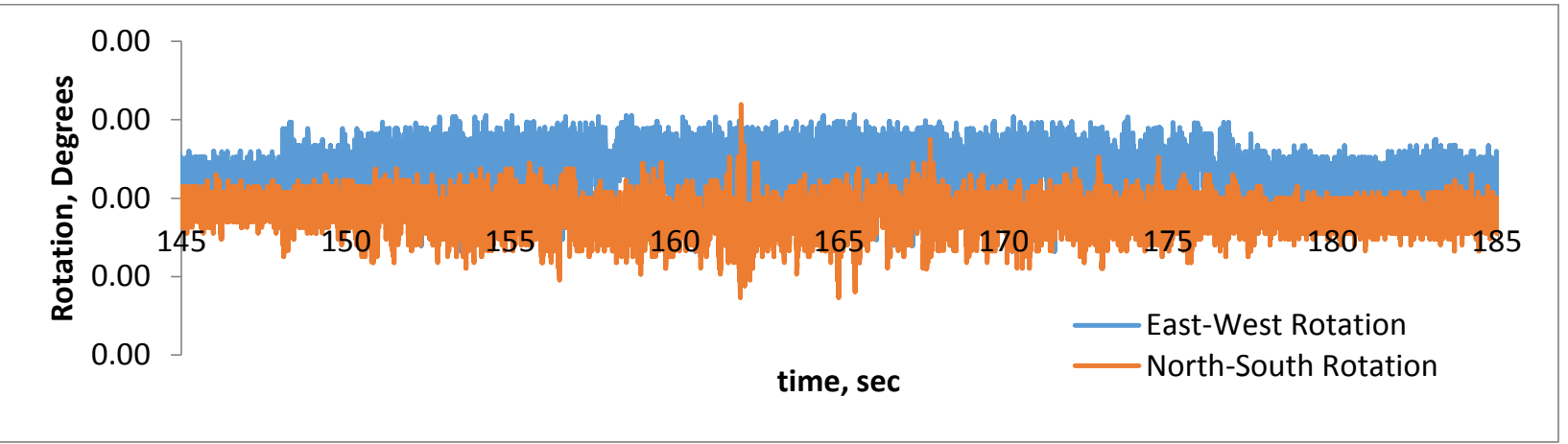

Figure 22: Horizontal Rotations.

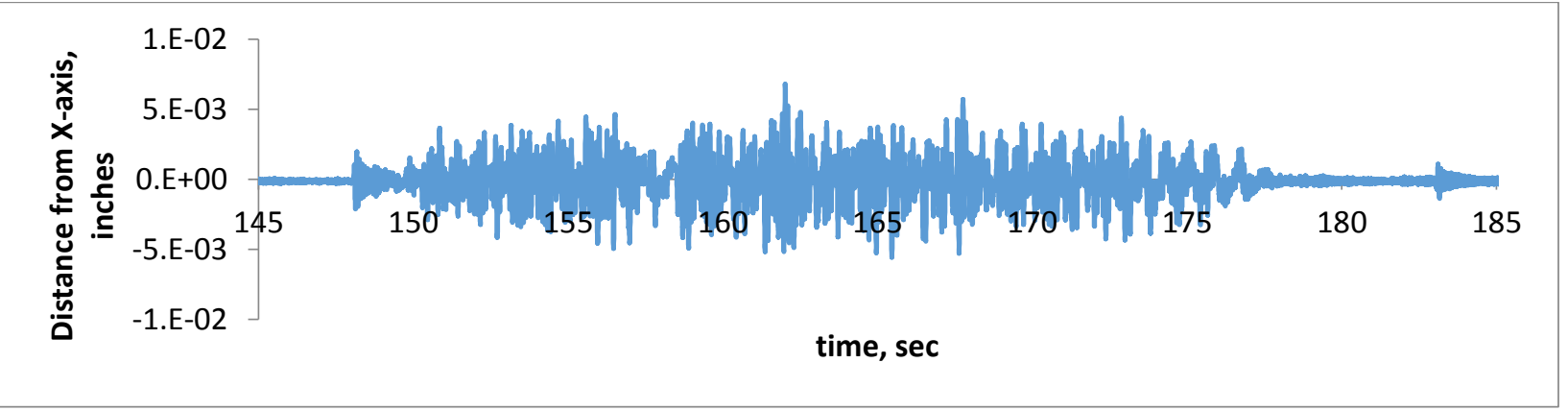

Figure 23: New X-Intercept as a function of time, ti. Negative is towards the east horizontal LVDT and positive is towards the west horizontal LVDT.

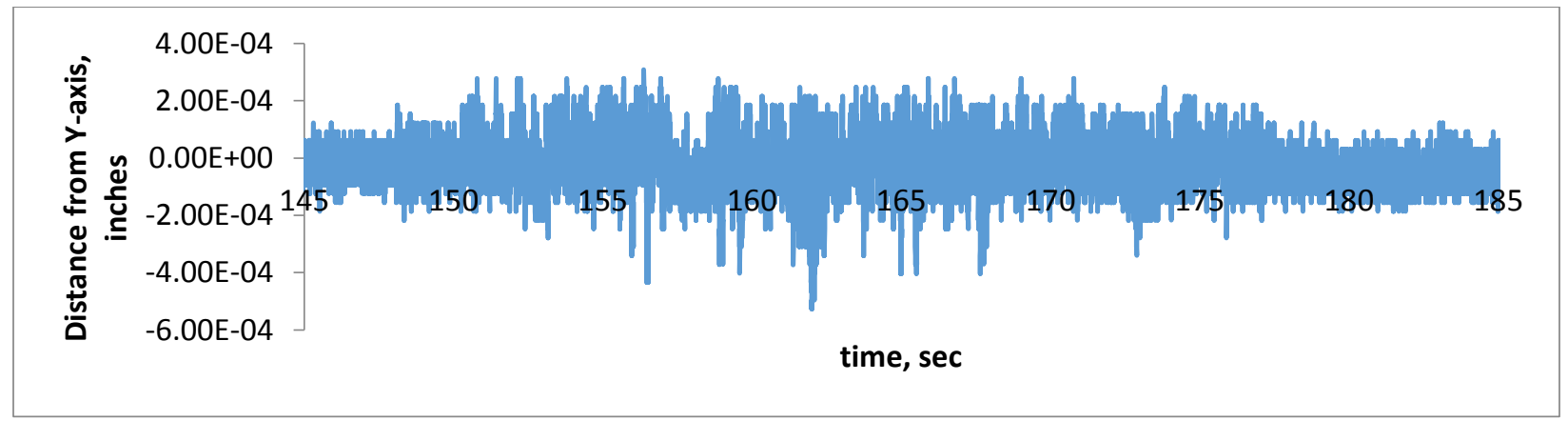

Figure 24: New Y-Intercept as a function of time, ti. Negative is towards the south horizontal LVDT and positive is towards the north horizontal LVDT. 


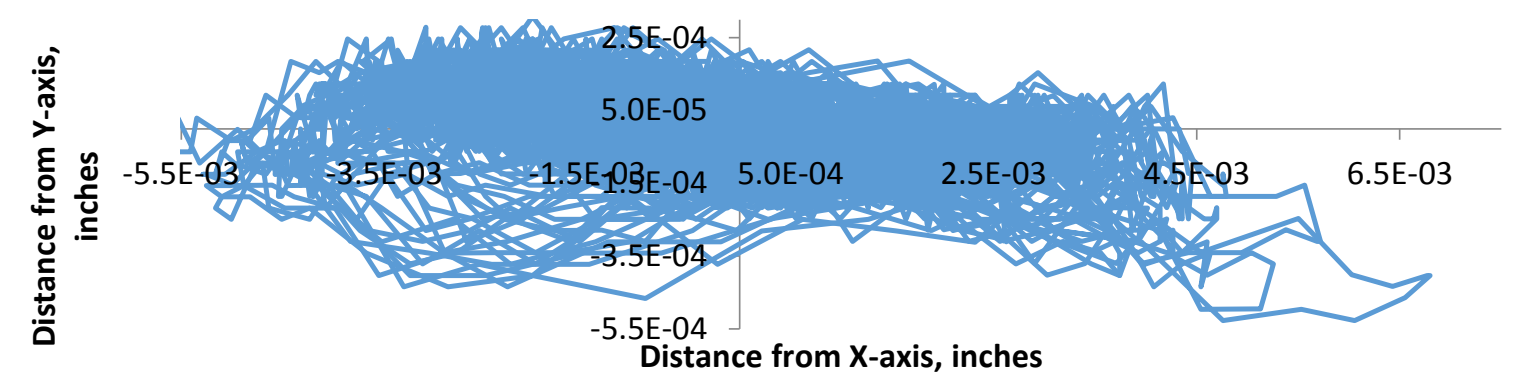

Figure 25: Changing X \& $Y$ Intercept as a function of time, ti.

\section{GM 125\%: Vertical Pivot Point and Rotation Angle}

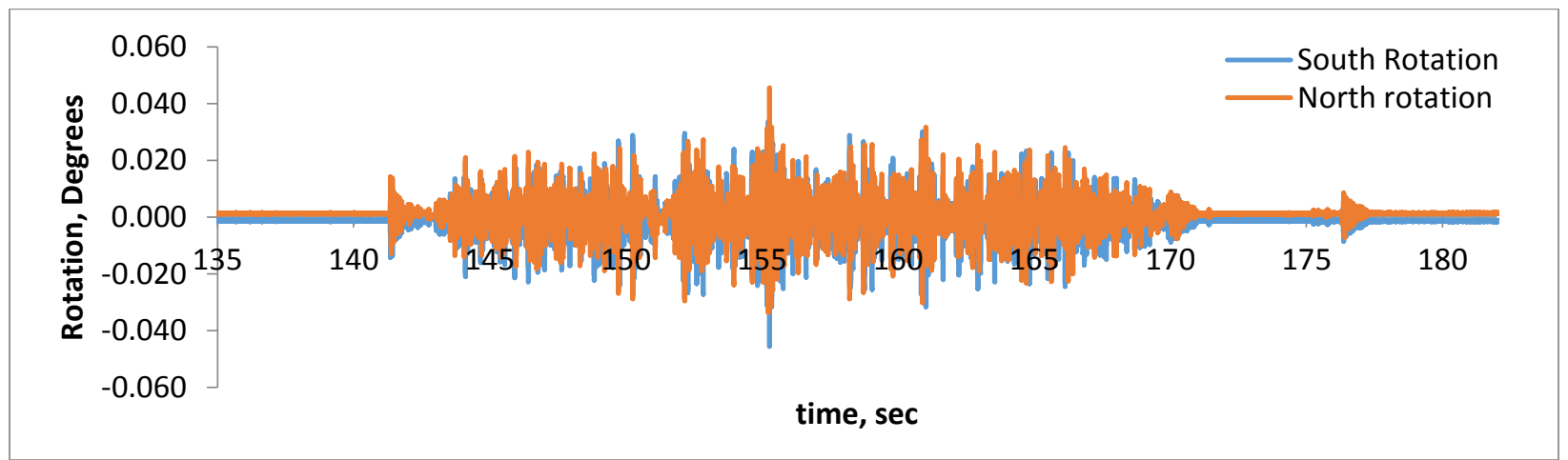

Figure 26: Rotations in the North-South Direction.

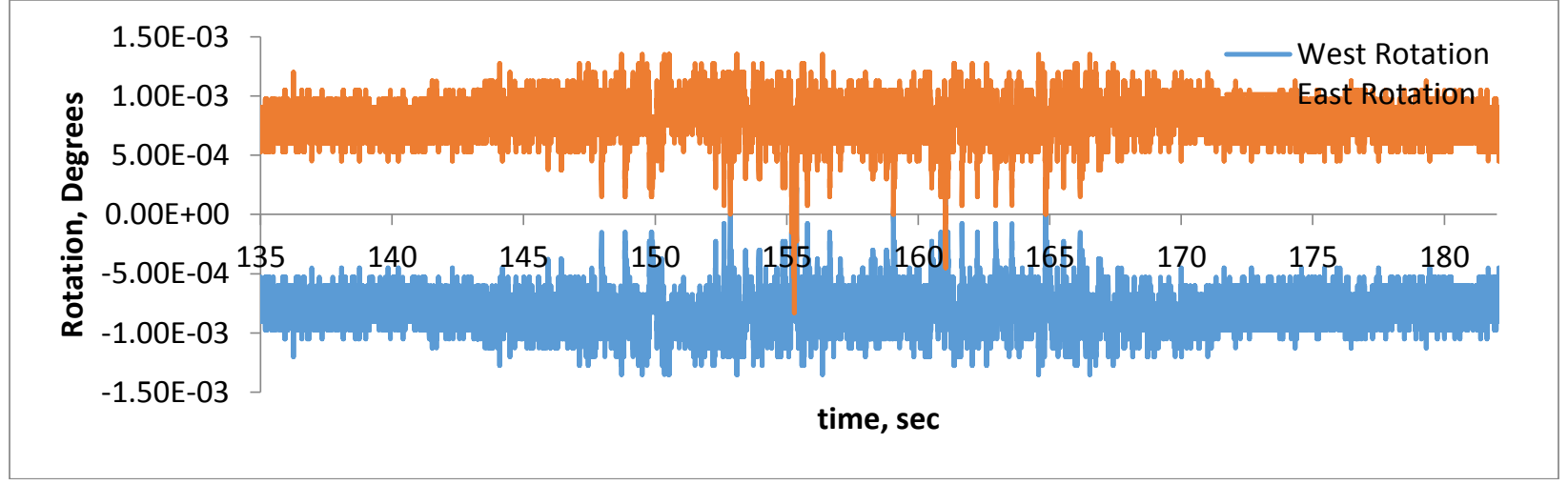

Figure 27: Rotations in the East-West Direction.

\section{GM 125\%: Horizontal Rotations and New X and Y intercepts}

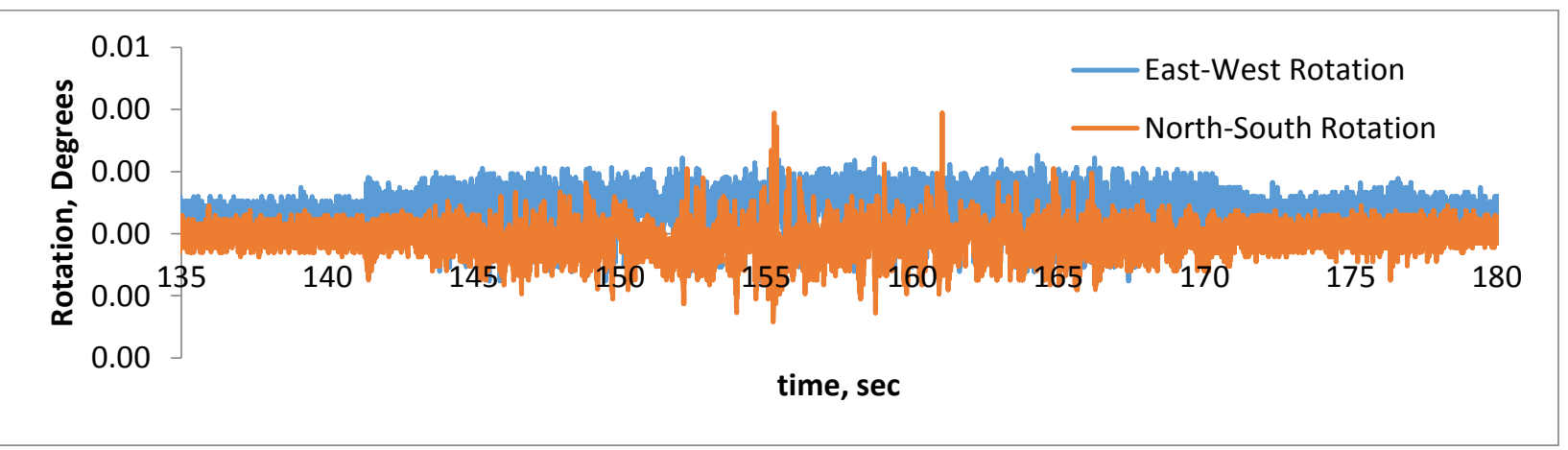

Figure 28: Horizontal Rotations. 


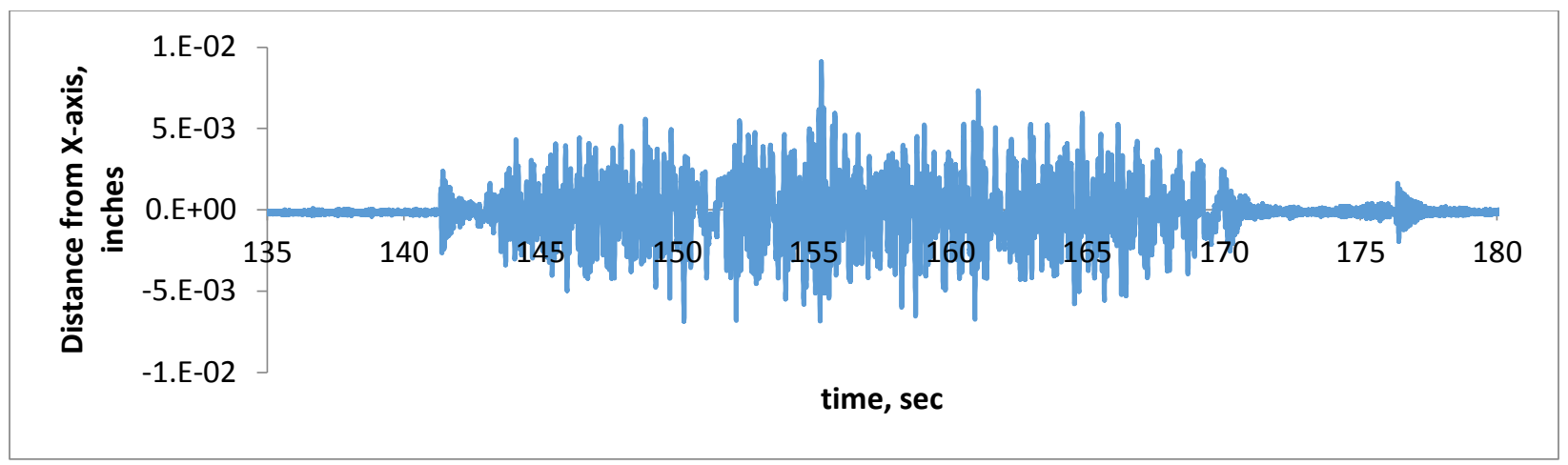

Figure 29: New X-Intercept as a function of time, ti. Negative is towards the east horizontal LVDT and positive is towards the west horizontal LVDT.

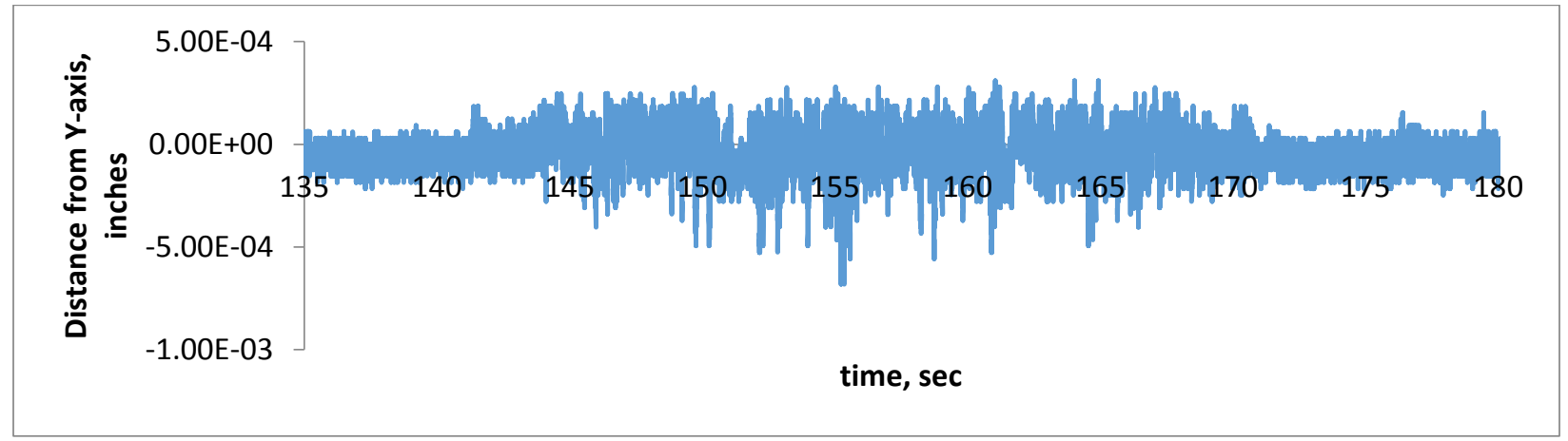

Figure 30: New Y-Intercept as a function of time, ti. Negative is towards the south horizontal LVDT and positive is towards the north horizontal LVDT.

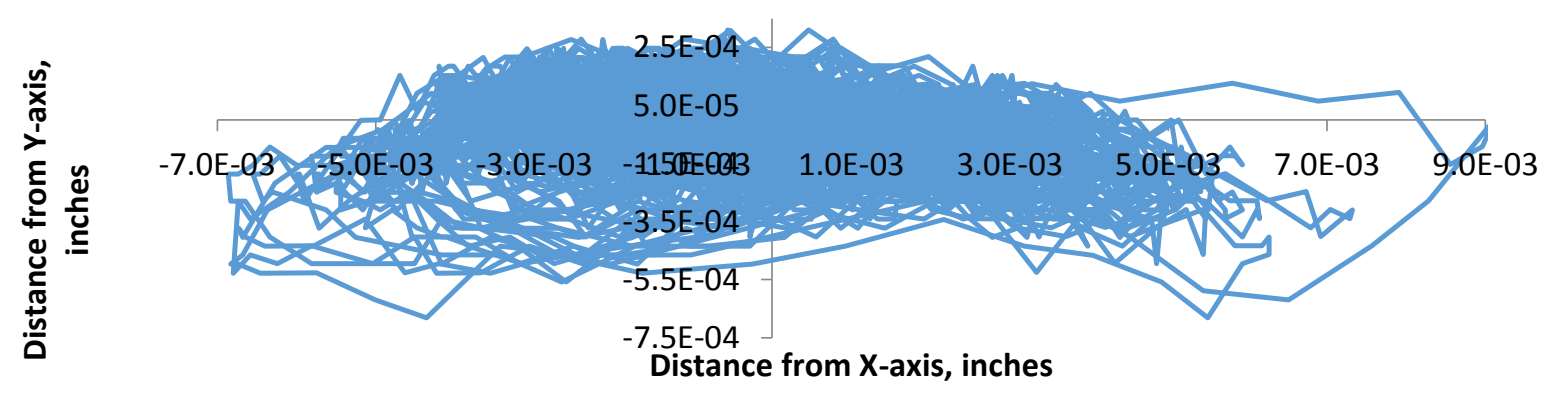

Figure 31: Changing X \& Y Intercept as a function of time, ti.

\section{GM 150\%: Vertical Pivot Point and Rotation Angle}

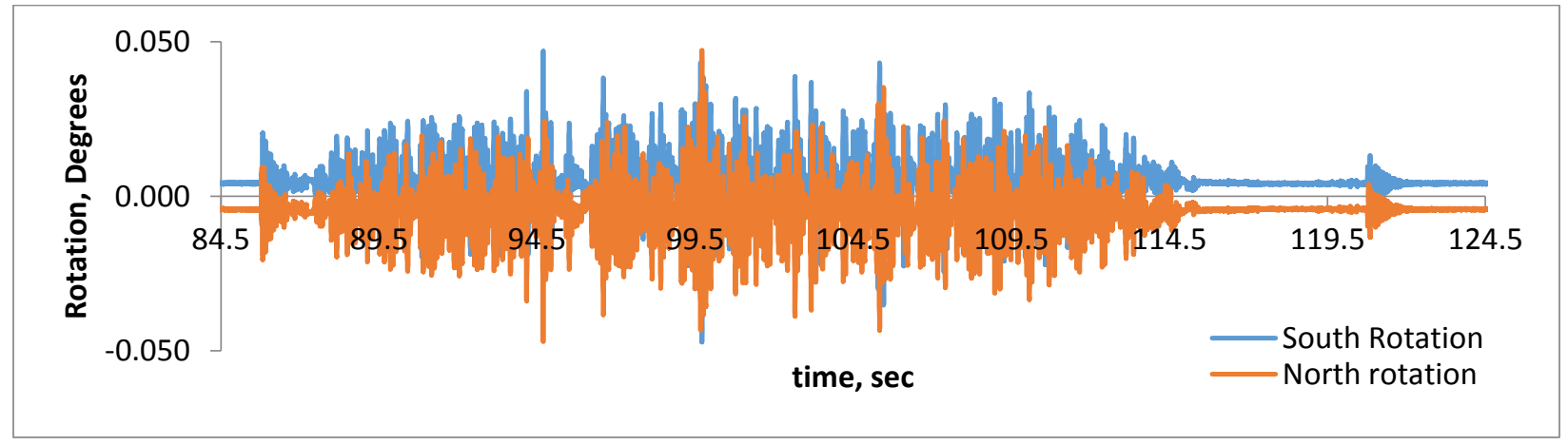

Figure 32: Rotations in the North-South Direction. 


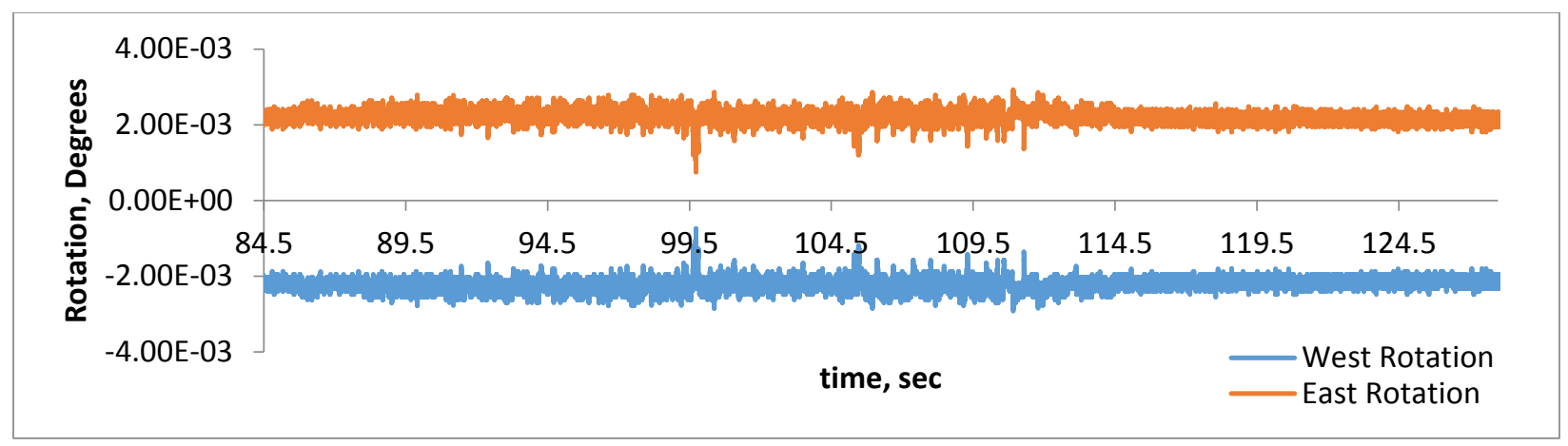

Figure 33: Rotations in the East-West Direction.

\section{GM 150\%: Horizontal Rotations and New X and Y intercepts}

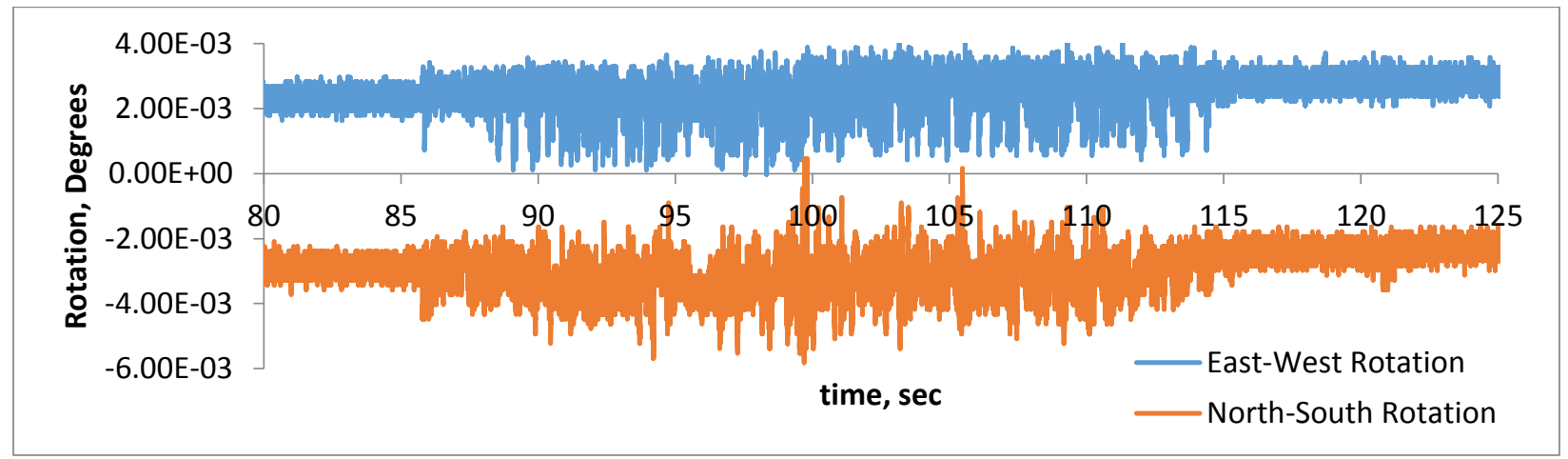

Figure 34: Horizontal Rotations.

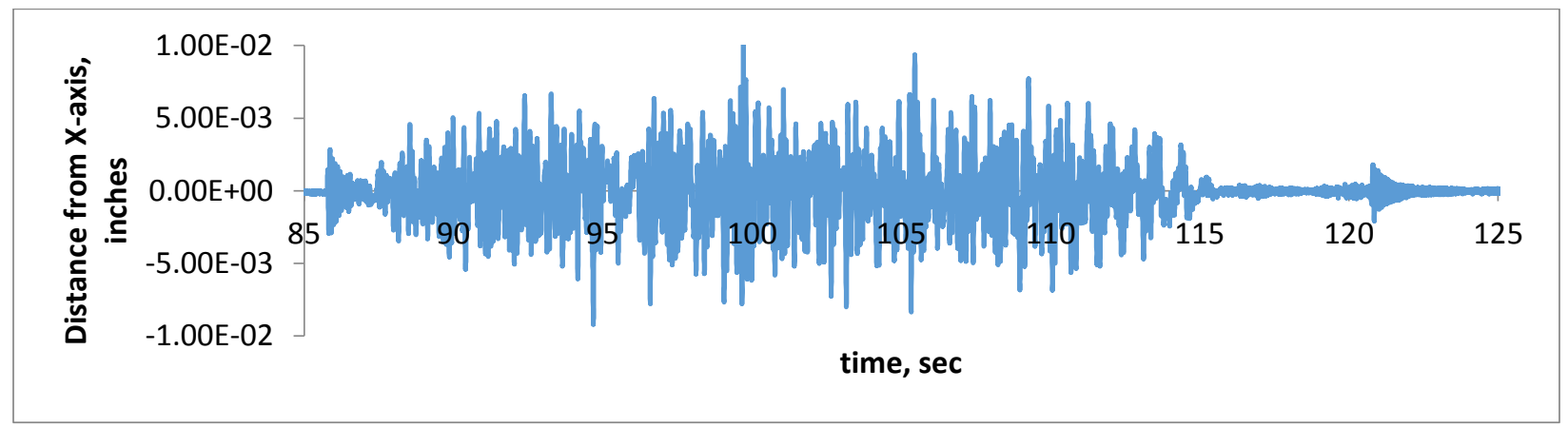

Figure 35: New X-Intercept as a function of time, ti. Negative is towards the east horizontal LVDT and positive is towards the west horizontal LVDT.

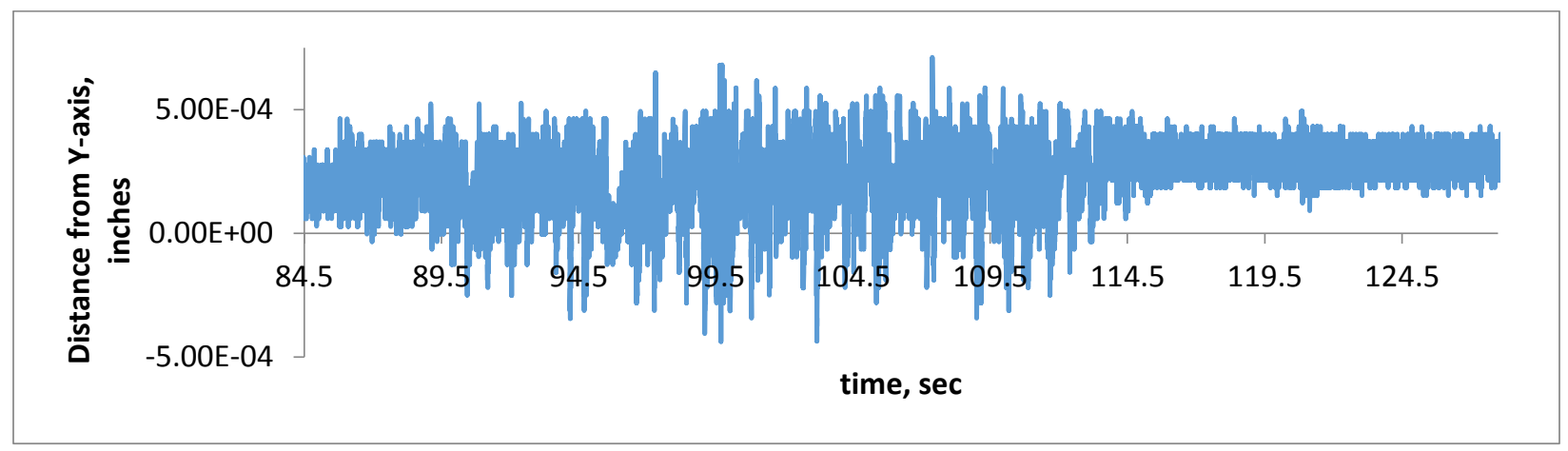

Figure 36: New Y-Intercept as a function of time, ti. Negative is towards the south horizontal LVDT and positive is towards the north horizontal LVDT. 


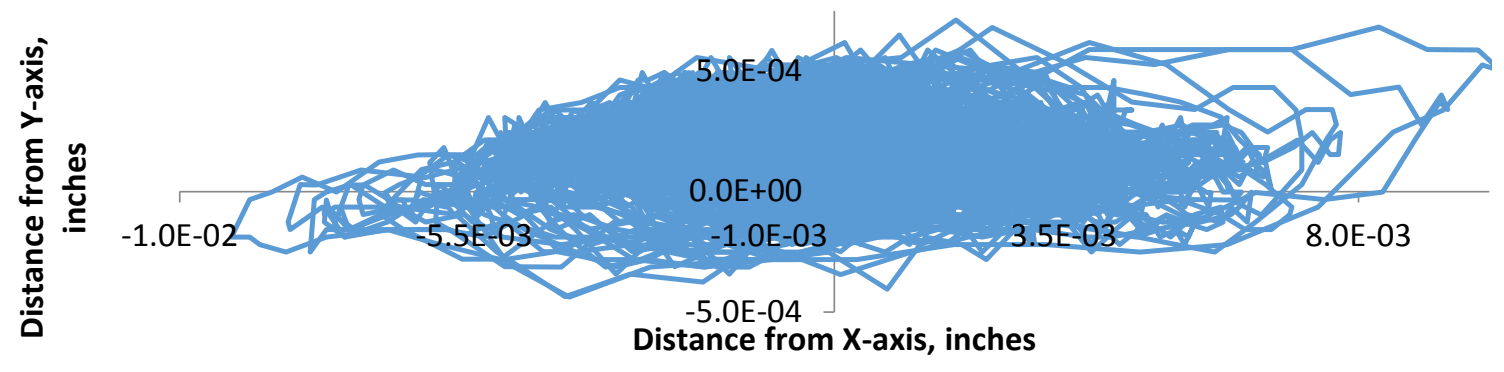

Figure 37: Changing X \& Y Intercept as a function of time, ti.

GM 175\%: Vertical Pivot Point and Rotation Angle

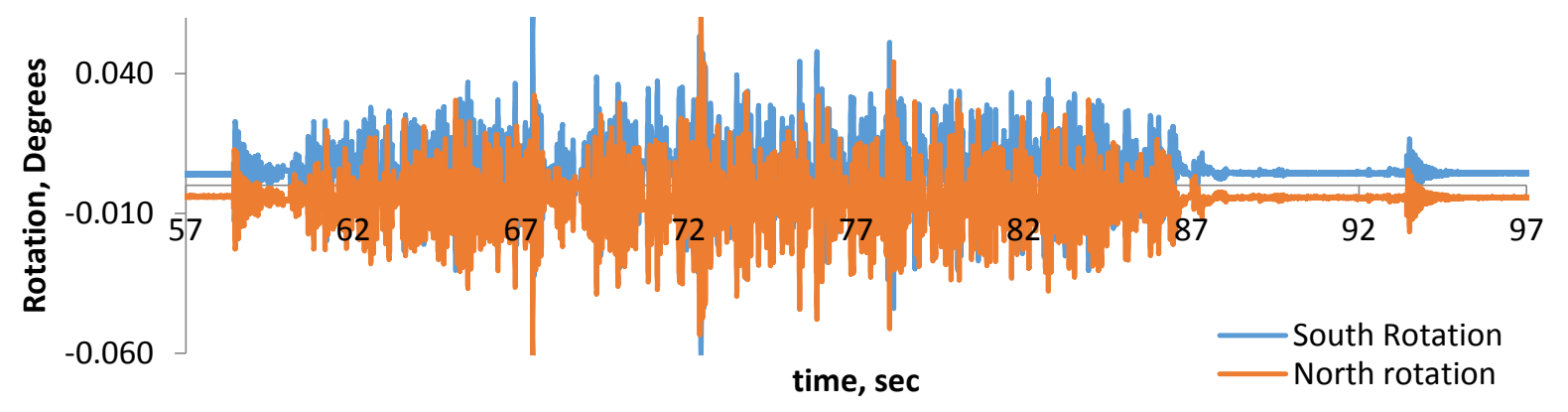

Figure 38: Rotations in the North-South Direction.

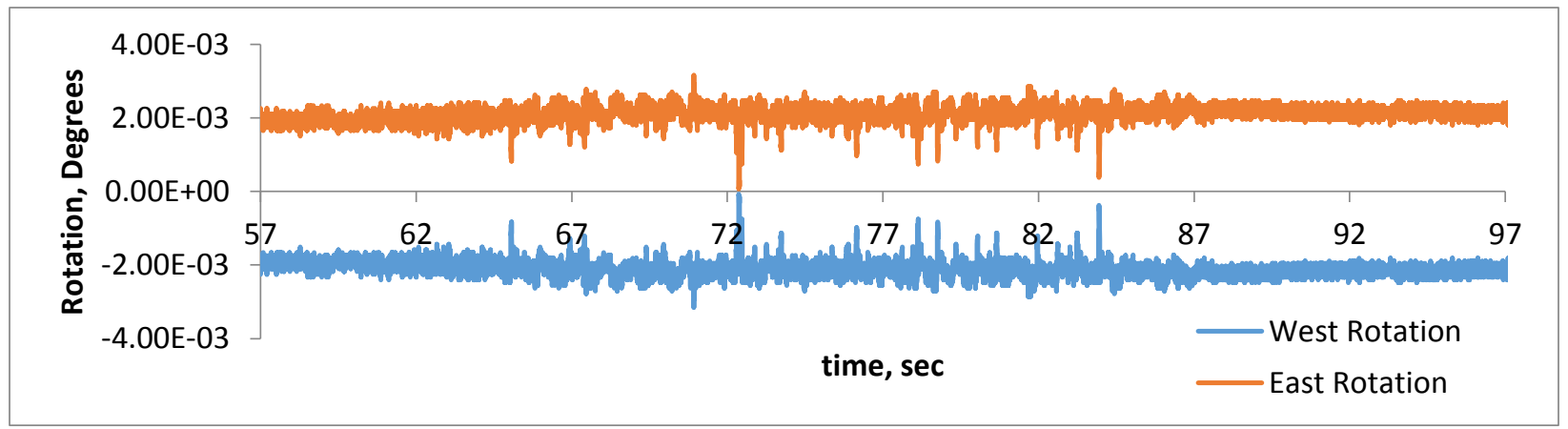

Figure 39: Rotations in the East-West Direction.

\section{GM 175\%: Horizontal Rotations and New X and Y intercepts}

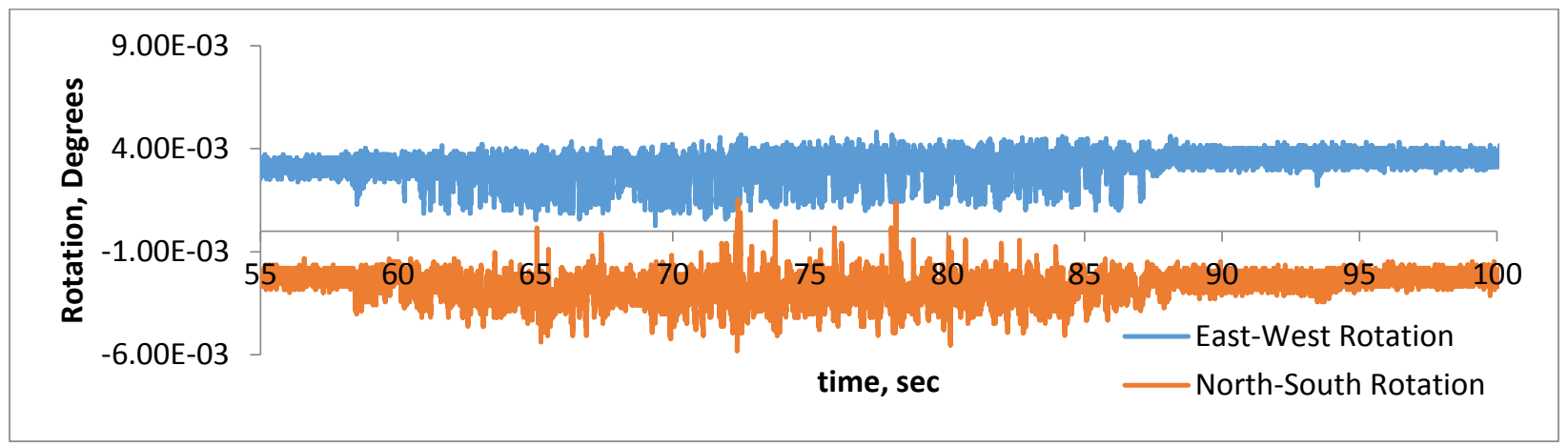

Figure 40: Horizontal Rotations. 


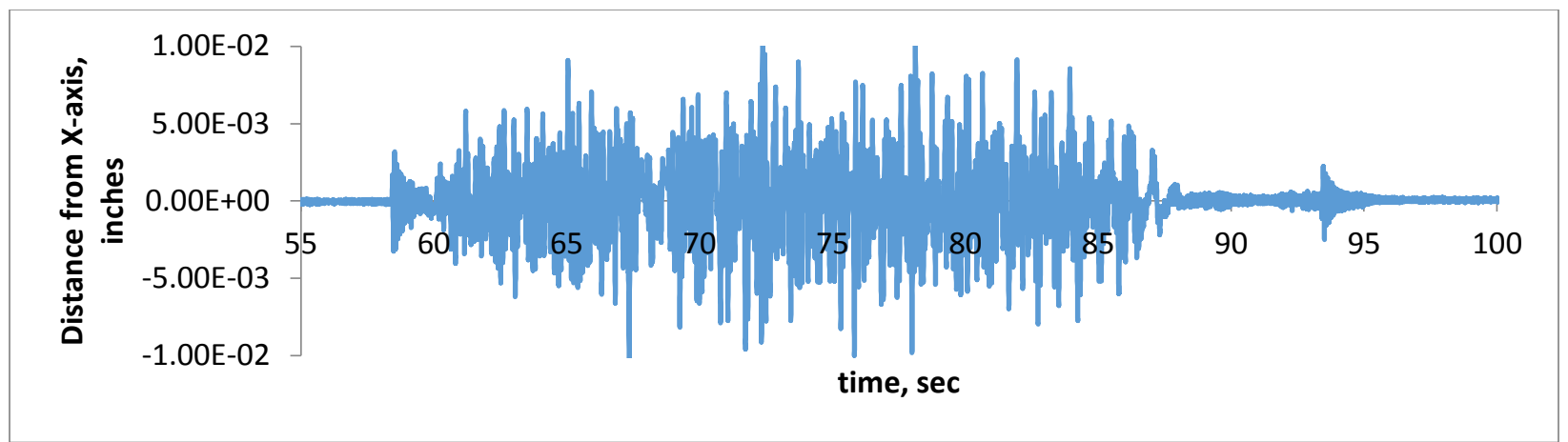

Figure 41: New X-Intercept as a function of time, ti. Negative is towards the east horizontal LVDT and positive is towards the west horizontal LVDT.

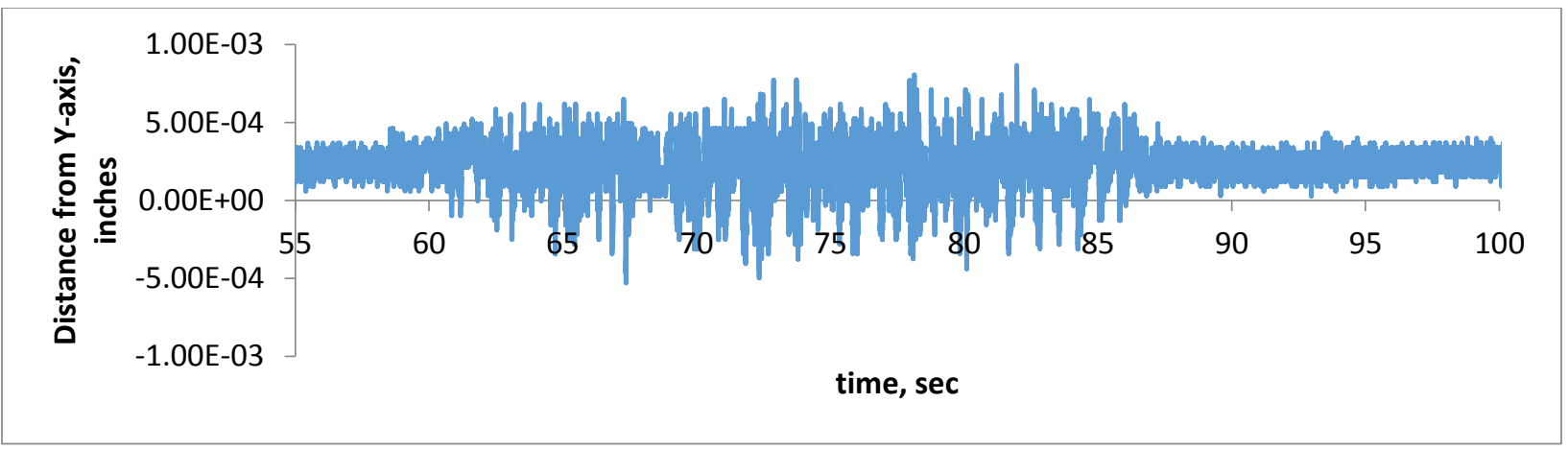

Figure 42: New Y-Intercept as a function of time, ti. Negative is towards the south horizontal LVDT and positive is towards the north horizontal LVDT.

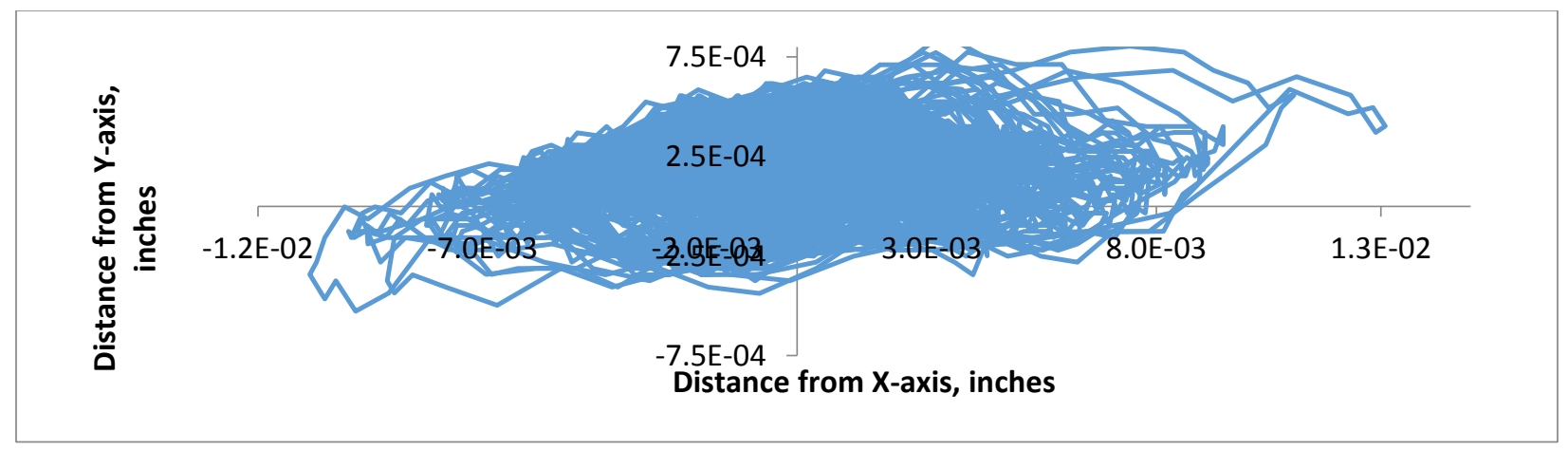

Figure 43: Changing $X \& Y$ Intercept as a function of time, ti.

\section{GM 175\% Repeat: Vertical Pivot Point and Rotation Angle}

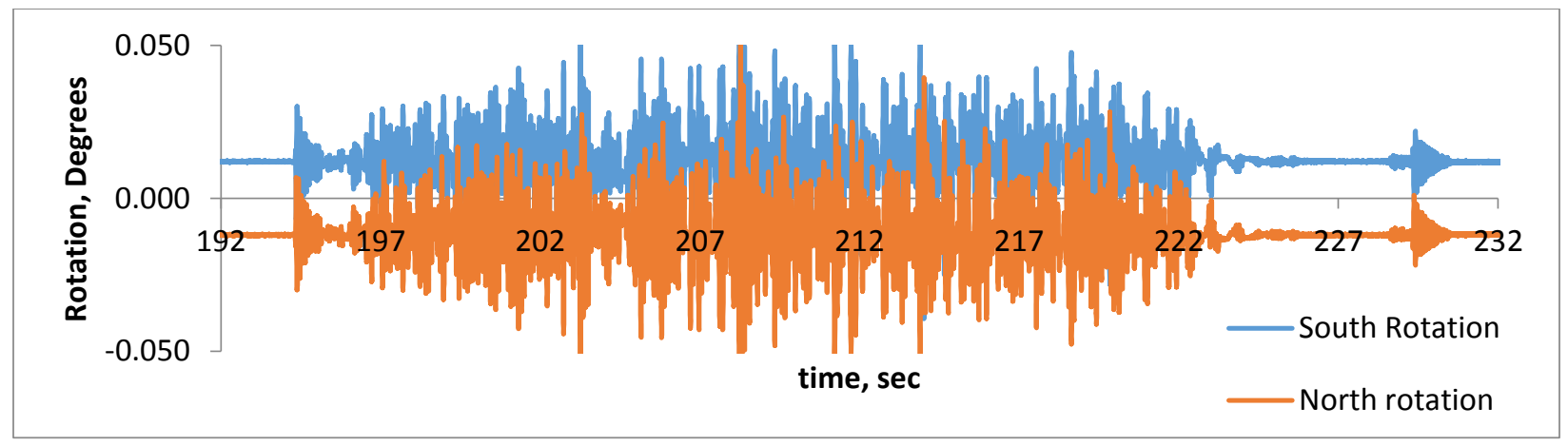

Figure 44: Rotations in the North-South Direction. 


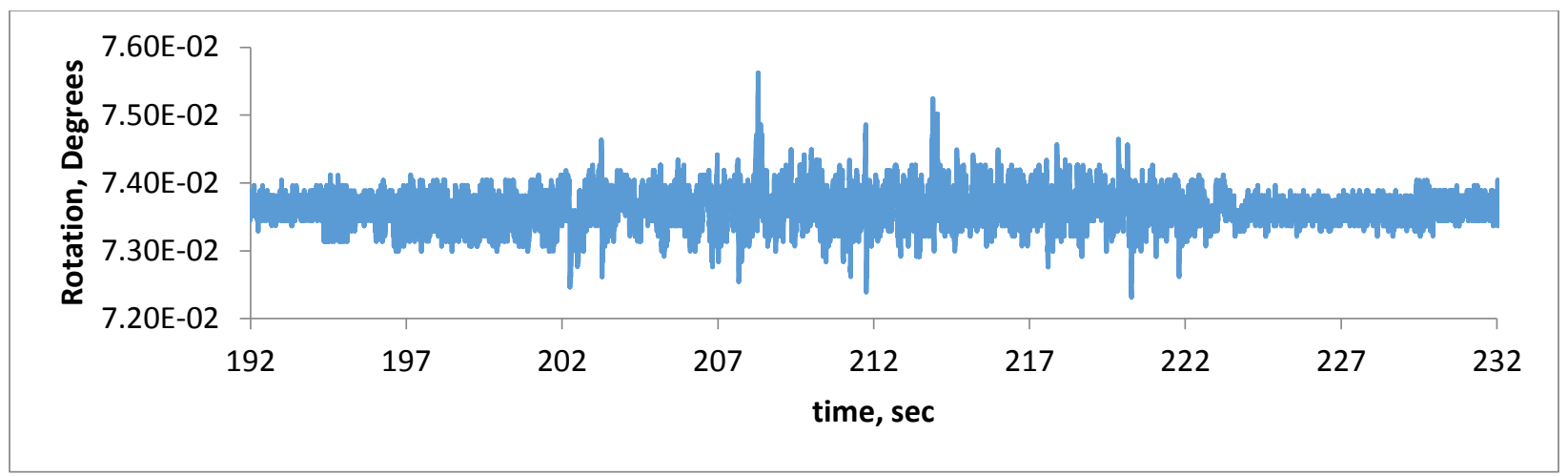

Figure 45: West Rotation.

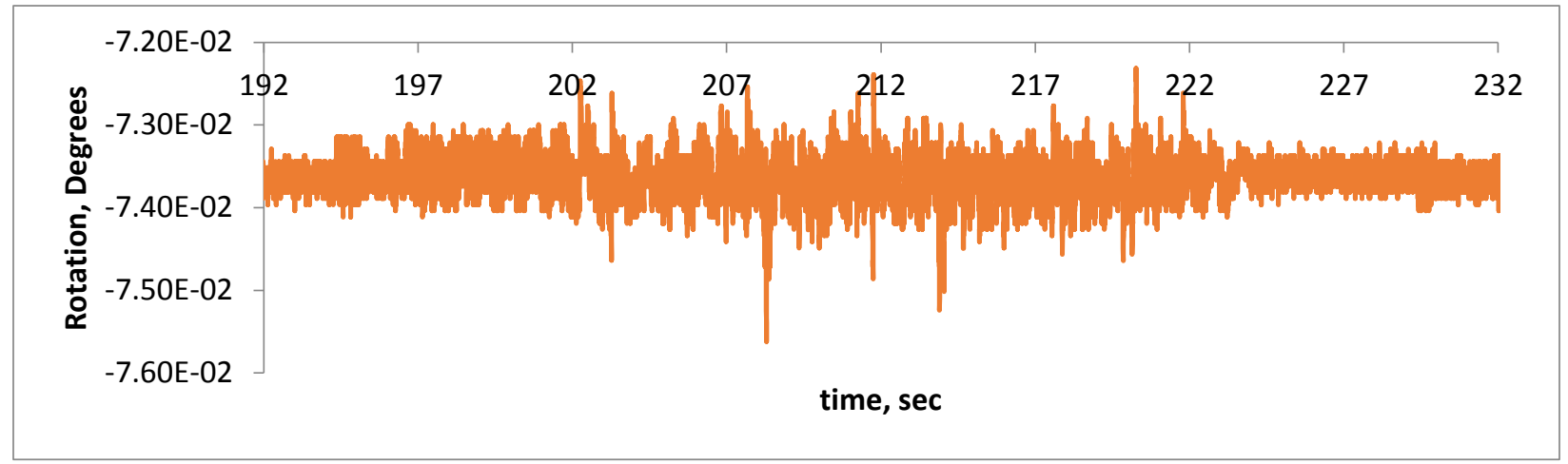

Figure 46: East Rotation.

GM 175\% Repeat: Horizontal Rotations and New $X$ and $Y$ intercepts

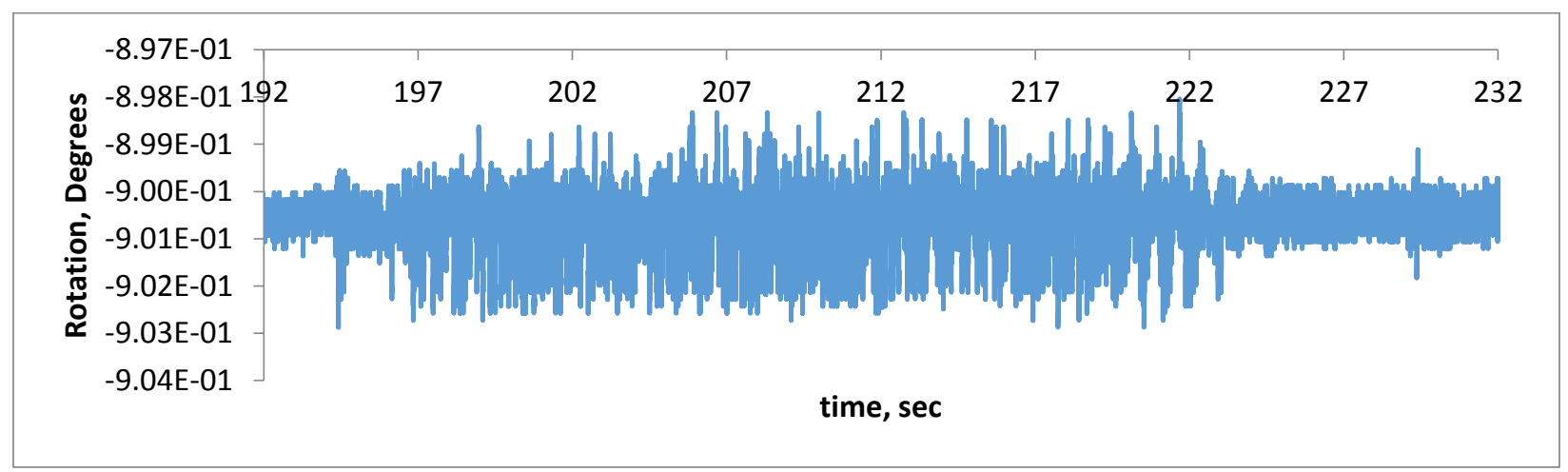

Figure 47: East-West Horizontal Rotation.

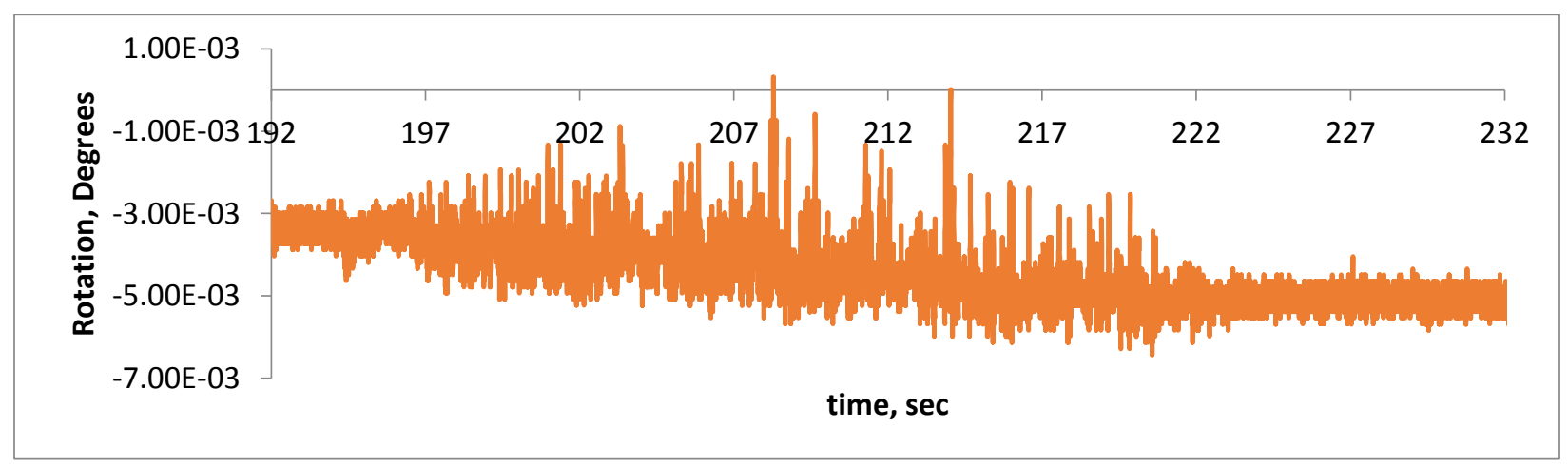

Figure 48: North-South Horizontal Rotation. 


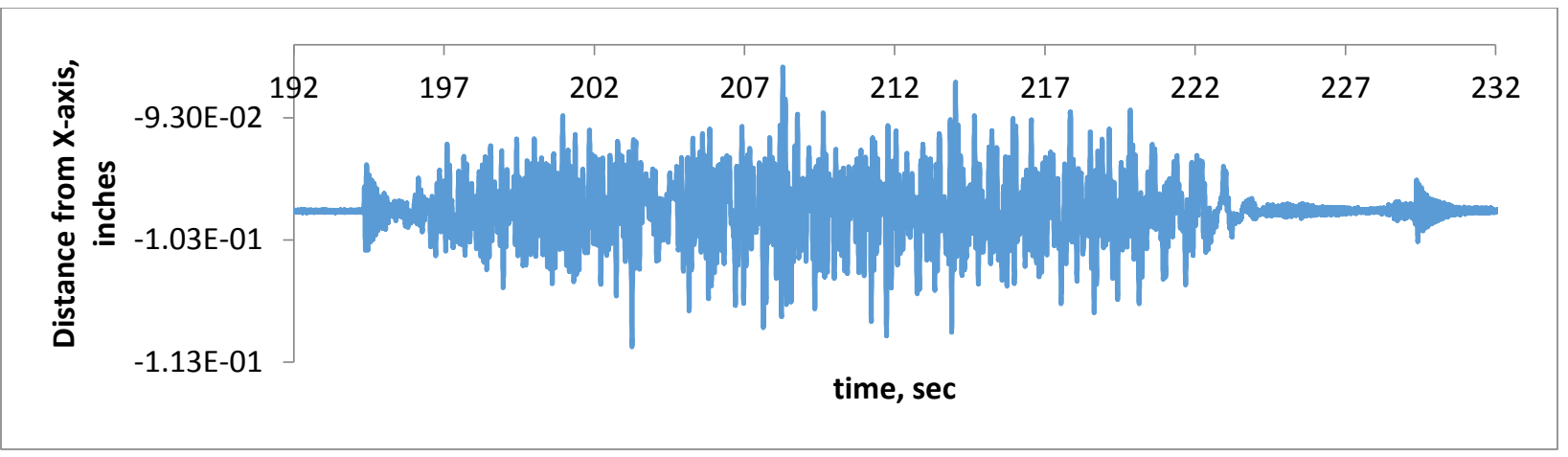

Figure 49: New X-Intercept as a function of time, ti. Negative is towards the east horizontal LVDT and positive is towards the west horizontal LVDT.

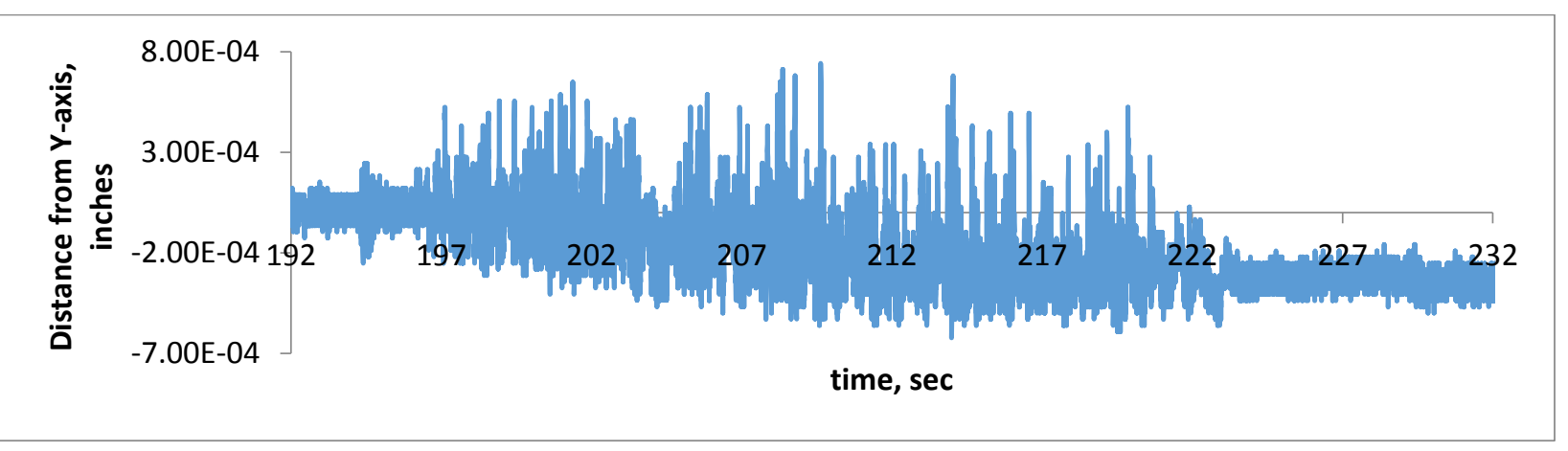

Figure 50: New Y-Intercept as a function of time, ti. Negative is towards the south horizontal LVDT and positive is towards the north horizontal LVDT.

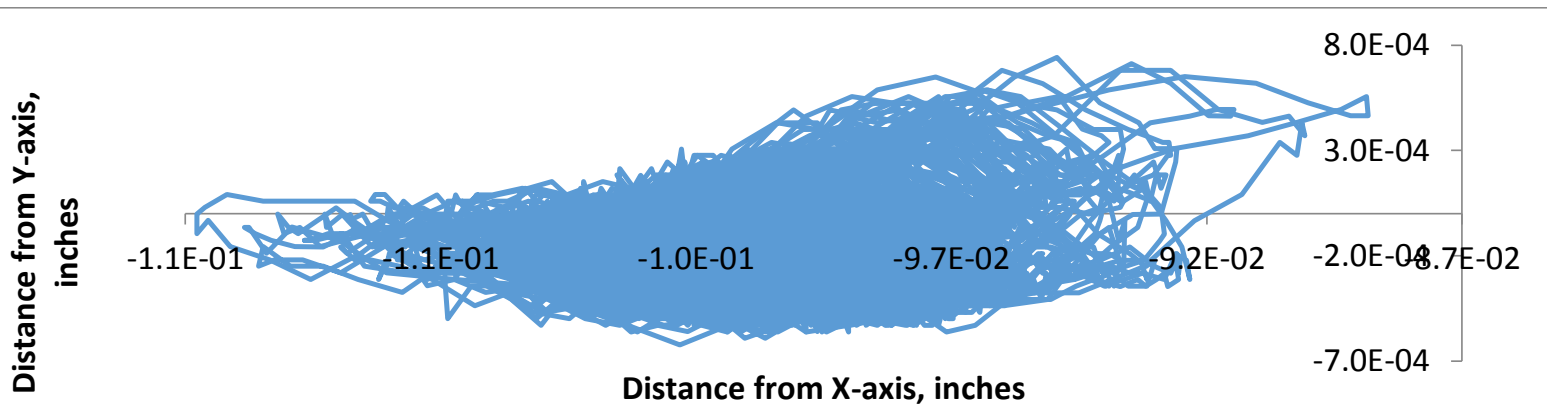

Figure 51: Changing $X \& Y$ Intercept as a function of time, ti.

GM 175\% Rerepeat: Vertical Pivot Point and Rotation Angle

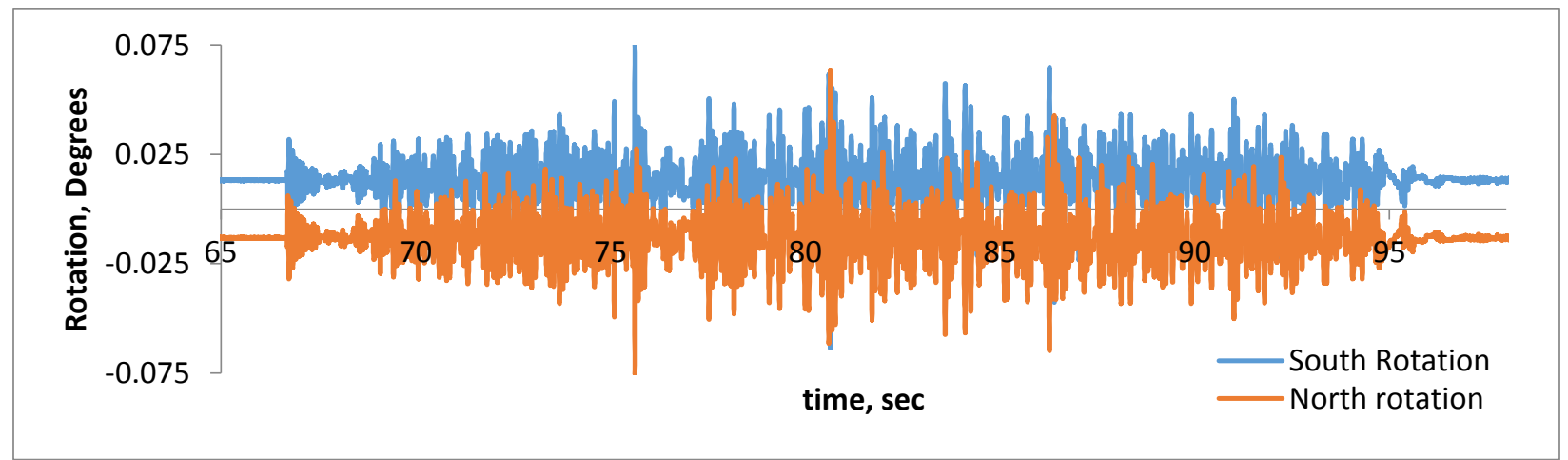

Figure 52: Rotations in the North-South Direction. 


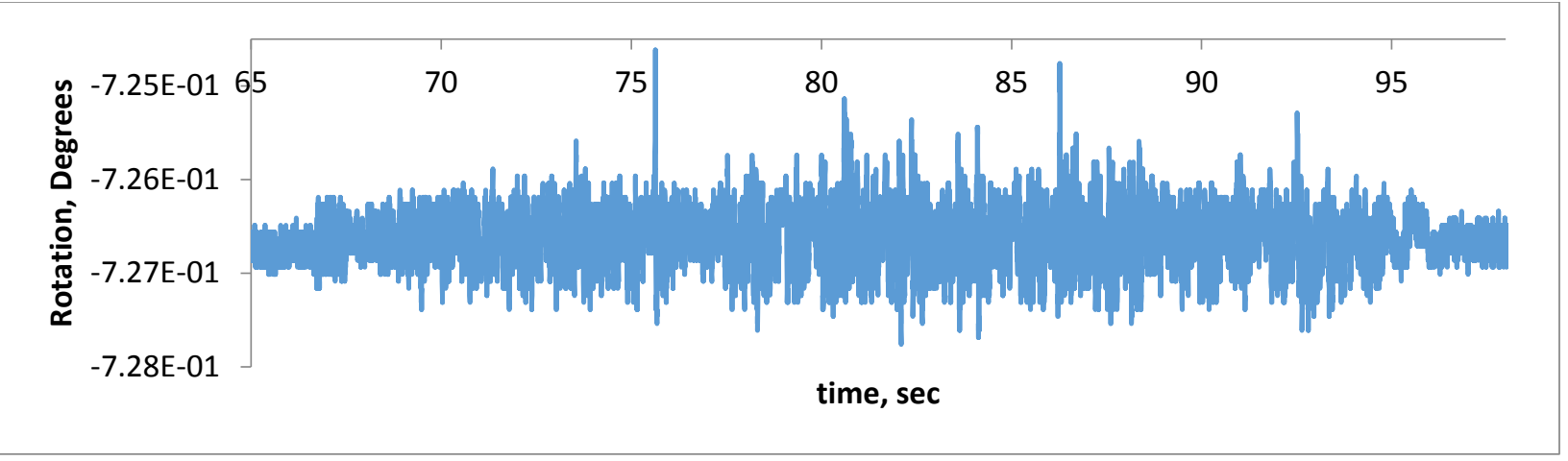

Figure 53: West Rotation.

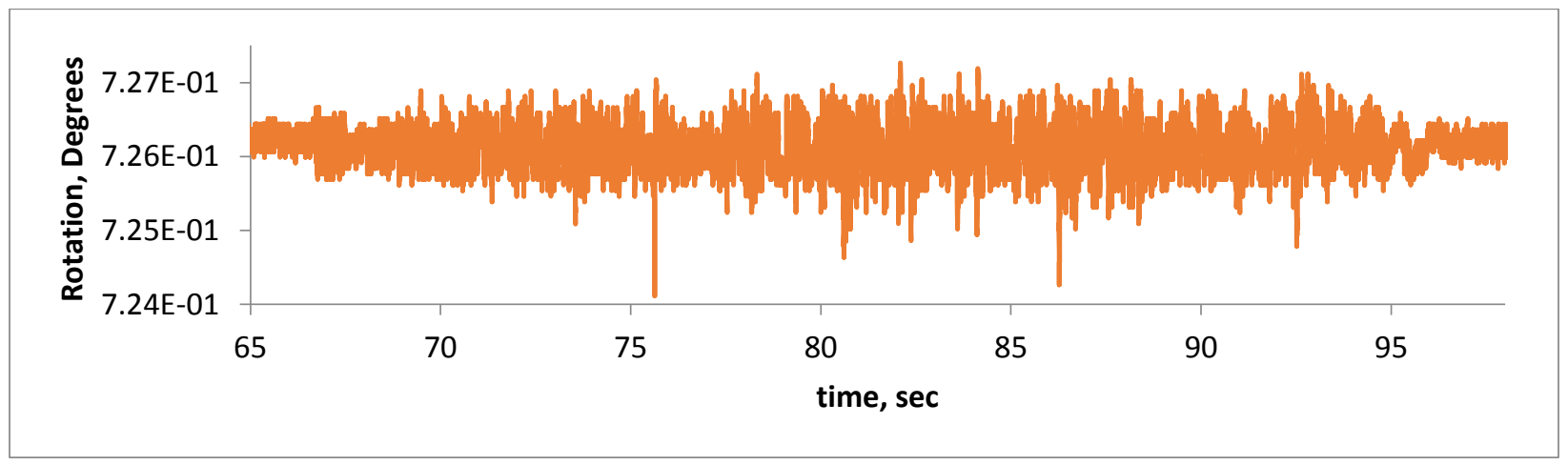

Figure 54: East Rotation.

GM 175\% Rerepeat: Horizontal Rotations and New $X$ and $Y$ intercepts

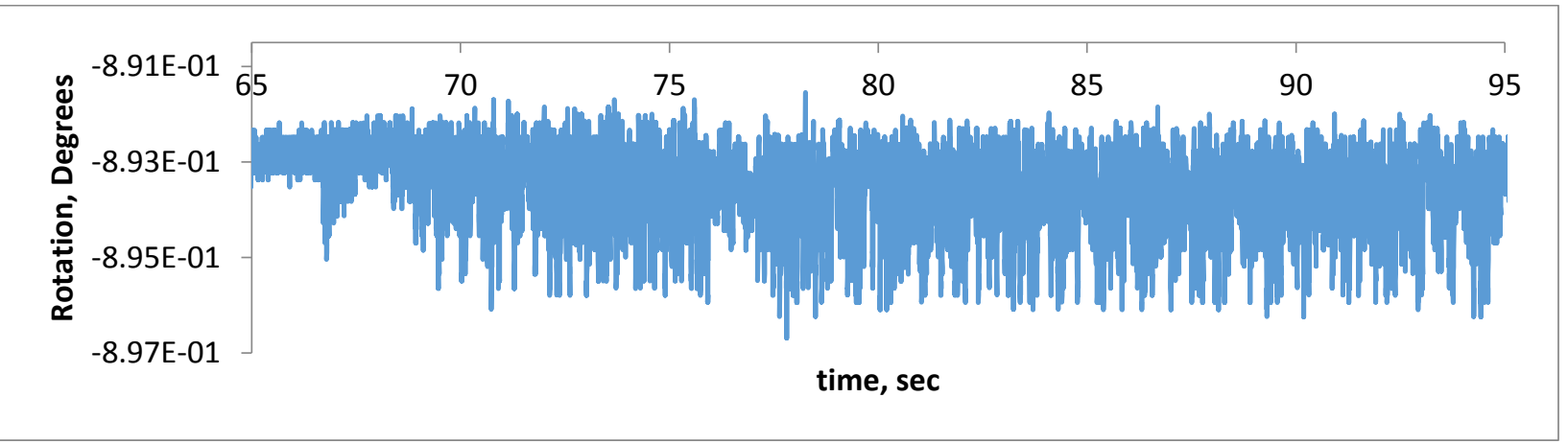

Figure 55: East-West Horizontal Rotation.

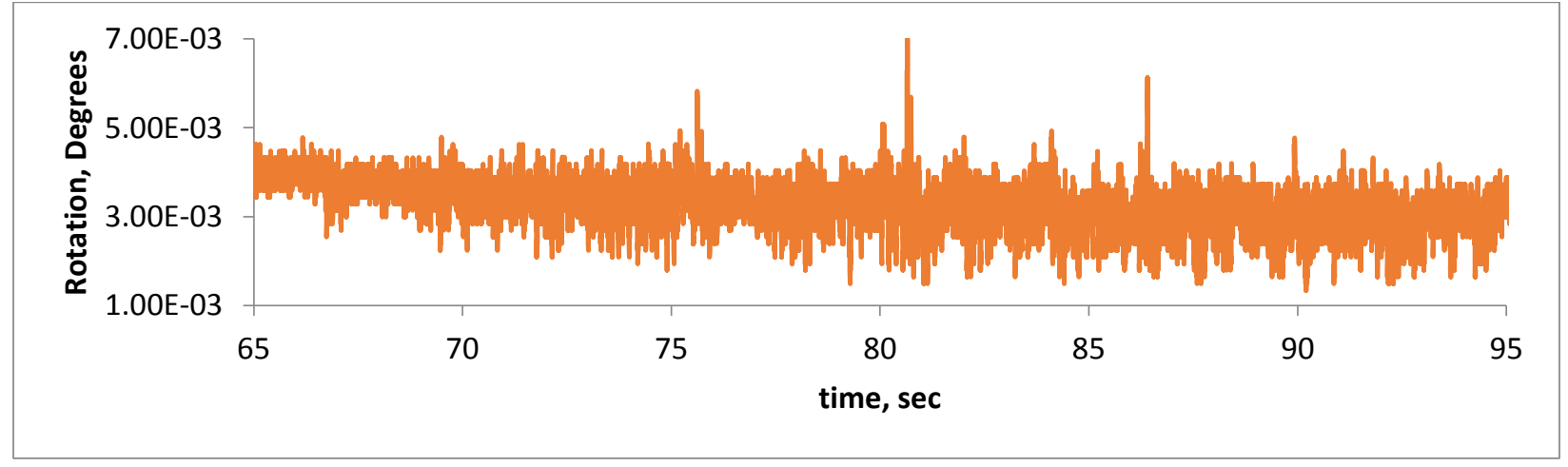

Figure 56: North-South Horizontal Rotation. 


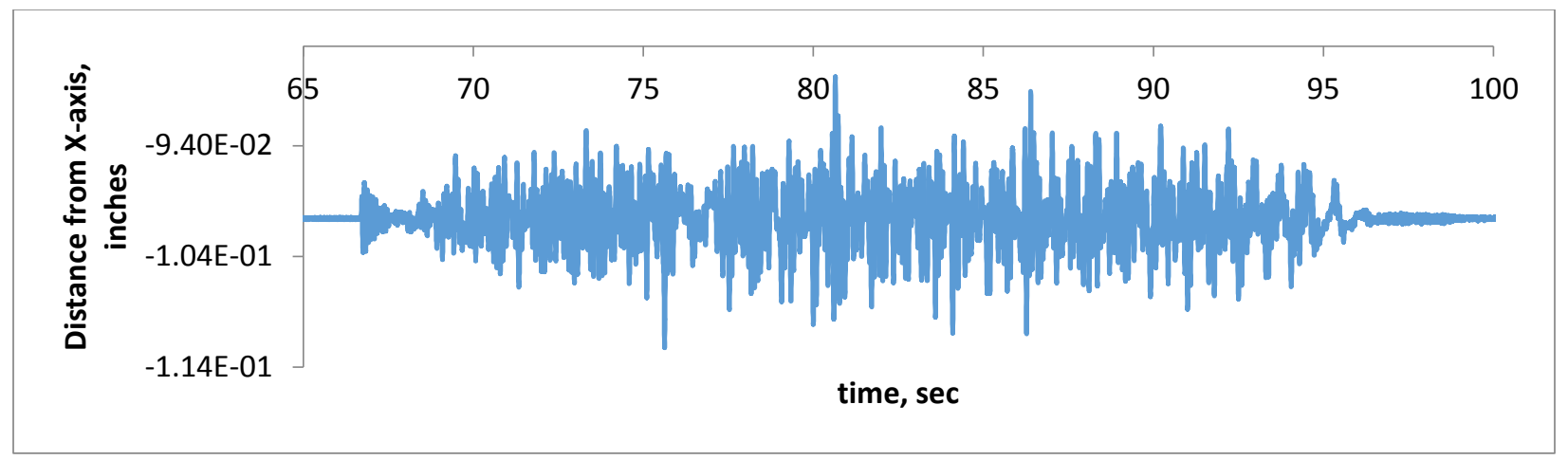

Figure 57: New X-Intercept as a function of time, ti. Negative is towards the east horizontal LVDT and positive is towards the west horizontal LVDT.

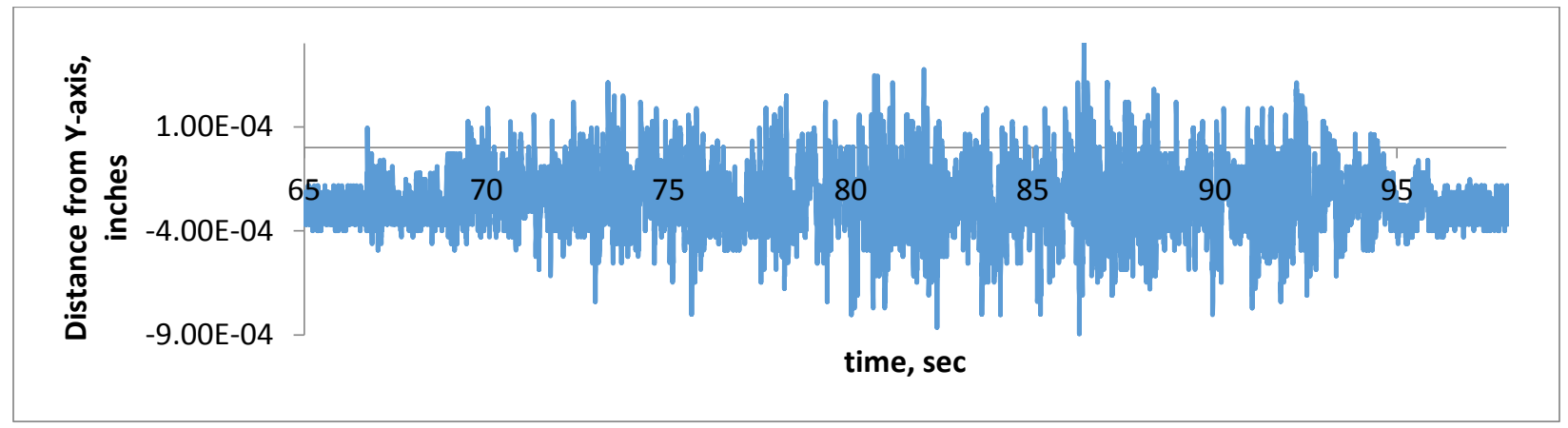

Figure 58: New Y-Intercept as a function of time, ti. Negative is towards the south horizontal LVDT and positive is towards the north horizontal LVDT.

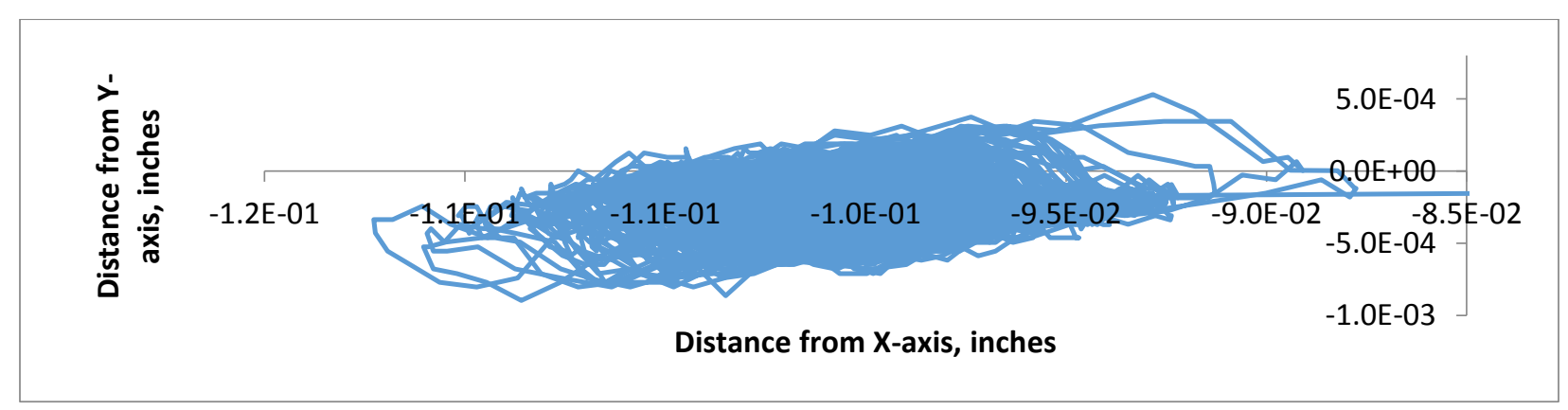

Figure 59: Changing $X \& Y$ Intercept as a function of time, ti.

\section{GM 200\%: Vertical Pivot Point and Rotation Angle}

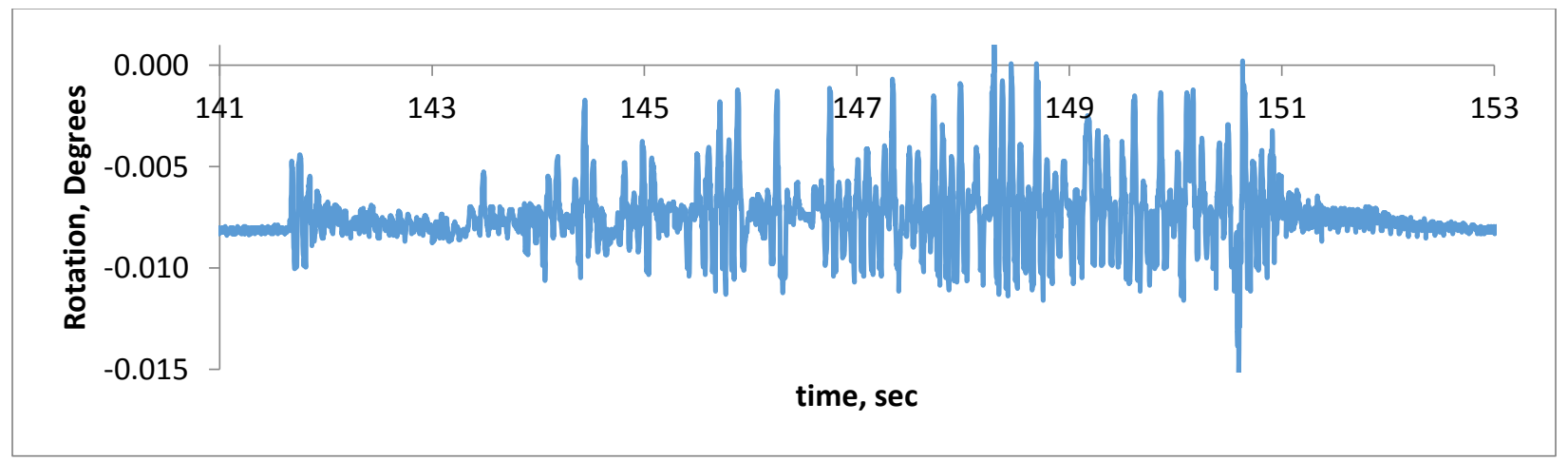

Figure 60: South Rotation. 


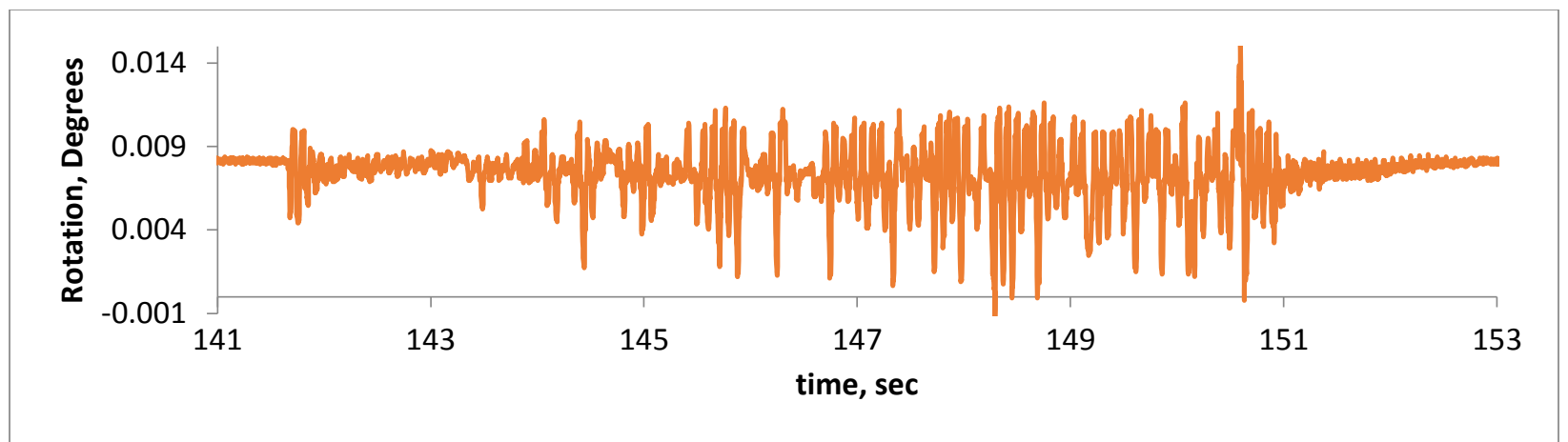

Figure 61: North Rotation.

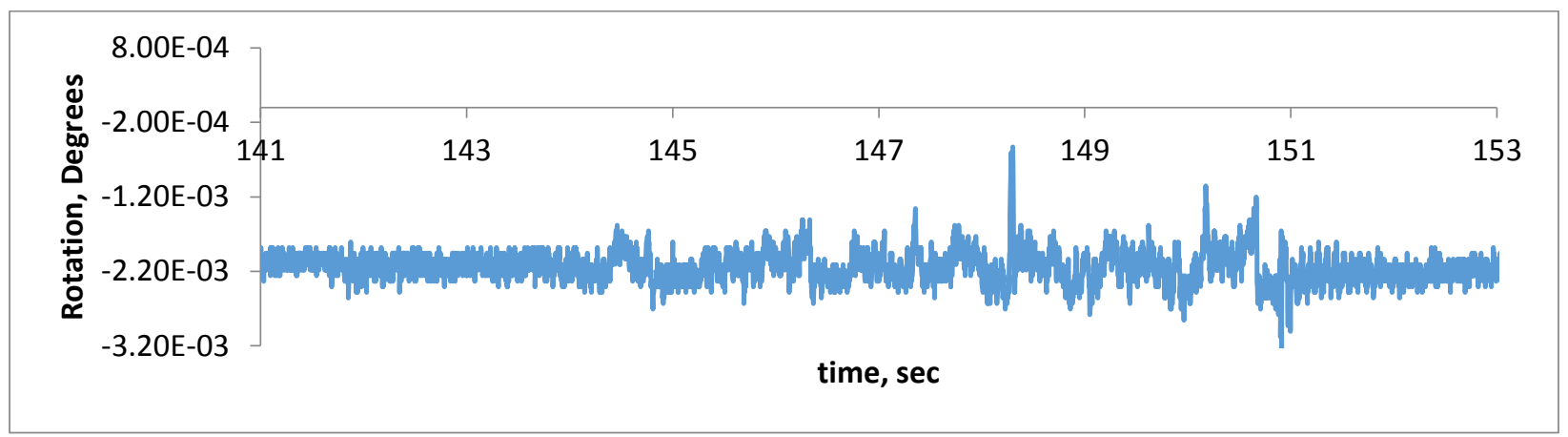

Figure 62: West Rotation

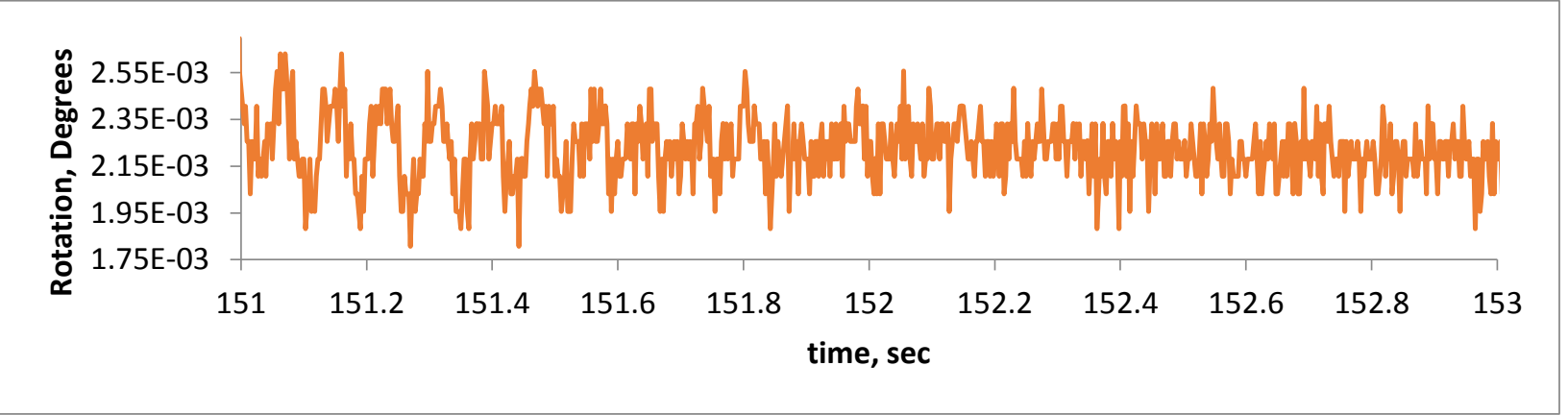

Figure 63: East Rotation.

GM 200\%: Horizontal Rotations and New X and Y intercepts

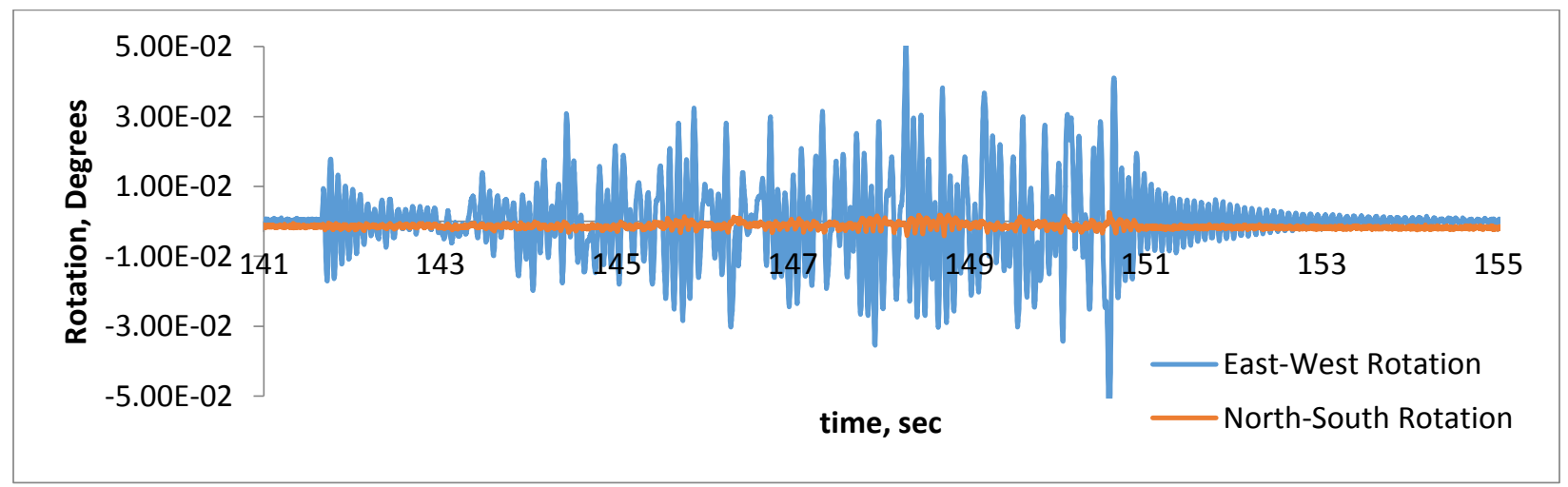

Figure 64: Horizontal Rotations. 


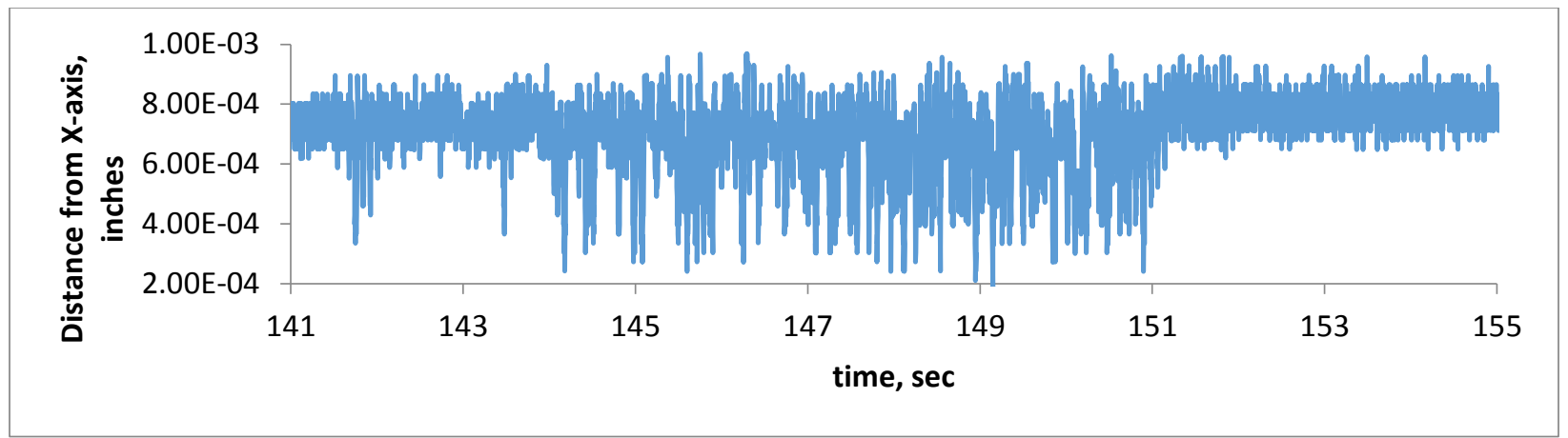

Figure 65: New X-Intercept as a function of time, ti. Negative is towards the east horizontal LVDT and positive is towards the west horizontal LVDT.

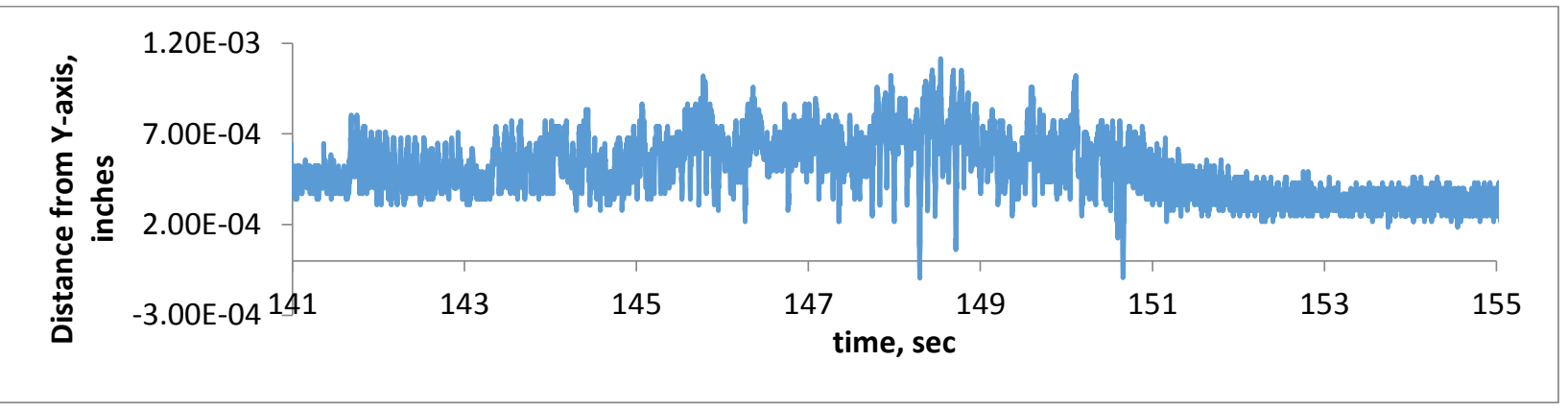

Figure 66: New Y-Intercept as a function of time, ti. Negative is towards the south horizontal LVDT and positive is towards the north horizontal LVDT.

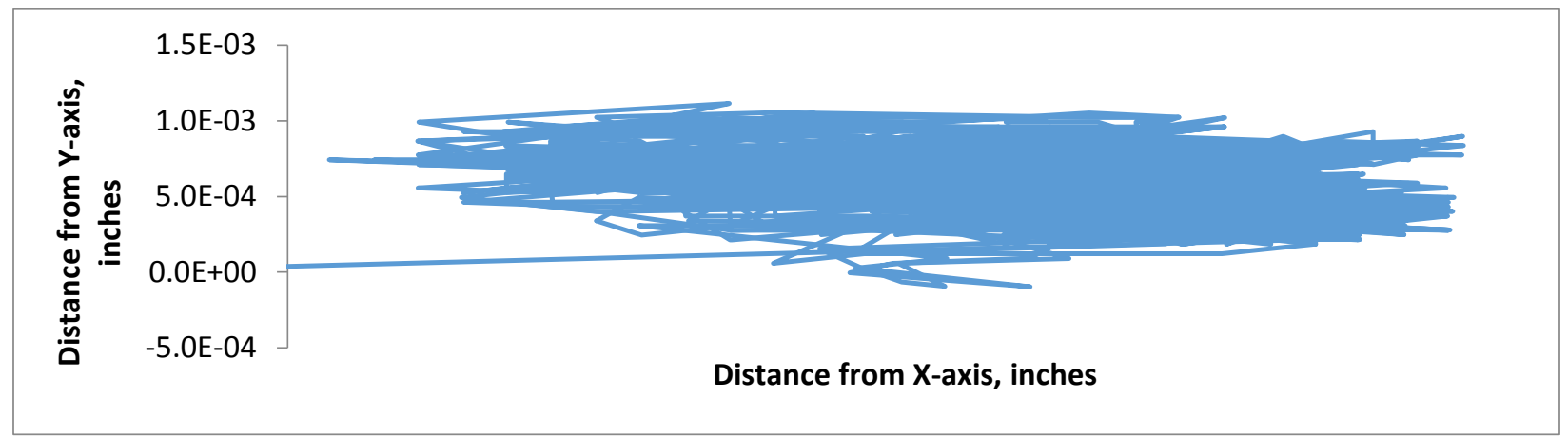

Figure 67: Changing $X \& Y$ Intercept as a function of time, $t$.

\section{GM 200\% Repeat: Vertical Pivot Point and Rotation Angle}

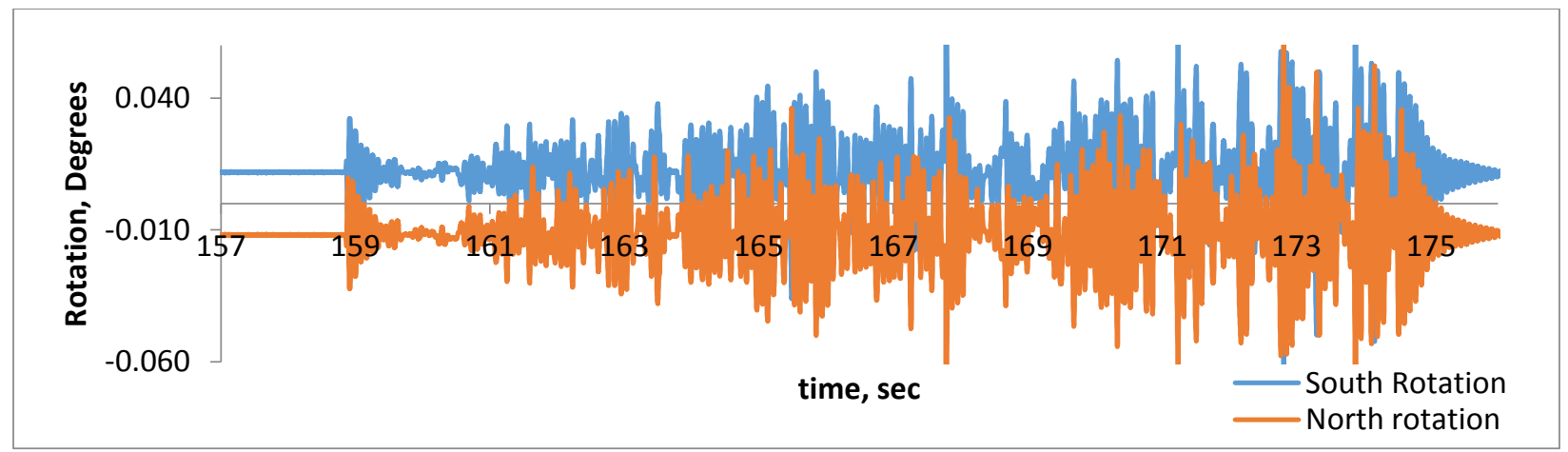

Figure 68: North and South Vertical Rotations. 


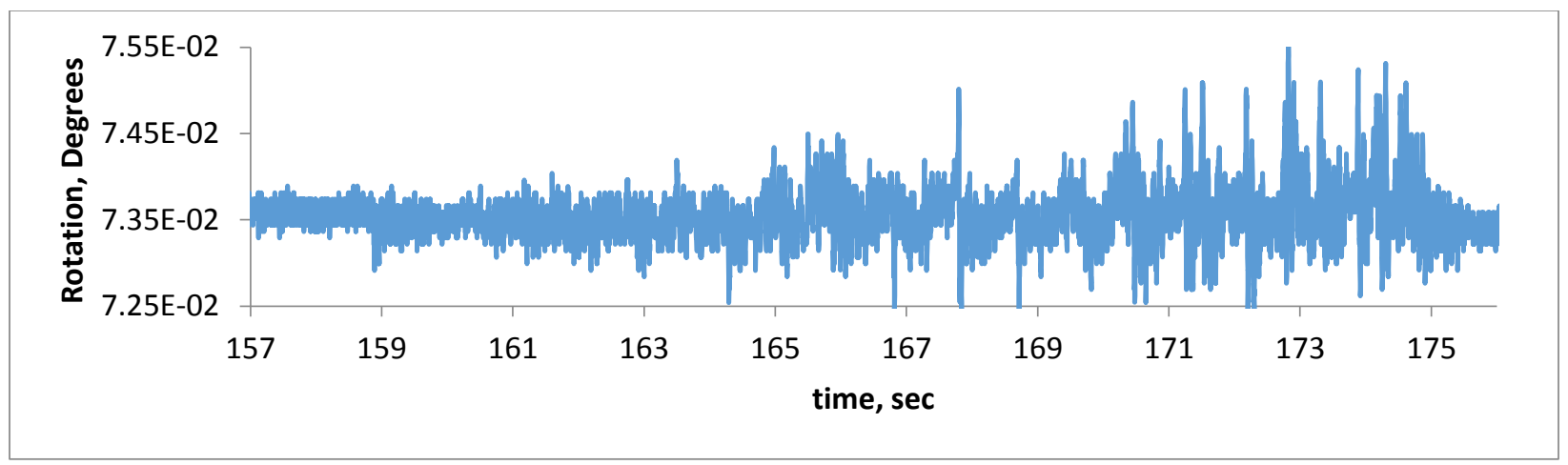

Figure 69: West Vertical Rotation.

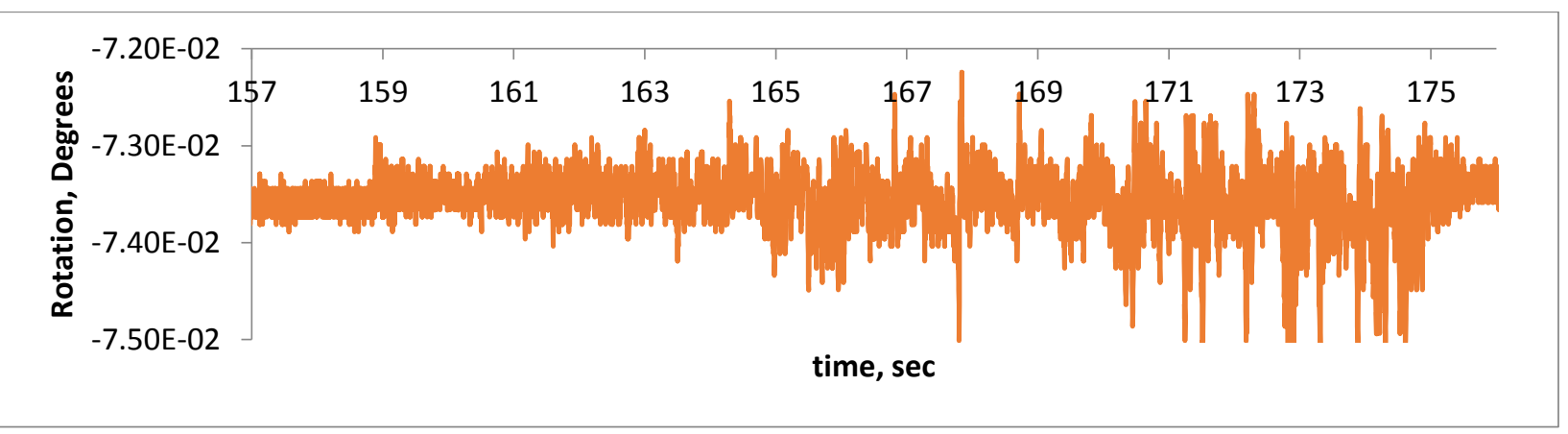

Figure 70: East Vertical Rotation.

GM 200\% Repeat: Horizontal Rotations and New X and Y intercepts

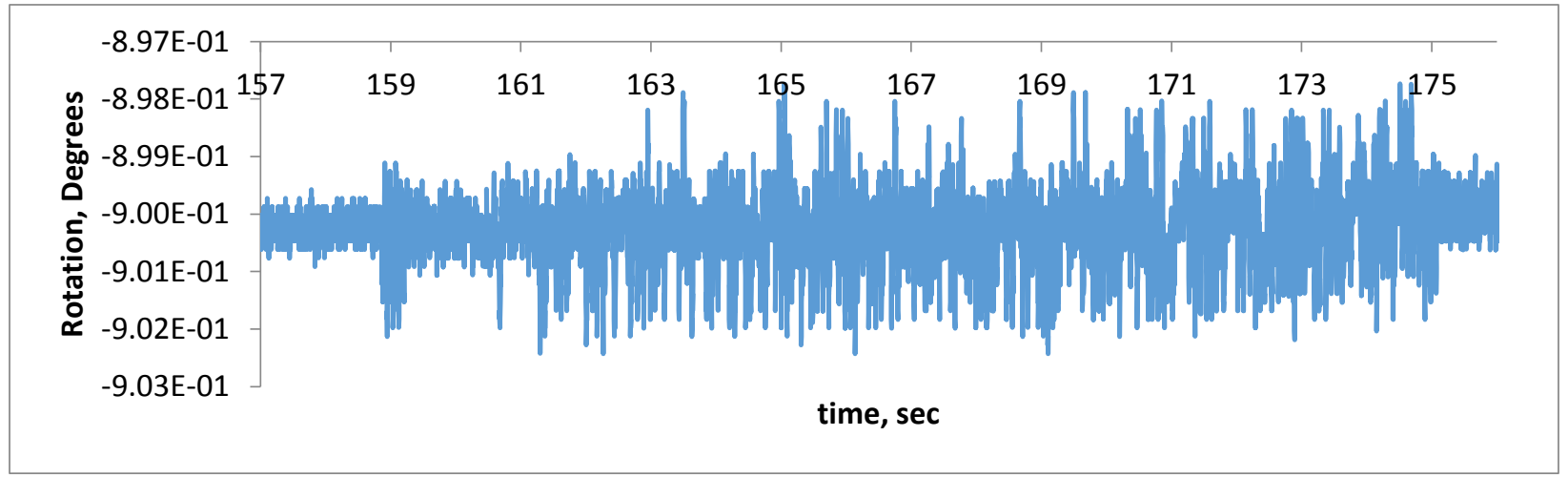

Figure 71: East-West Horizontal Rotation.

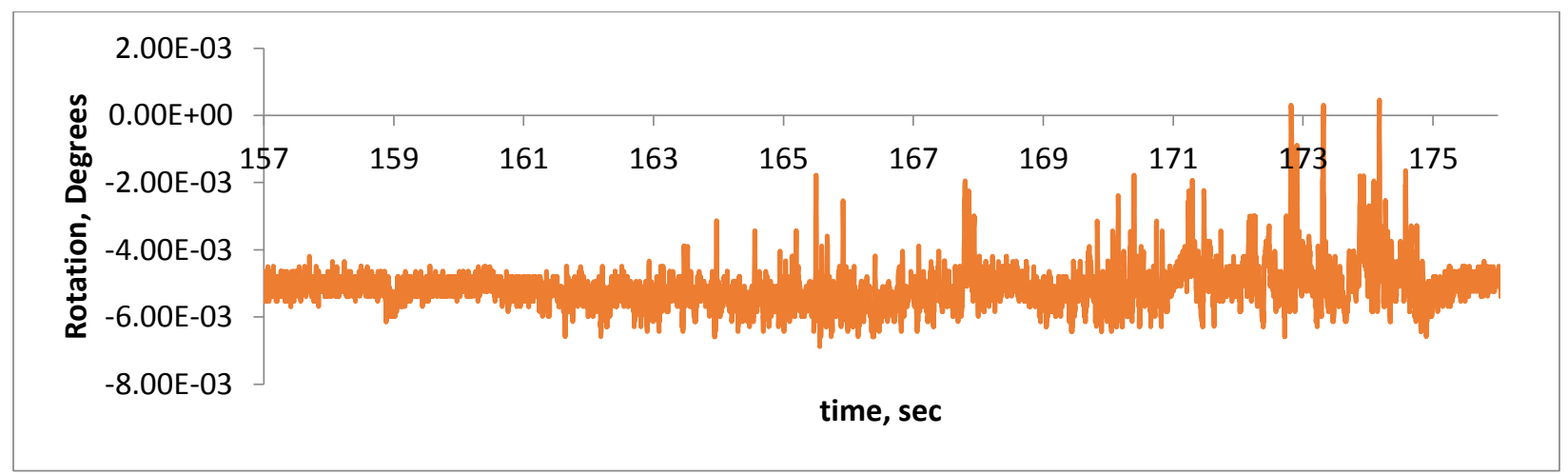

Figure 72: North-South Horizontal Rotation. 


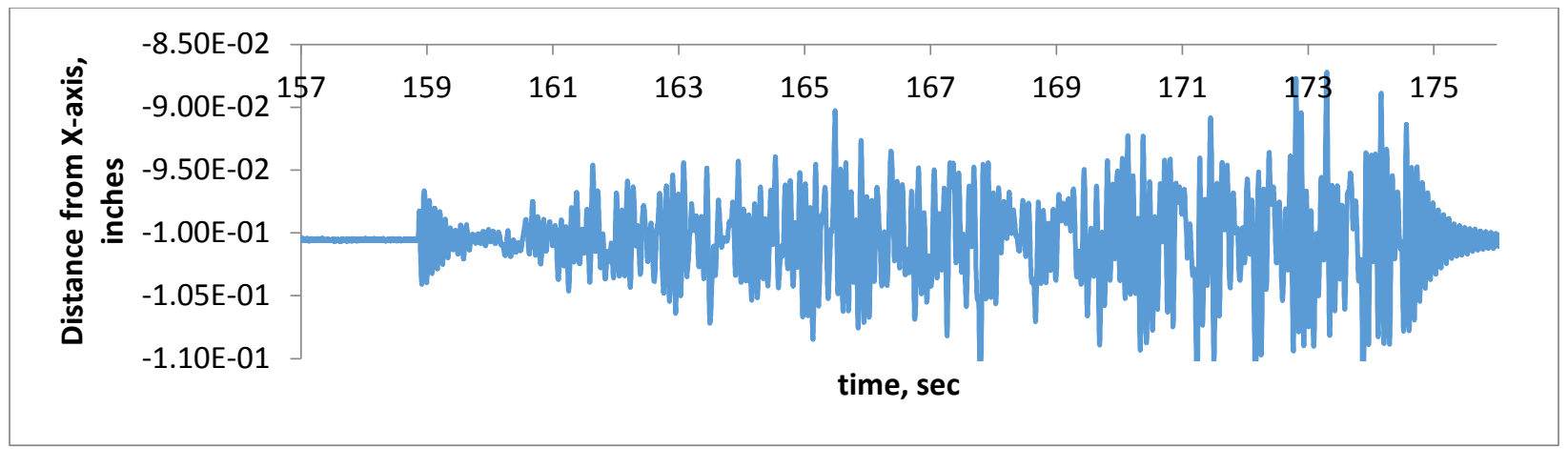

Figure 73: New X-Intercept as a function of time, ti. Negative is towards the east horizontal LVDT and positive is towards the west horizontal LVDT.

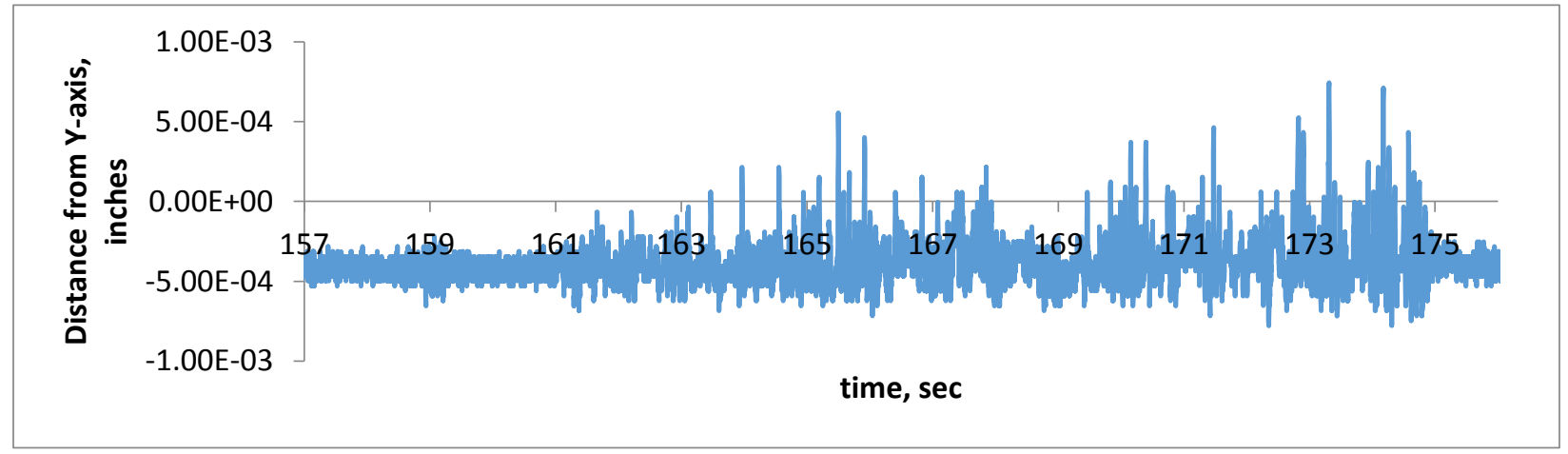

Figure 74: New Y-Intercept as a function of time, ti. Negative is towards the south horizontal LVDT and positive is towards the north horizontal LVDT.

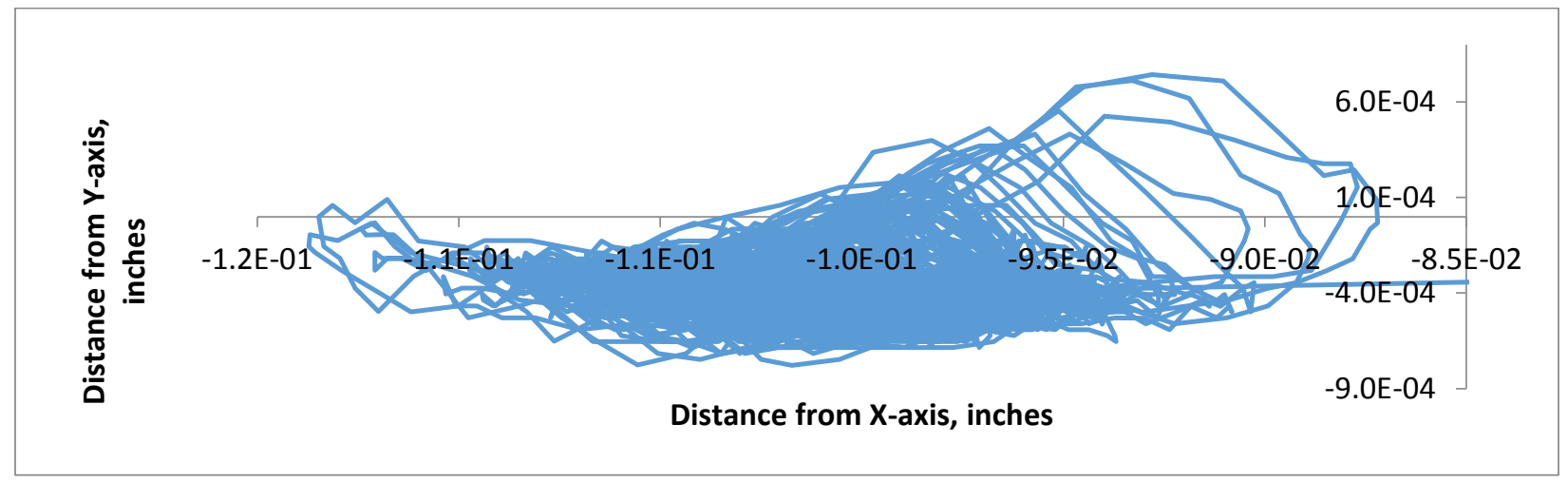

Figure 75: Changing X \& Y Intercept as a function of time, ti. 


\section{Appendix E \\ Figures for Analysis at the Porcelain Flange Interface Bushing 1 - Sine Beats}

\section{Table of Contents}

SB0.28g: Vertical Pivot Point and Rotation Angle 93

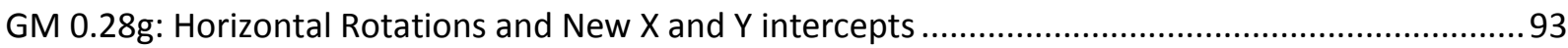

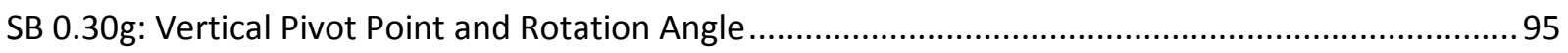

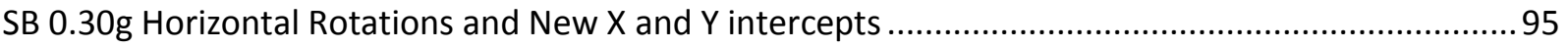

SB 0.33g: Vertical Pivot Point and Rotation Angle ............................................................................ 97

SB 0.33g: Horizontal Rotations and New X and $Y$ intercepts .......................................................... 98

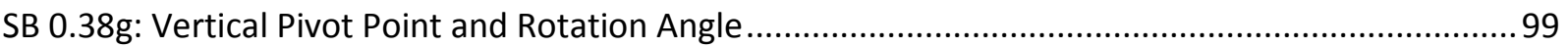

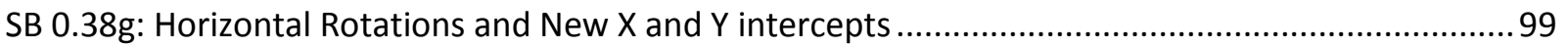

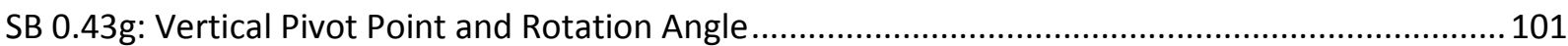

SB 0.43g: Horizontal Rotations and New $X$ and $Y$ intercepts ........................................................ 101

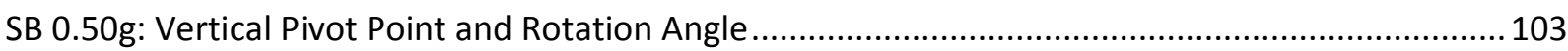

SB 0.50g: Horizontal Rotations and New $X$ and $Y$ intercepts .......................................................... 103

SB 0.50g Repeat: Vertical Pivot Point and Rotation Angle …......................................................... 103

SB 0.50g Repeat: Horizontal Rotations and New $X$ and $Y$ intercepts.............................................. 105

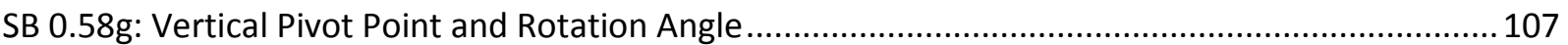

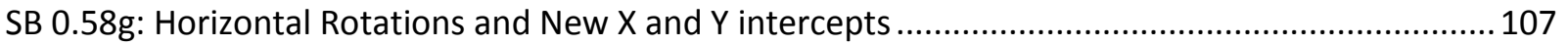

SB 0.65g: Vertical Pivot Point and Rotation Angle ............................................................................ 109

SB 0.65g: Horizontal Rotations and New $X$ and $Y$ intercepts ......................................................... 109

SB 0.75g: Vertical Pivot Point and Rotation Angle .......................................................................... 111

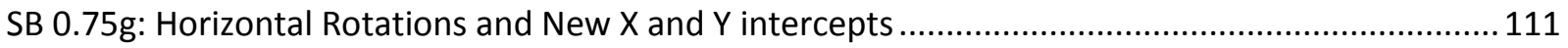

SB 0.88g: Vertical Pivot Point and Rotation Angle ................................................................................ 113

SB 0.88g: Horizontal Rotations and New $X$ and $Y$ intercepts ........................................................ 113

SB 1.0g: Vertical Pivot Point and Rotation Angle ................................................................................ 115

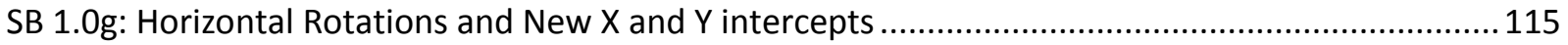

SB 1.125g: Vertical Pivot Point and Rotation Angle........................................................................ 117

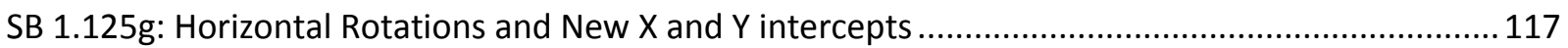

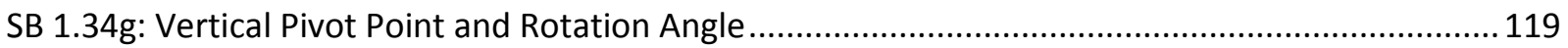

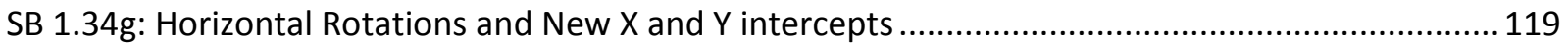

SB 1.52g: Vertical Pivot Point and Rotation Angle .............................................................................. 121

SB 1.52g: Horizontal Rotations and New $X$ and $Y$ intercepts ........................................................ 121 


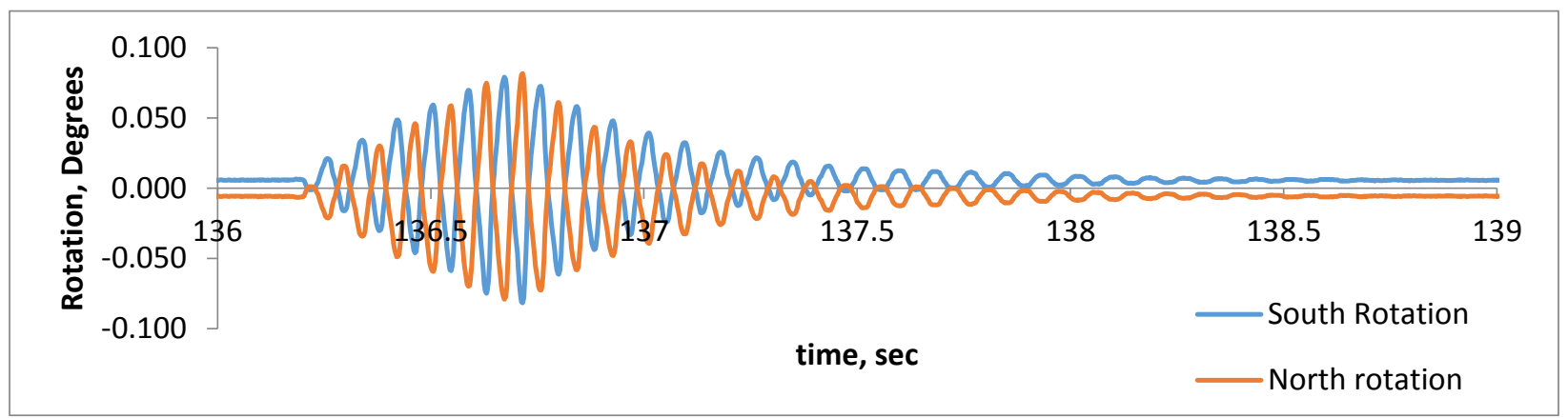

Figure 1: Rotations in the North-South Direction.

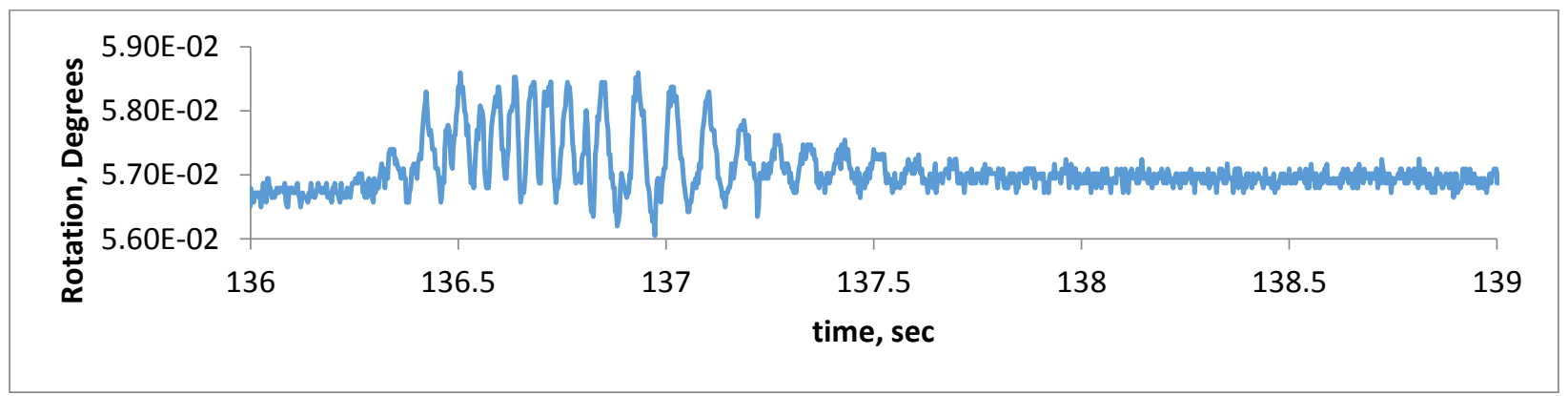

Figure 2: Rotations in the West Direction

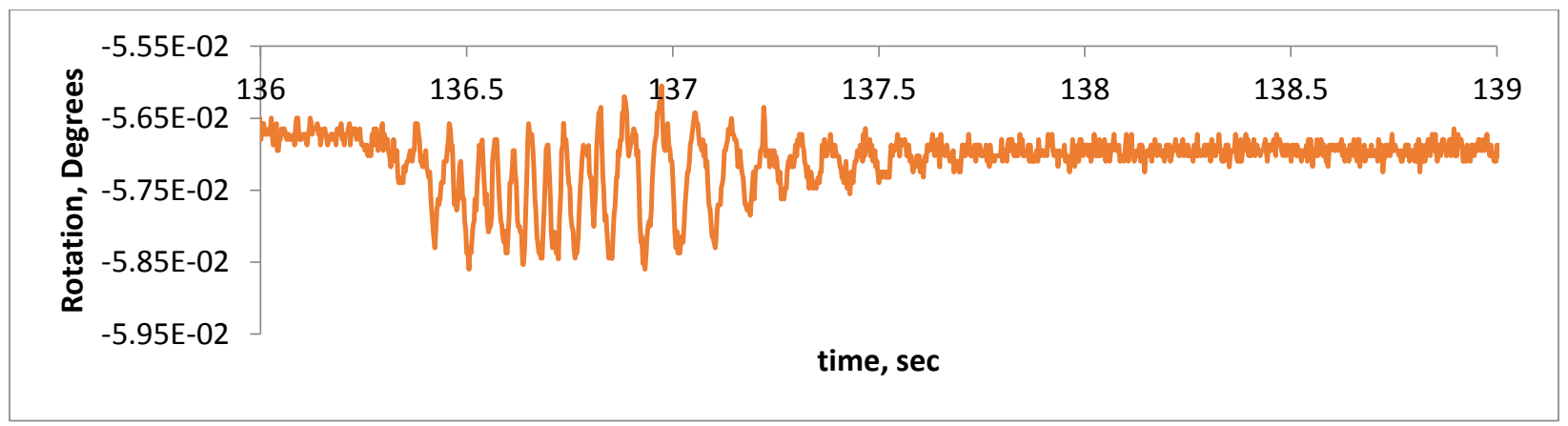

Figure 3: Rotations in the East Direction

GM 0.28g: Horizontal Rotations and New X and Y intercepts

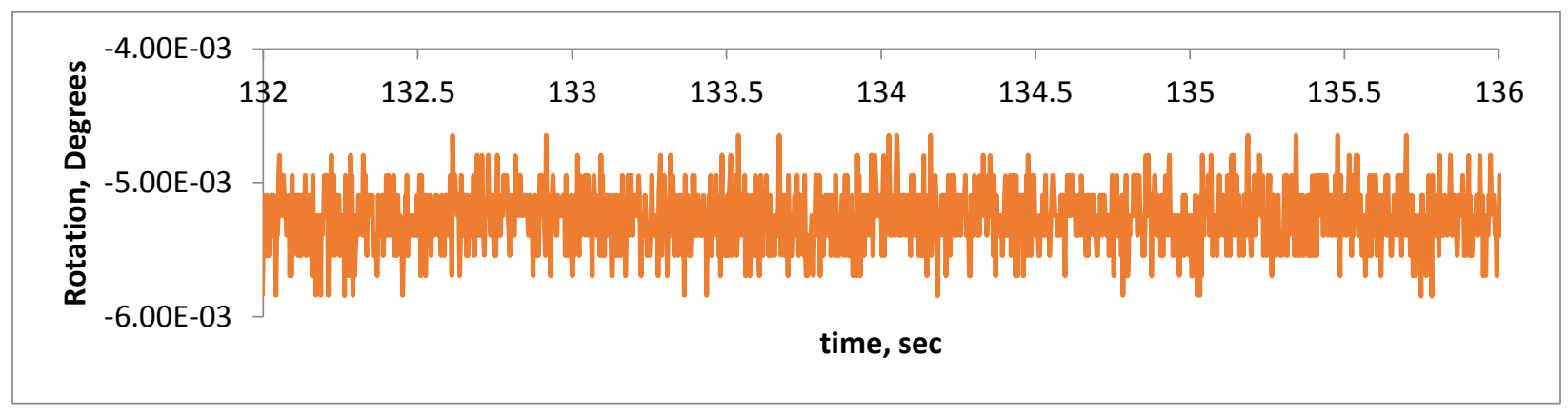

Figure 4: Horizontal North-South Rotations. 


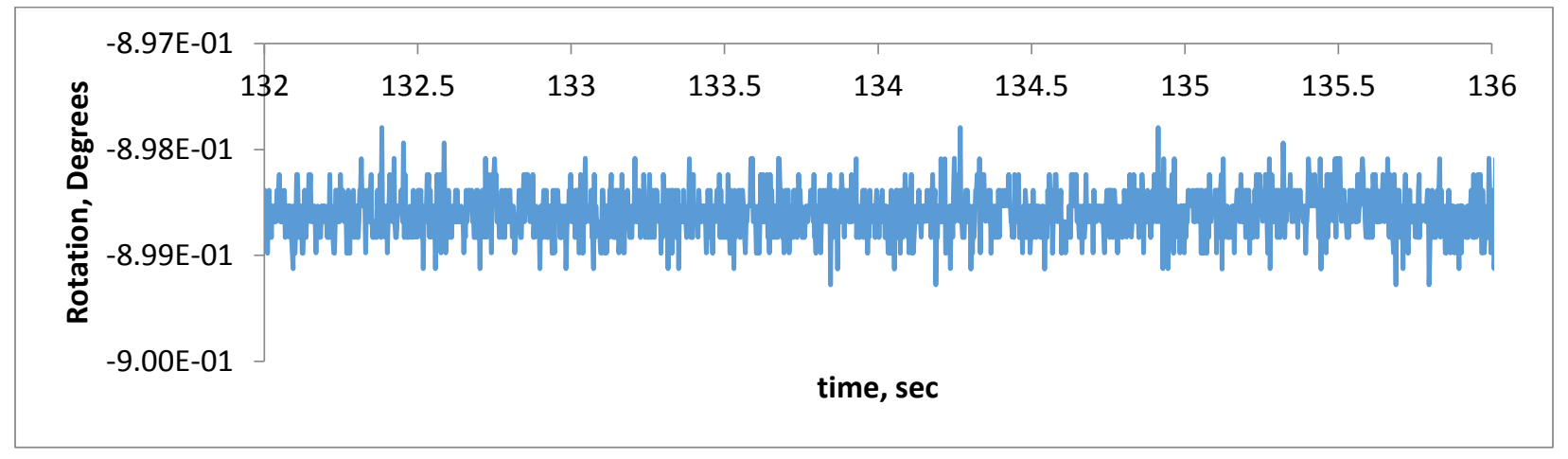

Figure 5: Horizontal East-West Rotations.

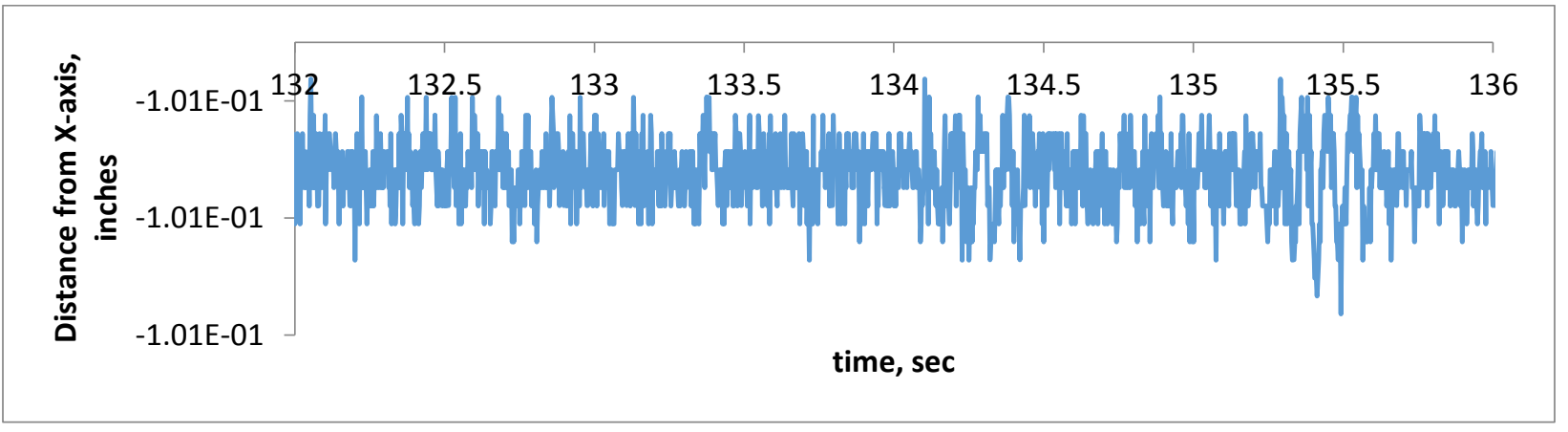

Figure 6: New X-Intercept as a function of time, ti. Negative is towards the east horizontal LVDT and positive is towards the west horizontal LVDT.

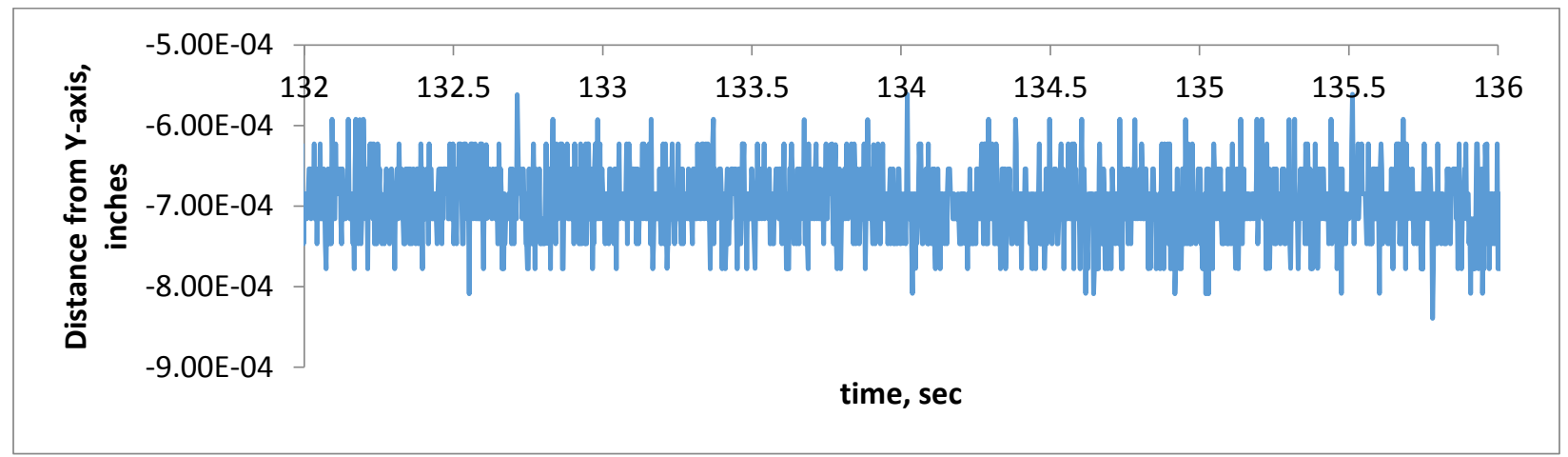

Figure 7: New Y-Intercept as a function of time, ti. Negative is towards the south horizontal LVDT and positive is towards the north horizontal LVDT.

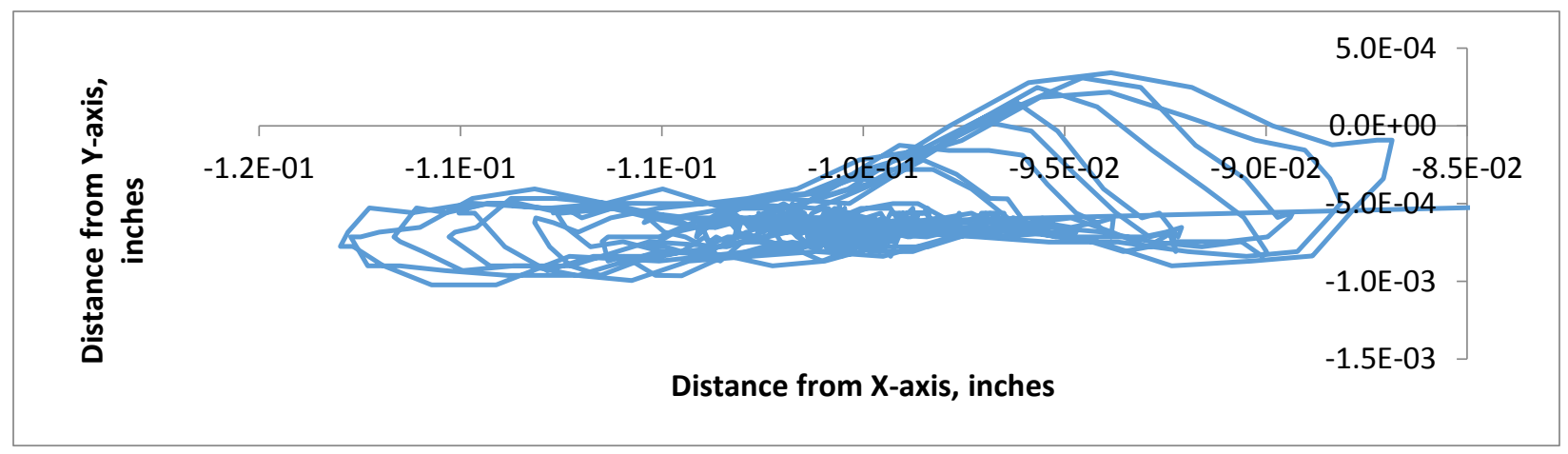

Figure 8: Changing $X \& Y$ Intercept as a function of time, ti. 


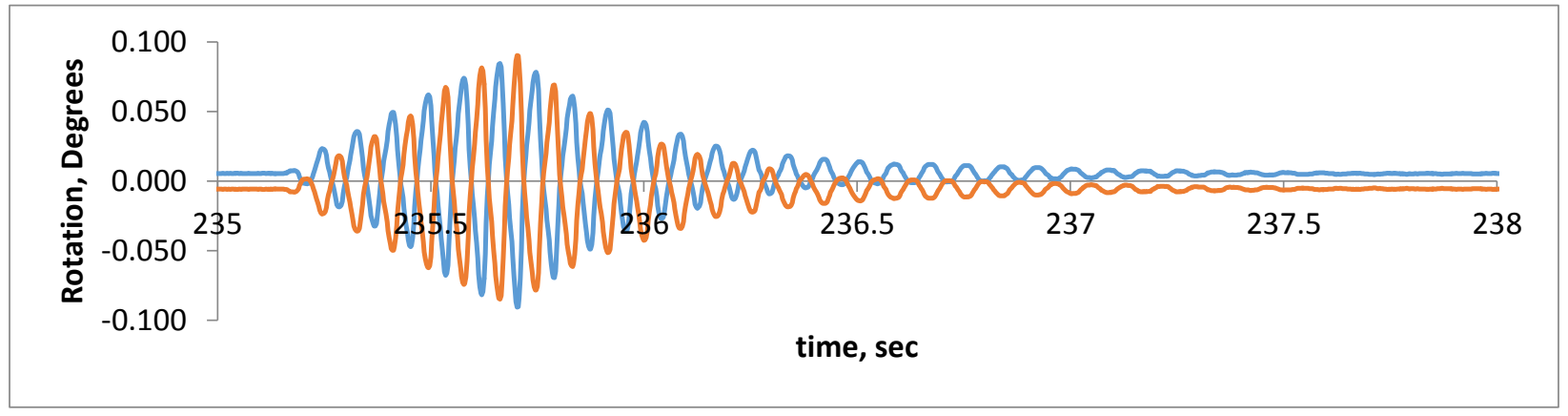

Figure 9: Rotations in the North-South Direction.

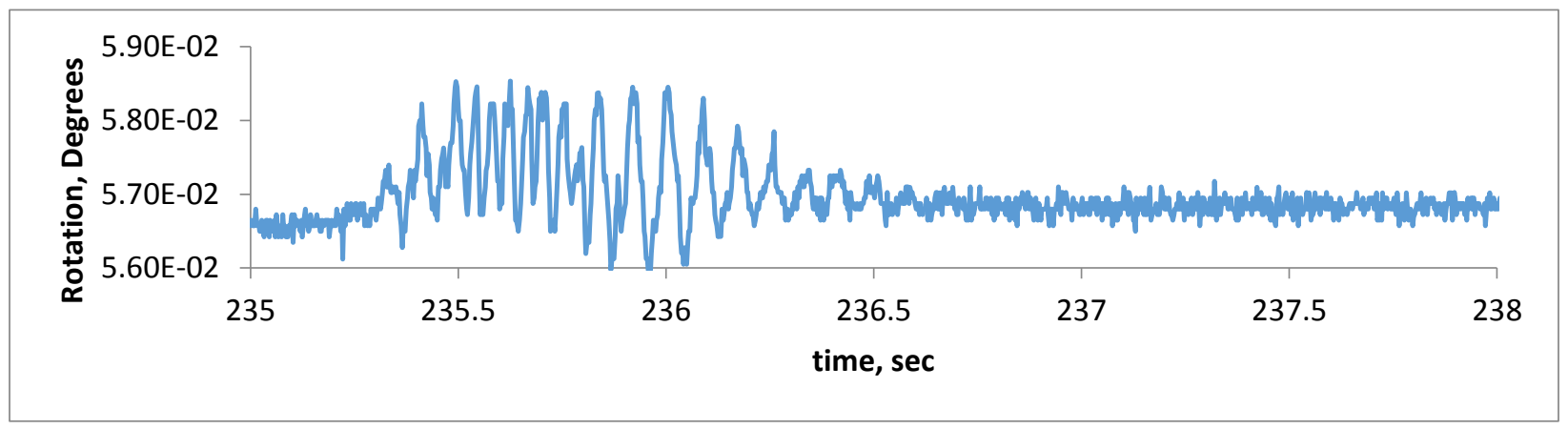

Figure 10: Rotations in the West Direction

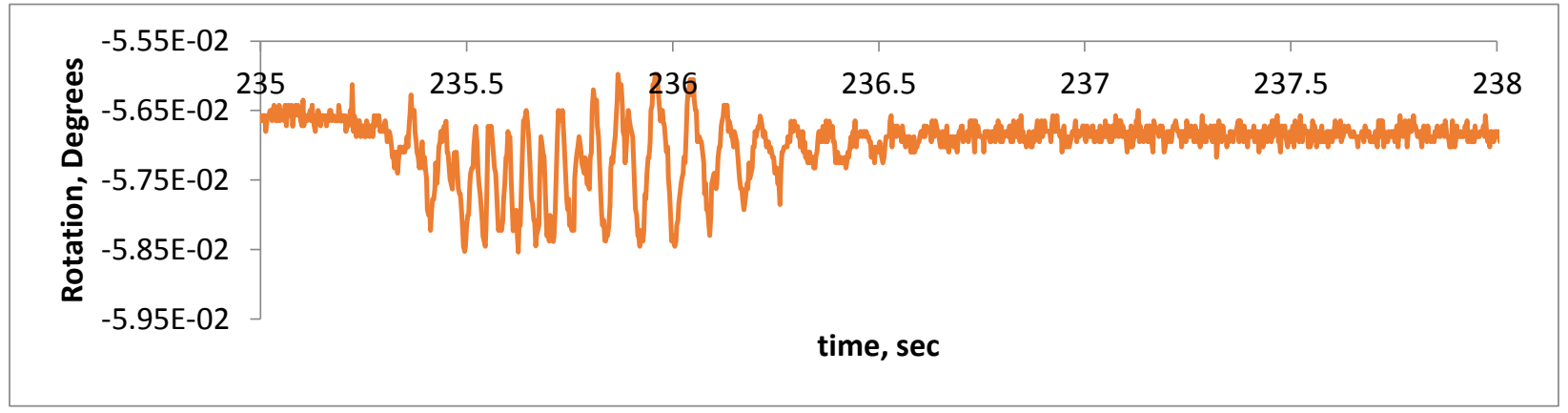

Figure 11: Rotations in the East Direction

SB 0.30g Horizontal Rotations and New X and Y intercepts

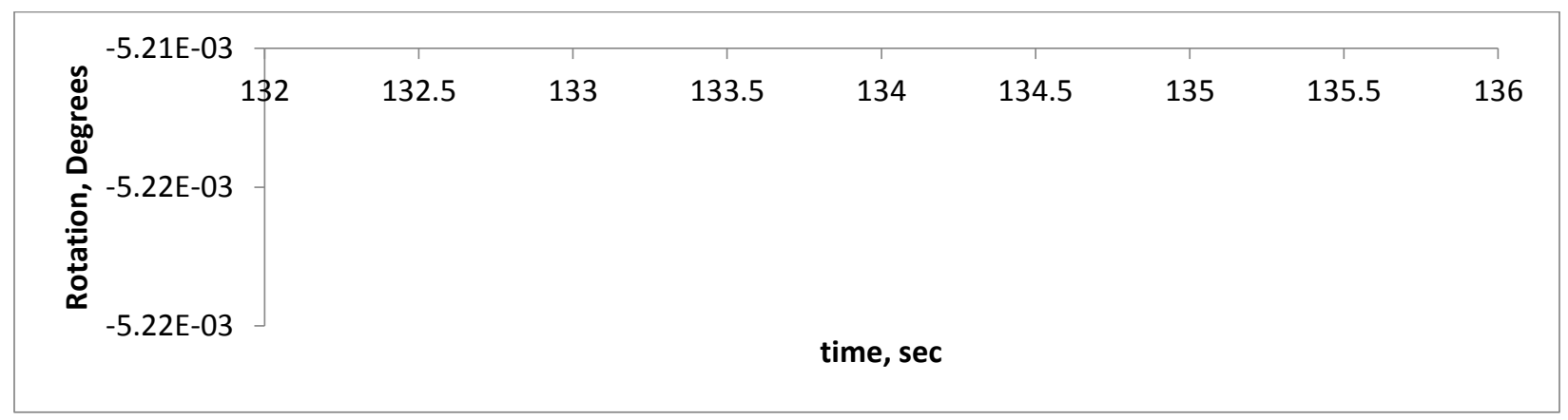

Figure 12: Horizontal North-South Rotations. 


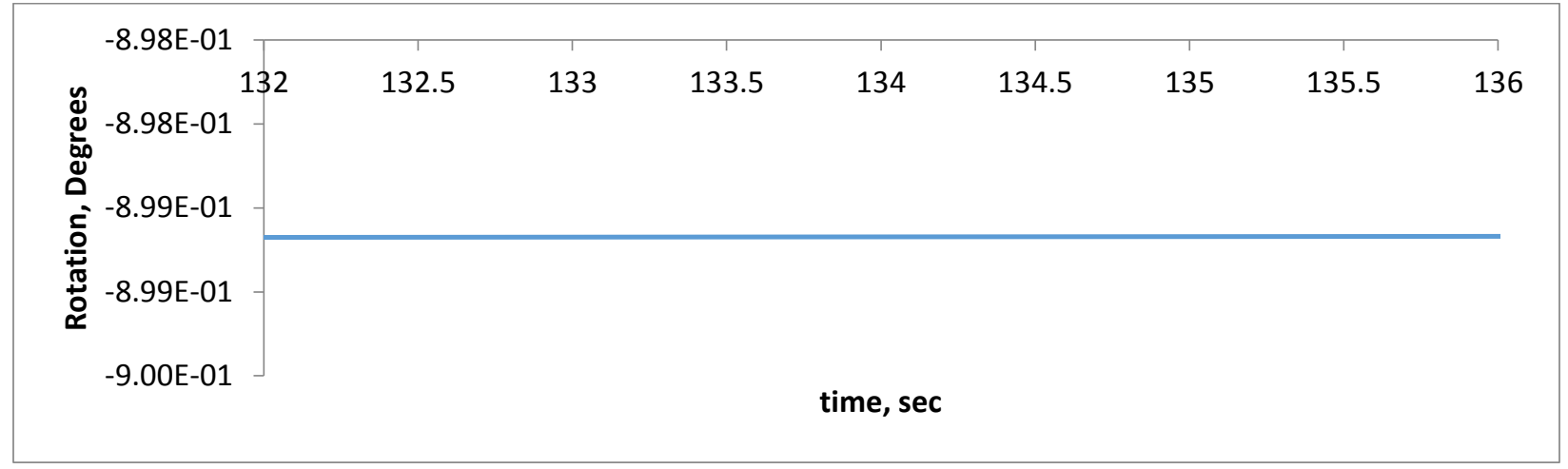

Figure 13: Horizontal East-West Rotations.

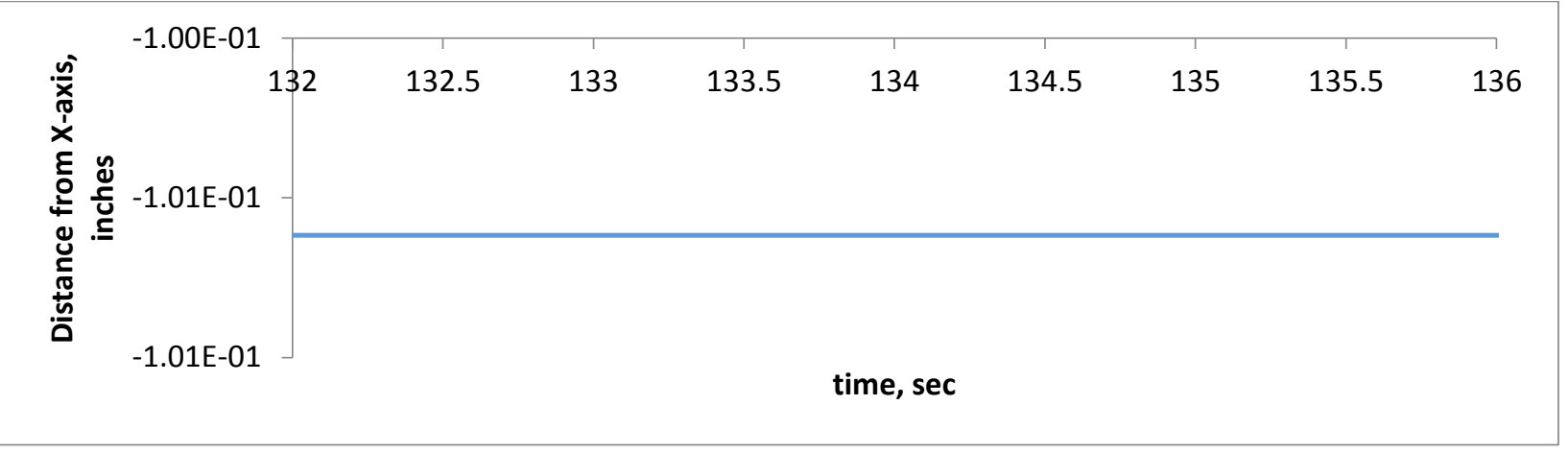

Figure 14: New X-Intercept as a function of time, ti. Negative is towards the east horizontal LVDT and positive is towards the west horizontal LVDT.

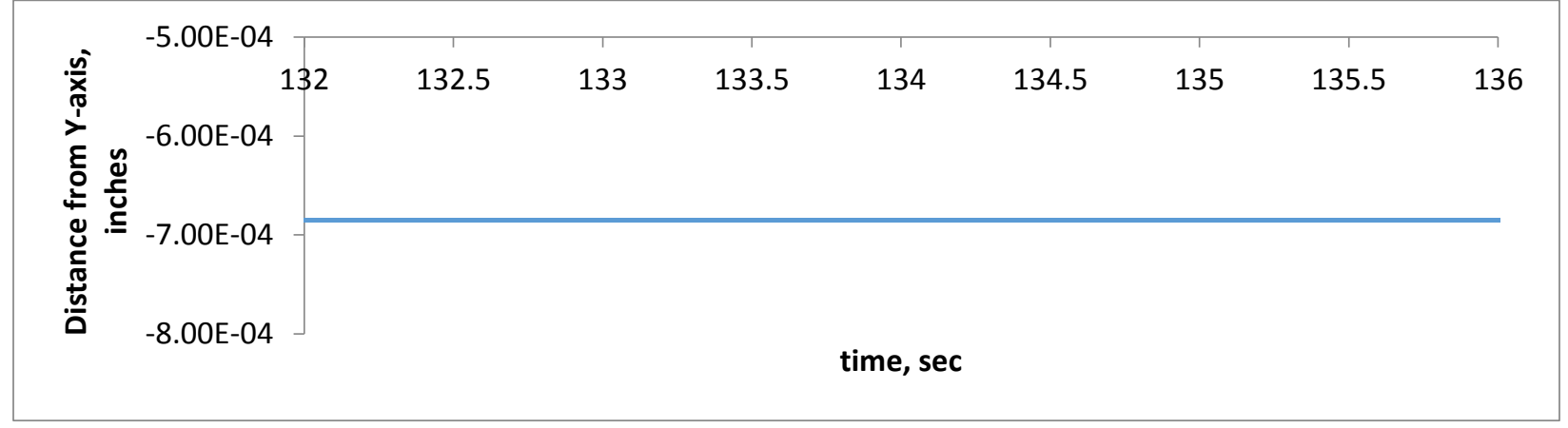

Figure 15: New Y-Intercept as a function of time, ti. Negative is towards the south horizontal LVDT and positive is towards the north horizontal LVDT.

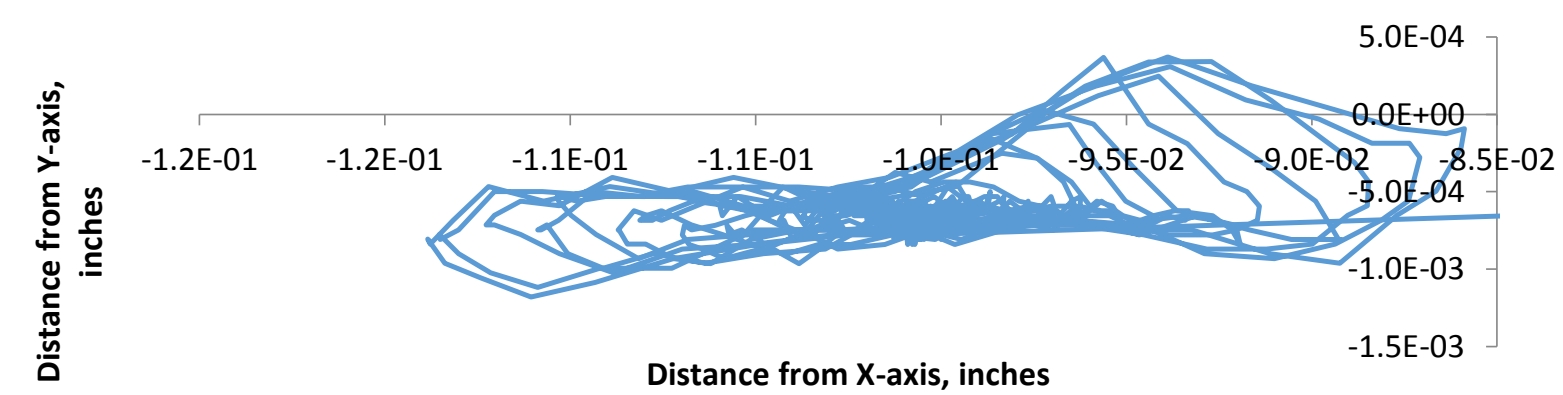

Figure 16: Changing X \& Y Intercept as a function of time, ti. 


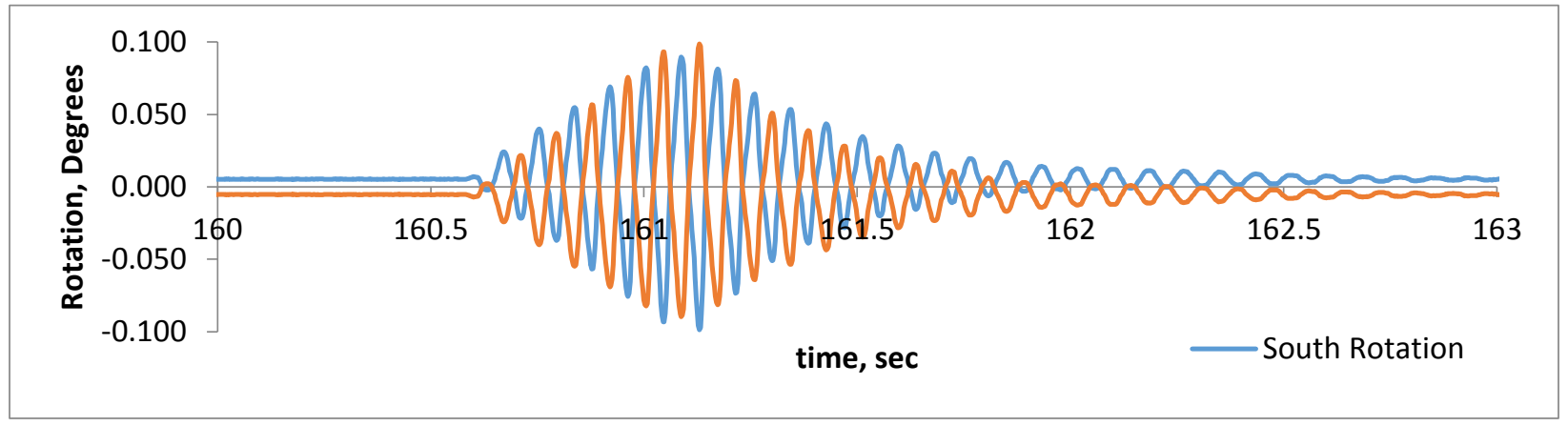

Figure 17: Rotations in the North-South Direction.

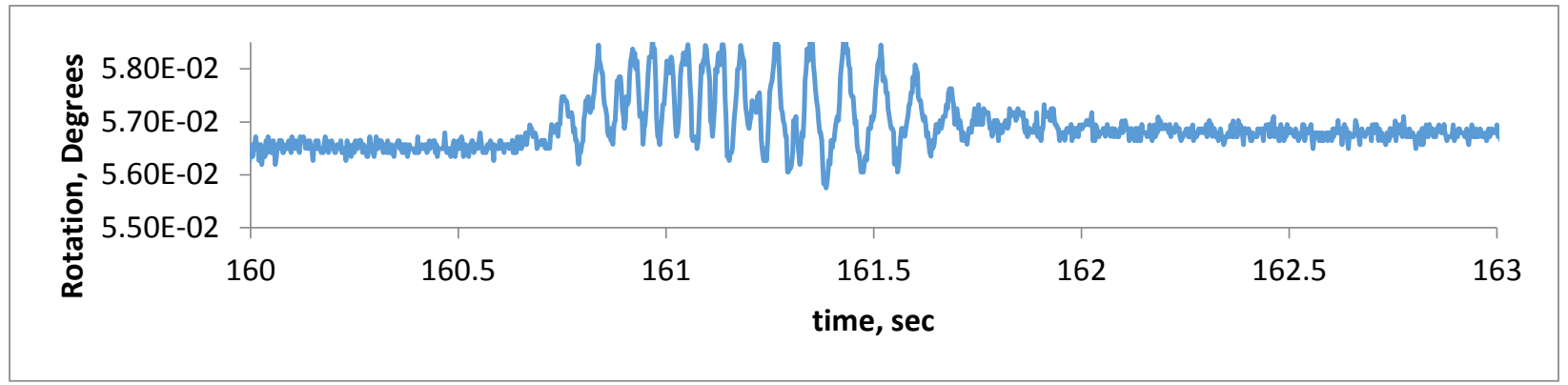

Figure 18: Rotations in the West Direction

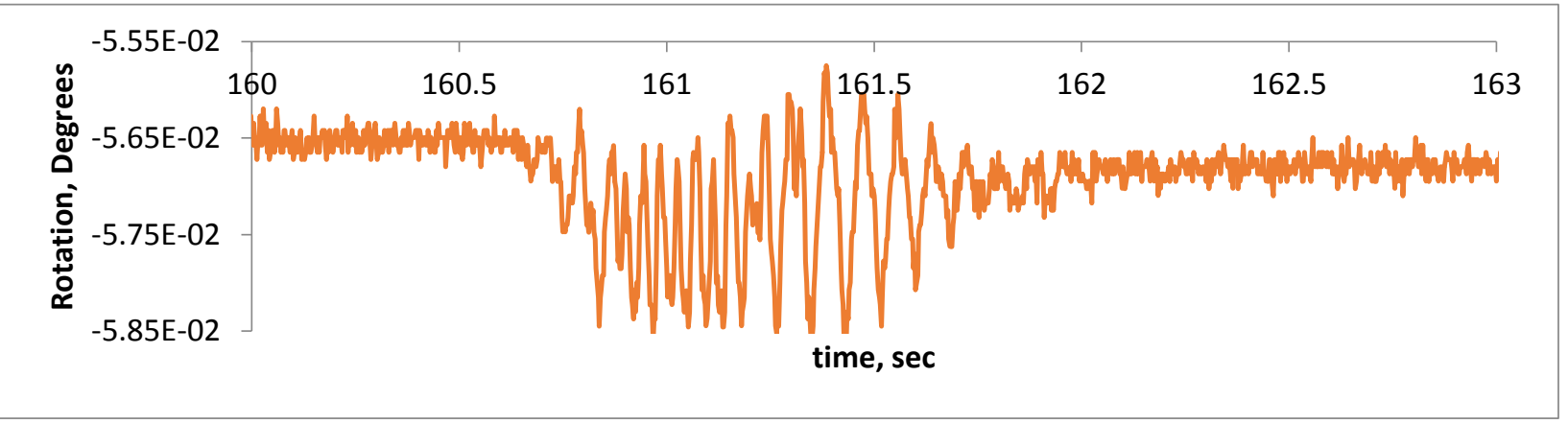

Figure 19: Rotations in the East Direction.

\section{SB $0.33 \mathrm{~g}$ Horizontal Rotations and New $X$ and $Y$ intercepts}

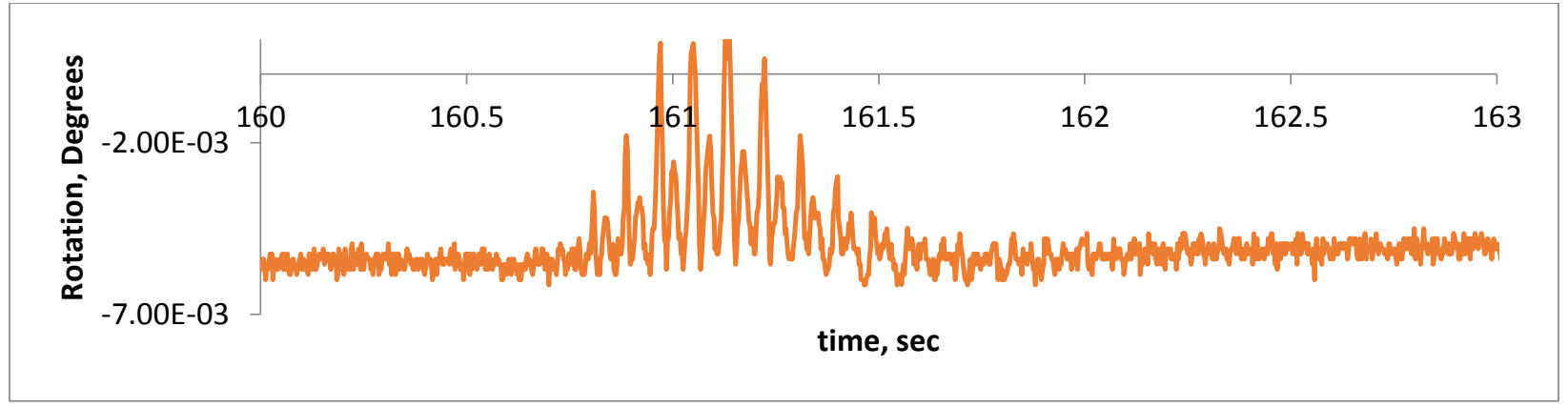

Figure 20: Horizontal North-South Rotations. 


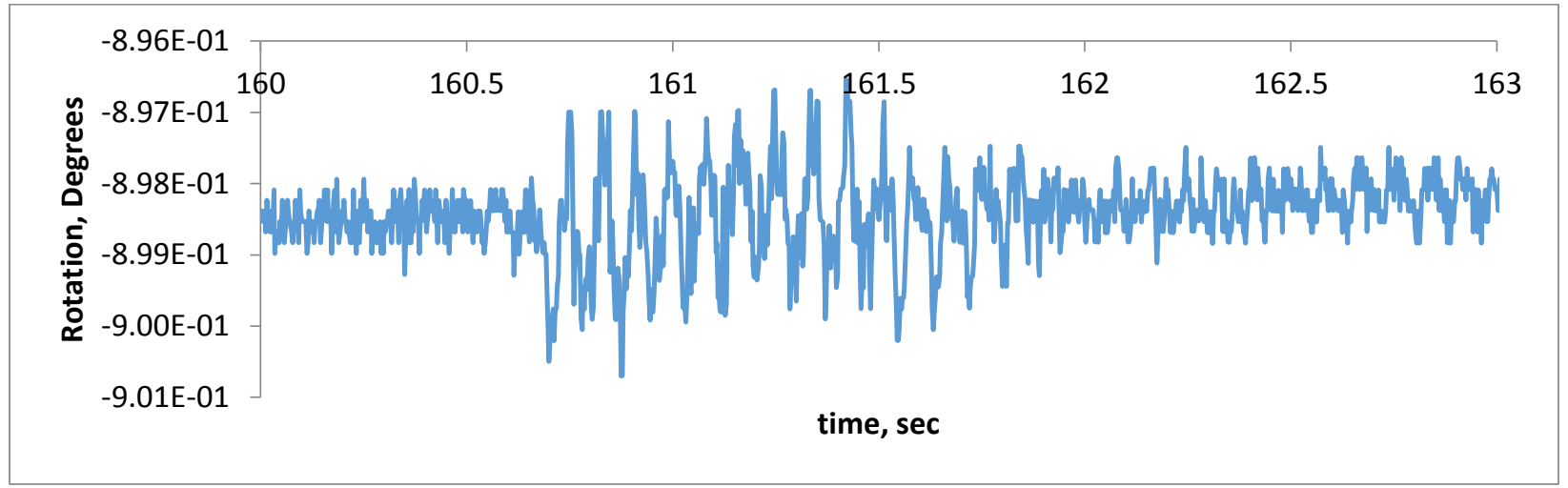

Figure 21: Horizontal East-West Rotations.

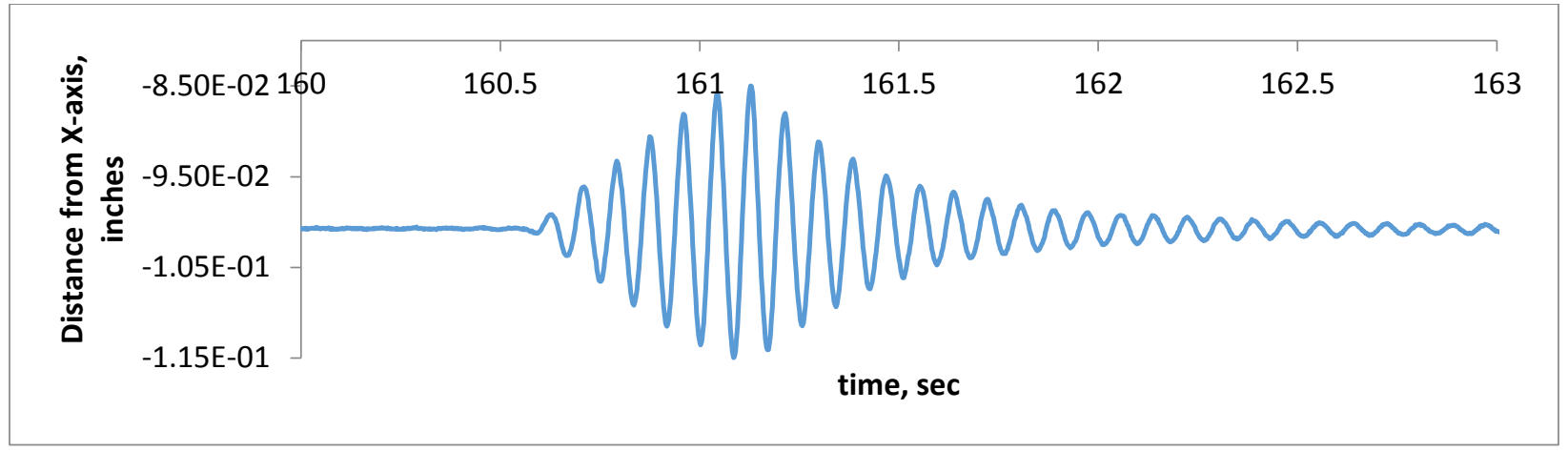

Figure 22: New X-Intercept as a function of time, ti. Negative is towards the east horizontal LVDT and positive is towards the west horizontal LVDT.

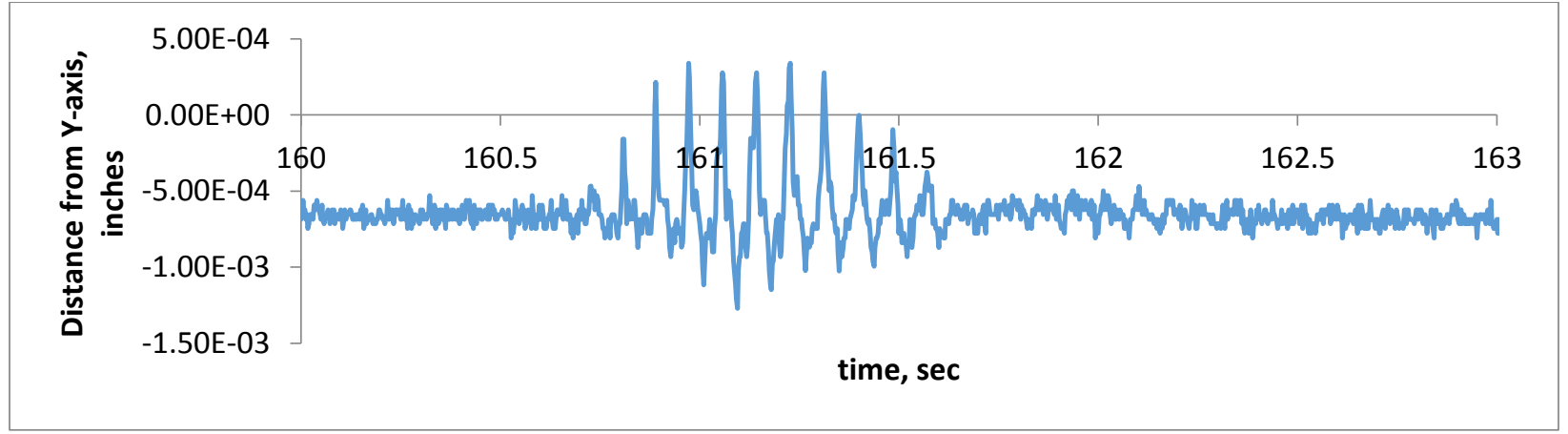

Figure 23: New Y-Intercept as a function of time, ti. Negative is towards the south horizontal LVDT and positive is towards the north horizontal LVDT.

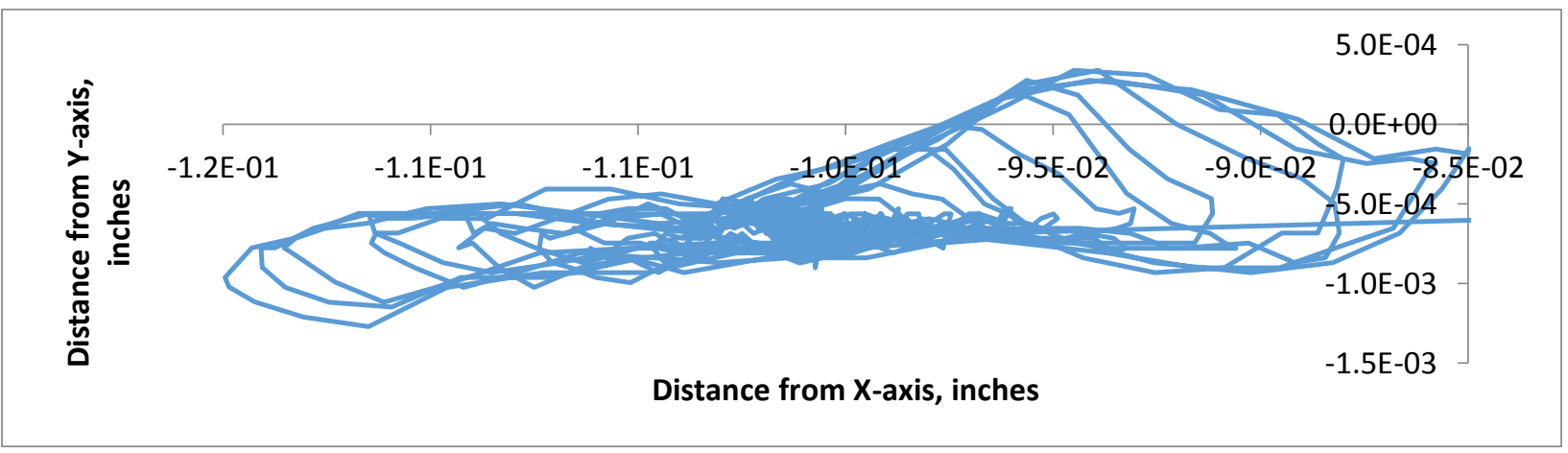

Figure 24: Changing X \& Y Intercept as a function of time, ti. 


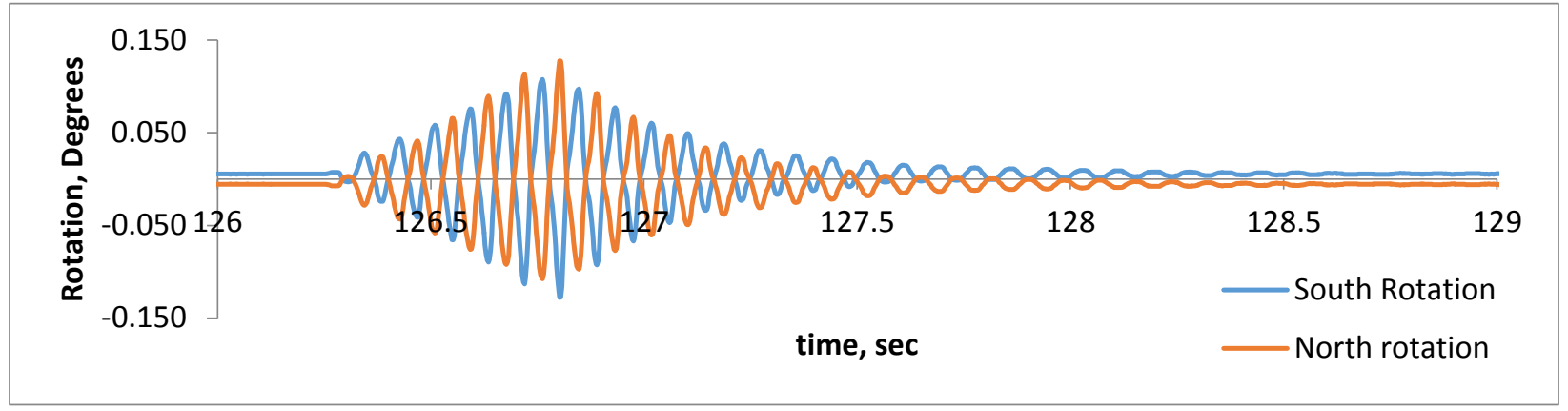

Figure 25: Rotations in the North-South Direction.

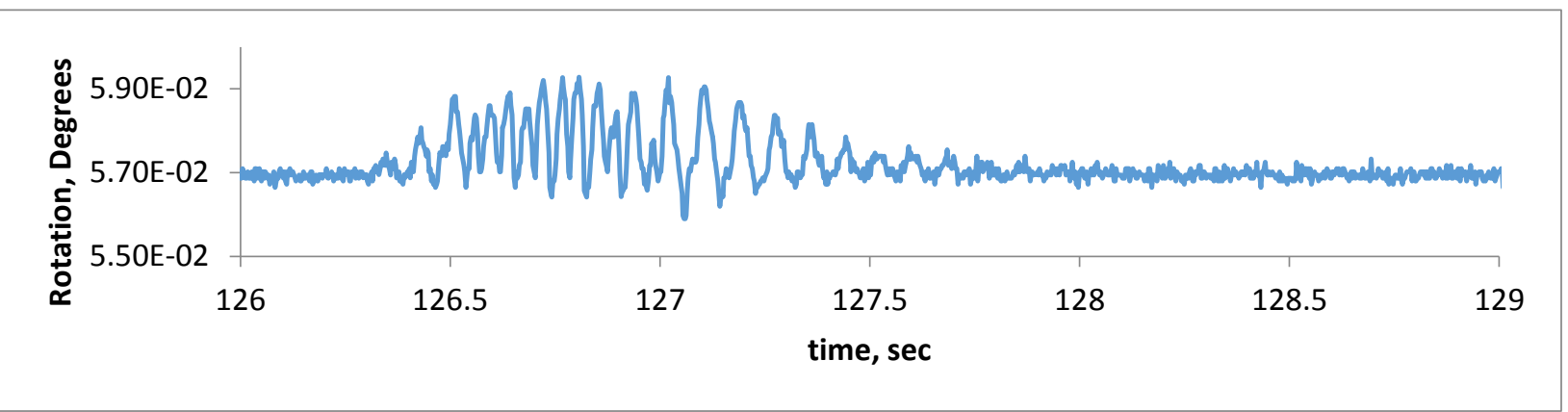

Figure 26: Rotations in the West Direction

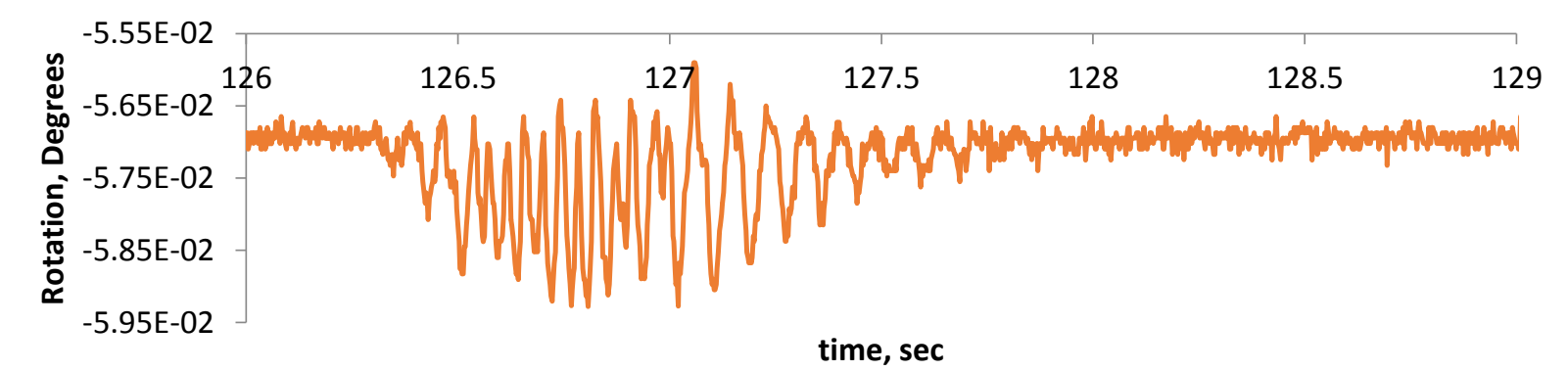

Figure 27: Rotations in the East Direction.

SB 0.38g: Horizontal Rotations and New X and Y intercepts

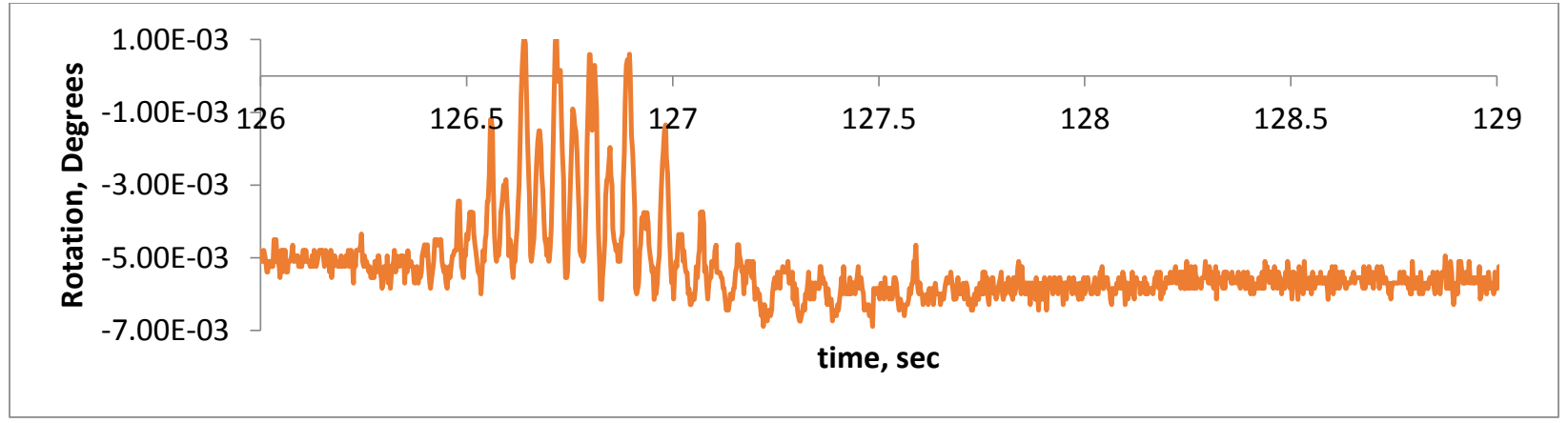

Figure 28: Horizontal North-South Rotations. 


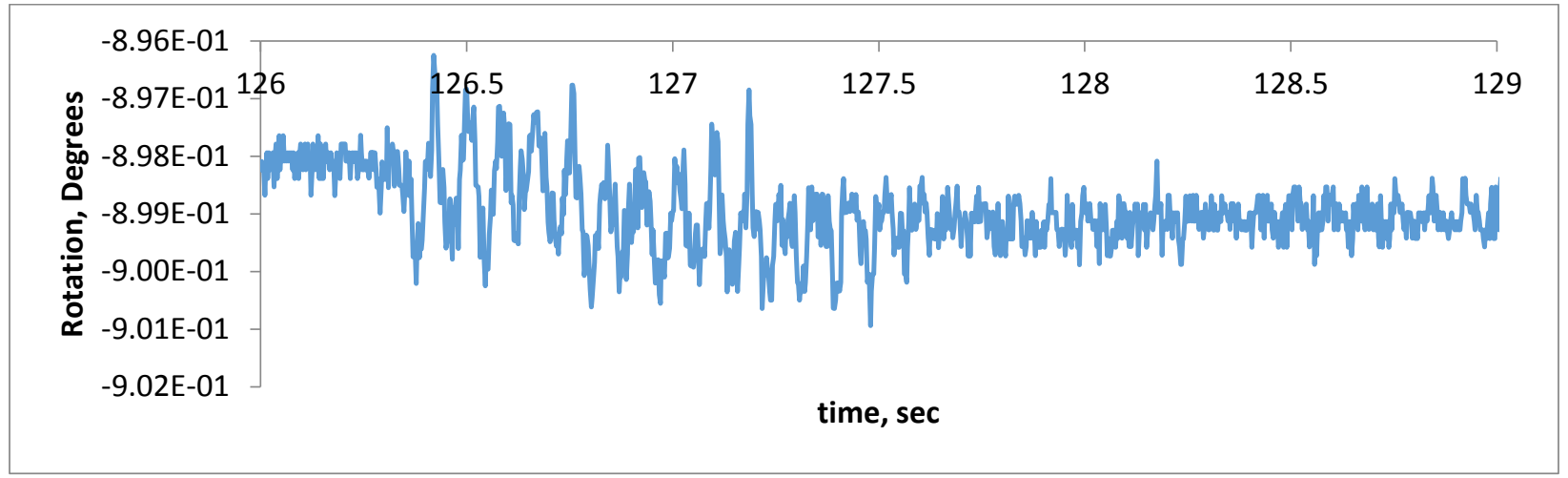

Figure 29: Horizontal East-West Rotations.

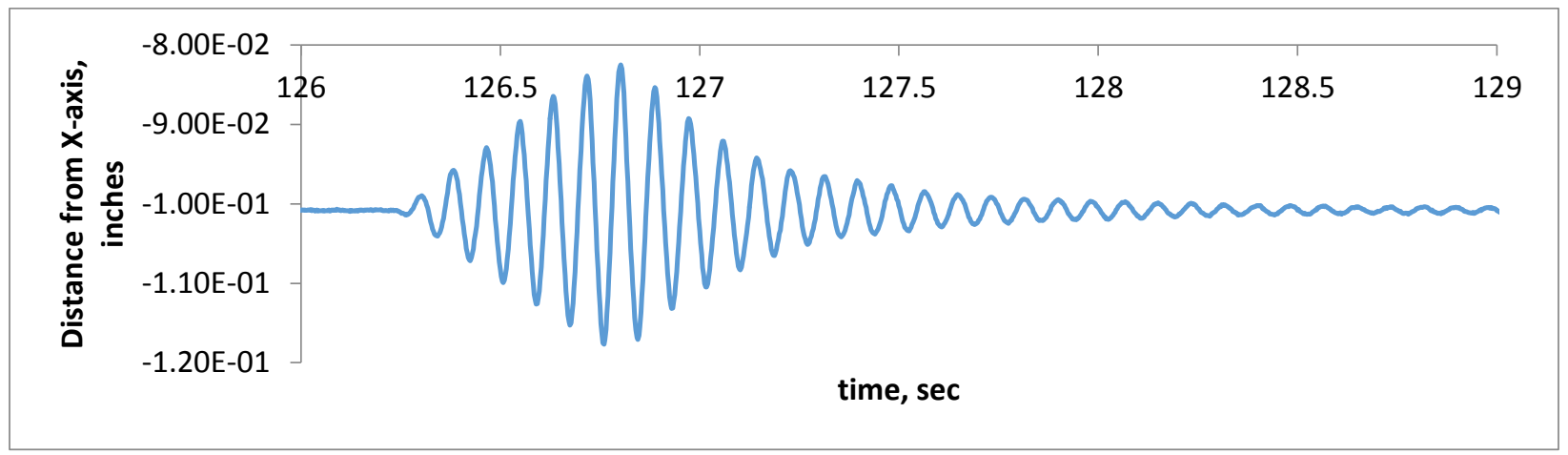

Figure 30: New X-Intercept as a function of time, ti. Negative is towards the east horizontal LVDT and positive is towards the west horizontal LVDT.

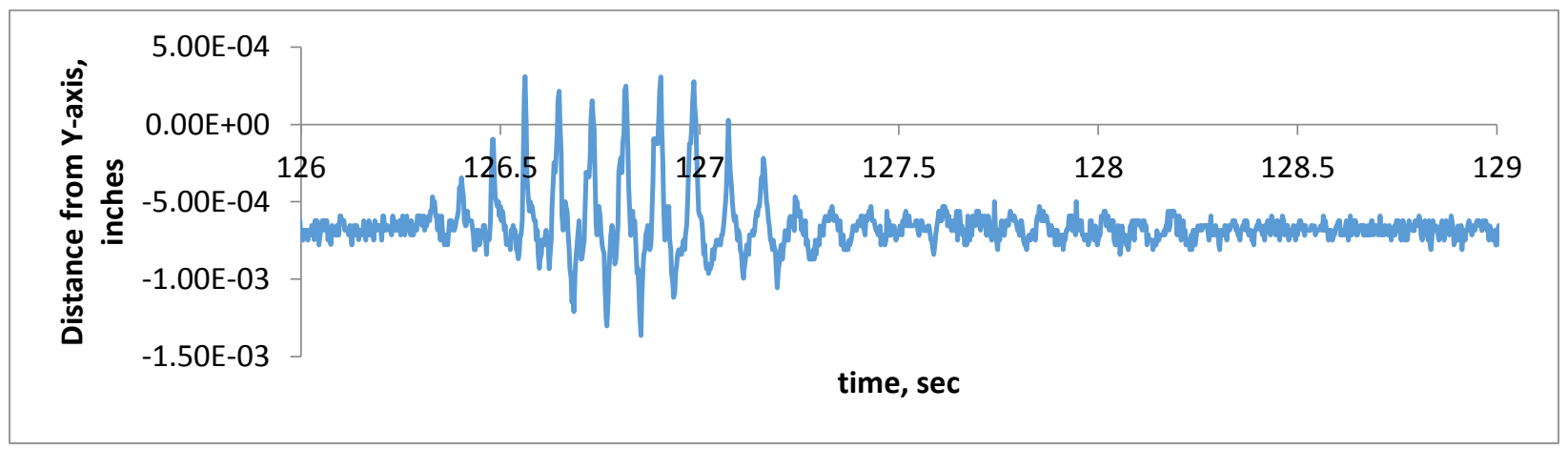

Figure 31: New Y-Intercept as a function of time, ti. Negative is towards the south horizontal LVDT and positive is towards the north horizontal LVDT.

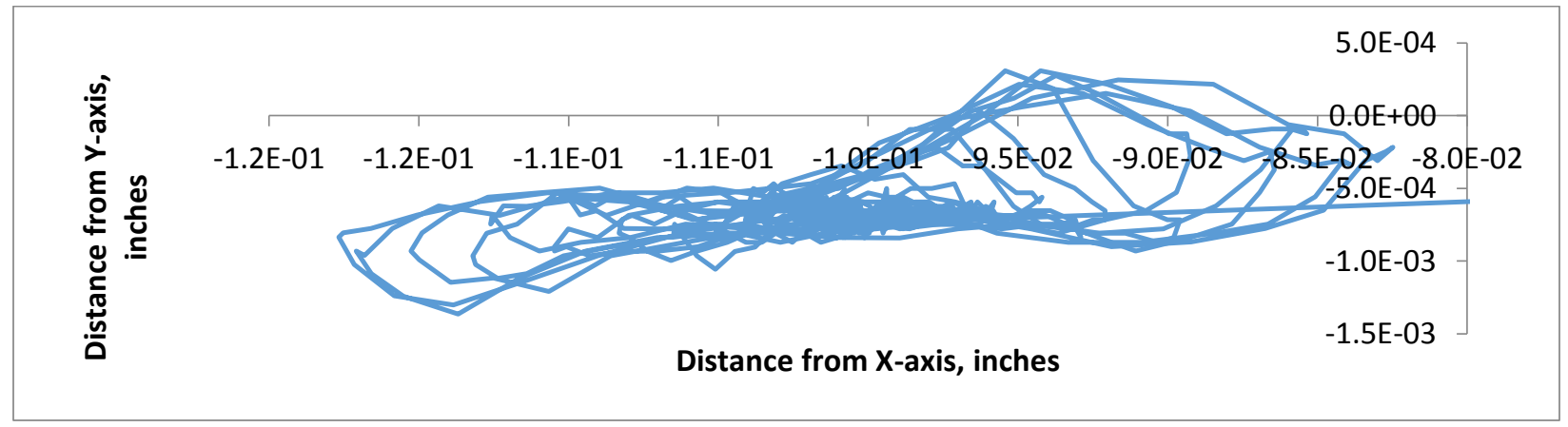

Figure 32: Changing $X \& Y$ Intercept as a function of time, ti. 


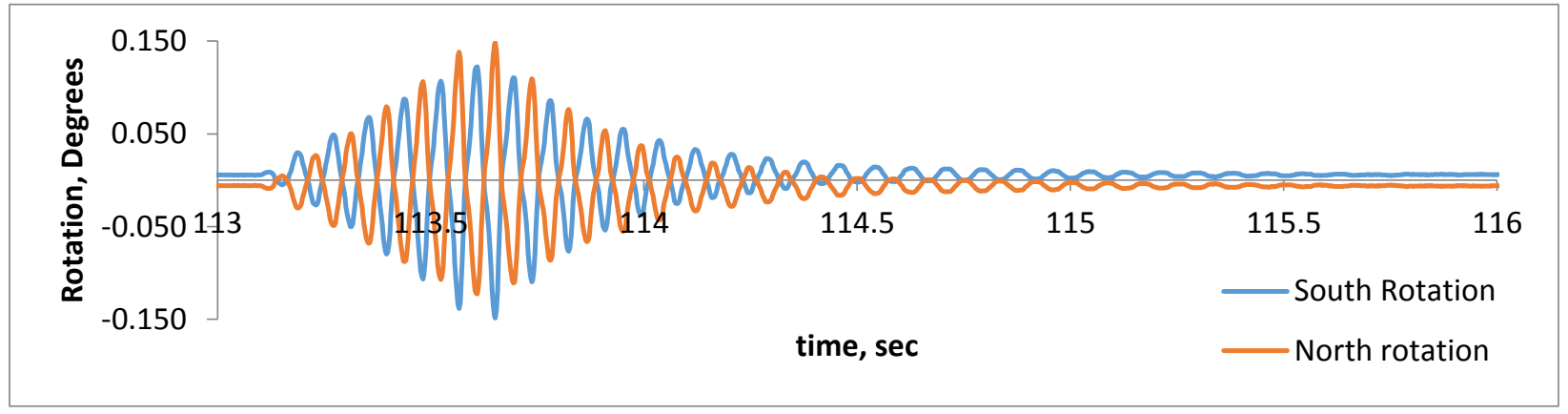

Figure 33: Rotations in the North-South Direction.

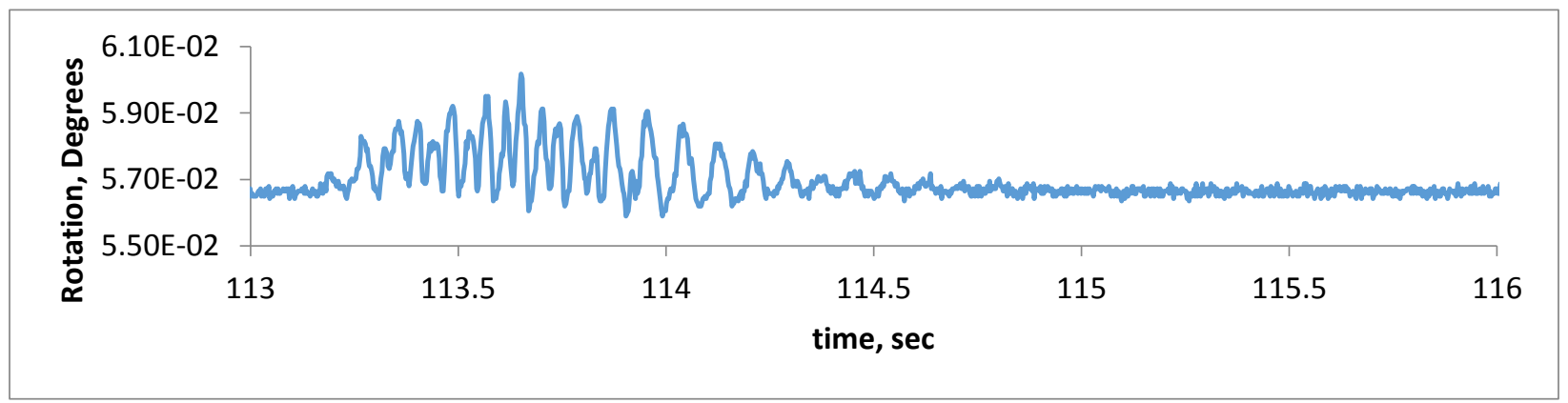

Figure 34: Rotations in the West Direction

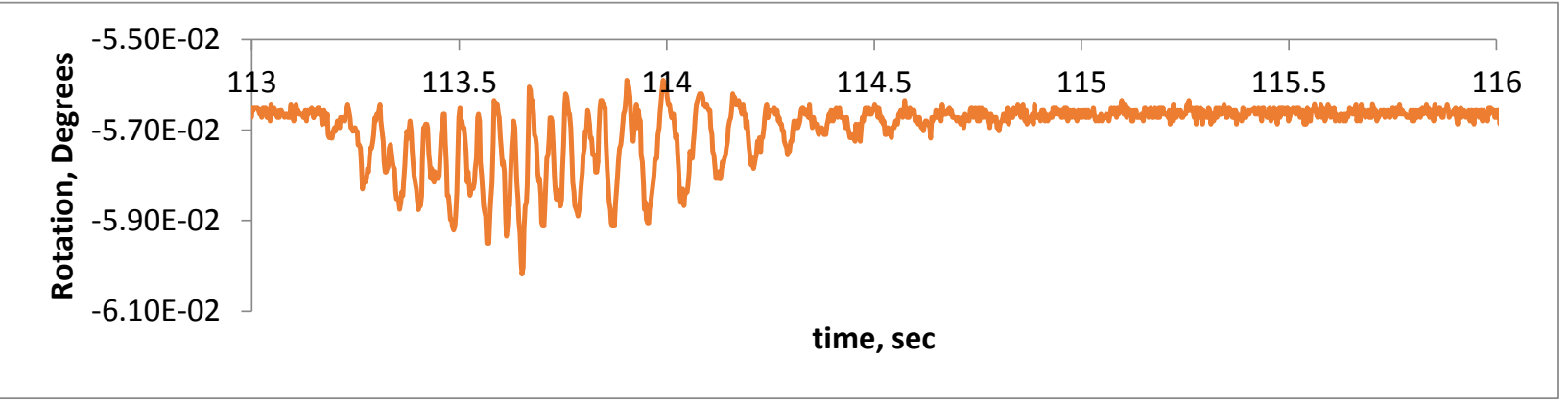

Figure 35: Rotations in the East Direction.

\section{SB 0.43g: Horizontal Rotations and New $X$ and $Y$ intercepts}

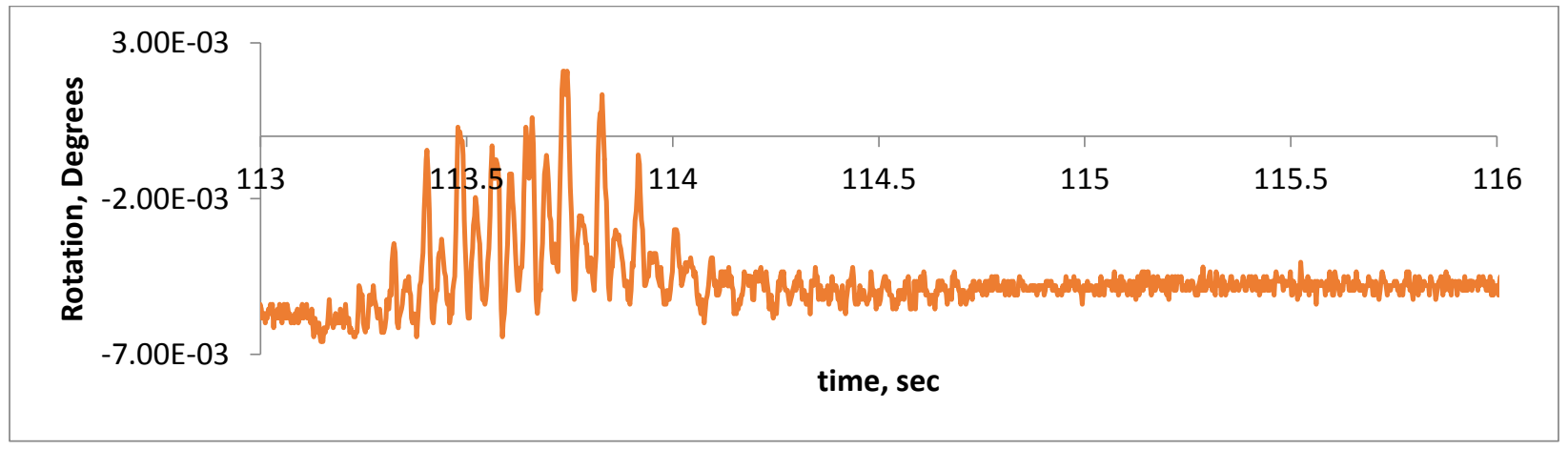

Figure 36: Horizontal North-South Rotations. 


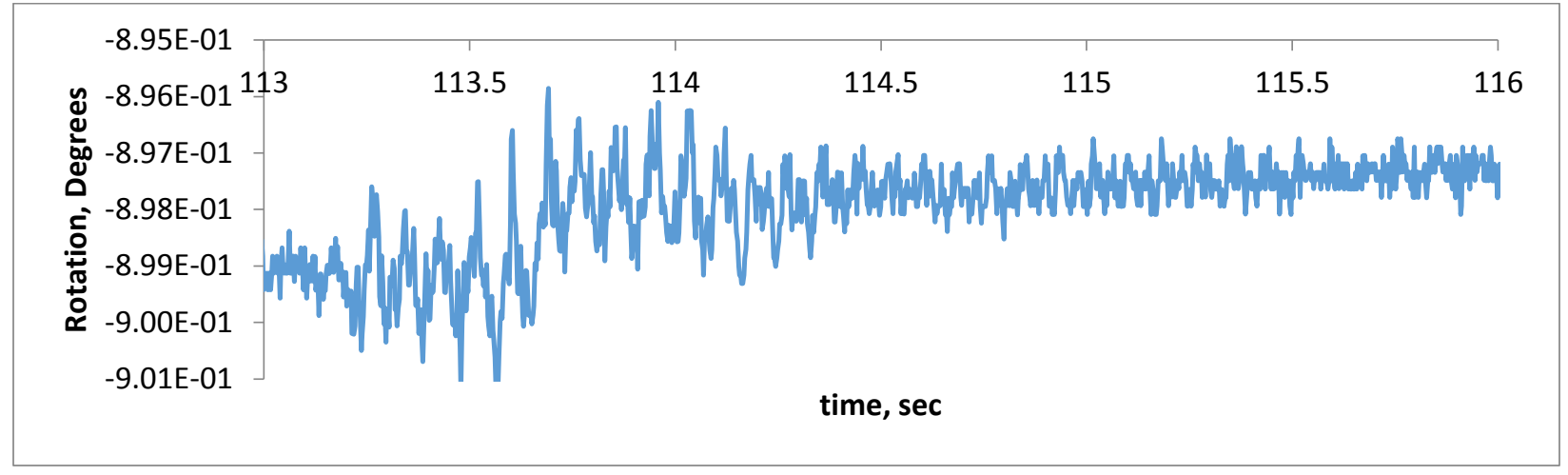

Figure 37: Horizontal East-West Rotations.

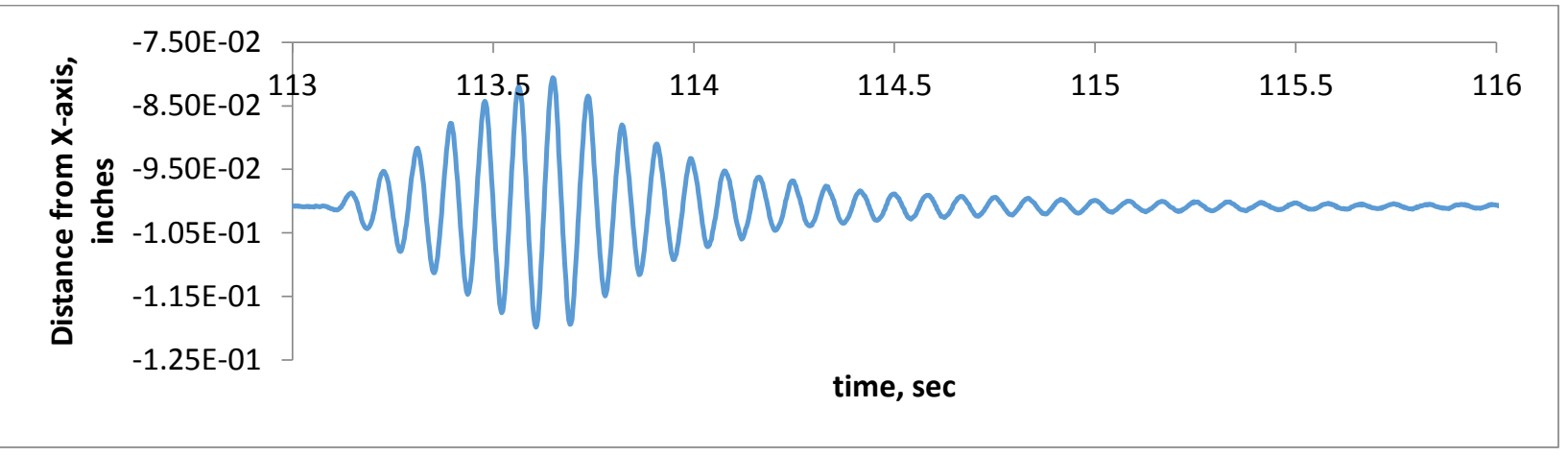

Figure 38: New X-Intercept as a function of time, ti. Negative is towards the east horizontal LVDT and positive is towards the west horizontal LVDT.

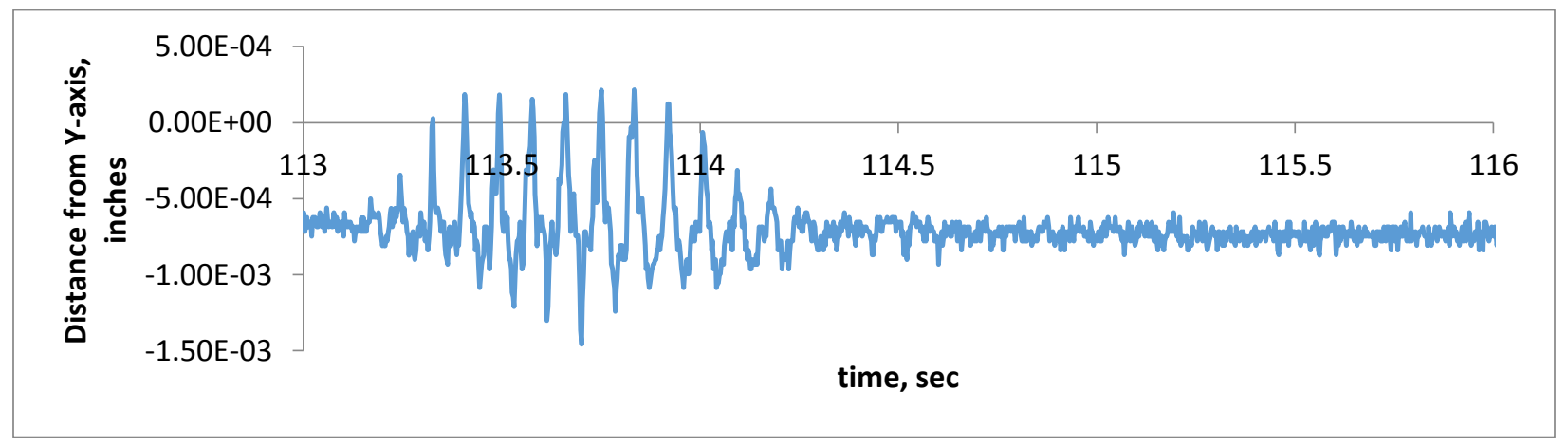

Figure 39: New Y-Intercept as a function of time, ti. Negative is towards the south horizontal LVDT and positive is towards the north horizontal LVDT.

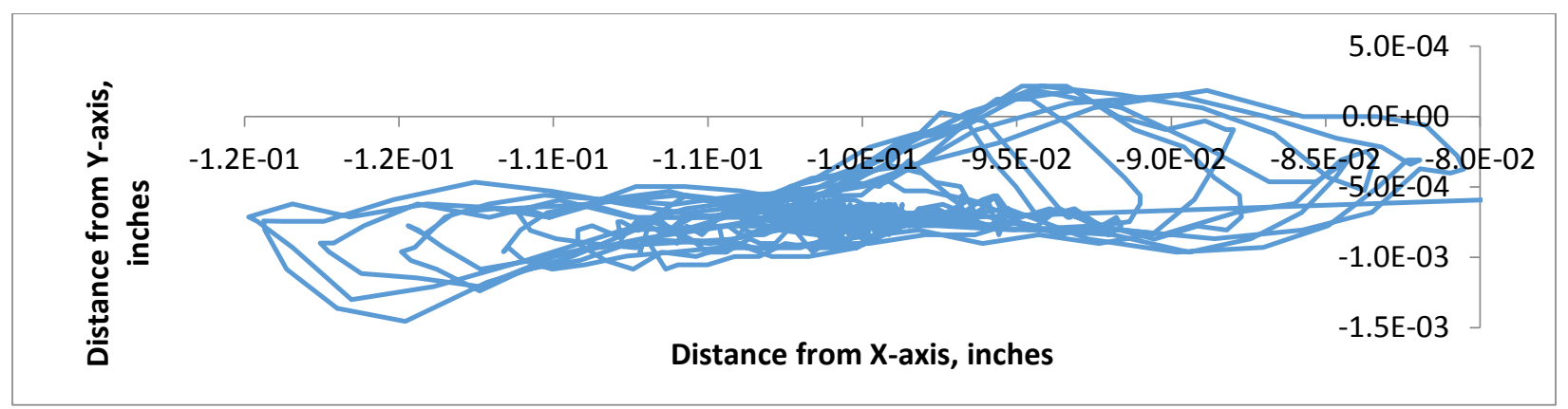

Figure 40: Changing $X \& Y$ Intercept as a function of time, ti. 


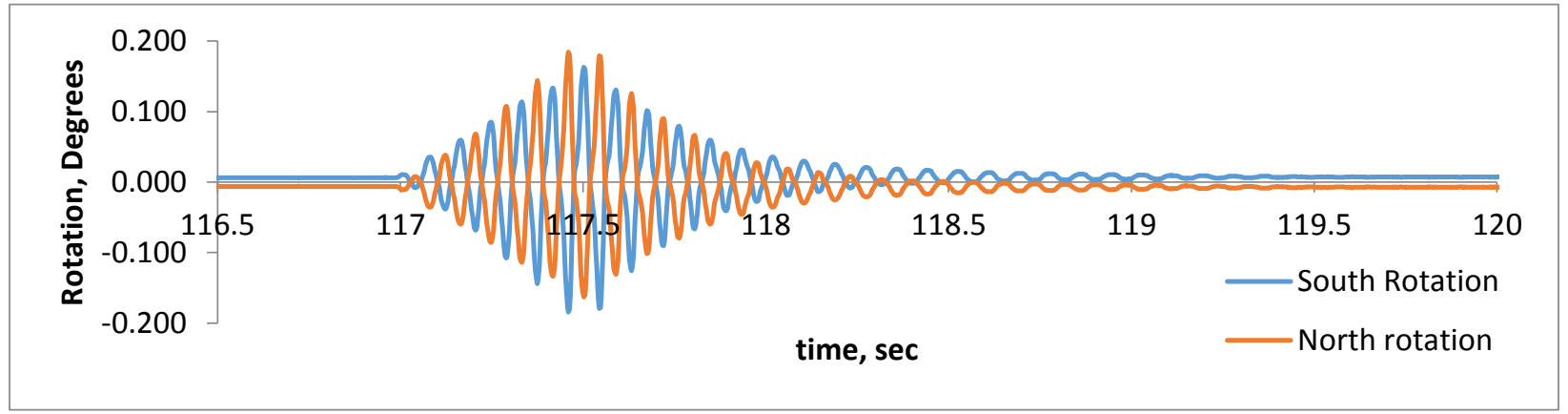

Figure 41: Rotations in the North-South Direction.

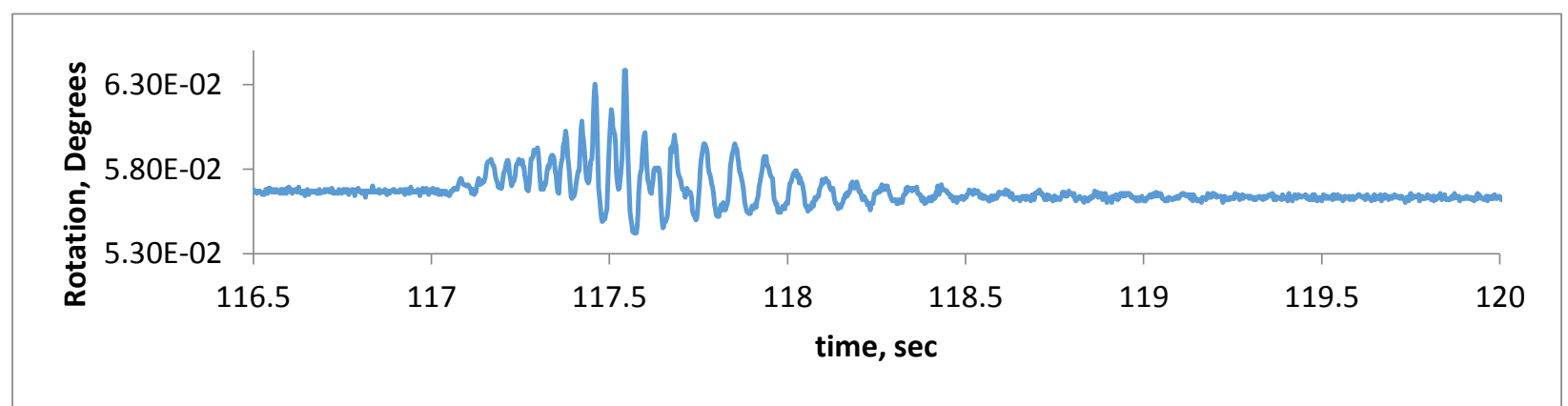

Figure 42: Rotations in the West Direction

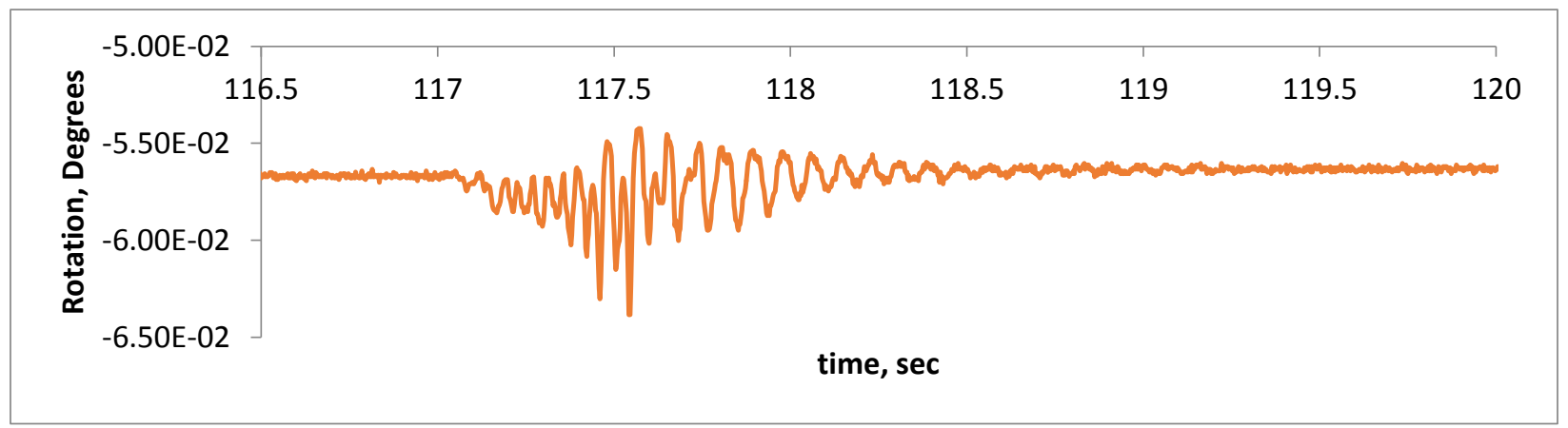

Figure 43: Rotations in the East Direction.

\section{SB 0.50g: Horizontal Rotations and New X and Y intercepts}

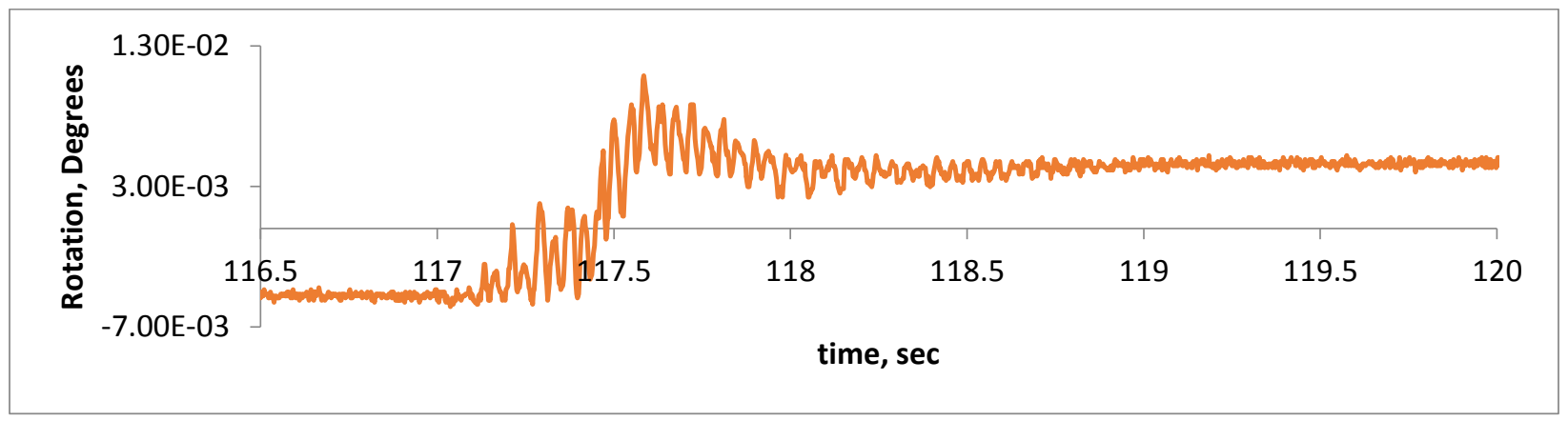

Figure 44: Horizontal North-South Rotations. 


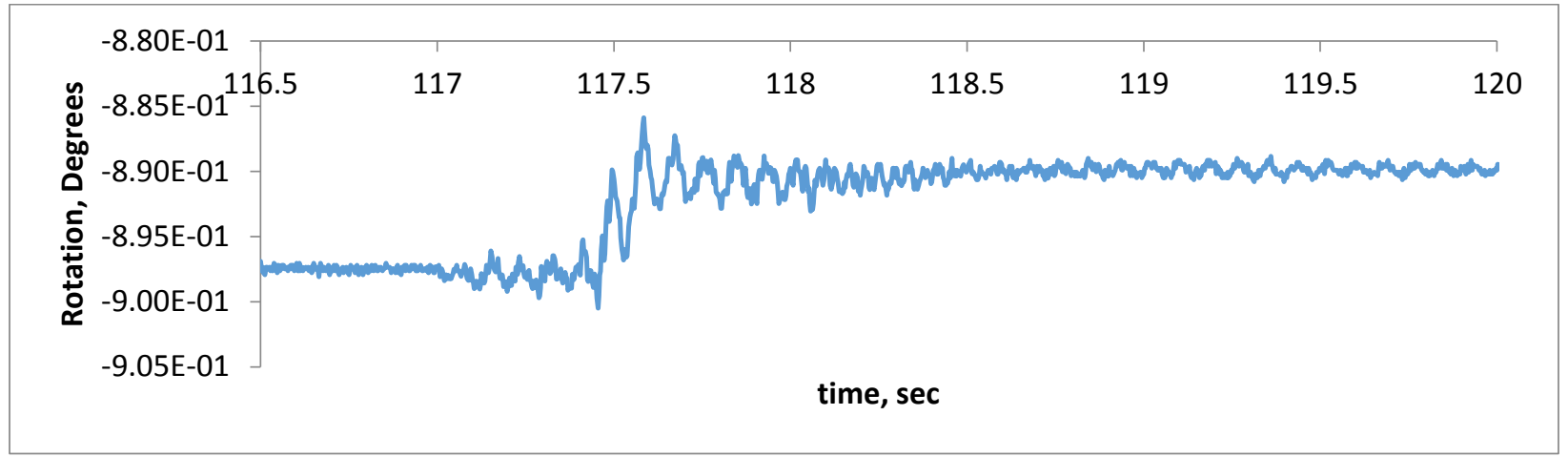

Figure 45: Horizontal East-West Rotations.

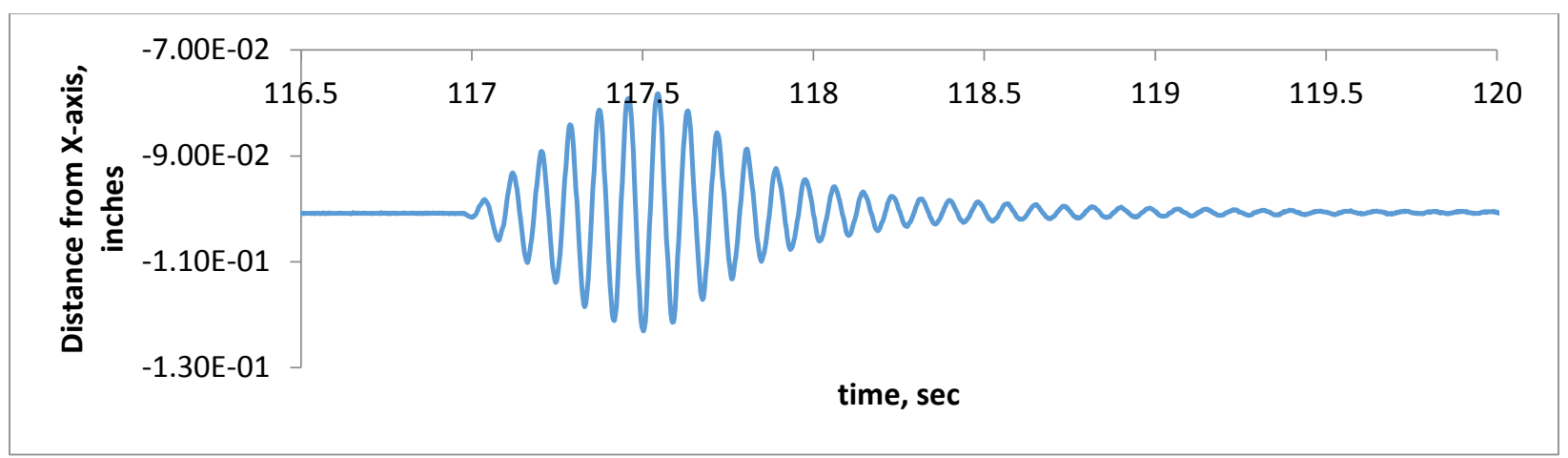

Figure 46: New X-Intercept as a function of time, ti. Negative is towards the east horizontal LVDT and positive is towards the west horizontal LVDT.

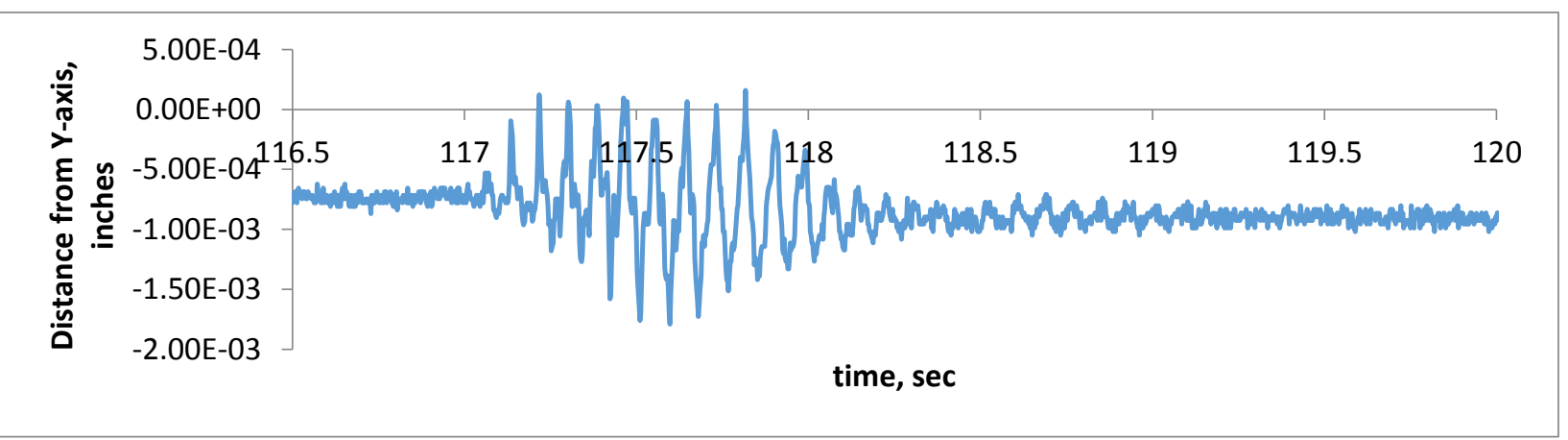

Figure 47: New Y-Intercept as a function of time, ti. Negative is towards the south horizontal LVDT and positive is towards the north horizontal LVDT.

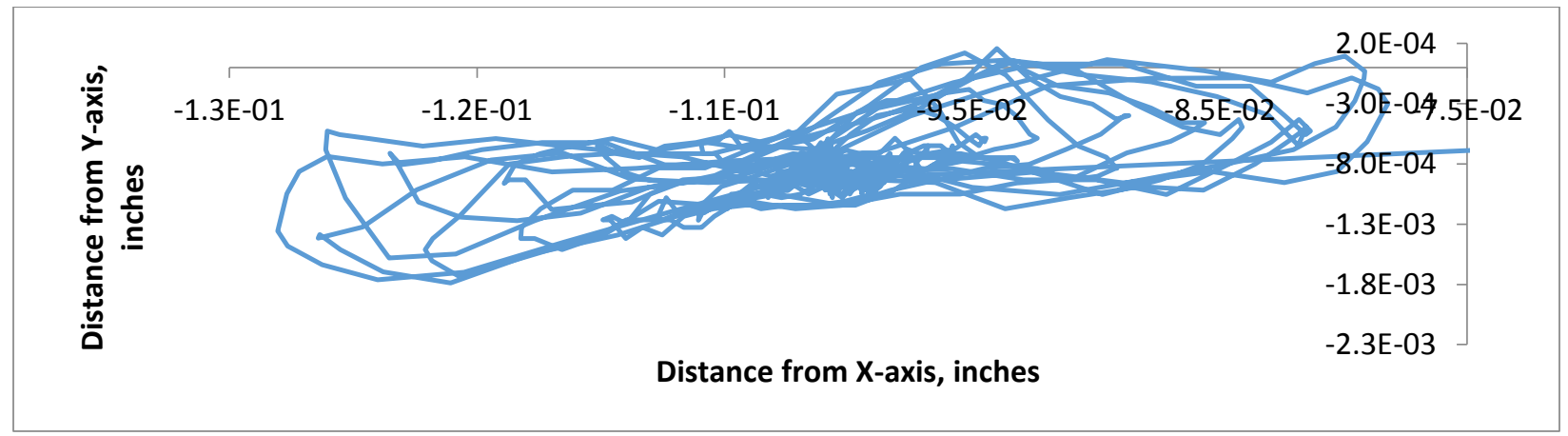

Figure 48: Changing X \& Y Intercept as a function of time, ti. 


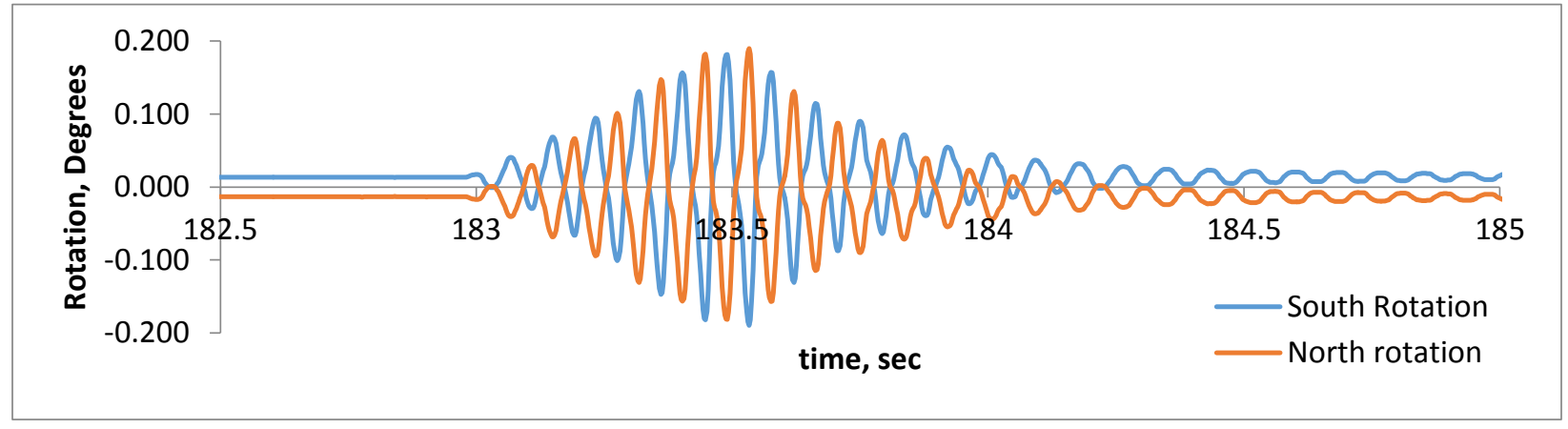

Figure 49: Rotations in the North-South Direction.

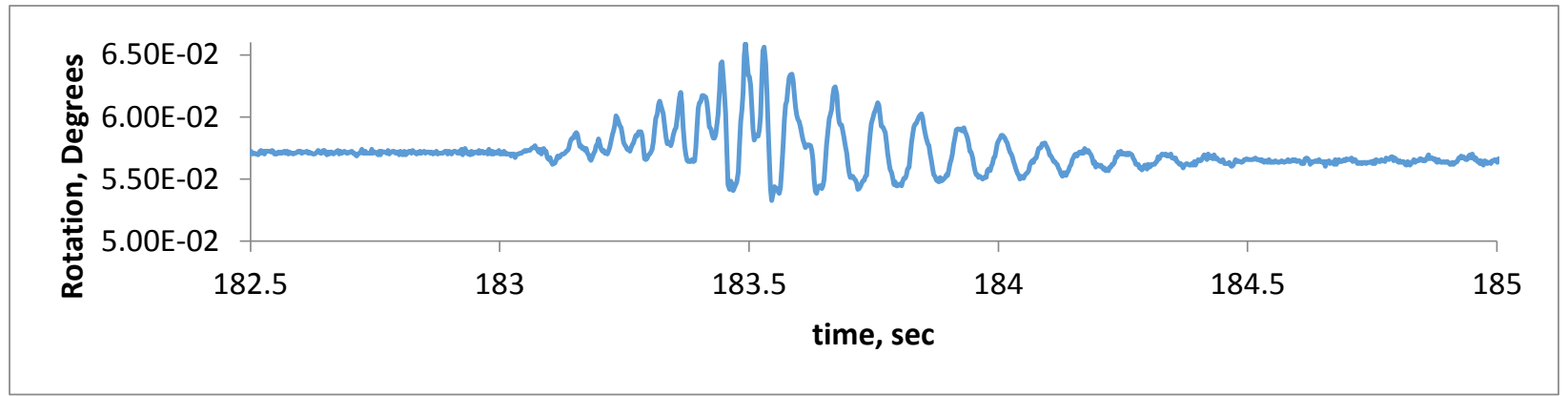

Figure 50: Rotations in the West Direction

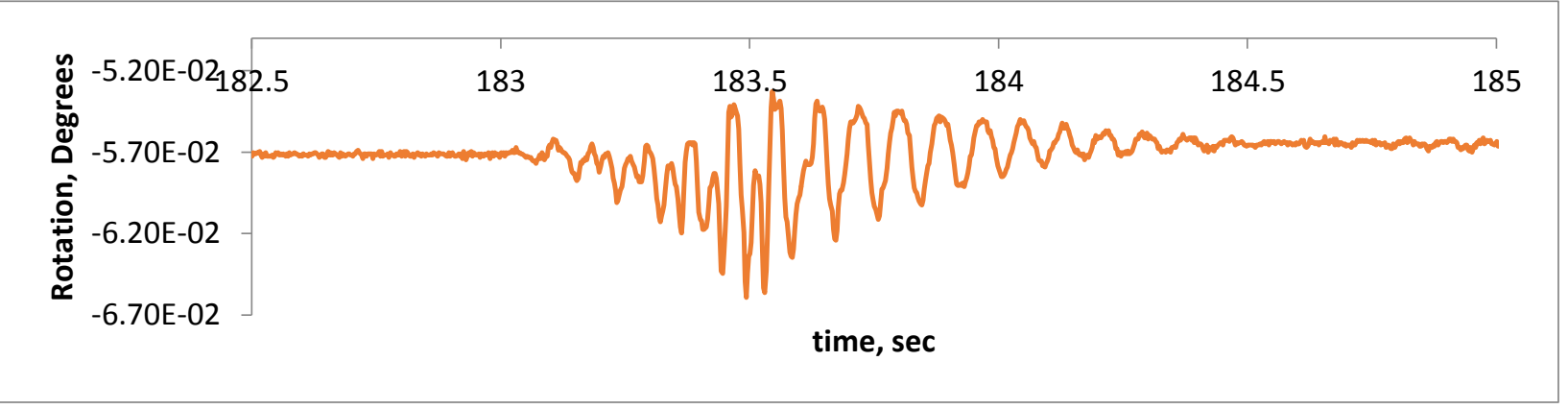

Figure 51: Rotations in the East Direction.

\section{SB $0.50 \mathrm{~g}$ Repeat: Horizontal Rotations and New $X$ and $Y$ intercepts}

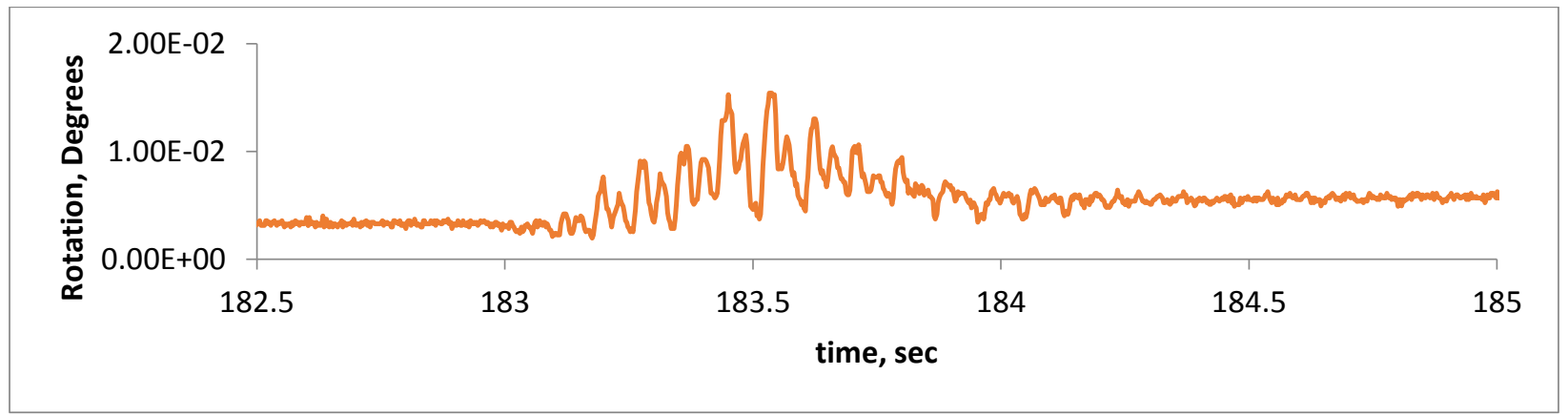

Figure 52: Horizontal North-South Rotations. 


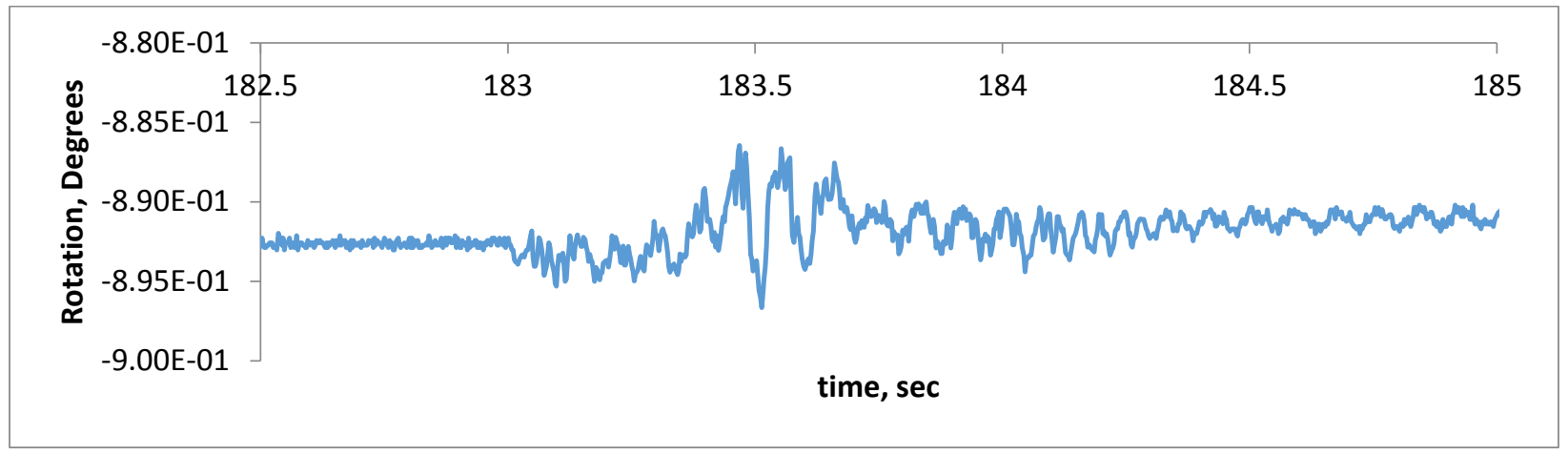

Figure 53: Horizontal East-West Rotations.

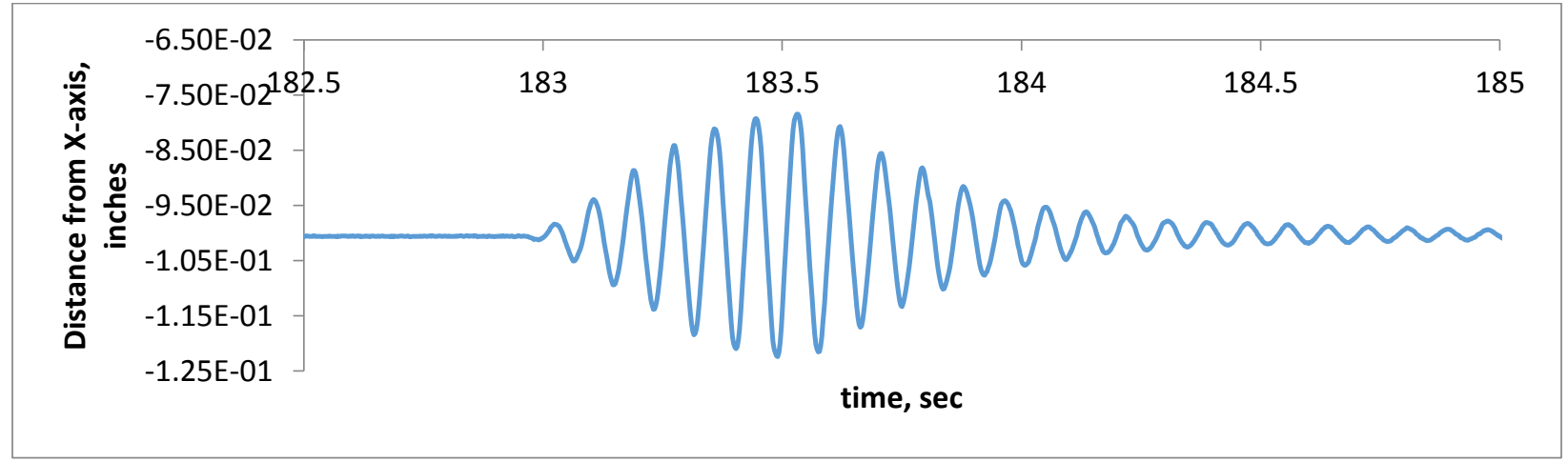

Figure 54: New X-Intercept as a function of time, ti. Negative is towards the east horizontal LVDT and positive is towards the west horizontal LVDT.

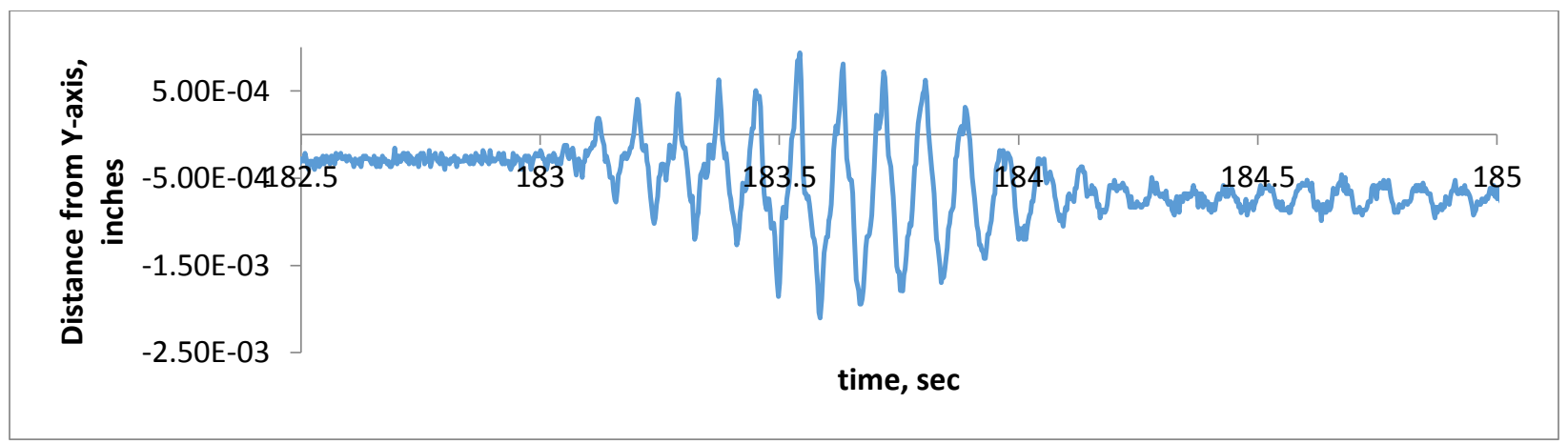

Figure 55: New Y-Intercept as a function of time, ti. Negative is towards the south horizontal LVDT and positive is towards the north horizontal LVDT.

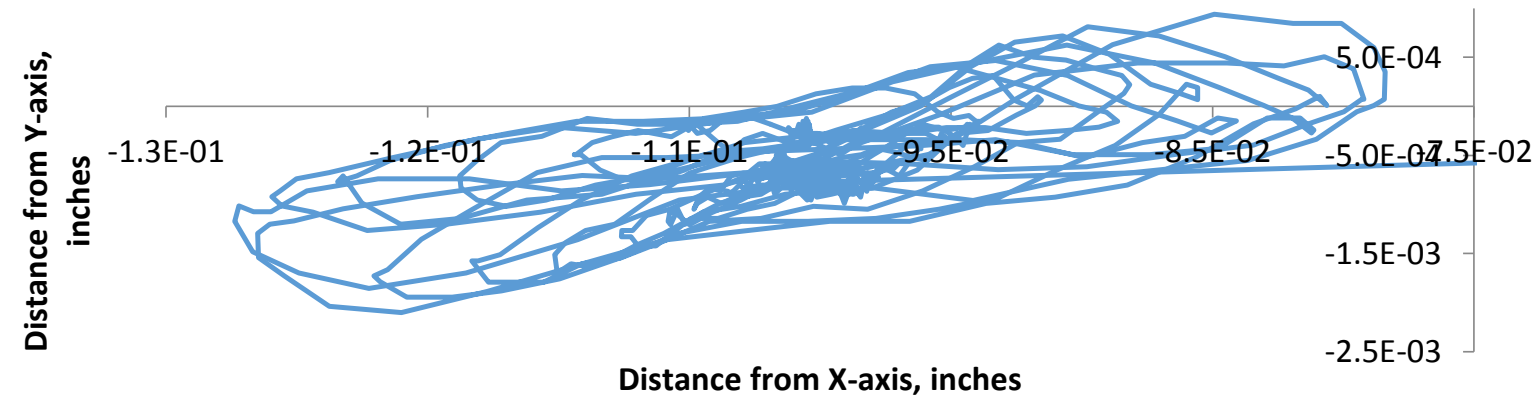

Figure 56: Changing X \& Y Intercept as a function of time, ti. 


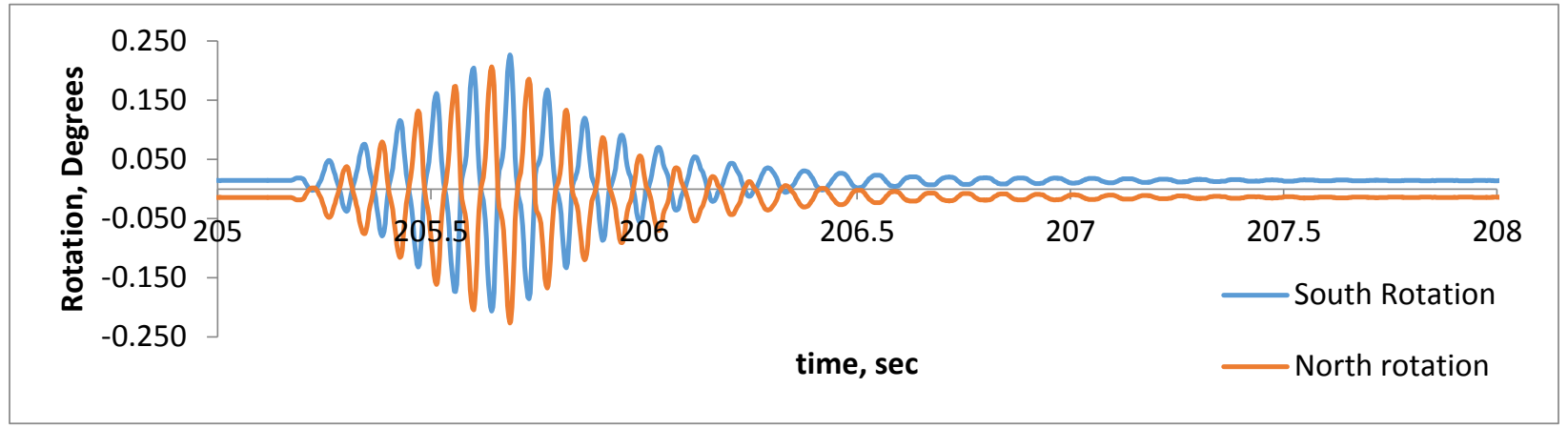

Figure 57: Rotations in the North-South Direction.

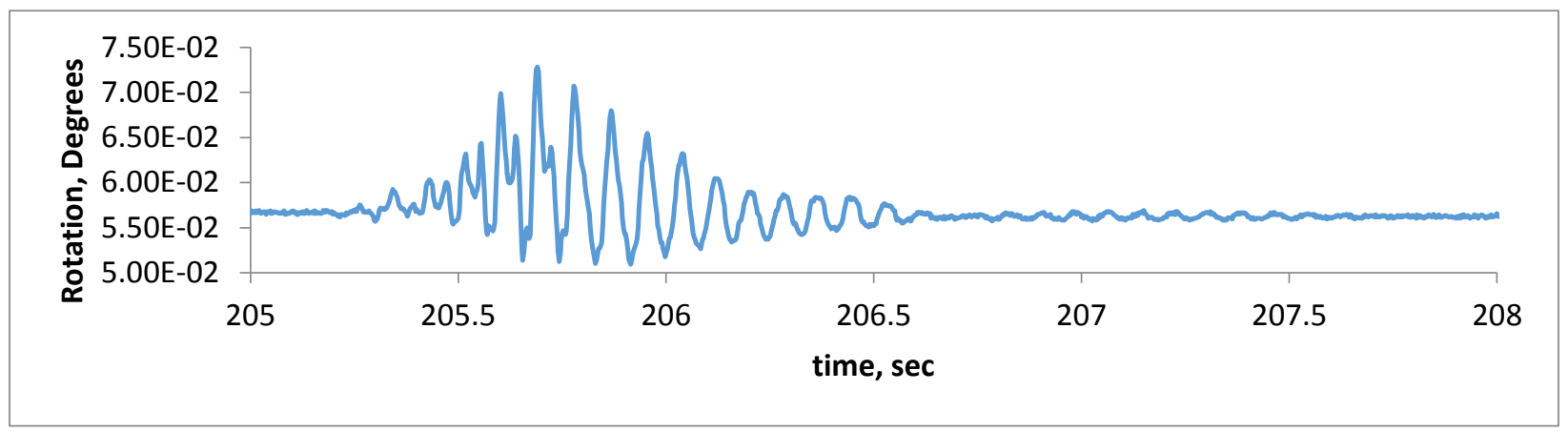

Figure 58: Rotations in the West Direction

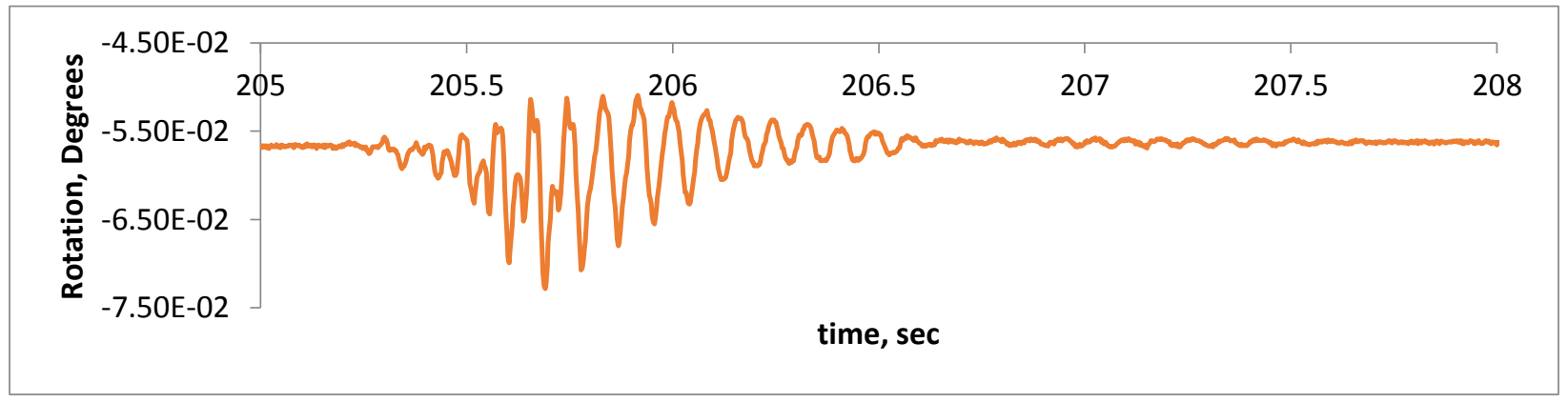

Figure 59: Rotations in the East Direction.

\section{SB 0.58g: Horizontal Rotations and New X and Y intercepts}

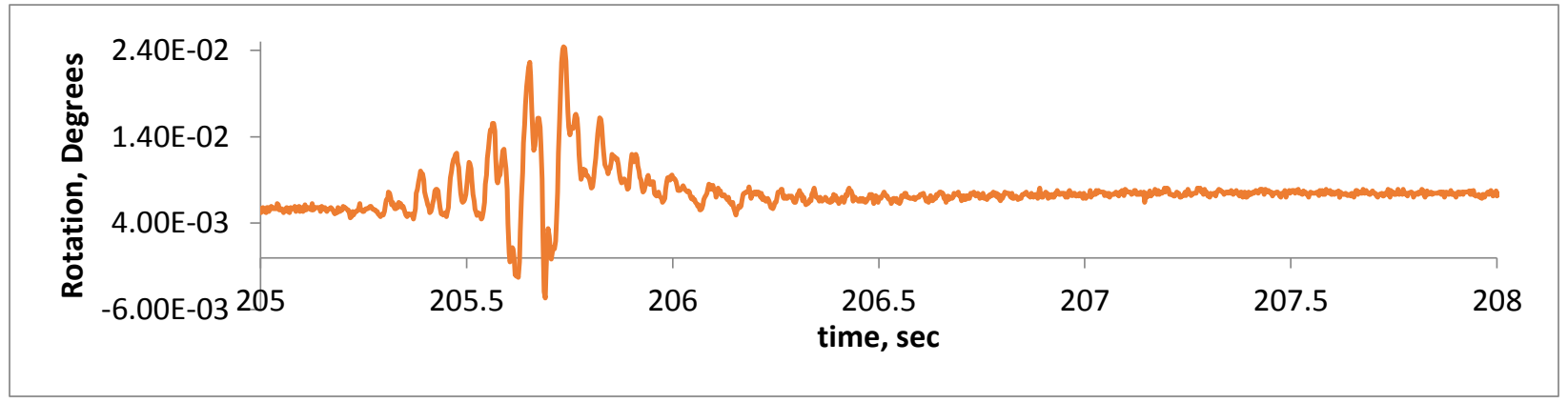

Figure 60: Horizontal North-South Rotations. 


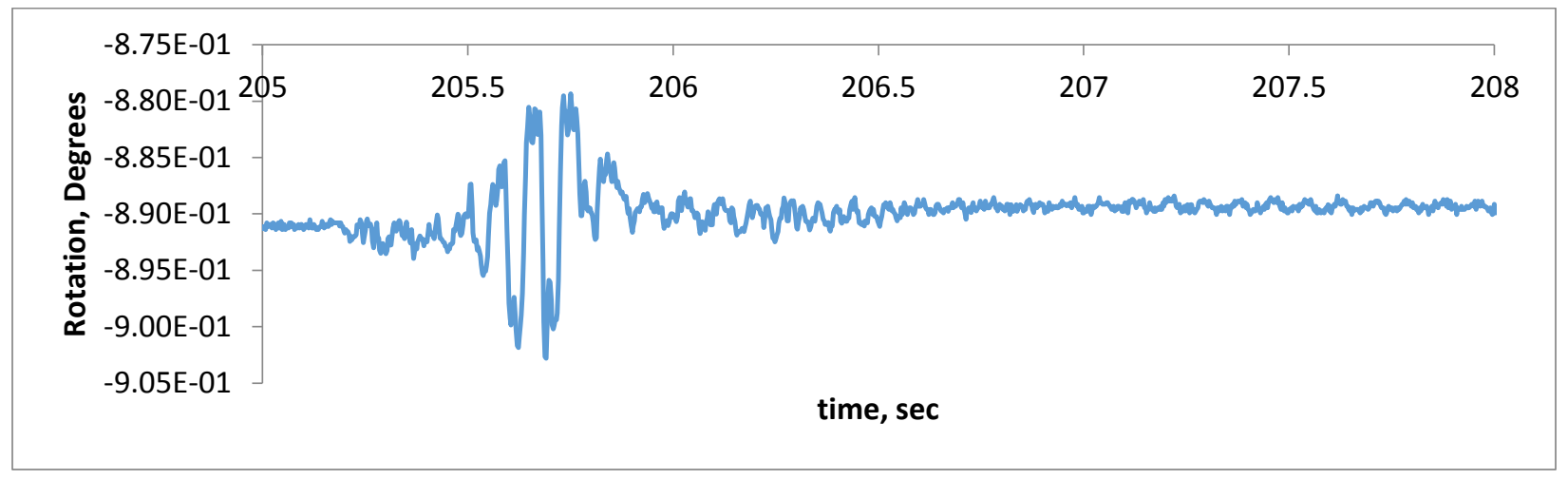

Figure 61: Horizontal East-West Rotations.

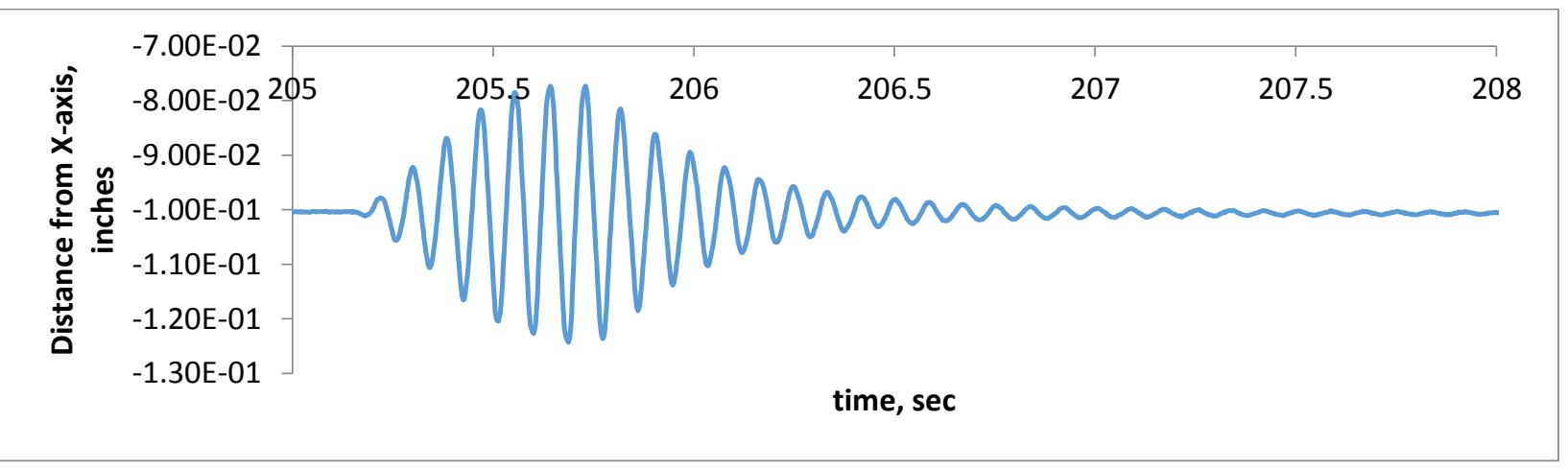

Figure 62: New X-Intercept as a function of time, ti. Negative is towards the east horizontal LVDT and positive is towards the west horizontal LVDT.

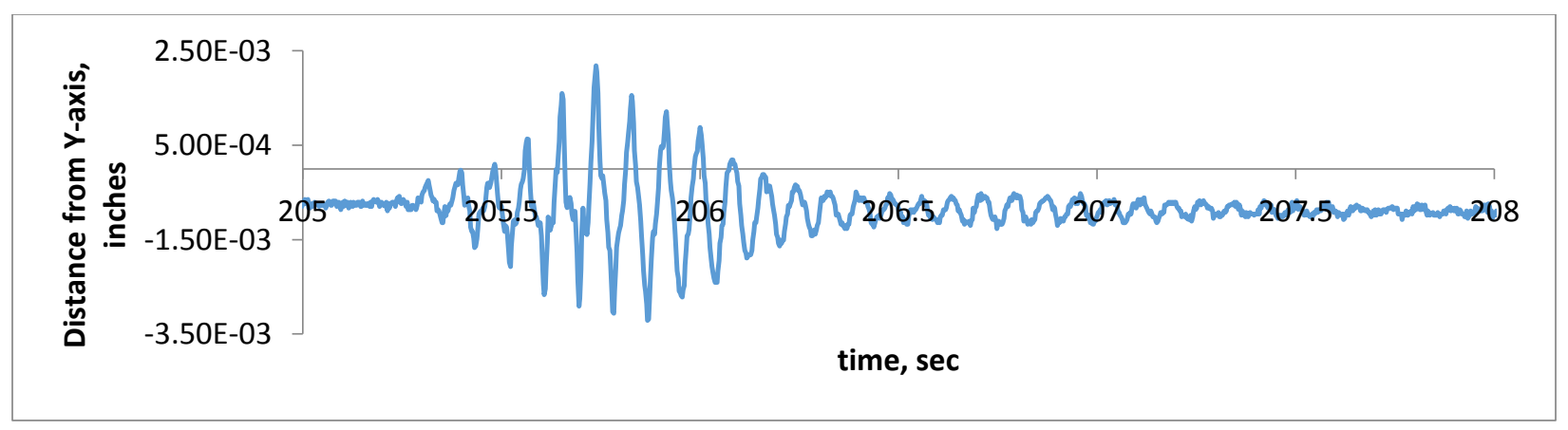

Figure 63: New Y-Intercept as a function of time, ti. Negative is towards the south horizontal LVDT and positive is towards the north horizontal LVDT.

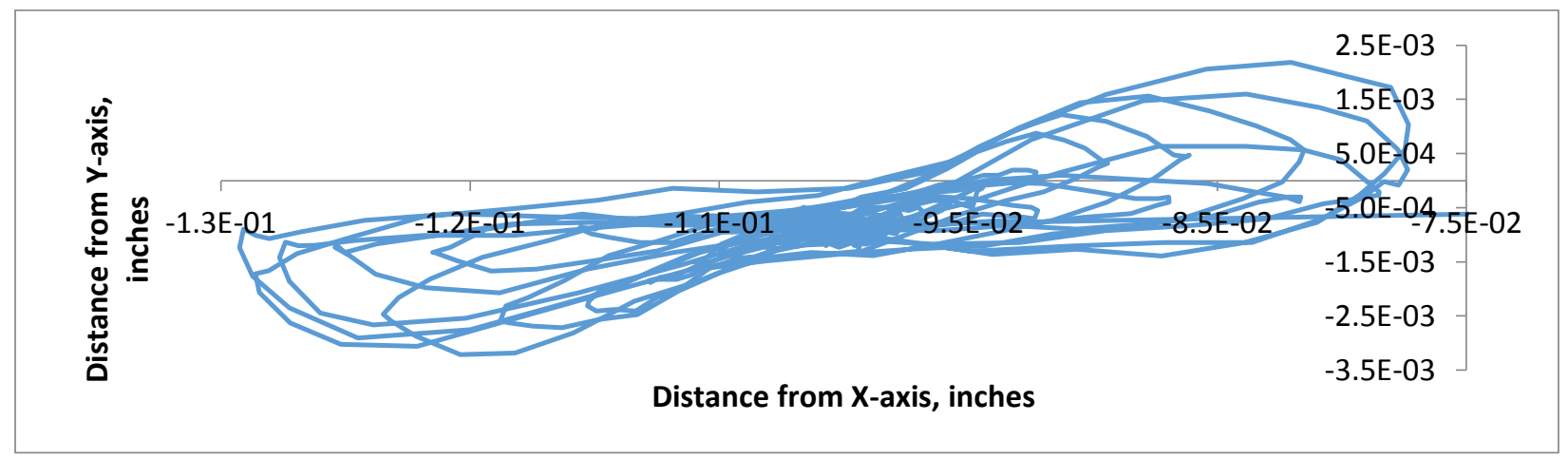

Figure 64: Changing $X \& Y$ Intercept as a function of time, ti. 


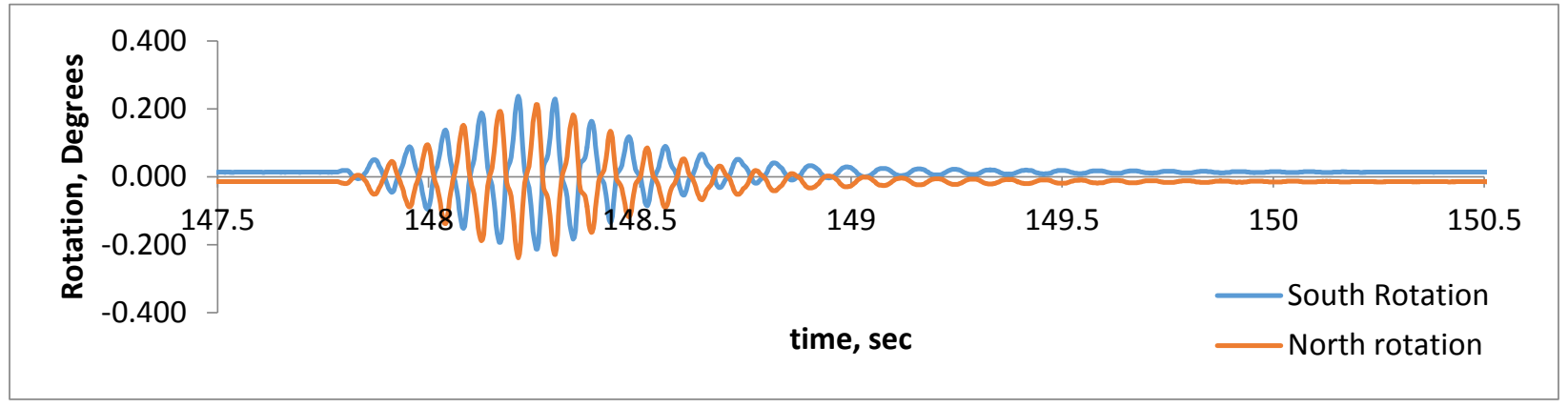

Figure 65: Rotations in the North-South Direction.

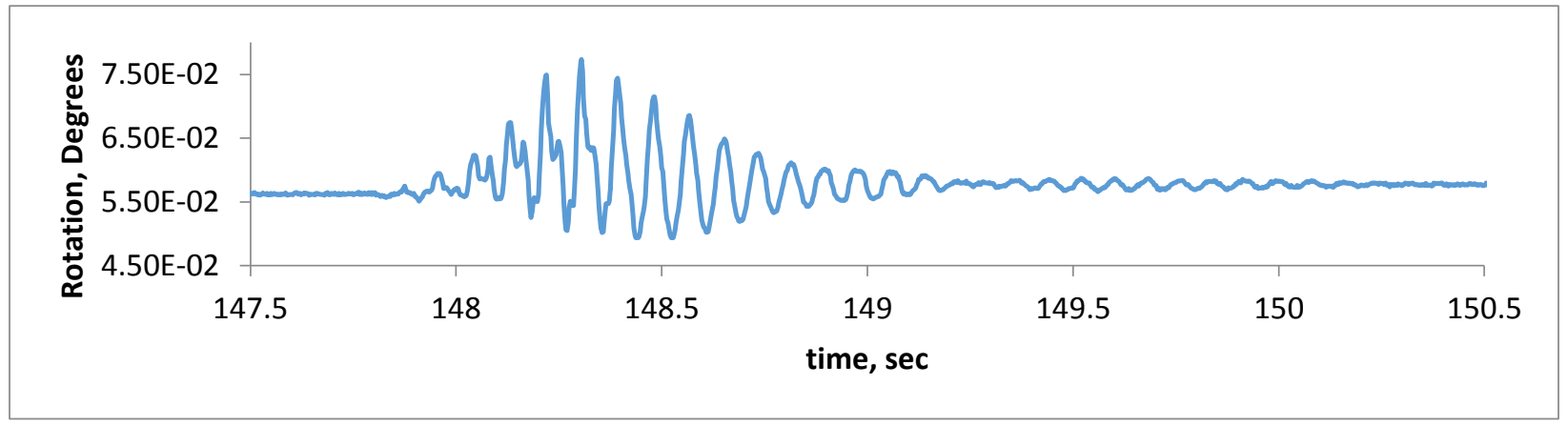

Figure 66: Rotations in the West Direction

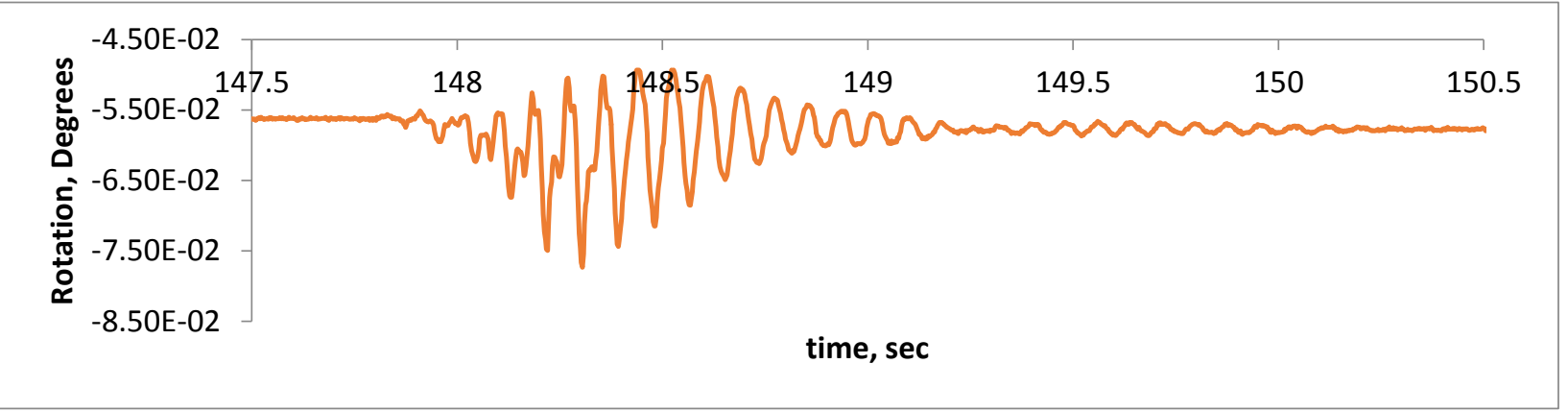

Figure 67: Rotations in the East Direction.

\section{SB 0.65g: Horizontal Rotations and New X and Y intercepts}

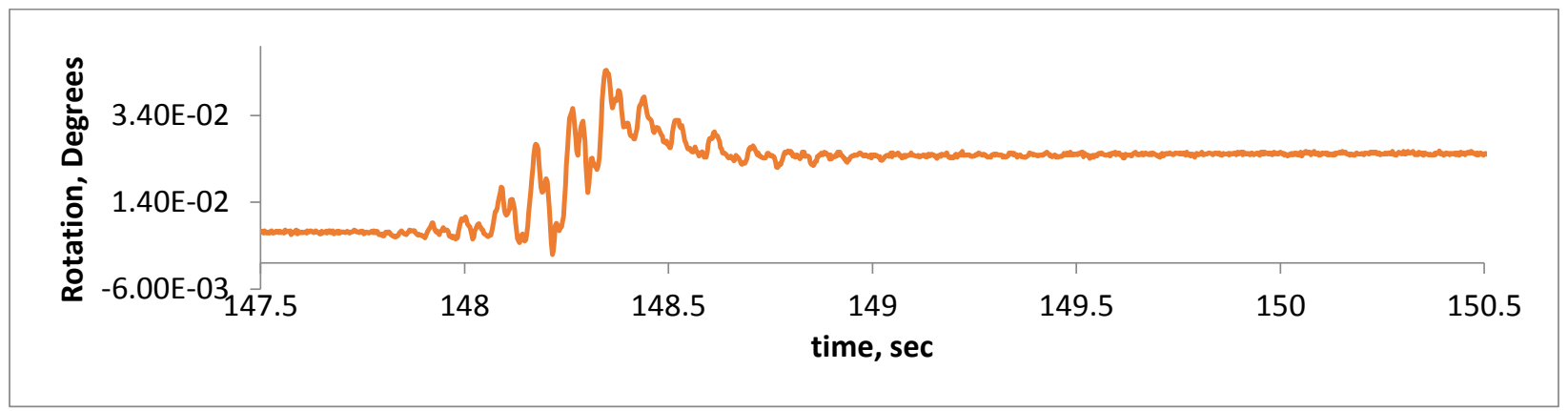

Figure 68: Horizontal North-South Rotations. 


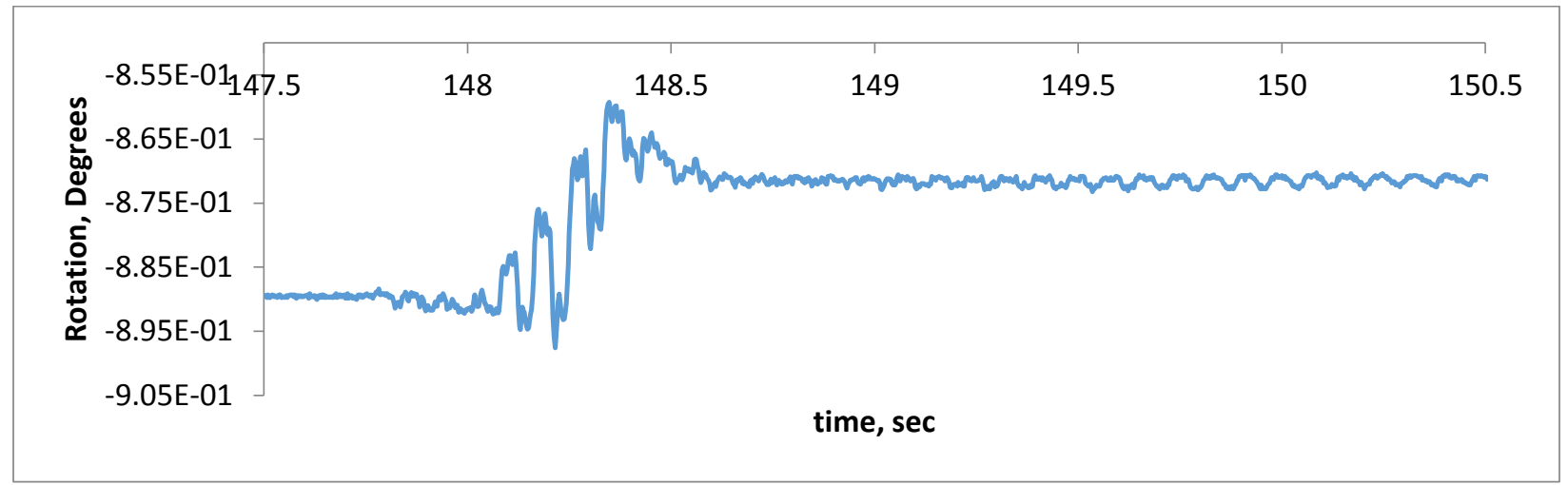

Figure 69: Horizontal East-West Rotations.

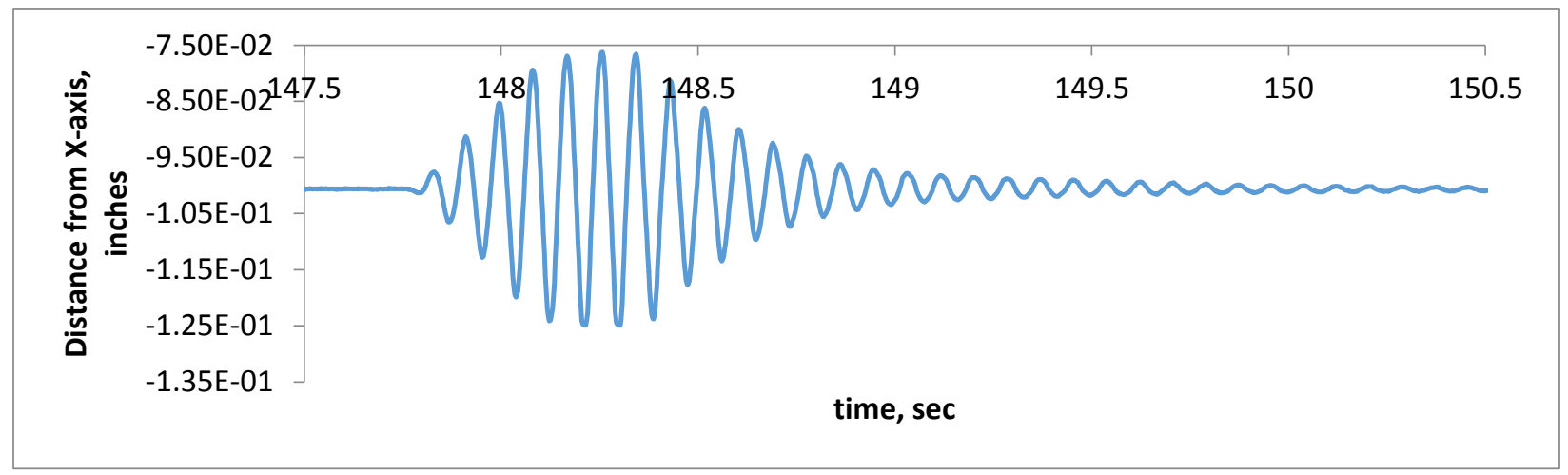

Figure 70: New X-Intercept as a function of time, ti. Negative is towards the east horizontal LVDT and positive is towards the west horizontal LVDT.

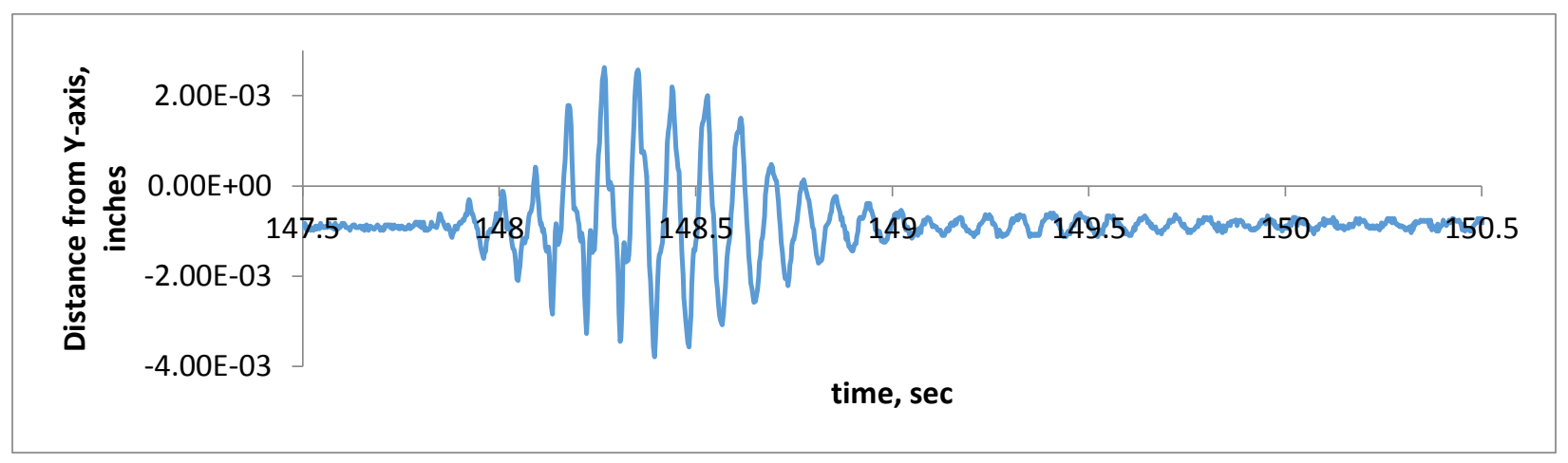

Figure 71: New Y-Intercept as a function of time, ti. Negative is towards the south horizontal LVDT and positive is towards the north horizontal LVDT.

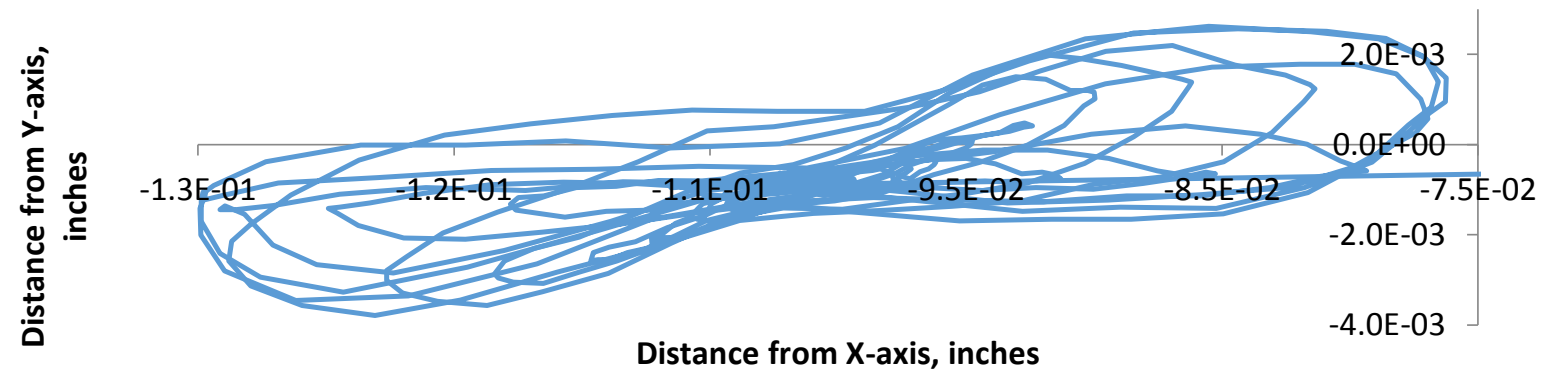

Figure 72: Changing X \& Y Intercept as a function of time, ti. 


\section{SB 0.75g: Vertical Pivot Point and Rotation Angle}

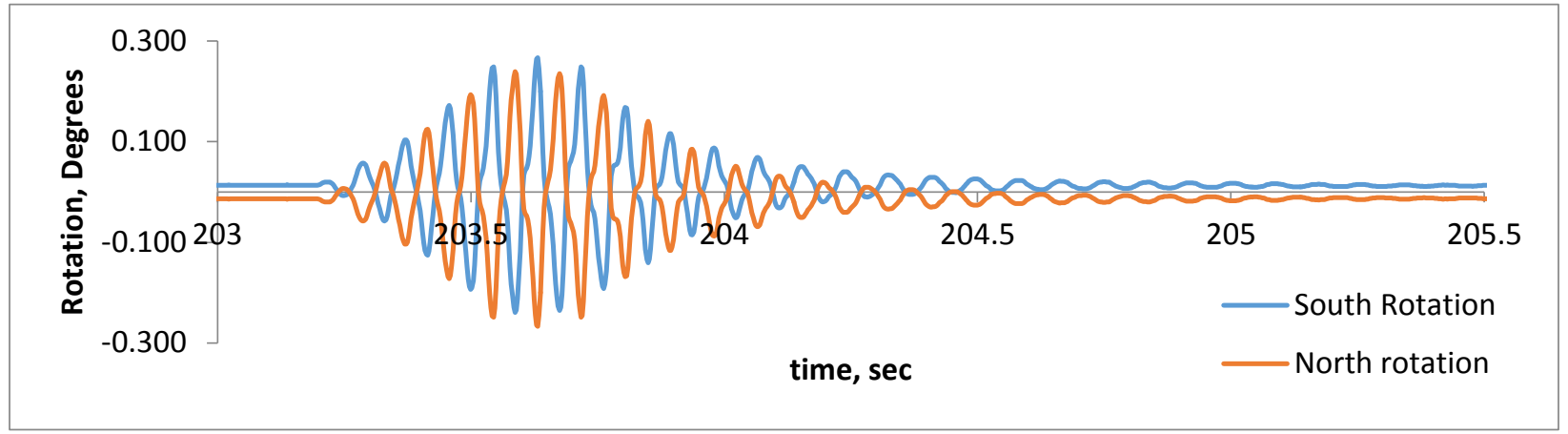

Figure 73: Rotations in the North-South Direction.

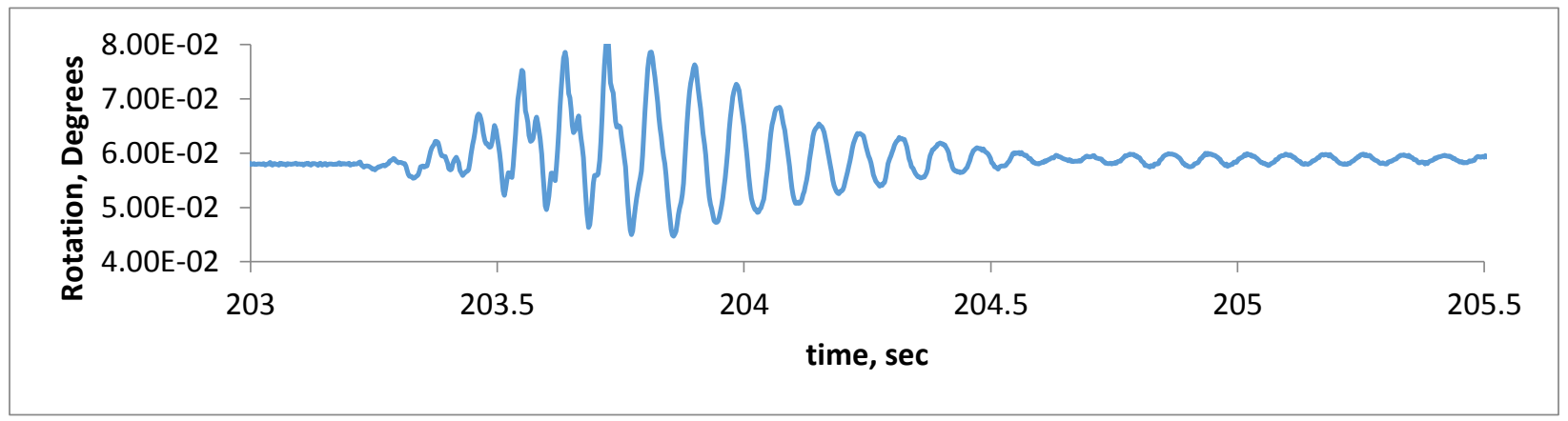

Figure 74: Rotations in the West Direction

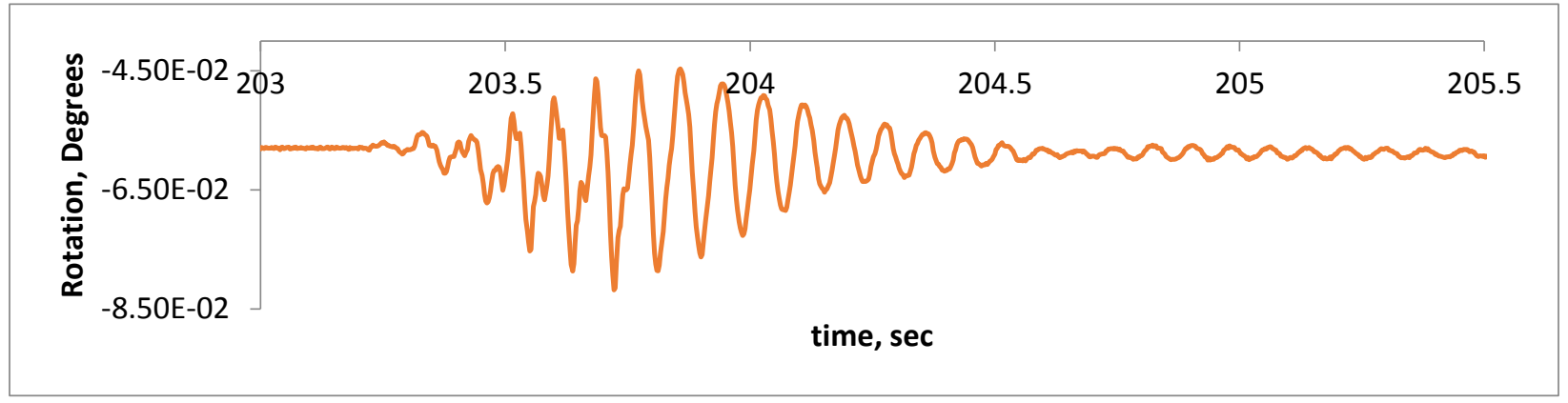

Figure 75: Rotations in the East Direction.

\section{SB 0.75g: Horizontal Rotations and New $X$ and $Y$ intercepts}

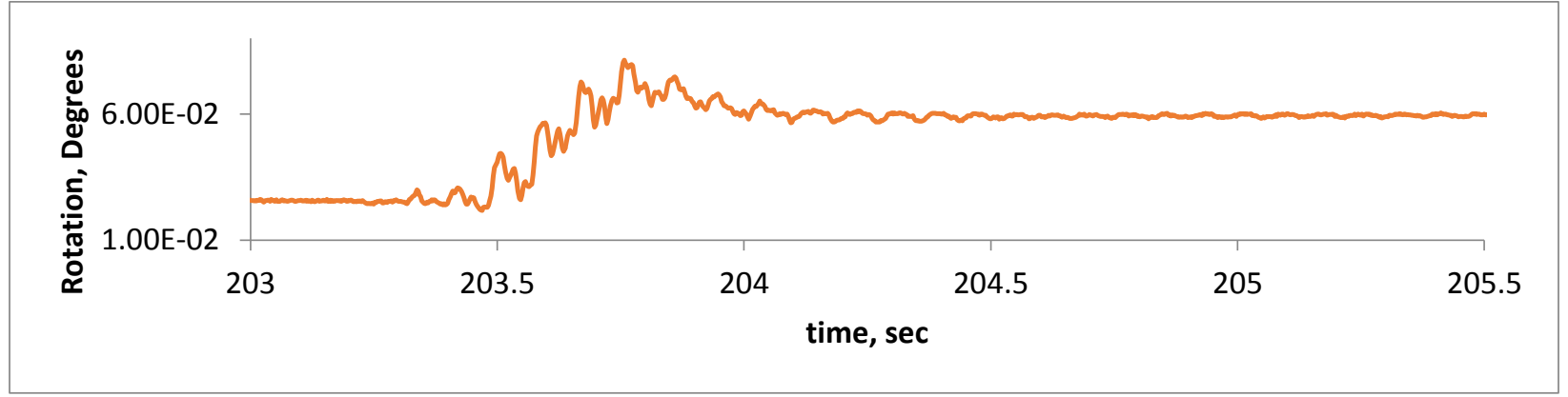

Figure 76: Horizontal North-South Rotations. 


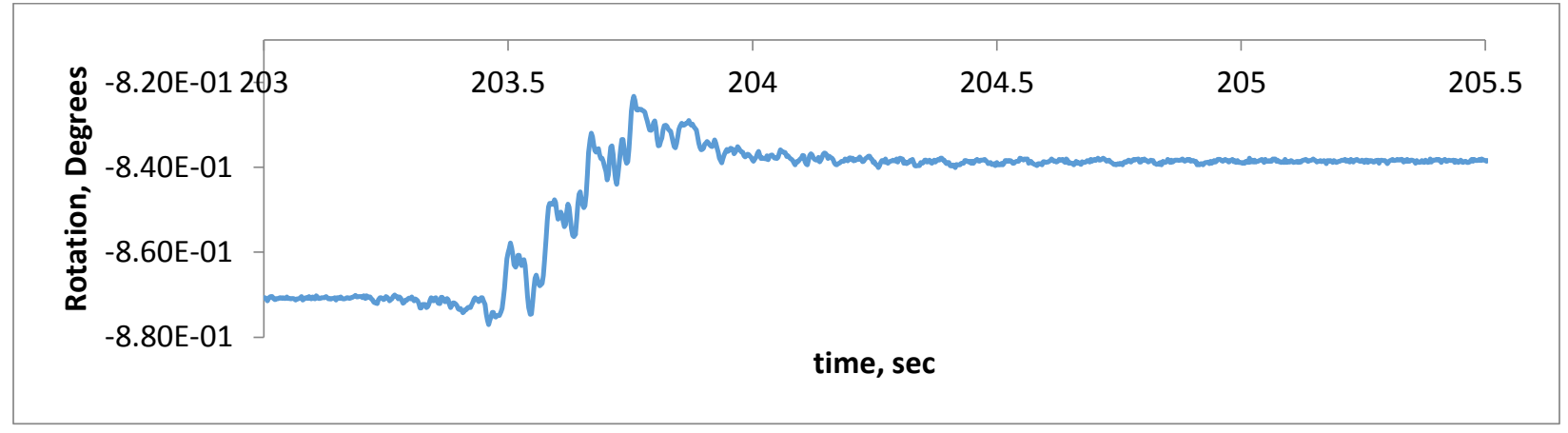

Figure 77: Horizontal East-West Rotations.

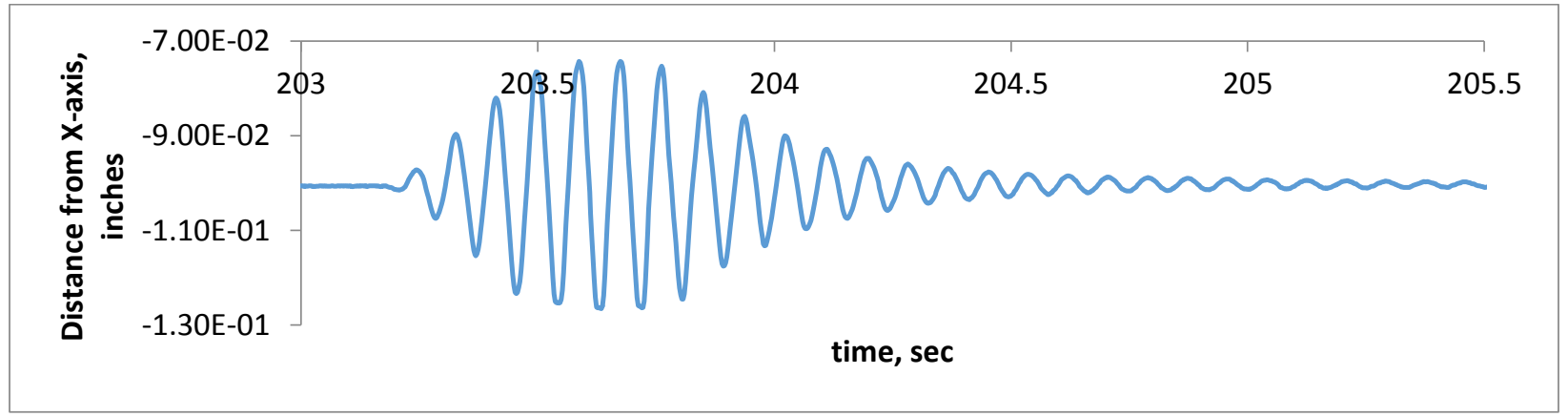

Figure 78: New X-Intercept as a function of time, ti. Negative is towards the east horizontal LVDT and positive is towards the west horizontal LVDT.

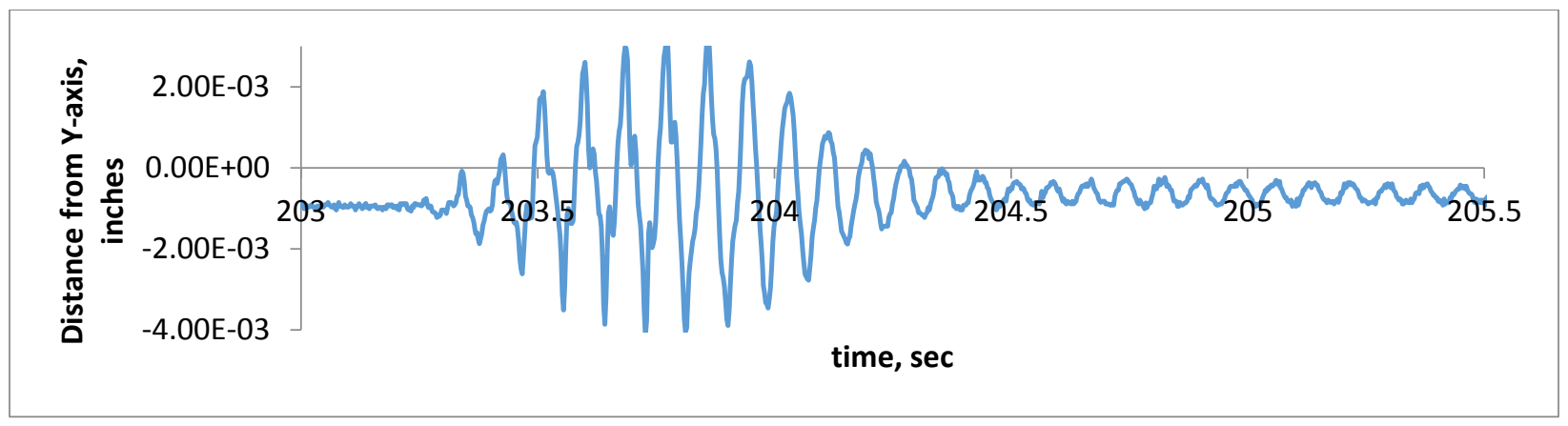

Figure 79: New Y-Intercept as a function of time, ti. Negative is towards the south horizontal LVDT and positive is towards the north horizontal LVDT.

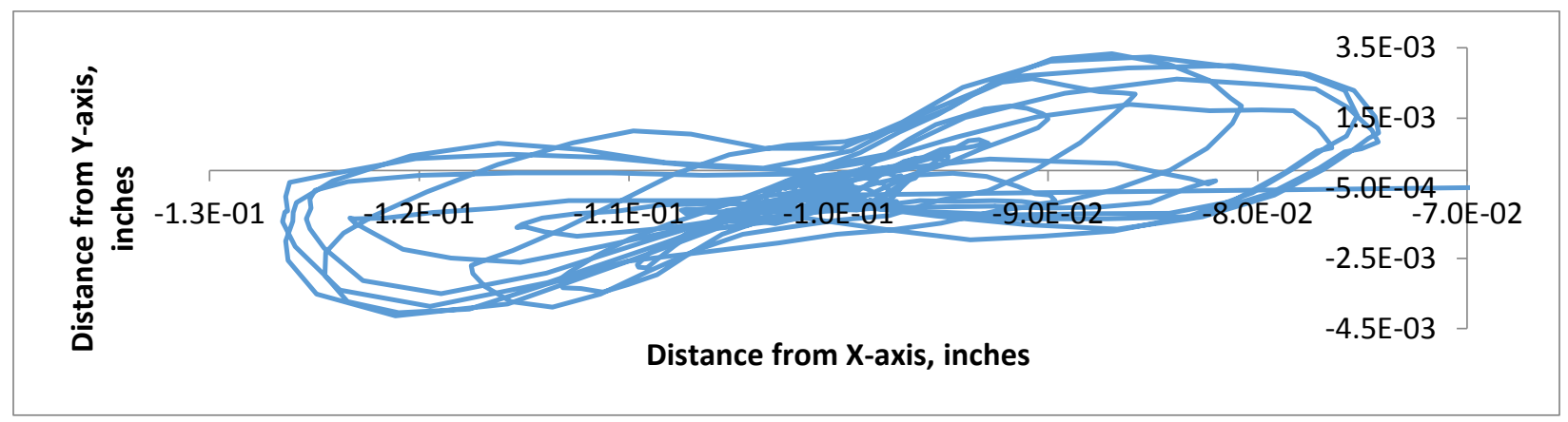

Figure 80: Changing $X \& Y$ Intercept as a function of time, ti. 


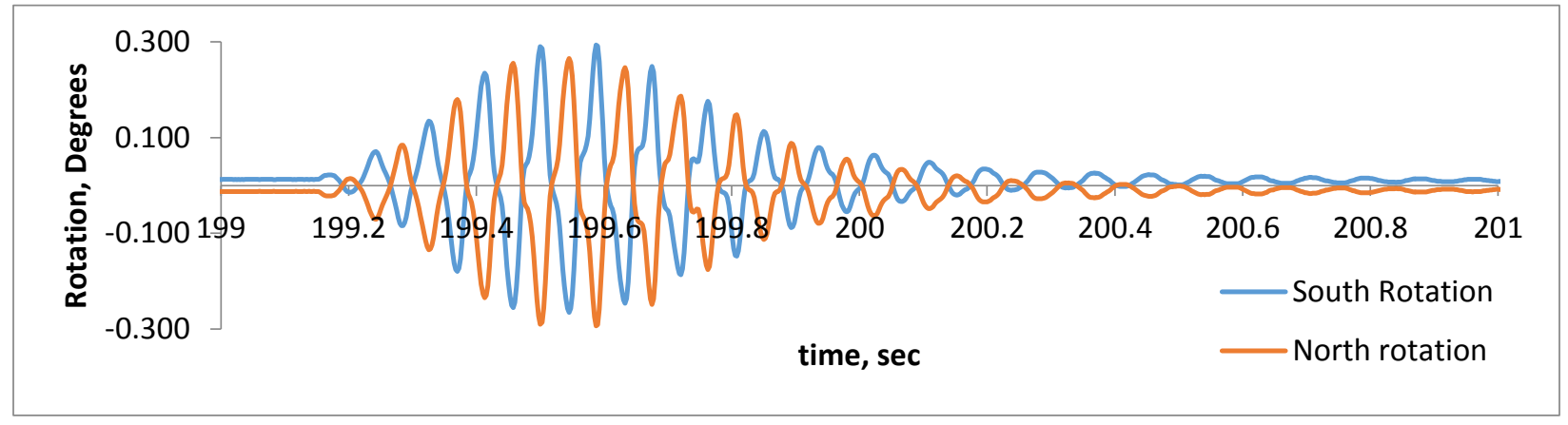

Figure 81: Rotations in the North-South Direction.

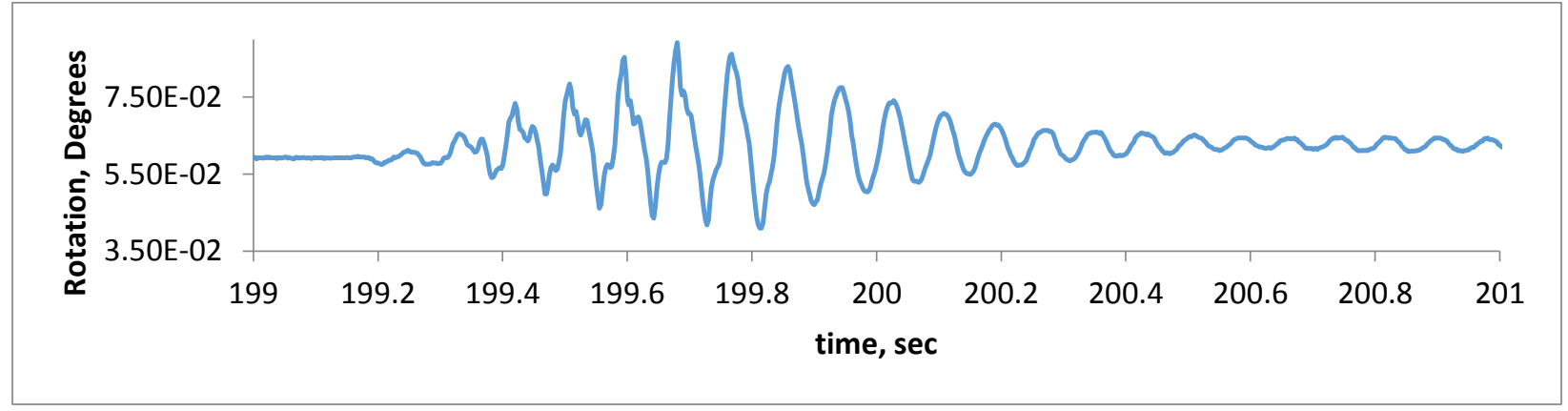

Figure 82: Rotations in the West Direction

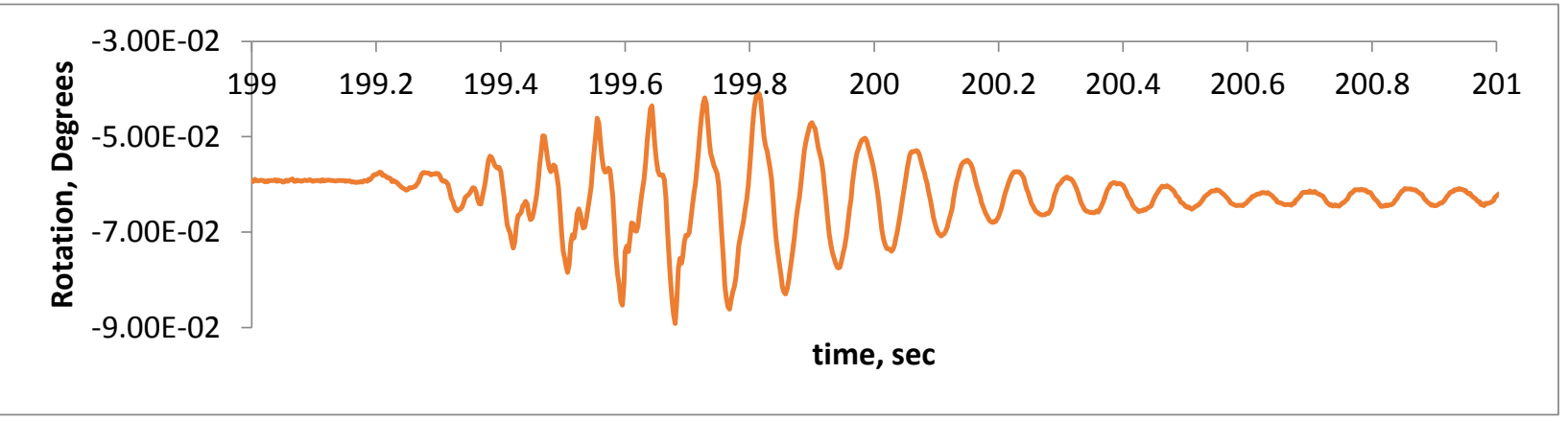

Figure 83: Rotations in the East Direction.

\section{SB 0.88g: Horizontal Rotations and New X and Y intercepts}

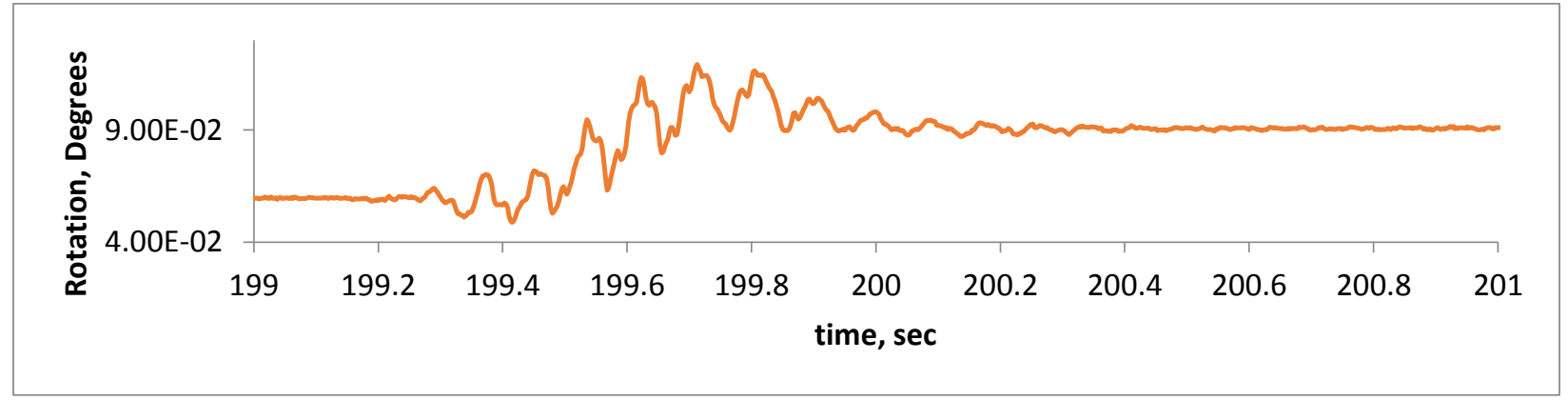

Figure 84: Horizontal North-South Rotations. 


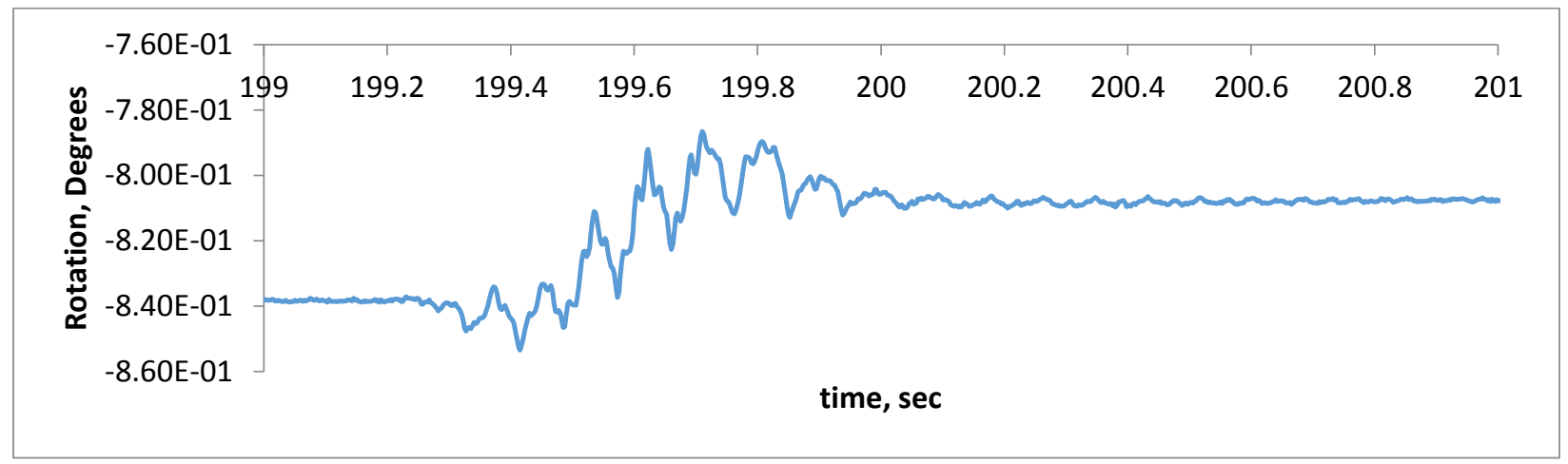

Figure 85: Horizontal East-West Rotations.

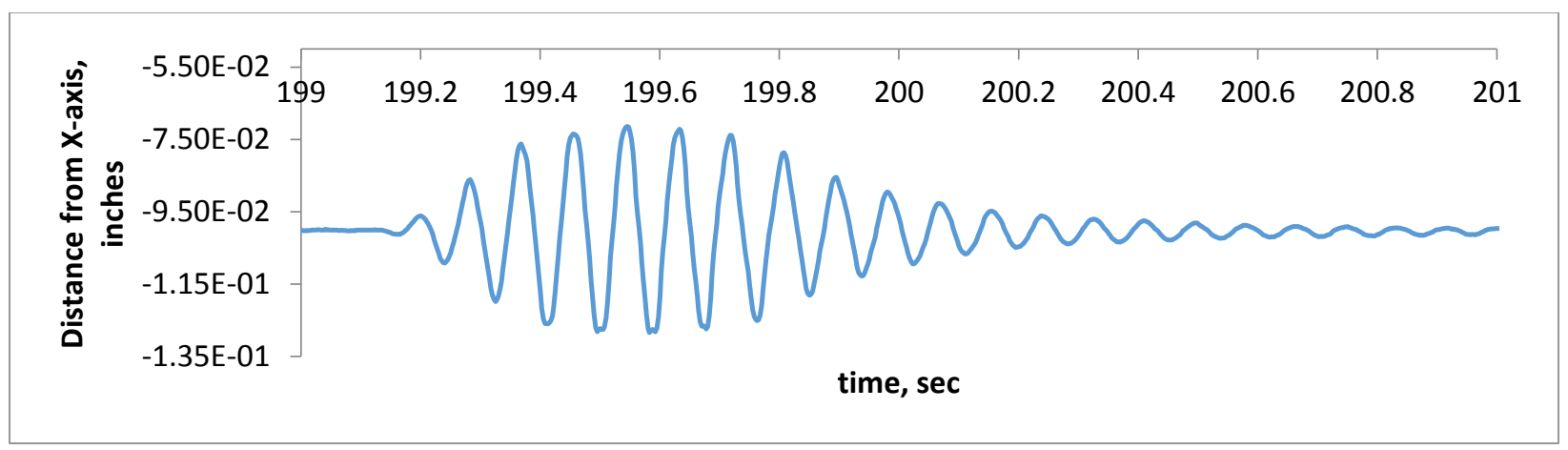

Figure 86: New X-Intercept as a function of time, ti. Negative is towards the east horizontal LVDT and positive is towards the west horizontal LVDT.

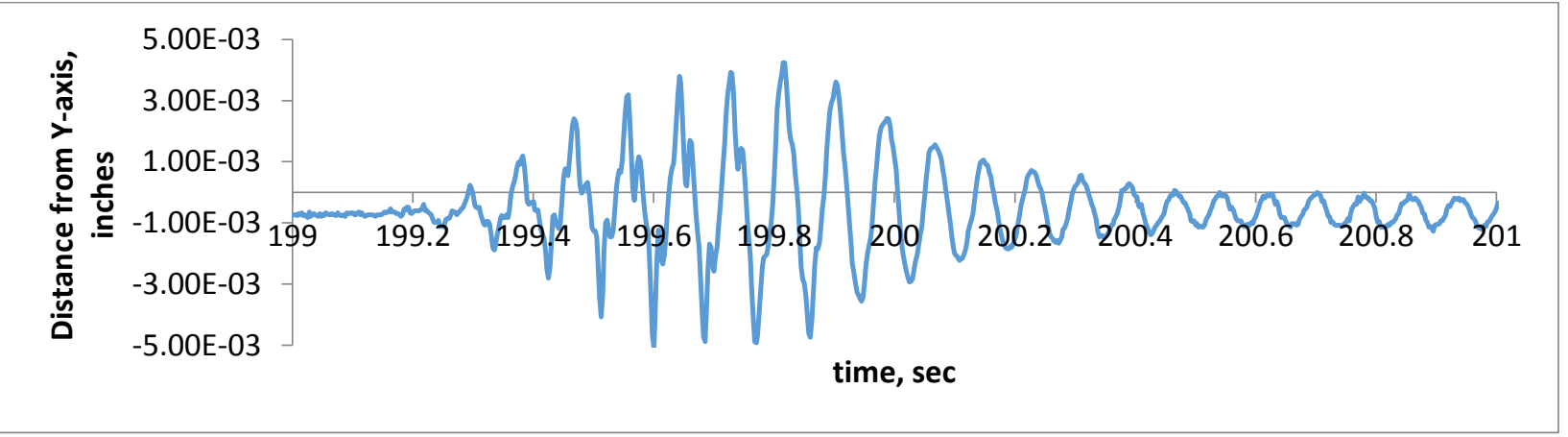

Figure 87: New Y-Intercept as a function of time, ti. Negative is towards the south horizontal LVDT and positive is towards the north horizontal LVDT.

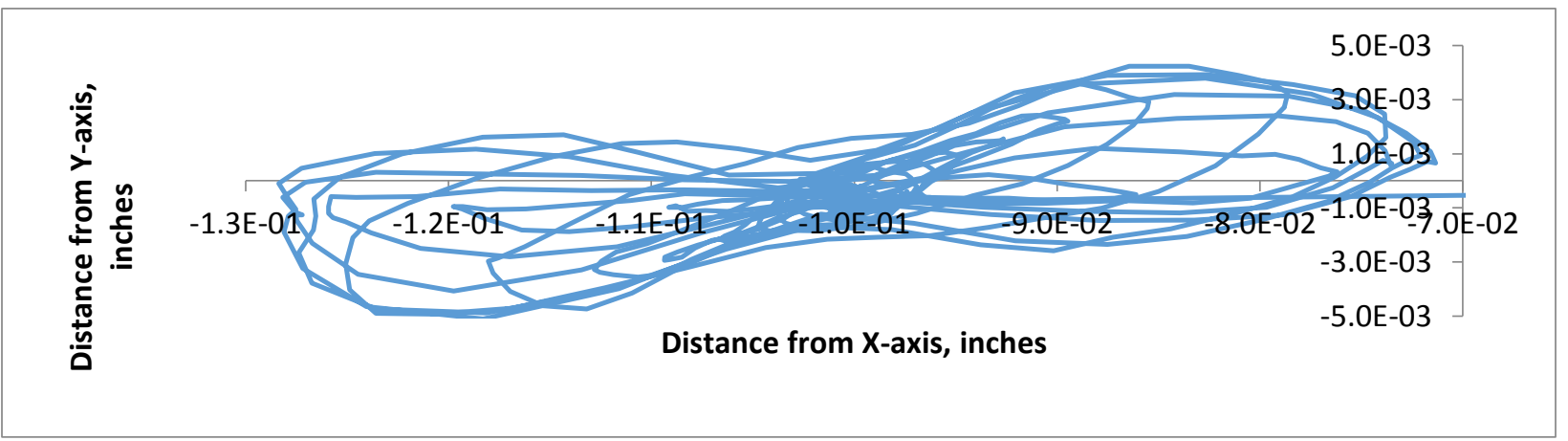

Figure 88: Changing $X \& Y$ Intercept as a function of time, ti. 


\section{SB 1.0g: Vertical Pivot Point and Rotation Angle}

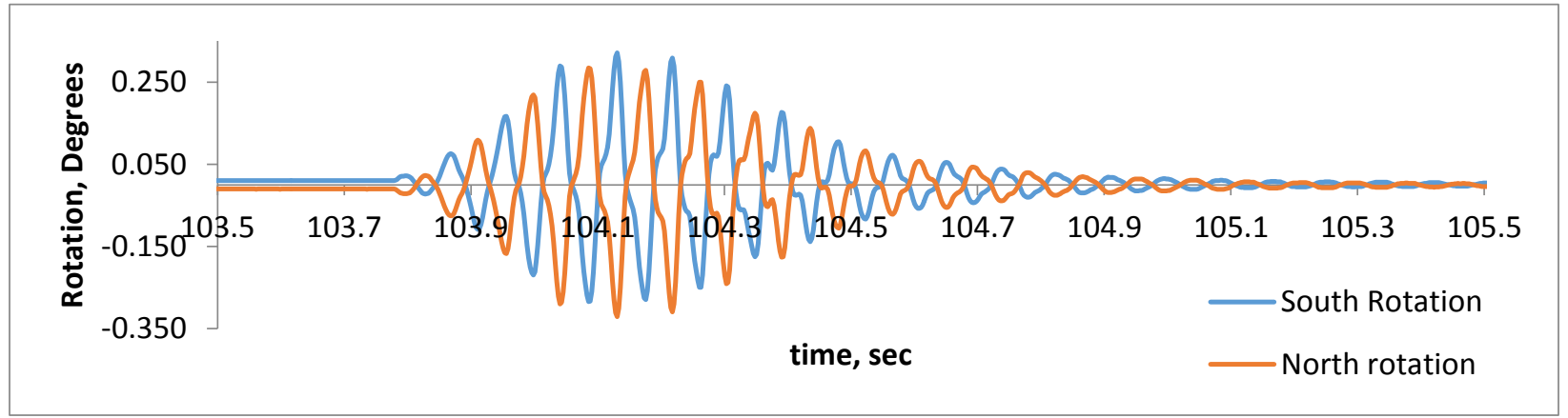

Figure 89: Rotations in the North-South Direction.

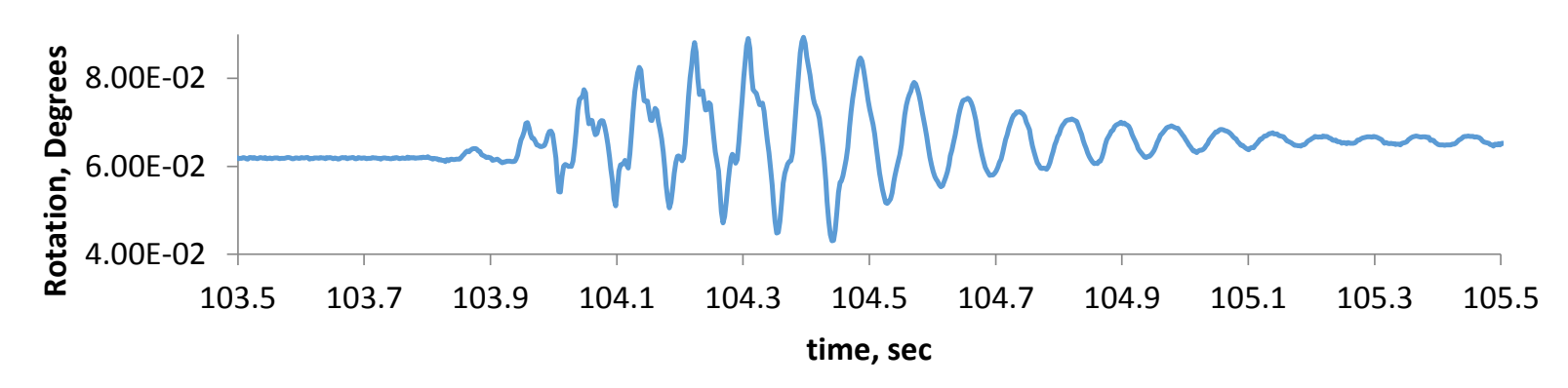

Figure 90: Rotations in the West Direction

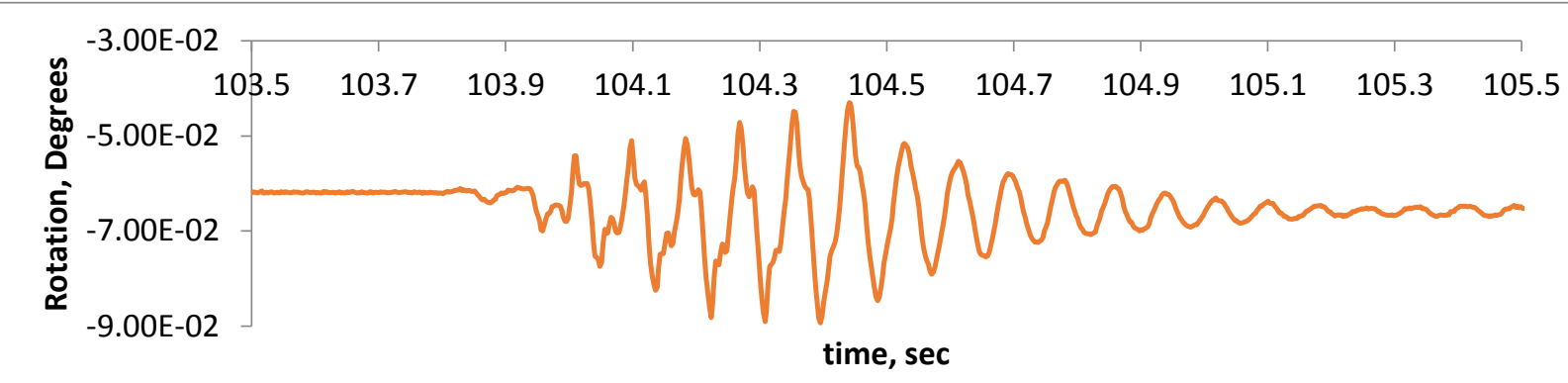

Figure 91: Rotations in the East Direction.

\section{SB 1.Og: Horizontal Rotations and New $X$ and $Y$ intercepts}

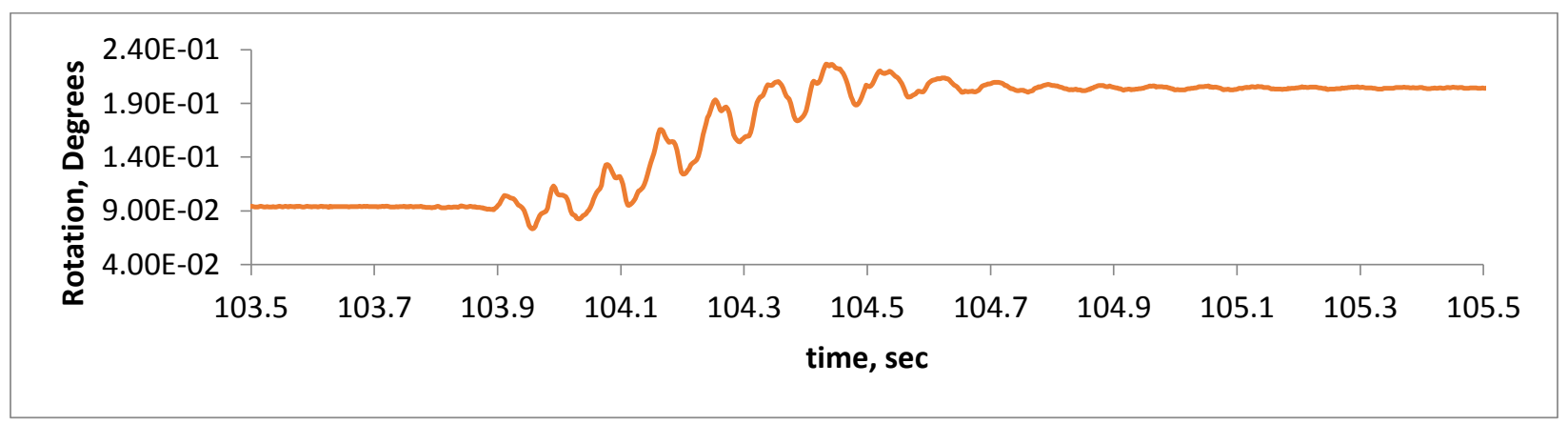

Figure 92: Horizontal North-South Rotations. 


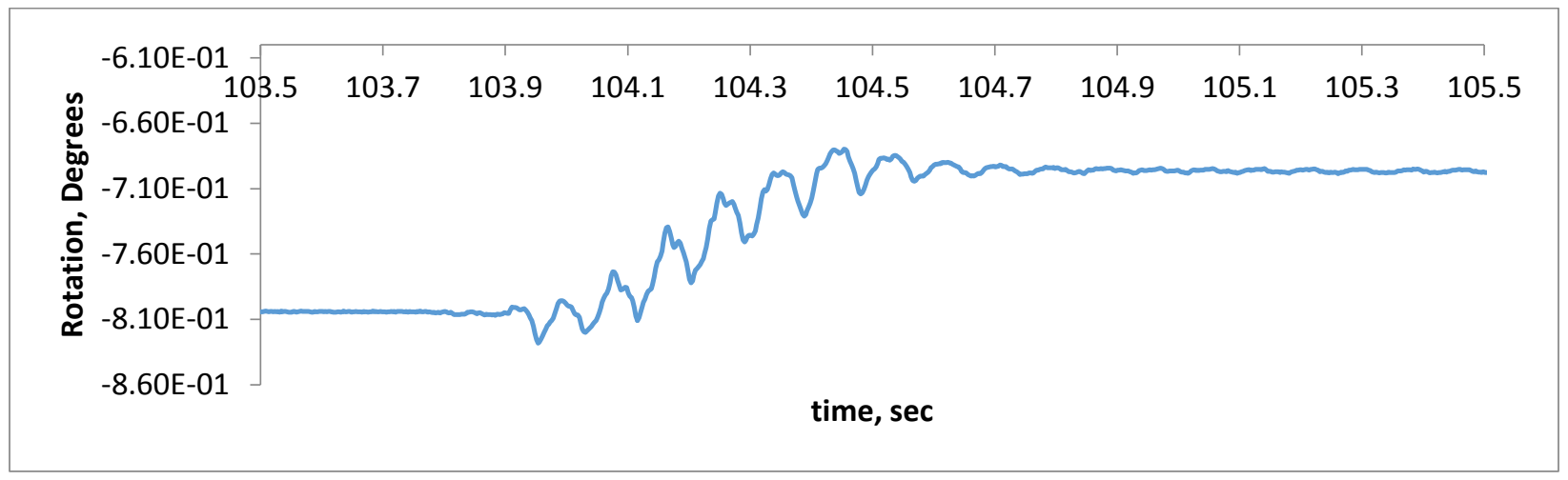

Figure 93: Horizontal East-West Rotations.

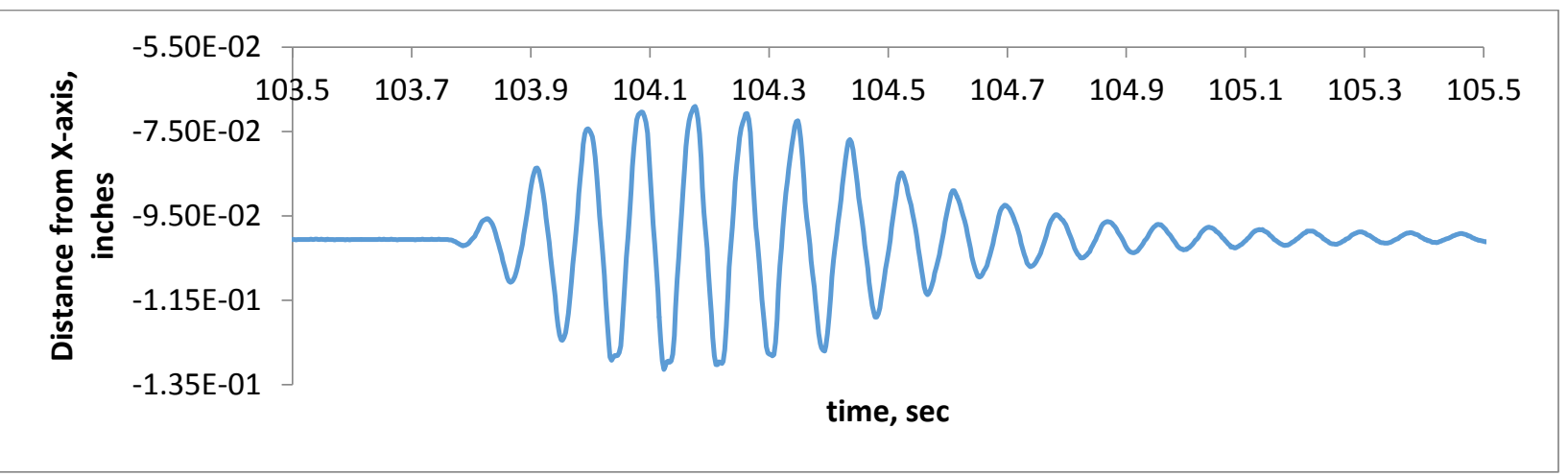

Figure 94: New X-Intercept as a function of time, ti. Negative is towards the east horizontal LVDT and positive is towards the west horizontal LVDT.

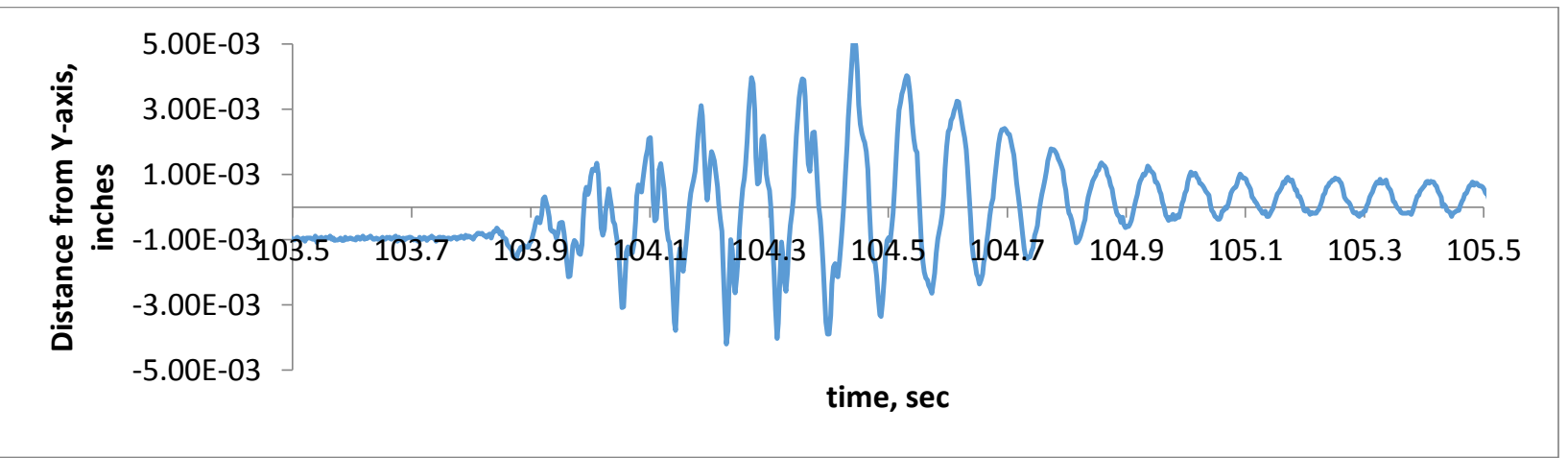

Figure 95: New Y-Intercept as a function of time, ti. Negative is towards the south horizontal LVDT and positive is towards the north horizontal LVDT.

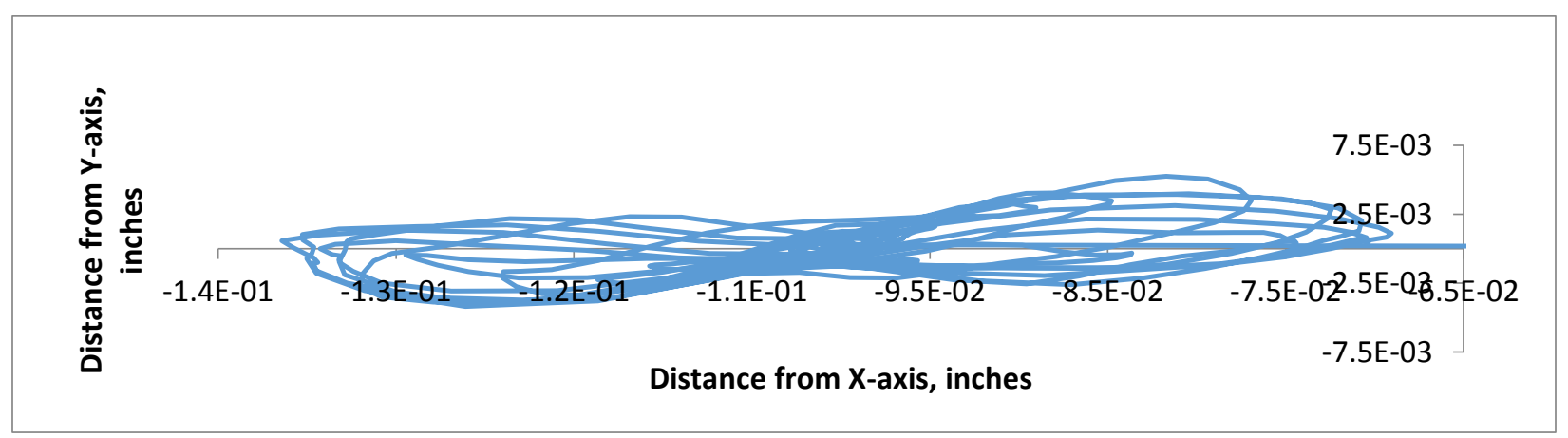

Figure 96: Changing $X \& Y$ Intercept as a function of time, ti. 


\section{SB 1.125g: Vertical Pivot Point and Rotation Angle}

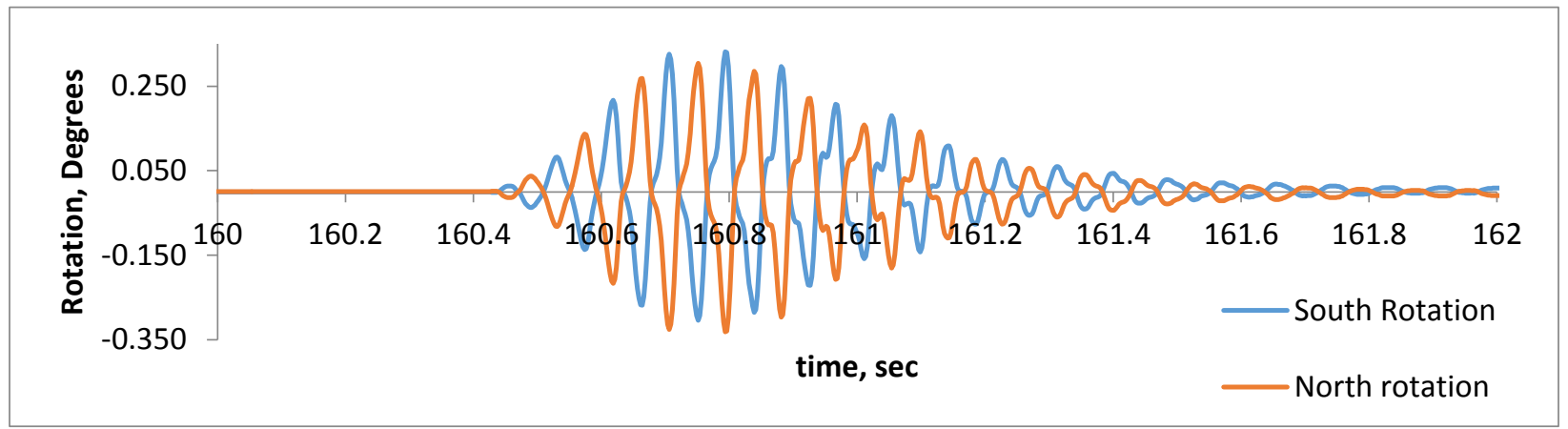

Figure 97: Rotations in the North-South Direction.

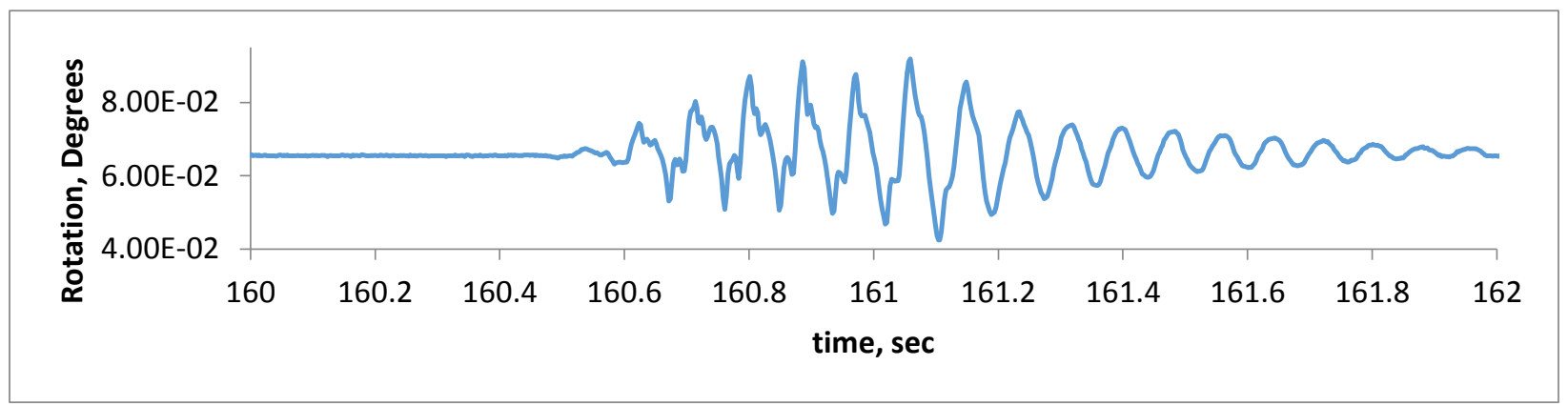

Figure 98: Rotations in the West Direction

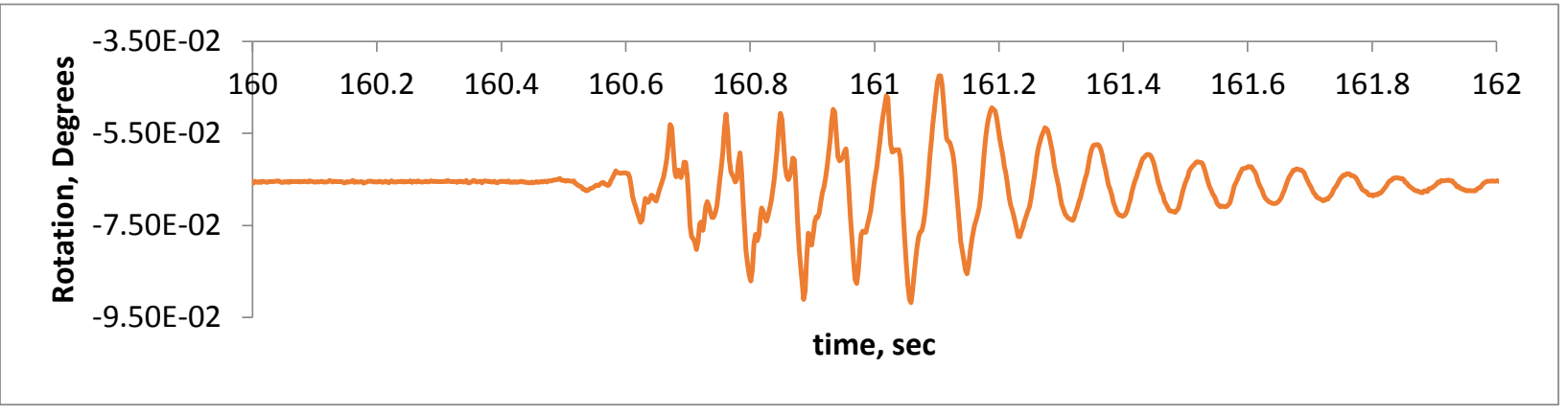

Figure 99: Rotations in the East Direction.

\section{SB 1.125g: Horizontal Rotations and New $X$ and $Y$ intercepts}

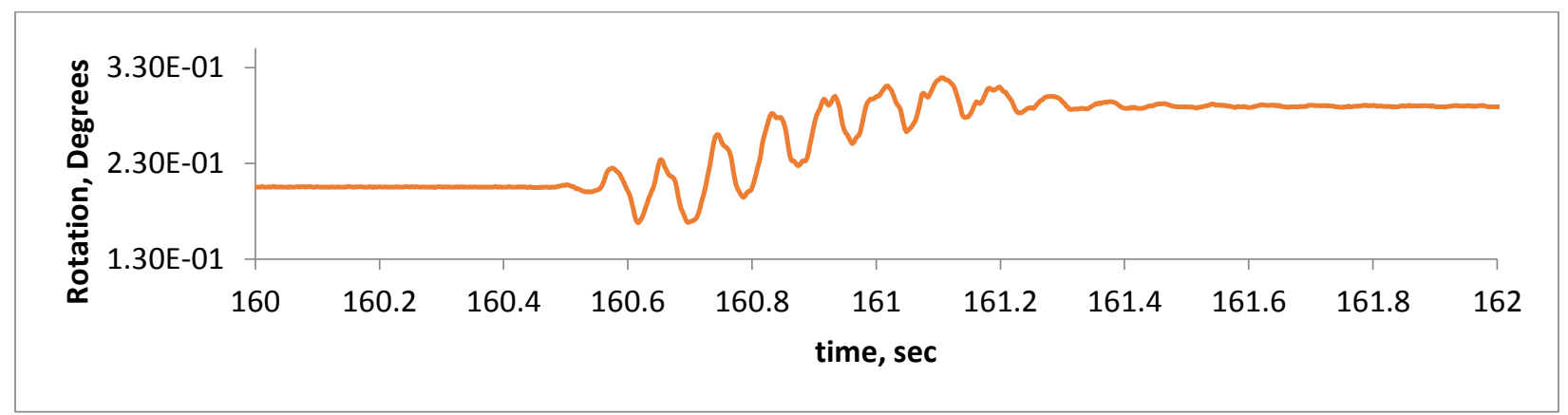

Figure 100: Horizontal North-South Rotations. 


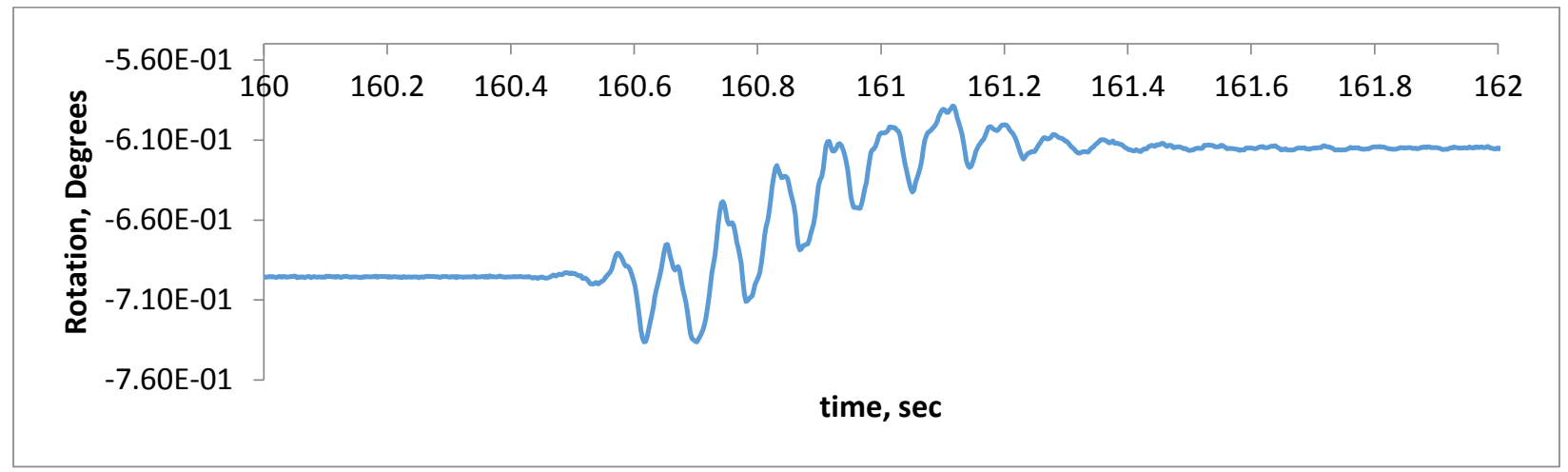

Figure 101: Horizontal East-West Rotations.

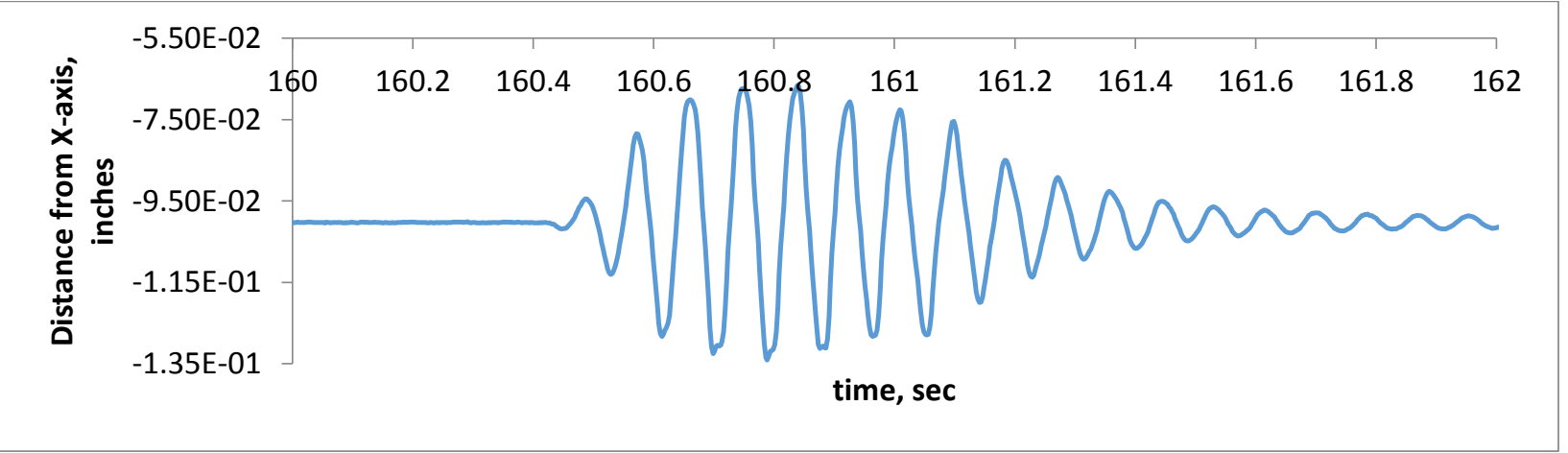

Figure 102: New X-Intercept as a function of time, ti. Negative is towards the east horizontal LVDT and positive is towards the west horizontal LVDT.

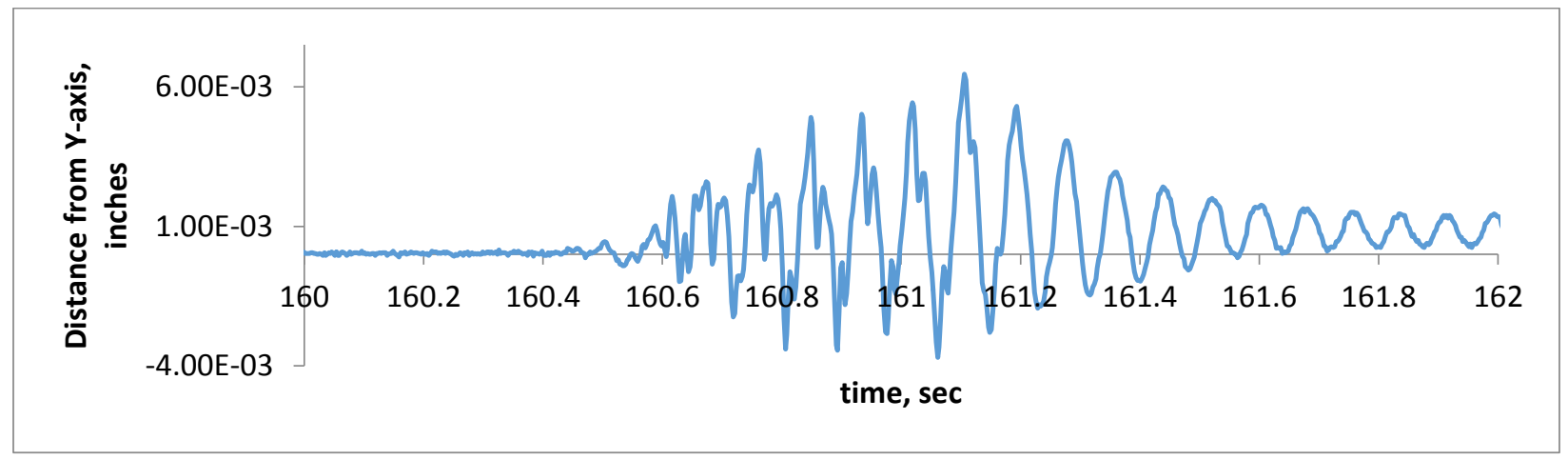

Figure 103: New Y-Intercept as a function of time, ti. Negative is towards the south horizontal LVDT and positive is towards the north horizontal LVDT.

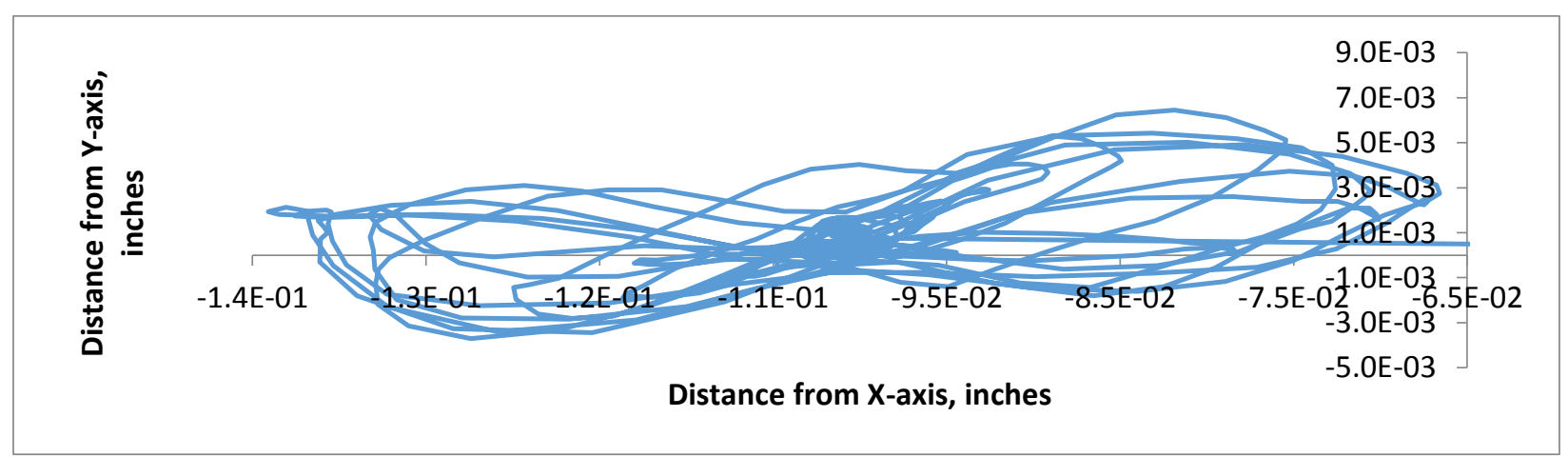

Figure 104: Changing $X \& Y$ Intercept as a function of time, ti. 


\section{SB 1.34g: Vertical Pivot Point and Rotation Angle}

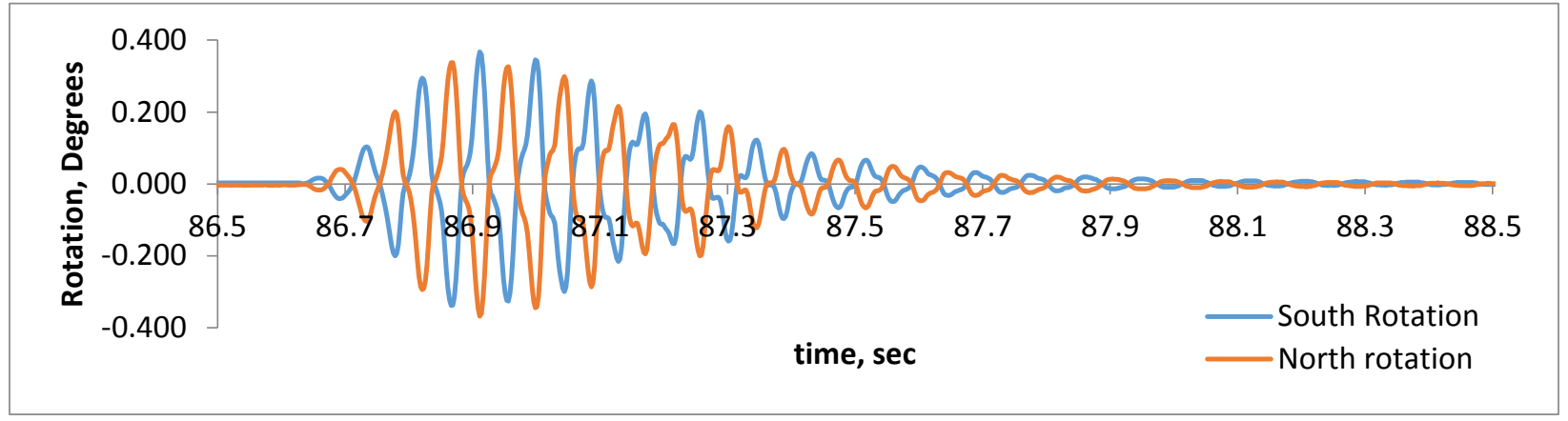

Figure 105: Rotations in the North-South Direction.

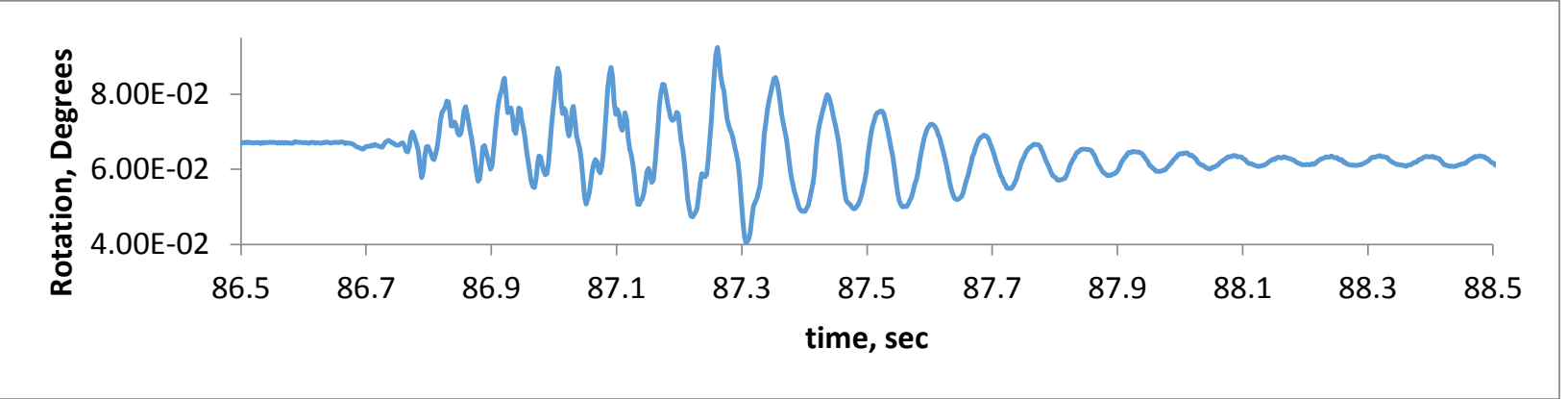

Figure 106: Rotations in the West Direction

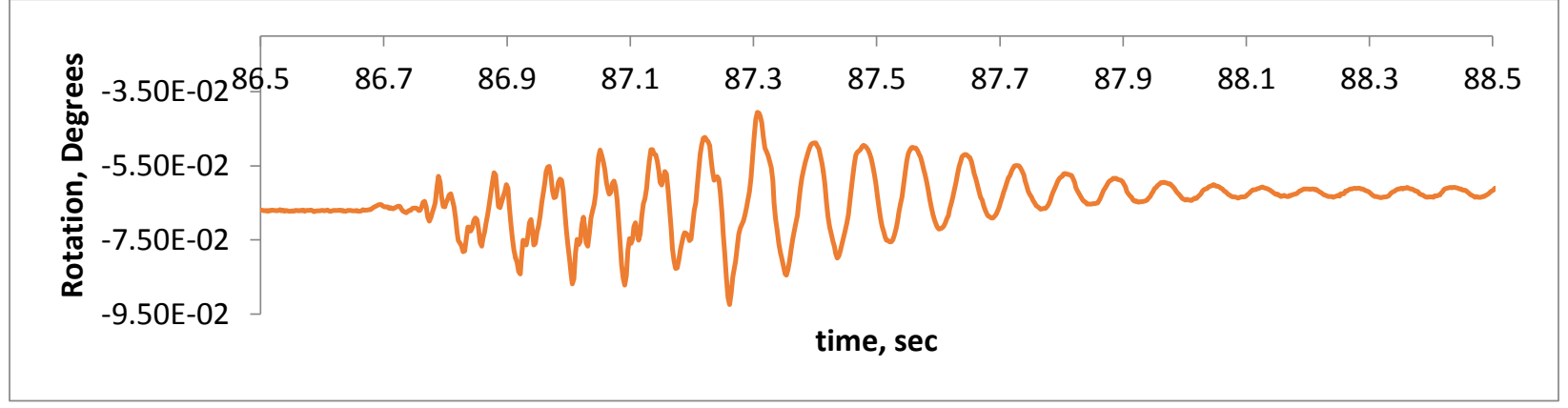

Figure 107: Rotations in the East Direction.

\section{SB 1.34g: Horizontal Rotations and New $X$ and $Y$ intercepts}

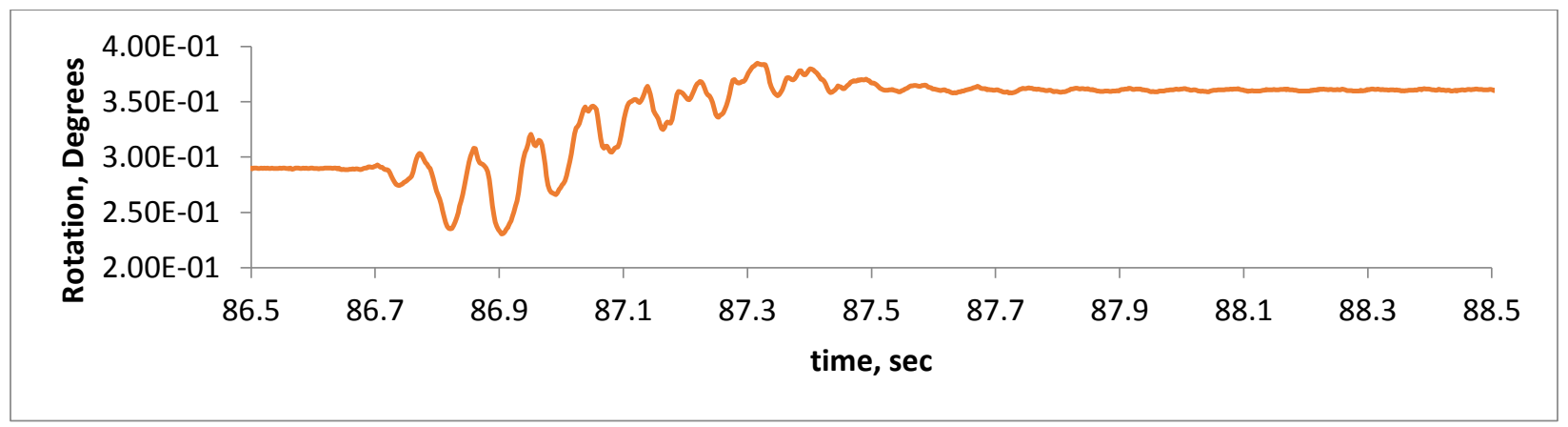

Figure 108: Horizontal North-South Rotations. 


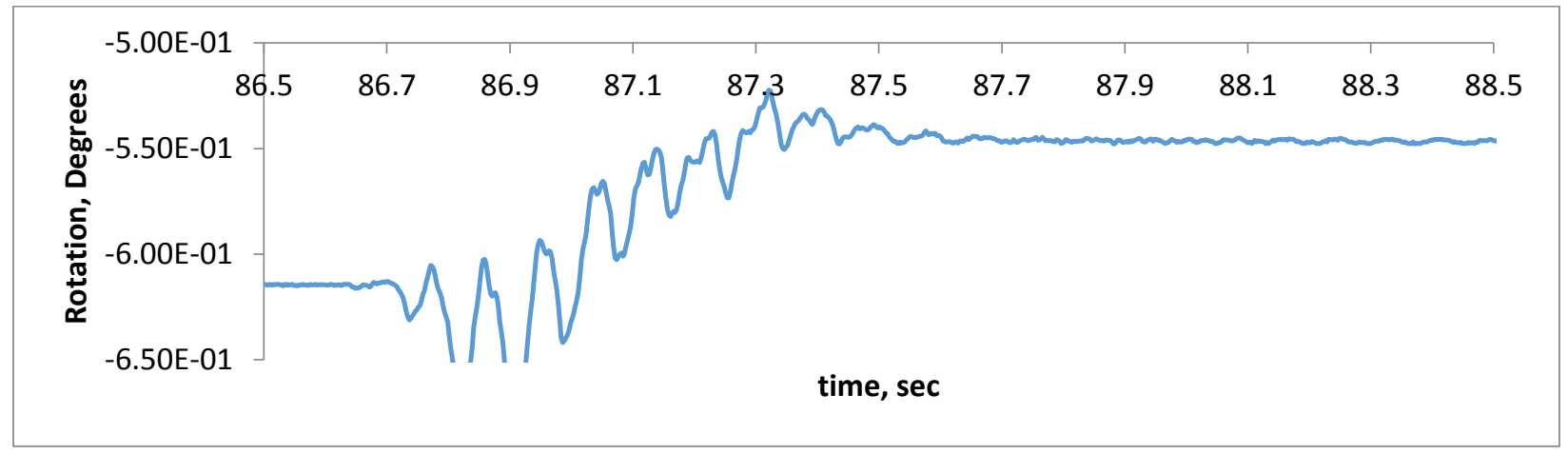

Figure 109: Horizontal East-West Rotations.

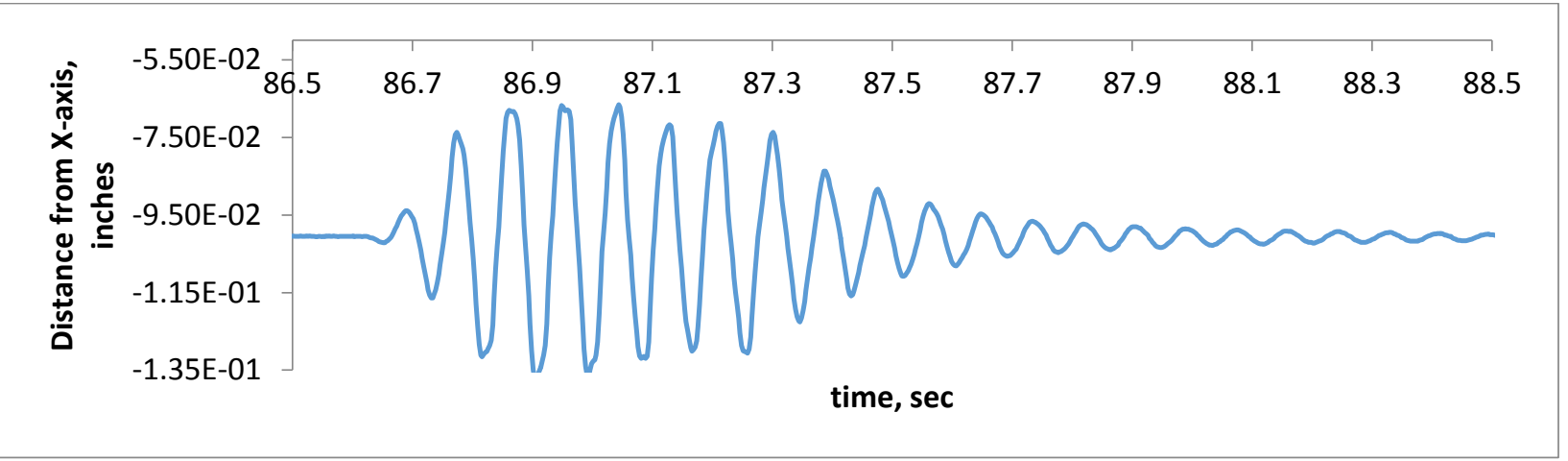

Figure 110: New X-Intercept as a function of time, ti. Negative is towards the east horizontal LVDT and positive is towards the west horizontal LVDT.

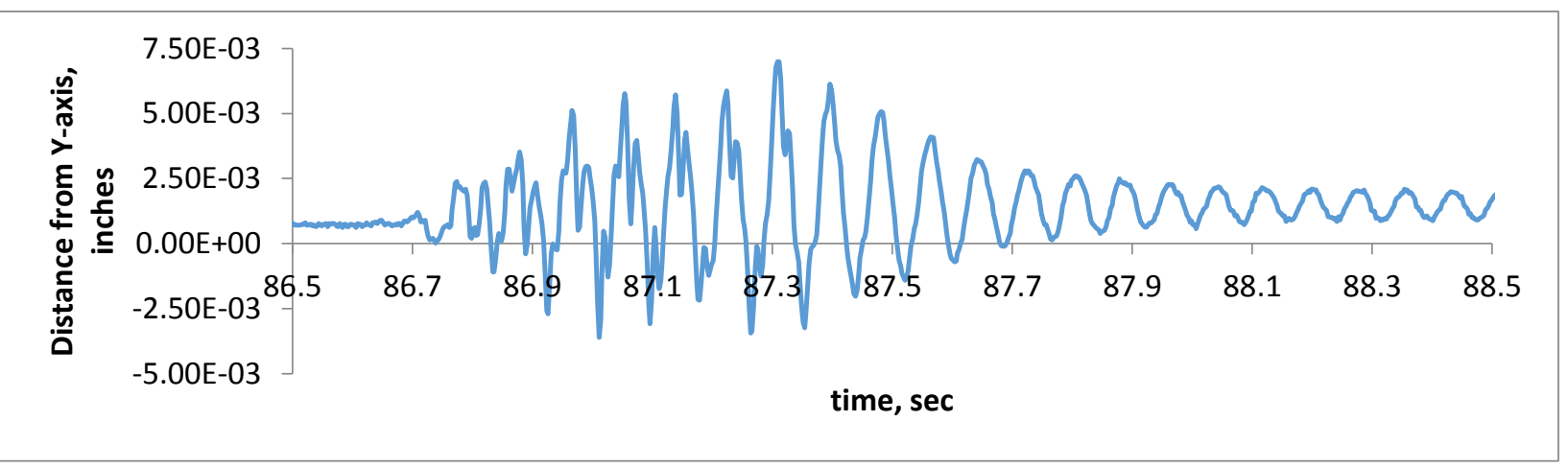

Figure 111: New Y-Intercept as a function of time, ti. Negative is towards the south horizontal LVDT and positive is towards the north horizontal LVDT.

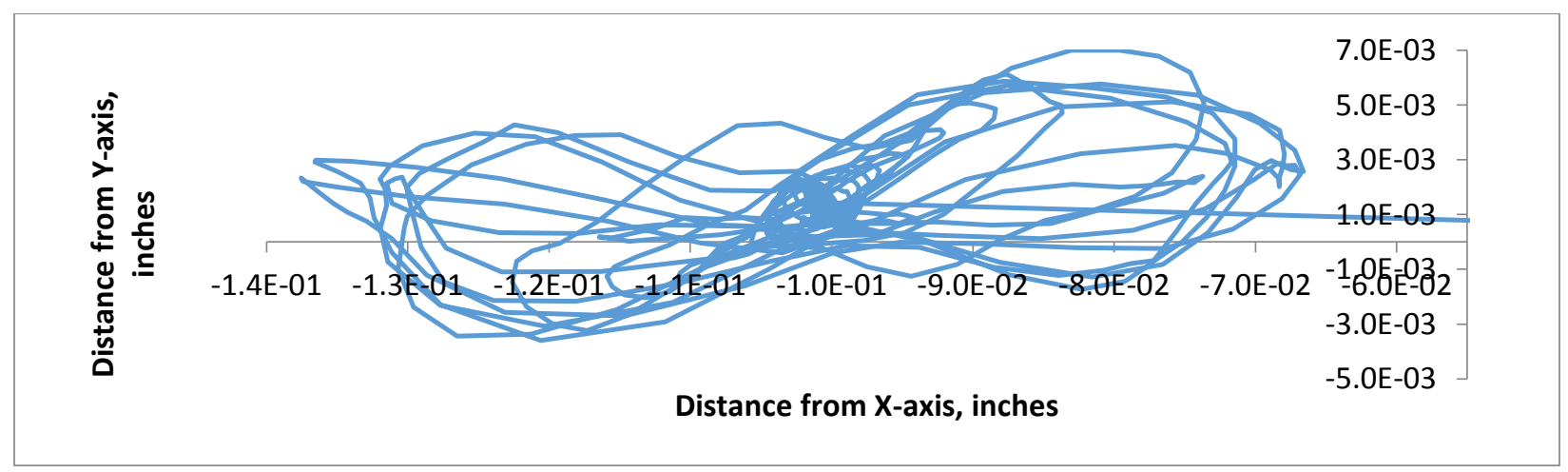

Figure 112: Changing $X \& Y$ Intercept as a function of time, ti. 


\section{SB 1.52g: Vertical Pivot Point and Rotation Angle}

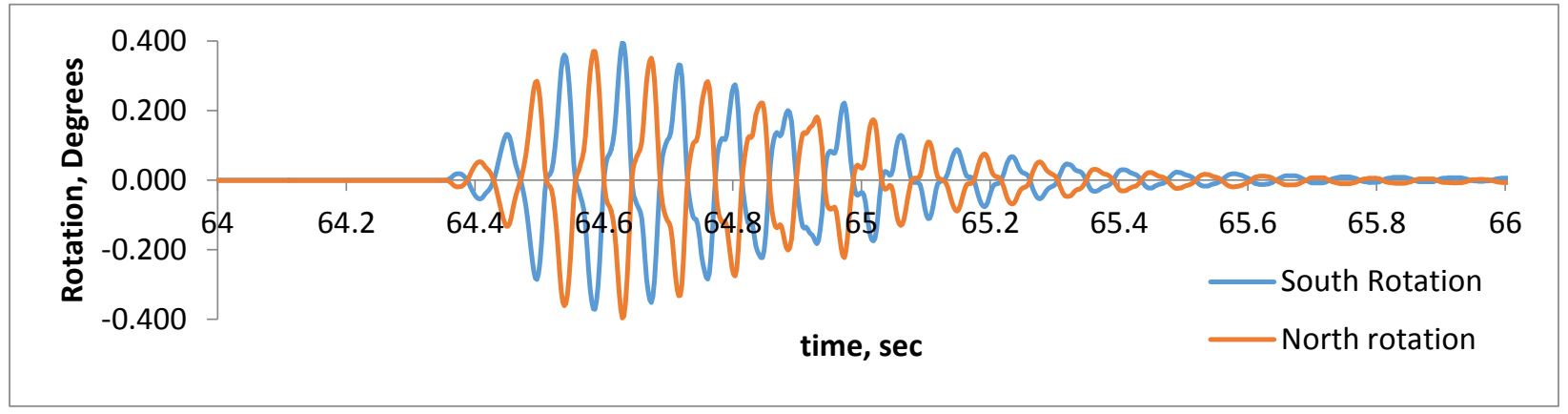

Figure 113: Rotations in the North-South Direction.

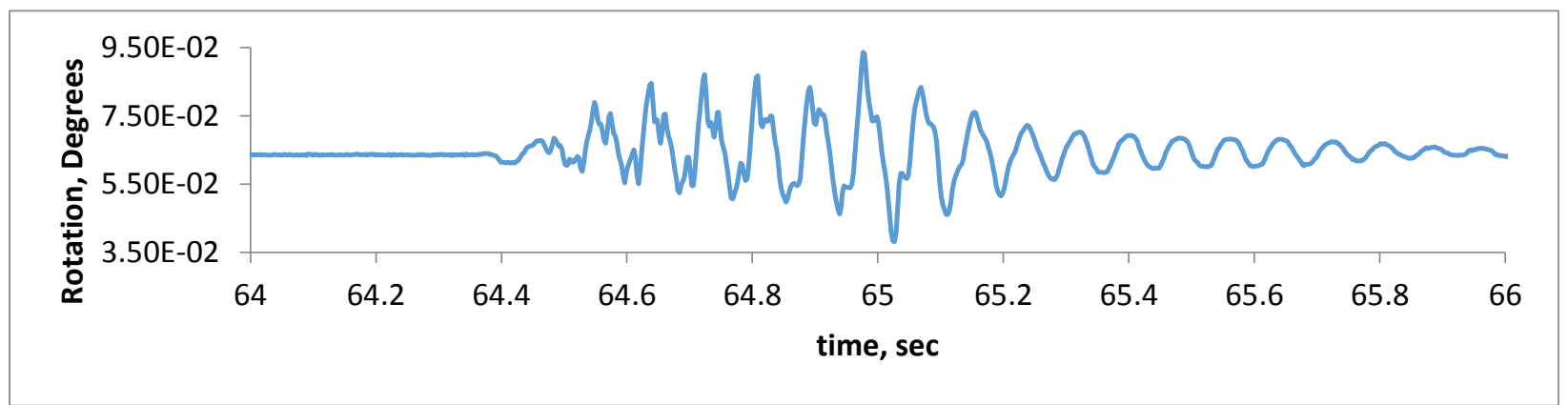

Figure 114: Rotations in the West Direction

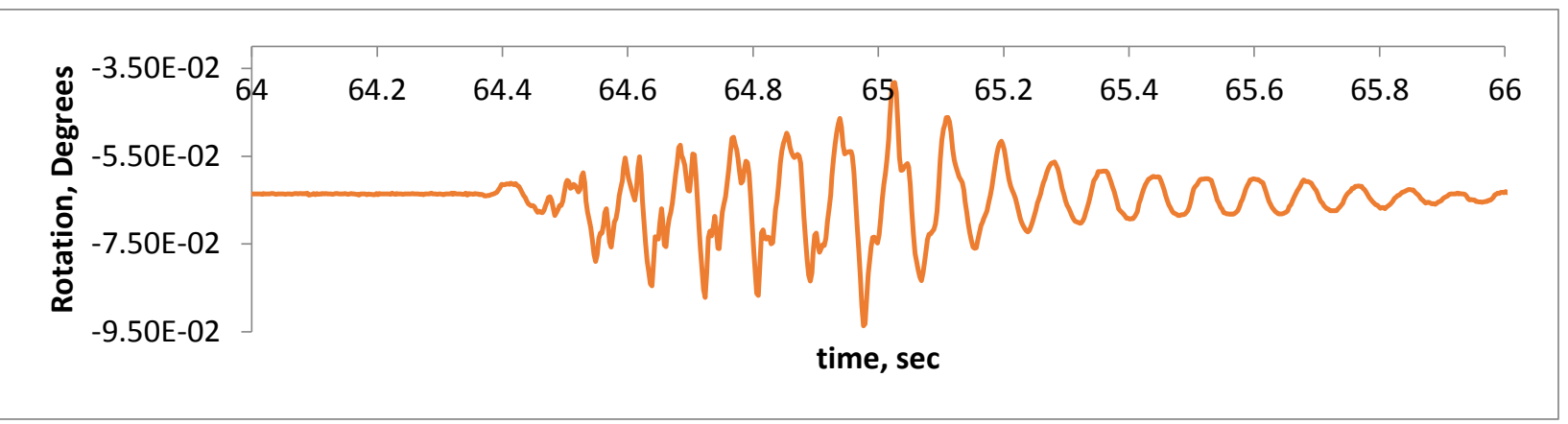

Figure 115: Rotations in the East Direction.

\section{SB 1.52g: Horizontal Rotations and New $X$ and $Y$ intercepts}

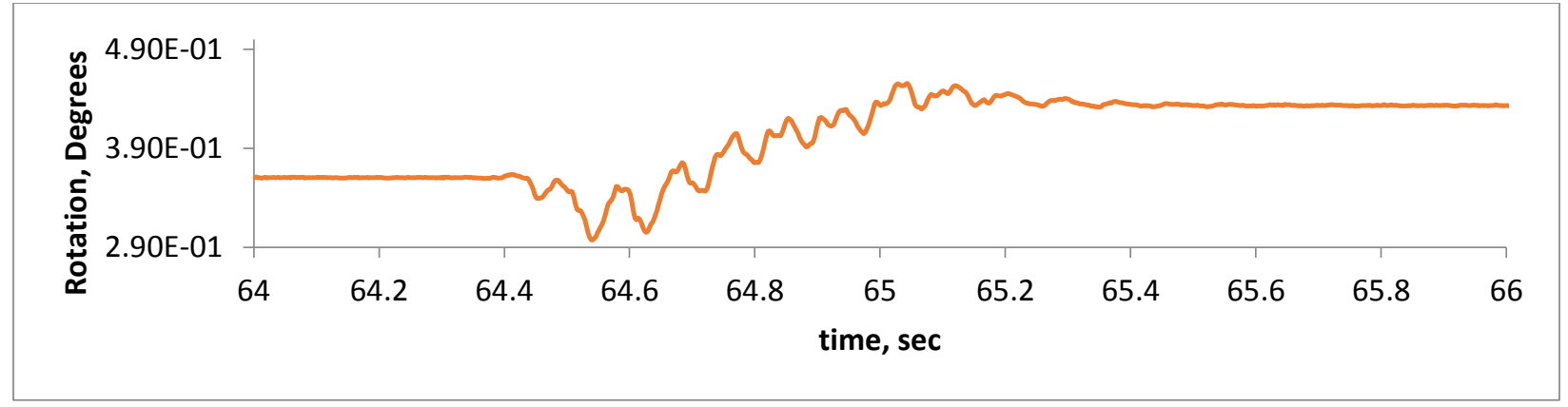

Figure 116: Horizontal North-South Rotations. 


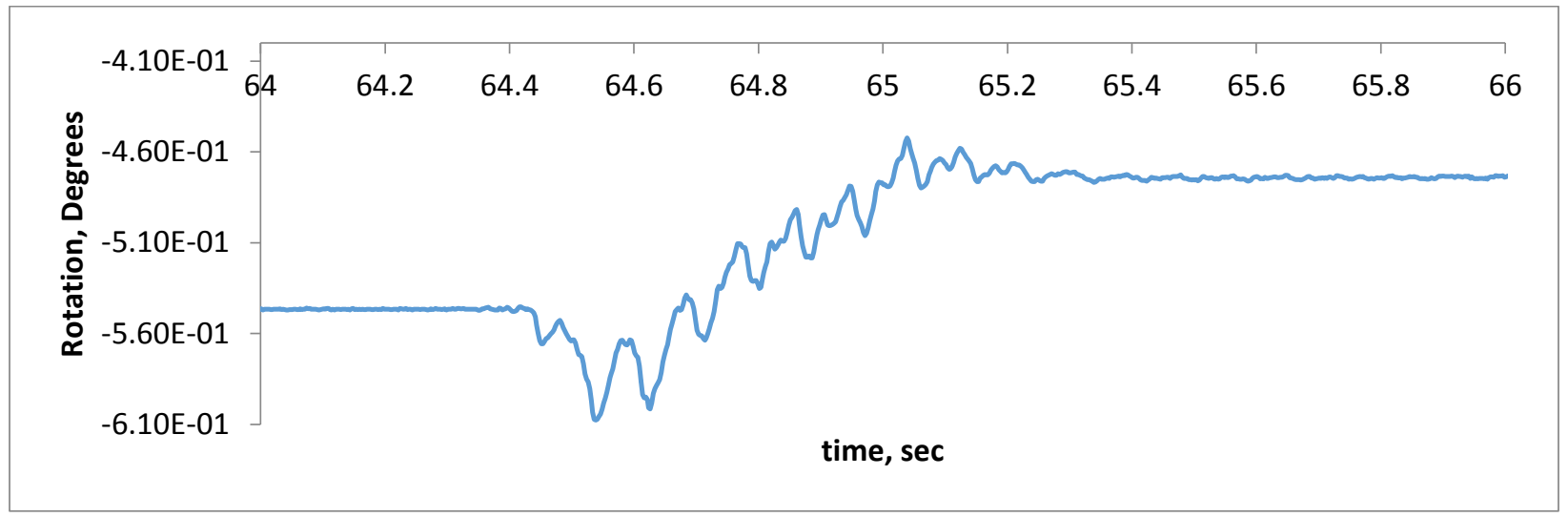

Figure 117: Horizontal East-West Rotations.

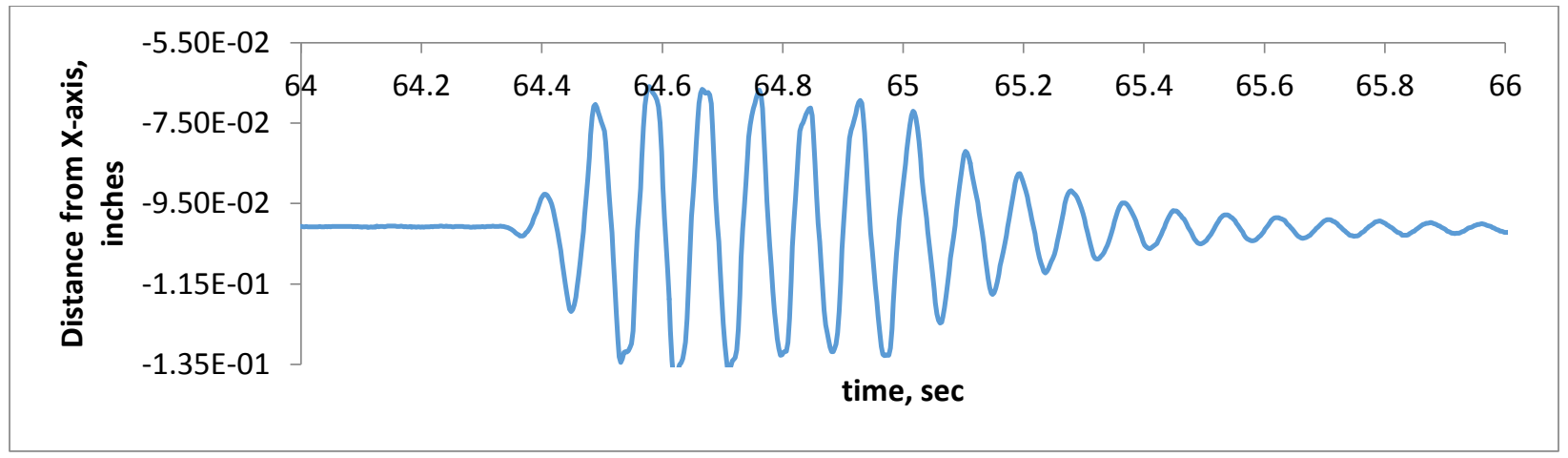

Figure 118: New X-Intercept as a function of time, ti. Negative is towards the east horizontal LVDT and positive is towards the west horizontal LVDT.

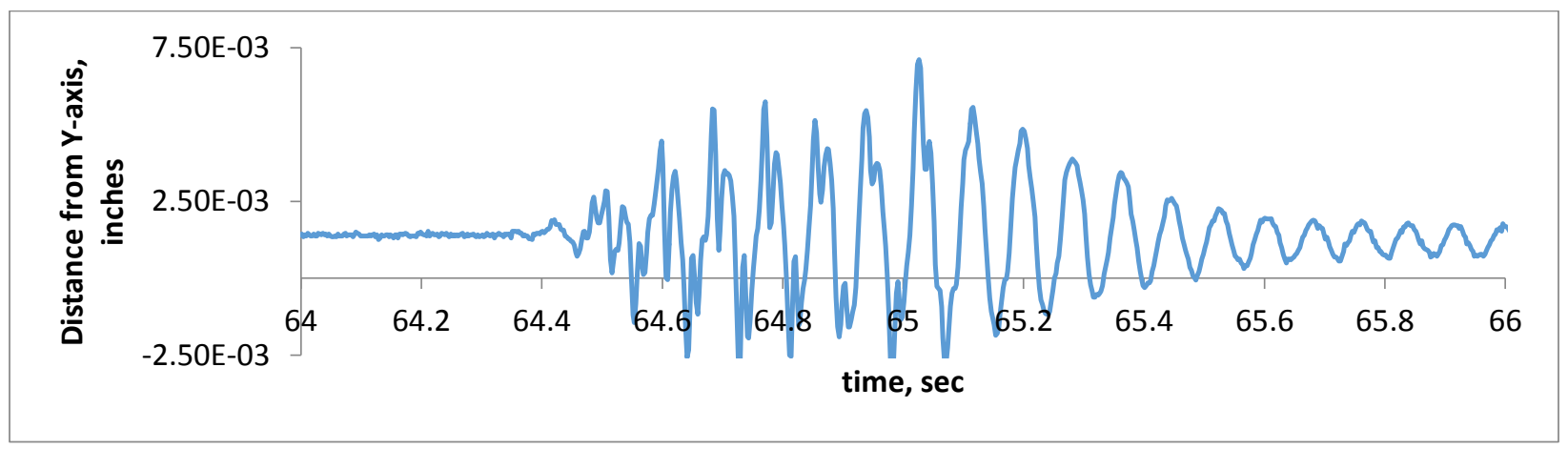

Figure 119: New Y-Intercept as a function of time, ti. Negative is towards the south horizontal LVDT and positive is towards the north horizontal LVDT.

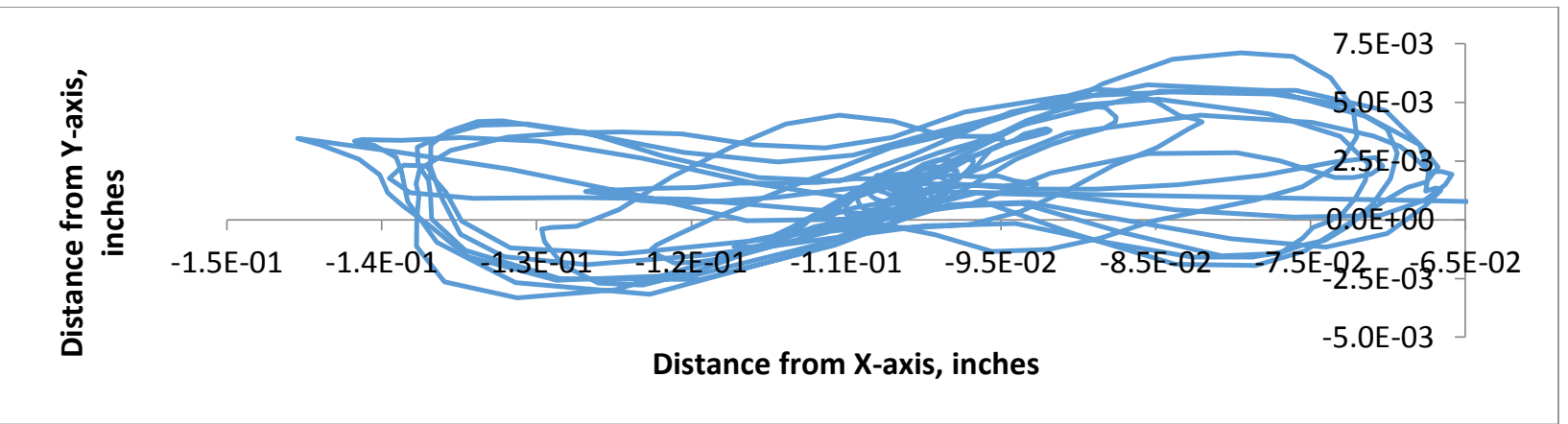

Figure 120: Changing X \& Y Intercept as a function of time, ti. 


\section{Appendix F \\ Figures for Interface Analysis at the Porcelain Flange Interface \\ Bushing 2 - Ground Motions}

\section{Table of Contents}

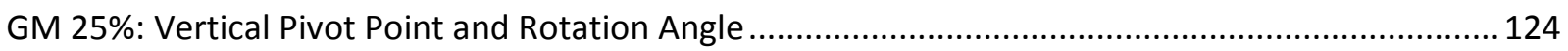

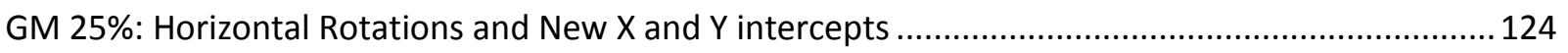

GM 50\%: Vertical Pivot Point and Rotation Angle ......................................................................... 126

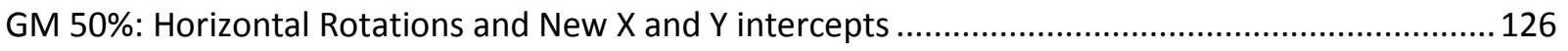

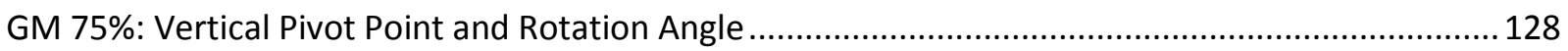

GM 75\%: Horizontal Rotations and New $X$ and $Y$ intercepts ......................................................... 128

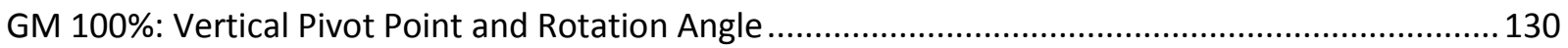

GM 100\%: Horizontal Rotations and New $X$ and $Y$ intercepts ..................................................... 130

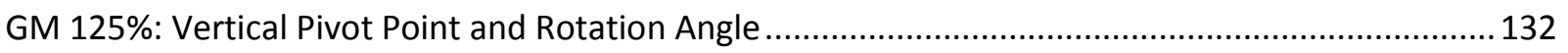

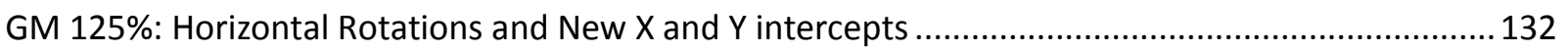

GM 137.5\%: Vertical Pivot Point and Rotation Angle ...................................................................... 134

GM 137.5\%: Horizontal Rotations and New $X$ and $Y$ intercepts ..................................................... 134

GM 150\%: Vertical Pivot Point and Rotation Angle ........................................................................ 136

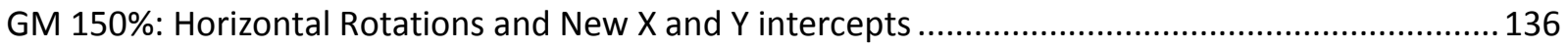

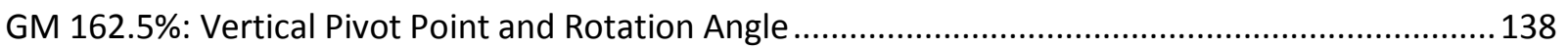

GM 162.5\%: Horizontal Rotations and New X and Y intercepts ..................................................... 138

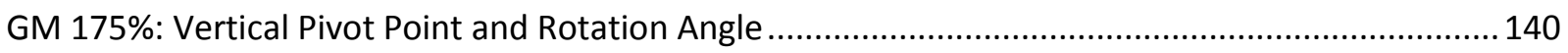

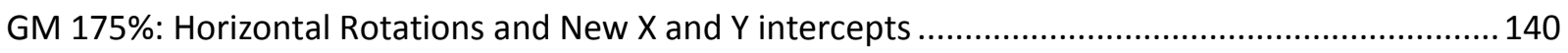




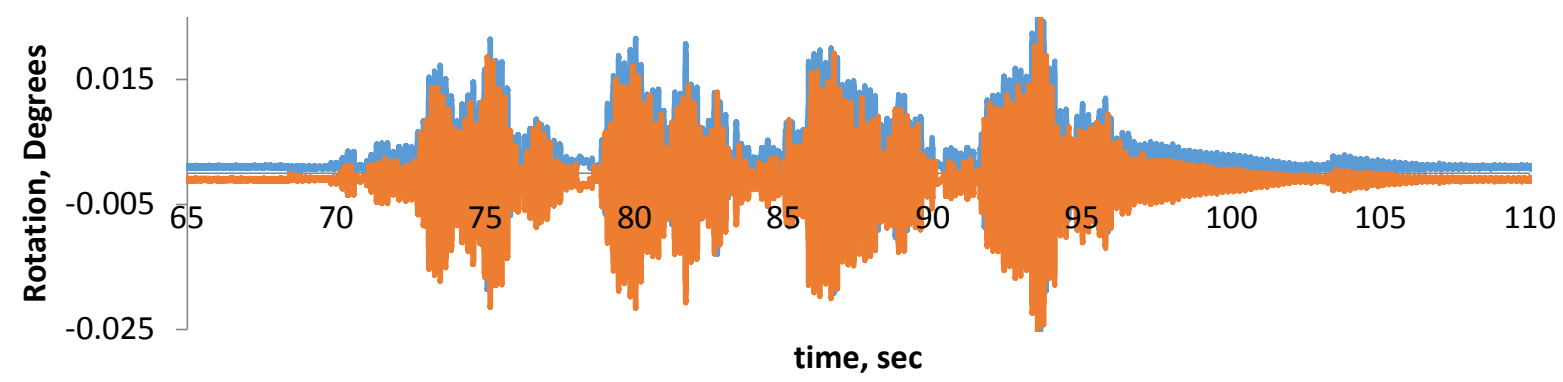

Figure 1: Rotations in the North-South Direction.

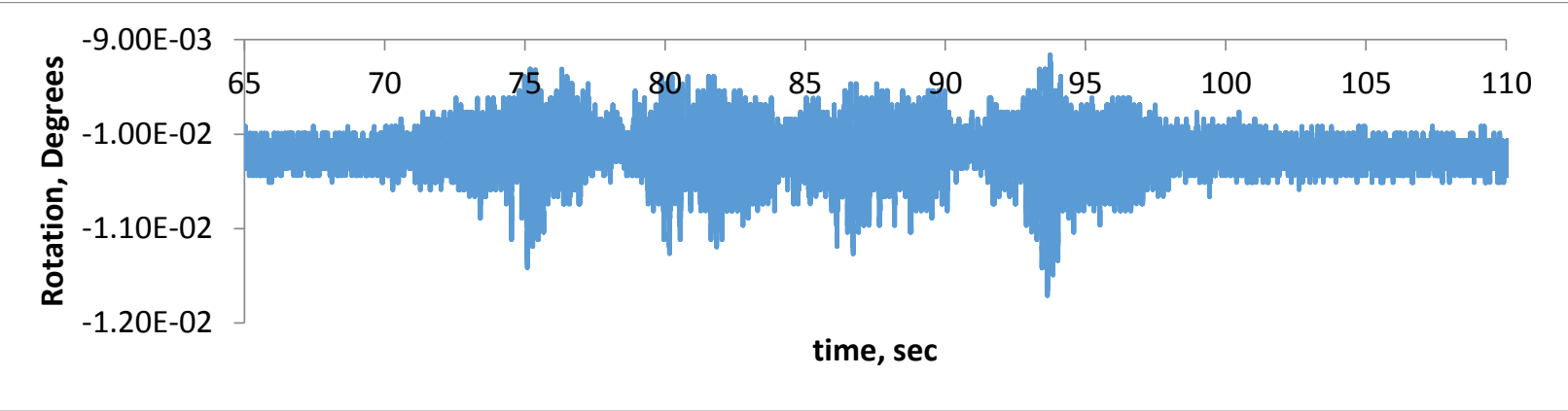

Figure 2: Rotations in the West Direction

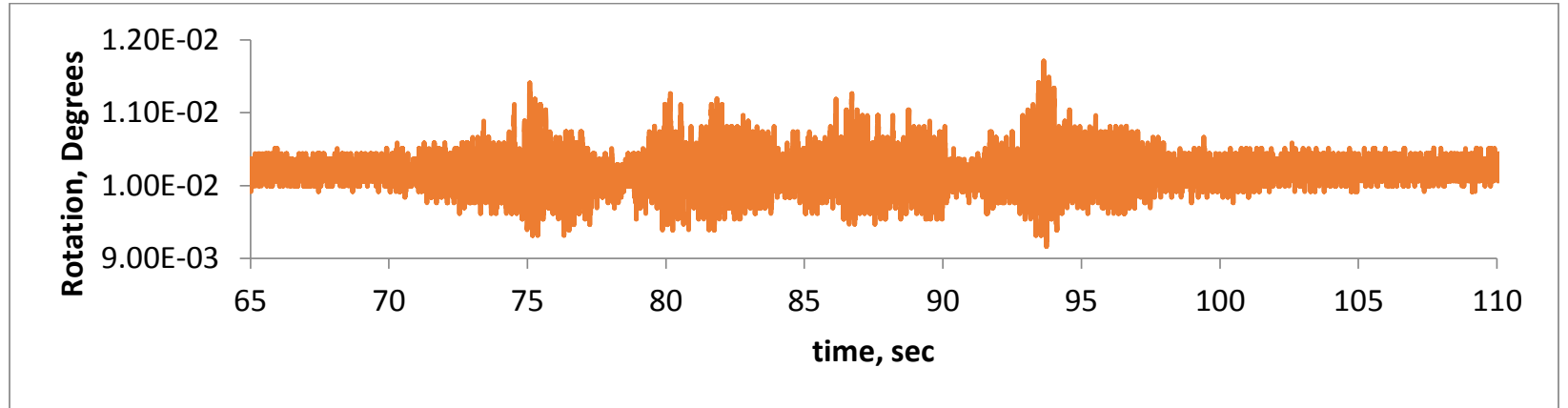

Figure 3: Rotations in the East Direction

\section{GM 25\%: Horizontal Rotations and New $X$ and $Y$ intercepts}

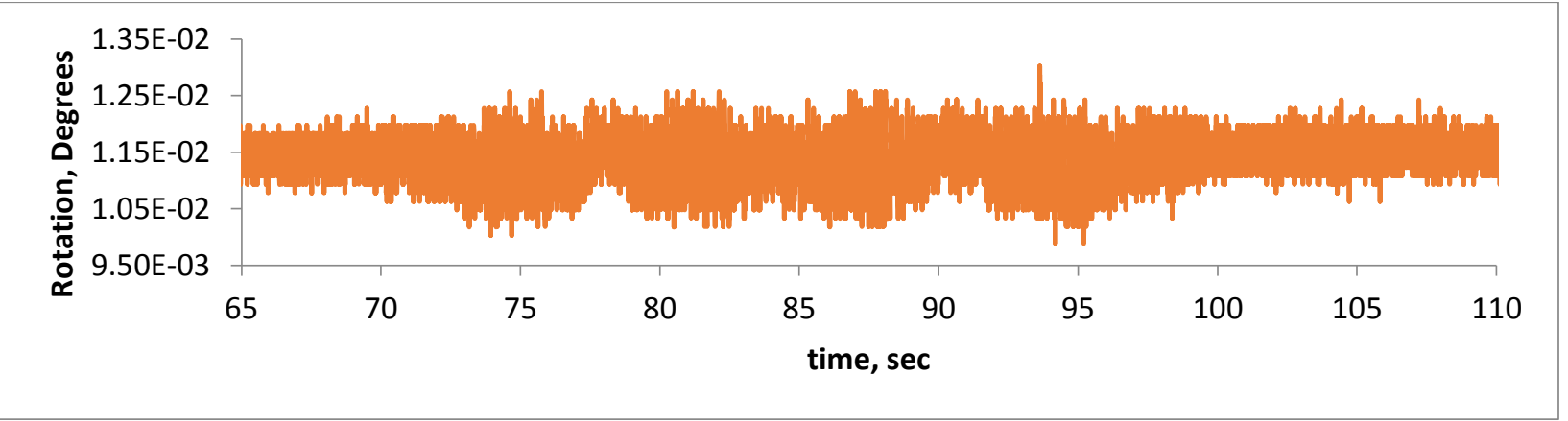

Figure 4: Horizontal North-South Rotations. 


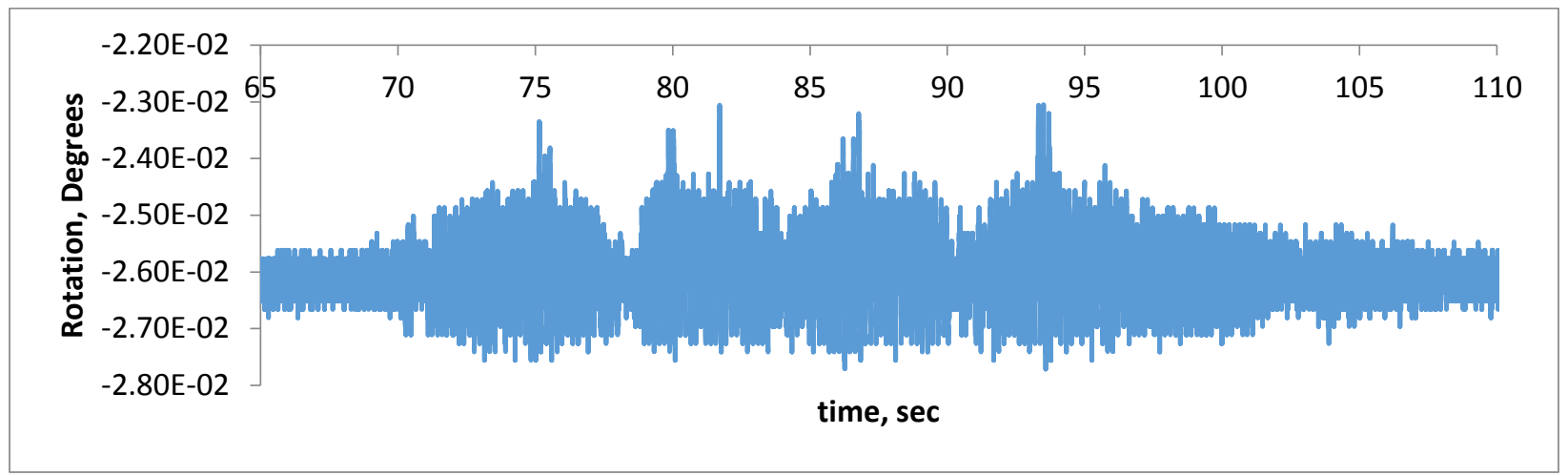

Figure 5: Horizontal East-West Rotations.

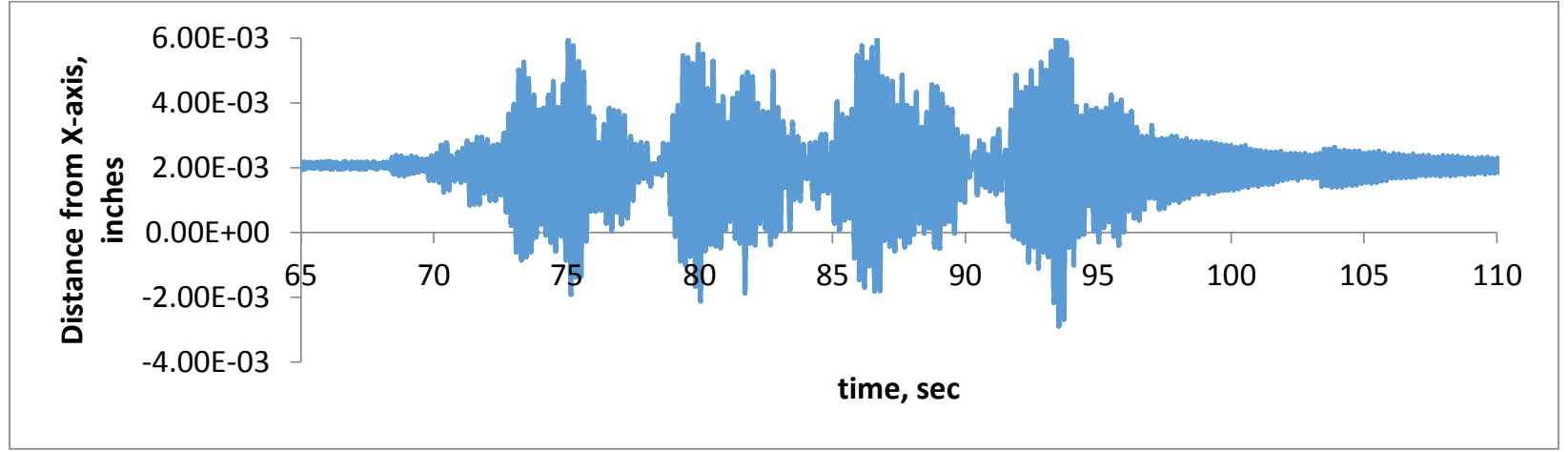

Figure 6: New X-Intercept as a function of time, ti. Negative is towards the east horizontal LVDT and positive is towards the west horizontal LVDT.

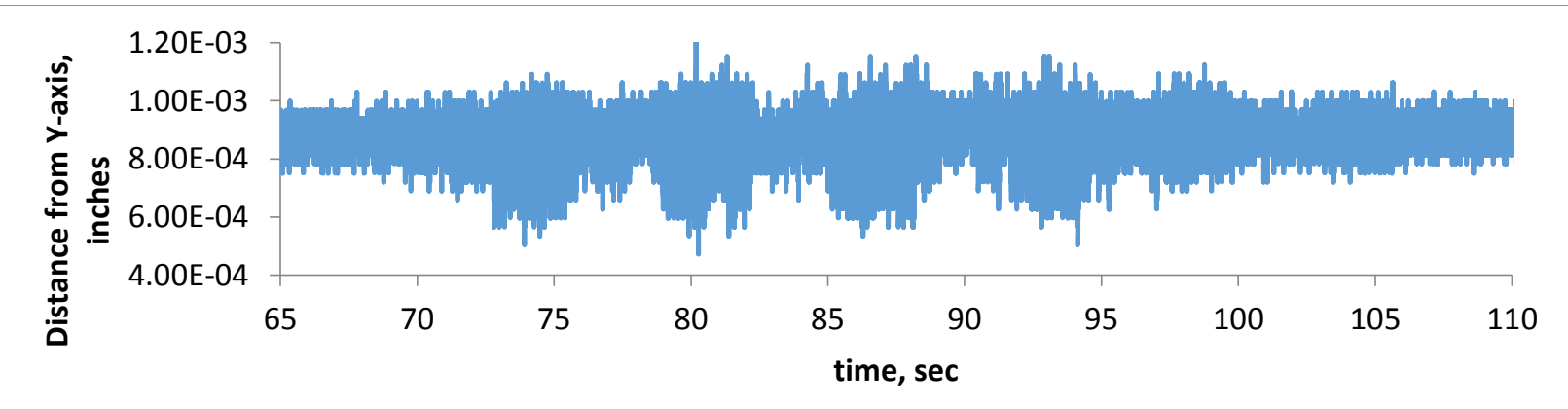

Figure 7: New Y-Intercept as a function of time, ti. Negative is towards the south horizontal LVDT and positive is towards the north horizontal LVDT.

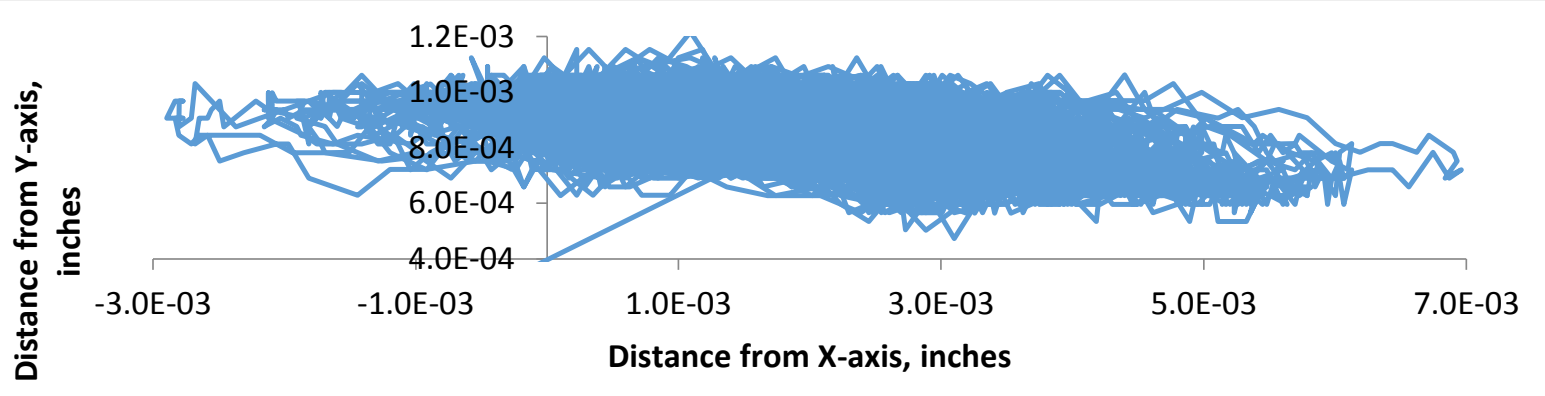

Figure 8: Changing X \& Y Intercept as a function of time, ti. 


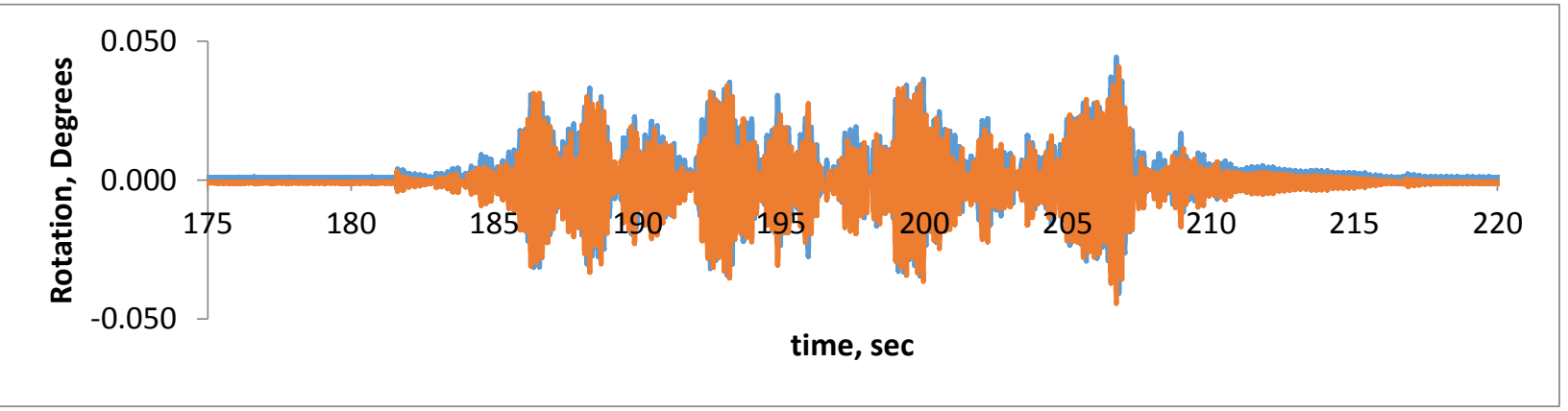

Figure 9: Rotations in the North-South Direction.

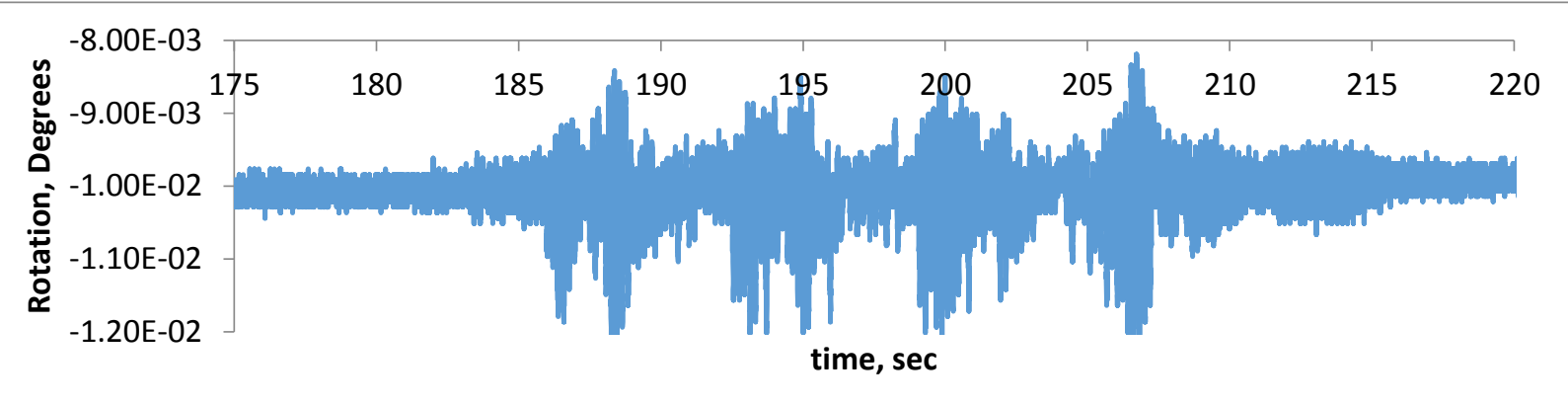

Figure 10: Rotations in the West Direction

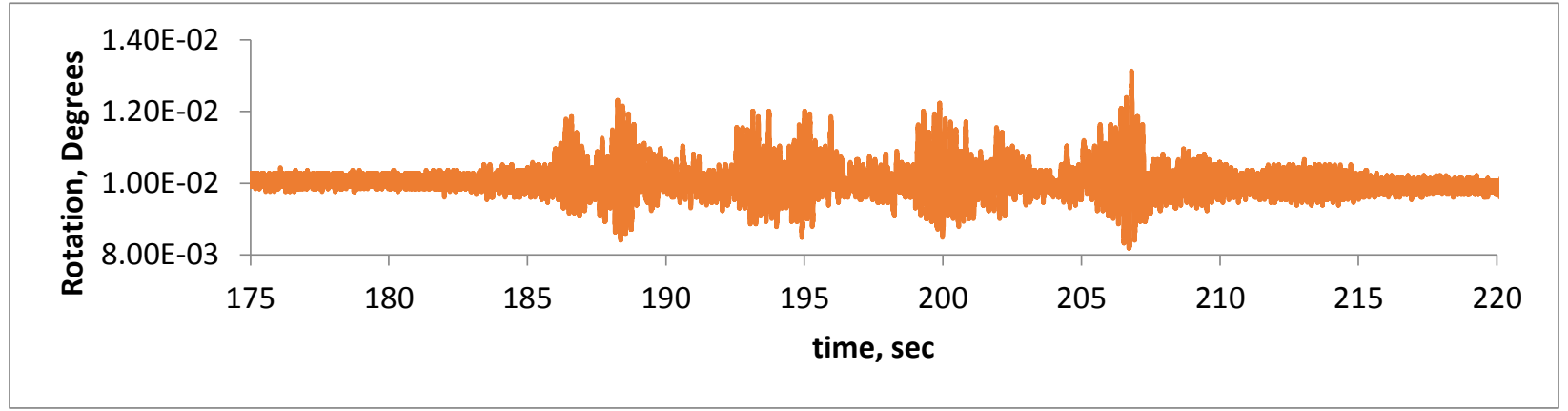

Figure 11: Rotations in the East Direction

\section{GM 50\%: Horizontal Rotations and New X and Y intercepts}

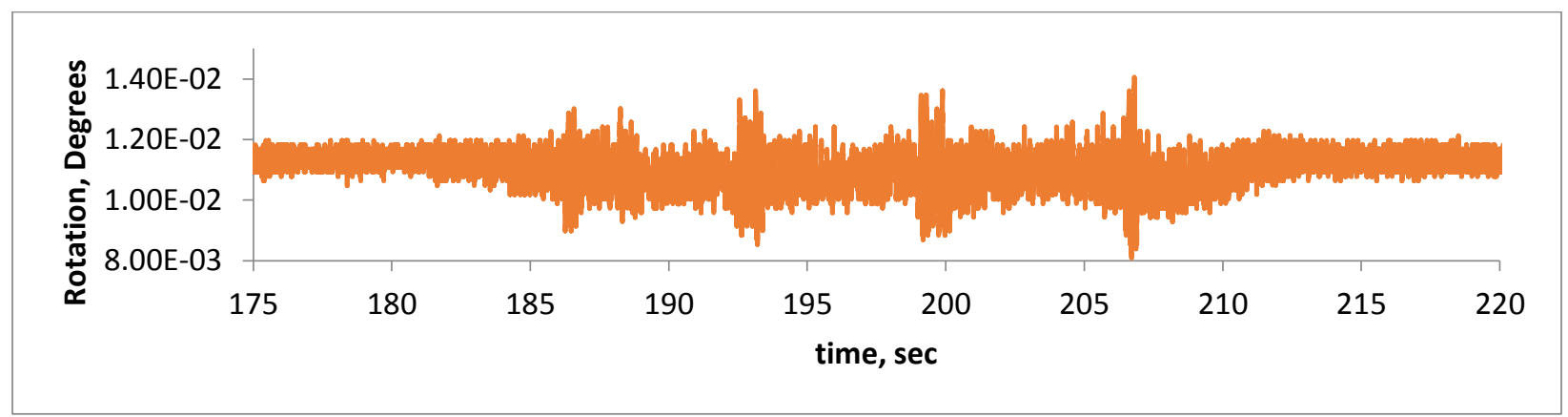

Figure 12: Horizontal North-South Rotations. 


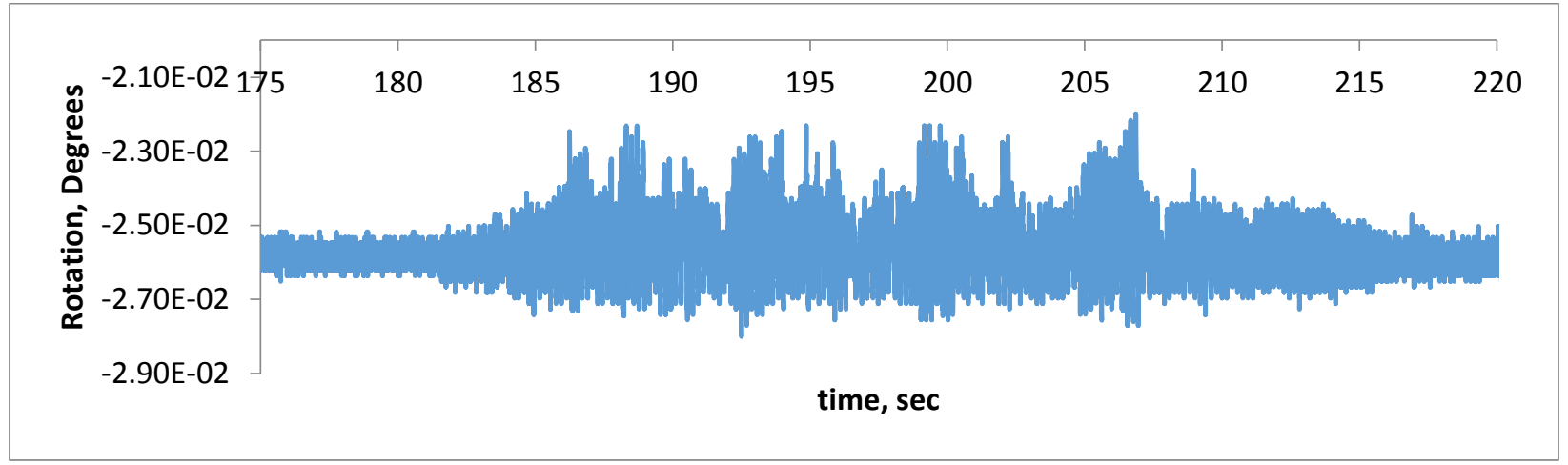

Figure 13: Horizontal East-West Rotations.

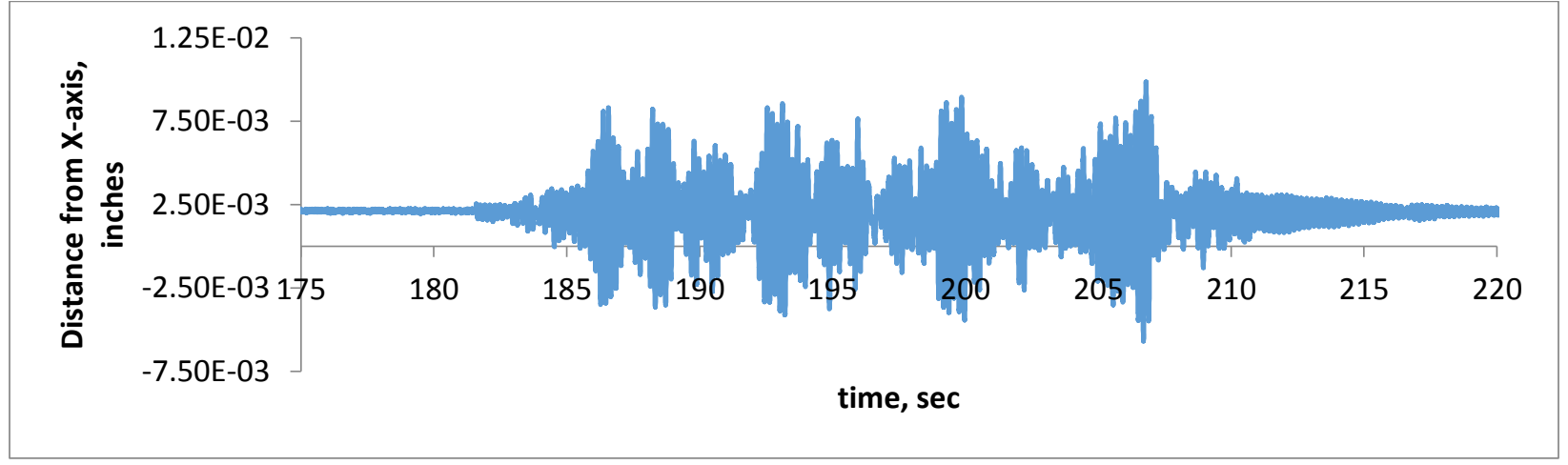

Figure 14: New X-Intercept as a function of time, ti. Negative is towards the east horizontal LVDT and positive is towards the west horizontal LVDT.

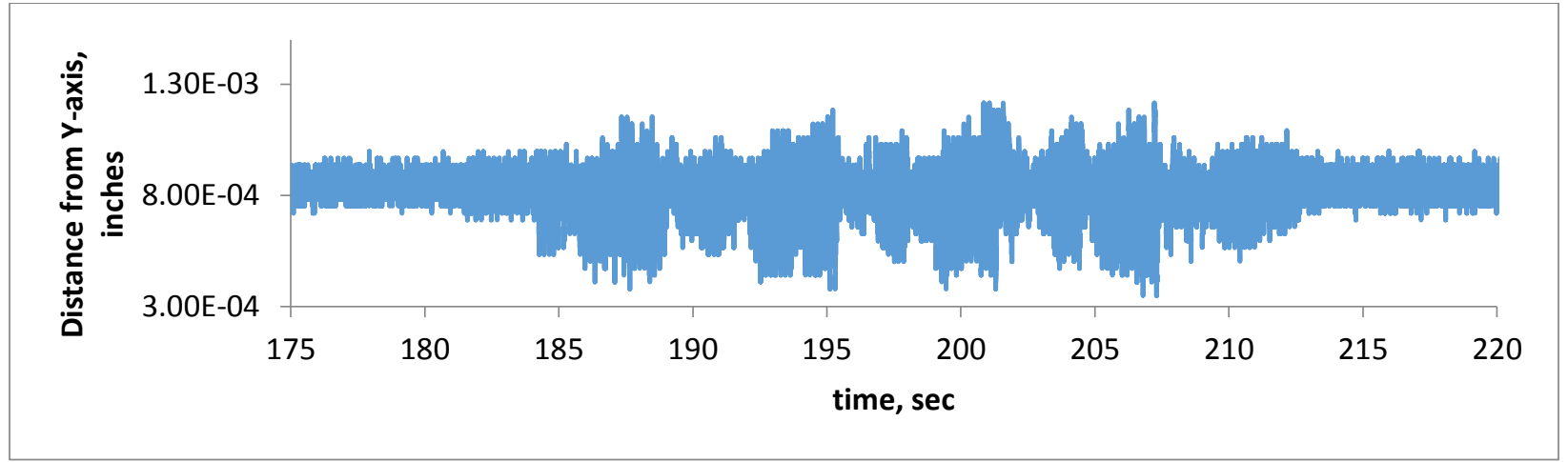

Figure 15: New Y-Intercept as a function of time, ti. Negative is towards the south horizontal LVDT and positive is towards the north horizontal LVDT.

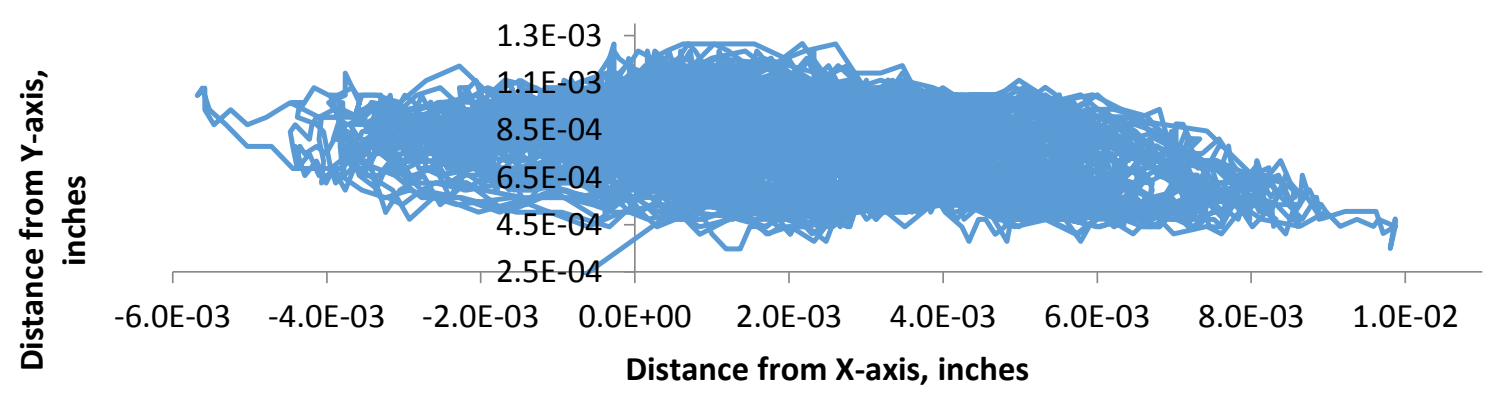

Figure 16: Changing X \& Y Intercept as a function of time, ti. 


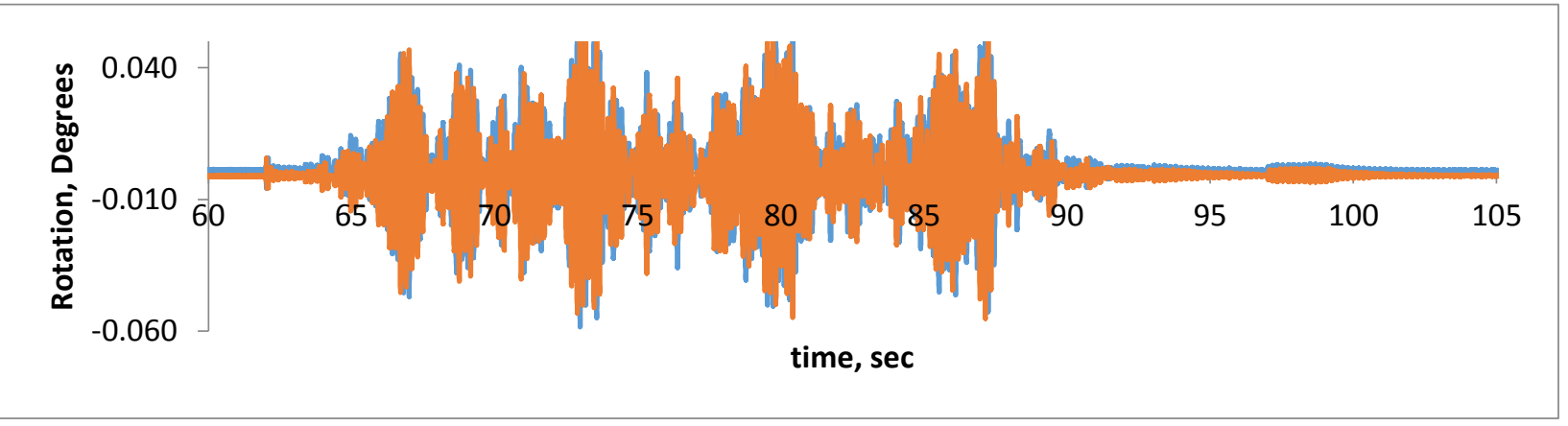

Figure 17: Rotations in the North-South Direction.

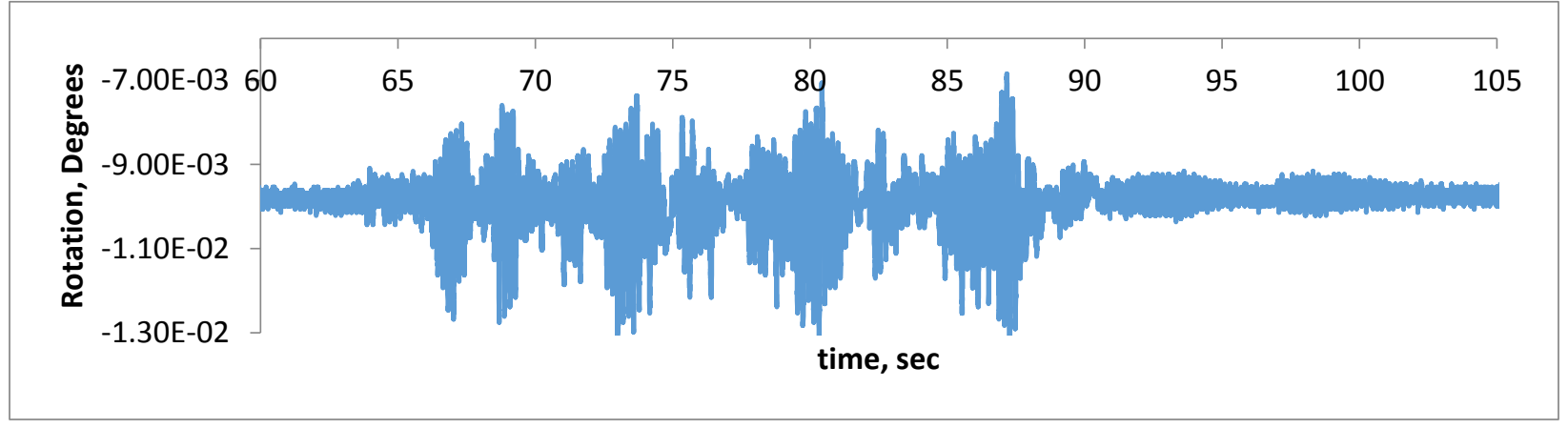

Figure 18: Rotations in the West Direction

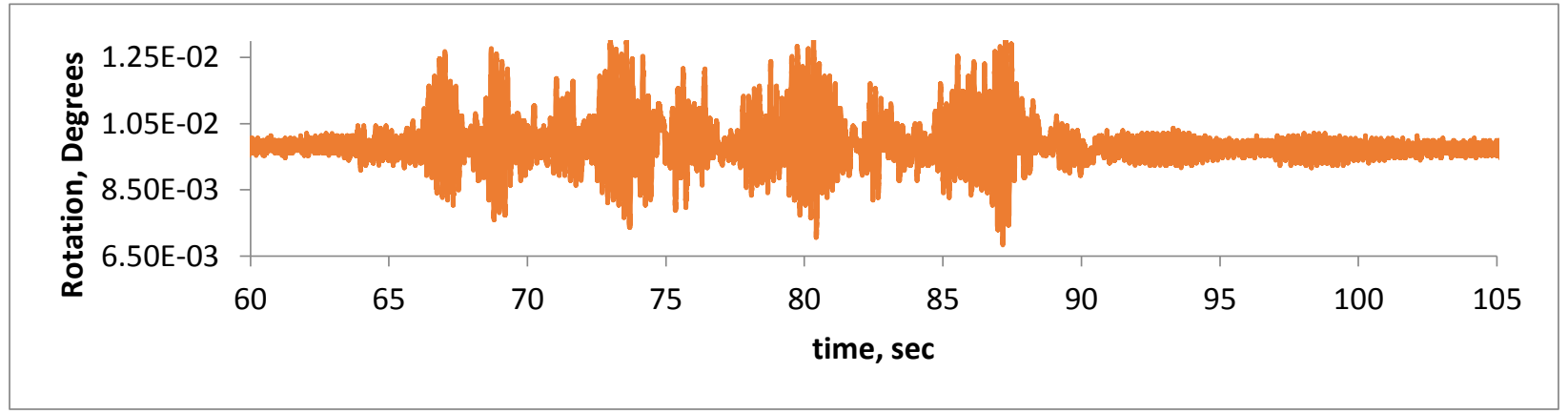

Figure 19: Rotations in the East Direction

GM 75\%: Horizontal Rotations and New $X$ and $Y$ intercepts

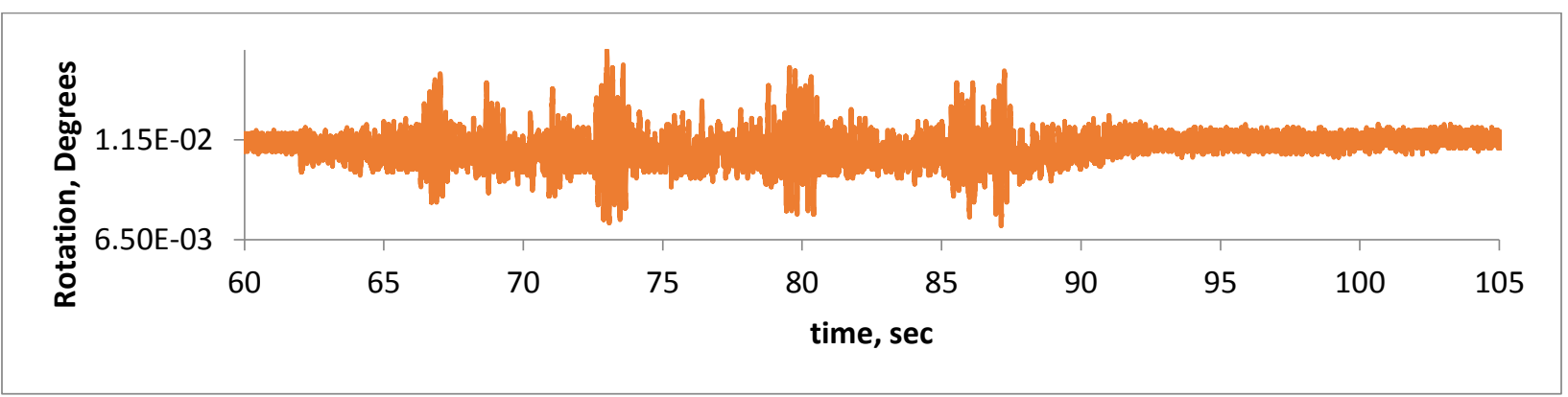

Figure 20: Horizontal North-South Rotations. 


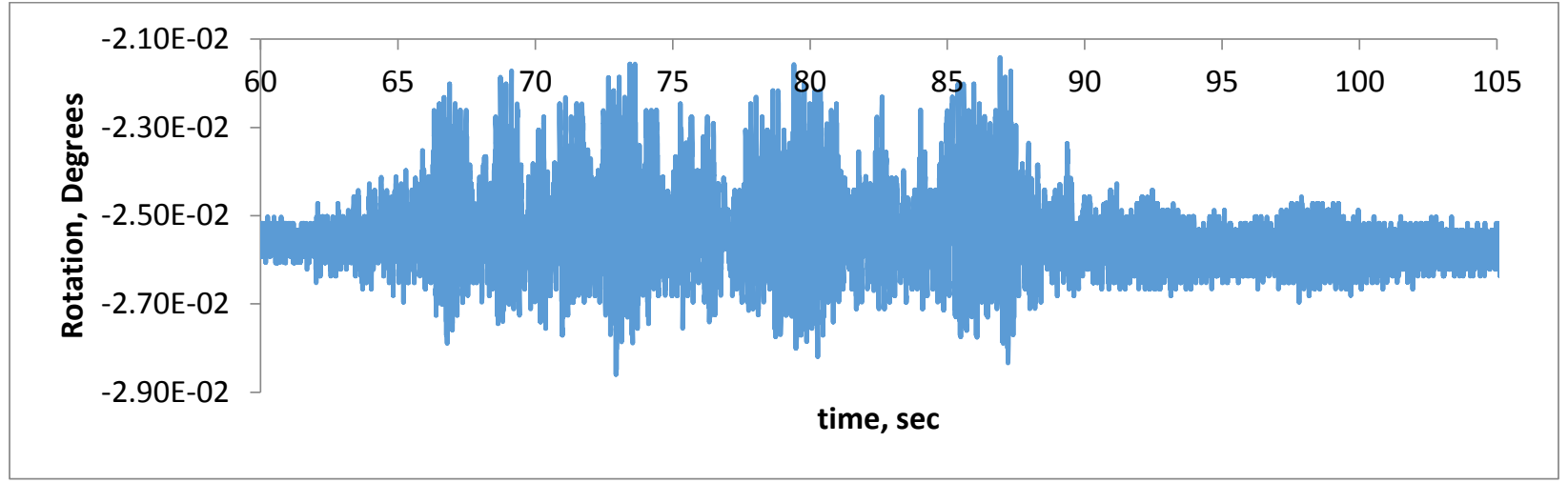

Figure 21: Horizontal East-West Rotations.

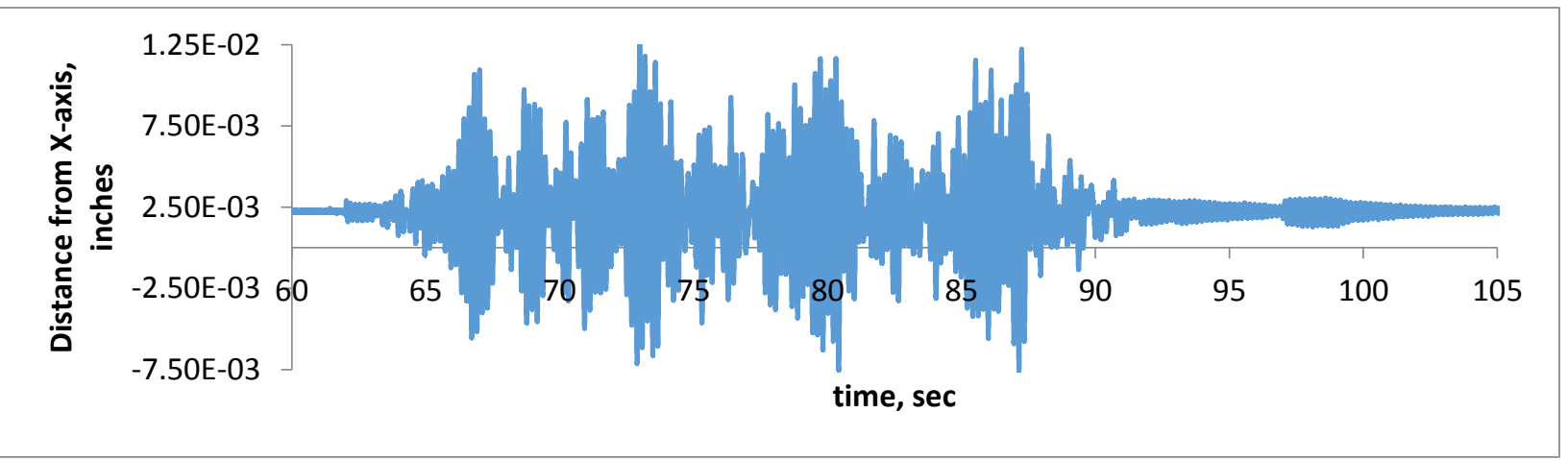

Figure 22: New X-Intercept as a function of time, ti. Negative is towards the east horizontal LVDT and positive is towards the west horizontal LVDT.

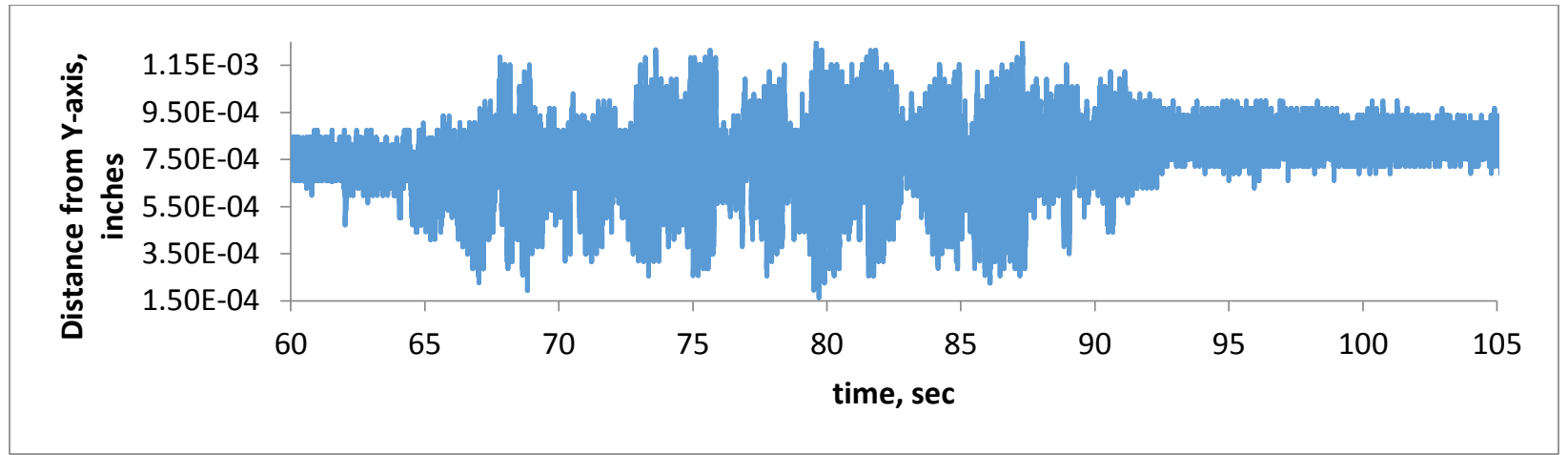

Figure 23: New Y-Intercept as a function of time, ti. Negative is towards the south horizontal LVDT and positive is towards the north horizontal LVDT.

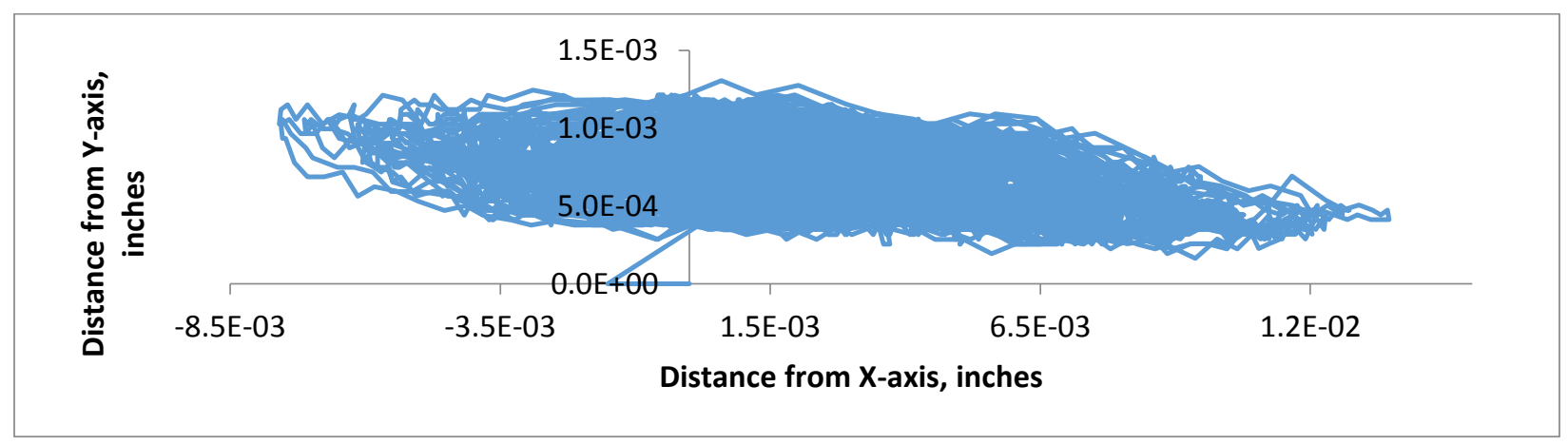

Figure 24: Changing $X \& Y$ Intercept as a function of time, ti. 


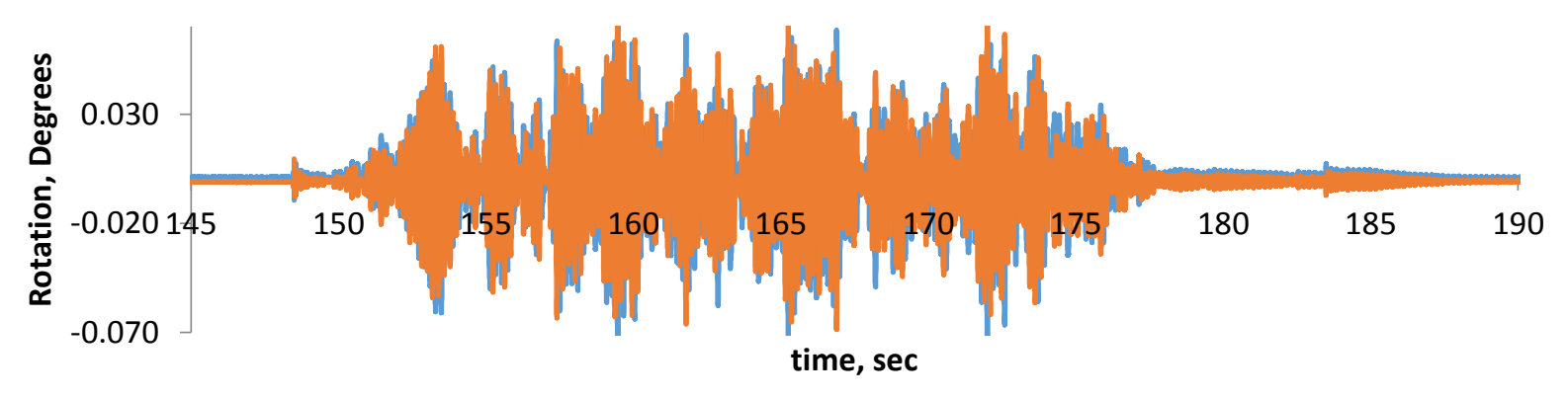

Figure 25: Rotations in the North-South Direction.

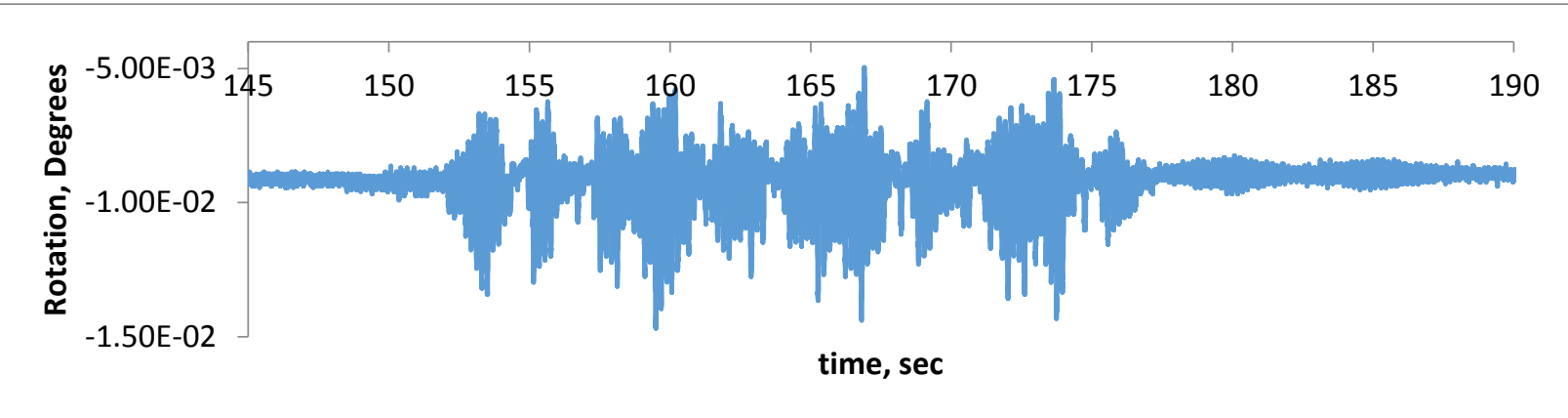

Figure 26: Rotations in the West Direction

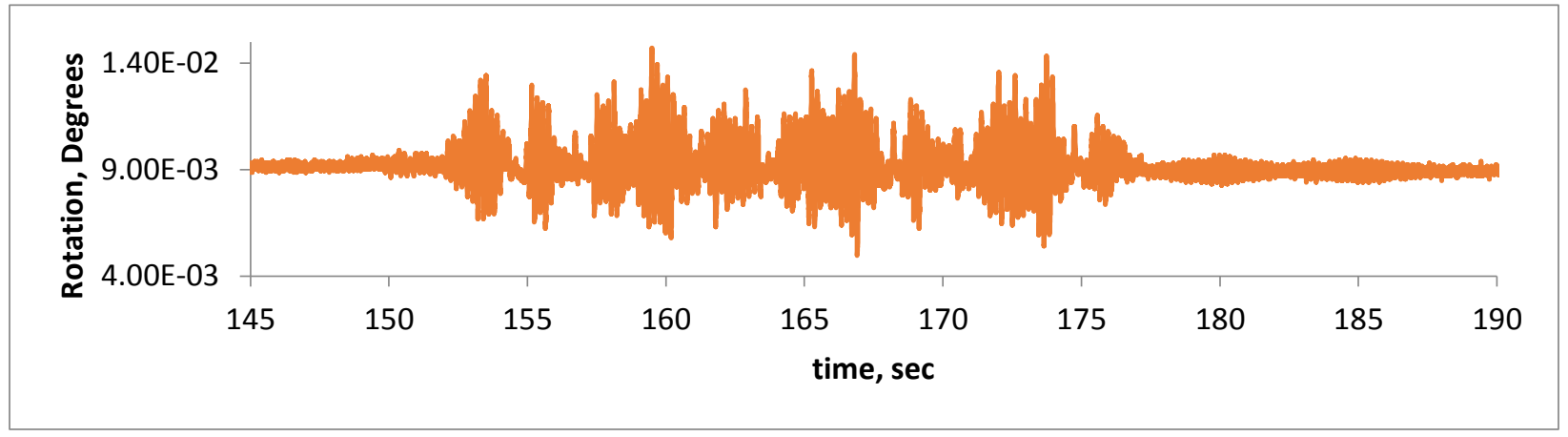

Figure 27: Rotations in the East Direction

GM 100\%: Horizontal Rotations and New $X$ and $Y$ intercepts

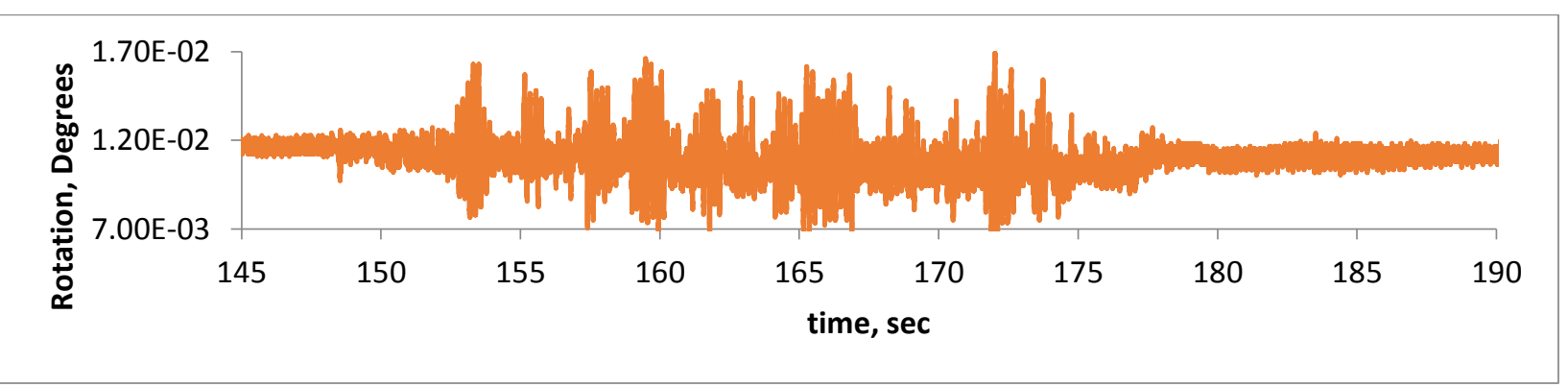

Figure 28: Horizontal North-South Rotations. 


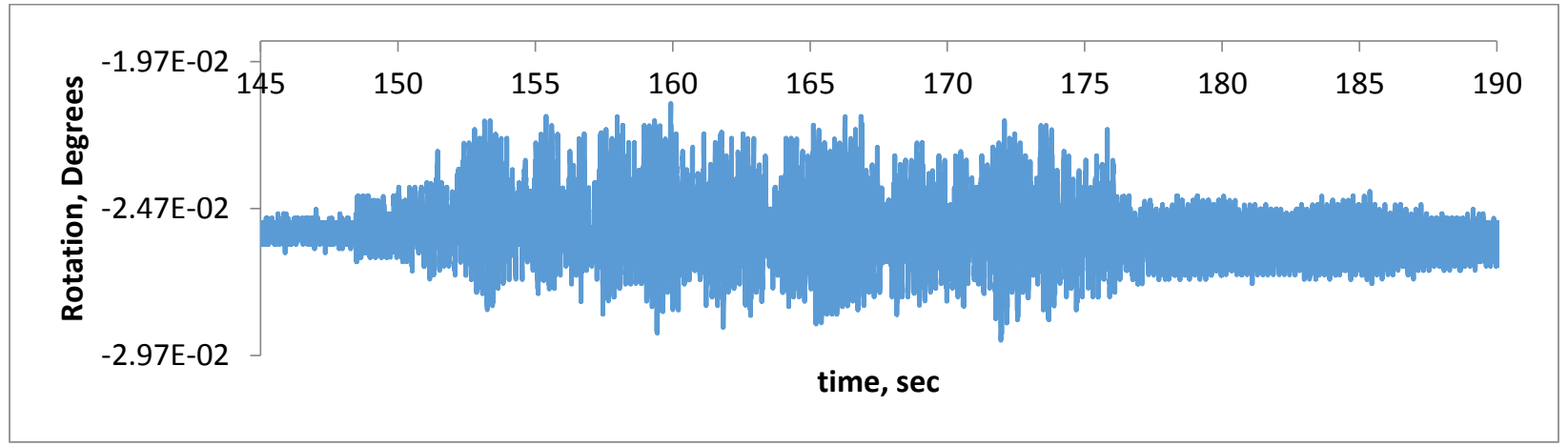

Figure 29: Horizontal East-West Rotations.

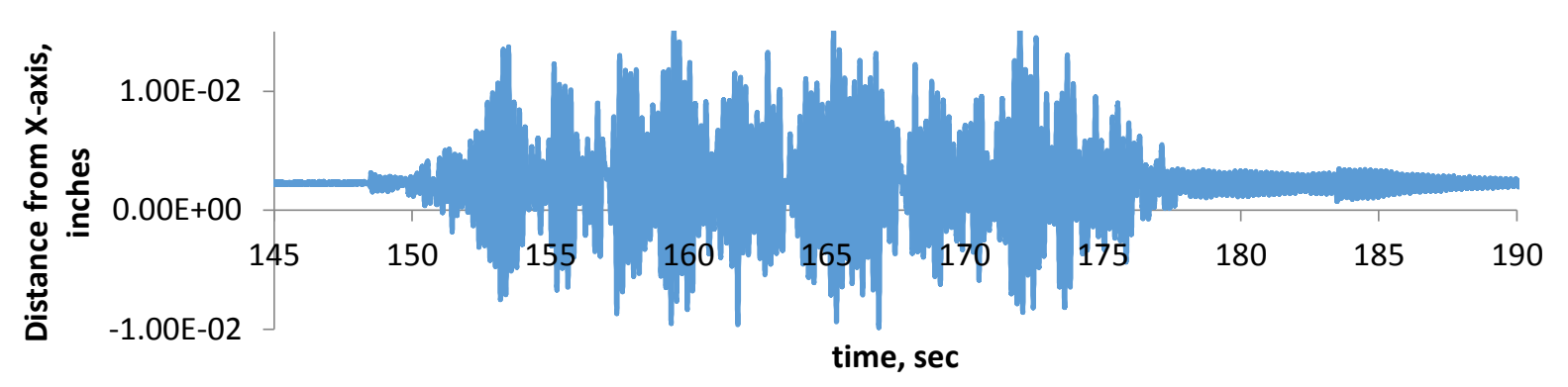

Figure 30: New X-Intercept as a function of time, ti. Negative is towards the east horizontal LVDT and positive is towards the west horizontal LVDT.

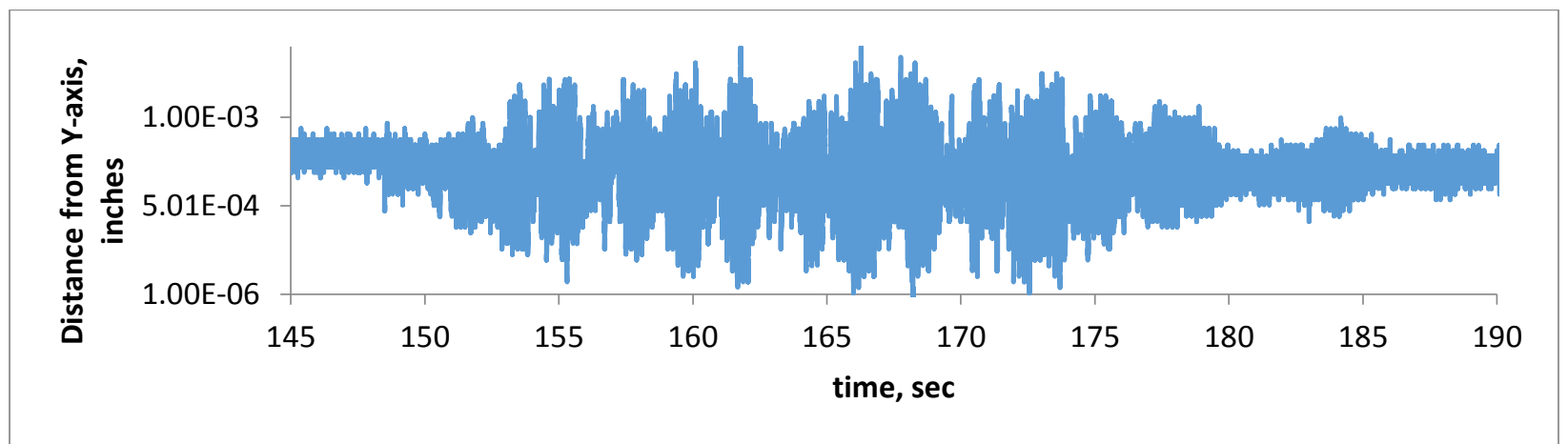

Figure 31: New Y-Intercept as a function of time, ti. Negative is towards the south horizontal LVDT and positive is towards the north horizontal LVDT.

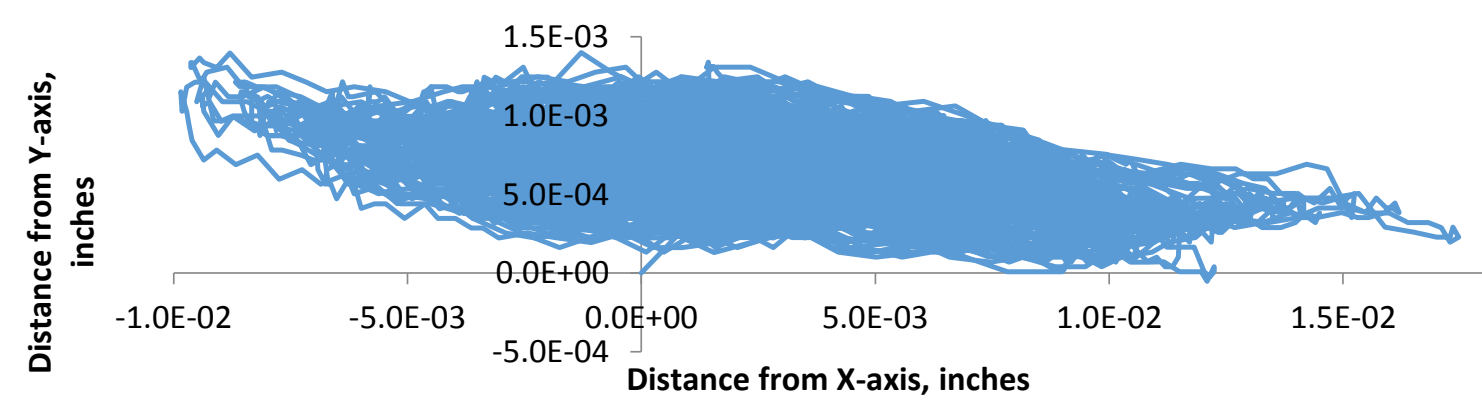

Figure 32: Changing $X \& Y$ Intercept as a function of time, ti. 


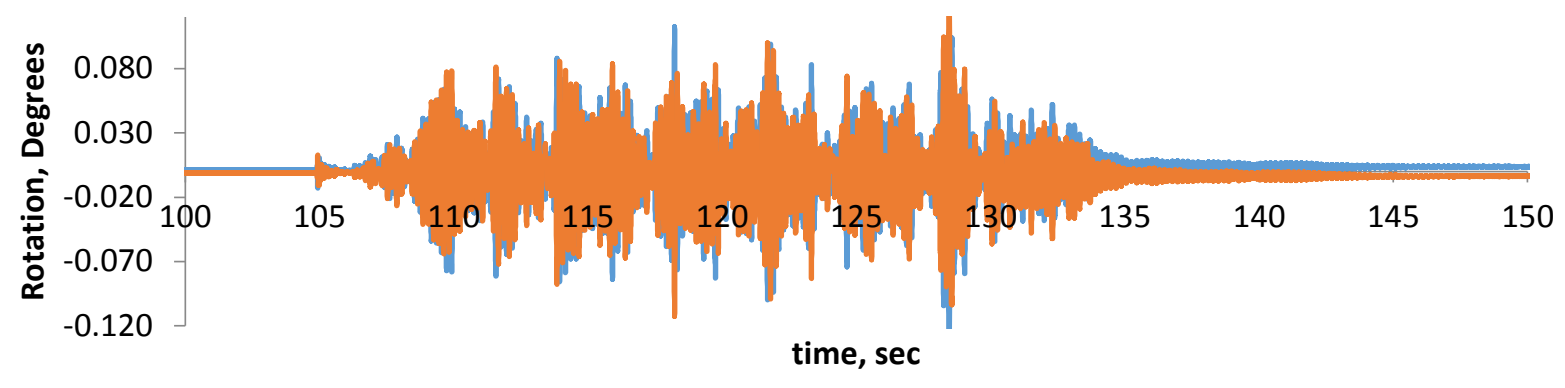

Figure 33: Rotations in the North-South Direction.

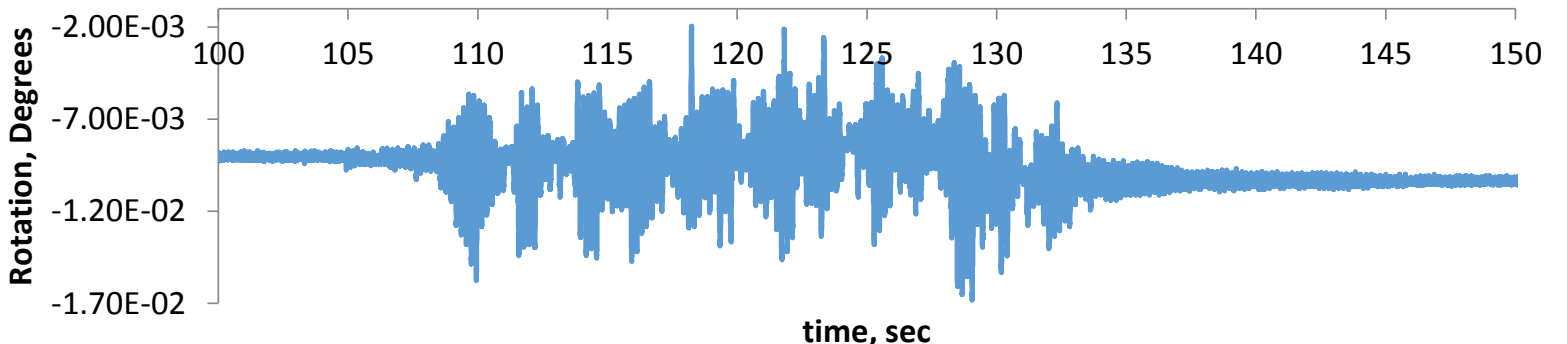

Figure 34: Rotations in the West Direction

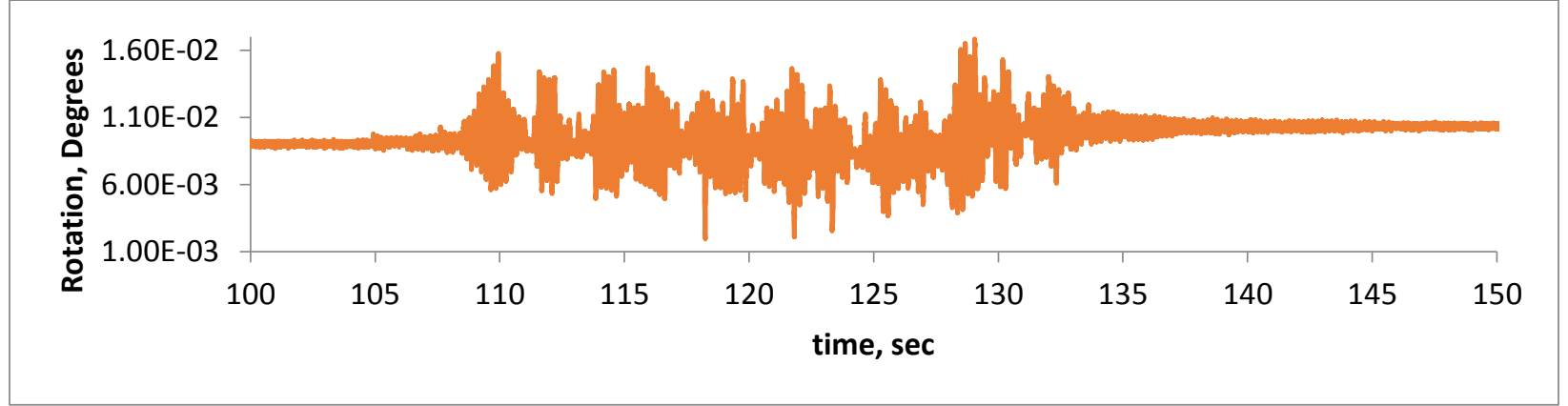

Figure 35: Rotations in the East Direction

\section{GM 125\%: Horizontal Rotations and New X and Y intercepts}

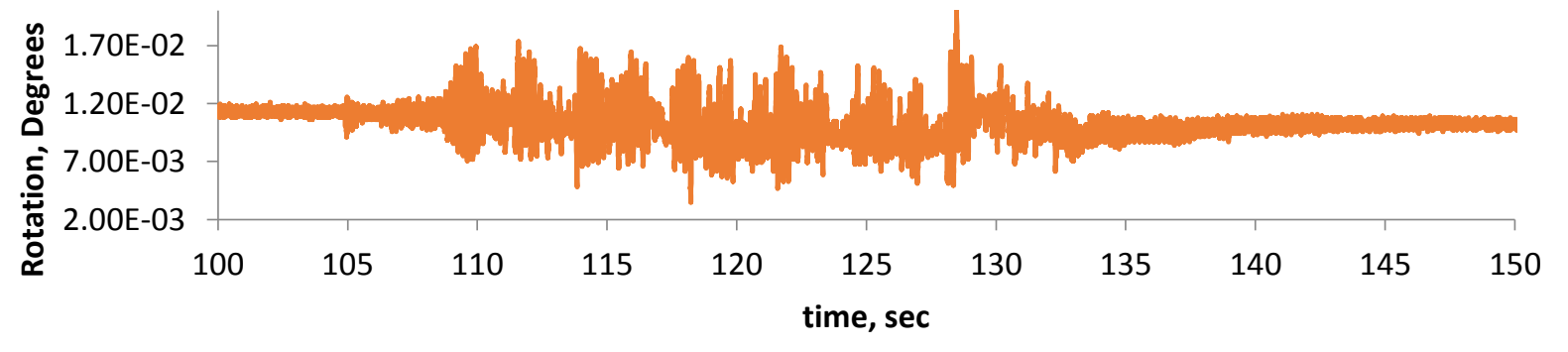

Figure 36: Horizontal North-South Rotations. 


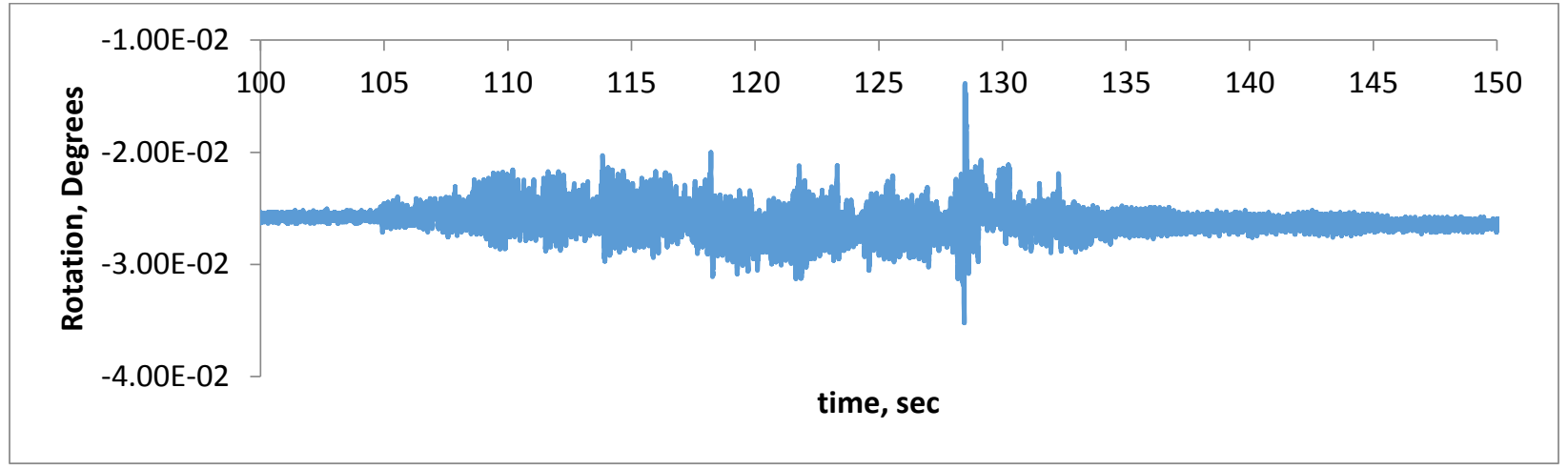

Figure 37: Horizontal East-West Rotations.

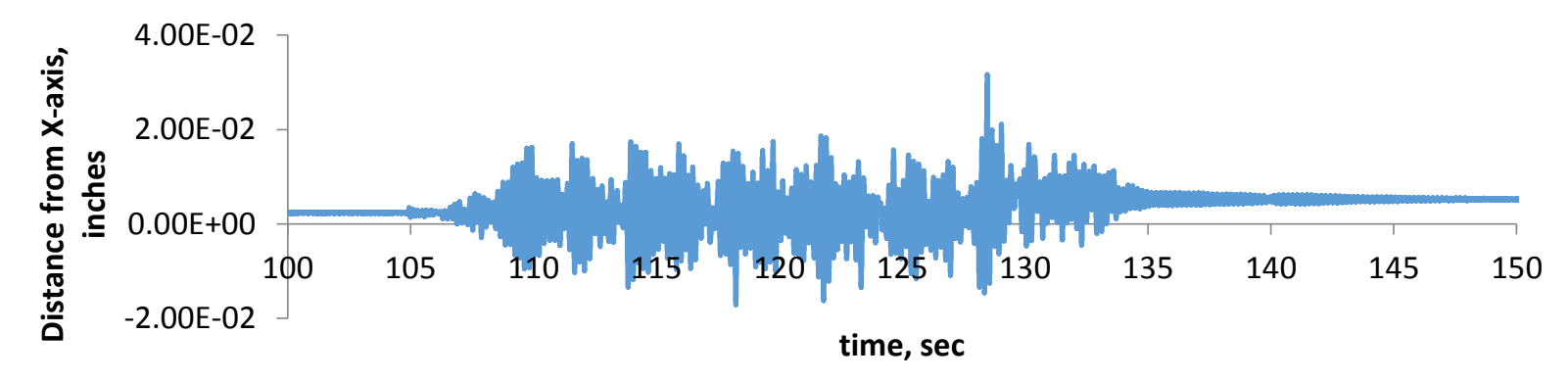

Figure 38: New X-Intercept as a function of time, ti. Negative is towards the east horizontal LVDT and positive is towards the west horizontal LVDT.

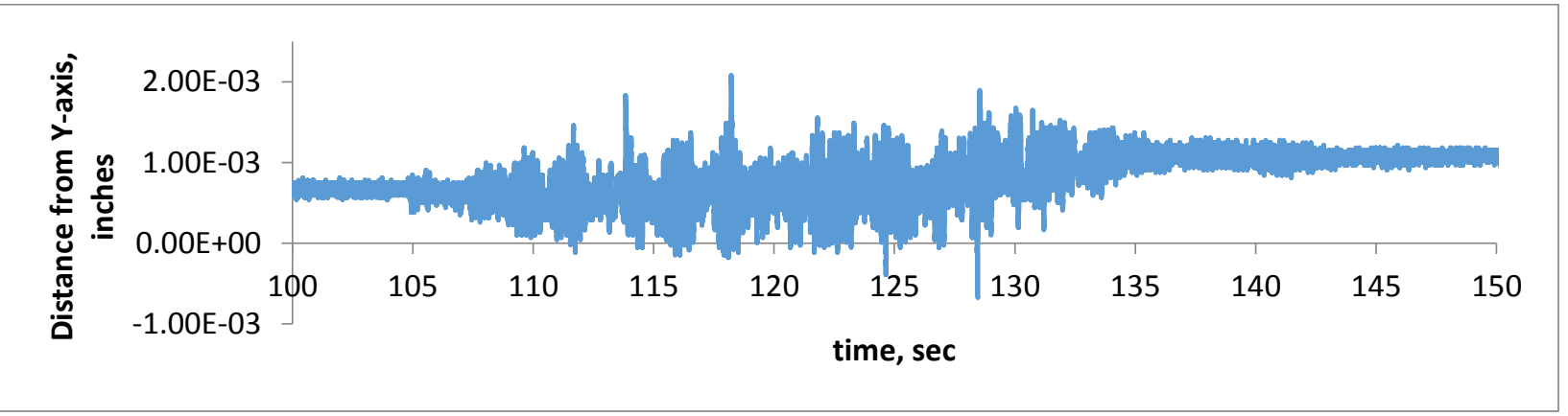

Figure 39: New Y-Intercept as a function of time, ti. Negative is towards the south horizontal LVDT and positive is towards the north horizontal LVDT.

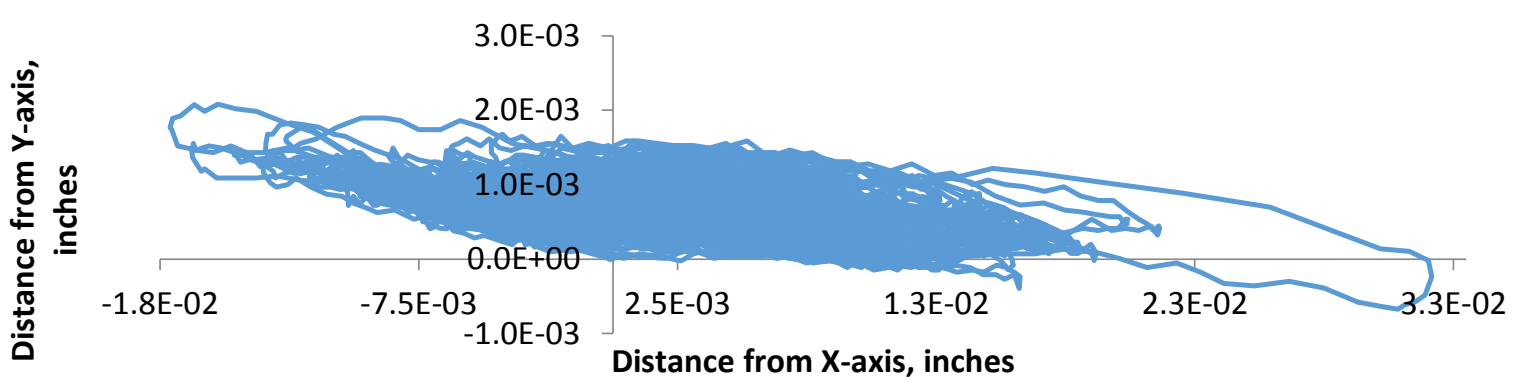

Figure 40: Changing X \& Y Intercept as a function of time, ti. 


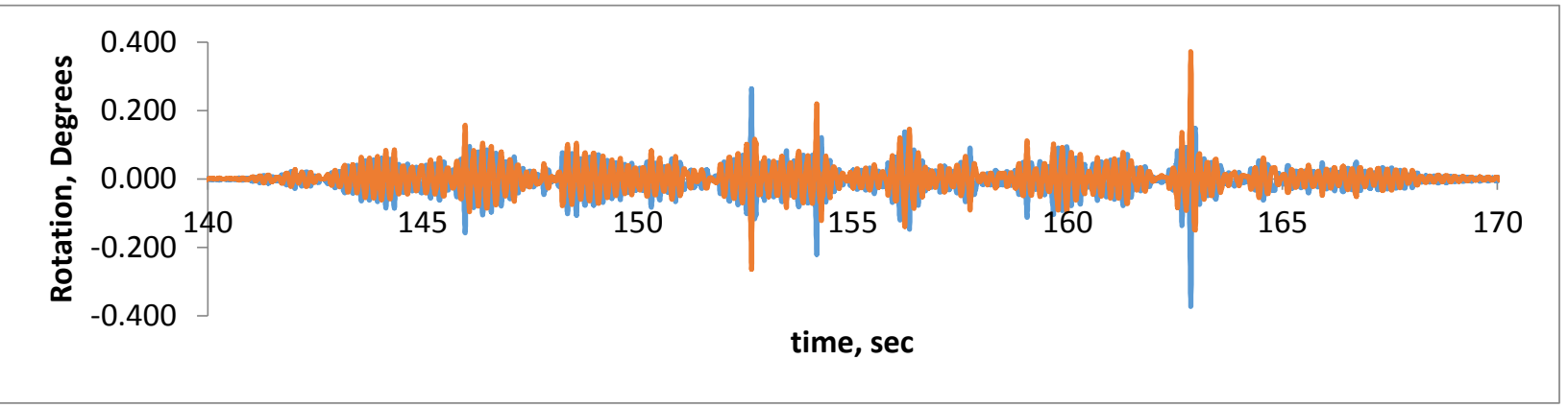

Figure 41: Rotations in the North-South Direction.

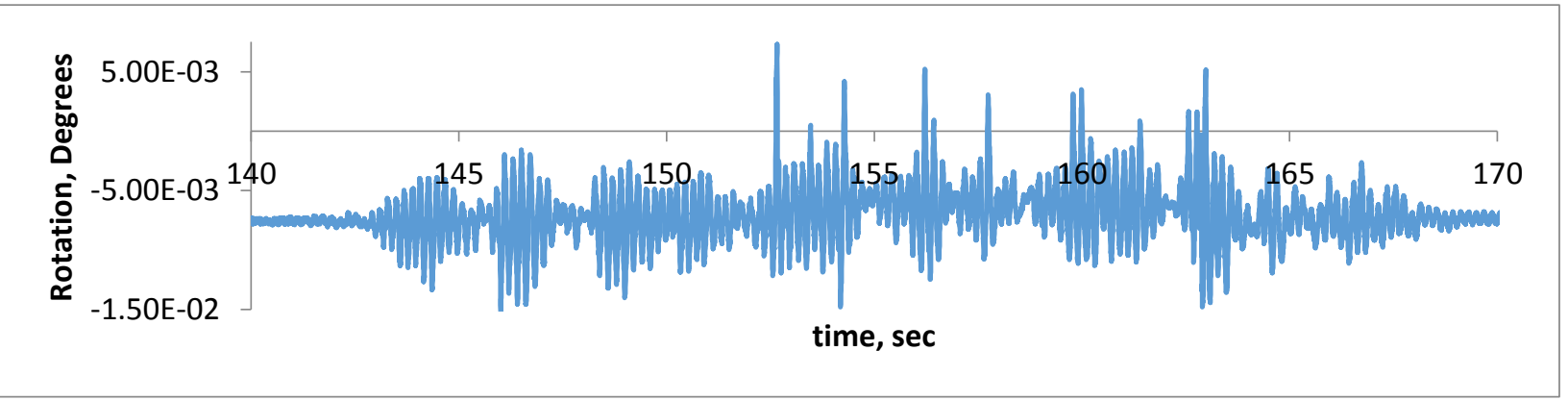

Figure 42: Rotations in the West Direction

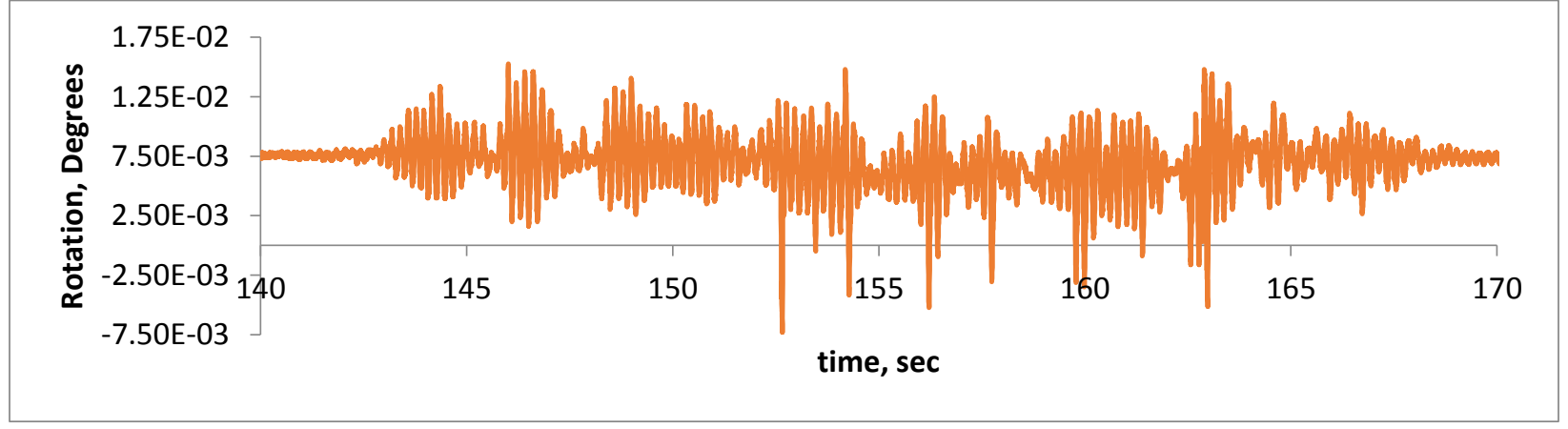

Figure 43: Rotations in the East Direction

\section{GM 137.5\%: Horizontal Rotations and New X and Y intercepts}

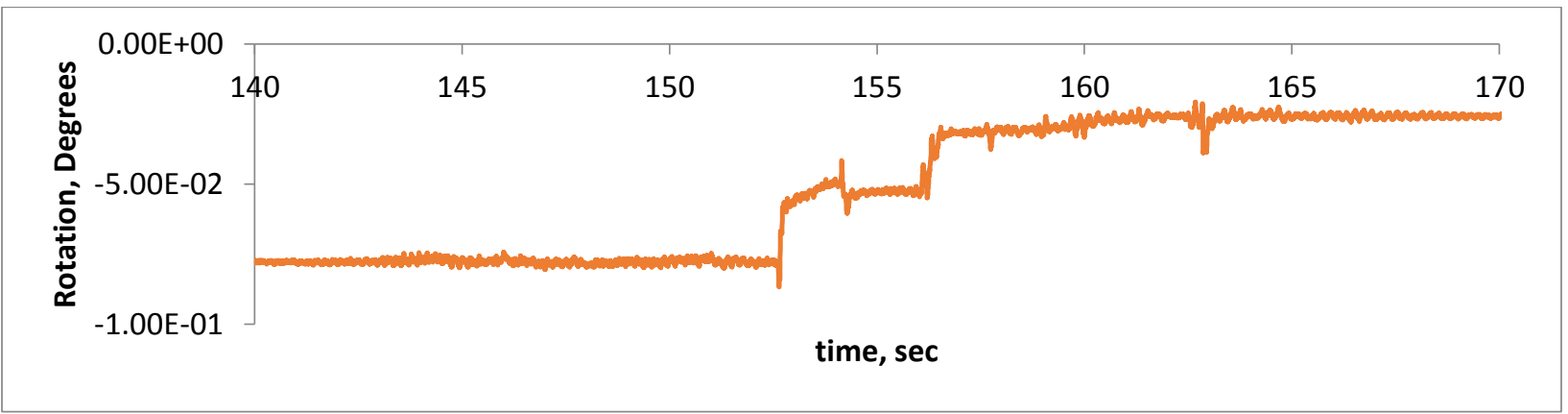

Figure 44: Horizontal North-South Rotations. 


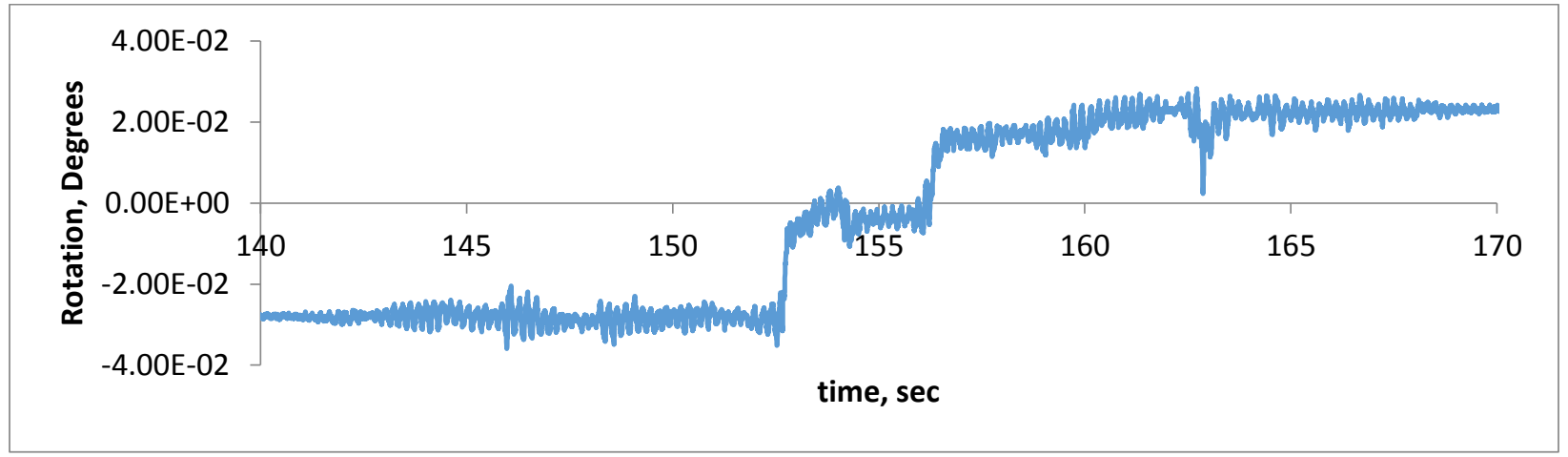

Figure 45: Horizontal East-West Rotations.

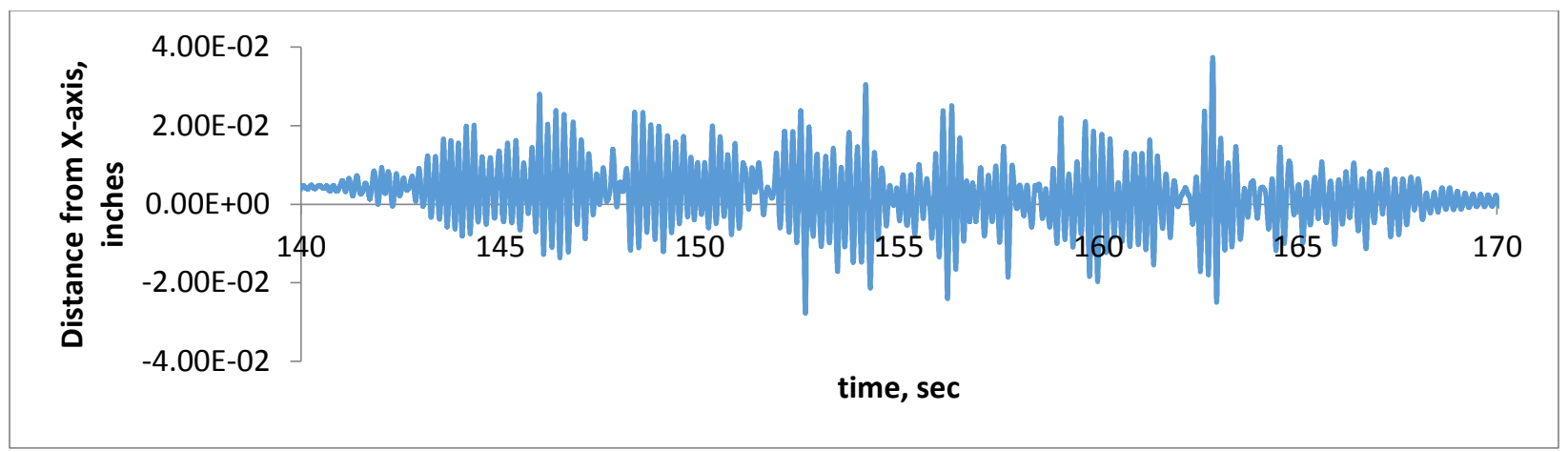

Figure 46: New X-Intercept as a function of time, ti. Negative is towards the east horizontal LVDT and positive is towards the west horizontal LVDT.

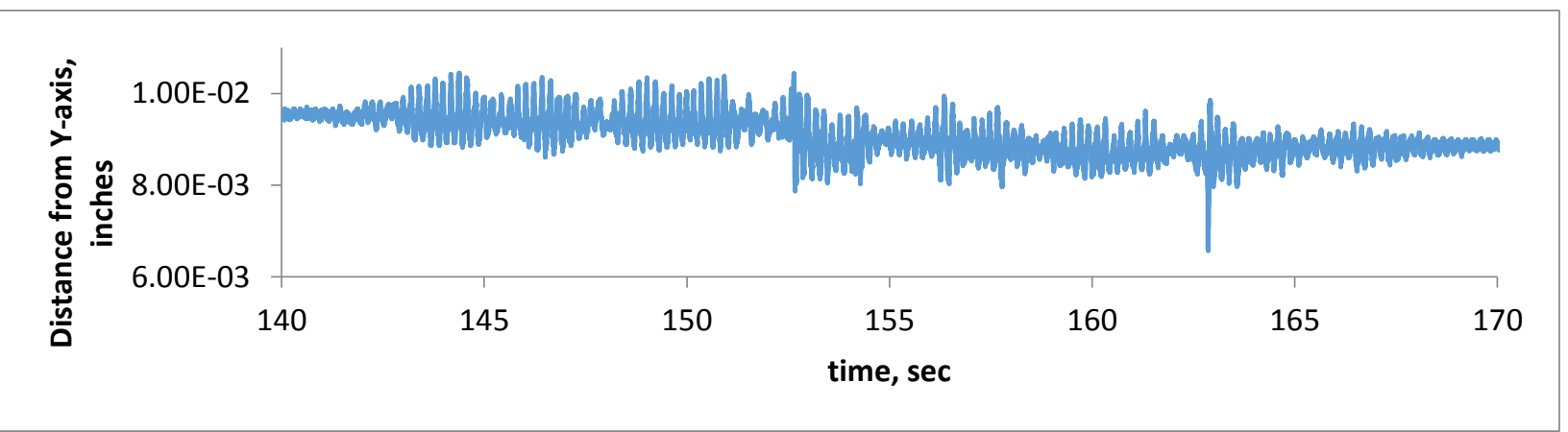

Figure 47: New Y-Intercept as a function of time, ti. Negative is towards the south horizontal LVDT and positive is towards the north horizontal LVDT.

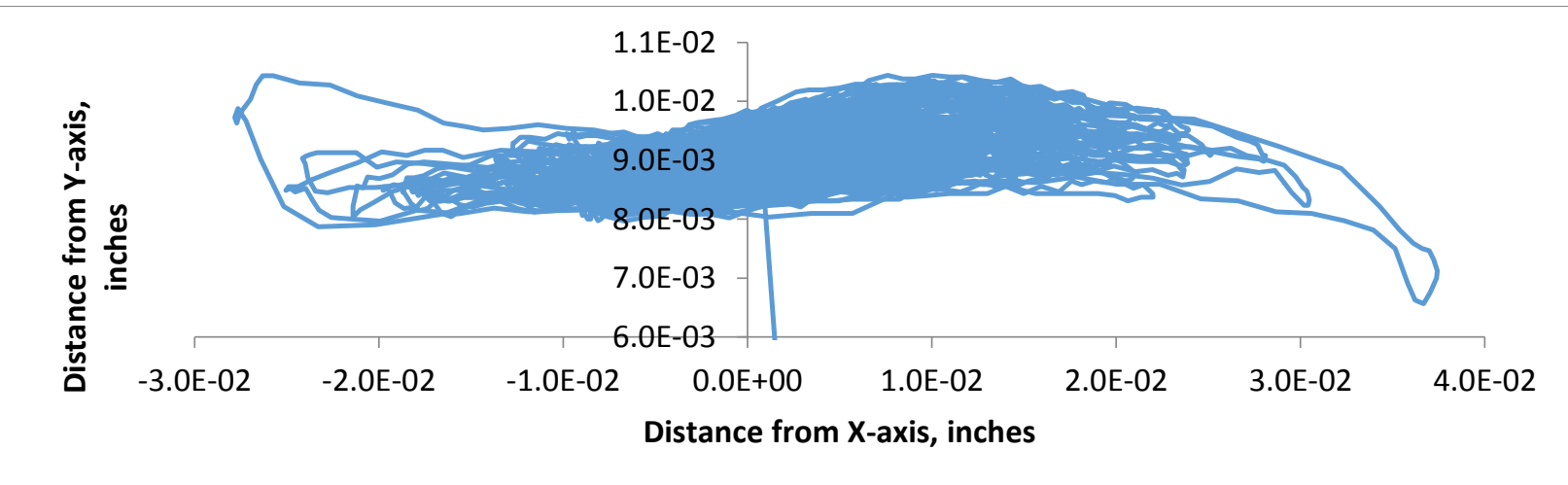

Figure 48: Changing X \& Y Intercept as a function of time, ti. 


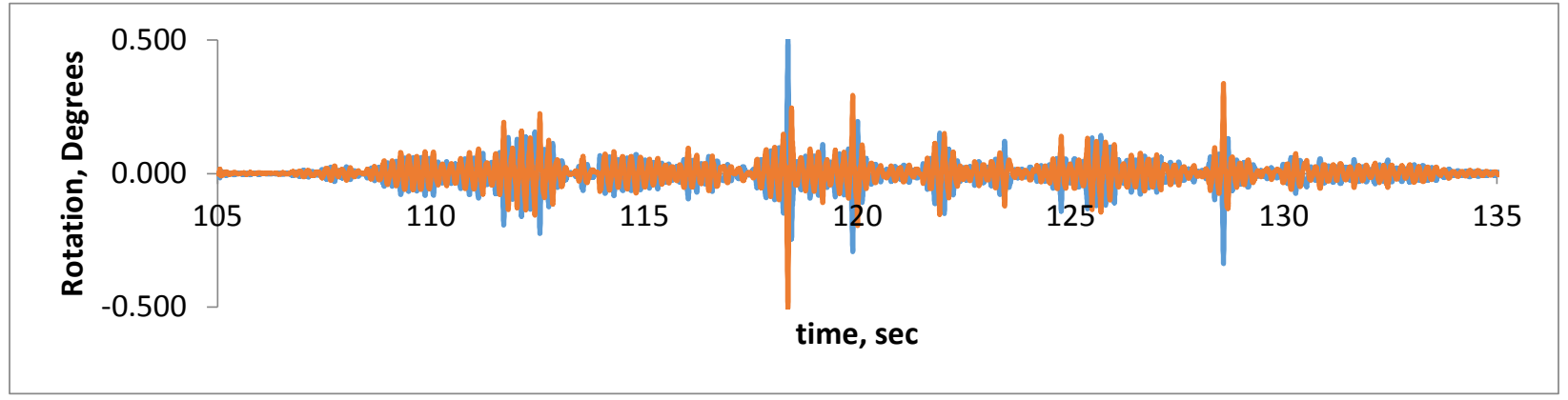

Figure 49: Rotations in the North-South Direction.

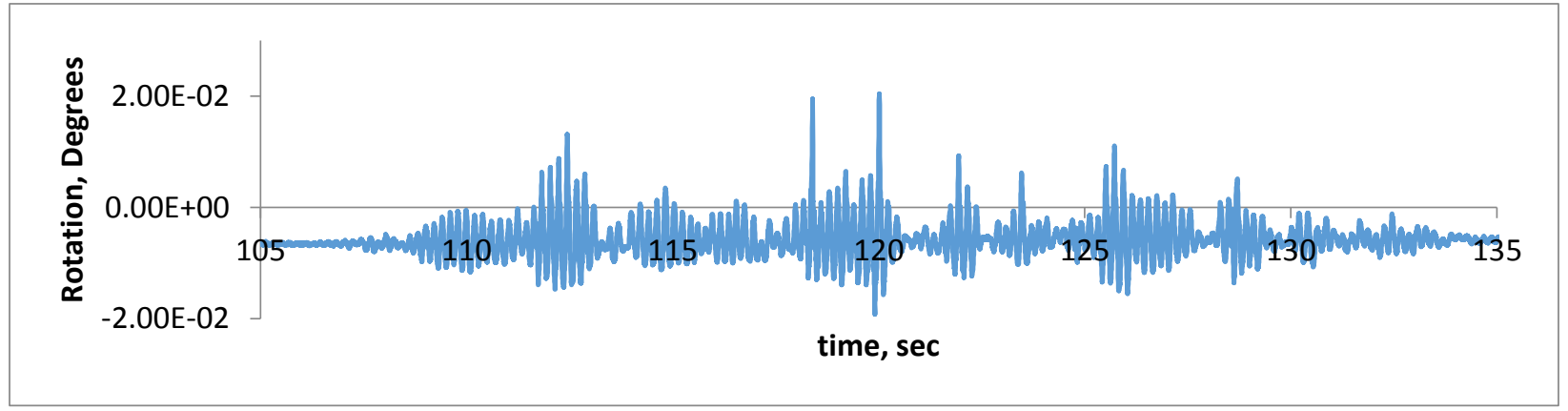

Figure 50: Rotations in the West Direction

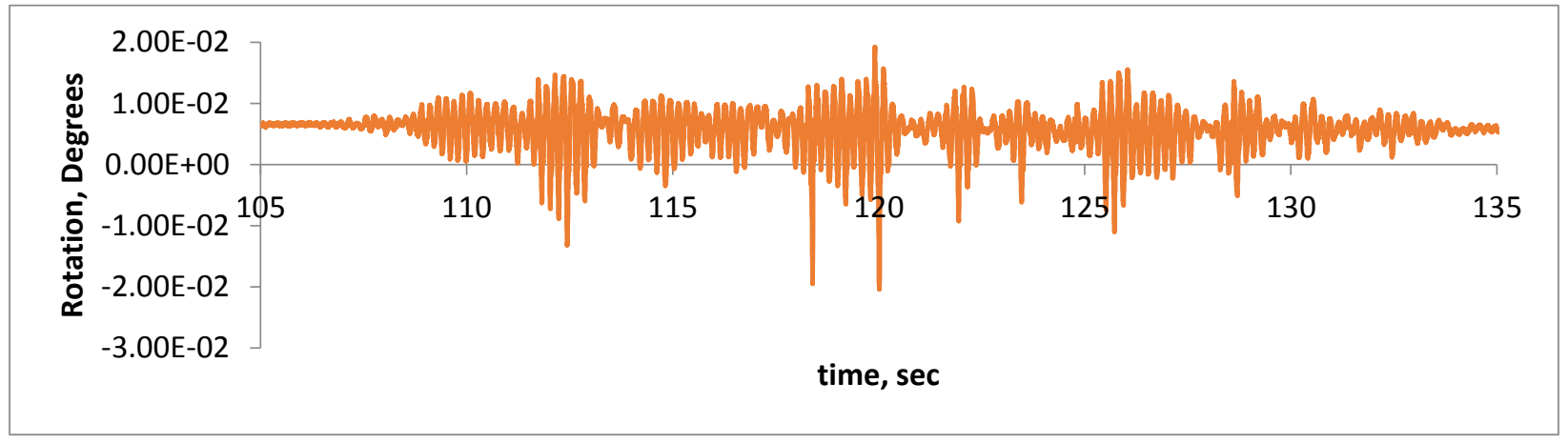

Figure 51: Rotations in the East Direction

GM 150\%: Horizontal Rotations and New $X$ and $Y$ intercepts

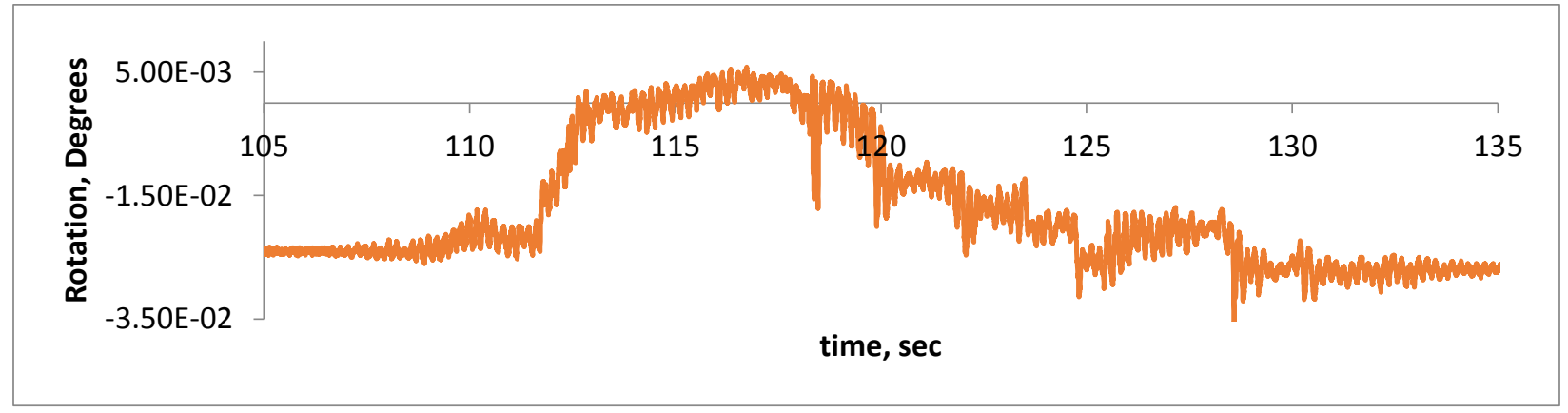

Figure 52: Horizontal North-South Rotations. 


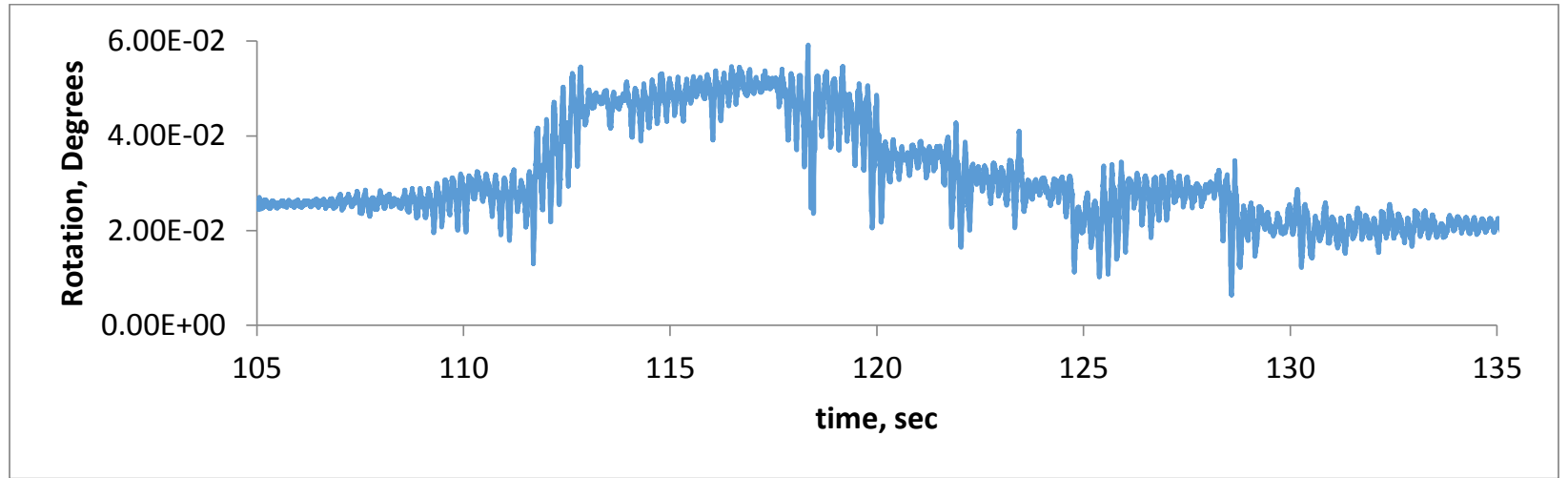

Figure 53: Horizontal East-West Rotations.

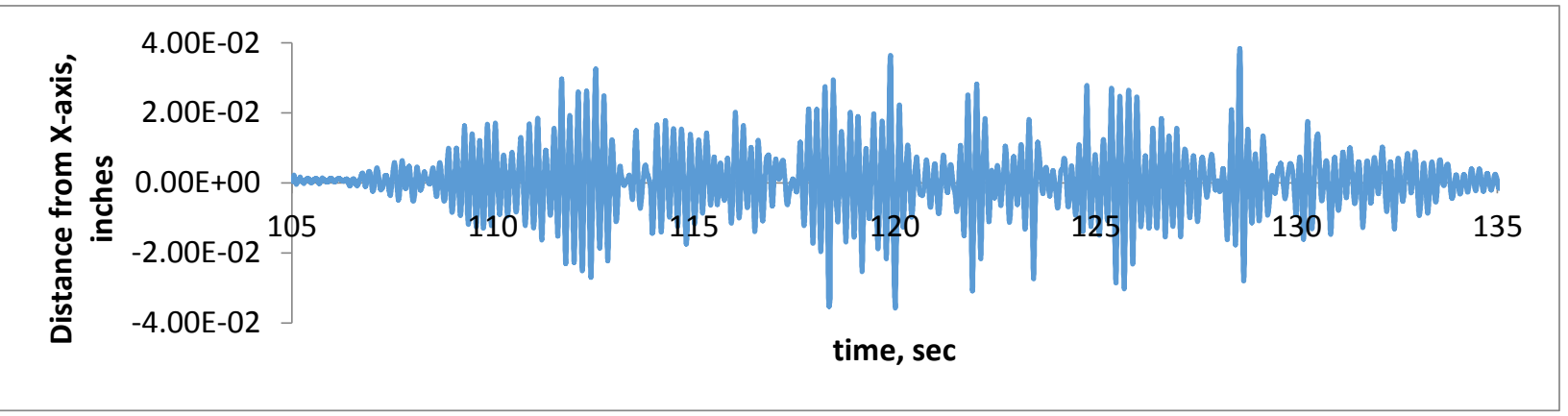

Figure 54: New X-Intercept as a function of time, ti. Negative is towards the east horizontal LVDT and positive is towards the west horizontal LVDT.

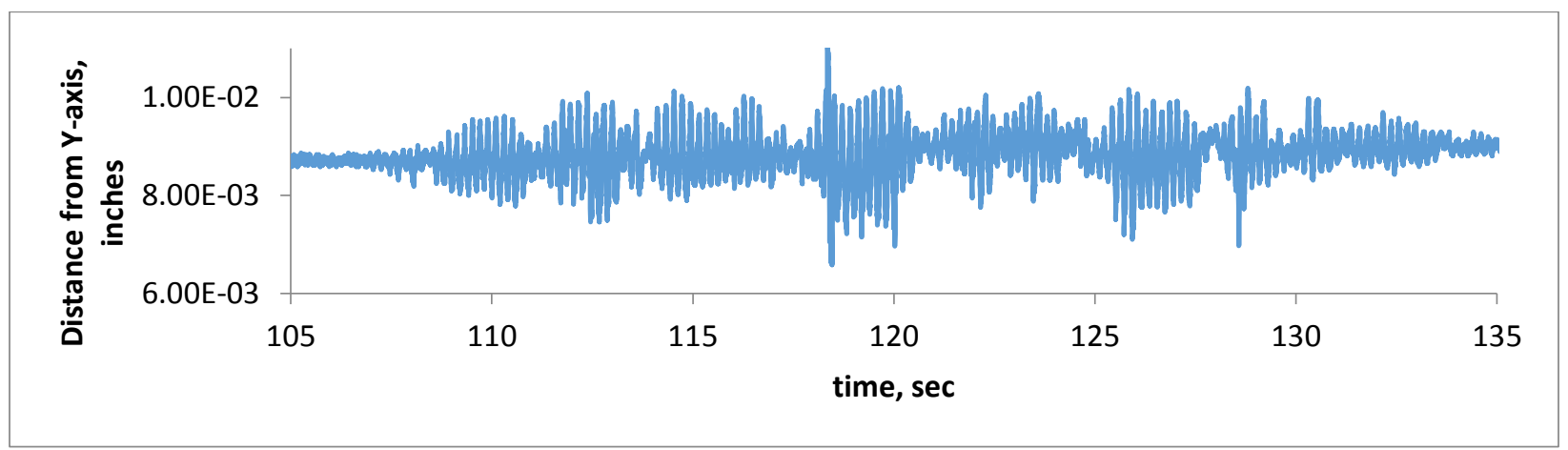

Figure 55: New Y-Intercept as a function of time, ti. Negative is towards the south horizontal LVDT and positive is towards the north horizontal LVDT.

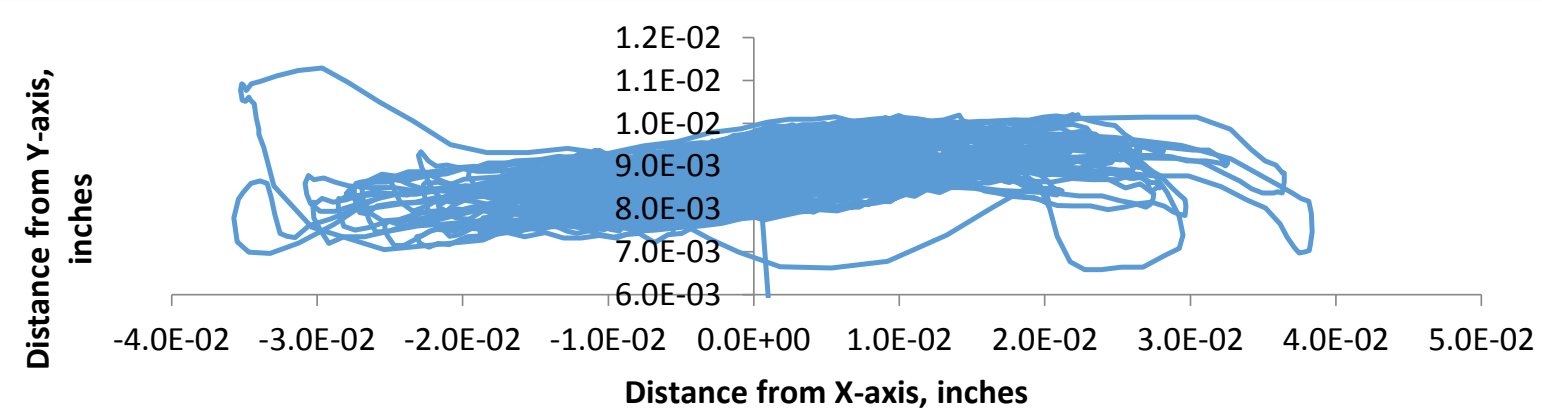

Figure 56: Changing X \& Y Intercept as a function of time, ti. 


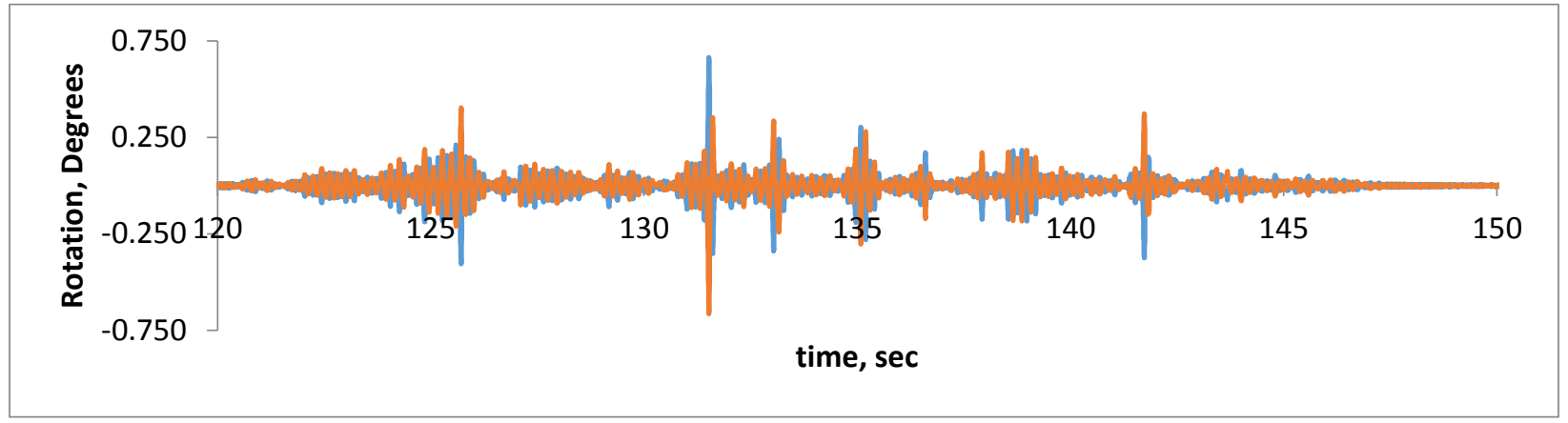

Figure 57: Rotations in the North-South Direction.

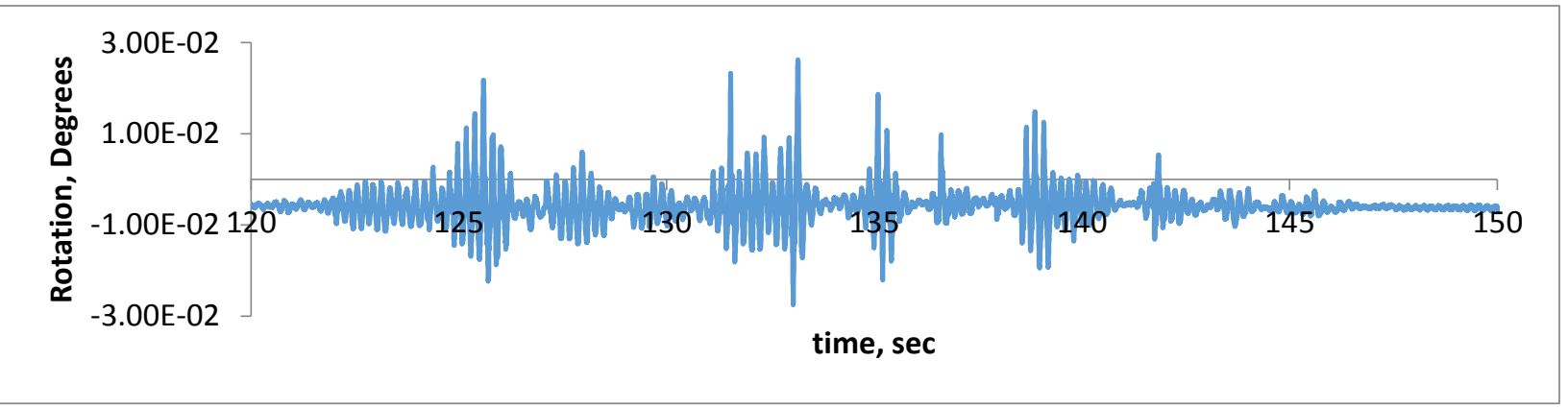

Figure 58: Rotations in the West Direction

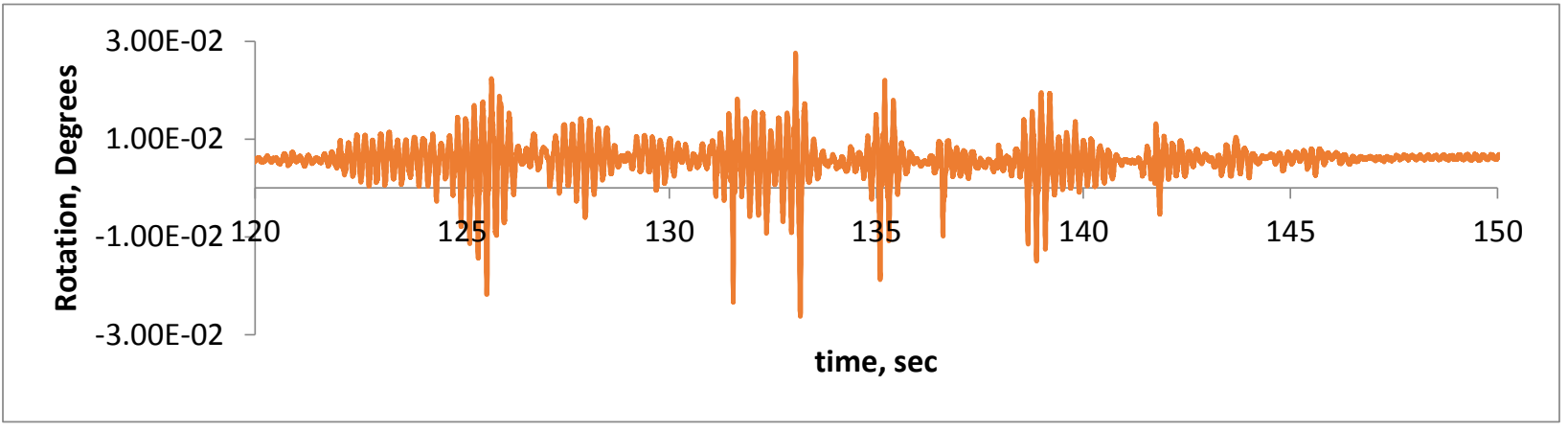

Figure 59: Rotations in the East Direction

GM 162.5\%: Horizontal Rotations and New $X$ and $Y$ intercepts

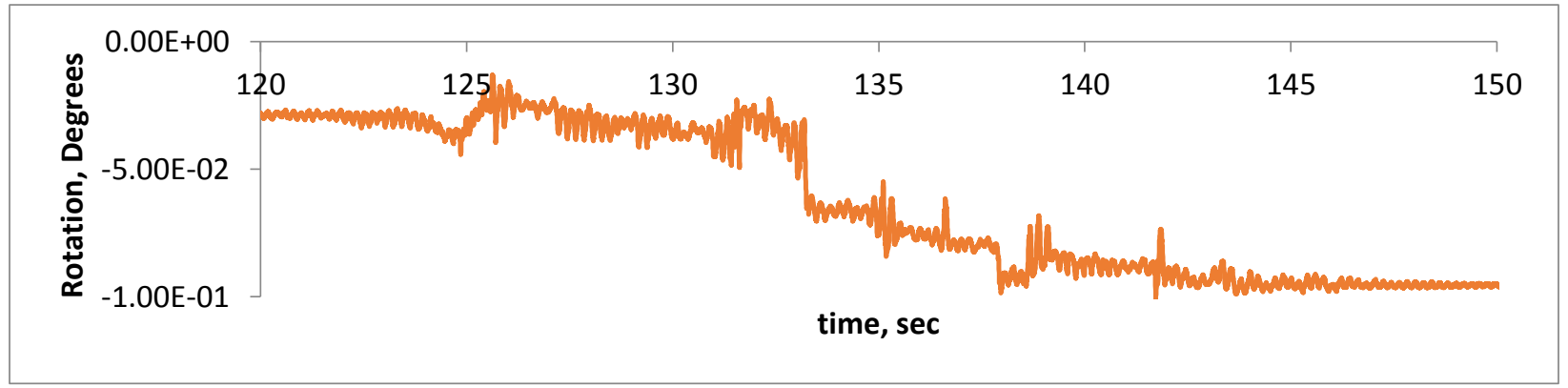

Figure 60: Horizontal North-South Rotations. 


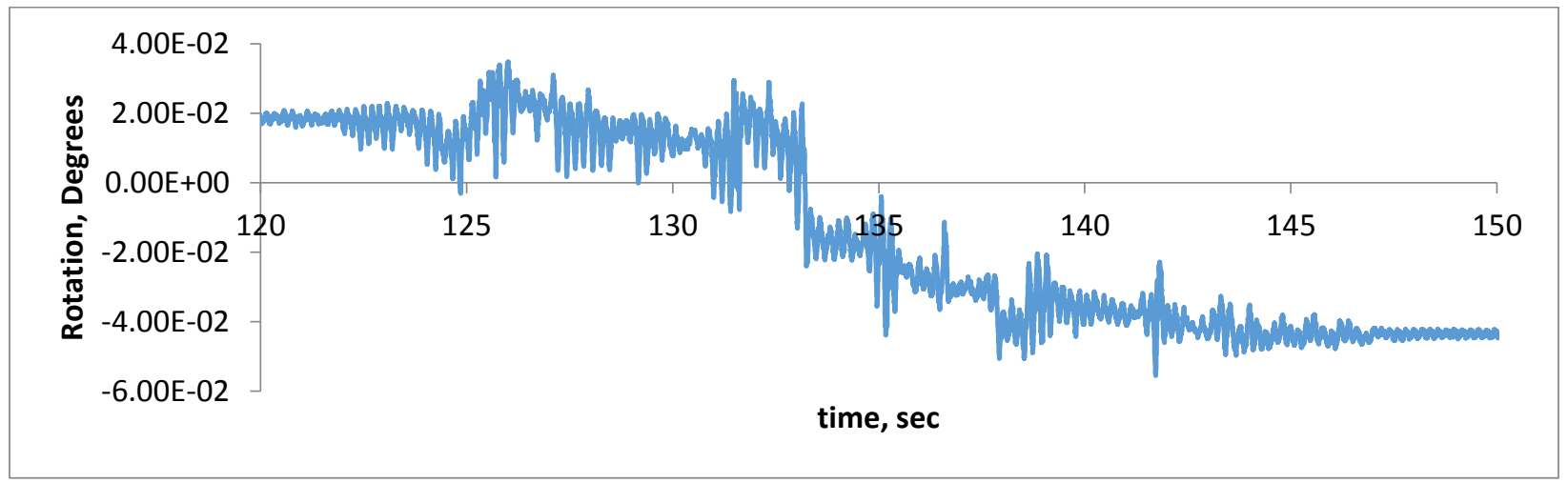

Figure 61: Horizontal East-West Rotations.

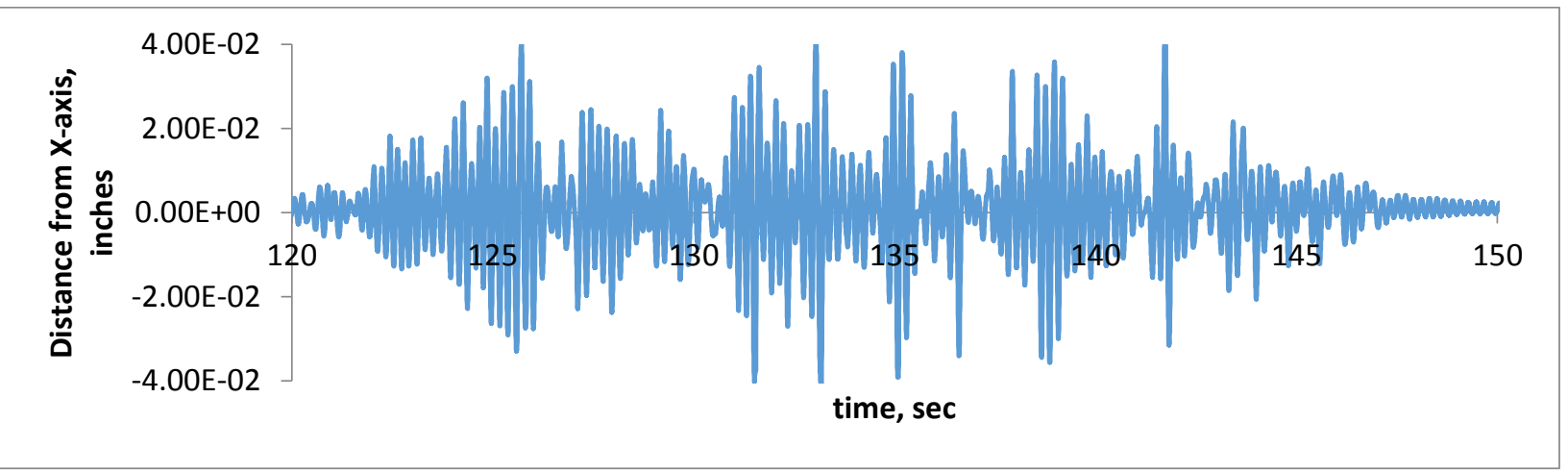

Figure 62: New X-Intercept as a function of time, ti. Negative is towards the east horizontal LVDT and positive is towards the west horizontal LVDT.

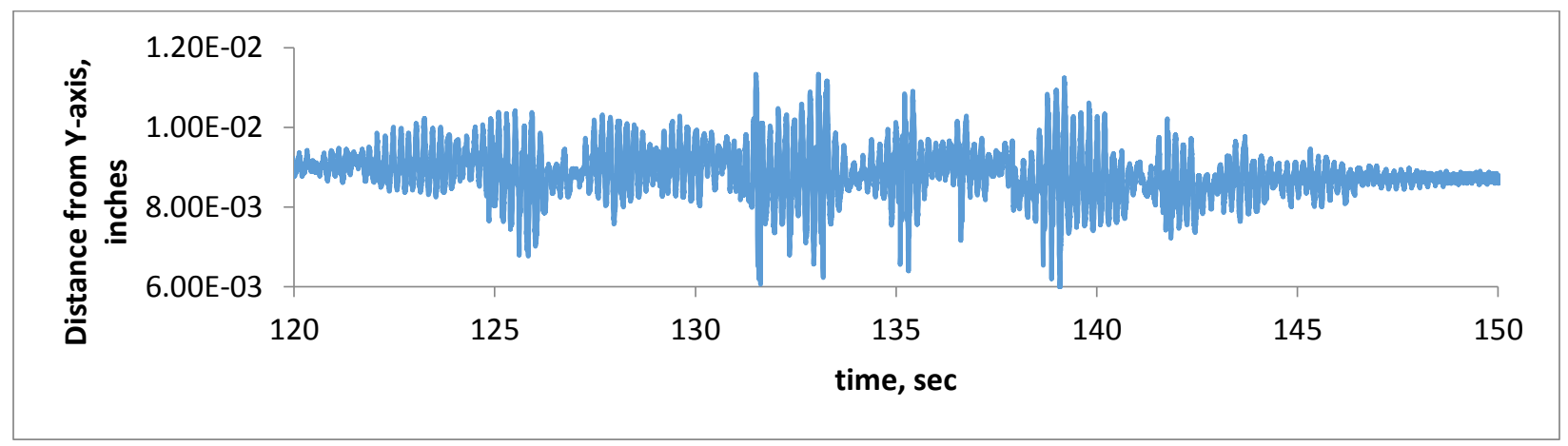

Figure 63: New Y-Intercept as a function of time, ti. Negative is towards the south horizontal LVDT and positive is towards the north horizontal LVDT.

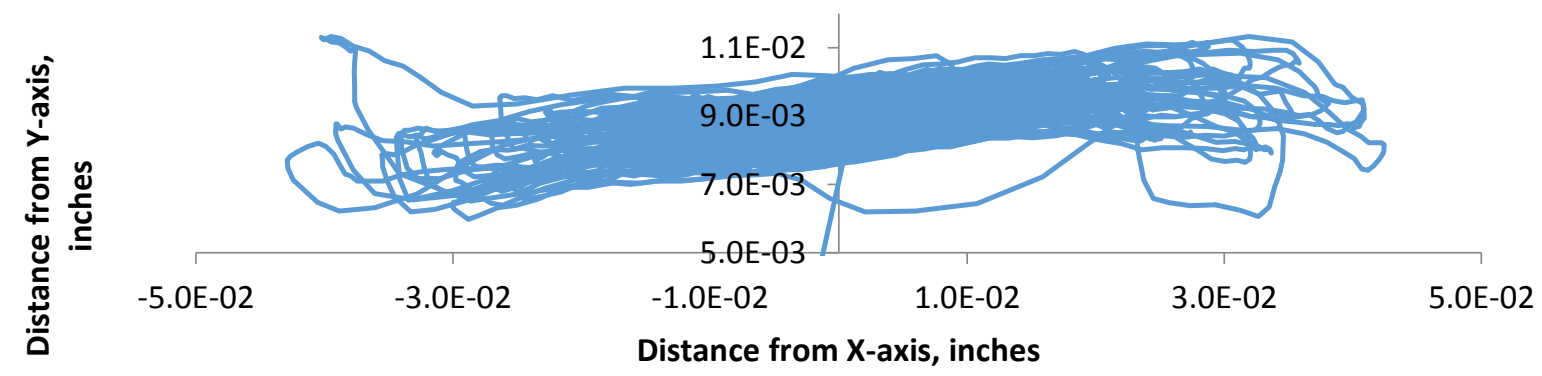

Figure 64: Changing $X \& Y$ Intercept as a function of time, ti. 


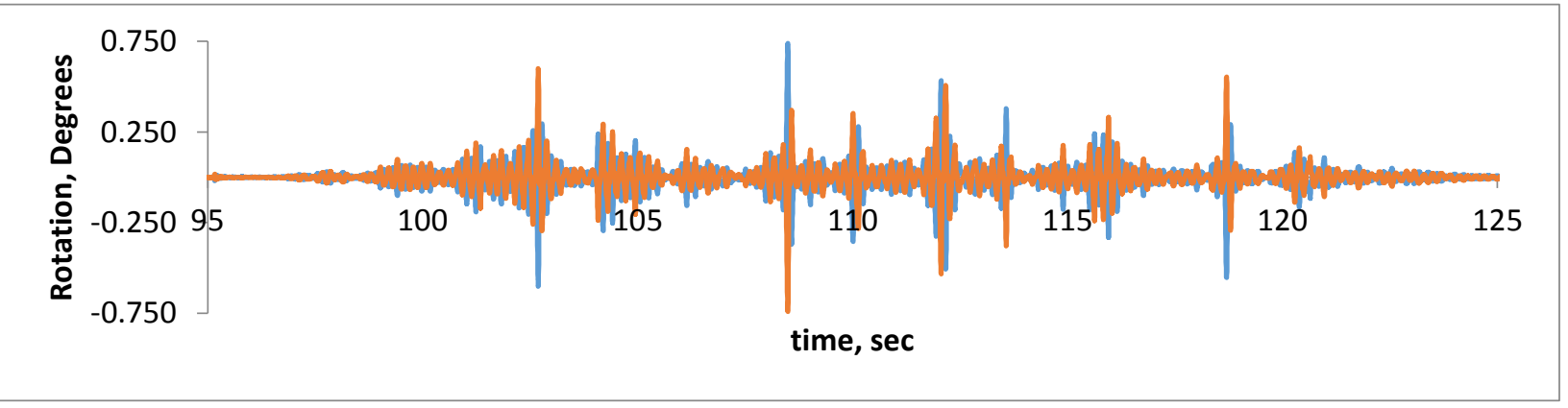

Figure 65: Rotations in the North-South Direction.

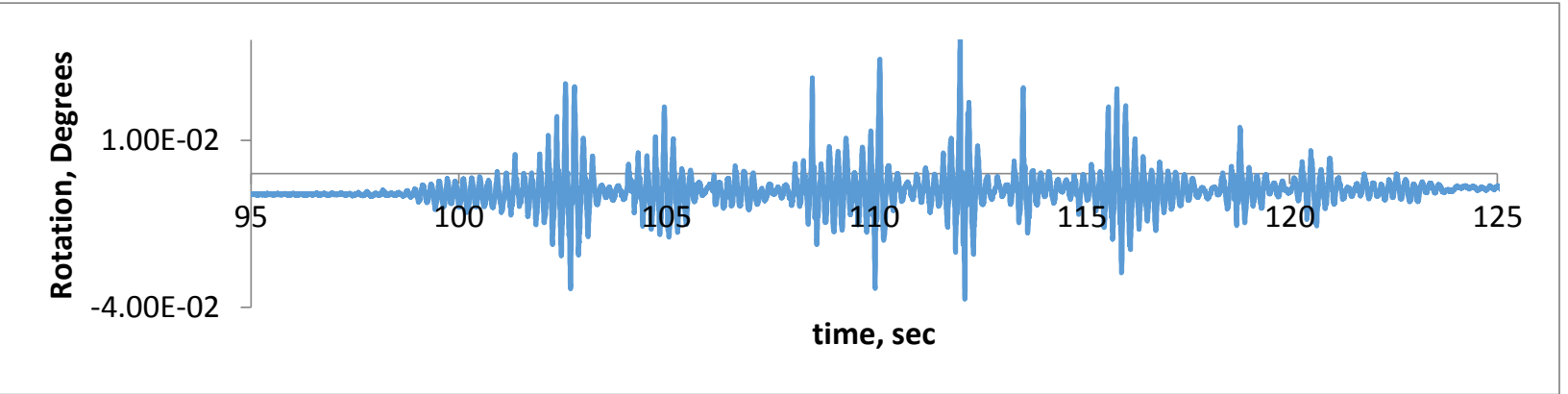

Figure 66: Rotations in the West Direction

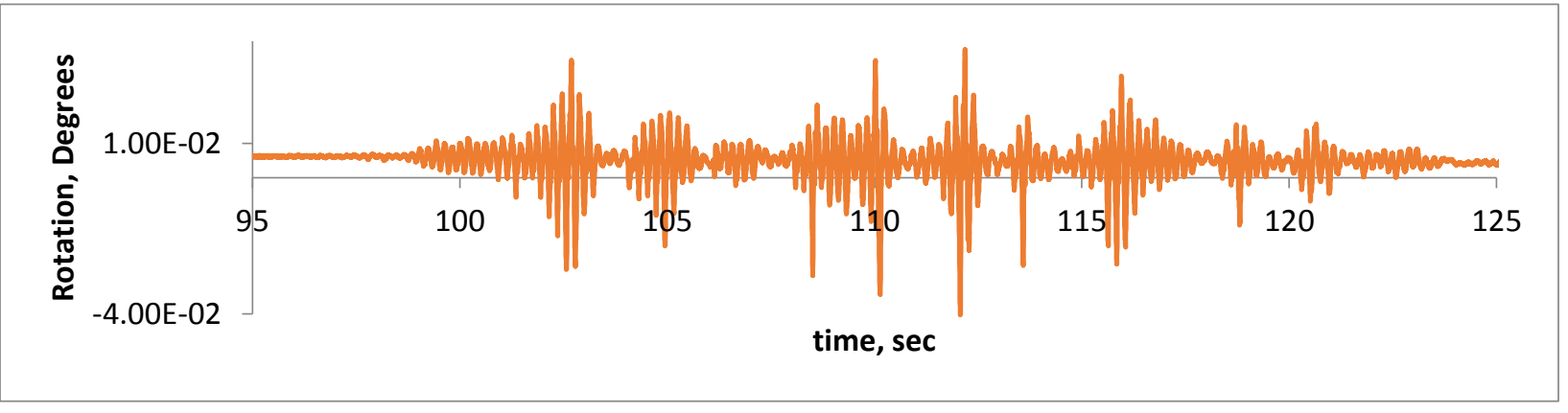

Figure 67: Rotations in the East Direction

GM 175\%: Horizontal Rotations and New $X$ and $Y$ intercepts

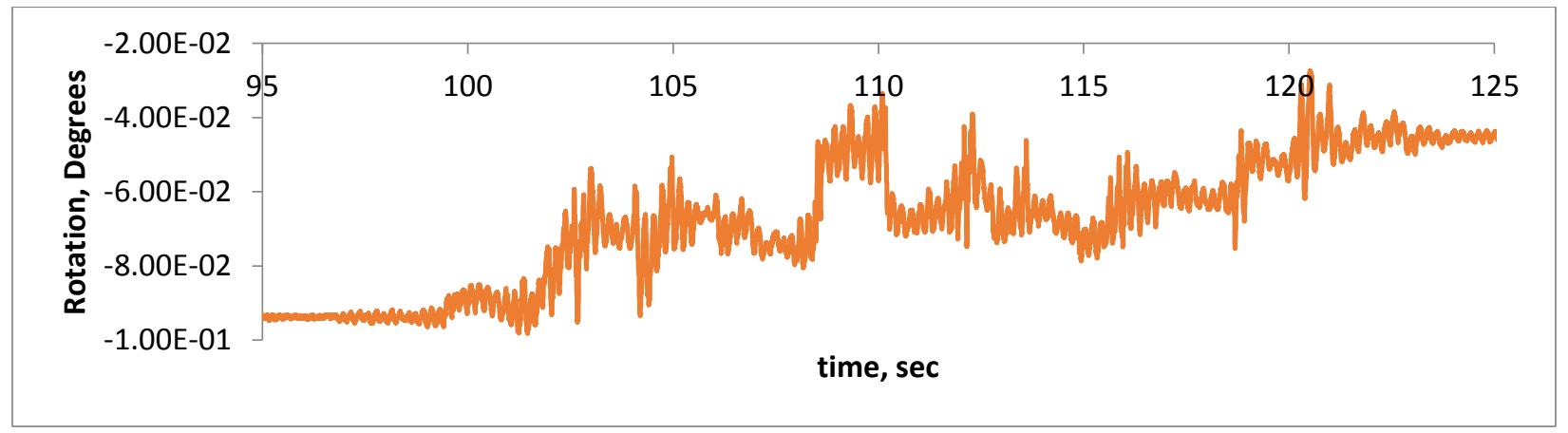

Figure 68: Horizontal North-South Rotations. 


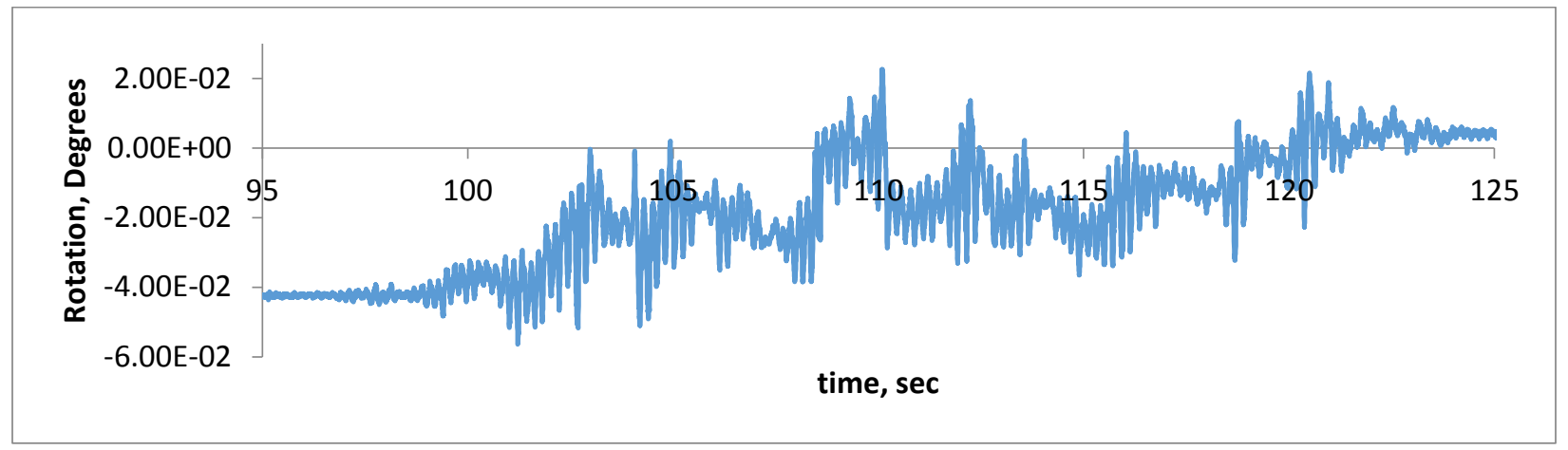

Figure 69: Horizontal East-West Rotations.

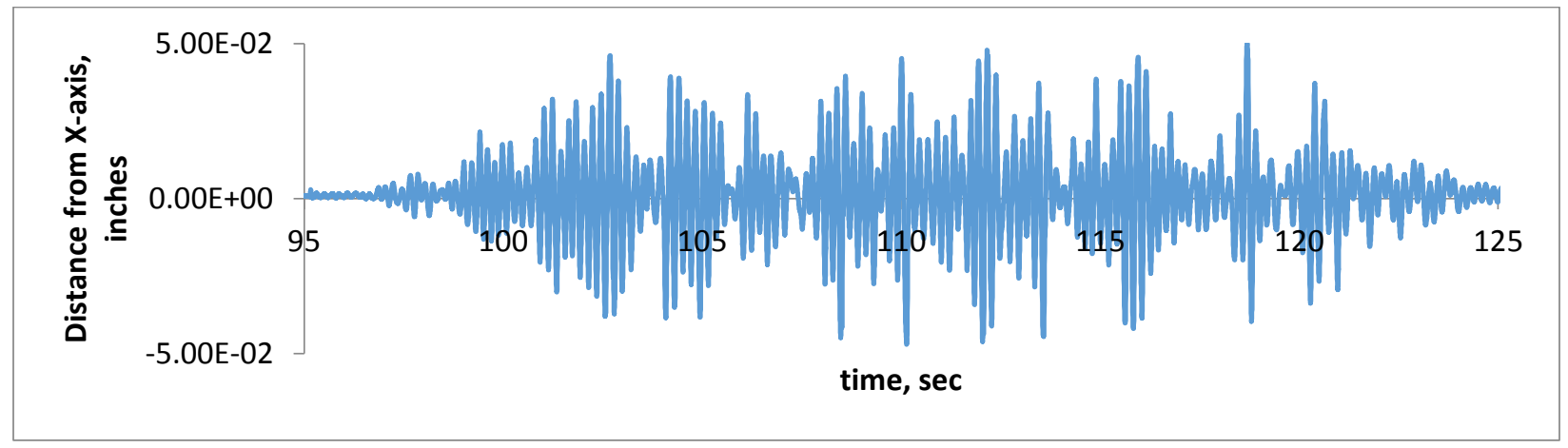

Figure 70: New X-Intercept as a function of time, ti. Negative is towards the east horizontal LVDT and positive is towards the west horizontal LVDT.

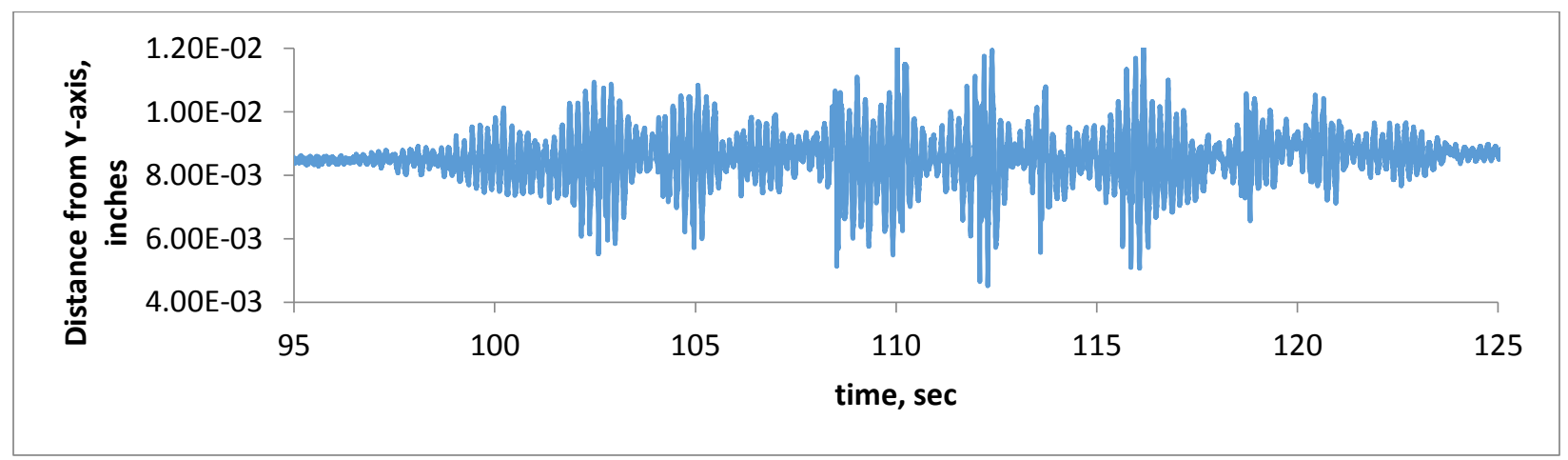

Figure 71: New Y-Intercept as a function of time, ti. Negative is towards the south horizontal LVDT and positive is towards the north horizontal LVDT.

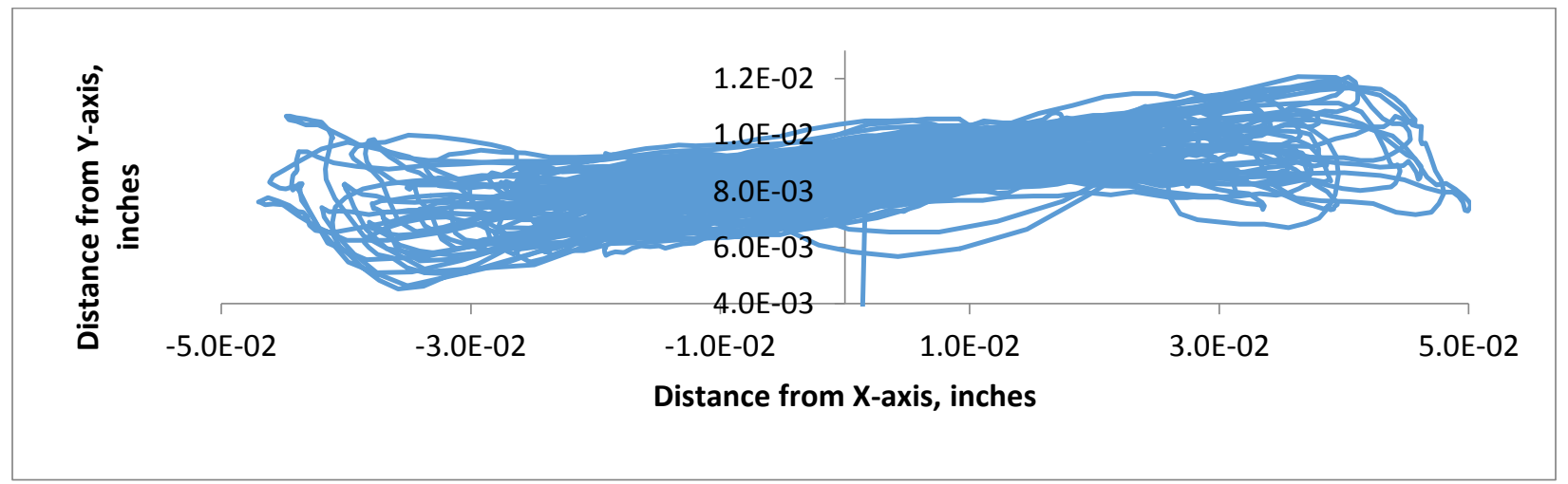

Figure 72: Changing X \& Y Intercept as a function of time, ti. 